Cochrane Database of Systematic Reviews

\title{
Interventions for the management of malignant pleural effusions: a network meta-analysis (Review)
}

Clive AO, Jones HE, Bhatnagar R, Preston NJ, Maskell N

Clive AO, Jones HE, Bhatnagar R, Preston NJ, Maskell N.

Interventions for the management of malignant pleural effusions: a network meta-analysis.

Cochrane Database of Systematic Reviews 2016, Issue 5. Art. No.: CD010529.

DOI: 10.1002/14651858.CD010529.pub2.

www.cochranelibrary.com 
TABLE OF CONTENTS

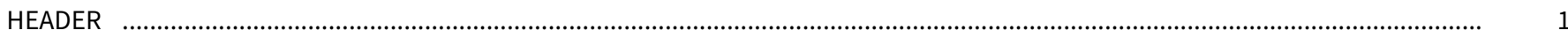

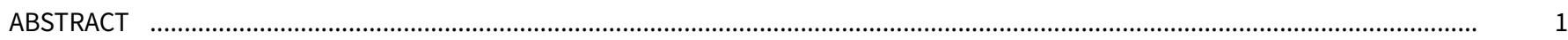

PLAIN LANGUAGE SUMMARY

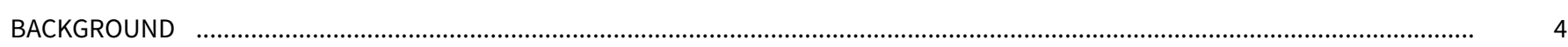

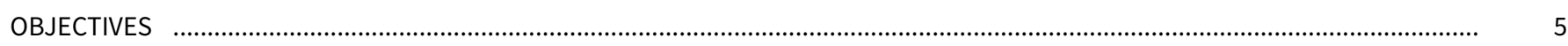

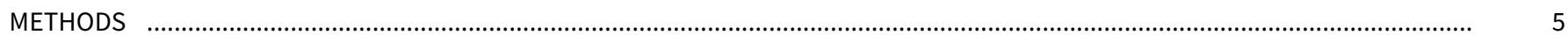

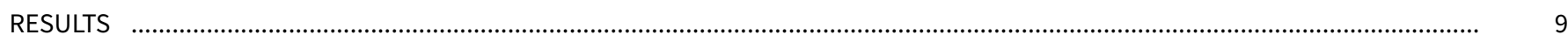

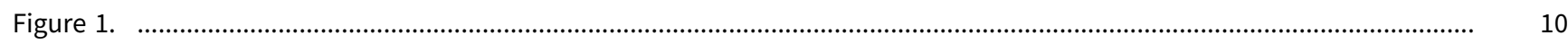

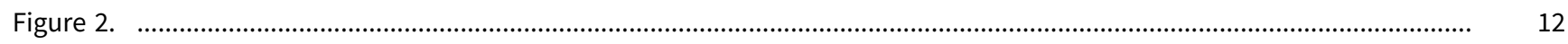

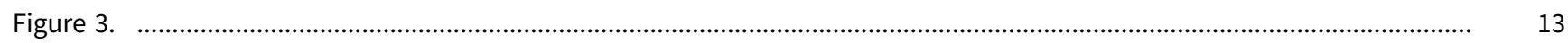

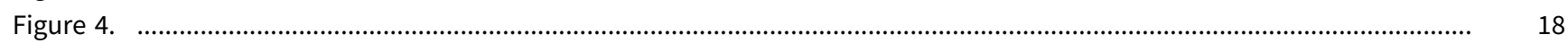

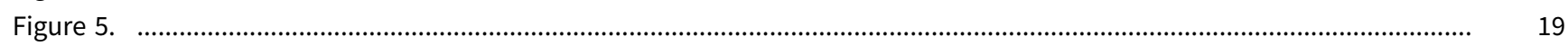

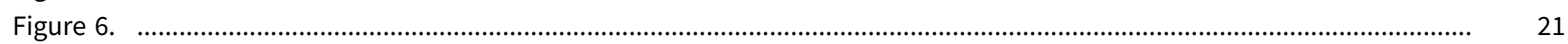

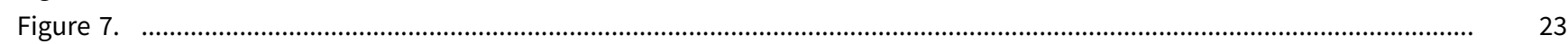

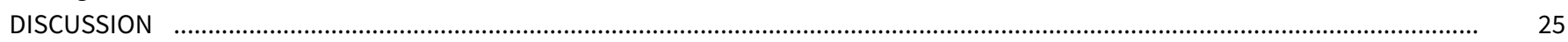

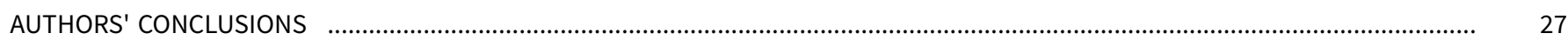

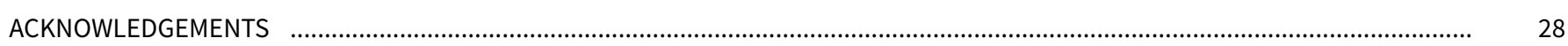

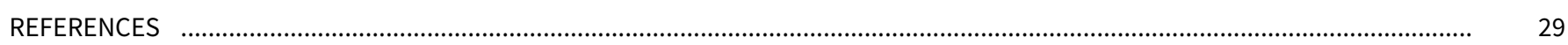

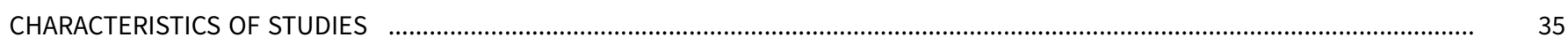

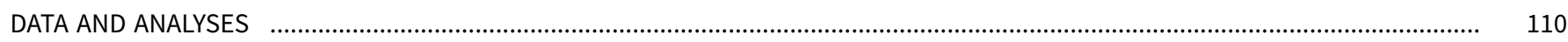

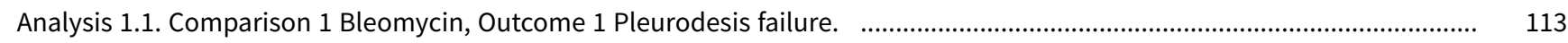

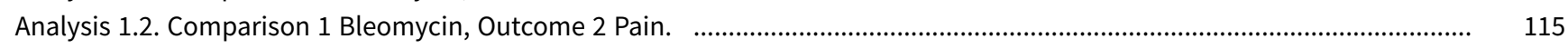

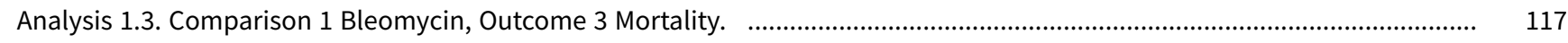

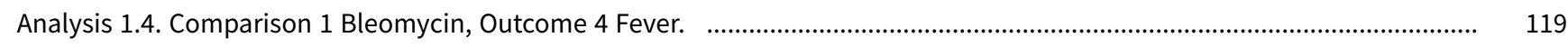

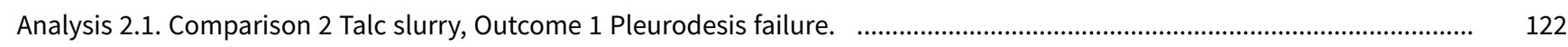

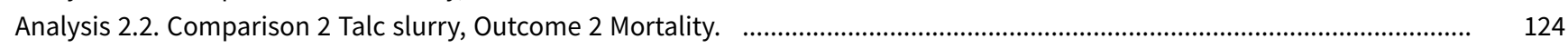

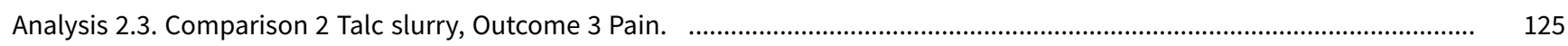

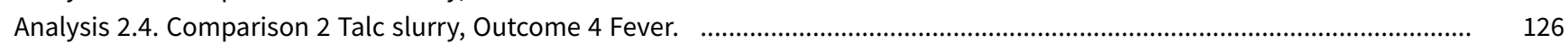

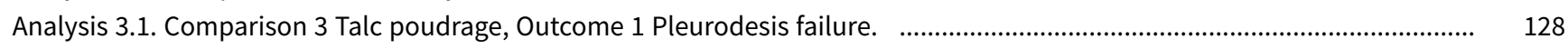

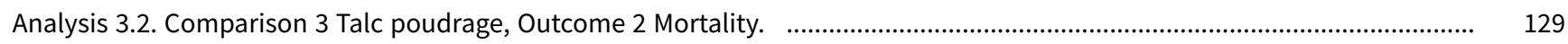

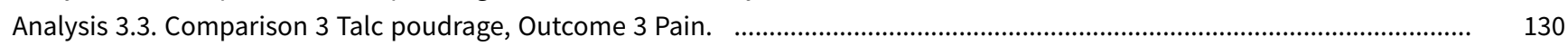

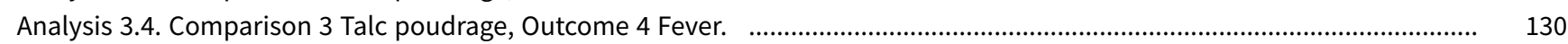

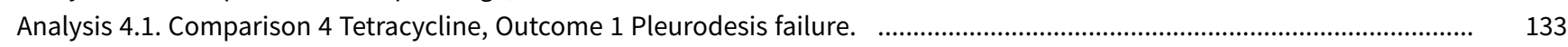

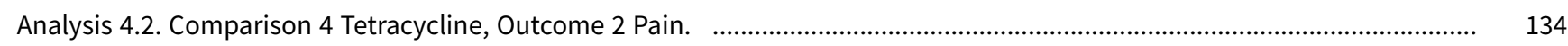

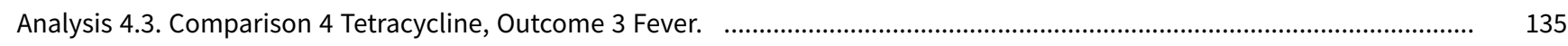

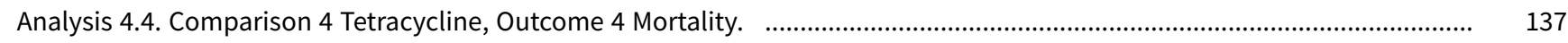

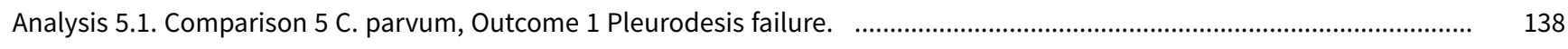

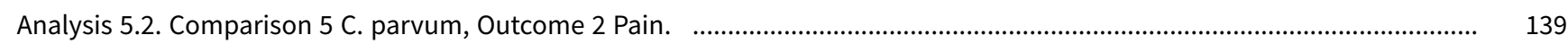

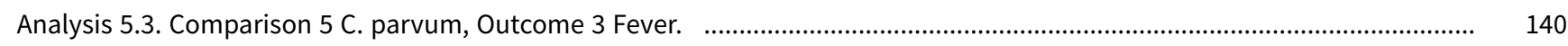

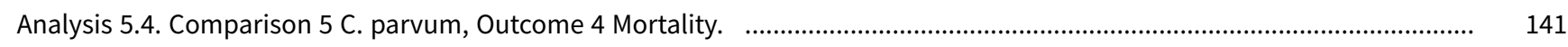

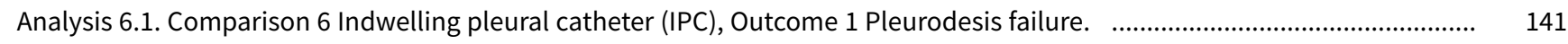

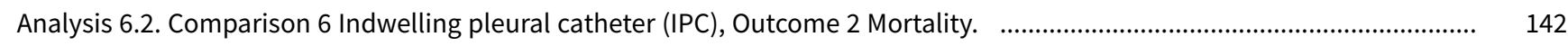

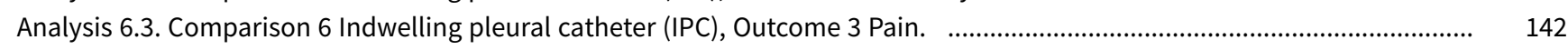

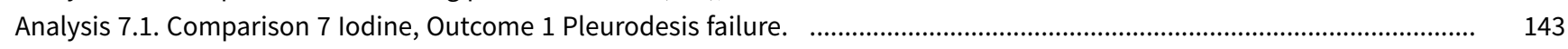

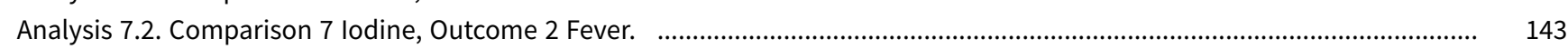

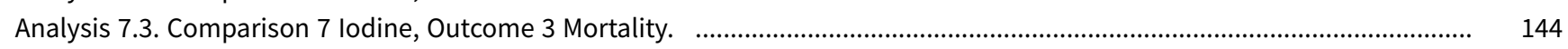

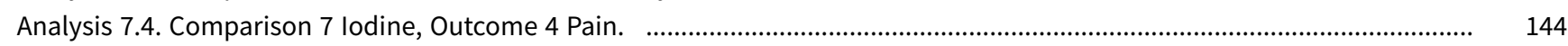

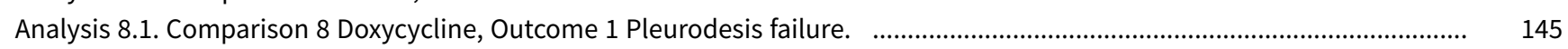

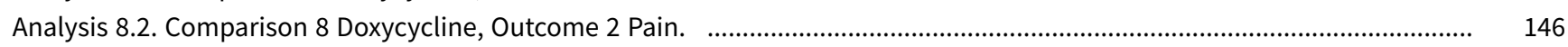

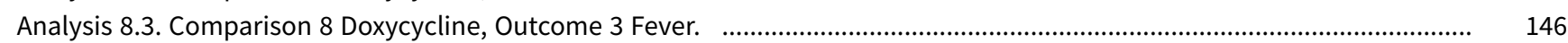

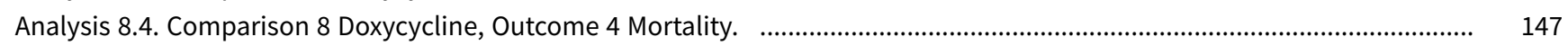

Interventions for the management of malignant pleural effusions: a network meta-analysis (Review) i

Copyright $\odot 2019$ The Cochrane Collaboration. Published by John Wiley \& Sons, Ltd. 
Analysis 9.1. Comparison 9 Mode of administration, Outcome 1 Pleurodesis failure.

Analysis 10.1. Comparison 10 Duration of drainage after pleurodesis administration, Outcome 1 Pleurodesis failure. ...............

Analysis 10.2. Comparison 10 Duration of drainage after pleurodesis administration, Outcome 2 Mortality. ............................

Analysis 11.1. Comparison 11 OK-432, Outcome 1 Pleurodesis failure.

Analysis 11.2. Comparison 11 OK-432, Outcome 2 Pain.

Analysis 11.3. Comparison 11 OK-432, Outcome 3 Fever.

Analysis 11.4. Comparison 11 OK-432, Outcome 4 Mortality.

Analysis 12.1. Comparison 12 Mepacrine, Outcome 1 Pain.

Analysis 12.2. Comparison 12 Mepacrine, Outcome 2 Fever.

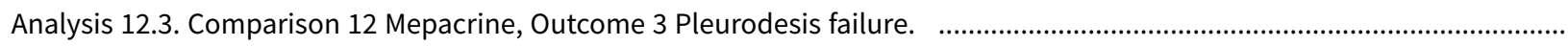

Analysis 12.4. Comparison 12 Mepacrine, Outcome 4 Mortality.

Analysis 13.1. Comparison 13 Interferon (IFN), Outcome 1 Pleurodesis failure.

Analysis 13.2. Comparison 13 Interferon (IFN), Outcome 2 Pain.

Analysis 13.3. Comparison 13 Interferon (IFN), Outcome 3 Fever.

Analysis 13.4. Comparison 13 Interferon (IFN), Outcome 4 Mortality.

Analysis 14.1. Comparison 14 Triethylenethiophophoramide, Outcome 1 Pleurodesis failure.

Analysis 14.2. Comparison 14 Triethylenethiophophoramide, Outcome 2 Pain.

Analysis 14.3. Comparison 14 Triethylenethiophophoramide, Outcome 3 Fever.

Analysis 15.1. Comparison 15 Adriamycin, Outcome 1 Pleurodesis failure.

Analysis 15.2. Comparison 15 Adriamycin, Outcome 2 Fever.

Analysis 15.3. Comparison 15 Adriamycin, Outcome 3 Pain.

Analysis 16.1. Comparison 16 Placebo, Outcome 1 Pleurodesis failure.

Analysis 16.2. Comparison 16 Placebo, Outcome 2 Pain.

Analysis 16.3. Comparison 16 Placebo, Outcome 3 Fever.

Analysis 17.1. Comparison 17 Mustine, Outcome 1 Pleurodesis failure.

Analysis 17.2. Comparison 17 Mustine, Outcome 2 Fever.

Analysis 17.3. Comparison 17 Mustine, Outcome 3 Mortality.

Analysis 17.4. Comparison 17 Mustine, Outcome 4 Pain.

Analysis 18.1. Comparison 18 Mitoxantrone, Outcome 1 Pleurodesis failure. -

Analysis 18.2. Comparison 18 Mitoxantrone, Outcome 2 Pain

Analysis 18.3. Comparison 18 Mitoxantrone, Outcome 3 Fever.

Analysis 18.4. Comparison 18 Mitoxantrone, Outcome 4 Mortality.

Analysis 19.1. Comparison 19 Drain size, Outcome 1 Pleurodesis failure.

Analysis 19.2. Comparison 19 Drain size, Outcome 2 Pain.

Analysis 19.3. Comparison 19 Drain size, Outcome 3 Mortality.

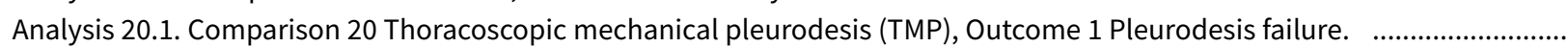

Analysis 20.2. Comparison 20 Thoracoscopic mechanical pleurodesis (TMP), Outcome 2 Mortality.

Analysis 21.1. Comparison 21 Other, Outcome 1 Pleurodesis failure.

Analysis 21.2. Comparison 21 Other, Outcome 2 Pain.

Analysis 21.3. Comparison 21 Other, Outcome 3 Fever.

Analysis 21.4. Comparison 21 Other, Outcome 4 Mortality.

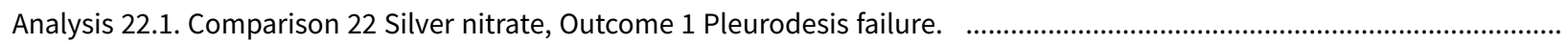

Analysis 22.2. Comparison 22 Silver nitrate, Outcome 2 Fever.

Analysis 23.2. Comparison 23 Cisplatin, Outcome 2 Pain.

Analysis 23.3. Comparison 23 Cisplatin, Outcome 3 Fever.

Analysis 23.4. Comparison 23 Cisplatin, Outcome 4 Mortality.

Analysis 24.1. Comparison 24 Duration of drainage prior to administration of sclerosant, Outcome 1 Pleurodesis failure.

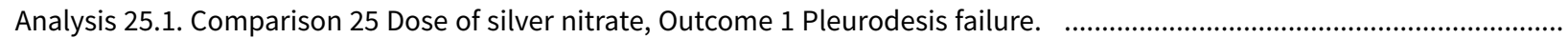

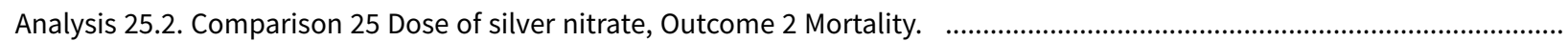

Analysis 25.3. Comparison 25 Dose of silver nitrate, Outcome 3 Pain. 
[Intervention Review]

\section{Interventions for the management of malignant pleural effusions: a network meta-analysis}

Amelia O Clive ${ }^{1}$, Hayley E Jones ${ }^{2}$, Rahul Bhatnagar ${ }^{1}$, Nancy J Preston ${ }^{3}$, Nick Maskell ${ }^{1}$

1Academic Respiratory Unit, University of Bristol, Bristol, UK. 2School of Social and Community Medicine, University of Bristol, Bristol, UK. IInternational Observatory on End of Life Care, Lancaster University, Lancaster, UK

Contact address: Amelia O Clive, Academic Respiratory Unit, University of Bristol, Southmead Road, Bristol, BS10 5NB, UK. Amelia.Clive@nbt.nhs.uk, ameliadunscombe@yahoo.co.uk.

Editorial group: Cochrane Pain, Palliative and Supportive Care Group

Publication status and date: Stable (no update expected for reasons given in 'What's new'), published in Issue 4, 2019.

Citation: Clive AO, Jones HE, Bhatnagar R, Preston NJ, Maskell N. Interventions for the management of malignant pleural effusions: a network meta-analysis. Cochrane Database of Systematic Reviews 2016, Issue 5. Art. No.: CD010529. DOI:

10.1002/14651858.CD010529.pub2.

Copyright @ 2019 The Cochrane Collaboration. Published by John Wiley \& Sons, Ltd.

\section{A B S T R A C T}

\section{Background}

Malignant pleural effusion (MPE) is a common problem for people with cancer as a result of malignant infiltration of the pleura. It is usually associated with considerable breathlessness. A number of treatment options are available to manage the uncontrolled accumulation of pleural fluid including administration of a pleurodesis agent (either via a chest tube or at thoracoscopy) or indwelling pleural catheter insertion.

\section{Objectives}

To ascertain the optimal management strategy for adults with malignant pleural effusion in terms of pleurodesis success. Additionally, to quantify differences in patient-reported outcomes and adverse effects between management strategies.

\section{Search methods}

We searched The Cochrane Central Register of Controlled Trials (CENTRAL), Ovid MEDLINE, Ovid EMBASE; EBSCO CINAHL; SCI-EXPANDED and SSCI (ISI Web of Science) to April 2015.

\section{Selection criteria}

We included randomised controlled trials of intrapleural interventions for adults with symptomatic MPE in the review.

\section{Data collection and analysis}

Two review authors independently extracted data on study design, study characteristics, outcome measures, potential effect modifiers and risk of bias.

The primary outcome measure was pleurodesis failure rate. Secondary outcome measures were adverse effects and complications, patient-reported control of breathlessness, quality of life, cost, mortality, duration of inpatient stay and patient acceptability.

We performed network meta-analysis with random effects to analyse the primary outcome data and those secondary outcomes with enough data. We also performed pair-wise random-effects meta-analyses of direct comparison data. If interventions were not deemed jointly randomisable, or insufficient data were available, we reported the results by narrative synthesis. We performed sensitivity analyses to explore heterogeneity and to evaluate only those pleurodesis agents administered via a chest tube at the bedside. 


\section{Main results}

Of the 1888 records identified, 62 randomised trials, including a total of 3428 patients, were eligible for inclusion. All studies were at high or uncertain risk of bias for at least one domain.

Network meta-analysis evaluating the rate of pleurodesis failure, suggested talc poudrage to be a highly effective method (ranked second of 16 (95\% credible interval ( $\mathrm{Cr}-\mathrm{I}) 1$ to 5)) and provided evidence that it resulted in fewer pleurodesis failures than eight other methods. The estimated ranks of other commonly used agents were: talc slurry (fourth; $95 \% \mathrm{Cr}-\mathrm{I} 2$ to 8 ), mepacrine (fourth; $95 \% \mathrm{Cr}-\mathrm{I} 1$ to 10 ), iodine (fifth; 95\% Cr-I 1 to 12), bleomycin (eighth; 95\% Cr-I 5 to 11 ) and doxycyline (tenth; 95\% Cr-I 4 to 15). The estimates were imprecise as evidenced by the wide credible intervals and both high statistical and clinical heterogeneity.

Most of the secondary outcomes, including adverse events, were inconsistently reported by the included studies and the methods used to describe them varied widely. Hence the majority of the secondary outcomes were reported descriptively in this review. We obtained sufficient data to perform network meta-analysis for the most commonly reported adverse events: pain, fever and mortality. The fever network was imprecise and showed substantial heterogeneity, but suggested placebo caused the least fever (ranked first of 11 (95\% Cr-I 1 to 7)) and mepacrine and Corynebacterium parvum (C. parvum) appeared to be associated with the most fever (ranked tenth (95\% Cr-I 6 to 11 ) and eleventh ( $95 \% \mathrm{Cr}-\mathrm{I} 7$ to 11 ) respectively). No differences between interventions were revealed by the network meta-analysis of the pain data. The only potential difference in mortality identified in the mortality network was that those receiving tetracycline appeared to have a longer survival than those receiving mitoxantrone (OR 0.16 ( $95 \%$ Confidence Interval ( $\mathrm{Cl}) 0.03$ to 0.72 )). Indwelling pleural catheters were examined in two randomised studies, both of which reported improved breathlessness when compared to talc slurry pleurodesis, despite lower pleurodesis success rates.

The risk of bias in a number of the included studies was substantial, for example the vast majority of studies were unblinded, and the methods used for sequence generation and allocation concealment were often unclear. Overall, however, the risk of bias for all studies was moderate. We have not reported the GRADE quality of evidence for the outcomes, as the role of GRADE is not well established in the context of Network Meta-analysis (NMA).

\section{Authors' conclusions}

Based on the available evidence, talc poudrage is a more effective pleurodesis method in MPE than a number of other frequently used methods, including tetracycline and bleomycin. However further data are required to definitively confirm whether it is more effective than certain other commonly used interventions such as talc slurry and doxycycline, particularly in view of the high statistical and clinical heterogeneity within the network and the high risk of bias of many of the included studies. Based on the strength of the evidence from both direct and indirect comparisons of randomised data of sclerosants administered at the bedside, there is no evidence to suggest large differences between the other highly effective methods (talc slurry, mepacrine, iodine and C. parvum). However, local availability, global experience of these agents and their adverse events, which may not be identified in randomised trials, must also be considered when selecting a sclerosant. Further research is required to delineate the roles of different treatments according to patient characteristics (e.g. according to their prognosis or presence of trapped lung) and to explore patient-centred outcomes, such as breathlessness and quality of life, in more detail. Careful consideration to minimise the risk of bias and standardise outcome measures is essential for future trial design.

\section{PLAIN LANGUAGE SUMMARY}

\section{Interventions for the management of fluid around the lungs (pleural fluid) caused by cancer}

\section{Review Question}

We reviewed the evidence about the effectiveness of different methods to manage fluid around the lung in patients with a build up of this fluid caused by cancer.

\section{Background}

Malignant pleural effusion (MPE) is a condition whereby cancer of the lining of the lung results in fluid building up in the space between the lung and rib cage (pleural cavity), often resulting in breathlessness. Treatment options include removal of the fluid using either a temporary chest drain, a camera examination of the pleural cavity (thoracoscopy) or a semi-permanent chest drain tunnelled under the skin (an indwelling pleural catheter). Introducing a chemical into the pleural cavity can also be used to prevent the fluid coming back (pleurodesis). We wanted to find out which method was the most effective in terms of preventing fluid build up and which was best in terms of side effects and patient-reported outcomes such as pain, fever, breathlessness and quality of life.

\section{Study Characteristics}

We searched databases for trials comparing different interventions in adults with symptomatic MPE to April 2015, written in any language. Since we were only interested in rigorously conducted research, we restricted our search to randomised controlled trials (in which participants are randomly allocated to the methods being tested). We analysed the majority of the data using a technique called 'network meta-analysis' which allows lots of different interventions to be compared in one analysis. This analysis ranks the interventions in order of their effectiveness. 


\section{Key Results}

We found 62 studies involving 3428 patients.

In the network meta-analysis, the use of thoracoscopy to remove the fluid and blow talc into the pleural cavity (talc poudrage) appeared to be more effective in preventing fluid build up than a number of other commonly used methods. However, we could not say definitely that it is better than some other methods such as giving talc or doxycycline through a chest drain.

Side effects, quality of life and patient satisfaction were reported inconsistently by the included studies, but are important factors to consider when selecting the best management strategy for a patient. There was enough data to perform network meta-analysis for pain, fever and mortality. We found placebo caused the least fever and Corynebacterium parvum (C. parvum) and mepacrine were likely to cause the most. We found no differences in the pain caused by the interventions evaluated. Only one comparison showed a possible difference, revealing that those receiving tetracycline may live longer than those receiving mitoxantrone. As we only evaluated randomised controlled trials, it is possible some harms of treatments were not identified by this review.

\section{Quality of the Evidence}

Many of the studies were of low quality and the characteristics of the individual studies were quite different to each other. This high risk of bias makes it difficult to reach definite conclusions.

\section{Conclusions}

The available evidence shows that talc poudrage can stop fluid building up. However, we can not be sure that this is definitely the best method, and further research is needed. It is also important to consider global experience of these agents and knowledge of their safety and side effects when selecting the most appropriate pleurodesis method. Indwelling pleural catheters may help improve patient breathlessness, but may be less good at stopping the fluid coming back.

Further research is also required to look at particular patient groups and explore patient-centred outcomes, such as breathlessness and quality of life in more detail. Ideally a fuller understanding of the potential harms of the treatments from the patients' perspective would also be beneficial. 


\section{B A C K G R O U N D}

Malignant pleural effusion (MPE) is a common clinical problem, with an estimated annual incidence of at least 150,000 in the USA alone (American Thoracic Society 2000). Fifteen percent of people diagnosed with cancer will develop pleural effusion during the course of their disease as a result of malignant infiltration of the pleura. It often confers a poor prognosis (Rodrîguez-Panadero 1989). Breathlessness results from compression of the underlying lung and impaired diaphragmatic and chest wall movement and is often relieved by pleural fluid aspiration.

\section{Description of the condition}

MPE is a condition whereby excess fluid accumulates in the pleural cavity, caused by direct pleural tumour invasion, resulting in increased permeability of the pleural microvessels and involvement of local lymph nodes causing reduced fluid reabsorption (Rodrîguez-Panadero 2008). The most common primary sites which metastasise to the pleura are lung cancer in men and breast cancer in women, but other primary sites include lymphoma, genitourinary and gastrointestinal malignancy (DiBonito 1992; Sears 1987). In addition, the pleura may be the primary site of the malignancy, as is the case in mesothelioma. In the majority of cases, the diagnosis of pleural malignancy is made by cytological analysis of the pleural fluid or pleural biopsy. Depending on the clinical situation, confirmation of malignancy elsewhere and an otherwise unexplained (usually exudative) effusion may also be attributed to malignancy. Survival of these patients varies widely (Bielsa 2008; Burrows 2000) and estimation of an individual's prognosis may help with the selection of the most appropriate management strategy (Clive 2014).

Trapped lung can occur when full lung expansion is limited by either a visceral pleural peel or endobronchial obstruction and in this situation, even once the fluid is drained, visceral and parietal pleural apposition does not occur. This results in pleurodesis attempts being less effective and often limits the treatment options to either an indwelling pleural catheter or surgery.

\section{Description of the intervention}

A number of different approaches may be used to manage MPE and the chosen method is likely to depend on clinical factors, patient preferences and local availability of the various techniques. Instillation of a sclerosant into the pleural cavity through an intercostal chest drain after complete fluid drainage has been the mainstay of treatment for many years (known as 'bedside' or 'slurry' pleurodesis). This technique aims to fuse the pleural layers together by means of local inflammation induced by the pleurodesis agent, thereby preventing pleural fluid reaccumulation. The optimal management strategy to maximise pleurodesis success in terms of the size of chest drain, patient positioning, use of analgesia and type of sclerosant is still the subject of debate (Roberts 2010). The role of intrapleural fibrinolytics to break down septations and loculations within the effusion prior to administration of the pleurodesis agent is also yet to be formally established (Davies 1999; Gilkeson 1999; Hsu 2006).

Thoracoscopy is an alternative method, which is used to drain the effusion and deliver a sclerosant into the pleural cavity. This can either be performed under conscious sedation (local anaesthetic thoracoscopy), or as a surgical procedure under general anaesthetic (Video Assisted Thoracoscopic Surgery (VATS)). In both techniques, the pleural fluid is drained and the pleural cavity is visualised using a fibre-optic camera. Loculations can be broken down and biopsies may be taken to gain a histological diagnosis. A pleurodesis agent can then be delivered by way of insufflation (poudrage) prior to the insertion of a chest drain (Rahman 2010).

An alternative approach in the management of MPE is the use of indwelling pleural catheters (IPCs). These are chest tubes, which are tunnelled under the skin and allow long-term, intermittent fluid drainage to be performed in the community, thereby minimising recurrent hospital attendances. They have an established role in the management of pleural effusions in patients with trapped lung, but are increasingly being used for the primary management of malignant effusions as an alternative to chemical pleurodesis (Davies 2012; Demmy 2012). In a proportion of patients with IPCs, spontaneous pleurodesis occurs, allowing the drain to be removed without recurrence of the effusion (Tremblay 2006).

In certain clinical scenarios, none of the above options may be suitable and simple pleural fluid aspiration or medical management of a patient's breathlessness (for example using opiates) may be deemed more appropriate. This may be the case for patients in the terminal phase of their illness where invasive techniques may be felt to confer unnecessary discomfort.

\section{How the intervention might work}

Pleurodesis aims to fibrose the pleural layers together in order to obliterate the pleural space and by so doing prevent fluid recurrence. For pleurodesis to be successful the visceral and parietal pleural surfaces must be opposed and hence if lung expansion is incomplete (for example if the effusion is very loculated or the patient has trapped lung), pleurodesis is more likely to fail. The sclerosant stimulates an inflammatory reaction within the pleural cavity, which results in fusion of the visceral and parietal pleura.

Indwelling pleural catheters allow intermittent pleural fluid drainage, which relieves the pressure on the diaphragm and chest wall and promotes lung re-expansion. By so doing, breathlessness is improved and spontaneous pleurodesis occurs in up to $50 \%$ of patients (Putnam 2000).

\section{Why it is important to do this review}

Due to wider availability of pleural interventions, such as thoracoscopy and indwelling pleural catheters, the management options available to patients with MPE are expanding. This review will help to delineate the specific roles of the different techniques and identify factors which may improve pleurodesis rates for those undergoing a bedside pleurodesis. This review includes an update of a Cochrane systematic review first published in 2004, 'Pleurodesis for malignant pleural effusions' (Shaw 2004) and will subsequently help to inform national guidelines in this area.

Given the availability of many pair-wise comparisons for the method of pleurodesis administration and type of pleurodesis agent, this is a multiple interventions review. Network metaanalysis has been performed to synthesise all the available evidence and investigate a treatment hierarchy. 


\section{O B JECTIVES}

To ascertain the optimal management strategy for adults with malignant pleural effusion in terms of pleurodesis success. Additionally, to quantify differences in patient-reported outcomes and adverse effects between management strategies.

\section{METHOD S}

\section{Criteria for considering studies for this review}

\section{Types of studies}

We only included reports of randomised controlled trials (RCTs) in this review. This would have included randomised cross-over trials and cluster randomised trials, although no studies of these types were identified. We included both single and multi-centre studies. Studies, which were stated to be randomised but were found to be at high risk of bias for adequate sequence generation or allocation concealment, were excluded.

\section{Types of participants}

\section{Inclusion}

- Adults over the age of 16 .

- Symptomatic pleural effusion resulting from an underlying malignant process (of any type and stage).

\section{Exclusion}

- Studies recruiting both malignant and non-malignant participants with no clear distinction between the two groups in the results section.

- Studies evaluating the effect of a drug administered via any method other than the intra-pleural route.

- Studies including participants with effusions within a variety of body cavities (e.g. pleural, peritoneal, pericardial), where the effect of the treatments in the subgroup of patients with pleural effusions cannot be distinguished in the results section.

\section{Types of interventions}

We identified studies comparing the following.

- Type of sclerosant.

- Mode of administration of sclerosant (thoracoscopic pleurodesis and bedside pleurodesis).

- Bedside or thoracoscopic pleurodesis and indwelling pleural catheter insertion.

- Techniques used to optimise pleurodesis success rate, namely:

* chest drain size;

* type of analgesia given;

* duration of drainage after instillation of sclerosant;

* patient positioning after pleurodesis (for example, patient rotation);

* use of intrapleural fibrinolytics.

We generated a network of interventions, including comparisons between the types of sclerosant, mode of administration and IPC use. We assumed that any participant meeting the inclusion criteria could be, in principle, randomised to any of the eligible interventions. This is referred to as the interventions being 'jointly randomisable'. However, if an intervention was not felt to be jointly randomisable, for example the treatment was specific to a certain tumour type, we reported the results separately from the network (Salanti 2012).

\section{Interventions of direct interest}

We included RCTs that evaluated one or more of the following intrapleural interventions: talc poudrage, talc slurry, bleomycin, tetracycline, doxycycline, iodine, C.parvum, IPC, mitoxantrone, mustine, mepacrine, interferon, triethylenethiophosphoramide and adriamycin, compared with another intervention or placebo. If we identified other sclerosants that we were not aware of, we considered them as eligible and we included them in the network after assessing their comparability with the pre-specified set of competing interventions. We reported the findings for these interventions in the results and the conclusions of the review.

\section{Types of outcome measures}

\section{Primary outcomes}

The efficacy of pleurodesis was our primary outcome measure.

Definitions of pleurodesis failure varied between studies and although current practice would define this by a lack of recurrence of symptoms or need for a repeat pleural intervention to manage the effusion, in some older studies, less clinically relevant definitions were used (for example, re-accumulation of effusion on imaging). We still included these studies in the review, and documented the method used to define pleurodesis for all studies in the assessment of the risk of bias.

For the purposes of the primary outcome, we used the following hierarchy of preferences to judge pleurodesis failure (if a study reported more than one definition of pleurodesis failure, the highest of these according to this hierarchy was used):

- need for a repeat pleural procedure to manage recurrence of the effusion, or ongoing drainage of pleural fluid from an indwelling pleural catheter (if applicable);

- evidence of significant pleural fluid re-accumulation on radiological imaging (for example, chest X-ray or ultrasound);

- pleurodesis failure in the opinion of the trial investigators.

Similarly, we selected the time point used to define pleurodesis efficacy was selected using the following hierarchy of preferences:

- 2 - 4 months;

- > 4 - 7 months;

- > 7 - 11 months;

- > 11 - 12 months;

- < 2 months;

- $>12$ months.

Participants who died before the time point at which pleurodesis efficacy was assessed, were classified according to their last known pleurodesis outcome prior to their death (i.e. their last observation carried forward). If these data were not provided, we used the available reported data. 


\section{Secondary outcomes}

- Adverse effects and complications due to interventions, specifically the presence or absence of pain and fever after the intervention.

- Patient-reported control of breathlessness, as measured by a valid and reliable scale (for example, visual analogue scale (VAS), numeric rating scale or dyspnoea/breathlessness specific multidimensional scale) ${ }^{\star}$

- The participants' quality of life and symptom control (including pain), as measured by a valid and reliable scale ${ }^{\star}$

- Relative costs of the comparative techniques as reported by the individual trials. For ease of comparison, data reported in other currencies were converted to USD. ${ }^{*}$

- The overall mortality (we used the data for the reported outcomes closest to three months).

- Median survival.

- Duration of inpatient stay in days (both total length of stay and from time of intervention until discharge). ${ }^{*}$

- Patient acceptability of the interventions as judged by a valid scale (for example, visual analogue scale or numeric rating scale). ${ }^{\star}$

* if available

\section{Search methods for identification of studies}

Trials that compared at least two of the interventions (including placebo) were eligible. We included all possible comparisons formed by the interventions of interest.

\section{Electronic searches}

To identify studies for inclusion in this review, we searched the following databases:

- The Cochrane Central Register of Controlled Trials (CENTRAL) (The Cochrane Library) Issue 3 of 12, 2015;

- MEDLINE (Ovid) 1948 to $1 / 04 / 15$;

- EMBASE (Ovid) 1974 to $1 / 04 / 15$;

- CINAHL (EBSCO) 1980 to April 2015;

- Web of Science Science Citation Index Expanded (SCIEXPANDED) and Social Sciences Citation Index (SSCI) searched to 2015.

The search strategies can be viewed in Appendix 1. There were no language restrictions. We included single and multi-centre studies.

\section{Searching other resources}

We screened the reference lists from the included studies for additional publications. We also searched the reference lists from relevant chapters in key resources, such as the British Thoracic Society Pleural Disease Guidelines (Roberts 2010).

\section{Data collection and analysis}

\section{Selection of studies}

One author screened all titles and abstracts retrieved by the search for relevance (AOC). We identified potentially eligible studies and obtained the full papers. Two review authors (AOC and NAM) independently assessed each study for inclusion in the review and any disagreement was resolved through discussion or by a third author (NP).

\section{Data extraction and management}

Two of the review authors (AOC with NAM, NP or RB) extracted data from each included study. We resolved disagreements through discussion and referral to one of the other review authors. If an author was involved in one of the included studies, they did not perform the data extraction for that study. Data collected included the following.

- Publication details including:

* title, author(s), date, country and other citation details;

* study aim and design;

* primary and secondary outcomes;

* number of participants randomised.

- Details of the interventions and comparison group including type of intervention, duration, dose, mode of administration and number of doses.

- Primary and secondary outcome measures (as detailed above) and data on adverse events and complications.

- Assessment of the study's risk of bias.

- Data on potential effect modifiers including the following study and patient characteristics:

- how pleurodesis was defined (radiology only or including clinical need as well as radiology);

- whether patients with trapped lung were included or not;

- the size of the chest tube through which bedside pleurodesis was administered (defined as small ( $<20$ French), large $(\geq 20$ French) or unknown);

- the time point at which pleurodesis was defined;

- the tumour types included in the study.

We had planned to look at specific areas of study quality, which were incorporated into the assessment of the risk of bias. We requested additional data from the study authors as required. One author (AOC) entered data suitable for pooling into the Cochrane Collaboration's statistical software, Review Manager (RevMan) (RevMan 2014). Where we performed network meta-analysis, we transferred data to the WinBUGS software (Lunn 2000).

\section{Assessment of risk of bias in included studies}

We limited inclusion to studies that were randomised as a minimum. Two of the review authors (AOC with NP, RB or NM) independently assessed risk of bias for each study, using the criteria outlined in the Cochrane Handbook for Systematic Reviews of Interventions (Higgins 2011a), and adapted from those used by the Cochrane Pregnancy and Childbirth Group, with any disagreements resolved by discussion. In our original protocol, we had planned to include sample size in our risk of bias assessment. However, in view of Cochrane guidance stating imprecision should not be considered a risk of bias, we did not perform this assessment (Higgins 2011a). We assessed the following for each study.

\section{Random sequence generation (checking for possible selection bias)}

We assessed the method used to generate the allocation sequence as: low risk of bias (any truly random process, e.g. random number table; computer random-number generator); unclear risk 
of bias (method used to generate sequence not clearly stated). We excluded studies using a non-random process i.e. at high risk of bias (e.g. odd or even date of birth; hospital or clinic record number).

\section{Allocation concealment (checking for possible selection bias)}

The method used to conceal allocation to interventions prior to assignment determines whether intervention allocation could have been foreseen in advance of, or during, recruitment, or changed after assignment. We assessed the methods as: low risk of bias (e.g. telephone or central randomisation; consecutively numbered sealed opaque envelopes); unclear risk of bias (method not clearly stated). We excluded studies at high risk of bias that did not conceal allocation (e.g. open list).

\section{Blinding of participants and personnel (checking for possible performance bias)}

We assessed the methods used to blind study participants and personnel from knowledge of which intervention a participant received. We assessed the methods as: low risk of bias (study stated there was blinding of participants and key study personnel and unlikely blinding could be broken, or no blinding or incomplete blinding but the outcome not likely to be influenced by lack of blinding); unclear risk of bias (insufficient information to permit judgement of low or high risk of bias); high risk of bias (no blinding or incomplete blinding, which is likely to influence the trial outcome or blinding attempted but likely it could have been broken and the outcome is likely to be influenced by lack of blinding).

\section{Blinding of outcome assessment (checking for possible detection bias)}

We assessed the methods used to blind outcome assessors from knowledge of which intervention a participant received. We assessed the methods as: low risk of bias (study stated that it was not blinded but the review authors judged that the outcome measurement is not likely to be influenced by lack of blinding or blinding of outcome assessment was ensured); unclear risk of bias (study provided an inadequate description to permit judgment of 'low risk' or 'high risk'); high risk of bias (no blinding of outcome assessment and outcome likely to be influenced by lack of blinding, or there was blinding of the outcome assessment but likely that the blinding could have been broken).

\section{Incomplete outcome data (checking for possible attrition bias due to the amount, nature and handling of incomplete outcome data)}

We assessed the methods used to deal with loss to follow up for each of the given studies. Due to the challenges of inevitable missing outcome data given the predictable attrition of patients due to death in the palliative care population, we took into account whether missing data had been justified, whether the rate was similar in the different treatment arms, whether the treatment being evaluated was felt to have an impact on the degree of missing outcome data and whether an intention to treat analysis had been attempted. We assessed the methods used to deal with incomplete data as: low risk (rate of missing data were balanced between the treatment arms, seemed reasonable and had been justified data had been analysed according to the patients' randomised treatment allocation; a suitable imputation method may have been used to account for missing data); unclear risk of bias (insufficient information given to allocate trial to 'high' or 'low' risk group); high risk of bias (imbalanced missing outcome data between the treatment arms or missing outcome data felt to be related to the true outcome; reasons for loss to follow up poorly justified; no attempt at ITT analysis; inappropriate imputation used).

\section{Selective Outcome Reporting}

We assessed the studies for selective outcome reporting using the following criteria: low risk of bias (all outcomes pre-defined and reported, for example in a published protocol, or all clinically relevant and reasonably expected outcomes were reported); uncertain risk of bias (unclear whether all pre-defined and clinically relevant outcomes were reported); high risk of bias (one or more clinically relevant and reasonably expected outcome was not reported and data on these outcomes were likely to have been recorded).

\section{Other sources of bias}

This section was used to report other biases, which were detected but did not fit into the above categories (for example, industry bias, academic bias or other methodological flaws that may have caused bias). We assessed the methods used to deal with other sources of bias as: low risk (the trial appeared to be free from other potential biases); unclear risk of bias; high risk of bias (other source of bias was identified).

\section{Measures of treatment effect}

\section{Relative treatment effects}

For proportions (dichotomous outcomes), such as pleurodesis efficacy and mortality, we calculated the Odds Ratio (OR) with $95 \%$ confidence intervals (Cls). For continuous data (such as length of hospital stay and cost) we planned to use the mean difference (MD) with $95 \% \mathrm{Cls}$ and also the number needed to treat (NNT) to benefit for efficacy outcome, and the number needed to harm (NNH) for adverse events.

We planned to treat ordinal outcome measures (for example, breathlessness scales and quality of life data) as continuous so long as the scale was long enough. If different scales were used by the included studies, we planned to use the standardised mean difference in meta-analyses.

We presented results from both pair-wise standard meta-analysis and network meta-analysis (NMA) as summary relative effect sizes (OR, MD or SMD with $95 \% \mathrm{Cls}$ ) for each possible pair of treatments (Deeks 2011).

\section{Relative treatment ranking}

Based on the results of the network meta-analysis, we estimated the rank of each competing intervention's effectiveness. We presented estimated ranks (medians) with $95 \%$ credible intervals (Cr-Is) (representing uncertainty about the true rank) produced from the Bayesian analyses (Higgins 2011b).

\section{Unit of analysis issues}

If repeated observations on the same participants occurred during the trial (for example, pleurodesis success rate at different time points), we analysed these separately. Only one measure per participant was used for the primary endpoint (according to the hierarchy of preferences detailed above Primary outcomes). 
For the purpose of meta-analysis, if a study had multiple doses for a certain substance, we combined and compared all relevant experimental intervention groups with the combination of all relevant control groups. We reported any evidence for effects of the different doses descriptively.

For cross-over trials, we planned to analyse data using pair-wise meta-analysis, taking into account the cross-over design. If metaanalysis had been performed containing cluster randomised trials and the presented results had not accounted for clustering, then we planned to make an appropriate adjustment, as described in the Cochrane Handbook (Higgins 2011b).

We treated multi-arm studies as multiple independent two-arm studies in the standard pair-wise meta-analysis. In the network meta-analysis, we accounted for the correlation between the effect sizes from multi-arm studies.

\section{Dealing with missing data}

We attempted to contact the study authors of included studies to clarify any missing data. We would have imputed the missing standard deviations based on the average standard deviations from the other included studies if standard deviations for mean scores had not been reported and it had not been possible to obtain the information from the study authors. We only included data for those participants whose results were known if an intention-totreat analysis was not reported by the study. However, we assessed the potential impact of these missing data in the 'Risk of bias' table.

\section{Assessment of heterogeneity}

\section{Assessment of clinical and methodological heterogeneity within treatment comparisons}

We extracted data from study reports regarding clinical heterogeneity such as details on the intervention and control treatments, participant characteristics and the outcomes evaluated.

We assessed the presence of clinical heterogeneity within each pair-wise comparison by comparing the study population characteristics across all eligible trials. We only performed metaanalysis when considered reasonable based on the degree of heterogeneity.

\section{Assessment of transitivity across treatment comparisons}

We assessed the assumption of transitivity by comparing the distribution of the potential effect modifiers across the different pair-wise comparisons.

\section{Assessment of reporting biases}

We performed searches in multiple databases to ensure all potentially eligible studies were identified (Electronic searches). The review authors were alert to duplicated publication of results when analysing the studies to ensure each participant was only included once in the analysis.

If unpublished studies were identified, we tried to obtain sufficient information in order for them to be included in the analysis. The same applied for data published in abstract format.

In studies published in a language other than English, we made every effort to obtain a translation of at least the abstract. If sufficient information was available, we included the study in the analysis.

\section{Data synthesis}

\section{Methods for direct treatment comparisons}

Since we expected some clinical heterogeneity between studies (for example due to different definitions of pleurodesis success, different time points and doses used), we believed that the assumption of a single fixed intervention effect across included studies was unlikely to be valid. Our primary analyses therefore employed random-effects models. Since pooled effect estimates from random-effects models give relatively more weight to smaller studies, which is often considered undesirable, we performed sensitivity analyses using fixed-effect meta-analysis models. We performed standard pair-wise meta-analysis using a randomeffects model in Cochrane's statistical software, RevMan 2014 for every treatment comparison with two or more studies.

For binary outcome data, we meta-analysed odds ratios (ORs). For continuous data we planned to use the mean difference (MD) or standardised mean difference (SMD) and perform a check to identify if continuous outcome data were skewed. If this was the case, we planned to analyse the data on a log scale.

If we assessed studies as unsuitable for meta-analysis, or insufficient studies were identified for meta-analysis to be performed, we planned to present data by means of a narrative synthesis.

If sufficient data were available, we used similar analysis methods to analyse the adverse effects data. Alternatively we summarised this qualitatively.

\section{Methods for indirect and mixed comparisons}

Wherever possible, we performed a multiple-intervention, network meta-analysis of primary and (separately) of each secondary outcome measure. We used a Bayesian random-effects model, fitted using the WinBUGS software (Lunn 2000). We assumed a binomial likelihood and an uninformative normal prior distribution, with mean 0 and standard deviation of 100 for all baseline event rates and intervention effects on the logit scale. When network meta-analyses were performed, we used the Stata software to generate a network plot (using the networkplot command) and inconsistency plot (using the ifplot command) (Chaimani 2013).

\section{Subgroup analysis and investigation of heterogeneity \\ Assessment of statistical heterogeneity}

In pair-wise meta-analyses we estimated the between-study standard deviation ( $\left.\mathrm{Tau}^{2}\right)$ separately for each intervention comparison. For the direct treatment comparisons, we quantified the heterogeneity across studies using the $1^{2}$ statistic, which we interpreted taking into account the magnitude and direction of effect as well as the confidence interval (Higgins 2003).

The assessment of statistical heterogeneity in the network metaanalysis was based on the magnitude of and credible intervals for the between-studies standard deviation (Tau) estimated from the NMA models. In network meta-analysis we assumed a common Tau 
across all comparisons. We assumed a vague uniform $(0,2)$ prior distribution for Tau.

As described below, reasons for heterogeneity were investigated using subgroup or sensitivity analyses.

\section{Assessment of statistical inconsistency}

Inconsistency in the network refers to differences between the direct and indirect effect estimates for the same comparison (Donegan 2013). We used both a loop-specific approach and a global approach to evaluate these effects.

To evaluate the presence of inconsistency locally we used the loopspecific approach. This assesses the consistency assumption in each closed loop of the network separately. We identified all the triangular loops (comprising three direct treatment comparisons, all compared with each other) and all the quadratic loops (involving four comparisons) in the network. We compared the differences between the direct and indirect estimates for these loops to generate inconsistency factors, with $95 \% \mathrm{Cls}$, calculated and displayed graphically using the 'ifplot' command in Stata (Chaimani 2013). We assumed the estimated between-study standard deviation (Tau) from the Bayesian analysis of the full network for each loop. We used the magnitude of the inconsistency factors to infer the presence and degree of inconsistency in each loop.

In addition to this, we used a global approach, involving formally comparing the fit of the network meta-analysis model (which assumes consistency) with that of an 'inconsistency' model (in which all consistency constraints are removed). The inconsistency model used is equivalent to fitting a random-effects meta-analysis model for all pair-wise comparisons, with a shared betweenstudies variance parameter but no assumptions about direct and indirect evidence forming coherent 'loops'. We calculated the Deviance Information Criterion (DIC) for each model. If the DIC for the inconsistency model was more than five units higher than that of the consistency model, this was viewed as evidence of inconsistency (Dias 2013).

\section{Assessment of statistical imprecision}

We evaluated precision of results, and subsequent rankings, based on their $95 \% \mathrm{Cls}$ (for pair-wise analysis) or Cr-Is (for Bayesian network meta-analysis).

\section{Sensitivity analysis}

\section{Sensitivity analysis and investigation of heterogeneity and inconsistency}

We conducted subgroup or sensitivity network meta-analyses by re-running the model on restricted numbers of studies according to the following potential effect modifiers, which we felt could be sources of inconsistency and/or heterogeneity:

- analysis only including studies which used a clinico-radiological definition of pleurodesis failure;

- analysis only including studies which analysed pleurodesis efficacy at one month after the intervention;

- analysis only including studies which analysed pleurodesis efficacy at three months after the intervention;

- analysis only including studies which analysed pleurodesis efficacy at more than six months after the intervention;

- analysis only including studies which excluded patients with trapped lung;

- analysis only including studies which administered bedside pleurodesis through a large-bore chest tube $(>20 \mathrm{Fr}$ )

- analysis only including studies at a lower risk of bias (two or fewer domains at high risk of bias).

In the protocol, we had planned to investigate different tumour types, age of participants and baseline performance status, although there were insufficient data on this in the included studies to perform these subgroup analyses.

\section{Sensitivity analysis}

We performed a post-hoc sensitivity network meta-analysis evaluating only pleurodesis agents delivered via a chest tube (as opposed to being given at thoracoscopy). We removed the trials evaluating talc poudrage and IPC use from the main network and repeated the analysis.

\section{RE S U L T S}

\section{Description of studies}

\section{Results of the search}

We performed the literature search in April 2015 (see Figure 1). 
Figure 1. Study flow diagram

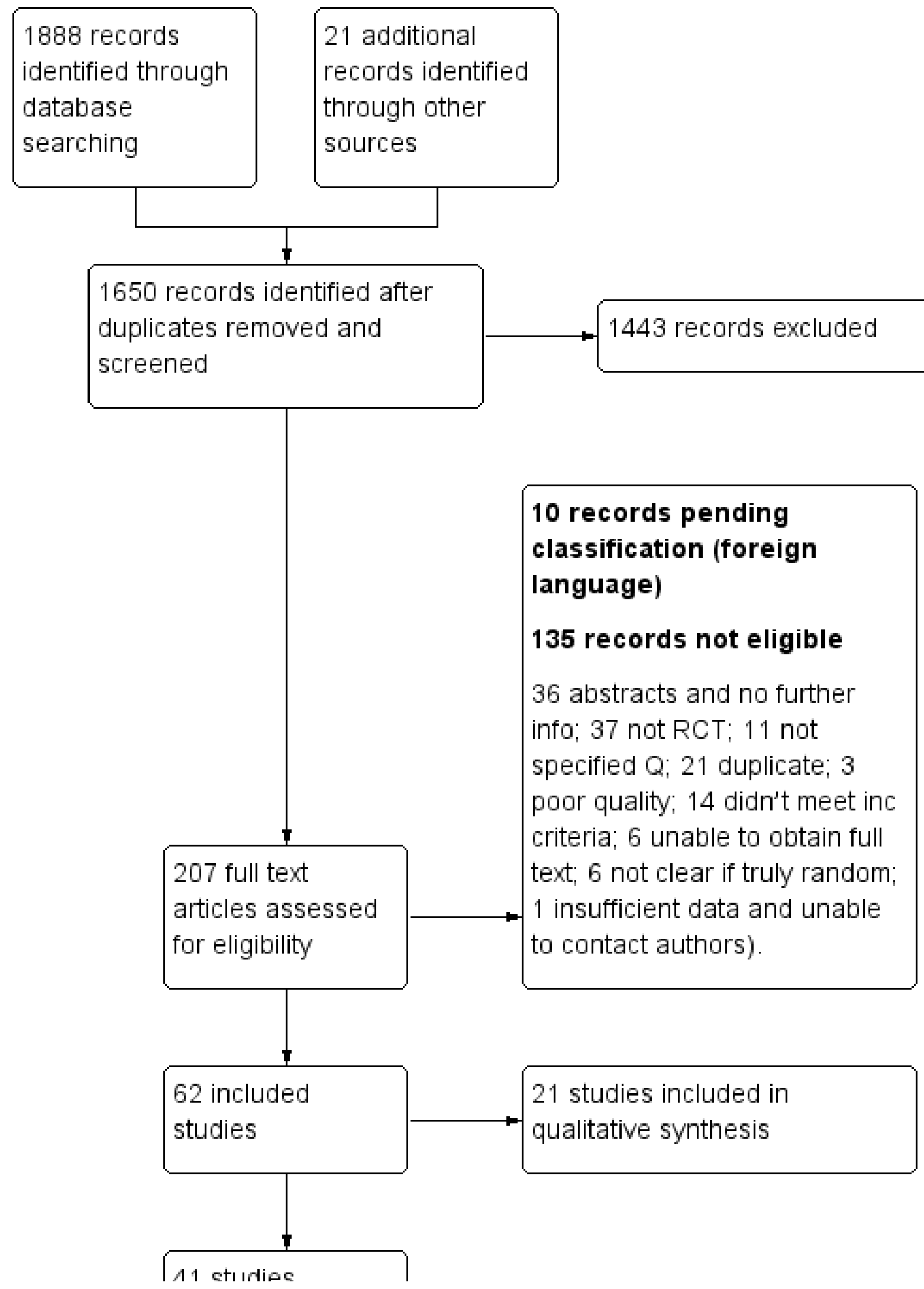


Figure 1. (Continued)

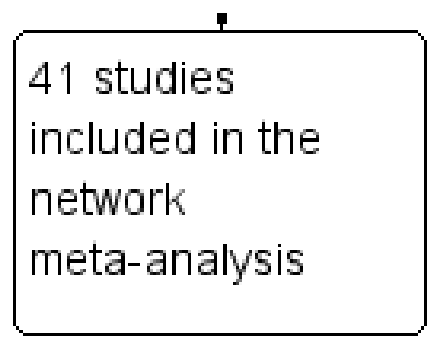

We identified 1888 records from database searches and 21 records from other sources before exclusion of duplicates. We screened 1650 abstracts, of which 207 full text articles were retrieved and assessed for eligibility by two independent researchers (AOC, NAM). Of these, 62 met the eligibility criteria (Characteristics of included studies) and 10 are pending classification as they are awaiting translation (Characteristics of studies awaiting classification). Six on-going studies were also identified (Characteristics of ongoing studies).

Across the 62 included studies, a total of 3428 participants were randomised between 1977 and 2015. There was one foreign language study which was translated from the German (Schmidt 1997).

\section{Included studies}

The majority of studies (39/62) explored the efficacy of a variety of pleurodesis agents. Talc was evaluated in 23 trials, making it the most studied agent. The other most commonly examined agents were bleomycin and tetracycline. Two studies compared indwelling pleural catheters with talc slurry (Davies 2012; Demmy 2012).

Four studies evaluated the mode of administration of the pleurodesis agent (three studies comparing talc poudrage with talc slurry (Dresler 2005; Terra 2009; Yim 1996) and one comparing instillation of tetracycline thoracoscopically or through an intercostal cannula (Evans 1993)). A number of studies evaluated alternative methods to improve pleurodesis (one study examined catheter size (Clementsen 1998); three evaluated the duration of drainage after pleurodesis (Goodman 2006; Villanueva 1994; Yildirim 2005); one evaluated the duration of drainage prior to instillation of the sclerosant (Ozkul 2014); one assessed whether patient rotation improved pleurodesis rate (Mager 2002) and one evaluated the effect of talc particle size (Maskell 2004)). We identified one RCT which examined the role of intrapleural fibrinolytics (Okur 2011). One RCT evaluated administration of three different doses of silver nitrate through a chest tube (Terra 2015).

Two studies compared talc pleurodesis with surgical methods to treat malignant effusion (one comparing either talc pleurodesis with pleurectomy (Rintoul 2014) and one comparing talc slurry with thoracoscopic mechanical pleurodesis (Crnjac 2004)).

Additionally, we identified seven studies of agents specifically for the treatment of effusions due to lung cancer (Du 2013; Ishida 2006; Kasahara 2006; Luh 1992; Masuno 1991; Yoshida 2007; Zhao 2009).
There were a number of methodological differences between the included studies. Forty five of 62 studies included all tumour types; two included all except mesothelioma, one included only mesothelioma; one included only adenocarcinoma; six only breast cancer, and in seven studies only lung cancer patients were included.

The methods to define pleurodesis failure varied between studies. Eighteen of 62 studies used radiological criteria only to define a pleurodesis failure, 44 of 62 studies also incorporated symptomatic recurrence or need for a repeat pleural intervention into their definition. The time point at which pleurodesis was defined varied widely between studies, from 1 to 12 months.

The pleurodesis techniques were not standardised. Studies used a variety of chest drain sizes and durations of pleural fluid drainage after the sclerosant was administered. Additionally, patients with trapped lung were excluded from 25 of 62 studies, but not from the others.

\section{Excluded studies}

We placed 11 studies in the excluded studies section, having initially identified them as eligible for inclusion but with reasons for exclusion identified later (Characteristics of excluded studies). One study had insufficient data for extraction (Tattersall 1982). Three studies included data for patients with ascites, which could not be separated from those with pleural effusions even after attempting to contact the study authors (Kwasniewska-Rokicinska 1979; Lissoni 1995; Nio 1999). As per the published protocol, seven studies were found to be high risk of bias for sequence generation and therefore excluded (Caglayan 2008; Dryzer 1993; Elayouty 2012; Engel 1981; Gust 1990; Maiche 1993; Manes 2000). Causes of the inadequate sequence generation included allocating patients to groups using alternation (Caglayan 2008); or according to certain clinical criteria (Maiche 1993), patient hospital number (Dryzer 1993), date of consent (Engel 1981) or date of diagnosis (Manes 2000). We excluded one study as the data contained both randomised and non-randomised data, which was not distinguishable (Gust 1990) and we could not obtain contact details for the study authors. Another stated patients were 'divided' between groups, not mentioning if this process was random (Elayouty 2012) and there was no response from the study authors when contacted to clarify this further.

\section{Risk of bias in included studies}

A summary assessment of the risk of bias is presented in the Characteristics of included studies, Figure 2 and Figure 3. No studies were at low risk of bias for all domains. 
Figure 2. Risk of bias graph: review authors' judgements about each risk of bias item presented as percentages across all included studies.

Random sequence generation (selection bias)

Allocation concealment (selection bias)

Blinding of participants and personnel (performance bias)

Blinding of outcome assessment (detection bias)

Incomplete outcome data (attrition bias)

Selective reporting (reporting bias)

Other bias

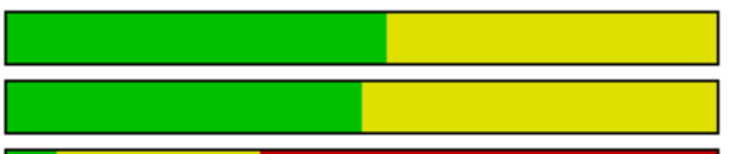

L
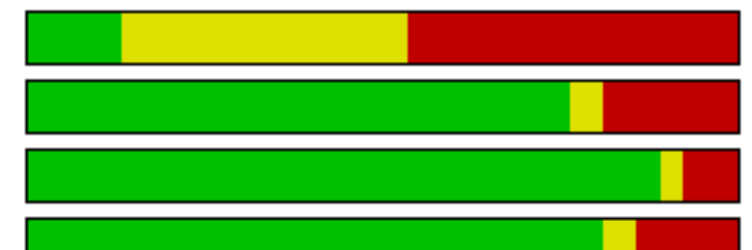

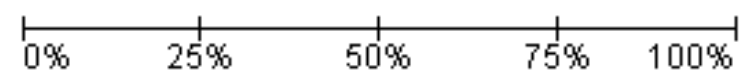


Figure 3. Risk of bias summary: review authors' judgements about each risk of bias item for each included study.

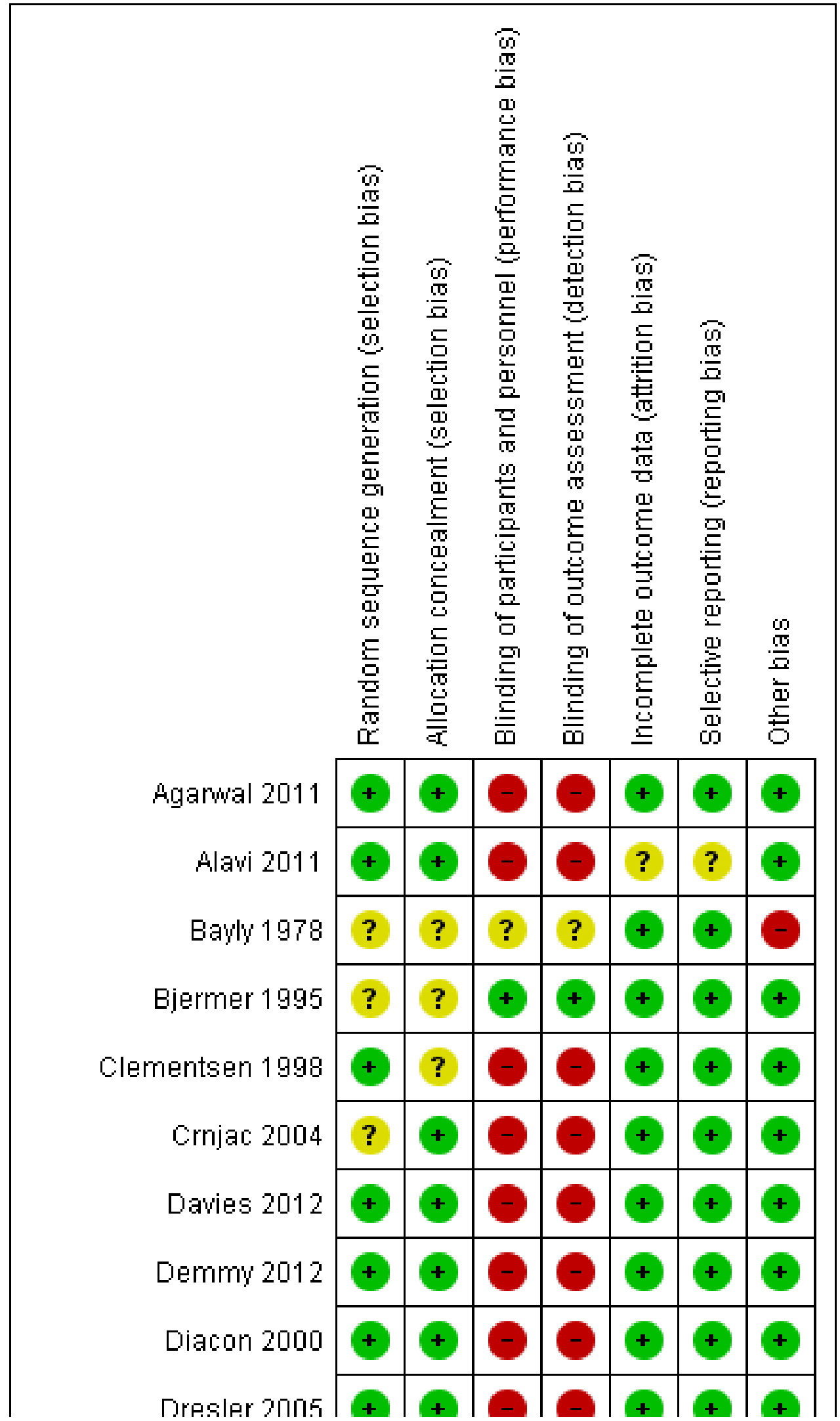


Figure 3. (Continued)

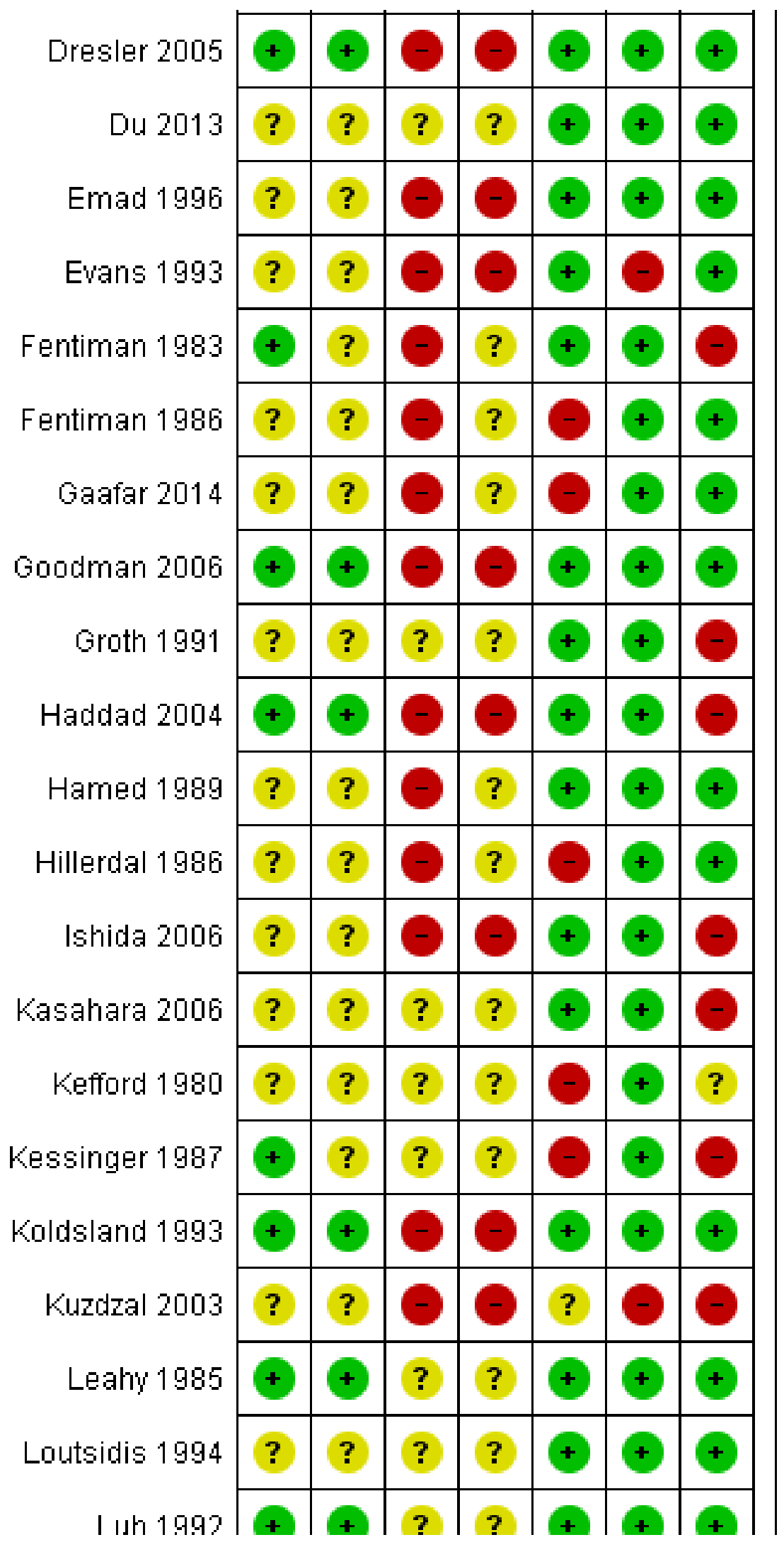


Figure 3. (Continued)

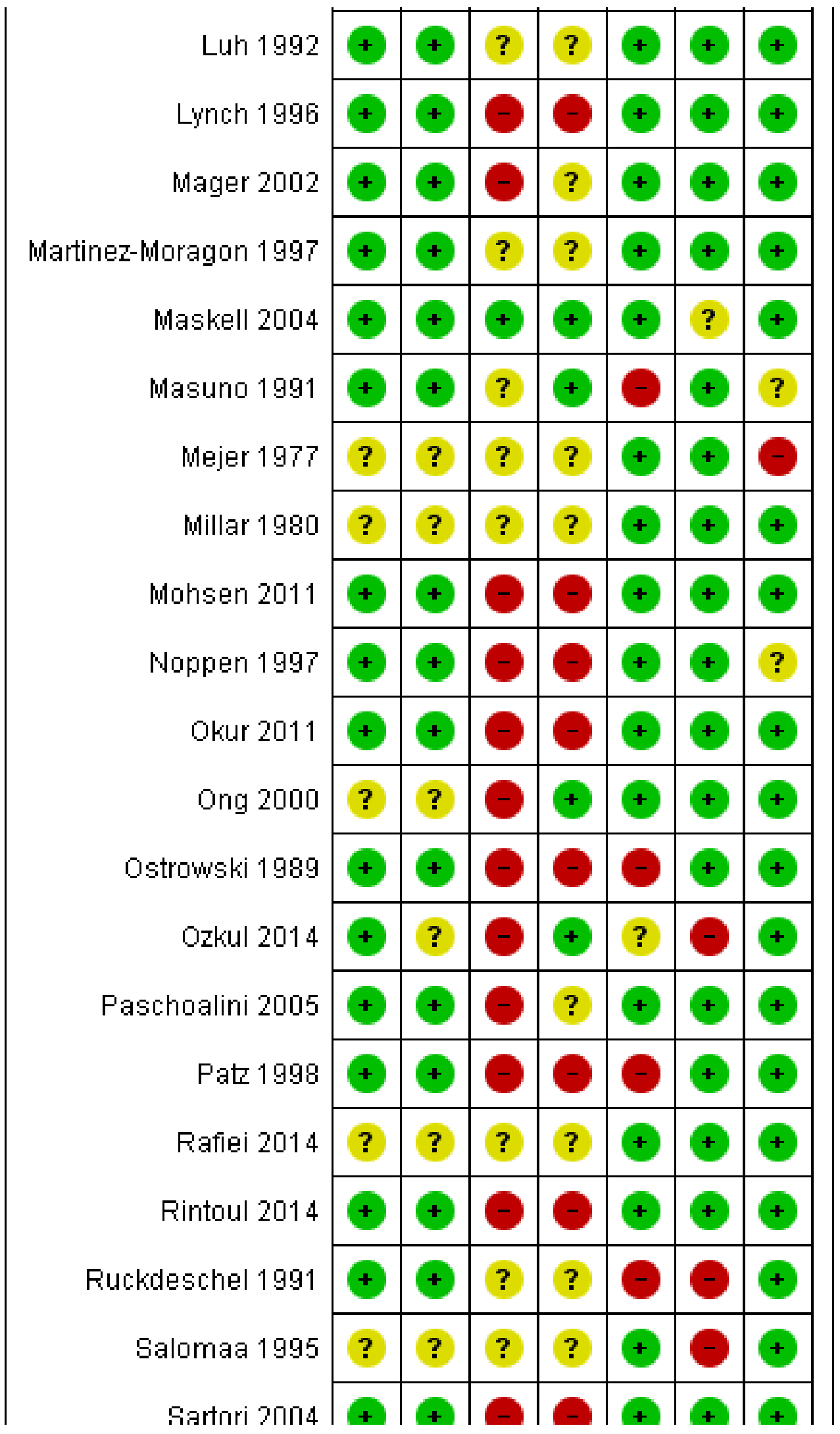


Figure 3. (Continued)

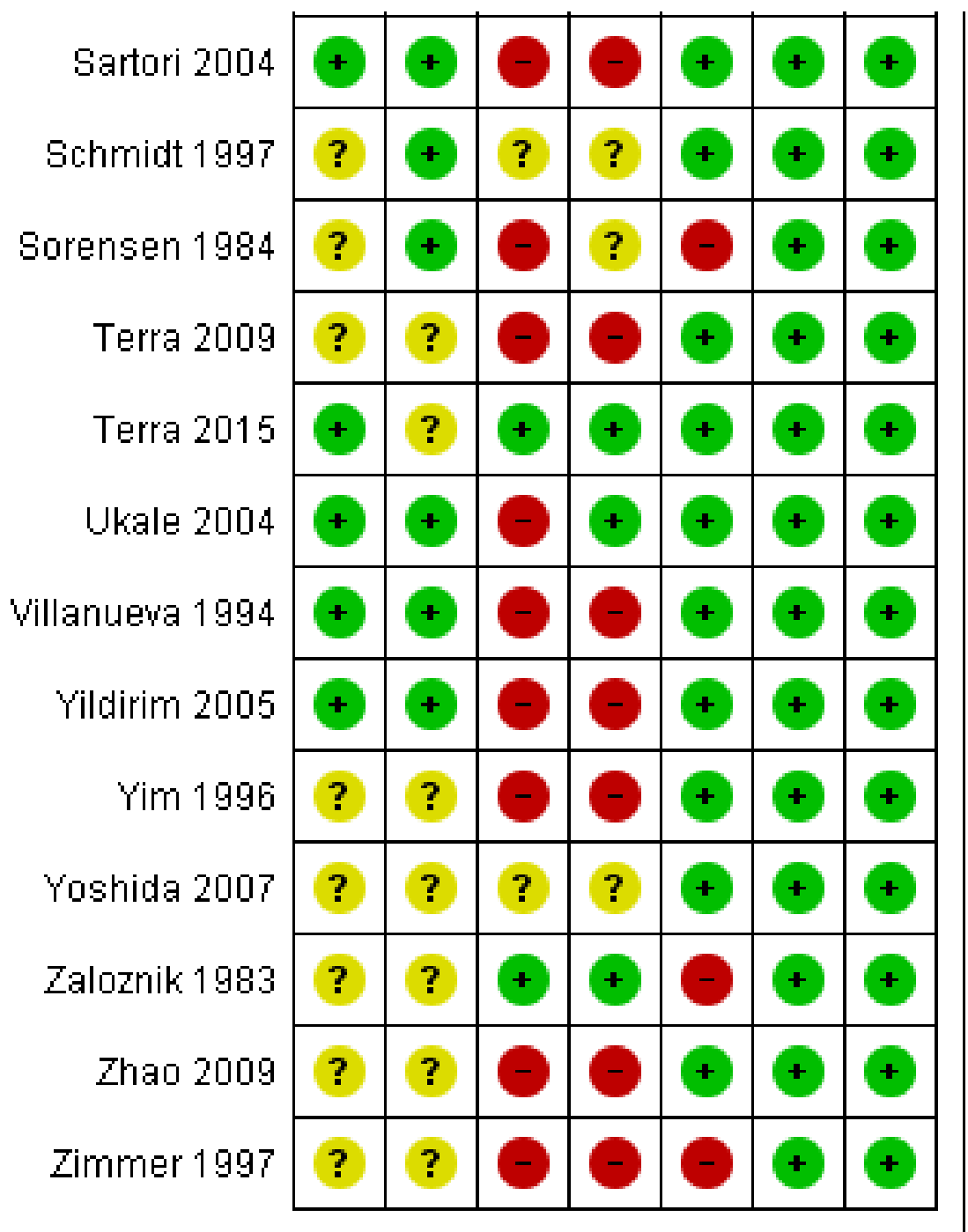

\section{Allocation}

Thirty three of 62 studies documented adequate sequence generation. The most commonly used methods were computer or telephone randomisation services, block randomisation, stratification, opaque sealed envelopes or a random number generator. Since studies with inadequate sequence generation were excluded as per the protocol, we assessed sequence generation as unclear in the remaining 29 studies. In all cases, the study was stated to have been randomised.

Regarding allocation concealment, we assessed 31 studies as low risk of bias for this domain. Since studies with inadequate allocation concealment were excluded as per the protocol, allocation concealment was 'unclear' for the remaining 31 studies.

\section{Blinding}

\section{Blinding of participants and personnel (performance bias)}

Due to the nature of many of the interventions evaluated in this review, blinding of the participants and clinicians was often not possible and therefore we assessed 40 of 62 studies as high risk of bias for this domain. Many of the pleurodesis agents have differing visual appearances and those studies randomising patients to different modes of administration of a pleurodesis agent, an indwelling pleural catheter or surgery, could not feasibly be blinded.

Four studies were assessed as low risk of performance bias (Bjermer 1995; Maskell 2004; Terra 2015; Zaloznik 1983).

\section{Blinding of outcome assessment (detection bias)}

The assessment of pleurodesis success could often not be blinded as it was reliant on participants (who were not blinded) reporting symptoms, in association with the radiological findings of effusion recurrence. Very few studies reported whether the radiological assessments were performed in a blinded fashion. Twenty nine of 62 studies were at high risk of detection bias, and a further 25 of 62 studies had an unclear risk of bias for this domain. Eight studies were low risk of detection bias (Bjermer 1995; Maskell 2004; Masuno 1991; Ong 2000; Ozkul 2014; Terra 2015; Ukale 2004; Zaloznik 1983). 


\section{Incomplete outcome data}

The majority of studies were low risk of bias because although some inevitable attrition due to death was reported, the rates were comparable for the treatment arms and were deemed reasonable for the size of the population. We classified 12 studies as high risk of bias (eight due to very high attrition rates (Kefford 1980; Kessinger 1987; Masuno 1991; Ostrowski 1989; Patz 1998; Ruckdeschel 1991; Sorensen 1984; Zaloznik 1983; Kefford 1980); one due to very imbalanced loss to follow up (LTFU) between the treatment arms (Fentiman 1986); one the number randomised was not stated (Zimmer 1997); one the numbers provided did not add up (Hillerdal 1986); one excluded patients from the analysis who discontinued treatment due to an allergic reaction (Gaafar 2014)). Three were unclear risk of bias (Kuzdzal 2003: number of randomised patients not stated, only number analysed; Alavi 2011: unable to access tables, and numbers only given as percentages, rather than absolute values; Ozkul 2014: numbers of patients lost to follow up not stated).

\section{Selective reporting}

The majority of studies were assessed to be at low risk of bias for selective outcome reporting. We classified two studies as unclear, one as minimal raw data were presented in the text and the tables could not be accessed (Alavi 2011) and the other because pleurodesis success data were not collected in an RCT of talc and tetracycline pleurodesis (although the study was not designed to evaluate this) (Maskell 2004). Five studies were high risk (four provided minimal or no data regarding side effects or survival, or both (Evans 1993; Kuzdzal 2003; Ozkul 2014; Salomaa 1995) and one did not report data on 15 of the randomised patients (Ruckdeschel 1991).

\section{Other potential sources of bias}

We classified nine of 62 studies as high risk of bias in the 'other' domain and three of 62 studies as unclear. This was for a variety of reasons (see Characteristics of included studies). The remaining studies had a low risk of bias for this domain.

\section{Effects of interventions \\ PRIMARY OUTCOME}

\section{Selection of trials for inclusion in the network}

All the interventions from the included studies were evaluated and assessed for inclusion in the network. A number of interventions were not felt to be jointly randomisable and hence were not included in the network. This was the case for specific surgical techniques (Crnjac 2004; Rintoul 2014), different talc particle sizes (Maskell 2004), interventions aimed to improve the efficacy of pleurodesis (Clementsen 1998; Evans 1993; Goodman 2006; Mager 2002; Okur 2011; Ozkul 2014; Villanueva 1994; Yildirim 2005), tumour-specific intra-pleural therapy (Du 2013; Ishida 2006; Kasahara 2006; Luh 1992; Masuno 1991; Yoshida 2007; Zhao 2009) and different doses of silver nitrate (Terra 2015).

Two interventions (silver nitrate and combined tetracycline and bleomycin), which we initially felt to be eligible for inclusion in the network had to be removed for the evaluation of pleurodesis efficacy. These agents were only evaluated in one trial each and no participants who received these agents had a pleurodesis failure, which led to computational problems such that a treatment effect could not be estimated (Emad 1996; Paschoalini 2005). One study was not included in the analysis of pleurodesis efficacy as there were no pleurodesis failures in either study arm (Yim 1996). Such studies cannot statistically contribute to the estimate of relative intervention effects (Higgins 2011b).

The majority of studies included all cell types and 36 of 62 trials $(58 \%)$ did not exclude patients with trapped lung. Pleurodesis was defined using symptom recurrence and radiology in 44 of 62 studies $(71 \%)$ and it was usually defined within four months of the intervention. It was very difficult to assess whether the distribution of potential effect modifiers was comparable for all the direct treatment comparisons because there were few studies per direct comparison (see Appendix 2).

The final network can be seen in Figure 4. Any studies in the systematic review which were not included in the network were reported descriptively. 
Figure 4. Network plot of the pleurodesis efficacy network. The nodes are weighted according to the number of participants randomised to the intervention. The edges (line thicknesses) are weighted according to the number of studies included in each comparison.

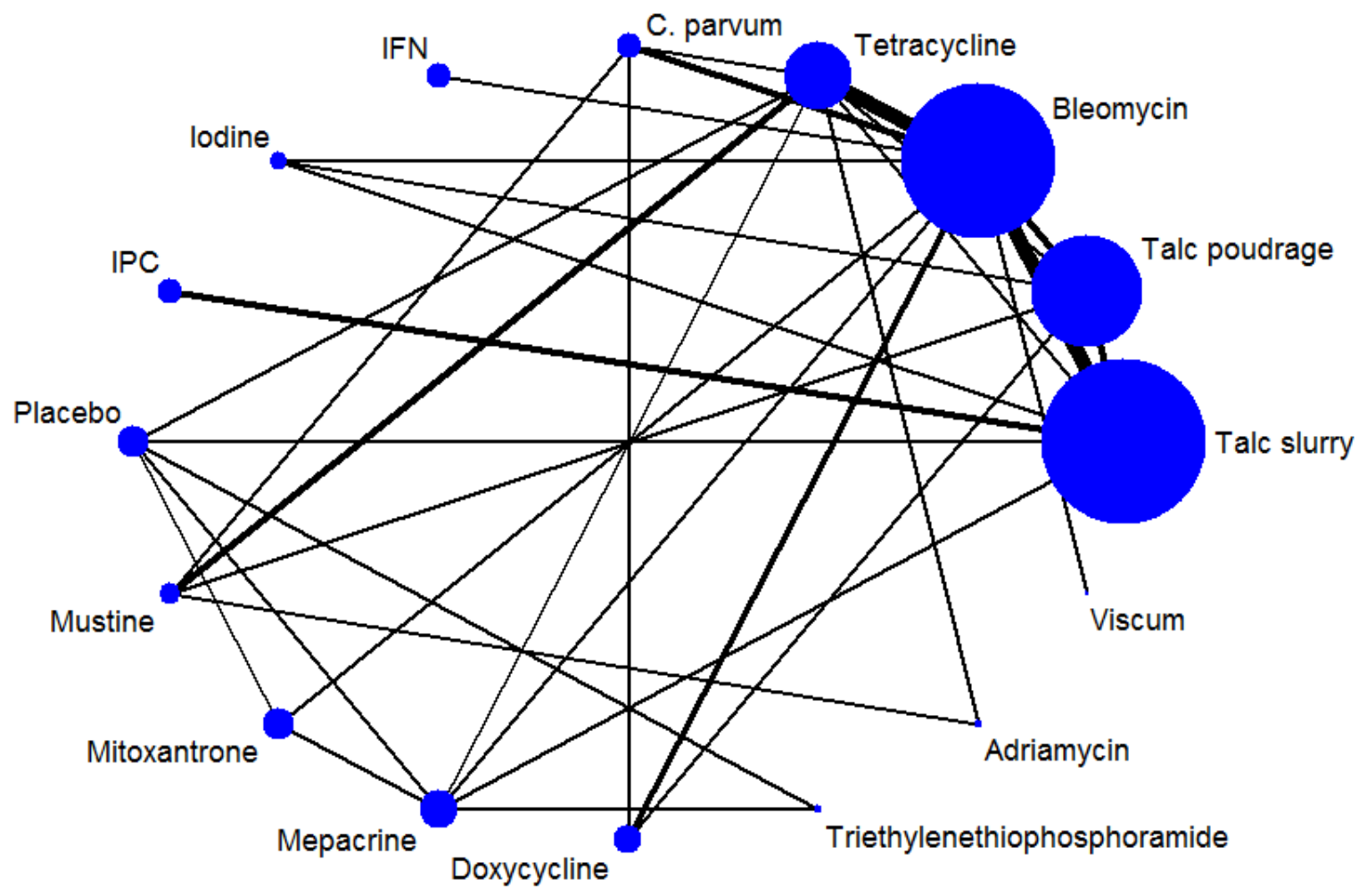

\section{Primary outcomes for the methods included in the network meta-analysis}

\section{Direct meta-analysis}

Results of the direct, pair-wise random-effects meta-analysis of the main pleurodesis agents are presented in Table 1. Given the small number of studies making the same direct comparisons, metaanalysis was only possible for eight direct comparisons.

In the majority of cases, there was no evidence against the null hypothesis of no true difference between interventions (Table 1). However in 10 of the direct comparisons, the OR and $95 \% \mathrm{Cl}$ lay away from the null value of 1 , giving evidence against the null hypothesis of no difference. A number of methods were less effective than talc poudrage at inducing pleurodesis, including bleomycin (OR $9.70(95 \% \mathrm{Cl} 2.10$ to 44.78$)$, participants $=57$; studies = 2) (Analysis 1.1), tetracycline (OR $12.10(95 \% \mathrm{Cl} 1.32$ to 111.30$)$, participants $=33$; studies $=1)$ (Analysis 4.1), mustine (OR $8.00(95 \%$ $\mathrm{Cl} 1.40$ to 45.76$)$, participants $=37$; studies $=1$ ) (Analysis 17.1) and doxycycline (OR $42.69(95 \% \mathrm{Cl} 2.13$ to 856.61$)$, participants = 31; studies =1) (Analysis 8.1). Interferon was less effective than bleomycin (OR 3.25 (95\% Cl 1.54 to 6.89), participants = 160; studies $=1$ ) (Analysis 13.1). Bleomycin was less effective than mepacrine (OR $0.16(0.03,0.89)$, participants $=36$; studies $=1$ ) (Analysis 12.3).
Those treated with an IPC had more pleurodesis failures than those receiving talc slurry (OR $3.35(95 \% \mathrm{Cl} 1.64$ to 6.83), participants = 160; studies $=2$ ) (Analysis 6.1). Triethylenephosphoramide was less effective than mepacrine (OR 4.95 (95\% Cl 1.02 to 24.10), participants $=29$; studies $=1$ ) (Analysis 14.1). There was also some evidence that tetracycline and mitoxantrone were less effective than bleomycin (OR 2.00 (95\% Cl 1.07 to 3.75); participants = 220; studies = 5) ) (Analysis 4.1$)$ and $\mathrm{OR} 3.18(95 \% \mathrm{Cl} 1.17$ to 8.65$)$; participants $=85$; studies $=1$ (Analysis 18.1) respectively). The comparison between talc slurry and talc poudrage gave some weak evidence that talc slurry may be less effective as the $95 \% \mathrm{Cl}$ was close to one (OR 1.31 (95\% Cl 0.92 to 1.85); participants = 599; studies $=3$ ) (Analysis 2.1).

The heterogeneity between studies making similar comparisons was generally low. However, the comparison between $C$. parvum and bleomycin revealed a very high level of heterogeneity (Tau ${ }^{2}=$ $10.59,1^{2}=94 \%$ ) because the two included studies had conflicting results: (OR 0.05 (95\% $\mathrm{Cl} 0.01$ to 0.29 ) in Hillerdal 1986; OR 5.69 (95\% Cl 1.38 to 23.48 ) in Ostrowski 1989) (Analysis 5.1). The number of participants in the comparison was small (98 patients randomised across the two studies; 78 of whom had sufficient data to be included in the primary outcome analysis) and Hillerdal 1986 was high risk of bias for two domains and unclear risk of 
bias for a further two. Hillerdal 1986 only included patients with adenocarcinoma or bronchogenic carcinoma, whereas Ostrowski 1989 included all cell types.

Sensitivity analysis of the direct comparisons using the fixed effect meta-analysis model did not reveal any clinically or statistically meaningful differences (see Appendix 3).

\section{Network meta-analysis}

The results of the relative efficacies of the pleurodesis methods generated by the network meta-analysis, which comprised 41 studies of 16 agents, including 2345 participants are shown in Table 2. The estimated ranks for each of the methods in terms of pleurodesis success are shown in Figure 5.

\section{Figure 5. Estimated $(95 \% \mathrm{Cr}-\mathrm{I})$ ranks for each of the pleurodesis methods from the main network}

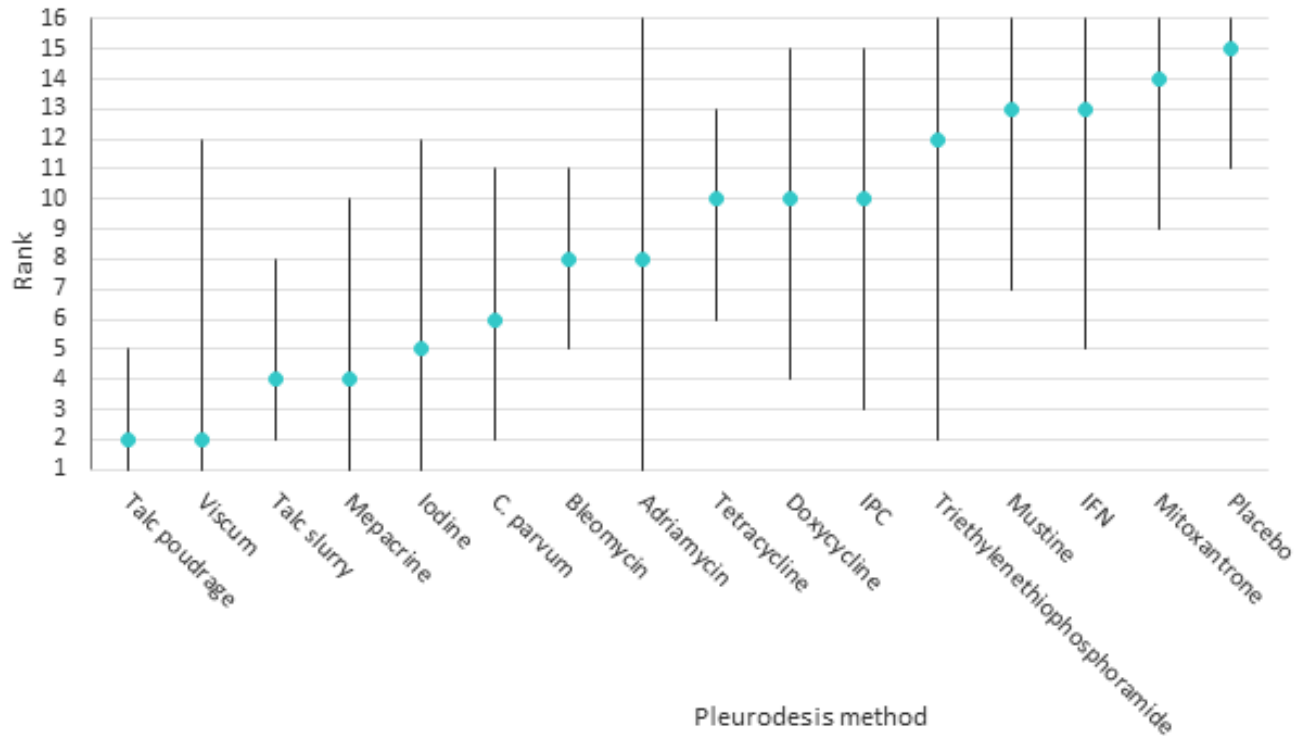

The network comparisons between talc poudrage and bleomycin, tetracycline, interferon (IFN), IPC, placebo, mustine, mitoxantrone and doxycycline, all provided evidence against the null hypotheses of no difference in favour of talc poudrage resulting in fewer pleurodesis failures (See Table 2). The estimated rank of talc poudrage was second of 16 pleurodesis methods (95\% Cr-I 1 to 5 ).

Other potentially efficacious agents were viscum, talc slurry, mepacrine, iodine and C. parvum, with estimated ranks of second (95\% Cr-I 1 to 12), fourth (95\% Cr-I 2 to 8), fourth (95\% Cr-I 1 to $10)$, fifth (95\% Cr-I 1 to 12$)$ and sixth (95\% $\mathrm{Cr}-\mathrm{I} 2$ to 11$)$ respectively (see Figure 5). The ORs and 95\% Cr-ls comparing talc slurry with tetracycline, placebo, mustine and mitoxantrone, lay far away from the null value of 1 , providing evidence that talc slurry is more effective than these other agents. The comparisons between talc slurry and bleomycin and IFN had 95\% Cr-I close to 1, providing some evidence that talc slurry may result in fewer pleurodesis failures.

The network provides some evidence that viscum is more effective than placebo and mitoxantrone, with ORs and 95\% Cr-ls lying far away from the null value of 1 . However, the direct evidence on this agent was from only a single small study of 17 patients and the confidence intervals for its estimated rank are very wide, reflecting uncertainty within the network as to its true rank.

Placebo was most probably the least successful pleurodesis agent, with an estimated rank of fifteenth of 16 methods (95\% Cr-I 11 to 16). The ORs and $95 \% \mathrm{Cr}$-Is comparing placebo with talc slurry, talc poudrage, bleomycin, C. parvum, iodine and mepacrine were all far away from 1, providing evidence that placebo is less effective.

\section{Heterogeneity}

The between-study standard deviation in treatment effect estimates (log odds ratios) across the whole network was estimated to be $\mathrm{Tau}=0.88$ (95\% $\mathrm{Cr}-\mathrm{I} 0.42$ to 1.48$)$, suggesting a high degree of heterogeneity, although the wide credible interval indicates a substantial degree of uncertainty around this.

We performed a number of sensitivity analyses to explore the heterogeneity found in the main network based on pre-defined potential clinical effect modifiers (see Appendix 4). Due to the smaller number of studies in these analyses, many of them contained fewer pleurodesis methods than the main network.

The majority of the sensitivity analyses found less evidence of true differences between the efficacies of individual methods. 
The estimated ranks were generally similar to the main network, although all ranks had very wide credible intervals and therefore were imprecise. The sensitivity analyses showed very wide credible intervals for the between-study standard deviation (representing heterogeneity), with the upper limits of $95 \% \mathrm{Cr}$-Is often being close to 2 . Since a uniform $(0,2)$ prior distribution was assumed for Tau in each analysis, it is likely that the upper limits would increase further still if a wider prior distribution was assumed.

However, the estimate of the between-studies standard deviation was reduced when we restricted analysis to those studies with a lower risk of bias (defined as two or fewer 'high risk' domains in the risk of bias tool). The credible intervals for Tau did however overlap, so it is unclear whether heterogeneity was truly reduced (Tau 0.46 (95\% Cr-1 0.03 to 1.09$)$ ) for the low risk of bias subgroup vs Tau 0.88 (95\% Cr-l 0.43 to 1.49) for the main network) (Appendix 4, Appendix 5 , Appendix 6). However, the overlapping credible intervals reflect considerable uncertainty about this. Results were fairly robust to exclusion of the higher risk studies, although with doxycycline and C. parvum perhaps appearing a little better, probably due to the removal of two particular studies (Kuzdzal 2003; Ostrowski 1989).
Due to the diversity of doses used for many of the pleurodesis agents evaluated, we were unable to examine the effect of dose on the degree of heterogeneity observed. This is one potential cause for the unexplained heterogeneity, which was not feasible to examine in the network.

\section{Inconsistency}

Several estimated loop-specific inconsistency factors (Chaimani 2013) were very large, suggesting potential inconsistencies between the direct and indirect evidence (see Figure 6). The $\mathrm{Cls}$ around the estimated inconsistency factors were also very wide, due to the small volume of evidence per loop. Only two inconsistency factors had $95 \% \mathrm{Cls}$ which did not cross the null value of 1 . The loop involving talc slurry, talc poudrage and bleomycin did provide evidence of a difference between the direct and indirect evidence, with a ratio of odds ratios (ROR) of 7.0 (95\% Cr-I 1.1 to 43.8). The talc slurry, bleomycin and mepacrine loop also showed significant inconsistency (ROR 10.2 (95\% Cr-I 1.1 to 96.9). There were no obvious differences between the distribution of potential effect modifiers between the three direct comparisons (see Appendix 2; Appendix 4) and hence these inconsistencies could not be explained. 
Figure 6. Inconsistency plot for the main network. Treatment codes: $01=$ Talc slurry; $02=$ Talc poudrage; $03=$ Bleomycin; 04 = Tetracycline; 05 = C. parvum; 06 = Interferon; 07 = lodine; 08 = Indwelling pleural catheter; $09=$ Placebo; 10 = Mustine; 11 = Mitoxantrone; 12 = Mepacrine; 13 = Doxycyline; 14 = Triethylenethiophosphoramide; $15=$ Adriamycin. Abbreviations: $R O R=$ Ratio of Odds Ratios; $95 \% \mathrm{Cl}=95 \%$ Confidence interval. Heterogeneity variance was set at 0.8847 (reflecting the estimation of Tau from the network)

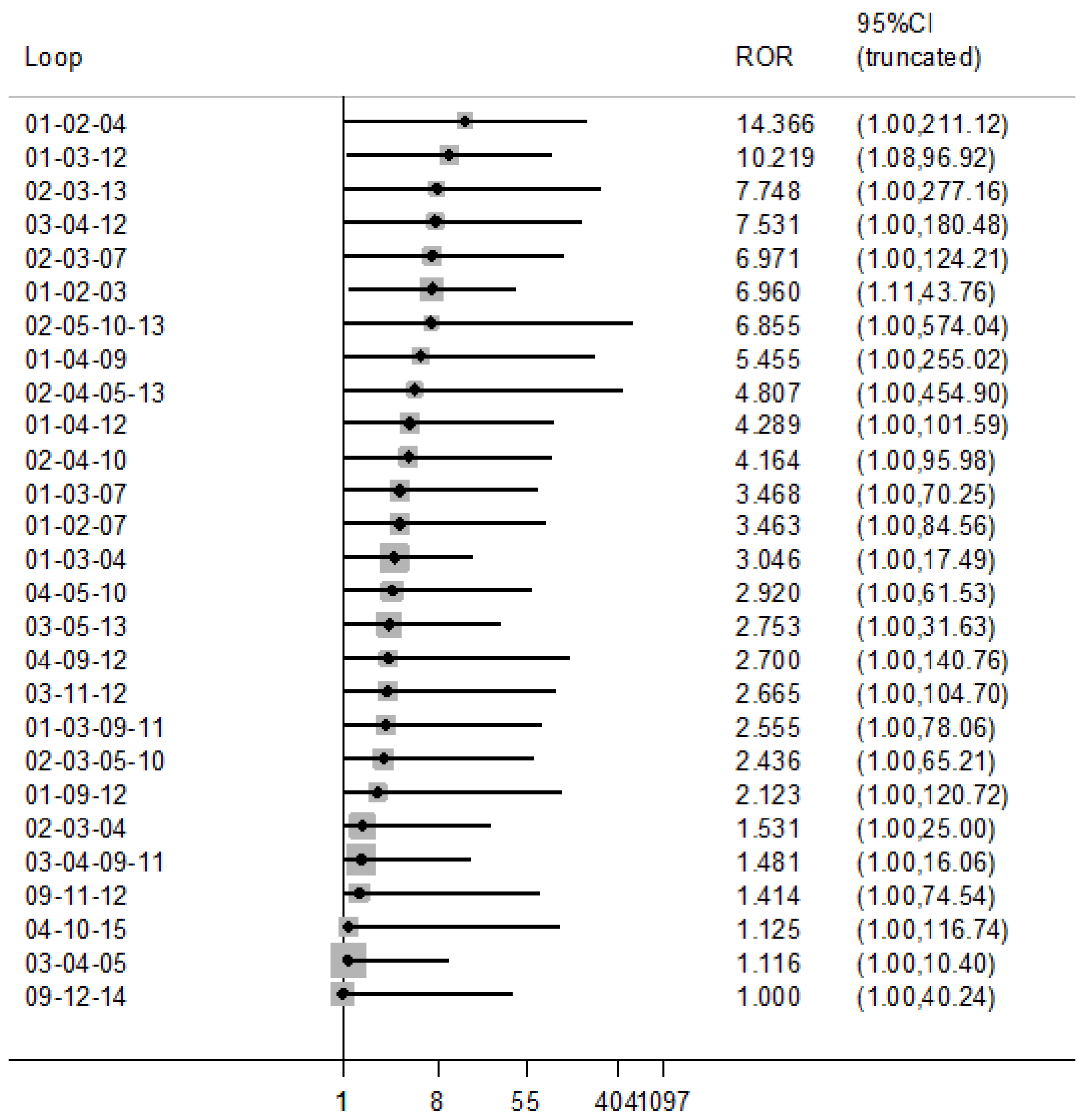

Across the entire network, there was no evidence of global inconsistency. The Deviance Information Criterion (DIC) was 398 for the consistency model and 404 for the inconsistency model, suggesting that the consistency model fits the data marginally better.

Similarly, there was no evidence of global inconsistency for any of the subgroup or sensitivity network meta-analyses (Appendix 4).
Additional post-hoc sensitivity analysis

The sensitivity analysis that only evaluated agents given through an intercostal chest tube included 29 studies of 13 agents (see Appendix 7 and Appendix 8). There was very little evidence of substantial differences between the agents, the credible intervals were wide and the estimated rankings for the individual agents were also very imprecise. 
The degree of heterogeneity was even higher than the main network (Tau 0.98 (95\% Cr-I 0.45 to 1.72). There was no evidence of global inconsistency (DICs for the consistency and inconsistency models were 271 and 276 respectively). Similar to the main network, there was evidence of loop-specific inconsistency for the talc slurry, bleomycin and mepacrine loop (ROR 10.2 (95\% Cr-I 1.1 to 96.5$)$ ).

\section{Primary outcomes for the methods not included in the network meta-analysis}

\section{Pleurodesis methods}

The results of the pair-wise comparisons of the pleurodesis methods not included in the network meta-analysis are shown in Table 3.

Two agents (silver nitrate and the combination of bleomycin and tetracycline together) were excluded as there were no pleurodesis failures for the agents, resulting in numerical difficulties when we attempted to include them in the network meta-analysis model. The pair-wise comparisons in these studies did not provide evidence against the null hypothesis of no true difference between interventions (see Table 3).

One study was not included in the network as it was a three-arm trial evaluating different doses of silver nitrate administered via a chest tube (Terra 2015). There were only two of 60 participants who had a failed pleurodesis, both in the group receiving the highest dose of silver nitrate.

Seven studies could not be included in the network meta-analysis as they evaluated tumour-specific therapies for patients with MPE due to non-small cell lung cancer (NSCLC) (Du 2013; Ishida 2006; Kasahara 2006; Luh 1992; Masuno 1991; Yoshida 2007; Zhao 2009). The results could not be generalised to patients with other tumour types and hence these interventions were not deemed jointly randomisable. All the studies randomised only small numbers of participants. However in four of the direct comparisons, the OR and $95 \% \mathrm{Cl}$ lay far away from the null value of 1 , giving evidence against the null hypothesis of no difference.

Du 2013 randomised patients with NSCLC to receive three cycles of either cisplatin and intra-pleural bevacizumab (a humanised monoclonal antibody to VEGF) or cisplatin alone. More patients in the cisplatin-alone group had pleurodesis failure than in the combination group (6/36 vs $17 / 34$ respectively; OR 5.00 ( $95 \% \mathrm{Cl} 1.66$ to 15.09); participants $=70$; studies $=1)($ Analysis 23.1) $($ Du 2013).

Masuno 1991 randomised NSCLC patients with MPE to receive up to two doses of either intra-pleural LC9018 (lyophilised Lactobacillus casei) and Adriamycin or Adriamycin alone. There were more pleurodesis failures in the control group compared to those who received LC9018 (23/38 vs 10/38 respectively; OR $4.29(95 \% \mathrm{Cl} 1.62$ to 11.35$)$; participants $=76$; studies $=1)($ Analysis 15.1$)$ (Masuno 1991).

Finally, Ishida 2006 conducted a three-arm trial, comparing intrapleural OK-432, an inactivated product of Streptococcus pyogenes $\mathrm{A} 3$ with anti-tumour immune-modulatory effects in lung cancer, with cisplatin and combined therapy (both OK-432 and cisplatin). Those treated with OK-432 alone had a higher pleurodesis failure rate than those receiving combination treatment (OR $12.44(95 \% \mathrm{Cl} 1.32$ to 117.03 ; participants $=32$; studies $=1$ ) but a lower failure rate than those receiving cisplatin alone (OR $0.48(95 \% \mathrm{Cl} 0.12$ to 1.92$)$; participants $=34$; studies $=1)$ (Analysis 11.1).

\section{Other methods to optimise pleurodesis}

We evaluated a number of methods to optimise pleurodesis, but these were not included in the network because they were not considered jointly randomisable (see Table 4). All the studies included very small numbers of patients and none provided evidence of a difference in pleurodesis failure rates between the treatments being compared (see Table 4). The results of the ongoing TIME- 1 and TIME- 3 studies will provide additional data regarding the effect of drain size, analgesia use and intrapleural fibrinolytics in the future. No randomised controlled trials examining the role of pleuro-peritoneal shunts were identified.

\section{SECONDARY OUTCOMES}

Due to the diversity of reporting techniques and outcome measures, it was not possible to perform a formal statistical analysis of many of the pre-defined secondary outcomes.

\section{Adverse effects/complications}

The majority of studies reported data on adverse effects of the interventions, however three studies did not (Evans 1993; Kuzdzal 2003; Villanueva 1994). Kefford 1980 reported side effects but the patients with pleural effusions could not be differentiated from those with ascites or pericardial effusions. Data on side effects were provided in personal communications with two study authors (Goodman 2006; Mager 2002). The methods used to describe the side effects observed varied widely between studies.

Network meta-analysis was used to compare rates of the most commonly reported side effects, fever and pain.

\section{Fever}

The direct evidence regarding fever is shown in Appendix 9. The fever network consisted of 23 trials of 11 different treatments, including 1518 participants. The odds ratios are shown in Table 5 and estimated rankings of the interventions in Figure 7. All the estimates had very wide credible intervals, indicating a large degree of imprecision. However, placebo appeared to be associated with the least fever (estimated rank first of 11 interventions (95\% Cr-I 1 to 7)). The methods associated with the most fever appeared to be C. parvum and mepacrine, with estimated ranks of eleventh $(95 \%$ Cr-I 7 to 11 ) and tenth ( $95 \% \mathrm{Cr}-\mathrm{I} 6$ to 11 ) respectively. However, the between-studies standard deviation (Tau) for the whole network was 1.35 (95\% Cr-I 0.58 to 1.95), suggesting a very high degree of heterogeneity. There was no evidence for global inconsistency (DIC for consistency and inconsistency models was 230 and 231 respectively). However, the loop-specific inconsistency factors were large, suggesting potential inconsistencies between the direct and indirect evidence. The $95 \% \mathrm{Cls}$ around the inconsistency factors were wide and crossed the null value of 1 in all but one loop. There was strong evidence of inconsistency regarding fever in the bleomycin/tetracycline/C. parvum loop (ROR 59.2 (95\% Cl 2.6 to 1353.7)). 
Figure 7. Estimated rank ( $95 \% \mathrm{Cr}-\mathrm{I})$ for causing fever (a low rank suggests less fever)

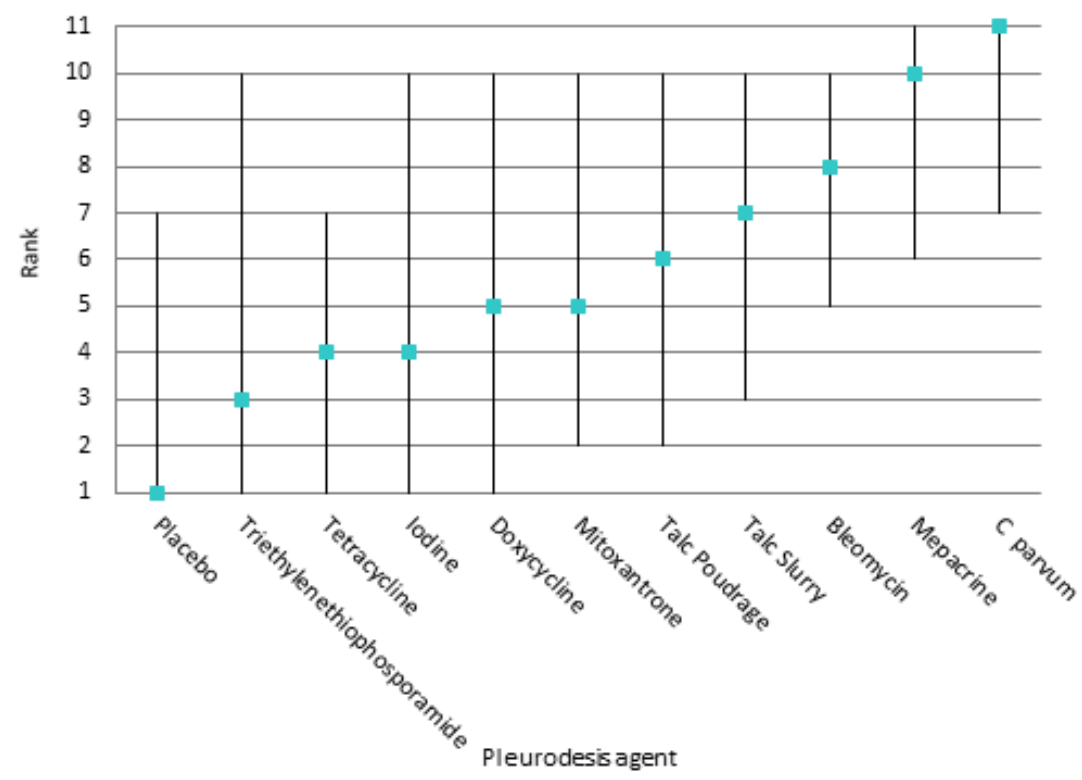

For those studies, which were not included in the network metaanalysis but provided data on fever, the majority revealed no difference between the interventions (Emad 1996; Kasahara 2006; Masuno 1991; Paschoalini 2005; Terra 2015). Two studies evaluating OK-432 revealed more fever in this group compared to the control groups (Ishida 2006; Luh 1992; Yoshida 2007) (Analysis 11.3). The mixed talc group had more fever than the graded talc group (OR $15.92(95 \% \mathrm{Cl} 1.81$ to 140.16; participants = 46; studies $=1)$ (Maskell 2004) (Analysis 21.3). The group who received cisplatin alone had less fever than those who also received rAd-p53 (OR 0.09 (95\% Cl 0.02 to 0.51 ; participants $=35$; studies $=1$ ) (Zhao 2009) (Analysis 23.3)

\section{Pain}

Six studies were not included in the network meta-analysis as they collected pain scores (rather than whether or not each patient had pain post procedure) (Agarwal 2011; Alavi 2011; Bjermer 1995; Davies 2012; Paschoalini 2005; Zimmer 1997). Bjermer 1995 reported higher levels of pain in the mepacrine group compared to the mitoxantrone group as measured by the $\mathrm{WHO}$ analgesic ladder (no raw figures provided) (WHO 2016). The other six studies did not provide evidence of a difference in pain between the methods studied.

Only 17 studies and nine treatments (including 1279 participants) could be included in the network meta-analysis regarding pain (see Appendix 10, Appendix 11 and Appendix 12). There was no evidence to support a difference between the methods in terms of the proportion of participants complaining of pain after the intervention. All the estimates had very wide confidence intervals, indicating a large degree of imprecision. The between-studies standard deviation (Tau) for the network was 0.65 (95\% Cr-I 0.05 to 1.63), indicating considerable heterogeneity. There was no evidence of global inconsistency (DIC 177 for the consistency model versus 177 for the inconsistency model). Several of the estimated inconsistency factors were large, although all had 95\% Cls which crossed 1 , indicating no clear evidence of loop-specific inconsistency.

Of those studies which reported pain outcomes but were not included in the network for pain, the majority revealed no difference between interventions (Kasahara 2006; Luh 1992; Masuno 1991; Okur 2011; Paschoalini 2005; Terra 2015; Yoshida 2007; Zhao 2009). Those who underwent a small-bore drain insertion had less pain at the time of insertion than those with a large-bore drain (OR 0.08 ( $95 \% \mathrm{Cl} 0.01$ to 0.75) (Clementsen 1998) (Analysis 19.2)). One study revealed more pain in the OK-432 groups than controls (Ishida 2006) (Analysis 11.2).

\section{Patient reported breathlessness}

Eleven studies reported information regarding control of breathlessness, using a variety of techniques (MRC dyspnoea scale (Mohsen 2011); VAS score (Bjermer 1995; Davies 2012; Diacon 2000; Terra 2015); 'dyspnoea index' (Demmy 2012); QLQ-C30/LC13 questionnaires (Rintoul 2014), functional class (Masuno 1991; Rafiei 2014; Zimmer 1997), scale of 0 - 10 (Alavi 2011)).

The two studies comparing talc slurry with IPC reported breathlessness scores (Davies 2012 using a VAS score and Demmy 2012 using a 'dyspnoea index'). Davies 2012 found dyspnoea improved in both study arms, to a similar extent at 42 days. However the IPC group had a greater improvement at six months 
compared to the talc group (mean difference of $-14 \mathrm{~mm}(95 \% \mathrm{Cl}$ -25.2 to -2.8$) \mathrm{P}=0.01$ ). Demmy 2012 found that the IPC group had better dyspnoea scores at 30 days than the talc slurry group (8.5 vs $6.1 ; \mathrm{P}=0.047$ ).

Rafiei 2014 found more patients receiving doxycycline had severe dyspnoea at two months compared to those receiving bleomycin $(5 / 20(24 \%)$ vs $1 / 21(5 \%)$ respectively; $P=0.01)$. Bjermer 1995 noted that those receiving mitoxantrone had a larger reduction in breathlessness than the mepacrine-treated patients (absolute values not reported; $P<0.001$ ). Masuno 1991 did not provide the absolute figures but reported "statistically significant" improvements in dyspnoea one week after treatment at 'the final judgement' in the LC9018 group. In the remaining studies reporting dyspnoea, no differences were identified between the study arms in terms of the degree of improvement of dyspnoea (Alavi 2011; Diacon 2000; Mohsen 2011; Rintoul 2014; Terra 2015; Zimmer 1997).

\section{Quality of life and symptom control}

Fifteen of 62 studies reported quality of life or assessed a symptoms score other than dyspnoea. The methods used were Karnofsky performance scale (Demmy 2012; Du 2013; Groth 1991; Masuno 1991; Zhao 2009), QLQ-C30 questionnaire (Davies 2012, Dresler 2005, Rintoul 2014), SF36 scale (Terra 2009), WHOQoL-bref scale (Terra 2015), EQ5D (Rintoul 2014), VAS Score (Diacon 2000), a symptom questionnaire (Bjermer 1995) and numeric pain scale (Alavi 2011; Paschoalini 2005; Zimmer 1997). Most studies did not report any evidence of a difference between the treatment groups (Alavi 2011; Davies 2012; Diacon 2000; Groth 1991; Paschoalini 2005; Terra 2009; Terra 2015 Zimmer 1997). Bjermer 1995 reported a bigger improvement in tiredness in the mitoxatrone group compared to the mepacrine group (absolute figures not provided; $P<0.001$ ). Dresler 2005 noted less fatigue in the talc poudrage group than the talc slurry group (absolute figures not provided; $P=0.016)$. Those participants who received LC9018 had better performance scores at one week than those who did not (absolute figures not provided; $P<0.05$ ) (Masuno 1991). Zhao 2009 found that more patients who received combination treatment with cisplatin and Ad-p53 had an improvement in their Performance Score at six weeks than those receiving cisplatin alone $(11 / 17$ (65\%) vs $6 / 18$ $(33 \%)$ respectively, $\mathrm{P}<0.05)$. The participants who underwent a VATS partial pleurectomy had better EQ5D scores at six months than the talc group in the MesoVATS study (MD 0.08 (0.003, 0.16); $\mathrm{P}=0.042$ ) but no difference in their QLQ-C30 scores (Rintoul 2014). Demmy 2012 did not provide data by treatment group. Du 2013 reported 30 patients $(83 \%)$ receiving bevacizumab and cisplatin had an improvement in their Karnofsky performance score as opposed to $15(50 \%)$ in the cisplatin group.

\section{Costs}

Only seven of 62 trials reported the relative costs of the interventions. Rapid pleurodesis was found to be cheaper than standard care in Yildirim 2005 (USD 245 (SD 71.5) vs USD 860 (SD 496) respectively). Talc slurry was cheaper than bleomycin in three studies: Ong 2000 evaluated the cost per dose (USD 1 vs USD 309 per dose respectively); Haddad 2004 calculated the complete cost for the entire procedure (USD 488 (SD 212.5) vs USD 796 (SD 207.3) respectively) and Zimmer 1997 calculated the cost of each treatment (USD 12.36 vs USD 955.83 respectively). Talc poudrage was also cheaper than bleomycin in Diacon 2000 (CHF 3893 (Swiss Francs) (USD 4206) vs CHF 4169 (USD 4504) respectively). The total cost of VATS pleurectomy was more than talc pleurodesis (GBP 14,252 (USD 21,682) vs GBP 10,436 (USD 15,876)) (Rintoul 2014). Dresler 2005 reported no difference between the cost of talc slurry and poudrage (no figures quoted).

\section{Mortality}

Thirty-four trials provided data on patient mortality. Evaluating the direct evidence, only two of these found evidence of a difference between the treatment arms. Evans 1993 found survival was longer after thoracoscopic tetracycline pleurodesis than bedside administration (total $\mathrm{n}=34 ; \mathrm{P}=0.03$ (raw data only available as a survival curve)). In the comparison between bleomycin and IFN, those receiving bleomycin appeared to live longer (OR $0.46(95 \% \mathrm{Cl}$ 0.25 to 0.87 ); $n=160$ ) (Analysis 1.3 ).

Twenty trials of 12 treatments, including 1430 participants, were incorporated into a network meta-analysis looking at mortality (see Appendix 13; Appendix 14 and Appendix 15). All but one of the OR $95 \%$ Cr-ls crossed 1, providing no evidence against the null hypothesis of no effect. There was limited evidence that those who received tetracycline lived longer than those receiving mitoxantrone (OR 0.16 (95\% Cr-I 0.03 to 0.72)) (see Appendix 14). Although some of the credible intervals were wide, they were generally narrower than those seen in the pleurodesis efficacy networks. The rankings were very imprecise, with wide confidence intervals: statistically there was no evidence that the rankings of any of the pleurodesis methods differed from each other. The degree of heterogeneity was low (Tau 0.40 (95\% Cr-I 0.02 to 1.21)). There was no evidence of global inconsistency (DIC 211 for the consistency model vs 217 for the inconsistency model) or loopspecific inconsistency.

The majority of studies, which were not included in the network also showed no differences in mortality (Clementsen 1998; Crnjac 2004; Goodman 2006; Ishida 2006; Mager 2002; Maskell 2004; Rintoul 2014; Terra 2015; Villanueva 1994; Yildirim 2005; Yoshida 2007; Zhao 2009). Evans 1993 reported a longer survival after surgical administration of tetracycline than after medical treatment although no raw data were provided $(P=0.03)$.

\section{Median survival}

Twenty-five studies reported median survivals for the treatment groups and only one of these found a survival difference between the treatment arms (Masuno 1991: median survival of 232 days in the LC9018 group versus 125 days in the control arm; $n=95 ; P=$ 0.008). Kasahara 2006 reported a longer median survival in those receiving high doseOK-432 than low dose, but did not report the spread or whether this difference was significant (33.6 days versus 22.6 days respectively; $\mathrm{n}=38$ ).

\section{Length of inpatient stay}

Sixteen of 62 studies reported total length of hospital stay. Many reported no evidence of a statistically significant difference between the groups (Bayly 1978; Haddad 2004; Lynch 1996; Ong 2000; Paschoalini 2005; Schmidt 1997; Terra 2009; Yim 1996; Zimmer 1997). Yildirim 2005 and Goodman 2006 reported shorter length of stay in the group whose drains were removed earlier following sclerosant administration compared to standard care (Yildirim 2005 : mean 2.33 days (SD 0.62) vs 8.33 (SD 4.85) respectively $(P<0.001) 27$ participants; Goodman 2006: median 4 days (IQR $4-8)$ vs $8(6-9)$ respectively $(P<0.01) 41$ participants). 
Ozkul 2014, which evaluated a rapid drainage strategy prior to sclerosant administration, also showed this group had a shorter length of stay than the standard care group (mean 2.2 days versus 9.0 days respectively $(P<0.001) 79$ participants). The talc group had a shorter length of stay than the VATS partial pleurectomy group in the MesoVATS study (median 3 days (IQR 2 - 5) vs 7 days (IQR 5 - 11) respectively ( $<0.001) ; 196$ participants) (Rintoul 2014). Those undergoing TMP had a shorter hospital stay than those receiving talc slurry in Crnjac 2004 (mean 5.5 days (SD 2.5) vs 7.5 (SD 3.3) respectively ( $P=0.001$ ); 87 participants). Mohsen 2011 found patients receiving iodine had a shorter length of stay than those undergoing talc poudrage (mean 4.5 days (SD 1.1) vs 5.7 (SD 2) respectively ( $\mathrm{P}=0.02) ; 42$ participants). In TIME-2, the IPC participants had a shorter inpatient stay than the talc slurry participants $(-3.5$ days $(95 \% \mathrm{Cl}-4.8$ to -1.5$)(\mathrm{P}<0.001) ; 106$ participants) (Davies 2012).

There were insufficient data to report length of hospital stay from date of the intervention to discharge.

\section{Patient acceptability}

Two trials reported patient acceptability of the interventions (Demmy 2012, Dresler 2005). Demmy 2012 did not provide raw data by treatment group. There was no difference between talc slurry and poudrage in terms of patients' perception of convenience in Dresler 2005 (no raw data provided).

The only trial evaluating the agent viscum reported that two of 13 participants in the viscum arm withdrew their consent for ongoing study participation after experiencing allergic reactions to the first dose. The outcomes for these participants were not available and hence the trial deemed them non-evaluable.

\section{DISCUSSION}

\section{Summary of main results}

The management of MPE has long been subject to debate and research. This systematic review of the current literature attempts to combine all the available randomised evidence regarding the wide variety of interventions for the condition.

Our primary outcome measure was pleurodesis efficacy. Our analysis showed that talc poudrage ranked highly compared with other agents. It has an estimated rank of second of 16 interventions (95\% $\mathrm{Cr}-\mathrm{I} 1$ to 5 ) and there was good evidence (robust to exclusion of higher risk of bias studies) for it being better than seven other pleurodesis methods including bleomycin and tetracycline. There was also some evidence in the full network for it being more efficacious than talc Slurry and doxycyline but this evidence was considerably weakened when the analysis was restricted to only lower risk of bias studies. Uncertainty around the relative efficacy of talc poudrage compared to some other agents is also exacerbated by the relatively high degree of unexplained heterogeneity within the networks and some loop-specific inconsistencies. The presently recruiting TAPPS trial, comparing talc poudrage with talc slurry will add further data to this comparison in the future (TAPPS), which may add further clarity regarding these conclusions.

The relative efficacy of the other methods examined in terms of pleurodesis success is also inconclusive. A number of agents appeared to be of comparable efficacy, both within the main network and in the sensitivity analysis, in which we looked only at agents used for bedside pleurodesis. This may be because the agents are truly equivalent in their ability to induce a pleurodesis, however these findings could equally reflect lack of evidence to date (statistical imprecision).

All the comparisons showed a substantial degree of both statistical and clinical heterogeneity. Aside from the analysis restricted to studies at lower risk of bias, which did appear to reduce the degree of heterogeneity somewhat, the other sensitivity analyses, selected on the basis of factors hypothesised to be clinical effect modifiers, did not appear to explain the high level of heterogeneity, since estimates of the between-study standard deviation remained very high. This signifies the complexity of this condition and the treatments, which results in substantial clinical heterogeneity. Possible explanations include different effects of varying tumour subtypes, early lung entrapment, which is not clinically detectable, varying drug doses and subtle procedural factors in terms of the pleurodesis technique such as adequacy of pleural fluid drainage prior to instillation of the sclerosant.

The available data for the secondary outcomes evaluated were more restricted. The network provided some evidence that mepacrine and C. parvum cause more fever than several other agents, however this network had very high unexplained heterogeneity and loop-specific inconsistency. Only two direct comparisons and one from the network meta-analysis found evidence of a difference in mortality between treatment groups.

The studies comparing IPC and talc slurry suggested those with an IPC experienced less dyspnoea, although we note the ongoing AMPLE study may add further data regarding this in the future (AMPLE Trial). There were insufficient data to formally analyse the other secondary outcome measures.

Although there were insufficient data to perform meta-analysis, we also evaluated a number of techniques that could improve the effectiveness of pleurodesis if the agent was delivered via a chest tube. There was a lack of evidence either way regarding the effect of the duration of drainage pre- or post-sclerosant administration, chest tube size, use of fibrinolytics and patient rotation on pleurodesis failure rate. There are a number of ongoing studies which will add further information regarding these factors in the future (TIME-1; TIME-3).

\section{Overall completeness and applicability of evidence}

This is the largest systematic review of the evidence surrounding interventions in MPE in the published literature. We used robust search strategies to identify all the available randomised evidence and have diligently contacted the study authors regarding missing data where possible.

However, despite this, we had to exclude a number of studies due to insufficient availability of study data. During the process of selecting studies for inclusion in this review, we identified a number of conference abstracts. Given the paucity of data contained in them, we did not feel it valid to include them without obtaining more detailed information. Despite attempting to contact the study authors, in 34 cases we could not obtain additional unpublished data and hence excluded the studies, suggesting the potential for publication bias, which could affect the validity of the results. The small number of studies for each pair-wise comparison (maximum 
of five), meant funnel plots would not be informative (Sterne 2011). As the interventions could not be logically ordered, we also decided a comparison-adjusted funnel plot for the network was not valid (Salanti 2014).

A number of the studies included in this review had very small numbers of participants, which raises the possibility of small study effects which may have resulted in an overestimation of treatment efficacy. Only five of the included studies had outcome data for more than 100 patients (Davies 2012; Dresler 2005; Rintoul 2014; Sartori 2004; Yoshida 2007). However, sensitivity analysis for the direct evidence using random- and fixed-effect models did not show any meaningful differences.

When evaluating different pleurodesis agents, we elected to combine different doses of each agent from the available studies for the purposes of comparison. This was necessary due to variation in the doses between studies, which would have made the network extremely complex. This is a limitation of our review, since differential treatment effects according to doses could have been missed. This is one possible explanation for the high levels of heterogeneity observed in our study, which we were unable to investigate further due to the complexity of the data. One included study was designed to compare different doses of silver nitrate and this revealed no difference in terms of pleurodesis efficacy or adverse events Terra 2015).

Many of the included studies failed to assess patient quality of life, symptom control, acceptability of the intervention to the patient, length of stay and costs. Although these were secondary objectives of our review, they are important factors when selecting management strategies and hence limit the applicability of the evidence from this review to everyday clinical practice. This may be particularly important when considering the potential benefits of IPCs which, despite having a lower pleurodesis rate, may be comparable to talc slurry in terms of control of breathlessness (Davies 2012; Demmy 2012) and may be more acceptable to certain patients due to the shorter length of hospital stay.

It is also important to consider the global availability of some of these agents, when considering the clinical applicability of our findings. In a survey of five English speaking countries, the most commonly used pleurodesis agents were talc poudrage, talc slurry, tetracycline, doxycycline and bleomycin (Lee 2003). Parenteral tetracycline derivatives and C. parvum are not widely available, which precludes their routine use. Other agents included in this review are unlicensed for use as a pleurodesis agent.

Our data regarding the adverse effects of these treatments are limited. As we have selected only RCTs for inclusion in this review, there is the potential that rare but important side effects were missed using our methodology. There are reports of adverse effects of pleurodesis agents resulting from absorption of the agent into the systemic circulation. For example, systemic absorption of mixed particle size talc is thought to be linked to rare but occasionally life-threatening acute respiratory distress syndrome (ARDS), a risk which is minimised by the use of graded (large particle) talc (Maskell 2004). Mepacrine gained popularity in Scandinavia as a pleurodesis agent, although rare psychotic episodes and seizures, thought to be related to systemic absorption if administered at high doses, limited its use (Bjorkman 1989).
We have only managed to synthesise the data on the main adverse events and so we cannot reliably infer the full side effect profiles of these treatments from this review. An appreciation of the side effect profile of these interventions is vital when weighing up the risks and benefits of the procedures, particularly as many of the patients in this population have a limited life expectancy and hence limiting discomfort during their remaining time is imperative.

Pleurodesis success is one important factor in the successful management of MPE, but may not be the 'be all and end all'. The definition of pleurodesis efficacy varied between studies, with many studies relying on radiology alone, which is increasingly felt to be inadequate without taking into account symptom recurrence as well. Many patients would rather avoid a hospital admission and be treated as an outpatient which may make use of an indwelling pleural catheter more appealing than a chemical pleurodesis. Moreover, those with a particularly poor prognosis may prefer to be symptomatically treated with a simple thoracentesis and optimal symptom control and avoid more invasive procedures. It was not possible to incorporate these subjective factors into the review process, but they are clearly a crucial element of clinical decision making in this population. Therefore, the 'best' approach may not be the same for all patient groups; a question we have not been able to adequately address in this review.

\section{Quality of the evidence}

The risk of bias in a number of the included studies is substantial. The vast majority of studies were unblinded, which in part reflects the nature of the interventions being randomised but also the symptom-based nature of the endpoints measured, precluding blinding of the outcome reporting as well. Documentation of the methods used for sequence generation and allocation concealment were frequently omitted and it was often not possible to obtain this information retrospectively. The sensitivity analysis evaluating only the studies with a lower risk of bias, showed the heterogeneity estimate was reduced in this subgroup, and the overall rankings of most interventions were relatively robust.

There was also variation in the methods used by the different studies to determine pleurodesis failure, in terms of the definition, how patient attrition was handled and the time point at which it was assessed. We did state how this would be handled a priori, using hierarchies of preferences, however these factors may have impacted on the results of the final meta-analysis.

Given the inevitable death of patients in this palliative population, true intention-to-treat analysis was often not performed, resulting in the potential for attrition bias. These missing data were handled differently by the various included studies. Some studies included patients on the basis of their 'last observation carried forward' (i.e. their last outcome prior to death) and others excluded these patients from the analysis completely. No studies used other imputation methods to account for these missing data.

The majority of the studies reported the main outcome measures of pleurodesis success, side effects and mortality. However, in a palliative population such as this, patient-focused outcomes, such as quality of life, symptom control, length of hospital stay and patient acceptability provide valuable, clinically relevant information, but were inconsistently reported in the included studies, precluding robust synthesis. The newer, suitably powered RCTs will report these important outcomes and hence future 
revisions of this review will hopefully be able to incorporate them into their findings.

We have not reported the Grading of Recommendations, Assessment, Development and Evaluations (GRADE) for our findings in this review and did not state in our protocol that we would. The role of GRADE is not well established in the context of Network Meta-analysis (NMA) and the approach to how it should be implemented is still a subject of debate (Puhan 2014, Salant 2014). We felt its inclusion would be highly complex and the results extremely subjective and hence elected not to incorporate it.

\section{Potential biases in the review process}

This review is based on the available published evidence and not on individual patient data, which would give a more accurate estimation of treatment effect and a clearer understanding of the heterogeneity (Deeks 2011). However, as several of the studies were published many years ago and individual patient information was therefore not available, patient level meta-analysis would not be possible without excluding the majority of the available evidence.

In order to allow inclusion of as many eligible studies as possible, we combined data obtained using different definitions of pleurodesis failure and timings in the same analysis. We predefined the methodology for this in the protocol using hierarchies of preferences. We performed sensitivity analyses to ensure the results were robust.

A potential source of bias in our primary outcome measure, pleurodesis efficacy, is the inevitable patient attrition due to mortality reported in many studies. If there had been real differences in mortality (and therefore drop out) across the interventions, this could bias the estimates of relative pleurodesis failure rates. However, analysis of the data on mortality and median survival times did not reveal evidence of differences in the vast majority of comparisons. Only two of 33 studies reporting overall mortality found a difference between treatment arms, and only one of the 24 studies which reported median survival times found a difference between treatment arms. The network metaanalysis of the mortality data only found evidence of one potential survival difference in the comparison between tetracycline and mitoxantrone.

Another very important consideration is the high degree of between-study heterogeneity across our treatment effect estimates. We have attempted to explore heterogeneity using subgroup analyses, but were unable to identify any specific reasons for it. The heterogeneity is likely to be related to a combination of factors related to study quality and the diversity of the methodology used in the included trials.

It should also be noted that the initial screening of titles and abstracts was performed by just one reviewer.

\section{Agreements and disagreements with other studies or reviews}

A number of other systematic reviews have been published in this area (Shaw 2004; Tan 2006; Xia 2014). All have presented only direct comparisons, rather than also incorporating indirect comparisons of alternative agents using network meta-analysis methods. We feel that network meta-analysis is more valid in this field as the diversity of the control groups used when comparing one agent with 'all others' means that important relative treatment effects may be either over or under estimated.

We used robust inclusion and exclusion criteria to identify eligible studies, which resulted in some studies included in other systematic reviews in this field being excluded from this one. These studies have been entered into the 'Excluded studies' section of this review, with justifications given for their exclusion. The main reasons were failure to use a truly random process to assign treatment groups and the inclusion of ascites or pericardial fluid accumulation, which could not be differentiated in the results section.

The previously published meta-analyses have all suggested that talc is the most effective agent and is best delivered thoracoscopically. Our data predominantly supports the use of thoracoscopic talc poudrage as an effective pleurodesis method, although we have found a lack of conclusive evidence to suggest it is more effective than some other methods. The choice of agent given via a chest tube based on our network of evidence is inconclusive, which differs from the conclusions drawn by other systematic reviews in this field. Talc does appear to be effective, although other agents such as mepacrine and $C$. parvum may be equally good.

\section{AUTHORS' CONCLUSIONS}

\section{Implications for practice}

This systematic review suggests that talc poudrage at thoracoscopy ranks highly as an effective method of delivering a sclerosant into the pleural cavity and is likely to be more effective at achieving a pleurodesis than many other commonly used methods such as bleomycin and tetracycline. However, there is a lack of definitive evidence to conclude it is certainly superior to some other commonly used methods, such as talc slurry and doxycycline. This is likely to be a reflection of the imprecision and unexplained heterogeneity within the network, as well as the high risk of bias of many of the included studies. The currently recruiting studies may provide further clarity regarding this and thereby help guide clinical practice more clearly in the future.

In contrast to previous systematic reviews, the main network and sensitivity analysis looking specifically at bedside pleurodesis agents (by excluding talc poudrage and IPCs) show less conclusive evidence of which agent is best. Talc, C. parvum, iodine, viscum and mepacrine all appear to be effective agents, although far more studies have directly evaluated talc than these other agents. We did not find evidence of a difference between these agents in terms of the main side effects (fever and pain) or mortality. However, graded (large particle talc) has less systemic absorption than mixed particle size talc and should therefore be used to reduce the rare but potentially catastrophic risk of ARDS (Maskell 2004).

This review was not designed to evaluate rarer but potentially clinically important adverse events, which may not have been identified by randomised controlled trials, which are important to consider when choosing a pleurodesis agent. Concerns regarding the dose-dependant systemic absorption of intra-pleural mepacrine, and the subsequent risk of transient psychotic episodes and seizures, have not been identified in the randomised trials of these agents, but are likely to limit its routine use (Bjorkman 1989). Viscum has only been appraised in one small clinical trial with 17 
evaluable participants. Minimal adverse event data were reported, but two out of 13 participants who received viscum experienced an allergic reaction necessitating their withdrawal from ongoing trial involvement (Gaafar 2014). A much fuller understanding of the toxicity of this drug and trial data from a larger number of participants is necessary before its routine clinical use can be recommended.

Worldwide, talc is reported to be the most commonly used pleurodesis agent (Lee 2003; Roberts 2010; Zarogoulidis 2013) and consequently it is likely to have the best appreciated side effect profile. Therefore, despite the equivalent efficacy seen in the network meta-analysis when compared to a number of other agents, if talc is available, this would appear to be a safe and effective choice for bedside pleurodesis supported by the largest body of evidence.

However, despite lower pleurodesis success rates, other techniques may have advantages over a traditional pleurodesis. Indwelling pleural catheters have been shown in two randomised studies to improve breathlessness to a greater extent than talc slurry pleurodesis (Davies 2012; Demmy 2012). They may also be associated with a shorter length of hospital stay (Davies 2012). Therefore, IPCs confer alternative, but highly clinically relevant benefits for patients, which make them appropriate as alternative first-line treatment options depending on the clinical scenario and patient preference.

\section{Implications for research}

An important limitation of this review is the heterogeneous reporting of outcome measures across trials and a paucity of data on patient-centred outcomes. This has important implications for future research. Selection of appropriate, clinically relevant, standardised outcome measures is essential to aid robust, unbiased analysis of trial data and facilitate future systematic reviews (Williamson 2012). Specific to this review, an internationally agreed definition of pleurodesis success and the timing at which it should be assessed would be hugely beneficial when combining data from future RCTs, along with a consensus about how to handle the inevitable patient attrition due to death.

The paucity of data regarding patient-focused outcomes such as quality of life and patient preference and also the health economic implications of the available interventions are important factors that warrant further research. Specifically, an improved understanding of the key outcomes which are important to patients with MPE would be beneficial.

Additionally, understanding the factors contributing to the high risk of bias in a large number of the previous studies in this field is crucial when designing future clinical trials in MPE. Attempting to minimise these risks by careful trial design has the potential to improve our evidence base and ensure robust, valid conclusions are drawn from the available evidence.

In light of the diversity of the doses used in the previously published studies, future work evaluating whether there is a dose response in terms of pleurodesis efficacy for the most effective agents may be beneficial.

There is a limited evidence regarding the most effective management of patients with trapped lung. Case series suggest trapped lung effects $10 \%$ to $20 \%$ of patients with MPE and the rapid recurrence of fluid after pleural interventions and the loss of elasticity of the visceral pleura often results in severe symptoms of recurrent breathlessness and pain during fluid aspirations (Brims 2012; Lan 1997; Warren 2008). Often these patients are excluded from MPE trials given the lack of efficacy of pleurodesis in this subgroup and hence there is a dearth of evidence on how best to manage them. Future RCTs to delineate the optimal management strategy in this population would be beneficial.

There is also a lack of robust randomised evidence for surgical interventions in this population. Audit data reports that $6 \%$ of the UK mesothelioma patients (for whom data were available) underwent a surgical procedure rather than a chemical pleurodesis between 2008 and 2012 (National Lung Cancer Audit Project Team 2014). Further RCT research in this area is warranted to better delineate the role of surgery.

As our knowledge about the pathology of MPE develops and our understanding of the different available techniques expands, a 'one size fits all' approach to malignant effusions is likely to be outdated and our hunt for the 'best' pleurodesis technique over-simplified. Different techniques are already known to have unique advantages and disadvantages and may therefore be suited to different cohorts of patients. Improved understanding of prognostication will help select the most appropriate management strategy for an individual (Clive 2014). Also, combining techniques to amalgamate the benefits of the varying methods is an exciting potential area of ongoing and future research (IPC-Plus; OPUS Trial).

\section{ACKNOWLEDGEMENTS}

The authors would like to thank Dr Deborah Caldwell for several helpful discussions.

Cochrane Review Group funding acknowledgement: The National Institute for Health Research (NIHR) is the largest single funder of the Cochrane PaPaS Group. Disclaimer: The views and opinions expressed in this review are those of the authors and do not necessarily reflect those of the NIHR, National Health Service (NHS) or the Department of Health. 


\section{RE F E R E N C E S}

\section{References to studies included in this review}

Agarwal 2011 \{published and unpublished data\}

Agarwal R, Paul AS, Aggarwal AN, Gupta D, Jindal SK. A randomized controlled trial of the efficacy of cosmetic talc compared with iodopovidone for chemical pleurodesis. Respirology 2011;16:1064-1069.

Alavi 2011 \{published data only (unpublished sought but not used)\} Alavi AA, Eshraghi M, Rahim MB, Meysami AP, Morteza A, Hajian $\mathrm{H}$. Povidone-iodine and bleomycin in the management of malignant pleural effusion. Acta Medica Iranica 2011;49(9):584-7.

\section{Bayly 1978 \{published data only\}}

Bayly TC, Kisner DL, Sybert A, Macdonald JS, Tsou E, Schein PS. Tetracycline and quinacrine in the control of malignant pleural effusions. A randomized trial. Cancer 1978;41:1188-92.

\section{Bjermer 1995 \{published data only\}}

Bjermer L, Gruber A, Sue-Chu M, Sandstrom T, Eksborg S, Henriksson R. Effects of intrapleural mitoxantrone and mepacrine on malignant pleural effusion - a randomised study. European Journal of Cancer Part A: General Topics 1995;31:2203-8.

\section{Clementsen 1998 \{published data only\}}

Clementsen P, Evald T, Grode G, Hansen M, Krag Jacobsen G, Faurschou P. Treatment of malignant pleural effusion: pleurodesis using a small percutaneous catheter. A prospective randomized study. Respiratory Medicine 1998;92:593-6.

\section{Crnjac 2004 \{published data only\}}

Crnjac A, Sok M, Kamenik M. Impact of pleural effusion pH on the efficacy of thoracoscopic mechanical pleurodesis in patients with breast carcinoma. European Journal of Cardio-Thoracic Surgery 2004;26:432-6.

\section{Davies 2012 \{published and unpublished data\}}

Davies HE, Mishra EK, Kahan BC, Wrightson JM, Stanton AE, Guhan A, et al. Effect of an indwelling pleural catheter vs chest tube and talc pleurodesis for relieving dyspnea in patients with malignant pleural effusion. JAMA 2012;307(22):2383-9.

\section{Demmy 2012 \{published and unpublished data\}}

Demmy TL, Gu L, Burkhalter JE, Toloza EM, D'Amico TA, Sutherland $S$, et al. Optimal management of malignant pleural effusions (results of CALGB 30102). Journal of the National Comprehensive Cancer Network 2012;10:975-82.

\section{Diacon 2000 \{published and unpublished data\}}

Diacon AH, Wyser C, Bolliger CT, Tamm M, Pless M, Perruchoud AP, et al. Prospective randomized comparison of thoracoscopic talc poudrage under local anesthesia versus bleomycin instillation for pleurodesis in malignant pleural effusions. American Journal of Respiratory \& Critical Care Medicine 2000;162:1445-9.
Dresler 2005 \{published and unpublished data\}

Dresler CM, Olak J, Herndon JE, Richards WG, Scalzetti E, Fleishman SB, et al. Phase III intergroup study of talc poudrage vs talc slurry sclerosis for malignant pleural effusion. Chest 2005;127:909-15.

Du 2013 \{published data only (unpublished sought but not used)\} Du N, Li X, Li F, Zhao H, Fan Z, Ma J, et al. Intrapleural combination therapy with bevacizumab and cisplatin for nonsmall cell lung cancer-mediated malignant pleural effusion. Oncology Reports 2013;29:2332-40.

\section{Emad 1996 \{published data only\}}

Emad A, Rezaian GR. Treatment of malignant pleural effusions with a combination of bleomycin and tetracycline. A comparison of bleomycin or tetracycline alone versus a combination of bleomycin and tetracycline. Cancer 1996;78:2498-501.

Evans 1993 \{published data only (unpublished sought but not used)\}

Evans TR, Stein RC, Pepper JR, Gazet JC, Ford HT, Coombes RC. $A$ randomised prospective trial of surgical against medical tetracycline pleurodesis in the management of malignant pleural effusions secondary to breast cancer. European Journal of Cancer 1993;29A:316-9.

Fentiman 1983 \{published data only\}

Fentiman IS, Rubens RD, Hayward JL. Control of pleural effusions in patients with breast cancer. A randomized trial. Cancer 1983;52:737-9.

\section{Fentiman 1986 \{published data only\}}

Fentiman I S, Rubens R D, Hayward J L. A comparison of intracavitary talc and tetracycline for the control of pleural effusions secondary to breast cancer. European Journal of Cancer \& Clinical Oncology 1986;22:1079-81.

Gaafar 2014 \{published data only (unpublished sought but not used)\}

Gaafar R, Abdel Rahman ARM, Aboulkasem F, El Bastawisy AE. Mistletoe preparation (Viscum Fraxini-2) as palliative treatment for malignant pleural effusion: a feasibility study with comparison to bleomycin. ecancermedicalscience 2014;8:424.

Goodman 2006 \{published and unpublished data\}

Goodman A, Davies CW. Efficacy of short-term versus longterm chest tube drainage following talc slurry pleurodesis in patients with malignant pleural effusions: a randomised trial. Lung Cancer 2006;54:51-5.

Groth 1991 \{published data only\}

Groth G, Gatzemeier U, Haussingen K, Heckmayr M, Magnussen $\mathrm{H}$, Neuhauss R, et al. Intrapleural palliative treatment of malignant pleural effusions with mitoxantrone versus placebo (pleural tube alone). Annals of Oncology 1991;2:213-5. 
Haddad 2004 \{published and unpublished data\}

Haddad FJ, Younes RN, Gross JL, Deheinzelin D. Pleurodesis in patients with malignant pleural effusions: talc slurry or bleomycin? Results of a prospective randomized trial. World Journal of Surgery 2004;28:749-53; discussion 753-4.

Hamed 1989 \{published data only (unpublished sought but not used)\}

Hamed H, Fentiman IS, Chaudary MA, Rubens RD. Comparison of intracavitary bleomycin and talc for control of pleural effusions secondary to carcinoma of the breast. British Journal of Surgery 1989;76:1266-7.

\section{Hillerdal 1986 \{published data only\}}

Hillerdal G, Kiviloog J, Nou E, Steinholtz L. Corynebacterium parvum in malignant pleural effusion. A randomized prospective study. European Journal of Respiratory Diseases 1986;69:204-6.

\section{Ishida 2006 \{published data only (unpublished sought but not used)\}}

Ishida A, Miyazawa T, Miyazu Y, Iwamoto Y, Zaima M, Kanoh K, et al. Intrapleural cisplatin and OK432 therapy for malignant pleural effusion caused by non-small cell lung cancer. Respirology 2006;11:90-7.

\section{Kasahara 2006 \{published data only\}}

Kasahara K, Shibata K, Shintani H, Iwasa K, Sone T, Kimura H, et al. Randomized phase II trial of OK-432 in patients with malignant pleural effusion due to non-small cell lung cancer. Anticancer Research 2006;26:1495-9.

\section{Kefford 1980 \{published data only\}}

Kefford RF, Woods RL, Fox RM, Tattersall MHN. Intracavitary Adriamycin nitrogen mustard and tetracycline in the control of malignant effusions. A randomized study. Medical Journal of Australia 1980;2:447-8.

\section{Kessinger 1987 \{published data only\}}

Kessinger A, Wigton RS. Intracavitary bleomycin and tetracycline in the management of malignant pleural effusions: a randomized study. Journal of Surgical Oncology 1987;36:81-3.

\section{Koldsland 1993 \{published and unpublished data\}}

Koldsland S, Svennevig JL, Lehne G, Johnson E. Chemical pleurodesis in malignant pleural effusions: a randomised prospective study of mepacrine versus bleomycin. Thorax 1993;48:790-3.

\section{Kuzdzal 2003 \{published data only (unpublished sought but not} used)\}

Kuzdzal J, Sladek K, Wasowski D, Soja J, Szlubowski A Reifland $A$, et al. Talc powder vs doxycycline in the control of malignant pleural effusion: a prospective, randomized trial. Medical Science Monitor 2003;9:PI54-9.

\section{Leahy 1985 \{published data only\}}

Leahy BC, Honeybourne D, Brear SG, Carroll KB, Thatcher N, Stretton TB. Treatment of malignant pleural effusions with intrapleural Corynebacterium parvum or tetracycline. European Journal of Respiratory Diseases 1985;66:50-4.

\section{Loutsidis 1994 \{published data only\}}

Loutsidis A, Bellenis I, Argiriou M, Exarchos N. Tetracycline compared with mechlorethamine in the treatment of malignant pleural effusions. A randomized trial. Respiratory Medicine 1994;88:523-6.

\section{Luh 1992 \{published data only\}}

Luh KT, Yang PC, Kuo SH, Chang DB, Yu CJ, Lee LN. Comparison of OK-432 and mitomycin C pleurodesis for malignant pleural effusion caused by lung cancer. A randomized trial. Cancer 1992;69:674-9.

\section{Lynch 1996 \{published data only\}}

Lynch TJ. Optimal therapy of malignant pleural effusions: report of a randomized trial of bleomycin, tetracycline, and talc and a meta-analysis. International Journal of Oncology 1996;8:183-90.

Mager 2002 \{published and unpublished data\}

Mager HJ, Maesen B, Verzijlbergen F, Schramel F. Distribution of talc suspension during treatment of malignant pleural effusion with talc pleurodesis. Lung Cancer 2002;36:77-81.

\section{Martinez-Moragon 1997 \{published data only\}}

Martinez-Moragon E, Aparicio J, Rogado MC, Sanchis J, Sanchis F, Gil-Suay V. Pleurodesis in malignant pleural effusions: a randomized study of tetracycline versus bleomycin. European Respiratory Journal 1997;10:2380-3.

Maskell 2004 \{published and unpublished data\} Maskell NA, Lee YCG, Gleeson FV, Hedley EL, Pengelly G, Davies RJO. Randomized trials describing lung inflammation after pleurodesis with talc of varying particle size. American Journal of Respiratory and Critical Care Medicine 2004;170:377-82

\section{Masuno 1991 \{published data only\}}

Masuno T, Kishimoto S, Ogura T, Honma T, Niitani H, Fukuoka M, et al. A comparative trial of LC9018 plus doxorubicin and doxorubicin alone for the treatment of malignant pleural effusion secondary to lung cancer. Cancer 1991;68:1495-500.

\section{Mejer 1977 \{published data only\}} Mejer J, Mortensen KM, Hansen HH. Mepacrine hydrochloride in the treatment of malignant pleural effusion. A controlled randomized trial. Scandinavian Journal of Respiratory Diseases 1977;58:319-23.

\section{Millar 1980 \{published data only\}}

Millar JW, Hunter AM, Horne NW. Intrapleural immunotherapy with Corynebacterium parvum in recurrent malignant pleural effusions. Thorax 1980;35:856-8.

\section{Mohsen 2011 \{published data only\}}

Mohsen TA, Zeid AA, Meshref M, Tawfeek N, Redmond K, Ananiadou OG, et al. Local iodine pleurodesis versus thoracoscopic talc insufflation in recurrent malignant pleural effusion: a prospective randomized control trial. European Journal of Cardio-Thoracic Surgery 2011; Vol. Volume:282-6. 


\section{Noppen 1997 \{published data only\}}

Noppen M, Degreve J, Mignolet M, Vincken W. A prospective, randomised study comparing the efficacy of talc slurry and bleomycin in the treatment of malignant pleural effusions. Acta Clinica Belgica 1997;52:258-62.

\section{Okur 2011 \{published and unpublished data\}}

Okur E, Baysungur V, Tezel C, Ergene G, Kuzu Okur H, Halezeroglu S. Streptokinase for malignant pleural effusions: a randomized controlled study. Asian Cardiovascular Thoracic Annals 2011;3/4:238-43.

\section{Ong 2000 \{published data only\}}

Ong KC, Indumathi V, Raghuram J, Ong YY. A comparative study of pleurodesis using talc slurry and bleomycin in the management of malignant pleural effusions. Respirology 2000;5:99-103.

\section{Ostrowski 1989 \{published data only\}}

Ostrowski MJ, Priestman TJ, Houston RF, Martin WM. A randomized trial of intracavitary bleomycin and Corynebacterium parvum in the control of malignant pleural effusions. Radiotherapy \& Oncology 1989;14:19-26.

Ozkul 2014 \{published data only (unpublished sought but not used)\}

Ozkul S, Turna A, Demirkaya A, Aksoy B, Kaynak K. Rapid pleurodesis is an outpatient alternative in patients with malignant pleural effusions: a prospective randomized controlled trial. Journal of Thoracic Disease 2014;6(12):1731-1735.

\section{Paschoalini 2005 \{published data only\}}

Paschoalini MS, Vargas FS, Marchi E, Pereira JR, Jatene FB, Antonangelo L, et al. Prospective randomized trial of silver nitrate vs talc slurry in pleurodesis for symptomatic malignant pleural effusions. Chest 2005;128:684-9.

\section{Patz 1998 \{published and unpublished data\}}

Patz EF, McAdams HP, Erasmus JJ, Goodman PC, Culhane DK, Gilkeson RC, et al. Sclerotherapy for malignant pleural effusions: a prospective randomized trial of bleomycin vs doxycycline with small-bore catheter drainage. Chest 1998;113:1305-11.

Rafiei 2014 \{published data only (unpublished sought but not used)\}

Rafiei R, Yazdani B, Ranjbar SM, Torabi Z, Asgary S, Najefi S, et al. Long-term results of pleurodesis in malignant pleural effusions: doxycycline vs bleomycin. Advanced Biomedical Research 2014;3:149.

\section{Rintoul 2014 \{published and unpublished data\}}

Rintoul RC, Ritchie AJ, Edwards JG, Waller DA, Coonar AS, Bennett $\mathrm{M}$, et al. Efficacy and cost of video-assisted thoracoscopic partial pleurectomy versus talc pleurodesis with malignant pleural mesothelioma (MesoVATS): an open-label, randomised, controlled trial. Lancet 2014;384(9948):1118-27.

\section{Ruckdeschel 1991 \{published data only\}}

Ruckdeschel JC, Moores D, Lee JY, Einhorn LH, Mandelbaum I, Koeller J, et al. Intrapleural therapy for malignant pleural effusions. A randomized comparison of bleomycin and tetracycline.[Erratum appears in Chest 1993 May;103(5):1640]. Chest 1991;100:1528-35.

\section{Salomaa 1995 \{published data only\}}

Salomaa E-R, Pulkki K, Helenius H. Pleurodesis with doxycycline or Corynebacterium parvum in malignant pleural effusion. Acta Oncologica 1995;34(1):117-21.

\section{Sartori 2004 \{published data only\}}

Sartori S, Tassinari D, Ceccotti P, Tombesi P, Nielsen I, Trevisani L, et al. Prospective randomized trial of intrapleural bleomycin versus interferon alfa- $2 \mathrm{~b}$ via ultrasound-guided small-bore chest tube in the palliative treatment of malignant pleural effusions. Journal of Clinical Oncology 2004;22:1228-33.

\section{Schmidt 1997 \{published data only\}}

Schmidt M, Schaarschmidt G, Chemaissani A. Pleurodesis in malignant pleural effusion: bleomycin vs. mitoxantrone [Pleurodese bei malignem Pleuraergub: Bleomycin vs. Mitoxantron]. Pneumologie 1997;51:367-72.

\section{Sorensen 1984 \{published data only\}}

Sorensen PG, Svendsen TL, Enk B. Treatment of malignant pleural effusion with drainage, with and without instillation of talc. European Journal of Respiratory Diseases 1984;65:131-5.

Terra 2009 \{published data only (unpublished sought but not used)\}

Terra RM, Junqueira JJ, Teixeira LR, Vargas FS, Pego-

Fernandes PM, Jatene FB. Is full postpleurodesis lung expansion a determinant of a successful outcome after talc pleurodesis?. Chest 2009;136:361-8.

Terra 2015 \{published data only (unpublished sought but not used)\}

Terra RM, Bellato RT, Teixeira LR, Chate RC, Pego-Fernandes PM. Safety and systemic consequences of pleurodesis with three different doses of silver nitrate in patients with malignant pleural effusion. Respiration 2015;89:276-83.

Ukale 2004 \{published and unpublished data\}

Ukale V, Agrenius V, Hillerdal G, Mohlkert D, Widstrom O. Pleurodesis in recurrent pleural effusions: a randomized comparison of a classical and a currently popular drug. Lung Cancer 2004;43:323-8.

\section{Villanueva 1994 \{published data only\}}

Villanueva AG, Gray AW, Shahian DM, Williamson WA, Beamis JF. Efficacy of short term versus long term tube thoracostomy drainage before tetracycline pleurodesis in the treatment of malignant pleural effusions. Thorax 1994;49:23-5.

Yildirim 2005 \{published and unpublished data\}

Yildirim E, Dural K, Yazkan R, Zengin N, Yildirim D, Gunal N, et al. Rapid pleurodesis in symptomatic malignant pleural effusion. European Journal of Cardio-Thoracic Surgery 2005;27:19-22. 
Yim 1996 \{published data only\}

Yim AP, Chan AT, Lee TW, Wan IY, Ho JK. Thoracoscopic talc insufflation versus talc slurry for symptomatic malignant pleural effusion. Annals of Thoracic Surgery 1996;62:1655-8.

Yoshida 2007 \{published data only (unpublished sought but not used)\}

Yoshida K, Sugiura T, Takifuji N, Kawahara M, Matsui K, Kudoh S, et al. Randomized phase II trial of three intrapleural therapy regimens for the management of malignant pleural effusion in previously untreated non-small cell lung cancer: JCOG 9515. Lung Cancer 2007;58:362-8.

\section{Zaloznik 1983 \{published data only\}}

Zaloznik AJ, Oswald SG, Langin M. Intrapleural tetracycline in malignant pleural effusions. A randomized study. Cancer 1983;51:752-5.

Zhao 2009 \{published data only (unpublished sought but not used)\} Zhao WZ, Wang JK, Li W, Zhang XL. Clinical research on recombinant human Ad-p53 injection combined with cisplatin in treatment of malignant pleural effusion induced by lung cancer. Chinese Journal of Cancer 2009;28:84-7.

Zimmer 1997 \{published data only (unpublished sought but not used)\}

Zimmer PW, Hill M, Casey K, Harvey E, Low DE. Prospective randomized trial of talc slurry vs bleomycin in pleurodesis for symptomatic malignant pleural effusions. Chest 1997;112:430-4.

\section{References to studies excluded from this review}

\section{Caglayan 2008 \{published data only\}}

Caglayan B, Torun E, Turan D, Fidan A, Gemici C, Sarac G, et al. Efficacy of iodopovidone pleurodesis and comparison of smallbore catheter versus large-bore chest tube. Annals of Surgical Oncology 2008;15:2594-9.

\section{Dryzer 1993 \{published data only\}}

Dryzer SR, Allen ML, Strange C, Sahn SA. A comparison of rotation and nonrotation in tetracycline pleurodesis. Chest 1993;104:1763-6.

\section{Elayouty 2012 \{published data only (unpublished sought but not} used)\}

Elayouty HD, Hassan TM, Alhadad ZA. Povidone-iodine versus bleomycin pleurodesis for malignant effusion in bronchogenic cancer guided by thoracic echography. Journal of Cancer Science \& Therapy 2012;4(7):182-4.

\section{Engel 1981 \{published data only\}}

Engel J. [Tetracyclin- und $\mathrm{Na}-\mathrm{OH}$-pleurodese in der palliativbehandlung maligner pleuraergasse]. Praxis der Pneumologie 1981;35:1124-8.

\section{Gust 1990 \{published data only\}}

Gust R, Kleine P, Fabel H. Fibrin glue and tetracycline pleurodesis in recurrent malignant pleural effusion
- a randomised controlled trial. Medizinische Klinik 1990;85(1):18-23.

Kwasniewska-Rokicinska 1979 \{published data only\}

Kwasniewska-Rokicinska C, Zielonkowa I, Dedyk-Drosik B, Drosik K. Results of ledakrin treatment of patients with neoplastic effusions. Nowotwory 1979;29:303-6.

Lissoni 1995 \{published data only (unpublished sought but not used)\}

Lissoni P, Barni S, Tancini G, Ardizzoia A, Tisi E, Angeli M, et al. Intracavitary therapy of neoplastic effusions with cytokines: comparison among interferon alpha, beta and interleukin-2. Support Care Cancer 1995;3:78-80.

Maiche 1993 \{published data only\}

Maiche AG, Virkkunen P, Kontkanen T, Moykkynen K, Porkka K. Bleomycin and mitoxantrone in the treatment of malignant pleural effusions. A comparative study. American Journal of Clinical Oncology 1993;16:50-3.

Manes 2000 \{published data only\}

Manes N, Rodriguez-Pandero F, Bravo JL, Hernandez H, Alix A Talc pleurodesis. Prospective and randomised study. Clinical follow-up. Chest 2000;118:131S.

Nio 1999 \{published data only\}

Nio Y, Nagami H, Tamura K, Tsubono M, Nio M, Sato M, et al. Multi-institutional randomized clinical study on the comparative effects of intracavital chemotherapy alone versus immunotherapy alone versus immunochemotherapy for malignant effusion. British Journal of Cancer 1999;80:775-85.

Tattersall 1982 \{published data only\}

Tattersall MHN. Intracavitary treatment of malignant pleural effusions. Chemioterapia 1982;1:288-92.

\section{References to studies awaiting assessment}

Bo 1998 \{published data only\}

Bo H, Yaohua W. Curative effect of highly agglutinative staphylococcin plus cisplatin in treatment of malignant pleural effusion and ascites. Chinese Journal of Clinical Oncology 1998;25:623-4.

\section{Cong 2010 \{published data only\}}

Cong YY, Liu MY, Cai L. Comparison of the therapeutic effects of pleural perfusion of NDP and CDDP in NSCLC patients with malignant pleural effusion. Chung-Hua Chung Liu Tsa Chih [Chinese Journal of Oncology] 2010;32:467-9.

Fukuoka 1984 \{published data only\}

Fukuoka M, Takada M, Tamai S, Negoro S, Matsui K, Ryu S, et al. Local application of anti-cancer drugs for the treatment of malignant pleural and pericardial effusion. Gan to Kagaku Ryoho [Japanese Journal of Cancer \& Chemotherapy] 1984;11:1543-9. 
Miyanaga 2011 \{published data only\}

Miyanaga A Gemma A. Pleuritis carcinomatosa. Gan to kagaku ryoho 2011;Cancer \& chemotherapy(38):524-7.

\section{Song 2013 \{published data only\}}

Song F, Pei X, Jin Q, Peng Y, Zhao J, Xie J. Clinical effect of pseudomonas aeruginosa injection on malignant pleural effusion. Chinese Journal of Clinical Oncology 2013;40(18):1127-9.

\section{Sun 2002 \{published data only\}}

Sun DX, Shen HD, Ji CL, Wei QL. Clinical observation of Yadanzhi grease and DDP on treating malignant pleural effusion. Chinese Traditional Patent Medicine 2002; Vol. 24:604-6.

\section{Won 1997 \{published data only\}}

Won SO, Choi J, Yong SK, Yong HD, Tae WJ, Maan HJ. Intrapleural doxycycline and bleomycin in the management of malignant pleural effusions: A randomized study. Tuberculosis and Respiratory Diseases 1997;44:85-92.

\section{Xu 2010 \{published data only\}}

Xu T, Gao H, Zhang T, Yang B. Clinical observation of highly agglutinative staphylococcin combined with nedaplatin for malignant pleural effusion as local treatment. Chinese Journal of Cancer Prevention and Treatment 2010;17:1229-30.

\section{Yu 2003 \{published data only\}}

Yu HY. Observation of curative effect of cisplatin and lentinan on patients with malignant pleural effusions. Journal of postgraduates of medicine 2003; Vol. 26:16-7.

\section{Zhuang 2012 \{published data only\}}

Zhuang HF, Ren JX, Zhou YH, Chen XY, Wu YF, Li FF, et al. Matrine injection combined with intrapleural cisplatin in treatment of 24 patients with hematologic malignancies complicated by pleural effusion. Chinese Journal of New Drugs 2012;21:1013-5.

\section{References to ongoing studies}

\section{AMPLE Trial \{published data only\}}

Fysh ETH, Thomas R, Read CA, Lam BCH, Yap E, Horwood FC, et al. Protocol of the Australasian Malignant Pleural Effusion (AMPLE) trial: a multicentre randomised study comparing indwelling pleural catheter versus talc pleurodesis. BMJ Open 2014;4:e006757.

\section{IPC-Plus \{published and unpublished data\}}

Bhatnagar R, Morley A, Maskell N on behalf of the IPC-Plus Trial Investigators. The efficacy of indwelling pleural catheter (IPC) placement versus IPC placement PLUS sclerosant (talc) in patients with malignant pleural effusions managed exclusively as out-patients (the IPC-PLUS trial). Lung Cancer 2014;83(S1):S51.

\section{OPUS Trial \{published and unpublished data\}}

Amjadi K. Effectiveness of doxycycline for treating pleural effusions related to cancer in an outpatient population (OPUS). https://clinicaltrials.gov/ct2/show/NCT01411202.

\section{TAPPS $\{$ published and unpublished data\}}

Bhatnagar R, Laskawiec-Szkonter M, Piotrowska HE, Kahan BC, Hooper CE, Davies HE, et al. Evaluating the efficacy of thoracoscopy and talc poudrage versus pleurodesis using talc slurry (The TAPPS Trial): protocol of an open-label randomised controlled trial. BMJ Open 2014;4(11):e007045.

TIME-1 \{published data only\}

RJO Davies. The First Therapeutic Intervention in Malignant Pleural Effusion Trial (TIME-1). https://clinicaltrials.gov/ct2/ show/NCT00896285.

\section{TIME-3 \{published and unpublished data\}}

Rahman N. A randomised controlled trial to evaluate whether use of intrapleural urokinase aids the drainage of multiseptated pleural effusion compared to placebo (TIME-3 Trial). http://www.isrctn.com/ISRCTN12852177.

\section{Additional references}

\section{American Thoracic Society 2000}

American Thoracic Society. Management of malignant pleural effusions. American Journal of Respiratory and Critical Care Medicine 2000;162:1987-2001.

\section{Bielsa 2008}

Bielsa S, Salud A, Martínez M, Esquerda A, Martín A, RodríguezPanadero $F$, et al. Prognostic significance of pleural fluid data in patients with malignant effusion. European Journal of Internal Medicine 2008;19:334-9.

\section{Bjorkman 1989}

Bjorkman S, Elisson LO, Gabrielsson J. Pharmacokinetcis of quinacrine after intrapleural instillation in rabbits and man. Journal of Pharmacy and Pharmacology 1989;41(3):160-3.

\section{Brims 2012}

Brims FJ, Arif M, Chauhan AJ. Outcomes and complications following medical thoracoscopy. The Clinical Respiratory Journal 2012;6(3):144-9.

\section{Burrows 2000}

Burrows CM, Mathews WC, Colt HG. Predicting survival in patients with recurrent symptomatic malignant pleural effusions: an assessment of the prognostic values of physiologic, morphologic and quality of life measures of extent of disease. Chest 2000;117:73-8.

\section{Chaimani 2013}

Chaimani A, Higgins JP, Mavridis D, Spyridonos P, Salanti G. Graphical tools for network meta-analysis in STATA. PLoS One 2013;8(10):e76654.

\section{Clive 2014}

Clive AO, Kahan BC, Hooper CE, Bhatnagar R, Morley AJ, ZahanEvans $\mathrm{N}$, et al. Predicting survival in malignant pleural effusion: development and validation of the LENT prognostic score. Thorax 2014;69(12):1098-104. 


\section{Davies 1999}

Davies CW, Traill ZC, Gleeson FV, Davies RJ. Intrapleural streptokinase in the management of malignant multiloculated pleural effusions. Chest 1999;115:729-33.

\section{Deeks 2011}

Deeks JJ, Higgins JPT, Altman DG (editors). Chapter 9: Analysing data and undertaking meta-analyses. In: Higgins JPT, Green $S$ (editors). Cochrane Handbook for Systematic Reviews of Interventions Version 5.1.0 (updated March 2011). The Cochrane Collaboration, 2011. Available from www.cochranehandbook.org.

\section{Dias 2013}

Dias S, Welton NJ, Sutton AJ, Caldwell DM, Lu G, Ades AE. Evidence synthesis for decision making 4: inconsistency in networks of evidence based on randomized controlled trials. Medical Decision Making 2013;33(5):641-56.

\section{DiBonito 1992}

DiBonito L, Falconieri G, Colautti I, Bonifacio D, Dudine S. The positive pleural effusion. A retrospective study of cytopathologic diagnoses with autopsy confirmation. Acta Cytologica 1992;36:329-32.

\section{Donegan 2013}

Donegan S, Williamson P, D'Alessandro U, Tudur-Smith C. Assessing key assumptions of network meta-analysis: a review of methods. Research Synthesis Methods 2013;4:291-323.

\section{Gilkeson 1999}

Gilkeson RC, Silverman P, Haaga JR. Using urokinase to treat malignant pleural effusions. American Journal of Roentgenology 1999;173:781-3.

\section{Higgins 2003}

Higgins JP, Thompson SG, Deeks JJ, Altman DG. Measuring inconsistency in meta-analysis. BMJ 2003;327(7414):557-60.

\section{Higgins 2011a}

Higgins JPT, Altman DG, Sterne JAC (editors). Chapter 8: Assessing risk of bias in included studies. In: Higgins JPT, Green S (editors). Cochrane Handbook for Systematic Reviews of Interventions Version 5.1.0 [updated March 2011]. The Cochrane Collaboration, 2011. Available from www.cochranehandbook.org.

\section{Higgins 2011b}

Higgins JPT, Deeks JJ, Altman DG (editors). Chapter 16: Special topics in statistics. In: Higgins JPT, Green S (editors), Cochrane Handbook for Systematic Reviews of Interventions Version 5.1.0 (updated March 2011). The Cochrane Collaboration, 2011. Available from www.cochrane-handbook.org.

\section{Hsu 2006}

Hsu LH, Soong TC, Feng AC, Liu MC. Intrapleural urokinase for the treatment of loculated malignant pleural effusions and trapped lungs in medically inoperable cancer patients. Journal of Thoracic Oncology 2006;1:460-7.

\section{Lan 1997}

Lan RS, Lo SK, Chuang ML, Yang CT, Tsao TC, Lee CH. Elastance of the pleural space: a predictor for the outcome of pleurodesis in patients with malignant pleural effusion. Annals of Internal Medicine 1997;126(10):768-74.

\section{Lee 2003}

Lee YCG, Baumann MH, Maskell NA, Waterer GW, Eaton TE, Davies RJO, et al. Pleurodesis practice for malignant pleural effusions in five English-speaking countries. Chest 2003;124:2229-38.

\section{Lunn 2000}

Lunn DJ, Thomas A, Best N, Spiegelhalter D. WinBUGS - a Bayesian modelling framework: concepts, structure and extensibility. Statistics and Computing 2000;10:325-37.

\section{National Lung Cancer Audit Project Team 2014 [Computer program]}

The National Lung Cancer Audit Project Team. National Lung Cancer Audit Report 2014: Mesothelioma. Health and Social Care Information Centre. Health and Social Care Information Centre, 2014.

\section{Puhan 2014}

Puhan MA, Schünemann HJ, Murad MH, Li T, BrignardelloPetersen R, Singh JA, et al. A GRADE Working Group approach for rating the quality of treatment effect estimates from network meta-analysis.. British Medical Journal 2014;349:g5630.

\section{Putnam 2000}

Putnam JB Jr, Walsh GL, Swisher SG, Roth JA, Suell DM, Vaporciyan AA, et al. Outpatient management of malignant pleural effusion by a chronic indwelling pleural catheter. Annals of Thoracic Surgery 2000;69:369-75.

\section{Rahman 2010}

Rahman NM, Ali NJ, Brown G, Chapman SJ, Davies RJ, Downer NJ, et al. Local anaesthetic thoracoscopy: British Thoracic Society pleural disease guideline 2010. Thorax 2010;65(Suppl 2):ii54-60.

\section{RevMan 2014 [Computer program]}

The Nordic Cochrane Centre, The Cochrane Collaboration. Review Manager (RevMan). Version 5.3. Copenhagen: The Nordic Cochrane Centre, The Cochrane Collaboration, 2014.

\section{Roberts 2010}

Roberts ME, Neville E, Berrisford RG, Antunes G, Ali NJ. Management of a malignant pleural effusion: British Thoracic Society pleural disease guideline 2010. Thorax 2010;65(Suppl 2):ii32-40.

\section{Rodrîguez-Panadero 1989}

Rodrîguez-Panadero F, Borderas Naranjo F, López Mejîas J. Pleural Metastatic tumours and effusions. Frequency and pathogenic mechanisms in a post-mortem series. European Respiratory Journal 1989;2:366-9. 


\section{Rodrîguez-Panadero 2008}

Rodrîguez-Panadero F. Effusions from malignancy. In: Light, Gary Lee editor(s). Textbook of pleural diseases. 2nd Edition. Hodder Arnold, 2008:323.

\section{Salanti 2012}

Salanti G. Indirect and mixed-treatment comparison, network, or multiple-treatments meta-analysis: many names, many benefits, many concerns for the next generation evidence synthesis tool. Research Synthesis Methods 2012;3:80-97.

\section{Salanti 2014}

Salanti G, Del Giovane C, Chaimani A, Caldwell DM, Higgins JP. Evaluating the quality of evidence from a network metaanalysis. PLoS One 2014;9(7):e99682.

\section{Sears 1987}

Sears D, Hajdu LI. The Cytologic diagnosis of malignant neoplasms in pleural and peritoneal effusions. Acta Cytologica 1987;31:85-97.

\section{Sterne 2011}

Sterne JAC, Egger M, Moher D (editors). Chapter 10: Addressing reporting biases. In: Higgins JPT, Green S (editors). Cochrane Handbook for Systematic Reviews of Intervention s. Version 5.1.0 (updated March 2011). The Cochrane Collaboration, 2011. Available from www.cochrane-handbook.org.

\section{Tan 2006}

Tan C, Sedrakyan A, Browne J, Swift S, Treasure T. The evidence on the effectiveness of management for malignant pleural effusion: a systematic review. European Journal of CardioThoracic Surgery 2006;29(5):829-38.

\section{Tremblay 2006}

Tremblay A, Michaud G. Single-center experience with 250 tunnelled pleural catheter insertions for malignant pleural effusion. Chest 2006;129:362-8.

\section{CHARACTERISTICS OF STUDIES}

Characteristics of included studies [ordered by study ID]

\section{Warren 2008}

Warren WH, Kalimi R, Khodadadian LM, Kim AW. Management of malignant pleural effusions using the Pleur $(\mathrm{x})$ catheter. Annals of Thoracic Surgery 2008;85(3):1049-55.

\section{WHO 2016}

World Health Organisation. WHO's cancer pain ladder for adults. http://www.who.int/cancer/palliative/painladder/en/ 2016. Accessed 20/04/2016.

\section{Williamson 2012}

Williamson P, Clarke M. The COMET (Core Outcome Measures in Effectivness Trials) Initiative: Its role in improving Cochrane Reviews. Cochrane Database of Systematic Reviews 2012;5:ED000041.

\section{Xia 2014}

Xia H, Wang XJ, Zhou Q, Shi HZ, Tong ZH. Efficacy and safety of talc pleurodesis for malignant pleural effusion: a meta-analysis. PLoS One 2014;9(1):e87060.

\section{Zarogoulidis 2013}

Zarogoulidis K, Zarogoulidis P, Darwiche K, Tsakiridis K, Machairiotis N, Kougioumtzi I, et al. Malignant pleural effusion and algorithm management. Journal of Thoracic Disease 2013;5(S4):S413-9.

\section{References to other published versions of this review}

\section{Shaw 2004}

Shaw PHS, Agarwal R. Pleurodesis for malignant pleural effusions. Cochrane Database of Systematic Reviews 2004, Issue 1. [DOI: 10.1002/14651858.CD002916.pub3]

Agarwal 2011

\begin{tabular}{ll} 
Methods & Single centre RCT comparing the efficacy of cosmetic talc with iodopovidone for pleurodesis (India) \\
\hline Participants & $\begin{array}{l}\text { Inclusion: recurrent symptomatic pleural effusion with improvement of breathlessness with thoracen- } \\
\text { tesis; or primary or secondary pneumothorax }\end{array}$ \\
& $\begin{array}{l}\text { Exclusion: allergy to iodine; thyroid disorder; trapped lung; air leak; advanced malignancy with expect- } \\
\text { ed survival < 30 days } \\
36 \text { participants randomised }\end{array}$
\end{tabular}

Interventions

$28 \mathrm{Fr}$ intercostal drain to completely drain effusion or treat pneumothorax. Pleurodesis agent given when $<150 \mathrm{ml} /$ day drainage and complete lung re-expansion on chest $x$-ray. All participants received intrapleural lignocaine $(2 \mathrm{mg} / \mathrm{kg})$ and IV tramadol prior to pleurodesis. 
After agent administered, chest tube clamped for four hours. Repeat administration of agent if $>250$ $\mathrm{ml} /$ day drainage. Drain removed when $<100 \mathrm{ml} /$ day output

Followed up at 1 week, 1 month, 3 months and 6 months and then every 3 months thereafter

\begin{tabular}{|c|c|}
\hline \multirow[t]{4}{*}{ Outcomes } & $\begin{array}{l}\text { Pleurodesis success according to need for thoracentesis (complete success = relief of symptoms relat- } \\
\text { ed to the effusion and no re-accumulation on CXR at } 30 \text { days; partial success = reduced dyspnoea relat- } \\
\text { ed to the effusion with only partial re-accumulation of fluid on chest } x \text {-ray and no requirement for ther- } \\
\text { apeutic thoracentesis; failure = lack of success as defined above) }\end{array}$ \\
\hline & Chest pain (measured by visual analogue scale score) \\
\hline & Complications \\
\hline & Time to pleurodesis \\
\hline
\end{tabular}

Notes People with trapped lung excluded.

Unpublished data obtained from authors relating to subgroup of participants in the study with malignant pleural effusion- only this data was included for the purposes of this review

Included in network meta-analysis for pleurodesis efficacy and fever.

\section{Risk of bias}

\begin{tabular}{|c|c|c|}
\hline Bias & Authors' judgement & Support for judgement \\
\hline $\begin{array}{l}\text { Random sequence genera- } \\
\text { tion (selection bias) }\end{array}$ & Low risk & Computer-generated randomisation sequence \\
\hline $\begin{array}{l}\text { Allocation concealment } \\
\text { (selection bias) }\end{array}$ & Low risk & Opaque sealed envelopes \\
\hline $\begin{array}{l}\text { Blinding of participants } \\
\text { and personnel (perfor- } \\
\text { mance bias) } \\
\text { All outcomes }\end{array}$ & High risk & $\begin{array}{l}\text { "Blinding of the allocation to treatments was not possible". Agents have differ- } \\
\text { ent appearances }\end{array}$ \\
\hline $\begin{array}{l}\text { Blinding of outcome as- } \\
\text { sessment (detection bias) } \\
\text { All outcomes }\end{array}$ & High risk & $\begin{array}{l}\text { Symptom recurrence, visucal analogue scale scores and complications would } \\
\text { all be biased by lack of patient blinding. Mortality would not be effected by } \\
\text { lack of blinding }\end{array}$ \\
\hline $\begin{array}{l}\text { Incomplete outcome data } \\
\text { (attrition bias) } \\
\text { All outcomes }\end{array}$ & Low risk & No loss to follow up. Intention-to-treat analysis performed \\
\hline $\begin{array}{l}\text { Selective reporting (re- } \\
\text { porting bias) }\end{array}$ & Low risk & All reported \\
\hline Other bias & Low risk & $\begin{array}{l}\text { Cosmetic talc used rather than medicinal talc, but sterilised and comparable } \\
\text { particle size by electron microscopy. No external funding for the study }\end{array}$ \\
\hline
\end{tabular}

\section{Alavi 2011}

Methods Single centre RCT of povidone-iodine and bleomycin pleurodesis for malignant pleural effusion (Iran)


Alavi 2011 (Continued)

Participants

Inclusion: biopsy or cytologically proven malignant pleural effusion (all tumour types); recurrent and symptomatic effusion; chest radiograph confirming lung expansion of $90 \%$ after thoracentesis; Karnofsky Performance Score $>70$

Exclusion: co-morbidities that preclude general anaesthesia; bleeding disorders; massive thoracic skin infiltration; active infectious disease

39 participants randomised

Interventions
All participants underwent a $28 \mathrm{Fr}$ intercostal drain under local anaesthetic (+/- IV opiates if required). Study agent administered intrapleurally the next day with $5 \mathrm{ml} \%$ lidocaine

Bleomycin group: $1 \mathrm{mg} / \mathrm{kg}$ bleomycin in $60 \mathrm{ml}$ saline. 1 dose

Povidone-iodine group: 5\% (volume unclear). 1 dose

After administration of the study agent, the drain was clamped for one hour and removed when < $200 \mathrm{ml}$ fluid output/day. If the fluid output remained high after 10 days, they were discharged home with a Heimlich valve in place

\section{Risk of bias}

Effusion recurrence on chest $x$-ray at 30 days

Pain (measured by numeric scale) at discharge and day 30

Dysponea (measured by numeric scale) at discharge and day 30

Minimal raw data in results section - tables quoted in text but not available on line. Attempted to contact study authors by e mails - no response

People with trapped lung excluded from trial entry

Pleurodesis success measured only using chest $x$-ray criteria

Included in network meta-analysis for pleurodesis efficacy.

\begin{tabular}{|c|c|c|}
\hline Bias & Authors' judgement & Support for judgement \\
\hline $\begin{array}{l}\text { Random sequence genera- } \\
\text { tion (selection bias) }\end{array}$ & Low risk & Block randomisation \\
\hline $\begin{array}{l}\text { Allocation concealment } \\
\text { (selection bias) }\end{array}$ & Low risk & Block randomisation \\
\hline $\begin{array}{l}\text { Blinding of participants } \\
\text { and personnel (perfor- } \\
\text { mance bias) } \\
\text { All outcomes }\end{array}$ & High risk & $\begin{array}{l}\text { Differing appearances of bleomycin and iodine make blinding not possible (al- } \\
\text { though not stated explicitly in paper) }\end{array}$ \\
\hline $\begin{array}{l}\text { Blinding of outcome as- } \\
\text { sessment (detection bias) } \\
\text { All outcomes }\end{array}$ & High risk & $\begin{array}{l}\text { Pain and dyspnoea may be biased by lack of blinding. Not stated whether CXRs } \\
\text { were evaluated by a blinded clinician. No response from study authors regard- } \\
\text { ing this }\end{array}$ \\
\hline $\begin{array}{l}\text { Incomplete outcome data } \\
\text { (attrition bias) } \\
\text { All outcomes }\end{array}$ & Unclear risk & $\begin{array}{l}\text { Unable to see the tables. Response rates only given as \% (no actual numbers), } \\
\text { so unclear whether there was LTFU }\end{array}$ \\
\hline $\begin{array}{l}\text { Selective reporting (re- } \\
\text { porting bias) }\end{array}$ & Unclear risk & Raw data not provided for many of the outcomes. Tables missing \\
\hline
\end{tabular}


Alavi 2011 (Continued)
Other bias
Low risk
No other biases identified

\section{Bayly 1978}

\begin{tabular}{|c|c|}
\hline Methods & $\begin{array}{l}\text { Two-centre RCT of intrapleural quinacrine (mepacrine) vs tetracycline via tube thoracostomy for malig- } \\
\text { nant pleural effusion (USA) }\end{array}$ \\
\hline \multirow[t]{3}{*}{ Participants } & $\begin{array}{l}\text { Inclusion: (1) documented cancer with pleural effusion (2) pleural fluid cytology or pleural biopsy con- } \\
\text { firming malignancy or exudate effusion presumed to be malignant (3) symptomatic from the effusion } \\
\text { or rapidly re-accumulating effusion }>500 \mathrm{ml}\end{array}$ \\
\hline & All cell types. No exclusion criteria \\
\hline & 20 participants randomised. \\
\hline \multirow[t]{4}{*}{ Interventions } & Both groups had a closed tube thoracostomy, drained overnight prior to the installation \\
\hline & Quinacrine group: intrapleural quinacrine (100 mg in $30 \mathrm{ml}$ normal saline) once daily for four days \\
\hline & Tetracycline group: one dose of intrapleural tetracycline (500 mg in $30 \mathrm{ml} \mathrm{N}$ saline) \\
\hline & $\begin{array}{l}\text { The drains were clamped for six hours post installation with patient rotation. Drain removed when }<60 \\
\mathrm{ml} / 24 \text { hour drainage }\end{array}$ \\
\hline \multirow[t]{2}{*}{ Outcomes } & $\begin{array}{l}\text { Pleurodesis success (defined on chest x-ray criteria only at } 30 \text { days as 'Complete response' (complete } \\
\text { lack of re-accumulation of pleural fluid); 'Partial response' (re-accumulation of pleural fluid }<50 \% \text { of } \\
\text { the volume present before the sclerosis); 'Failure' (re-accumulation of fluid to }>50 \% \text { of the volume } \\
\text { present before the attempted sclerosis)) }\end{array}$ \\
\hline & Side effects of treatment (pain, fever) \\
\hline \multirow[t]{4}{*}{ Notes } & People with trapped lung not excluded. \\
\hline & CR and PR counted as a pleurodesis success for purposes of analysis \\
\hline & $\begin{array}{l}\text { One participant allocated to quinacrine arm having had treatment failure with tetracycline not includ- } \\
\text { ed in the analysis }\end{array}$ \\
\hline & Included in network meta-analysis for pleurodesis efficacy and pain. \\
\hline
\end{tabular}

\section{Risk of bias}

\begin{tabular}{lll}
\hline Bias & Authors' judgement & Support for judgement \\
\hline $\begin{array}{l}\text { Random sequence genera- } \\
\text { tion (selection bias) }\end{array}$ & Unclear risk & Not specified and unable to contact study authors \\
\hline $\begin{array}{l}\text { Allocation concealment } \\
\text { (selection bias) }\end{array}$ & Unclear risk & Not specified and unable to contact study authors \\
\hline $\begin{array}{l}\text { Blinding of participants } \\
\text { and personnel (perfor- } \\
\text { mance bias) }\end{array}$ & Unclear risk & No comment on whether study was blinded \\
$\begin{array}{l}\text { All outcomes } \\
\text { Blinding of outcome as- } \\
\text { sessment (detection bias) } \\
\text { All outcomes }\end{array}$ & Unclear risk & $\begin{array}{l}\text { Not stated whether CXR evaluation was blinded. Pain and fever outcomes may } \\
\text { have been affected if patients were unblinded to treatment allocation, howev- } \\
\text { er not stated in the paper whether this was the case }\end{array}$ \\
\hline \hline
\end{tabular}


Bayly 1978 (Continued)

Incomplete outcome data Low risk Two of 14 randomised to tetracycline excluded from analysis (one died and (attrition bias) one LTFU). No LTFU in mepacrine arm (overall LTFU 13\%)

All outcomes

\begin{tabular}{lll}
$\begin{array}{l}\text { Selective reporting (re- } \\
\text { porting bias) }\end{array}$ & Low risk & All specified endpoints reported \\
\hline Other bias & High risk & $\begin{array}{l}\text { Eight of } 22 \text { participants included in the study did not have proven pleural ma- } \\
\text { lignancy }\end{array}$ \\
\hline
\end{tabular}

\section{Bjermer 1995}

\section{Methods} fied)
RCT of mitoxantrone versus mepacrine via an intercostal drain (Sweden - number of centres not speci-
Cytologically proven, symptomatic MPE with an expected survival of greater than three months (Karnofsky Performance Score $>60$ ). Excluded if cytotoxic chemotherapy in the preceding month

All cell types included

30 participants randomised
Both groups had a 12-14 Fr chest tube inserted and effusion drained. Pleurodesis agent was given through the chest tube and patient's position changed for two hours after administration

Group 1: 1 dose of intrapleural mitoxantrone $30 \mathrm{mg}$ in $50 \mathrm{ml} \mathrm{N}$ saline was given; the drain was closed for 48 hours and removed after the 'pleural cavity was emptied'

Group 2: 2 doses of intrapleural mepacrine chloride $200 \mathrm{mg}$ in $20 \mathrm{ml} \mathrm{N}$ saline were given on consecutive days and the drain removed when $<150 \mathrm{ml}$ fluid production/day

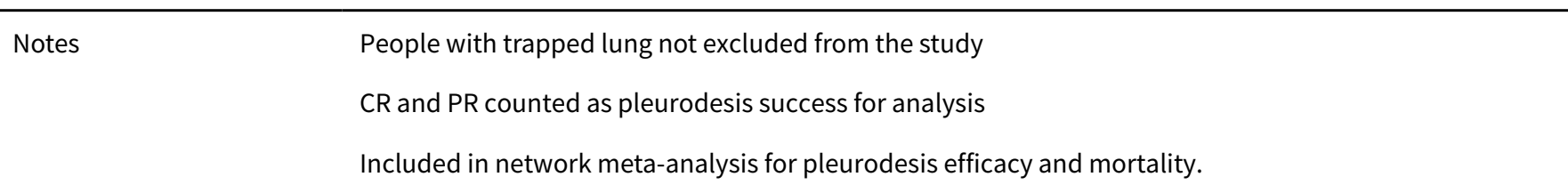

\section{Risk of bias}

\begin{tabular}{lll}
\hline Bias & Authors' judgement & Support for judgement \\
\hline $\begin{array}{l}\text { Random sequence genera- } \\
\text { tion (selection bias) }\end{array}$ & Unclear risk & Not specified and unable to find contact details for study authors \\
\hline $\begin{array}{l}\text { Allocation concealment } \\
\text { (selection bias) }\end{array}$ & Unclear risk & Not specified and unable to find contact details for study authors \\
\hline
\end{tabular}


Bjermer 1995 (Continued)

$\begin{array}{ll}\begin{array}{l}\text { Blinding of participants } \\ \text { and personnel (perfor- }\end{array} & \text { Low risk }\end{array}$
ipants were blinded to treatment allocation mance bias)

All outcomes

\begin{tabular}{|c|c|c|}
\hline $\begin{array}{l}\text { Blinding of outcome as- } \\
\text { sessment (detection bias) } \\
\text { All outcomes }\end{array}$ & Low risk & $\begin{array}{l}\text { Participants blind to treatment allocation, therefore fever, pain and symptom } \\
\text { scores unbiased. "Radiological evaluation was made by an independent radi- } \\
\text { ologist' }\end{array}$ \\
\hline
\end{tabular}

Incomplete outcome data Low risk (attrition bias) All outcomes One participant in each study arm did not receive treatment due to "unexpected medical emergencies", therefore deemed non-evaluable. Follow-up data clearly documented for the remaining patients

\begin{tabular}{lll}
\hline $\begin{array}{l}\text { Selective reporting (re- } \\
\text { porting bias) }\end{array}$ & Low risk & All pre-specified outcomes reported \\
\hline Other bias & Low risk & $\begin{array}{l}\text { Drain suction use was imbalanced between the treatment arms (10/14 re- } \\
\text { ceived suction in mepacrine group vs } 1 / 14 \text { in mitoxantrone group) }\end{array}$
\end{tabular}

\section{Clementsen 1998}

Methods Single centre RCT of tetracycline pleurodesis using a small percutaneous catheter ( $\mathrm{CH} 10)$, $\mathrm{Compared} \mathrm{to}$
a large-bore chest tube (CH24) inserted after thoracoscopy (Denmark)

\begin{tabular}{ll}
\hline Participants & $\begin{array}{l}\text { Symptomatic, recurrent MPE, proven on pleural fluid cytology. Expected survival of }>3 \text { months (all tu- } \\
\text { mour types included) } \\
21 \text { participants randomised }\end{array}$
\end{tabular}

Interventions Group 1: small percutaneous catheter $(\mathrm{CH} 1065 \mathrm{~cm})$ inserted under local anaesthesia

Group 2: medical thoracoscopy, followed by insertion of a large-bore chest tube $(\mathrm{CH} 24)$

Both groups received pleurodesis with $500 \mathrm{mg}$ tetracycline and $100 \mathrm{mg}$ bupivicaine intrapleurally. The drain was clamped for six hours after instillation after which suction was applied. Drain removed when fluid output $<200 \mathrm{ml}$ in 24 hours

\begin{tabular}{ll}
\hline Outcomes & $\begin{array}{l}\text { Treatment response at 3, } 6 \text { and } 9 \text { weeks defined by roentgenographic response ('Complete response' } \\
\text { - no recurrence of pleural fluid; 'Partial response' - slight re-accumulation with blunted costophrenic } \\
\text { angle; 'No response' - complete recurrence of pleural fluid) and clinical response (by the need for new } \\
\text { thoracentesis) } \\
\text { Questionnaire evaluating discomfort in connection with the tube and the pleurodesis }\end{array}$ \\
\hline Notes & $\begin{array}{l}\text { Trapped lung not accounted for in inclusion/exclusion criteria, but one patient excluded as they had } \\
\text { hydropneumothorax at time of instillation }\end{array}$ \\
CR and PR included as pleurodesis successes for analysis \\
Not included in network meta-analysis
\end{tabular}

\section{Risk of bias}

\begin{tabular}{lll}
\hline Bias & Authors' judgement & Support for judgement \\
\hline $\begin{array}{l}\text { Random sequence genera- } \\
\text { tion (selection bias) }\end{array}$ & Low risk & "Allocation by lot" \\
\hline
\end{tabular}


Clementsen 1998 (Continued)

$\begin{aligned} & \text { Allocation concealment } \\ & \text { (selection bias) }\end{aligned}$
Unclear risk Not stated

\begin{tabular}{|c|c|c|}
\hline $\begin{array}{l}\text { Blinding of participants } \\
\text { and personnel (perfor- } \\
\text { mance bias) } \\
\text { All outcomes }\end{array}$ & High risk & $\begin{array}{l}\text { Not possible to blind, as different drain sizes used (although not stated explic- } \\
\text { itly in the paper) }\end{array}$ \\
\hline
\end{tabular}

\begin{tabular}{lll}
\hline Blinding of outcome as- & High risk & "All data were evaluated by the same physician, who was without knowledge \\
sessment (detection bias) & & $\begin{array}{l}\text { of the result of the randomisation". However, symptom-based adverse events } \\
\text { and symptomatic need for repeat pleural intervention may be biased by lack } \\
\text { of patient blinding }\end{array}$ \\
All outcomes &
\end{tabular}

\begin{tabular}{|c|c|c|}
\hline $\begin{array}{l}\text { Incomplete outcome data } \\
\text { (attrition bias) } \\
\text { All outcomes }\end{array}$ & Low risk & $\begin{array}{l}\text { All data reported and justified. Missing outcome data balanced between the } \\
\text { two treatment arms (two excluded from group } 1 \text { (one died of cancer soon after } \\
\text { drain insertion and one developed hydropneumothorax necessitating large- } \\
\text { bore drain), one excluded from group } 2 \text { (patient withdrew consent for study } \\
\text { participation) }\end{array}$ \\
\hline
\end{tabular}

\begin{tabular}{lll}
\hline $\begin{array}{l}\text { Selective reporting (re- } \\
\text { porting bias) }\end{array}$ & Low risk & All outcomes reported \\
\hline Other bias & Low risk & No other biases identified \\
\hline
\end{tabular}

\section{Crnjac 2004}

\begin{tabular}{ll}
\hline Methods & Single centre RCT comparing thoracoscopic mechanical pleurodesis (TMP) with talc slurry (Slovenia) \\
\hline Participants & Inclusion: breast carcinoma and a resulting morphologically confirmed MPE \\
& Exclusion: unfit for general anaesthetic (GA) \\
87 participants randomised
\end{tabular}

TMP arm: thoracoscopy (under GA) with adhesiolysis, pleural biopsy and scarification of the visceral
and parietal pleura to induce bleeding. Chest tube inserted at the end of procedure
Talc slurry arm: chest tube inserted under local anaesthetic. $5 \mathrm{~g}$ talc in $100 \mathrm{ml}$ saline insufflated through
chest tube
Participants in both arms had the drain removed when $<100 \mathrm{ml} / 24$ hour drainage

\begin{tabular}{ll}
\hline Outcomes & Recurrence of effusion on chest x-ray (CXR) at 1 day, 1 week, 1 month, 3 months and 6 months \\
Duration of chest tube drainage & Duration of hospitalisation \\
Complications & Mortality (30 days and 6 months) \\
\hline Notes & People with trapped lung not excluded. \\
& Pleurodesis success defined using CXR criteria alone \\
& Not included in network meta-analysis \\
\hline
\end{tabular}


Crnjac 2004 (Continued)

Risk of bias

\begin{tabular}{|c|c|c|}
\hline Bias & Authors' judgement & Support for judgement \\
\hline $\begin{array}{l}\text { Random sequence genera- } \\
\text { tion (selection bias) }\end{array}$ & Unclear risk & Not stated \\
\hline $\begin{array}{l}\text { Allocation concealment } \\
\text { (selection bias) }\end{array}$ & Low risk & Sealed envelopes \\
\hline $\begin{array}{l}\text { Blinding of participants } \\
\text { and personnel (perfor- } \\
\text { mance bias) } \\
\text { All outcomes }\end{array}$ & High risk & Not feasible to blind the study as comparing talc slurry with thoracoscopy \\
\hline $\begin{array}{l}\text { Blinding of outcome as- } \\
\text { sessment (detection bias) } \\
\text { All outcomes }\end{array}$ & High risk & $\begin{array}{l}\text { Not stated whether radiological assessments were done in a blinded fashion. } \\
\text { Complication reporting, time of tube drainage may be effected by lack of pa- } \\
\text { tient and personnel blinding. Mortality outcome not effected by lack of blind- } \\
\text { ing }\end{array}$ \\
\hline $\begin{array}{l}\text { Incomplete outcome data } \\
\text { (attrition bias) } \\
\text { All outcomes }\end{array}$ & Low risk & $\begin{array}{l}\text { ITT analysis performed. Minimal missing data. } 6 / 45 \text { patients died within six } \\
\text { months in TMP group vs } 8 / 42 \text { in talc slurry arm }\end{array}$ \\
\hline $\begin{array}{l}\text { Selective reporting (re- } \\
\text { porting bias) }\end{array}$ & Low risk & All stated outcomes reported \\
\hline \multirow[t]{2}{*}{ Other bias } & Low risk & $\begin{array}{l}\text { No documentation of patient experience (e.g. QOL or degree of discomfort), } \\
\text { relative costs or need for repeat pleural intervention }\end{array}$ \\
\hline & & $\begin{array}{l}\text { Pleurodesis success defined using radiology only. Participants who did not } \\
\text { have evidence of recurrence at death were classified as pleurodesis successes }\end{array}$ \\
\hline
\end{tabular}

Davies 2012

Methods $\quad$ Unblinded, multi-centre RCT comparing indwelling pleural catheter (IPC) with talc slurry pleurodesis
(UK)- TIME-2 Trial.
(UK)- TIME-2 Trial.

Participants Inclusion criteria: clinically confident diagnosis of MPE requiring pleurodesis

Exclusion criteria: age $<18$, expected survival of $<3$ months, chylothorax, previous ipsilateral lobectomy or pneumonectomy, previous attempted pleurodesis, pleural infection, WCC $<1000 /$ microlitre, hypercapnic ventilatory failure, pregnancy, lactating mothers, irreversible bleeding diathesis, irreversible visual impairment

106 participants randomised

Interventions Group 1: IPC inserted with drainage three times a week (or as required to relieve dyspnoea)

Group 2: $12 \mathrm{~F}$ Seldinger chest tube and $4 \mathrm{~g}$ talc slurry as an inpatient

All patients had standard oncological management for the primary tumour

Outcomes

Primary outcome: mean daily dyspnoea visual analogue score (VAS) over the first 42 days

Secondary outcomes: proportion achieving clinically significant decrease in mean VAS dyspnoea; mean VAS dyspnoea at 6 weeks, 3 months and 6 months; mean daily chest pain VAS over the first 42 days; 
Davies 2012 (Continued)

mean VAS chest pain at 6 weeks, 3 months and 6 months; nights spent in hospital; self-reported quality of life; frequency of adverse events

Notes

Participants with trapped lung in group 2 did not receive talc pleurodesis, but remained in trial follow-up

Pleurodesis in the IPC group was defined as removal of IPC following spontaneous cessation of drainage with no significant fluid recurrence on chest x-ray (CXR) or ultrasound scan (USS) and no further ipsilateral pleural intervention. In the talc group, pleurodesis failure defined as the need for further ipsilateral pleural intervention

If participants died during follow up, included as a pleurodesis success if no intervention prior to death Included in network meta-analysis for pleurodesis efficacy and mortality.

\section{Risk of bias}

\begin{tabular}{|c|c|c|}
\hline Bias & Authors' judgement & Support for judgement \\
\hline $\begin{array}{l}\text { Random sequence genera- } \\
\text { tion (selection bias) }\end{array}$ & Low risk & Central telephone randomisation \\
\hline $\begin{array}{l}\text { Allocation concealment } \\
\text { (selection bias) }\end{array}$ & Low risk & Central telephone randomisation \\
\hline $\begin{array}{l}\text { Blinding of participants } \\
\text { and personnel (perfor- } \\
\text { mance bias) } \\
\text { All outcomes }\end{array}$ & High risk & $\begin{array}{l}\text { Not possible to blind participants or personnel due to nature of interventions } \\
\text { (IPC vs talc slurry) }\end{array}$ \\
\hline $\begin{array}{l}\text { Blinding of outcome as- } \\
\text { sessment (detection bias) } \\
\text { All outcomes }\end{array}$ & High risk & $\begin{array}{l}\text { VAS scores, QOL and symptom recurrence (which informs assessment of pleu- } \\
\text { rodesis efficacy) could be biased by lack of blinding }\end{array}$ \\
\hline $\begin{array}{l}\text { Incomplete outcome data } \\
\text { (attrition bias) } \\
\text { All outcomes }\end{array}$ & Low risk & LTFU clearly documented with reasons given \\
\hline $\begin{array}{l}\text { Selective reporting (re- } \\
\text { porting bias) }\end{array}$ & Low risk & All predefined endpoints reported \\
\hline Other bias & Low risk & No other biases identified \\
\hline
\end{tabular}

Demmy 2012

\begin{tabular}{ll}
\hline Methods & $\begin{array}{l}\text { Multi-centre RCT comparing bedside talc pleurodesis and daily tunnelled catheter drainage for man- } \\
\text { agement of malignant pleural effusion (USA) }\end{array}$ \\
\hline Participants & $\begin{array}{l}\text { Inclusion: symptomatic patients with histo/cytologically proven malignancy and a previously untreat- } \\
\text { ed, unilateral pleural effusion requiring management; ECOG performance score } 0 \text {-2 }\end{array}$ \\
& $\begin{array}{l}\text { Exclusion: active pleural infection; talc allergy; contraindications to talc use; trapped lung; survival < 60 } \\
\text { days; severe comorbid medical conditions }\end{array}$ \\
& 68 participants randomised \\
\hline Interventions & $\begin{array}{l}\text { Talc pleurodesis group: } 4 \mathrm{~g} \text { to } 5 \mathrm{~g} \text { sterile talc slurry in } 100 \mathrm{ml} \text { saline infused into pleural space via }>24 \mathrm{Fr} \\
\text { chest drain. Tube clamped for two hours. Drain removed when < } 150 \text { ml drainage/24hours }\end{array}$ \\
\hline
\end{tabular}


Demmy 2012 (Continued)

Indwelling pleural catheter (IPC) group: PleurX catheter inserted and drained daily (output volumes recorded). Removed when $<30 \mathrm{ml}$ output on three consecutive days

\section{Outcomes}

Primary: compare the proportion of maintained successful treatments 30 days after the intervention (success defined as being (1) alive (2) no effusion recurrence (3) > 90\% lung re-expansion after complete drainage (4) completion of the intervention by two weeks ie drain removed or IPC functioning normally)

Secondary: Quality of life (QOL); dyspnoea; patient satisfaction and acceptability; lung expansion; pleurodesis success; fluid drainage volume; days device in place; removal of device before death; survival

\section{Notes}

Pleurodesis success measured at 30 days according to chest $x$-ray (CXR) and need for repeat pleural intervention

People with known trapped lung excluded from trial entry

Included in network meta-analysis for pleurodesis efficacy and mortality.

\section{Risk of bias}

\begin{tabular}{lll}
\hline Bias & Authors' judgement & Support for judgement \\
\hline $\begin{array}{l}\text { Random sequence genera- } \\
\text { tion (selection bias) }\end{array}$ & Low risk & Permuted block randomisation via a web-based randomisation service \\
\hline $\begin{array}{l}\text { Allocation concealment } \\
\text { (selection bias) }\end{array}$ & Low risk & Permuted block randomisation via a web-based randomisation service \\
\hline $\begin{array}{l}\text { Blinding of participants } \\
\text { and personnel (perfor- } \\
\text { mance bias) }\end{array}$ & High risk & $\begin{array}{l}\text { Due to nature of interventions, not possible to blind participants or personnel } \\
\text { (IPC vs talc slurry) }\end{array}$ \\
\hline
\end{tabular}

\begin{tabular}{lll}
\hline $\begin{array}{l}\text { Blinding of outcome as- } \\
\text { sessment (detection bias) }\end{array}$ & High risk & $\begin{array}{l}\text { "Pleurodesis success was classified by an unblinded local investigator" (per- } \\
\text { sll outcomes }\end{array}$ \\
\hline
\end{tabular}

Incomplete outcome data Low risk Five excluded from analysis in each arm, but justifications given

(attrition bias)

All outcomes

\begin{tabular}{lll}
\hline $\begin{array}{l}\text { Selective reporting (re- } \\
\text { porting bias) }\end{array}$ & Low risk & All reported \\
\hline Other bias & Low risk & Target recruitment numbers not reached \\
\hline
\end{tabular}

\section{Diacon 2000}

Methods $\quad \begin{aligned} & \text { Prospective, single centre RCT of thoracoscopic talc poudrage versus bedside bleomycin pleurodesis } \\ & \text { via a small-bore chest tube (Switzerland) }\end{aligned}$
via a small-bore chest tube (Switzerland)
Participants
Inclusion criteria: documented MPE (all cell types); complete lung expansion on post drainage chest x- ray (CXR); improvement in symptoms after drainage; expected survival of $>1$ month; capable of under- going medical thoracoscopy
Exclusion criteria: loculated effusion; previous drainages or previous pleurodesis; adverse reaction to the study medication; severe coagulation disorder


Diacon 2000 (Continued)

$$
36 \text { participants randomised }
$$

Interventions Group 1: bedside pleurodesis via small-bore chest tube (OD = $2.7 \mathrm{~mm})$ of $60 \mathrm{IU}$ bleomycin. Tube unclamped after two hours and left on suction until removal at least 48 hours later

Group 2: thoracoscopy with induced pneumothorax under sedation. $5 \mathrm{~g}$ talc sprayed into pleural cavity under direct vision after drainage of effusion and disruption of adhesions. Drain kept under suction for at least 48 hours

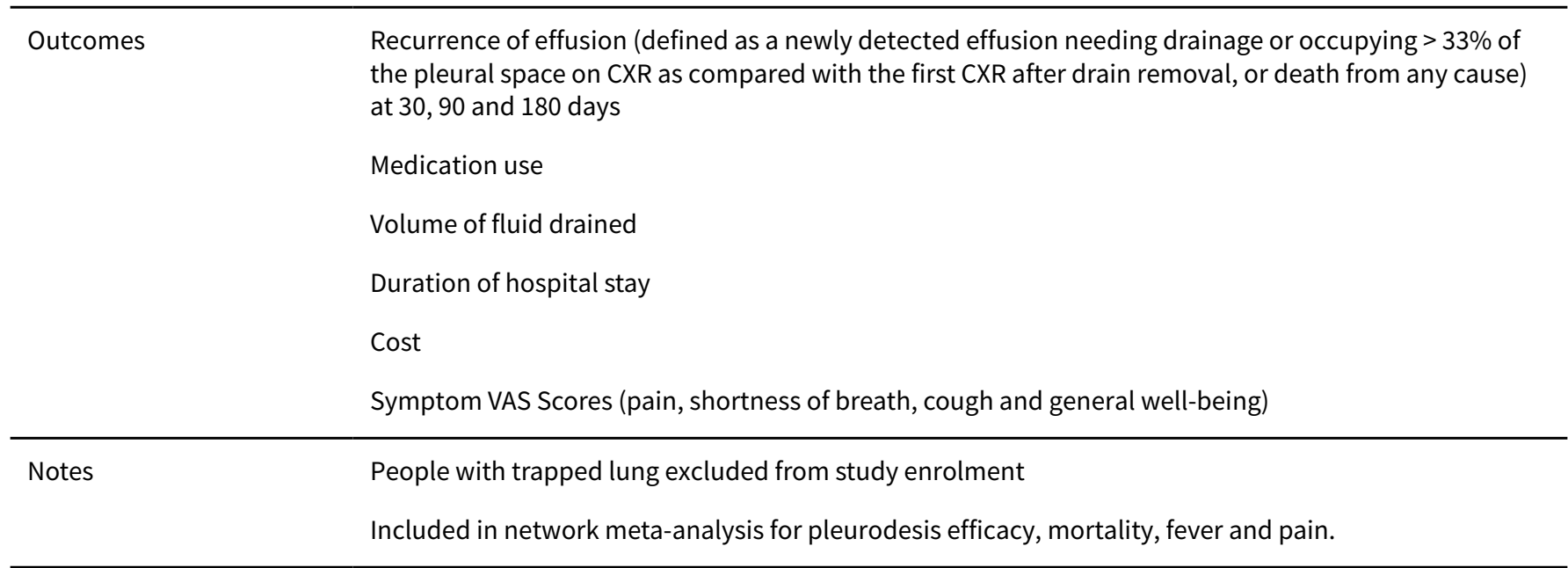

\section{Risk of bias}

\begin{tabular}{|c|c|c|}
\hline Bias & Authors' judgement & Support for judgement \\
\hline $\begin{array}{l}\text { Random sequence genera- } \\
\text { tion (selection bias) }\end{array}$ & Low risk & Computer-generated randomisation sequence \\
\hline $\begin{array}{l}\text { Allocation concealment } \\
\text { (selection bias) }\end{array}$ & Low risk & Sequential sealed envelopes \\
\hline $\begin{array}{l}\text { Blinding of participants } \\
\text { and personnel (perfor- } \\
\text { mance bias) } \\
\text { All outcomes }\end{array}$ & High risk & $\begin{array}{l}\text { Not possible to blind participants or personnel due to nature of interventions } \\
\text { (talc poudrage vs bleomycin via chest tube) }\end{array}$ \\
\hline $\begin{array}{l}\text { Blinding of outcome as- } \\
\text { sessment (detection bias) } \\
\text { All outcomes }\end{array}$ & High risk & $\begin{array}{l}\text { Not stated if radiology was interpreted by a blinded physician. However length } \\
\text { of stay, VAS scores and symptom recurrence may be biased by lack of partic- } \\
\text { ipant blinding. Mortality would not be affected by unblinded nature of the } \\
\text { study }\end{array}$ \\
\hline $\begin{array}{l}\text { Incomplete outcome data } \\
\text { (attrition bias) } \\
\text { All outcomes }\end{array}$ & Low risk & Five withdrawals in total, but a similar number in each group \\
\hline $\begin{array}{l}\text { Selective reporting (re- } \\
\text { porting bias) }\end{array}$ & Low risk & All stated outcomes reported \\
\hline Other bias & Low risk & No external funding source \\
\hline
\end{tabular}


Dresler 2005

Methods

Multi-centre RCT comparing talc poudrage with talc slurry pleurodesis in MPE. Both groups received $4 \mathrm{~g}$ - $5 \mathrm{~g}$ sterile talc intrapleurally (USA)

Participants Inclusion criteria: history of malignancy (all tumour types), pleural effusion requiring sclerosis, ECOG performance status $0-2$, life expectancy $>2$ months, ability to undergo general anaesthesia

Exclusion criteria: pregnancy, previous intrapleural therapy or radiation therapy encompassing the entire hemithorax, changes in systemic therapy within two weeks, chylous or bilateral effusions requiring therapy

501 participants randomised
TS Group: talc administered as a slurry in $100 \mathrm{ml}$ saline through a chest tube at the bedside

TTI Group: talc insufflated during thoracoscopy in the operating room

Outcomes

Primary endpoint: the percentage of patients whose lung initially re-expanded $>90 \%$ and who had a successful pleurodesis at 30 days after treatment (defined according to cvhest $\mathrm{x}$-ray (CXR) criteria)

Secondary endpoint: time to recurrence of effusion; frequency of complications and toxicities; ability to re-expand the lung as assessed by CXR; oain; patient satisfaction; quality of life (QOL).

\begin{tabular}{ll}
\hline Notes & People with trapped lung excluded from analysis \\
Included in network meta-analysis for pleurodesis efficacy, mortality, pain and fever.
\end{tabular}

\section{Risk of bias}

\begin{tabular}{|c|c|c|}
\hline Bias & Authors' judgement & Support for judgement \\
\hline $\begin{array}{l}\text { Random sequence genera- } \\
\text { tion (selection bias) }\end{array}$ & Low risk & Computer-generated randomisation lists \\
\hline $\begin{array}{l}\text { Allocation concealment } \\
\text { (selection bias) }\end{array}$ & Low risk & Computer-generated randomisation lists \\
\hline $\begin{array}{l}\text { Blinding of participants } \\
\text { and personnel (perfor- } \\
\text { mance bias) } \\
\text { All outcomes }\end{array}$ & High risk & $\begin{array}{l}\text { Not possible to blind the study due to the nature of the interventions (talc } \\
\text { poudrage vs talc slurry) }\end{array}$ \\
\hline $\begin{array}{l}\text { Blinding of outcome as- } \\
\text { sessment (detection bias) } \\
\text { All outcomes }\end{array}$ & High risk & $\begin{array}{l}\text { Not stated if radiological assessment was blinded. QOL and complications } \\
\text { may be affected by lack of patient and personnel blinding }\end{array}$ \\
\hline $\begin{array}{l}\text { Incomplete outcome data } \\
\text { (attrition bias) } \\
\text { All outcomes }\end{array}$ & Low risk & $\begin{array}{l}\text { Missing data accounted for and balanced between the treatment arms ( } 10 \text { in } \\
\text { slurry group and } 9 \text { in thoracoscopy group excluded as ineligible or participant } \\
\text { withdrew consent; } 33 / 163 \text { slurry participants and } 25 / 177 \text { thoracoscopy partici- } \\
\text { pants died within } 30 \text { days of randomisation) }\end{array}$ \\
\hline $\begin{array}{l}\text { Selective reporting (re- } \\
\text { porting bias) }\end{array}$ & Low risk & All outcomes reported on \\
\hline Other bias & Low risk & $\begin{array}{l}\text { Trapped lung defined by different means in the two treatment arms, which } \\
\text { may have effected their primary endpoint. However, this does not have an im- } \\
\text { pact on the pleurodesis success rates }\end{array}$ \\
\hline
\end{tabular}




\begin{tabular}{ll}
\hline Methods & $\begin{array}{l}\text { Single centre RCT of intrapleural cisplatin +/- bevacizumab in MPE due to non-small cell lung cancer } \\
\text { (NSCLC) (China) }\end{array}$ \\
\hline Participants & $\begin{array}{l}\text { Inclusion: Advanced NSCLC; large uni- or bilateral pleural effusion; positive pleural fluid cytology; no in- } \\
\text { trapleural therapy in previous month; Karnofsky performance score > 60\%; age > 18; predicted survival } \\
>3 \text { months; no major organ disfunction; no previous chemotherapy in previous six weeks }\end{array}$ \\
& $\begin{array}{l}\text { Exclusion: squamous cell carcinoma; allergy to biological agents; no detectable lesions; uncontrolled } \\
\text { central nervous system metastasis; pregnancy or breastfeeding; infected wound; refractory psychiatric } \\
\text { illness }\end{array}$ \\
& 72 participants randomised
\end{tabular}

Interventions

Participants underwent pleural fluid drainage by thoracentesis. Treatment given intrapleurally. Rest for two hours. Then rotate every 15 mins. Given every two weeks for 3 cycles

Cisplatin: $30 \mathrm{mg}$ cisplatin intrapleurally

Cisplatin and bevacizumab: $30 \mathrm{mg}$ cisplatin and $300 \mathrm{mg}$ bevacizumab intrapleurally

Outcomes

Treatment response ('Complete remission (CR)' = accumulated fluid disappeared and stable for at least four weeks; 'Partial remission (PR)' = > 50\% of the accumulated fluid had disappeared, symptoms had improved and the remaining fluid had not increased for at least four weeks; 'Remission not obvious $(\mathrm{NC})^{\prime}=<50 \%$ of the accumulated fluid had disappeared; 'Progression (PD)' = accumulated fluid had increased). Treatment success defined as CR + PR

Progression-free survival

Overall survival

Adverse reactions

Quality of life (QOL)

Pleural fluid VEGF levels

Notes

People with trapped lung eligible for trial involvement

Pleurodesis defined clinically and using radiology

Not included in network meta-analysis

\section{Risk of bias}

\begin{tabular}{lll}
\hline Bias & Authors' judgement & Support for judgement \\
\hline $\begin{array}{l}\text { Random sequence genera- } \\
\text { tion (selection bias) }\end{array}$ & Unclear risk & Methods not stated and no response from study authors to clarify \\
\hline $\begin{array}{l}\text { Allocation concealment } \\
\text { (selection bias) }\end{array}$ & Unclear risk & Methods not stated and no response from study authors to clarify \\
\hline $\begin{array}{l}\text { Blinding of participants } \\
\text { and personnel (perfor- } \\
\text { mance bias) }\end{array}$ & Unclear risk & Not stated if blinded and no response from study authors to clarify \\
All outcomes & \\
\hline
\end{tabular}

Blinding of outcome as- Unclear risk sessment (detection bias)

Not stated if anyone was blinded. If not blinded, QOL, performance status, side All outcomes effects and symptom recurrence could be biased by lack of blinding 
Du 2013 (Continued)

Incomplete outcome data Low risk Missing data accounted for. ITT analysis
(attrition bias)

All outcomes

\begin{tabular}{lll}
\hline $\begin{array}{l}\text { Selective reporting (re- } \\
\text { porting bias) }\end{array}$ & Low risk & All outcomes reported on \\
\hline Other bias & Low risk & No other biases identified \\
\hline
\end{tabular}

Emad 1996

Methods Three-arm, single centre RCT comparing intrapleural bleomycin, tetracycline and combination treatment for pleurodesis of MPE (Iran)

Inclusion: histologically or cytologically proven, symptomatic MPE (all cell types)
Exclusion: none
60 participants randomised

Interventions All participants had 28 Fr intercostal drain inserted into 6th intercostal space. Complete drainage of the effusion was confirmed on chest x-ray (CXR). All participants given $10-15 \mathrm{ml} 1 \%$ lignocaine intrapleurally

Tetracycline arm: $20 \mathrm{mg} / \mathrm{kg}$ tetracycline (max $2 \mathrm{~g}$ ) in $50 \mathrm{ml}$ saline given intrapleurally. 1 dose

Bleomycin arm: $1 \mathrm{u} / \mathrm{kg}$ (max 60 units) in $50 \mathrm{ml}$ saline given intrapleurally. 1 dose

Combination arm: $20 \mathrm{mg} / \mathrm{kg}$ tetracycline in $40 \mathrm{ml}$ saline and $1 \mathrm{u} / \mathrm{kg}$ bleomycin in $50 \mathrm{ml}$ saline, given intrapleurally, one after the other (tube clamped for five mins between instillations)

Drain clamped for two hours post instillation with patient rotation. Suction connected after 24 hours. Drain removed when $<50 \mathrm{ml} / 8$ hours drainage and complete lung expansion on CXR

\begin{tabular}{ll}
\hline Outcomes & $\begin{array}{l}\text { Pleurodesis success (defined as 'complete response' (no accumulation of effusion on CXR), 'partial re- } \\
\text { sponse' (effusion recurred but did not require aspiration) or 'failure' (participant required repeat thora- } \\
\text { centesis for re-accumulation of the effusion) at } 30 \text { days (also at } 60 \text { days, } 90 \text { days and } 6 \text { months) } \\
\text { Side effects }\end{array}$ \\
\hline All participants in the study were receiving chemotherapy or tamoxifen, or both \\
People with trapped lung not excluded from participation in the study \\
Participants who died prior to the analysed time point were excluded from the analysis \\
Combination of clinical need for repeat intervention and radiological re-accumulation of effusion used \\
to define pleurodesis failure \\
Included in network meta-analysis for pleurodesis efficacy, mortality and fever.
\end{tabular}

\section{Risk of bias}

\begin{tabular}{lll}
\hline Bias & Authors' judgement & Support for judgement \\
\hline $\begin{array}{l}\text { Random sequence genera- } \\
\text { tion (selection bias) }\end{array}$ & Unclear risk & "'...simple randomised manner". No further details given \\
\hline
\end{tabular}


Emad 1996 (Continued)

\begin{tabular}{|c|c|c|}
\hline $\begin{array}{l}\text { Allocation concealment } \\
\text { (selection bias) }\end{array}$ & Unclear risk & Not stated \\
\hline $\begin{array}{l}\text { Blinding of participants } \\
\text { and personnel (perfor- } \\
\text { mance bias) } \\
\text { All outcomes }\end{array}$ & High risk & $\begin{array}{l}\text { Not stated explicitly and unable to contact authors. However, different vol- } \\
\text { umes and regimes were used for the two groups }\end{array}$ \\
\hline $\begin{array}{l}\text { Blinding of outcome as- } \\
\text { sessment (detection bias) } \\
\text { All outcomes }\end{array}$ & High risk & $\begin{array}{l}\text { Not stated if radiology reported blindly. Complication-reporting may have } \\
\text { been affected by lack of participant blinding }\end{array}$ \\
\hline $\begin{array}{l}\text { Incomplete outcome data } \\
\text { (attrition bias) } \\
\text { All outcomes }\end{array}$ & Low risk & $\begin{array}{l}\text { Minimal data on baseline patient characteristics, but all outcome data report- } \\
\text { ed and withdrawals justified. Six participants died within six months of ran- } \\
\text { domisation ( } 2 \text { in tetracycline arm; } 1 \text { in bleomycin arm and } 3 \text { in combination } \\
\text { arm) }\end{array}$ \\
\hline $\begin{array}{l}\text { Selective reporting (re- } \\
\text { porting bias) }\end{array}$ & Low risk & All stated outcomes reported \\
\hline Other bias & Low risk & No other biases identified \\
\hline
\end{tabular}

Evans 1993

\begin{tabular}{|c|c|}
\hline Methods & Single centre RCT of medical vs surgical pleurodesis with tetracycline (UK) \\
\hline \multirow[t]{3}{*}{ Participants } & $\begin{array}{l}\text { Inclusion criteria: cytology-proven MPE and histological or cytological evidence of metastatic breast } \\
\text { cancer }\end{array}$ \\
\hline & $\begin{array}{l}\text { Exclusion criteria: unsuitable for general anaesthetic (GA); > } 75 \text { years old; severe non-metastatic lung } \\
\text { disease; evidence of life-threatening metastatic disease at other sites }\end{array}$ \\
\hline & 34 participants randomised \\
\hline
\end{tabular}

Interventions Medical group: intercostal cannula inserted into mid-axillary line 7 th/8th intercostal space and fluid aspirated. When drainage complete, $500 \mathrm{mg}$ tetracycline in $100 \mathrm{ml} \mathrm{N}$ saline inserted IP. Drain removed after 24 hours

Surgical group: under GA, bronchoscopy then thoracoscopy performed. $500 \mathrm{ml}$ tetracycline in $100 \mathrm{ml}$ saline inserted after fluid removed. Drain removed at 24 hours

\begin{tabular}{ll}
\hline Outcomes & Fluid re-accumulation on chest $x$-ray (CXR) \\
& Need for repeat pleural aspirations \\
& Mortality \\
\hline Notes & Pleurodesis failure defined as need for repeat aspiration. Trapped lung not accounted for \\
& Not included in network meta-analysis \\
\hline
\end{tabular}

\section{Risk of bias}

\begin{tabular}{lll}
\hline Bias & Authors' judgement & Support for judgement \\
\hline $\begin{array}{l}\text { Random sequence genera- } \\
\text { tion (selection bias) }\end{array}$ & Unclear risk & No details given regarding randomisation \\
\hline
\end{tabular}




\section{Evans 1993 (Continued)}

\begin{tabular}{|c|c|c|}
\hline $\begin{array}{l}\text { Allocation concealment } \\
\text { (selection bias) }\end{array}$ & Unclear risk & No details given regarding randomisation \\
\hline $\begin{array}{l}\text { Blinding of participants } \\
\text { and personnel (perfor- } \\
\text { mance bias) } \\
\text { All outcomes }\end{array}$ & High risk & Unable to blind due to nature of the interventions (surgery vs chest tube) \\
\hline $\begin{array}{l}\text { Blinding of outcome as- } \\
\text { sessment (detection bias) } \\
\text { All outcomes }\end{array}$ & High risk & $\begin{array}{l}\text { Need for repeat aspirations and other treatments given for cancer after pleu- } \\
\text { rodesis may have been biased by lack of blinding of personnel and partici- } \\
\text { pants. Not stated if CXRs were reported by a blinded person }\end{array}$ \\
\hline $\begin{array}{l}\text { Incomplete outcome data } \\
\text { (attrition bias) } \\
\text { All outcomes }\end{array}$ & Low risk & $\begin{array}{l}\text { Reasons given for withdrawals ( } 5 / 34 \text { excluded ( } 15 \%) \text { - } 3 \text { never received the } \\
\text { treatment; } 1 \text { was randomised in error; } 1 \text { participant's records were lost) }\end{array}$ \\
\hline $\begin{array}{l}\text { Selective reporting (re- } \\
\text { porting bias) }\end{array}$ & High risk & No data on safety or side effects \\
\hline Other bias & Low risk & No other biases identified \\
\hline
\end{tabular}

\section{Fentiman 1983}

\begin{tabular}{ll}
\hline Methods & $\begin{array}{l}\text { Single centre RCT of talc poudrage and mustine (via chest tube) in patients with breast cancer. All pa- } \\
\text { tients underwent VATS procedure under general anaesthetic. (UK) }\end{array}$ \\
\hline Participants & $\begin{array}{l}\text { Inclusion criteria: histologically confirmed breast cancer and radiologically verified pleural effusion } \\
\text { Exclusion criteria: no previous local treatment; non-malignant cause for the effusion } \\
46 \text { participants randomised }\end{array}$ \\
\hline Interventions & $\begin{array}{l}\text { Talc group: talc poudrage performed during VATS (dose of talc not stated), two chest drains in place for } \\
\text { five days (with or without suction) }\end{array}$ \\
& $\begin{array}{l}\text { Mustine group: after VATS and once lung fully re-expanded on CXR, 15 mg mustine solution instilled via } \\
\text { intercostal drain. Clamped for two hours. Drain removed when drainage stopped }\end{array}$ \\
\hline Outcomes & $\begin{array}{l}\text { Success of pleurodesis (defined by lack of re-accumulation of effusion on CXR) at one month; complica- } \\
\text { tions }\end{array}$ \\
\hline If died prior to one-month follow up, excluded from analysis of pleurodesis success \\
Participants with trapped lung eligible for enrolment \\
Included in network meta-analysis for pleurodesis efficacy and mortality.
\end{tabular}

\section{Risk of bias}

\begin{tabular}{lll}
\hline Bias & Authors' judgement & Support for judgement \\
\hline $\begin{array}{l}\text { Random sequence genera- } \\
\text { tion (selection bias) }\end{array}$ & Low risk & $\begin{array}{l}\text { Stratified for metastatic disease requiring treatment. "balanced randomisa- } \\
\text { tion" }\end{array}$ \\
\hline $\begin{array}{l}\text { Allocation concealment } \\
\text { (selection bias) }\end{array}$ & Unclear risk & Not stated \\
\hline
\end{tabular}


Fentiman 1983 (Continued)

Blinding of participants and personnel (perfor-

mance bias)

All outcomes

\begin{tabular}{lll}
\hline $\begin{array}{l}\text { Blinding of outcome as- } \\
\text { sessment (detection bias) } \\
\text { All outcomes }\end{array}$ & Unclear risk & $\begin{array}{l}\text { Not stated whether radiographic interpretation of CXRs were performed by a } \\
\text { blinded person. Reporting of complications could be biased by lack of partici- } \\
\text { pant and personnel blinding }\end{array}$ \\
\hline $\begin{array}{l}\text { Incomplete outcome data } \\
\text { (attrition bias) } \\
\text { All outcomes }\end{array}$ & Low risk & $\begin{array}{l}3 / 23 \text { non-evaluable in talc group; } 6 / 23 \text { non-evaluable in mustine group. All } \\
\text { non-evaluable patients died prior to one-month follow up }\end{array}$ \\
\hline $\begin{array}{l}\text { Selective reporting (re- } \\
\text { porting bias) }\end{array}$ & Low risk & All stated outcomes reported \\
\hline Other bias & High risk & $\begin{array}{l}\text { Different number of intercostal drains in the two groups. Different duration of } \\
\text { drainage for two groups }\end{array}$ \\
\hline
\end{tabular}

Fentiman 1986

\begin{tabular}{ll}
\hline Methods & Single centre RCT of intrapleural talc and tetracycline in MPE secondary to breast cancer (UK) \\
\hline Participants & $\begin{array}{l}\text { Inclusion criteria: histologically confirmed breast cancer and a symptomatic pleural effusion on radiol- } \\
\text { ogy }\end{array}$
\end{tabular}

Exclusion criteria: previous treatment for effusion, other than simple needle aspiration; non-malignant cause for effusion; unsuitable for general anaesthetic; history of sensitivity to tetracycline

41 participants randomised

Talc group: thoracoscopy, talc insufflated (dose not stated). Intercostal drain remained in situ for five
days
Tetracycline group: thoracoscopy. Tetracycline $500 \mathrm{mg}$ in $40 \mathrm{ml} \mathrm{N}$ saline inserted 16 - 24 hours later via
chest tube. Intercostal drain left in place for 3 - 5 days

\begin{tabular}{ll}
\hline Outcomes & Pleurodesis success (defined by lack of re-accumulation on CXR); complications; mortality \\
\hline Notes & Pleurodesis success defined according to CXR only \\
& Participants with trapped lung eligible for trial entry \\
& Included in network meta-analysis of pleurodesis efficacy and mortality.
\end{tabular}

\section{Risk of bias}

\begin{tabular}{lll}
\hline Bias & Authors' judgement & Support for judgement \\
\hline $\begin{array}{l}\text { Random sequence genera- } \\
\text { tion (selection bias) }\end{array}$ & Unclear risk & "randomised with stratification for metastatic disease" \\
\hline $\begin{array}{l}\text { Allocation concealment } \\
\text { (selection bias) }\end{array}$ & Unclear risk & Not stated \\
\hline
\end{tabular}


Fentiman 1986 (Continued)

Blinding of participants

High risk Not possible to blind patients or personnel due to the nature of the procedures and personnel (performance bias)

All outcomes

\begin{tabular}{lll}
\hline Blinding of outcome as- & Unclear risk & Not stated whether radiographic interpretation of CXRs were performed by a \\
sessment (detection bias) & blinded person. Reporting of complications could be biased by lack of partici- \\
All outcomes & pant and personnel blinding
\end{tabular}

\begin{tabular}{lll}
\hline $\begin{array}{l}\text { Incomplete outcome data } \\
\begin{array}{l}\text { (attrition bias) } \\
\text { All outcomes }\end{array}\end{array}$ & High risk & $\begin{array}{l}\text { Participants were excluded from the primary analysis if they died within the } \\
\text { first month. Higher proportion of deaths in the talc group }(6 / 18=33 \%) \text { com- } \\
\text { pared to the tetracycline group }(2 / 23=9 \%)\end{array}$ \\
\hline $\begin{array}{l}\text { Selective reporting (re- } \\
\text { porting bias) }\end{array}$ & Low risk & All stated outcomes reported \\
\hline Other bias & Low risk & No other biases identified \\
\hline
\end{tabular}

Gaafar 2014

\begin{tabular}{ll}
\hline Methods & Single centre, prospective RCT comparing intrapleural administration of mistletoe preparation (viscum \\
fraxini-2) with bleomycin in patients with MPE (Egypt)
\end{tabular}

Inclusion: histologically confirmed, recurrent, symptomatic MPE (all cell types); > 18 years old; ECOG
performance score $\leq 2 ;$ adequate bone marrow, liver and kidney function; written consent; ability to
comply with the follow up
Exclusion: chronic air leak; known hypersensitivity to mistletoe; uncorrectable bleeding tendency; en-
cysted pleural effusion; pregnancy/breastfeeding; currently active second malignancy; co-enrolment in
another clinical trial; previous unsuccessful pleurodesis; pleural infection
23 participants randomised

Interventions Participants underwent effusion drainage using a chest tube or needle drainage (depending on effusion size). Agent injected through the needle or chest tube

viscum group: 5 ampoules in $10 \mathrm{ml}$ 5\% glucose instilled intrapleurally

Bleomycin group: 60 units delivered intrapleurally

\begin{tabular}{ll}
\hline Outcomes & Pleurodesis efficacy (assessed at six weeks) \\
Toxicity (measured using NCl common terminology for adverse events)
\end{tabular}

\begin{tabular}{ll}
\hline Notes & People with trapped lung not excluded from participation \\
& Pleurodesis defined using radiology and symptomatic effusion recurrence \\
Included in network meta-analysis for pleurodesis efficacy.
\end{tabular}

\section{Risk of bias}

\section{Bias}

Authors' judgement Support for judgement

Random sequence genera- Unclear risk tion (selection bias) 
Gaafar 2014 (Continued)

\begin{tabular}{|c|c|c|}
\hline $\begin{array}{l}\text { Allocation concealment } \\
\text { (selection bias) }\end{array}$ & Unclear risk & "randomised". No other details given and no response from study authors \\
\hline $\begin{array}{l}\text { Blinding of participants } \\
\text { and personnel (perfor- } \\
\text { mance bias) } \\
\text { All outcomes }\end{array}$ & High risk & Not stated explicitly but drugs were of different formulations \\
\hline $\begin{array}{l}\text { Blinding of outcome as- } \\
\text { sessment (detection bias) } \\
\text { All outcomes }\end{array}$ & Unclear risk & Not stated if outcome assessment was blinded \\
\hline $\begin{array}{l}\text { Incomplete outcome data } \\
\text { (attrition bias) } \\
\text { All outcomes }\end{array}$ & High risk & $\begin{array}{l}\text { Two patients in viscum arm excluded from analysis as treatment was discon- } \\
\text { tinued due to an allergic reaction }\end{array}$ \\
\hline $\begin{array}{l}\text { Selective reporting (re- } \\
\text { porting bias) }\end{array}$ & Low risk & Data available although minimal data on side effects \\
\hline Other bias & Low risk & No other risks of bias identified \\
\hline
\end{tabular}

\section{Goodman 2006}

\begin{tabular}{ll}
\hline Methods & Single centre RCT evaluating duration of chest tube drainage after a talc slurry pleurodesis (UK) \\
\hline Participants & $\begin{array}{l}\text { Inclusion criteria: confirmed MPE requiring palliation of breathlessness due to the effusion (all cell } \\
\text { types) } \\
\text { Exclusion criteria: expected survival < 3 months; Karnofsky score < 40; previous unsuccessful pleurode- } \\
\text { sis; ipsilateral endobronchial obstruction; evidence of trapped lung } \\
41 \text { participants randomised }\end{array}$ \\
\hline Interventions & $\begin{array}{l}\text { All participants had } 8 \text { - } 14 \text { Fr intercostal drain inserted under ultrasound guidance. } 4 \text { g talc slurry when } \\
\text { effusion fully drained and trapped lung excluded on CXR }\end{array}$ \\
& $\begin{array}{l}\text { In one group, drain removed after } 24 \text { hours. In the other group, drain removed at } 72 \text { hours. Drains re- } \\
\text { moved regardless of fluid drainage }\end{array}$ \\
\hline Outcomes & $\begin{array}{l}\text { Pleurodesis failure at one month (defined according to fluid recurrence requiring repeat aspiration). } \\
\text { Length of hospital stay. Mortality }\end{array}$ \\
\hline Notes & $\begin{array}{l}\text { People with trapped lung excluded from the study. Study didn't complete recruitment numbers re- } \\
\text { quired by the power calculation } \\
\text { Participants who died in first month after randomisation excluded from the analysis } \\
\text { Not included in network meta-analysis }\end{array}$ \\
\hline
\end{tabular}

\section{Risk of bias}

\begin{tabular}{lll}
\hline Bias & Authors' judgement & Support for judgement \\
\hline $\begin{array}{l}\text { Random sequence genera- } \\
\text { tion (selection bias) }\end{array}$ & Low risk & Sealed envelopes in random blocks of 10 \\
\hline
\end{tabular}


Goodman 2006 (Continued)

Allocation concealment $\quad$ Low risk
(selection bias)

\begin{tabular}{|c|c|c|}
\hline $\begin{array}{l}\text { Blinding of participants } \\
\text { and personnel (perfor- } \\
\text { mance bias) } \\
\text { All outcomes }\end{array}$ & High risk & $\begin{array}{l}\text { Not possible to blind due to nature of interventions (drain removal after } 24 \text { or } \\
48 \text { hours) }\end{array}$ \\
\hline $\begin{array}{l}\text { Blinding of outcome as- } \\
\text { sessment (detection bias) } \\
\text { All outcomes }\end{array}$ & High risk & $\begin{array}{l}\text { Need for repeat pleural interventions, length of stay may be biased by lack of } \\
\text { blinding. Mortality data not biased }\end{array}$ \\
\hline $\begin{array}{l}\text { Incomplete outcome data } \\
\text { (attrition bias) } \\
\text { All outcomes }\end{array}$ & Low risk & $\begin{array}{l}\text { Deaths within the first month well matched between the two arms ( } 3 \text { patients } \\
\text { in each arm). No other LTFU }\end{array}$ \\
\hline $\begin{array}{l}\text { Selective reporting (re- } \\
\text { porting bias) }\end{array}$ & Low risk & $\begin{array}{l}\text { All predefined outcomes reported. Unpublished data on complications provid- } \\
\text { ed by the authors }\end{array}$ \\
\hline Other bias & Low risk & No other biases identified \\
\hline
\end{tabular}

\section{Groth 1991}

\begin{tabular}{ll}
\hline Methods & $\begin{array}{l}\text { RCT comparing intrapleural mitoxantrone with normal saline after thoracoscopy in patients with MPE } \\
\text { (Germany) }\end{array}$
\end{tabular}

\begin{tabular}{|c|c|}
\hline \multirow[t]{3}{*}{ Participants } & Inclusion: complete resolution of the effusion after thoracoscopy; malignancy on pleural biopsy \\
\hline & Exclusion: No chemotherapy within four weeks of pleurodesis \\
\hline & 103 participants randomised \\
\hline
\end{tabular}

\begin{tabular}{|c|c|}
\hline \multirow[t]{4}{*}{ Interventions } & All participants underwent thoracoscopy. After 24 hours participants were randomised \\
\hline & Mitoxantrone arm: 30 mg mitoxantrone given intrapleurally \\
\hline & Control arm: isotonic saline instilled intrapleurally \\
\hline & $\begin{array}{l}\text { Drain clamped for } 48 \text { hours and if }>300 \mathrm{ml} \text { effusion after } 48 \text { hours, a second dose was given; if not the } \\
\text { drain was removed. If a second dose was given, the drain was removed } 48 \text { hours later }\end{array}$ \\
\hline
\end{tabular}

\begin{tabular}{|c|c|}
\hline \multirow[t]{4}{*}{ Outcomes } & $\begin{array}{l}\text { Pleural fluid re-accumulation at two months (defined as a complete response (complete disappear- } \\
\text { ance of all pleural effusion), partial response (half of the effusion or doubling of the time for thoraco- } \\
\text { centesis) no change (the same volume of effusion) or progressive disease (uncontrollable effusion) }\end{array}$ \\
\hline & Toxicity \\
\hline & Remission duration \\
\hline & Survival \\
\hline \multirow[t]{3}{*}{ Notes } & Treatment response definitions somewhat unclear \\
\hline & People with trapped lung eligible for trial involvement \\
\hline & Included in network meta-analysis for pleurodesis efficacy and fever. \\
\hline
\end{tabular}

\section{Risk of bias}

Interventions for the management of malignant pleural effusions: a network meta-analysis (Review) Copyright (c) 2019 The Cochrane Collaboration. Published by John Wiley \& Sons, Ltd. 
Groth 1991 (Continued)

\begin{tabular}{|c|c|c|}
\hline Bias & Authors' judgement & Support for judgement \\
\hline $\begin{array}{l}\text { Random sequence genera- } \\
\text { tion (selection bias) }\end{array}$ & Unclear risk & Not specified \\
\hline $\begin{array}{l}\text { Allocation concealment } \\
\text { (selection bias) }\end{array}$ & Unclear risk & Not specified \\
\hline $\begin{array}{l}\text { Blinding of participants } \\
\text { and personnel (perfor- } \\
\text { mance bias) } \\
\text { All outcomes }\end{array}$ & Unclear risk & $\begin{array}{l}\text { No mention of blinding or whether drugs were of similar appearances or vol- } \\
\text { umes }\end{array}$ \\
\hline $\begin{array}{l}\text { Blinding of outcome as- } \\
\text { sessment (detection bias) } \\
\text { All outcomes }\end{array}$ & Unclear risk & $\begin{array}{l}\text { Not stated whether CXR interpretation was blinded to treatment allocation. } \\
\text { Side effects and performance status reporting could be biased if participants } \\
\text { and personnel were not blinded }\end{array}$ \\
\hline $\begin{array}{l}\text { Incomplete outcome data } \\
\text { (attrition bias) } \\
\text { All outcomes }\end{array}$ & Low risk & $\begin{array}{l}\text { 8/103 participants excluded from the analysis ( } 7 \text { died within four weeks of ran- } \\
\text { domisation due to tumour progression; } 1 \text { was lost to follow up) }\end{array}$ \\
\hline $\begin{array}{l}\text { Selective reporting (re- } \\
\text { porting bias) }\end{array}$ & Low risk & All reported \\
\hline Other bias & High risk & Ambiguous definitions of pleurodesis success \\
\hline
\end{tabular}

Haddad 2004

\begin{tabular}{|c|c|}
\hline Methods & Single centre RCT comparing talc slurry and bleomycin pleurodesis (Brazil) \\
\hline \multirow[t]{3}{*}{ Participants } & $\begin{array}{l}\text { Inclusion: documented recurrent symptomatic MPE (with positive cytology or confirmed metastatic } \\
\text { disease elsewhere with no other cause found for the effusion); symptomatic relief by therapeutic aspi- } \\
\text { ration; complete lung re-expansion after therapeutic aspiration }\end{array}$ \\
\hline & $\begin{array}{l}\text { Exclusion: previous unsuccessful pleurodesis; pleural infection; chronic air leak; karnofsky perfor- } \\
\text { mance score }<30 \%\end{array}$ \\
\hline & 71 participants randomised \\
\hline \multirow[t]{4}{*}{ Interventions } & $\begin{array}{l}28 \text { - } 36 \mathrm{Fr} \text { chest tube inserted under local anaesthetic. Lung re-expansion confirmed prior to randomisa- } \\
\text { tion }\end{array}$ \\
\hline & Talc group: $4 \mathrm{~g}$ talc in $100 \mathrm{ml}$ saline intrapleurally \\
\hline & Bleomycin group: 60 units of bleomycin in $100 \mathrm{ml}$ saline intrapleurally \\
\hline & $\begin{array}{l}\text { After instillation, drain clamped for four hours, then put on suction for } 24 \text { hours. Drain removed when < } \\
200 \mathrm{ml} / 24 \text { hours drained }\end{array}$ \\
\hline \multirow[t]{4}{*}{ Outcomes } & $\begin{array}{l}\text { Pleurodesis success (defined as no recurrence of effusion on clinical and radiologic follow-up or patient } \\
\text { symptom-free with small residual effusion not requiring thoracentesis) at } 1,3 \text { and } 6 \text { months }\end{array}$ \\
\hline & Length of hospital stay \\
\hline & Cost analysis \\
\hline & Complications \\
\hline
\end{tabular}


Haddad 2004 (Continued)

Notes

People with trapped lung excluded from trial entry

Included in network meta-analysis for pleurodesis efficacy and mortality

\section{Risk of bias}

\begin{tabular}{|c|c|c|}
\hline Bias & Authors' judgement & Support for judgement \\
\hline $\begin{array}{l}\text { Random sequence genera- } \\
\text { tion (selection bias) }\end{array}$ & Low risk & Computer-generated randomisation sequence \\
\hline $\begin{array}{l}\text { Allocation concealment } \\
\text { (selection bias) }\end{array}$ & Low risk & Computer randomisation \\
\hline $\begin{array}{l}\text { Blinding of participants } \\
\text { and personnel (perfor- } \\
\text { mance bias) } \\
\text { All outcomes }\end{array}$ & High risk & "Study not blinded" (personal communication with authors) \\
\hline $\begin{array}{l}\text { Blinding of outcome as- } \\
\text { sessment (detection bias) } \\
\text { All outcomes }\end{array}$ & High risk & $\begin{array}{l}\text { "study not blinded" (personal communication with authors). Not stated if radi- } \\
\text { ology reported blindly but pleurodesis efficacy also based on symptom recur- } \\
\text { rence, so could be biased by lack of participant blinding }\end{array}$ \\
\hline $\begin{array}{l}\text { Incomplete outcome data } \\
\text { (attrition bias) } \\
\text { All outcomes }\end{array}$ & Low risk & All reported \\
\hline $\begin{array}{l}\text { Selective reporting (re- } \\
\text { porting bias) }\end{array}$ & Low risk & $\begin{array}{l}\text { All outcomes reported and further clarification received from authors regard- } \\
\text { ing complications and mortality }\end{array}$ \\
\hline Other bias & High risk & $\begin{array}{l}\text { High levels of steroid use in participants, which may have effected pleurodesis } \\
\text { success rates. Steroid use not well balanced between the treatment arms ( } 4 / 37 \\
\text { in talc group, } 8 / 34 \text { in beomycin group) }\end{array}$ \\
\hline
\end{tabular}

Hamed 1989

\begin{tabular}{ll}
\hline Methods & Prospective, single centre RCT of bleomycin and talc in MPE secondary to breast cancer (UK) \\
\hline Participants & Inclusion criteria: breast carcinoma with radiographically confirmed pleural effusion \\
& $\begin{array}{l}\text { Exclusion criteria: previous local treatment (apart from simple aspiration); evidence of a non-malignant } \\
\text { cause for the effusion }\end{array}$ \\
& 29 participants randomised \\
\hline
\end{tabular}

Interventions

All participants had effusion drained to dryness under general anaesthetic

Talc group: talc pleurodesis (dose and mode of administration not specified, but assumed to be poudrage from text)

Bleomycin group: chest tube inserted. Bleomycin $1 \mathrm{mg} / \mathrm{kg}$ in $50 \mathrm{ml}$ normal saline instilled after a CXR confirming lung re-expansion

$\begin{array}{ll}\text { Outcomes } & \begin{array}{l}\text { Success of pleurodesis (defined as continued absence of re-accumulation of pleural fluid on all fol- } \\ \text { low-up radiographs) }\end{array}\end{array}$


Hamed 1989 (Continued)

Contacted study authors for more information, but no reply

People with trapped lung eligible for study entry

Included in network meta-analysis for pleurodesis efficacy

\section{Risk of bias}

\begin{tabular}{|c|c|c|}
\hline Bias & Authors' judgement & Support for judgement \\
\hline $\begin{array}{l}\text { Random sequence genera- } \\
\text { tion (selection bias) }\end{array}$ & Unclear risk & Not stated \\
\hline $\begin{array}{l}\text { Allocation concealment } \\
\text { (selection bias) }\end{array}$ & Unclear risk & Not stated \\
\hline $\begin{array}{l}\text { Blinding of participants } \\
\text { and personnel (perfor- } \\
\text { mance bias) } \\
\text { All outcomes }\end{array}$ & High risk & $\begin{array}{l}\text { Not possible to blind due to the nature of the interventions (talc poudrage vs } \\
\text { bleomycin) }\end{array}$ \\
\hline $\begin{array}{l}\text { Blinding of outcome as- } \\
\text { sessment (detection bias) } \\
\text { All outcomes }\end{array}$ & Unclear risk & Not stated whether radiology reporting was blinded \\
\hline $\begin{array}{l}\text { Incomplete outcome data } \\
\text { (attrition bias) } \\
\text { All outcomes }\end{array}$ & Low risk & $\begin{array}{l}\text { A number of participants not included in the primary analysis, but bal- } \\
\text { anced numbers between the two treatment arms ( } 4 / 13 \text { in talc group, } 3 / 16 \text { in } \\
\text { bleomycin group) }\end{array}$ \\
\hline $\begin{array}{l}\text { Selective reporting (re- } \\
\text { porting bias) }\end{array}$ & Low risk & All reported \\
\hline Other bias & Low risk & No other biases identified \\
\hline
\end{tabular}

Hillerdal 1986

\begin{tabular}{ll} 
Methods & Multi-centre RCT of pleurodesis using Corynbacterium parvum vs bleomycin (Sweden) \\
\hline Participants & $\begin{array}{l}\text { Inclusion criteria: pleural effusion due to metastases from cytologically- or histologically-proven bron- } \\
\text { chogenic carcinoma or adenocarcinoma; at least two previous aspirations of effusion }\end{array}$ \\
40 participants randomised
\end{tabular}

Interventions

Corynebacterium parvum $7 \mathrm{mg}$ in $10-20 \mathrm{ml}$ saline IP or bleomycin $60 \mathrm{mg}$ in $100 \mathrm{ml}$ saline intrapleurally

A second dose of the allocated agent was given if the first was ineffective

No details given about method of drainage prior to instillation of pleurodesis agent or how long the drain remained in place

Outcomes

Pleurodesis success ("Success" = no recurrence of fluid within six weeks; "Partial success" = 2 instillations required within six weeks, with no recurring effusion within six weeks of the second instillation)

Notes People with trapped lung eligible for trial entry

For the purposes of this review, if participants required more than one treatment due to effusion recurrence within six weeks, they were counted as a failure 


\section{Risk of bias}

\begin{tabular}{|c|c|c|}
\hline Bias & Authors' judgement & Support for judgement \\
\hline $\begin{array}{l}\text { Random sequence genera- } \\
\text { tion (selection bias) }\end{array}$ & Unclear risk & Not stated \\
\hline $\begin{array}{l}\text { Allocation concealment } \\
\text { (selection bias) }\end{array}$ & Unclear risk & Not stated \\
\hline $\begin{array}{l}\text { Blinding of participants } \\
\text { and personnel (perfor- } \\
\text { mance bias) } \\
\text { All outcomes }\end{array}$ & High risk & No specific mention of blinding but drugs reconstituted in different volumes \\
\hline $\begin{array}{l}\text { Blinding of outcome as- } \\
\text { sessment (detection bias) } \\
\text { All outcomes }\end{array}$ & Unclear risk & $\begin{array}{l}\text { Definition of pleurodesis efficacy quite vague and not stated if blinded. Side } \\
\text { effect reporting may be influenced by lack of blinding of participants and per- } \\
\text { sonnel }\end{array}$ \\
\hline $\begin{array}{l}\text { Incomplete outcome data } \\
\text { (attrition bias) } \\
\text { All outcomes }\end{array}$ & High risk & No data on mortality. Numbers don't add up for side effects data \\
\hline $\begin{array}{l}\text { Selective reporting (re- } \\
\text { porting bias) }\end{array}$ & Low risk & All stated outcomes reported \\
\hline Other bias & Low risk & No other biases identified \\
\hline
\end{tabular}

Ishida 2006

\begin{tabular}{|c|c|}
\hline Methods & Single centre RCT of intrapleural cisplatin vsOK-432 vs combination (Japan) \\
\hline \multirow[t]{3}{*}{ Participants } & $\begin{array}{l}\text { Inclusion criteria: symptomatic, histocytologically confirmed pleural malignancy secondary to Non- } \\
\text { small cell lung cancer(NSCLC), ECOG performance score } 0-3 \text {, adequate renal, haematological and car- } \\
\text { diac function }\end{array}$ \\
\hline & Exclusion Criteria: previous intrapleural therapy, trapped lung or atelectasis after chest tube inserted \\
\hline & 49 participants randomised \\
\hline
\end{tabular}

Interventions All participants underwent pleural fluid drainage via a $20 \mathrm{Fr}$ chest tube. After administration of the allocated treatment, chest drain was clamped for six hours and then connected to $20 \mathrm{~cm} \mathrm{H} 2 \mathrm{O}$ suction. Drain removed when $<100 \mathrm{ml} /$ day

Cisplatin group: $50 \mathrm{mg}$ cisplatin via chest tube on day 1 and 4

ok-432 group: one dose of 5 KEOK-432 via chest tube

Combination group: $50 \mathrm{mg}$ cisplatin on day 1 and 4, followed by 5 KEOK-432 on day 7

\begin{tabular}{ll}
\hline Outcomes & $\begin{array}{l}\text { Effusion recurrence (as defined by a newly detected effusion needing drainage or occupying }>33 \% \text { of } \\
\text { pleural space on CXR); mortality; adverse events }\end{array}$ \\
\hline Notes & people with trapped lung excluded from the study \\
& Study authors contacted for further information, but no response
\end{tabular}


Ishida 2006 (Continued)

Not included in network meta-analysis

\section{Risk of bias}

\begin{tabular}{|c|c|c|}
\hline Bias & Authors' judgement & Support for judgement \\
\hline $\begin{array}{l}\text { Random sequence genera- } \\
\text { tion (selection bias) }\end{array}$ & Unclear risk & Not stated \\
\hline $\begin{array}{l}\text { Allocation concealment } \\
\text { (selection bias) }\end{array}$ & Unclear risk & Not stated \\
\hline $\begin{array}{l}\text { Blinding of participants } \\
\text { and personnel (perfor- } \\
\text { mance bias) } \\
\text { All outcomes }\end{array}$ & High risk & $\begin{array}{l}\text { No mention of blinding but participants received different dosing regimes de- } \\
\text { pending on study arm }\end{array}$ \\
\hline $\begin{array}{l}\text { Blinding of outcome as- } \\
\text { sessment (detection bias) } \\
\text { All outcomes }\end{array}$ & High risk & $\begin{array}{l}\text { Adverse event reporting could be affected by knowledge of treatment alloca- } \\
\text { tion. Not stated whether CXR interpretation was performed in a blinded fash- } \\
\text { ion for definition of pleurodesis efficacy }\end{array}$ \\
\hline $\begin{array}{l}\text { Incomplete outcome data } \\
\text { (attrition bias) } \\
\text { All outcomes }\end{array}$ & Low risk & $\begin{array}{l}\text { Number of deaths clearly stated. If participants died, still included in analysis } \\
\text { for pleurodesis success prior to death }\end{array}$ \\
\hline $\begin{array}{l}\text { Selective reporting (re- } \\
\text { porting bias) }\end{array}$ & Low risk & All pre-defined outcomes reported \\
\hline Other bias & High risk & $\begin{array}{l}\text { Drain left in for different duration in the three groups. Steroids were given to } \\
\text { participants who received cisplatin }\end{array}$ \\
\hline
\end{tabular}

\section{Kasahara 2006}

Methods $\quad$ Multicentre phase 2 trial ofOK-432, evaluating two different doses of intrapleural (IP) OK-432 (Japan)

Participants Inclusion criteria: histological or cytological proof of MPE with non-small cell lung cancer (NSCLC); no previous therapy for MPE; age > 20; ECOG performance score 0-3; life expectancy > 12weeks; adequate organ and bone marrow function; daily chest tube drainage $<200 \mathrm{ml}$

Exclusion criteria: previous TB pleuritis; unstable heart disease or diabetes; active double cancer; pregnancy; lactation; allergy to OK-432 or benzylpenicillin

38 participants randomised

Interventions

All participants underwent chest tube drainage. Two doses ofOK-432 given (on days 1 and 3)

Arm A: IPOK-432 at a dose of $10 \mathrm{KE}$ in $100 \mathrm{ml}$ saline

Arm B: IPOK-432 at a dose of $1 \mathrm{KE}$ in $100 \mathrm{ml}$ saline

Outcomes

MPE control on day 28 (defined as a complete response (the effusion disappeared completely and no further treatment required), partial response (the effusion persisted but local treatment was not needed) or no change (further local treatment was needed or the residual effusion volume was $>100 \mathrm{ml}$ )

MPE control rate

Duration of drainage 
Kasahara 2006 (Continued)

Fluid volume drained

Time to progression

Drug adverse events

Overall survival

\begin{tabular}{|c|c|}
\hline \multirow[t]{3}{*}{ Notes } & People with trapped lung included in the study \\
\hline & For purposes of this review, complete and partial responses were counted as pleurodesis successes \\
\hline & Not included in network meta-analysis \\
\hline
\end{tabular}

\section{Risk of bias}

\begin{tabular}{|c|c|c|}
\hline Bias & Authors' judgement & Support for judgement \\
\hline $\begin{array}{l}\text { Random sequence genera- } \\
\text { tion (selection bias) }\end{array}$ & Unclear risk & Not stated \\
\hline $\begin{array}{l}\text { Allocation concealment } \\
\text { (selection bias) }\end{array}$ & Unclear risk & Not stated \\
\hline $\begin{array}{l}\text { Blinding of participants } \\
\text { and personnel (perfor- } \\
\text { mance bias) } \\
\text { All outcomes }\end{array}$ & Unclear risk & Not stated whether blinded. Drugs diluted in same volume in both study arms \\
\hline $\begin{array}{l}\text { Blinding of outcome as- } \\
\text { sessment (detection bias) } \\
\text { All outcomes }\end{array}$ & Unclear risk & $\begin{array}{l}\text { Need for repeat intervention and side effects could be biased if patients and } \\
\text { personnel unblinded, but not stated if this was the case }\end{array}$ \\
\hline $\begin{array}{l}\text { Incomplete outcome data } \\
\text { (attrition bias) } \\
\text { All outcomes }\end{array}$ & Low risk & No loss to follow up \\
\hline $\begin{array}{l}\text { Selective reporting (re- } \\
\text { porting bias) }\end{array}$ & Low risk & All stated outcomes reported \\
\hline Other bias & High risk & $\begin{array}{l}\text { In arm B, if low dose ineffective, patients given a high dose of OK- } 432 \text { anyway } \\
\text { (prior to measurement of primary outcome) } \\
\text { Paper does not state whether patients were symptomatic from MPE at enrol- } \\
\text { ment }\end{array}$ \\
\hline
\end{tabular}

\section{Kefford 1980}

\begin{tabular}{ll}
\hline Methods & Single centre RCT of intrapleural Adriamycin, nitrogen mustard and rolitetracycline (Australia) \\
\hline Participants & $\begin{array}{l}\text { Histocytologically confirmed malignant effusions (pleural or pericardial or peritoneal); no previous in- } \\
\text { tracavitary chemotherapy; no concurrent radiotherapy or systemic treatment } \\
38 \text { participants reported as being randomised in total ( } 26 \text { of whom had malignant pleural effusion). } \\
\text { However in the discussion it refers to } 90 \text { participants being randomised originally }\end{array}$ \\
\hline Interventions & $\begin{array}{l}\text { All participants had a needle thoracentesis to dryness. The drug was diluted in } 20 \mathrm{ml} \text { saline and inject- } \\
\text { ed through needle as a bolus }\end{array}$
\end{tabular}


Kefford 1980 (Continued)

Adriamycin group: $30 \mathrm{mg}$ intrapleurally

Nitrogen mustard group: 20 mg intrapleurally

Rolitetracycline group: 500 mg intrapleurally

\begin{tabular}{ll} 
Outcomes & $\begin{array}{l}\text { Pleurodesis success at eight weeks (defined as complete response (CR) (absence of significant effusion } \\
\text { on CXR), partial response (reduction in frequency of aspiration with improvement in exercise tolerance } \\
\text { and CXR) or no response) } \\
\text { Complications }\end{array}$ \\
\hline Notes & $\begin{array}{l}\text { People with trapped lung eligible for the trial } \\
\text { For the purposes of this review, only data on participants with pleural effusions included in our analysis } \\
\text { Included in network meta-analysis for pleurodesis efficacy. }\end{array}$
\end{tabular}

\section{Risk of bias}

\begin{tabular}{lll}
\hline Bias & Authors' judgement & Support for judgement \\
\hline $\begin{array}{l}\text { Random sequence genera- } \\
\text { tion (selection bias) }\end{array}$ & Unclear risk & Not stated \\
\hline $\begin{array}{l}\text { Allocation concealment } \\
\text { (selection bias) }\end{array}$ & Unclear risk & Not stated \\
\hline $\begin{array}{l}\text { Blinding of participants } \\
\text { and personnel (perfor- } \\
\text { mance bias) } \\
\text { All outcomes }\end{array}$ & Unclear risk & No mention of whether anyone was blinded \\
\hline
\end{tabular}

\begin{tabular}{ll} 
Blinding of outcome as- & Unclear risk \\
sessment (detection bias) & \\
All outcomes & Not stated if CXR interpretation was done blind to treatment allocation \\
\hline
\end{tabular}

$\begin{array}{ll}\begin{array}{l}\text { Incomplete outcome data } \\ \text { (attrition bias) }\end{array} & \text { High risk } \\ \text { All outcomes } & \begin{array}{l}\text { "More than half of the original } 90 \text { patients randomised were ineligible for as- } \\ \text { sessment because of subsequent systemic therapy... or... early death". Al- } \\ \text { though in the results, it states } 38 \text { participants were randomised }\end{array}\end{array}$

\begin{tabular}{lll}
\hline $\begin{array}{l}\text { Selective reporting (re- } \\
\text { porting bias) }\end{array}$ & Low risk & $\begin{array}{l}\text { Only a brief report and side effects data for the pleural and peritoneal effu- } \\
\text { sions combined. However, generally all predefined outcomes reported }\end{array}$ \\
\hline Other bias & Unclear risk & $\begin{array}{l}\text { Six participants received more than one of the treatments, but not clear } \\
\text { whether re-randomised separately each time }\end{array}$ \\
\hline
\end{tabular}

\section{Kessinger 1987}

\begin{tabular}{|c|c|}
\hline Methods & Single centre RCT comparing intrapleural (IP) bleomycin and tetracycline in MPE (USA) \\
\hline \multirow[t]{3}{*}{ Participants } & $\begin{array}{l}\text { Inclusion: histologically proven malignancy; symptomatic pleural effusion with either }>3 \mathrm{~g} / \mathrm{dl} \text { protein } \\
\text { or malignant cells on cytology }\end{array}$ \\
\hline & Exclusion: allergy to either study drug \\
\hline & 42 procedures randomised in 34 participants \\
\hline
\end{tabular}


Kessinger 1987 (Continued)

Interventions

\author{
All participants underwent chest tube drainage \\ Tetracycline arm: $500 \mathrm{mg}$ tetracycline in $50 \mathrm{ml}$ saline IP. 1 dose \\ Bleomycin arm: 89 units in $50 \mathrm{ml}$ saline IP. 1 dose
}

For both arms, drain clamped for eight hours after instillation and participant moved positions. Thereafter, tube opened and suction applied. Drain removed when $<40 \mathrm{ml} / 24$ hours drained (or on day 7 if ongoing high output)

\section{Risk of bias}

\begin{tabular}{|c|c|c|}
\hline Bias & Authors' judgement & Support for judgement \\
\hline $\begin{array}{l}\text { Random sequence genera- } \\
\text { tion (selection bias) }\end{array}$ & Low risk & "Toss of coin" \\
\hline $\begin{array}{l}\text { Allocation concealment } \\
\text { (selection bias) }\end{array}$ & Unclear risk & Not stated \\
\hline $\begin{array}{l}\text { Blinding of participants } \\
\text { and personnel (perfor- } \\
\text { mance bias) } \\
\text { All outcomes }\end{array}$ & Unclear risk & No mention of blinding. Both drugs administered in $50 \mathrm{ml}$ saline \\
\hline $\begin{array}{l}\text { Blinding of outcome as- } \\
\text { sessment (detection bias) } \\
\text { All outcomes }\end{array}$ & Unclear risk & $\begin{array}{l}\text { Not stated. No mention of whether CXR interpretation was performed by a } \\
\text { blinded individual }\end{array}$ \\
\hline $\begin{array}{l}\text { Incomplete outcome data } \\
\text { (attrition bias) } \\
\text { All outcomes }\end{array}$ & High risk & $\begin{array}{l}11 / 34 \text { ( } 32 \%) \text { participants non-evaluable for pleurodesis outcome ( } 3 \text { in } \\
\text { bleomycin group and } 8 \text { in tetracycline group) }\end{array}$ \\
\hline $\begin{array}{l}\text { Selective reporting (re- } \\
\text { porting bias) }\end{array}$ & Low risk & All stated outcomes reported \\
\hline Other bias & High risk & $\begin{array}{l}\text { Unclear whether participants who were given both agents because the first } \\
\text { agent failed were included in the analysis }\end{array}$ \\
\hline
\end{tabular}

\section{Koldsland 1993}

\section{Methods}

Single centre, prospective RCT of mepacrine versus bleomycin as pleurodesis agent in malignant pleural effusion (Norway) 
Koldsland 1993 (Continued)

Participants
Inclusion: malignant pleural effusion; previous treatment with a therapeutic tap; life expectancy of $>1$ month

Exclusion: previous pleurodesis; renal failure; participantrequiring continuous oxygen

40 patients randomised.
28 or $32 \mathrm{Fr}$ chest tube inserted under local anaesthetic. Suction applied until fluid production about $100 \mathrm{ml} /$ day and no effusion on CXR. Tube clamped and sclerosing agent injected. Patient rotation for two hours after instillation. Drain removed when $<100 \mathrm{ml} /$ day output

Mepacrine group: $800 \mathrm{mg}$ mepacrine in $20 \mathrm{ml}$ saline

Bleomycin group: $60 \mathrm{mg}$ bleomycin in $100 \mathrm{ml}$ saline

\begin{tabular}{|c|c|}
\hline \multirow[t]{3}{*}{ Outcomes } & $\begin{array}{l}\text { Pleurodesis success (classified as (1) no re-accumulation (2) small amounts of fluid re-accumulation } \\
\text { with no or mild symptoms (3) re-accumulation of fluid with severe dyspnoea needing thoracocentesis) }\end{array}$ \\
\hline & Median survival \\
\hline & Side effects \\
\hline \multirow[t]{3}{*}{ Notes } & People with trapped lung not excluded from trial entry \\
\hline & $\begin{array}{l}\text { For purposes of this review, participants with no re-accumulation or small amount of re-accumulation } \\
\text { with no or mild symptoms were counted as pleurodesis successes }\end{array}$ \\
\hline & Included in network meta-analysis for pleurodesis efficacy, fever and pain \\
\hline
\end{tabular}

\section{Risk of bias}

\section{Bias}

Random sequence genera- Low risk tion (selection bias)

\begin{tabular}{lll}
\hline $\begin{array}{l}\text { Allocation concealment } \\
\text { (selection bias) }\end{array}$ & Low risk & Sealed envelopes \\
\hline $\begin{array}{l}\text { Blinding of participants } \\
\text { and personnel (perfor- } \\
\text { mance bias) } \\
\text { All outcomes }\end{array}$ & High risk & Not stated specifically but drugs reconstituted in different volumes \\
\hline $\begin{array}{l}\text { Blinding of outcome as- } \\
\text { sessment (detection bias) } \\
\text { All outcomes }\end{array}$ & High risk & $\begin{array}{l}\text { Participant reporting of symptoms may be effected by lack of blinding. Not } \\
\text { stated whether CXR interpretation was blind to treatment allocation }\end{array}$ \\
\hline $\begin{array}{l}\text { Incomplete outcome data } \\
\text { (attrition bias) } \\
\text { All outcomes }\end{array}$ & Low risk & High mortality in first three months, therefore data only analysed at month 1 \\
\hline $\begin{array}{l}\text { Selective reporting (re- } \\
\text { porting bias) }\end{array}$ & Low risk & All stated outcomes reported \\
\hline \begin{tabular}{l} 
Other bias \\
\hline
\end{tabular} & Low risk & No other biases identified \\
\hline
\end{tabular}

\section{Authors' judgement Support for judgement}

Randomised using sealed envelopes 
Kuzdzal 2003

\begin{tabular}{ll}
\hline Methods & Single centre, prospective RCT of talc vs doxycyline in the control of MPE (Poland) \\
\hline Participants & Inclusion criteria: pleural effusion with clinical suspicion of malignant origin \\
& $\begin{array}{l}\text { Exclusion criteria: failure to confirm malignancy by pleural biopsy; mesothelioma; failure to achieve full } \\
\text { re-expansion of the lung }\end{array}$ \\
& 33 participants randomised \\
\hline
\end{tabular}

Interventions

All participants all VATS under general anaesthetic and pleural biopsy. First dose of sclerosant given at end of procedure. Tube removed when full re-expansion, no air leak and $<150 \mathrm{ml} /$ day drainage. Rotation after procedure

Talc: single $10 \mathrm{~g}$ dose intrapleurally by insufflation

Doxycycline: $500 \mathrm{mg}$ in $25 \mathrm{ml}$ solution given intrapleurally. Up to 3 doses (if daily drainage $>150 \mathrm{ml} /$ day)

\begin{tabular}{|c|c|}
\hline \multirow[t]{2}{*}{ Outcomes } & $\begin{array}{l}\text { 'Long term' and 'short term' pleurodesis outcome (defined by need for repeat thoracentesis as 'Excel- } \\
\text { lent' (no fluid re-accumulation), 'Good' (limited residual fluid, not increasing, no indications for thora- } \\
\text { centesis) or 'Poor' (fluid re-accumulation requiring thoracentesis) }\end{array}$ \\
\hline & Complications \\
\hline \multirow[t]{3}{*}{ Notes } & $\begin{array}{l}\text { For purposes of this review, 'Excellent' and 'Good' pleurodesis outcomes included as pleurodesis suc- } \\
\text { cesses for analysis }\end{array}$ \\
\hline & Study authors emailed for further information, but no response \\
\hline & Included in network meta-analysis for pleurodesis efficacy \\
\hline
\end{tabular}

Risk of bias

\begin{tabular}{|c|c|c|}
\hline Bias & Authors' judgement & Support for judgement \\
\hline $\begin{array}{l}\text { Random sequence genera- } \\
\text { tion (selection bias) }\end{array}$ & Unclear risk & Not stated \\
\hline $\begin{array}{l}\text { Allocation concealment } \\
\text { (selection bias) }\end{array}$ & Unclear risk & Not stated \\
\hline $\begin{array}{l}\text { Blinding of participants } \\
\text { and personnel (perfor- } \\
\text { mance bias) } \\
\text { All outcomes }\end{array}$ & High risk & $\begin{array}{l}\text { Unable to blind due to the nature of the interventions, although not stated ex- } \\
\text { plicitly }\end{array}$ \\
\hline $\begin{array}{l}\text { Blinding of outcome as- } \\
\text { sessment (detection bias) } \\
\text { All outcomes }\end{array}$ & High risk & $\begin{array}{l}\text { Pleurodesis efficacy defined by symptom recurrence and hence could be bi- } \\
\text { ased by lack of blinding. Not stated whether assessment of fluid re-accumula- } \\
\text { tion was performed by a blinded individual }\end{array}$ \\
\hline $\begin{array}{l}\text { Incomplete outcome data } \\
\text { (attrition bias) } \\
\text { All outcomes }\end{array}$ & Unclear risk & Number of participants randomised not clear from paper \\
\hline $\begin{array}{l}\text { Selective reporting (re- } \\
\text { porting bias) }\end{array}$ & High risk & Treatment complications and survival not reported \\
\hline Other bias & High risk & Number of doses for the two arms, therefore potential for confounding \\
\hline
\end{tabular}


Leahy 1985

\begin{tabular}{|c|c|}
\hline Methods & $\begin{array}{l}\text { RCT (two recruiting centres) of intrapleural Corynebacterium parvum and tetracycline for pleurodesis of } \\
\text { malignant pleural effusion (UK) }\end{array}$ \\
\hline Participants & $\begin{array}{l}\text { Inclusion: histologically or cytologically proven MPE } \\
\text { Exclusion: participants on chemotherapy; participants receiving treatment with steroids } \\
36 \text { patients randomised. }\end{array}$ \\
\hline Interventions & $\begin{array}{l}\text { Effusion aspirated to dryness prior to administering study agent. After agent instilled, the participants } \\
\text { moved from side to side for six hours. If the participant had symptomatic recurrence of the effusion } \\
\text { within a month, the allocated treatment was repeated } \\
\text { Tetracycline group: } 500 \mathrm{mg} \text { in } 20 \mathrm{ml} \text { saline given intrapleurally. The tetracycline was administered via } \\
\text { an intercostal tube at one centre and with needle drainage at the other centre } \\
\text { C. parvum group: } 7 \mathrm{mg} \text { in } 20 \mathrm{ml} \text { saline intrapleurally through a needle, after the effusion was drained to } \\
\text { dryness }\end{array}$ \\
\hline Outcomes & $\begin{array}{l}\text { Symptomatic recurrence of pleural effusion one month after the last dose } \\
\text { Side effects (pain, fever, nausea and vomiting, rash) }\end{array}$ \\
\hline Notes & $\begin{array}{l}\text { People with trapped lung eligible for trial entry } \\
\text { The side effects were reported per procedure rather than per patient } \\
\text { For this review, if participants had a successful pleurodesis after the second dose of study agent, these } \\
\text { were included in the analysis as a success. For the tetracycline group, the results from the two adminis- } \\
\text { tration methods were combined for the purposes of analysis } \\
\text { Included in network meta-analysis for pleurodesis efficacy, fever, pain and mortality. }\end{array}$ \\
\hline
\end{tabular}

\section{Risk of bias}

\begin{tabular}{|c|c|c|}
\hline Bias & Authors' judgement & Support for judgement \\
\hline $\begin{array}{l}\text { Random sequence genera- } \\
\text { tion (selection bias) }\end{array}$ & Low risk & Computer randomisation \\
\hline $\begin{array}{l}\text { Allocation concealment } \\
\text { (selection bias) }\end{array}$ & Low risk & Computer randomisation \\
\hline $\begin{array}{l}\text { Blinding of participants } \\
\text { and personnel (perfor- } \\
\text { mance bias) } \\
\text { All outcomes }\end{array}$ & Unclear risk & Blinding not mentioned in the paper. Both drugs reconstituted in $20 \mathrm{ml}$ saline \\
\hline
\end{tabular}

\begin{tabular}{lll}
\hline $\begin{array}{l}\text { Blinding of outcome as- } \\
\text { sessment (detection bias) } \\
\text { All outcomes }\end{array}$ & Unclear risk & $\begin{array}{l}\text { If study was unblinded, reporting of side effects, symptomatic pleural fluid re- } \\
\text { accumulation could be biased }\end{array}$ \\
\hline $\begin{array}{l}\text { Incomplete outcome data } \\
\text { (attrition bias) } \\
\text { All outcomes }\end{array}$ & Low risk & $\begin{array}{l}\text { Participants excluded from analysis if died prior to one month, but the num- } \\
\text { bers were small and fairly well balanced between the groups }(1 / 17 \text { in } C . \\
\text { parvum group; } 3 / 19 \text { in tetracycline group ie } 11 \% \text { LTFU in total) }\end{array}$ \\
\hline $\begin{array}{l}\text { Selective reporting (re- } \\
\text { porting bias) }\end{array}$ & Low risk & Thorough reporting of toxicity \\
\hline
\end{tabular}


Leahy 1985 (Continued)
Other bias
Low risk
No other biases identified

Loutsidis 1994

\begin{tabular}{ll} 
Methods & $\begin{array}{l}\text { Single centre RCT of tetracycline and mechlorethamine (mustine) for pleurodesis of malignant pleural } \\
\text { effusions (Greece) }\end{array}$ \\
\hline Participants & $\begin{array}{l}\text { Inclusion: documented MPE (all tumour types); respiratory distress was the main problem of the partic- } \\
\text { ipants }\end{array}$ \\
& Exclusion: other therapy given simultaneously (chemotherapy or radiation therapy) \\
& 40 participants randomised
\end{tabular}

$\begin{array}{ll}\text { Interventions } & \begin{array}{l}\text { All participants had a } 32 \text { Fr intercostal drain inserted with local anaesthetic and effusion drained } \\ \text { overnight. Complete drainage confirmed on CXR }\end{array}\end{array}$

After pleurodesis, drain flushed with $20 \mathrm{ml}$ saline. Participants rotated and drain unclamped after two hours and put onto $-20 \mathrm{~cm} \mathrm{H} 2 \mathrm{O}$ suction. Drain removed when $<50 \mathrm{ml} /$ day drainage

Tetracycline group: $500 \mathrm{mg}$ tetracycline in $20 \mathrm{ml}$ 2\% lignocaine intrapleurally. 1 dose

Mechlorethamine group: $0.2 \mathrm{mg} / \mathrm{kg}$ of mechlorethamine in $20 \mathrm{ml}$ saline intrapleurally. 1 dose

\begin{tabular}{ll}
\hline Outcomes & $\begin{array}{l}\text { Response to therapy at } 60 \text { days ('complete response' (CR) (complete lack of re-accumulation of pleur- } \\
\text { al fluid for at least } 60 \text { days), 'partial response' (PR) (small pleural effusion, asymptomatic, not requiring } \\
\text { further treatment), 'failure' (all other cases)) } \\
\text { Side effects }\end{array}$ \\
\hline Motes & Minimal data provided on baseline participantcharacteristics of the two groups \\
& For the purposes of this review, CR and PR included as a successful pleurodesis \\
& People with trapped lung included in the study \\
Included in network meta-analysis for pleurodesis efficacy
\end{tabular}

\section{Risk of bias}

\begin{tabular}{|c|c|c|}
\hline Bias & Authors' judgement & Support for judgement \\
\hline $\begin{array}{l}\text { Random sequence genera- } \\
\text { tion (selection bias) }\end{array}$ & Unclear risk & Not stated \\
\hline $\begin{array}{l}\text { Allocation concealment } \\
\text { (selection bias) }\end{array}$ & Unclear risk & Not stated \\
\hline $\begin{array}{l}\text { Blinding of participants } \\
\text { and personnel (perfor- } \\
\text { mance bias) } \\
\text { All outcomes }\end{array}$ & Unclear risk & $\begin{array}{l}\text { No mention of blinding in the paper. Drugs given in the same volume but not } \\
\text { stated whether their appearances were similar }\end{array}$ \\
\hline $\begin{array}{l}\text { Blinding of outcome as- } \\
\text { sessment (detection bias) } \\
\text { All outcomes }\end{array}$ & Unclear risk & $\begin{array}{l}\text { Not stated if CXR interpretation was blinded for assessment of pleurodesis effi- } \\
\text { cacy }\end{array}$ \\
\hline
\end{tabular}


Loutsidis 1994 (Continued)

Incomplete outcome data Low risk All participants followed up until the primary endpoint at 60 days

(attrition bias)

All outcomes

\begin{tabular}{lll}
$\begin{array}{l}\text { Selective reporting (re- } \\
\text { porting bias) }\end{array}$ & Low risk & All stated outcomes reported \\
\hline Other bias & Low risk & No other biases identified \\
\hline
\end{tabular}

Luh 1992

\begin{tabular}{ll} 
Methods & Single centre RCT of OK-432 and mitomycin C pleurodesis in lung cancer patients with MPE (Taiwan) \\
\hline Participants & Inclusion criteria: histo/cyto proven MPE due to lung cancer; effusion requiring repeated thoracentesis; \\
ECOG performance score 0-3 & \\
Exclusion criteria: previous anticancer chemotherapy within four weeks; previous radiation therapy to \\
the ipsilateral chest within four weeks; concomitant systemic chemo or radio-therapy; history or evi- \\
dence of penicillin allergy \\
55 participants randomised
\end{tabular}

\begin{tabular}{|c|c|}
\hline \multirow[t]{3}{*}{ Interventions } & $\begin{array}{l}\text { All participants hospitalised and a chest drain or pigtail catheter inserted into effusion. Drainage until< } \\
200 \mathrm{ml} / \text { day. Tube clamped for one hour after drug administration. Drug administration repeated week- } \\
\text { ly for four weeks or until effusion resolved }\end{array}$ \\
\hline & ok-432 group: $1 \mathrm{KE}$ intrapleurally \\
\hline & Mitomycin C: $8 \mathrm{mg}$ in $30 \mathrm{ml}$ water intrapleurally \\
\hline \multirow[t]{3}{*}{ Outcomes } & $\begin{array}{l}\text { Pleurodesis success at four weeks (defined as 'complete response' (CR) (no fluid accumulation and par- } \\
\text { ticipants free of symptoms), 'partial response' (PR) (recurrence of effusion }<50 \% \text { of original effusion } \\
\text { volume, not symptomatic and no need for thoracentesis for symptom relief) or 'failure' (recurrence of } \\
\text { effusion }>50 \% \text { of the original volume, symptomatic and need for thoracentesis to relieve symptoms)) }\end{array}$ \\
\hline & Survival \\
\hline & Effusion-free period \\
\hline
\end{tabular}

\begin{tabular}{ll}
\hline Notes & People with trapped lung included in the study \\
For this review, PR \& CR counted as pleurodesis successes \\
Not included in network meta-analysis
\end{tabular}

\section{Risk of bias}

\begin{tabular}{lll}
\hline Bias & Authors' judgement & Support for judgement \\
\hline $\begin{array}{l}\text { Random sequence genera- } \\
\text { tion (selection bias) }\end{array}$ & Low risk & Sealed envelopes \\
\hline $\begin{array}{l}\text { Allocation concealment } \\
\text { (selection bias) }\end{array}$ & Low risk & Sealed envelopes \\
\hline $\begin{array}{l}\text { Blinding of participants } \\
\text { and personnel (perfor- } \\
\text { mance bias) }\end{array}$ & Unclear risk & No mention of whether the study was blinded \\
\hline
\end{tabular}


Luh 1992 (Continued)

All outcomes

Blinding of outcome as-
sessment (detection bias) $\quad$ Unclear risk $\quad$ Not stated

All outcomes

\begin{tabular}{|c|c|c|}
\hline $\begin{array}{l}\text { Incomplete outcome data } \\
\text { (attrition bias) }\end{array}$ & Low risk & Two participants excluded due to early death, both in OK-432 arm \\
\hline
\end{tabular}

All outcomes

\begin{tabular}{lll}
\hline $\begin{array}{l}\text { Selective reporting (re- } \\
\text { porting bias) }\end{array}$ & Low risk & All stated outcomes reported \\
\hline Other bias & Low risk & No other biases identified \\
\hline
\end{tabular}

Lynch 1996

\begin{tabular}{ll}
\hline Methods & RCT of bleomycin, tetracycline and talc for pleurodesis of malignant pleural effusion \\
\hline Participants & $\begin{array}{l}\text { Inclusion: MPE (either cytology positive or an exudative effusion attributed to a histologically con- } \\
\text { firmed malignancy elsewhere) (all cell types); life expectancy }>2 \text { months }\end{array}$ \\
& Exclusion: contraindication to placement of a chest tube; allergy to bleomycin, talc or tetracycline \\
50 participants randomised
\end{tabular}

Interventions

Chest tube placed using blunt dissection and allowed to drain for at least 24 hours until $<150 \mathrm{ml} /$ day output. Sclerosing agent instilled intrapleurally. Participants repositioned every seven minutes after agent instilled. Then, tube unclamped and suction applied, until $<150 \mathrm{ml} / 24$ hours drainage when the drain was removed. If the drainage remained high, a second instillation was attempted

Bleomycin group: 60 units bleomycin in $50 \mathrm{ml} 5 \%$ dextrose

Tetracycline group: $750 \mathrm{mg}$ tetracycline in $100 \mathrm{ml}$ saline, with $100 \mathrm{mg}$ lidocaine

Talc group: $5 \mathrm{~g}$ talc in $250 \mathrm{ml}$ saline, with $100 \mathrm{mg}$ lidocaine

\begin{tabular}{|c|c|}
\hline \multirow[t]{4}{*}{ Outcomes } & $\begin{array}{l}\text { Successs of sclerosis at } 30 \text { days (defined as a lack of significant re-accumulation on CXR with control of } \\
\text { symptoms due to the effusion) }\end{array}$ \\
\hline & Survival \\
\hline & Median length of hospitalisation from date of sclerosis to discharge \\
\hline & Side effects \\
\hline \multirow[t]{4}{*}{ Notes } & Participantswho died within 30 days of the sclerosis were included as treatment failures in the study \\
\hline & Small difference in median age and cell types between the treatment arms \\
\hline & Trapped lung not accounted for \\
\hline & Included in network meta-analysis for pleurodesis efficacy, fever and pain \\
\hline
\end{tabular}

\section{Risk of bias}

Bias Authors' judgement Support for judgement


Lynch 1996 (Continued)

\begin{tabular}{lll}
$\begin{array}{l}\text { Random sequence genera- } \\
\text { tion (selection bias) }\end{array}$ & Low risk & Random number generator \\
\hline $\begin{array}{l}\text { Allocation concealment } \\
\text { (selection bias) }\end{array}$ & Low risk & Random number generator \\
\hline
\end{tabular}

\begin{tabular}{|c|c|c|}
\hline $\begin{array}{l}\text { Blinding of participants } \\
\text { and personnel (perfor- } \\
\text { mance bias) } \\
\text { All outcomes }\end{array}$ & High risk & $\begin{array}{l}\text { Not stated explicitly if the study was blinded, but the different drugs were giv- } \\
\text { en as different volumes }\end{array}$ \\
\hline $\begin{array}{l}\text { Blinding of outcome as- } \\
\text { sessment (detection bias) } \\
\text { All outcomes }\end{array}$ & High risk & $\begin{array}{l}\text { Symptom and side effect reporting would be affected by lack of blinding. Not } \\
\text { stated if CXR interpretation was blinded }\end{array}$ \\
\hline $\begin{array}{l}\text { Incomplete outcome data } \\
\text { (attrition bias) } \\
\text { All outcomes }\end{array}$ & Low risk & $\begin{array}{l}4 / 50(8 \%) \text { loss to follow up for primary outcome but balanced between the } \\
\text { treatment arms }\end{array}$ \\
\hline $\begin{array}{l}\text { Selective reporting (re- } \\
\text { porting bias) }\end{array}$ & Low risk & All reported \\
\hline Other bias & Low risk & No other biases identified \\
\hline
\end{tabular}

\section{Mager 2002}

\begin{tabular}{ll}
\hline Methods & Single centre RCT evaluating the distribution of talc during a talc slurry pleurodesis - comparing rota- \\
tion with non-rotation of participants after instillation of talc slurry (Netherlands)
\end{tabular}

Inclusion: symptomatic MPE confirmed by cytology or histology (all cell types)
Exclusion: haemorrhagic disease; trapped lung; previous pleurodesis on ipsilateral side; other disease
which would interfere with the study; participants on systemic treatment or expected to be within four
weeks of pleurodesis; expected survival < 1month
20 participants randomised

Interventions Chest drain inserted and pleurodesis performed when drainage $<150 \mathrm{ml} / 24$ hours and lung fully re-expanded. Talc suspension was radiolabeled. Dynamic scintigraphy performed during, immediately after and one hour after instillation

Rotation arm: sequence of four positions changing every 10 mins after instillation of talc for one hour Non-rotation arm: strict bed rest in supine position after instillation

Tube removed when $<100 \mathrm{ml} / 24$ hour fluid drained

\begin{tabular}{ll}
\hline Outcomes & $\begin{array}{l}\text { Distribution of talc in the thoracic cavity, measured on scintigram immediately after instillation of talc } \\
\text { and after one hour } \\
\text { Success rate of pleurodesis (defined on CXR) at four weeks }\end{array}$ \\
\hline Notes & People with trapped lung excluded \\
& Not included in network meta-analysis
\end{tabular}

\section{Risk of bias}


Mager 2002 (Continued)

\begin{tabular}{|c|c|c|}
\hline Bias & Authors' judgement & Support for judgement \\
\hline $\begin{array}{l}\text { Random sequence genera- } \\
\text { tion (selection bias) }\end{array}$ & Low risk & Sealed envelopes (10 allocating participant to rotation and 10 to non-rotation) \\
\hline $\begin{array}{l}\text { Allocation concealment } \\
\text { (selection bias) }\end{array}$ & Low risk & Sealed envelopes \\
\hline $\begin{array}{l}\text { Blinding of participants } \\
\text { and personnel (perfor- } \\
\text { mance bias) } \\
\text { All outcomes }\end{array}$ & High risk & Unable to blind due to the nature of the interventions \\
\hline $\begin{array}{l}\text { Blinding of outcome as- } \\
\text { sessment (detection bias) } \\
\text { All outcomes }\end{array}$ & Unclear risk & Not stated if CXR reporting was performed by a blinded individual \\
\hline $\begin{array}{l}\text { Incomplete outcome data } \\
\text { (attrition bias) } \\
\text { All outcomes }\end{array}$ & Low risk & $\begin{array}{l}\text { Small numbers but no LTFU. Minimal data on baseline participant characteris- } \\
\text { tics }\end{array}$ \\
\hline $\begin{array}{l}\text { Selective reporting (re- } \\
\text { porting bias) }\end{array}$ & Low risk & $\begin{array}{l}\text { No serious side effects. Some discomfort in rotation group (not quantified). All } \\
\text { study participants alive at one months' follow up. (Personal communication) }\end{array}$ \\
\hline Other bias & Low risk & CXR only used to define pleurodesis. Small numbers in the study \\
\hline
\end{tabular}

Martinez-Moragon 1997

\begin{tabular}{ll}
\hline Methods & Single centre RCT of tetracycline vs bleomycin pleurodesis in MPE (Spain) \\
\hline Participants & $\begin{array}{l}\text { Inclusion: MPE (all cell types) causing respiratory symptoms, proved by cytological examination or } \\
\text { pleural biopsy and an expected survival of at least one month, with a KPS } \geq 50\end{array}$ \\
& $\begin{array}{l}\text { Exclusion: prior intrapleural instillation therapy; chest radiotherapy during the preceding two weeks; } \\
\text { previously received systemic bleomycin; trapped lung; allergy to study drugs }\end{array}$ \\
70 participants randomised
\end{tabular}

All participants underwent tube thoracostomy with suction drainage until $<100 \mathrm{ml} /$ day output
Tetracycline group: $1.5 \mathrm{~g}$ in $100 \mathrm{ml}$ saline intrapleurally, with $9 \mathrm{ml} 5 \%$ lignocaine
Bleomycin group: $60 \mathrm{mg}$ in $100 \mathrm{ml}$ saline intrapleurally
Tube clamped for four hours after instillation, then suction drainage. Drain removed when $<100-150$
$\mathrm{ml} /$ day output

Outcomes Response to pleurodesis (defined as 'complete response' (CR) (no clinical or radiological recurrence of effusion), 'partial response' (PR) (small amount of fluid re-accumulation on CXR but no symptoms), 'failure' (re-accumulation of fluid causing symptoms or needing thoracocentesis))

Adverse effects of the procedure

$\begin{array}{ll}\text { Notes } & \text { People with trapped lung excluded from trial entry } \\ \text { For this review, CRs and PRs included as pleurodesis successes }\end{array}$


Martinez-Moragon 1997 (Continued)

Included in network meta-analysis for pleurodesis efficacy, fever and pain

\section{Risk of bias}

\begin{tabular}{|c|c|c|}
\hline Bias & Authors' judgement & Support for judgement \\
\hline $\begin{array}{l}\text { Random sequence genera- } \\
\text { tion (selection bias) }\end{array}$ & Low risk & Computer randomisation \\
\hline $\begin{array}{l}\text { Allocation concealment } \\
\text { (selection bias) }\end{array}$ & Low risk & Computer randomisation \\
\hline $\begin{array}{l}\text { Blinding of participants } \\
\text { and personnel (perfor- } \\
\text { mance bias) } \\
\text { All outcomes }\end{array}$ & Unclear risk & $\begin{array}{l}\text { No mention of blinding in the paper. Agents given in the same volume but no } \\
\text { comment on whether appearances were similar }\end{array}$ \\
\hline $\begin{array}{l}\text { Blinding of outcome as- } \\
\text { sessment (detection bias) } \\
\text { All outcomes }\end{array}$ & Unclear risk & $\begin{array}{l}\text { Not stated if CXR interpretation was blinded. Other symptom and side effect } \\
\text { outcomes could be biased if participants and personnel not blind to treatment } \\
\text { allocation, but not stated if this was the case }\end{array}$ \\
\hline $\begin{array}{l}\text { Incomplete outcome data } \\
\text { (attrition bias) } \\
\text { All outcomes }\end{array}$ & Low risk & $8 / 70(11 \%)$ excluded from analysis due to death (5) or LTFU (3) \\
\hline $\begin{array}{l}\text { Selective reporting (re- } \\
\text { porting bias) }\end{array}$ & Low risk & All stated outcomes reported \\
\hline Other bias & Low risk & No other biases identified \\
\hline
\end{tabular}

Maskell 2004

$\begin{array}{ll}\text { Methods } & \text { Single centre RCT comparing pleurodesis using mixed particle Talc }(>50 \% \text { of particles are }<20 \mu \mathrm{m}) \text { vs } \\ \text { graded Talc }(<50 \% \text { of particles are }<20 \mu \mathrm{m})(\mathrm{UK})\end{array}$

Participants Inclusion: Symptomatic pleural effusion, proven to be malignant by cytology or pleural biopsy (all cell types).

Exclusion: Expected survival $<6$ weeks; bleeding diathesis contraindicating intercostal drain insertion; extensive trapped lung; previous ipsilateral pleurodesis; Age <18; Inability to give informed consent.

48 patients randomised.

Interventions

$12 \mathrm{Fr}$ intercostal drain inserted. Drainage until $<150 \mathrm{ml} /$ day output. Agent instilled and left in for 2 hours, before suction being applied. Drain removed after 48 hours.

Mixed particle talc group: $>50 \%$ of talc particles are $<20 \mu \mathrm{m}$. Single $4 \mathrm{~g}$ intrapleural dose.

Graded talc group: $<50 \%$ of talc particles are $<20 \mu \mathrm{m}$. Single $4 \mathrm{~g}$ intrapleural dose.

Change in Aa gradient 48hours post pleurodesis breathing air
Change in $\mathrm{PaO} 2$ at 48 hours post pleurodesis
Clinical efficacy of pleurodesis at 3 months
Presence/absence of fever at 48 hours


Maskell 2004 (Continued)

\section{Change in CRP}

Change in IL8

Notes $\quad$ Patients with trapped lung excluded. Pleurodesis success defined as no re-accumulation of pleural flu-
id sufficient to require drainage.

Paper presented 2 trials and only trial 2 was relevant to this review (trial 1 was RCT of mixed talc vs tetracycline, but pleurodesis success data was not collected)

Not included in network meta-analysis

\section{Risk of bias}

\begin{tabular}{lll}
\hline Bias & Authors' judgement & Support for judgement \\
\hline $\begin{array}{l}\text { Random sequence genera- } \\
\text { tion (selection bias) }\end{array}$ & Low risk & pre-sealed numbered, opaque, sealed envelopes with stratification \\
\hline $\begin{array}{l}\text { Allocation concealment } \\
\text { (selection bias) }\end{array}$ & Low risk & pre-sealed numbered, opaque, sealed envelopes with stratification \\
\hline $\begin{array}{l}\text { Blinding of participants } \\
\text { and personnel (perfor- } \\
\text { mance bias) } \\
\text { All outcomes }\end{array}$ & Low risk & $\begin{array}{l}\text { 'investigators and patients blind to treatment allocation' (personal communi- } \\
\text { cation with authors) }\end{array}$ \\
\hline
\end{tabular}

\begin{tabular}{|c|c|c|}
\hline $\begin{array}{l}\text { Blinding of outcome as- } \\
\text { sessment (detection bias) }\end{array}$ & Low risk & $\begin{array}{l}\text { 'investigators and patients blind to treatment allocation' (personal communi- } \\
\text { cation with authors) }\end{array}$ \\
\hline
\end{tabular}

Incomplete outcome data Low risk Missing data justified and balanced between the 2 groups (3 patients LTFU)
(attrition bias)
All outcomes

\begin{tabular}{|c|c|c|}
\hline $\begin{array}{l}\text { Selective reporting (re- } \\
\text { porting bias) }\end{array}$ & Unclear risk & $\begin{array}{l}\text { The study comprised of two sections and pleurodesis success only reported } \\
\text { for the particle size section. The RCT of talc/tetracycline did not report pleu- } \\
\text { rodesis success but this was not one of the pre-defined outcome measures. }\end{array}$ \\
\hline Other bias & Low risk & No other biases identified \\
\hline
\end{tabular}

\section{Masuno 1991}

\begin{tabular}{ll}
\hline Methods & $\begin{array}{l}\text { Multicentre RCT of LC9018 plus doxorubicin vs doxorubicin alone in MPE secondary to lung cancer } \\
\text { (Japan) }\end{array}$ \\
LC9018 is a biologic response modifier prepared from heat-killed, freeze-dried Lactobacillus casei YIT \\
9018
\end{tabular}


Masuno 1991 (Continued)

Interventions
Effusion completely drained. Both treatment arms received a maximum of two intrapleural doses, 1 week apart

Control group: doxorubicin $40 \mathrm{mg}$ in $20-50 \mathrm{ml}$ saline

LC9018 group: as control group, then LC9018 $0.2 \mathrm{mg}$ in 20-50 $\mathrm{ml}$ saline

People with trapped lung excluded post randomisation
For this review, CR and PR counted as pleurodesis success
Not included in network meta-analysis
NB: doxorubicin is the generic name for Adriamycin

\section{Risk of bias}

\begin{tabular}{lll}
\hline Bias & Authors' judgement & Support for judgement \\
\hline $\begin{array}{l}\text { Random sequence genera- } \\
\text { tion (selection bias) }\end{array}$ & Low risk & Central telephone randomisation system \\
\hline $\begin{array}{l}\text { Allocation concealment } \\
\text { (selection bias) }\end{array}$ & Low risk & Central telephone randomisation system \\
\hline $\begin{array}{l}\text { Blinding of participants } \\
\text { and personnel (perfor- } \\
\text { mance bias) }\end{array}$ & Unclear risk & Not clear \\
All outcomes & \\
\hline
\end{tabular}

\begin{tabular}{|c|c|c|}
\hline $\begin{array}{l}\text { Blinding of outcome as- } \\
\text { sessment (detection bias) } \\
\text { All outcomes }\end{array}$ & Low risk & "Blinded committee assessed data regarding safety and efficacy" \\
\hline
\end{tabular}

\begin{tabular}{lll}
\hline $\begin{array}{l}\text { Incomplete outcome data } \\
\text { (attrition bias) } \\
\text { All outcomes }\end{array}$ & High risk & $\begin{array}{l}\text { 19/95 participants excluded from final analysis, for a variety of reasons, includ- } \\
\text { ing five participants with protocol violations }\end{array}$ \\
\hline $\begin{array}{l}\text { Selective reporting (re- } \\
\text { porting bias) }\end{array}$ & Low risk & All stated outcomes reported \\
\hline Other bias & Unclear risk & $\begin{array}{l}\text { Primary outcome measure included CXR resolution and conversion to cytol- } \\
\text { ogy negative effusion. Not clear from methodology whether some participants } \\
\text { who were asymptomatic had effusion drained to evaluate cytology status and } \\
\text { were then classified as 'failures' }\end{array}$ \\
\hline
\end{tabular}


Mejer 1977

Methods

Single centre RCT of mepacrine hydrochloride, triethylenethiophosphoramide and pleurocentesis alone in the treatment of MPE (Denmark)

\section{Participants}

Inclusion: unilateral MPE (positive cytology, > 200 IU/L LDH and > $30 \mathrm{~g} / \mathrm{L}$ protein) (all cell types); one previous pleurocentesis of $>500 \mathrm{ml}$

Exclusion: participant receiving chemotherapy or radiotherapy

41 participants randomised

\begin{tabular}{|c|c|}
\hline \multirow[t]{4}{*}{ Interventions } & $\begin{array}{l}\text { Pleurocenteis with intrapleural instillation of the study agent, three times a week for one week } \\
\text { Mepacrine group: } 100 \mathrm{mg} \text { for first dose, } 200 \mathrm{mg} \text { for second dose, } 200 \mathrm{mg} \text { for third dose (ie } 500 \mathrm{mg} \text { in to- } \\
\text { tal) }\end{array}$ \\
\hline & Triethylenethiophosphoromide group: 20 mg at each instillation (ie 60 mg total) \\
\hline & Pleurocentesis group: $10 \mathrm{ml}$ saline at each instillation \\
\hline & $\begin{array}{l}\text { All participants were followed up at } 3 \text { weeks, } 6 \text { weeks, } 2 \text { months and } 3 \text { months, when a pleurocentesis } \\
\text { was performed }\end{array}$ \\
\hline \multirow[t]{2}{*}{ Outcomes } & $\begin{array}{l}\text { Treatment effect (a beneficial effect was defined as }<500 \mathrm{ml} \text { fluid aspirated at each pleurocentesis per- } \\
\text { formed up to three months) }\end{array}$ \\
\hline & Side effects \\
\hline \multirow[t]{3}{*}{ Notes } & People with trapped lung not excluded from trial entry \\
\hline & Minimal data presented on whether the treatment groups were well balanced at baseline \\
\hline & Included in network meta-analysis for pleurodesis efficacy, pain and fever \\
\hline
\end{tabular}

\section{Risk of bias}

\begin{tabular}{|c|c|c|}
\hline Bias & Authors' judgement & Support for judgement \\
\hline $\begin{array}{l}\text { Random sequence genera- } \\
\text { tion (selection bias) }\end{array}$ & Unclear risk & No details given \\
\hline $\begin{array}{l}\text { Allocation concealment } \\
\text { (selection bias) }\end{array}$ & Unclear risk & No details given \\
\hline $\begin{array}{l}\text { Blinding of participants } \\
\text { and personnel (perfor- } \\
\text { mance bias) } \\
\text { All outcomes }\end{array}$ & Unclear risk & No mention of blinding in the paper \\
\hline $\begin{array}{l}\text { Blinding of outcome as- } \\
\text { sessment (detection bias) } \\
\text { All outcomes }\end{array}$ & Unclear risk & No mention of blinding in the paper \\
\hline $\begin{array}{l}\text { Incomplete outcome data } \\
\text { (attrition bias) } \\
\text { All outcomes }\end{array}$ & Low risk & Minimal early deaths (3/25) and numbers well matched between the groups \\
\hline $\begin{array}{l}\text { Selective reporting (re- } \\
\text { porting bias) }\end{array}$ & Low risk & All stated outcomes reported \\
\hline
\end{tabular}


Mejer 1977 (Continued)

Other bias High risk Unsure if groups well balanced at baseline. Pleurodesis success defined by aspirating fluid on all participants and not by clinical need for pleural intervention

Millar 1980

\begin{tabular}{ll}
\hline Methods & RCT of intrapleural Corynebacterium parvum vs mustine in recurrent MPE (UK) \\
\hline Participants & $\begin{array}{l}\text { Recurrent effusion associated with histologically proved malignant disease (all cell types); at least two } \\
\text { previous pleural aspirations; symptoms of dyspnoea, cough or local pain } \\
21 \text { participants randomised }\end{array}$ \\
\hline Interventions & Effusion completely aspirated using an Abrams pleural biopsy needle \\
& Group A: intrapleural mustine $20 \mathrm{mg}$ (max 2 doses) \\
& Group B: intrapleural C. parvum 7 mg (max 2 doses) \\
\hline Outcomes & $\begin{array}{l}\text { Response to pleurodesis (defined by fluid re-accumulation on CXR and need for repeat aspiration - suc- } \\
\text { cess/partial success/failure) at four weeks } \\
\text { Symptoms (nausea, vomiting, pain) }\end{array}$ \\
\hline Notes & $\begin{array}{l}\text { Trapped lung not accounted for } \\
\text { Only 'success' counted as a pleurodesis success for analysis (not partial successes as these participants } \\
\text { required a further aspiration of effusion) }\end{array}$ \\
\hline
\end{tabular}

\section{Risk of bias}

\begin{tabular}{|c|c|c|}
\hline Bias & Authors' judgement & Support for judgement \\
\hline $\begin{array}{l}\text { Random sequence genera- } \\
\text { tion (selection bias) }\end{array}$ & Unclear risk & Not stated \\
\hline $\begin{array}{l}\text { Allocation concealment } \\
\text { (selection bias) }\end{array}$ & Unclear risk & Not stated \\
\hline $\begin{array}{l}\text { Blinding of participants } \\
\text { and personnel (perfor- } \\
\text { mance bias) } \\
\text { All outcomes }\end{array}$ & Unclear risk & No mention of blinding in the paper \\
\hline $\begin{array}{l}\text { Blinding of outcome as- } \\
\text { sessment (detection bias) } \\
\text { All outcomes }\end{array}$ & Unclear risk & $\begin{array}{l}\text { No mention of blinding in the paper. If unblinded, symptom and side effect re- } \\
\text { porting could have been biased }\end{array}$ \\
\hline $\begin{array}{l}\text { Incomplete outcome data } \\
\text { (attrition bias) } \\
\text { All outcomes }\end{array}$ & Low risk & $\begin{array}{l}\text { Three participants excluded from analysis as died before primary outcome } \\
\text { measure }\end{array}$ \\
\hline $\begin{array}{l}\text { Selective reporting (re- } \\
\text { porting bias) }\end{array}$ & Low risk & All stated outcomes reported \\
\hline
\end{tabular}


Millar 1980 (Continued)

Other bias Low risk Unclear who provided C. parvum and their study involvement

Mohsen 2011

Methods Single Centre RCT of thoracoscopic talc poudrage versus povidone-iodine pleurodesis through an intercostal drain (Egypt)

$\begin{array}{ll}\text { Participants } & \text { Inclusion: MPE as a complication of breast carcinoma } \\ & \text { Exclusion: performance status }>3 \text {; allergy to iodine; trapped lung; no change in MRC dyspnoea scale af- } \\ \text { ter thoracentesis; pleural fluid } \mathrm{pH}<7.2 \text {; pleural fluid glucose }<60 \mathrm{mg} / \mathrm{dl} \text {; extrathoracic metastasis } \\ \\ 42 \text { participants randomised }\end{array}$

All participants underwent a VATS drainage and adhesiolysis
Talc poudrage group: $4 \mathrm{~g}$ talc insufflation under thoracoscopic guidance at the end of the VATS proce-
dure
lodine group: recovered from VATS. Then later that day, $20 \mathrm{ml} 10 \%$ povidone-iodine in $30 \mathrm{ml}$ saline in-
jected through the chest drain at the bedside. Drain clamped for four hours after instillation

Officacy of pleurodesis at two months (response defined as 'complete response' (CR) (absence of fluid
re-accumulation), 'partial response' (PR) (residual pleural fluid or re-accumulation, which did not re-
quire further thoracocentesis or remained asymptomatic) or 'failure' (additional pleural procedures
were necessary)
Complications
Length of hospital stay (in days)
Survival
Change in MRC dyspnoea score

$\begin{array}{ll}\text { Notes } & \text { People with trapped lung excluded from trial entry } \\ \text { CR }+ \text { PR counted as pleurodesis success for analysis } \\ \text { Included in network meta-analysis for pleurodesis efficacy, mortality and fever }\end{array}$

\section{Risk of bias}

\begin{tabular}{lll}
\hline Bias & Authors' judgement & Support for judgement \\
\hline $\begin{array}{l}\text { Random sequence genera- } \\
\text { tion (selection bias) }\end{array}$ & Low risk & Computer randomisation software used \\
\hline $\begin{array}{l}\text { Allocation concealment } \\
\text { (selection bias) }\end{array}$ & Low risk & Computer randomisation software used \\
\hline $\begin{array}{l}\text { Blinding of participants } \\
\text { and personnel (perfor- } \\
\text { mance bias) }\end{array}$ & High risk & Not able to blind given the nature of the interventions \\
\begin{tabular}{l} 
All outcomes \\
\hline
\end{tabular}
\end{tabular}


Mohsen 2011 (Continued)

$\begin{array}{lll}\text { Blinding of outcome as- } & \text { High risk } & \text { Symptom and side effect reporting would be effected by lack of blinding. Not } \\ \text { sessment (detection bias) } & \text { stated if radiology was interpreted blindly. Mortality would not be biased by } \\ \text { All outcomes } & \text { lack of blinding }\end{array}$

\begin{tabular}{lll}
\hline $\begin{array}{l}\text { Incomplete outcome data } \\
\text { (attrition bias) } \\
\text { All outcomes }\end{array}$ & Low risk & $\begin{array}{l}\text { Minimal missing data (primary outcome data available for all patients at two } \\
\text { months) }\end{array}$ \\
\hline $\begin{array}{l}\text { Selective reporting (re- } \\
\text { porting bias) }\end{array}$ & Low risk & All stated outcomes reported \\
\hline Other bias & Low risk & No other biases identified \\
\hline
\end{tabular}

\section{Noppen 1997}

\begin{tabular}{|c|c|}
\hline Methods & Single centre RCT of talc vs bleomycin in MPE (Belgium) \\
\hline \multirow[t]{3}{*}{ Participants } & $\begin{array}{l}\text { Inclusion criteria: hist/cytologically proven, symptomatic MPE; karnofsky performance score } \geq 50 \text {; ex- } \\
\text { pected survival of one year or less. }\end{array}$ \\
\hline & Exclusion criteria: previous pleurodesis attempt \\
\hline & 26 participants randomised \\
\hline \multirow[t]{3}{*}{ Interventions } & $\begin{array}{l}14 \text { Fr chest drain with suction drainage until completely drained. Intrapleural lignocaine and subcuta- } \\
\text { neous morphine given prior to instillation of study drug. After instillation of drug, drain clamped for } 30 \\
\text { mins and then left on suction drainage until output }<150 \mathrm{ml} / 24 \text { hours }\end{array}$ \\
\hline & Bleomycin group: $1 \mathrm{mg} / \mathrm{kg}$ bleomycin in $50 \mathrm{ml}$ saline intrapleurally. 1 dose \\
\hline & Talc group: $5 \mathrm{~g}$ in $50 \mathrm{ml}$ saline intrapleurally. 1 dose \\
\hline \multirow[t]{3}{*}{ Outcomes } & $\begin{array}{l}\text { Response to therapy (defined by re-accumulation on CXR and need for repeat procedure). Time point } \\
\text { unclear }\end{array}$ \\
\hline & Side effects \\
\hline & Survival \\
\hline \multirow[t]{2}{*}{ Notes } & People with trapped lung were included in the study \\
\hline & Included in network meta-analysis for pleurodesis efficacy and fever \\
\hline
\end{tabular}

\section{Risk of bias}

\begin{tabular}{lll}
\hline Bias & Authors' judgement & Support for judgement \\
\hline $\begin{array}{l}\text { Random sequence genera- } \\
\text { tion (selection bias) }\end{array}$ & Low risk & Computer-generated numerical table \\
\hline $\begin{array}{l}\text { Allocation concealment } \\
\text { (selection bias) }\end{array}$ & Low risk & Computer-generated numerical table \\
\hline $\begin{array}{l}\text { Blinding of participants } \\
\text { and personnel (perfor- } \\
\text { mance bias) } \\
\text { All outcomes }\end{array}$ & High risk & Not stated explicitly but drugs have different appearances \\
\hline
\end{tabular}


Noppen 1997 (Continued)

Blinding of outcome as- High risk Symptom recurrence and side effects could be biased by lack of blinding. Not sessment (detection bias) stated if CXR interpretation was blinded

All outcomes

Incomplete outcome data Low risk No LTFU. Outcome data provided on all participants
(attrition bias)

(attrition bias)

All outcomes

Selective reporting (re- Low risk Time point used to define pleurodesis not specified
porting bias)

\begin{tabular}{ll}
\hline Other bias $\quad$ Unclear risk $\quad$ No fixed endpoint for follow up \\
\hline
\end{tabular}

Okur 2011

\begin{tabular}{|c|c|}
\hline Methods & Single centre RCT of intrapleural streptokinase in MPE undergoing chest drainage (Turkey) \\
\hline \multirow[t]{3}{*}{ Participants } & Inclusion: definitive diagnosis of MPE with dyspnoea \\
\hline & Exclusion: mesothelioma; endobronchial tumour causing obstruction; anticoagulant medication \\
\hline & 48 participants randomised between Jan 2007 and Dec 2008 \\
\hline \multirow[t]{2}{*}{ Interventions } & $\begin{array}{l}\text { All participants had } 10 \mathrm{Fr} \text { pleural catheter inserted under local anaesthetic. Pleurodesis ( } 5 \mathrm{~g} \text { talc in } 50 \\
\mathrm{ml} \text { saline) given only in those patients with complete lung re-expansion and }<250 \mathrm{ml} \text { drain output per } \\
\text { day. Drain removed when output }<150 \mathrm{ml} / \text { day or after three days }\end{array}$ \\
\hline & $\begin{array}{l}\text { Those randomised to streptokinase received } 3 \text { doses of } 250000 \mathrm{IU} \text { in } 100 \mathrm{ml} \mathrm{N} \text { saline at } 12 \text {-hourly inter- } \\
\text { vals intrapleurally prior to pleurodesis }\end{array}$ \\
\hline \multirow[t]{2}{*}{ Outcomes } & Primary: lung expansion on chest $\mathrm{X}$-ray \\
\hline & $\begin{array}{l}\text { Secondary: success of pleurodesis at one month; Volume of 24-hour pleural drainage before and after } \\
\text { fibrinolytic }\end{array}$ \\
\hline \multirow[t]{4}{*}{ Notes } & $\begin{array}{l}\text { Pleurodesis defined as "no accumulation of moderate to massive pleural fluid or any accumulation } \\
\text { which causes dyspnoea" }\end{array}$ \\
\hline & Didn't pleurodese those with trapped lung. \\
\hline & Degree of loculation or septation on imaging at baseline was not recorded. \\
\hline & Not included in network meta-analysis \\
\hline
\end{tabular}

\section{Risk of bias}

\begin{tabular}{lll}
\hline Bias & Authors' judgement & Support for judgement \\
\hline $\begin{array}{l}\text { Random sequence genera- } \\
\text { tion (selection bias) }\end{array}$ & Low risk & Web-based random-number generator \\
\hline $\begin{array}{l}\text { Allocation concealment } \\
\text { (selection bias) }\end{array}$ & Low risk & Web-based random-number generator \\
\hline $\begin{array}{l}\text { Blinding of participants } \\
\text { and personnel (perfor- } \\
\text { mance bias) }\end{array}$ & High risk & $\begin{array}{l}\text { Nature of interventions precluded blinding (one group got } 3 \text { doses of drug and } \\
\text { other group got nothing) }\end{array}$ \\
\hline
\end{tabular}


Okur 2011 (Continued)

All outcomes

\begin{tabular}{|c|c|c|}
\hline $\begin{array}{l}\text { Blinding of outcome as- } \\
\text { sessment (detection bias) }\end{array}$ & High risk & $\begin{array}{l}\text { No mention of blinding and side effects and symptom reporting could be influ- } \\
\text { enced by lack of blinding }\end{array}$ \\
\hline
\end{tabular}

All outcomes

Incomplete outcome data Low risk
(attrition bias)

LTFU for pleurodesis success ( $1 / 17$ in control group; $4 / 23$ in streptokinase

All outcomes group - 1 died; 1 in intensive care; 3 LTFU). Only those with full lung re-expansion were given pleurodesis and this could have been affected by giving streptokinase, which might effect pleurodesis success rate, although this was not the study's primary outcome measure

\begin{tabular}{lll}
\hline $\begin{array}{l}\text { Selective reporting (re- } \\
\text { porting bias) }\end{array}$ & Low risk & All stated outcomes reported \\
\hline Other bias & Low risk & No other biases identified \\
\hline
\end{tabular}

Ong 2000

\begin{tabular}{|c|c|}
\hline Methods & Single centre RCT of talc vs bleomycin in MPE (Singapore) \\
\hline \multirow[t]{3}{*}{ Participants } & Inclusion: symptomatic, unilateral MPE confirmed by cytology or pleural biopsy (all cell types) \\
\hline & $\begin{array}{l}\text { Exclusion: trapped lung or loculated effusion; incomplete drainage (e.g. > } 100 \mathrm{ml} / \text { day for } 10 \text { days); pre- } \\
\text { viously treated effusions; life expectancy < 1month }\end{array}$ \\
\hline & 50 participants randomised \\
\hline \multirow[t]{3}{*}{ Interventions } & $\begin{array}{l}20 \text { - } 24 \mathrm{Fr} \text { tube thoracostomy until complete lung re-expansion on CXR and }<100 \mathrm{ml} / \text { day for two days. } \\
\text { Both drugs diluted in } 50 \mathrm{ml} \text { saline and } 10 \mathrm{ml} 1 \% \text { lignocaine. After study drug inserted, drain clamped for } \\
\text { six hours with patient rotation. Then suction applied. Drain removed when }<200 \mathrm{ml} / \text { day drainage }\end{array}$ \\
\hline & Talc group: 1 dose. $5 \mathrm{~g}$ talc intrapleurally \\
\hline & Bleomycin group: 1 dose. 1 unit/kg bleomycin intrapleurally \\
\hline \multirow[t]{3}{*}{ Outcomes } & $\begin{array}{l}\text { Treatment response at one month (according to recurrence of effusion on CXR. Scoring system 0-3 } \\
\text { used for size of effusion) }\end{array}$ \\
\hline & Hospital stay (days) \\
\hline & Side effects within 48 hours of pleurodesis \\
\hline \multirow[t]{3}{*}{ Notes } & People with trapped lung excluded from trial entry \\
\hline & Pleurodesis success based only on radiology \\
\hline & Included in network meta-analysis for pluerodesis efficacy, pain, fever and mortality \\
\hline
\end{tabular}

\section{Risk of bias}

\begin{tabular}{lll}
\hline Bias & Authors' judgement & Support for judgement \\
\hline $\begin{array}{l}\text { Random sequence genera- } \\
\text { tion (selection bias) }\end{array}$ & Unclear risk & Not stated \\
\hline $\begin{array}{l}\text { Allocation concealment } \\
\text { (selection bias) }\end{array}$ & Unclear risk & Not stated \\
\hline \hline
\end{tabular}


Ong 2000 (Continued)

Blinding of participants High risk Not stated explicitly, however drugs have differing appearances and personnel (performance bias)

All outcomes

\begin{tabular}{|c|c|c|}
\hline $\begin{array}{l}\text { Blinding of outcome as- } \\
\text { sessment (detection bias) } \\
\text { All outcomes }\end{array}$ & Low risk & $\begin{array}{l}\text { "A single investigator who was blinded to treatment allocation scored all the } \\
\text { follow up chest x rays" }\end{array}$ \\
\hline $\begin{array}{l}\text { Incomplete outcome data } \\
\text { (attrition bias) } \\
\text { All outcomes }\end{array}$ & Low risk & $\begin{array}{l}12 / 50 \text { patients excluded due to death or LTFU in first month, but balanced be- } \\
\text { tween treatment arms }\end{array}$ \\
\hline $\begin{array}{l}\text { Selective reporting (re- } \\
\text { porting bias) }\end{array}$ & Low risk & All stated outcomes reported \\
\hline Other bias & Low risk & No other biases identified \\
\hline
\end{tabular}

Ostrowski 1989

\begin{tabular}{|c|c|}
\hline Methods & Multi-centre RCT bleomycin vs Corynebacterium parvum in MPE (UK) \\
\hline \multirow[t]{3}{*}{ Participants } & $\begin{array}{l}\text { Inclusion criteria: histocytologically proven malignancy with effusion (all cell types); life expectancy of } \\
>30 \text { days }\end{array}$ \\
\hline & $\begin{array}{l}\text { Exclusion criteria: previous intrapleural drug administration; change in cancer treatment in previous } 30 \\
\text { days }\end{array}$ \\
\hline & 58 participants randomised \\
\hline \multirow[t]{3}{*}{ Interventions } & $\begin{array}{l}\text { Aspiration of effusion with a cannula. Study drug instilled through the cannula. After cannula removed, } \\
\text { participantrepositioned every five minutes }\end{array}$ \\
\hline & Bleomycin group: $60 \mathrm{mg}$ bleomycin in $100 \mathrm{ml}$ saline. Single dose intrapleurally \\
\hline & C. parvum group: $7 \mathrm{mg}$ in $20 \mathrm{ml}$ saline. Single dose intrapleurally \\
\hline \multirow[t]{4}{*}{ Outcomes } & $\begin{array}{l}\text { Efficacy of pleurodesis agent at } 30 \text { days (defined as 'complete response' (CR) (no re-accumulation of } \\
\text { fluid confirmed by CXR), 'partial response' (PR) (minimal fluid re-accumulation not sufficient to pro- } \\
\text { duce symptoms \&/or need for a further aspiration) or 'failure') }\end{array}$ \\
\hline & Duration of treatment response \\
\hline & Toxicity \\
\hline & Efficacy of pleurodesis at 2, 3, 6, 9 and 12 months \\
\hline \multirow[t]{3}{*}{ Notes } & People with trapped lung included in the study \\
\hline & For this review, CR and PR counted as pleurodesis success \\
\hline & Included in network meta-analysis for pleurodesis efficacy, mortality, fever and pain \\
\hline
\end{tabular}

\section{Risk of bias}

Bias Authors' judgement Support for judgement


Ostrowski 1989 (Continued)

Random sequence genera- Low risk Sequentially labelled sealed envelopes
tion (selection bias)

Allocation concealment
(selection bias)

Blinding of participants High risk Not stated explicitly, but agents given as different volumes
and personnel (perfor-
mance bias)
All outcomes

\begin{tabular}{lll}
\hline $\begin{array}{l}\text { Blinding of outcome as- } \\
\text { sessment (detection bias) } \\
\text { All outcomes }\end{array}$ & High risk & $\begin{array}{l}\text { Symptom recurrence and side effect reporting would be influenced by lack of } \\
\text { blinding. Not stated if CXR assessment was blinded. Mortality data would not } \\
\text { be biased by lack of blinding }\end{array}$ \\
\hline $\begin{array}{l}\text { Incomplete outcome data } \\
\begin{array}{l}\text { (attrition bias) } \\
\text { All outcomes }\end{array}\end{array}$ & High risk & $\begin{array}{l}14 / 58(24 \%) \text { excluded from primary analysis due to death or not receiving } \\
\text { drug. But, balanced numbers between the groups }\end{array}$ \\
\hline $\begin{array}{l}\text { Selective reporting (re- } \\
\text { porting bias) }\end{array}$ & Low risk & All stated outcomes reported \\
\hline Other bias & Low risk & No other biases identified \\
\hline
\end{tabular}

\section{Ozkul 2014}

\begin{tabular}{|c|c|}
\hline Methods & $\begin{array}{l}\text { Single centre, prospective RCT comparing rapid and standard drainage prior to talc slurry pleurodesis } \\
\text { (Turkey) }\end{array}$ \\
\hline \multirow[t]{3}{*}{ Participants } & $\begin{array}{l}\text { Inclusion: potentially recurrent histologically \&/or cytologically proven malignant pleural effusion (all } \\
\text { cell types) }\end{array}$ \\
\hline & Exclusion: participants whose lung did not expand; endobronchial lesion; suitable for curative therapy \\
\hline & 79 participants randomised \\
\hline \multirow[t]{3}{*}{ Interventions } & $\begin{array}{l}\text { All participants underwent insertion of a } 12 \mathrm{Fr} \text { chest drain in the posterior axillary lune with local anaes- } \\
\text { thetic (bupivacaine) and IM ketorolac }\end{array}$ \\
\hline & $\begin{array}{l}\text { Rapid group: } 1 \text { litre drained every eight hours until complete drainage. Then talc slurry administered } \\
\text { once CXR showed complete fluid evacuation and no trapped lung }\end{array}$ \\
\hline & $\begin{array}{l}\text { Standard group: drainage of a maximum of } 1.5 \text { litre/day. Talc slurry administered once CXR showed } \\
\text { complete fluid evaluation and no trapped lung and pleural fluid drainage }<300 \mathrm{ml} / \text { day }\end{array}$ \\
\hline \multirow[t]{2}{*}{ Outcomes } & Primary outcome: efficacy of pleurodesis assessed at $1,2,3$, and 6 months \\
\hline & Secondary outcome: hospital length of stay \\
\hline \multirow[t]{3}{*}{ Notes } & people with trapped lung excluded from study entry \\
\hline & $\begin{array}{l}\text { Pleurodesis efficacy defined using a combination of radiology and symptomatic effusion re-accumula- } \\
\text { tion }\end{array}$ \\
\hline & Not included in network meta-analysis \\
\hline
\end{tabular}

\section{Risk of bias}


Ozkul 2014 (Continued)

\begin{tabular}{|c|c|c|}
\hline Bias & Authors' judgement & Support for judgement \\
\hline $\begin{array}{l}\text { Random sequence genera- } \\
\text { tion (selection bias) }\end{array}$ & Low risk & Internet-based random-number generator \\
\hline $\begin{array}{l}\text { Allocation concealment } \\
\text { (selection bias) }\end{array}$ & Unclear risk & Not stated and no response from study authors \\
\hline $\begin{array}{l}\text { Blinding of participants } \\
\text { and personnel (perfor- } \\
\text { mance bias) } \\
\text { All outcomes }\end{array}$ & High risk & $\begin{array}{l}\text { Not possible to blind given nature of two treatment groups with such different } \\
\text { drainage regimes }\end{array}$ \\
\hline $\begin{array}{l}\text { Blinding of outcome as- } \\
\text { sessment (detection bias) } \\
\text { All outcomes }\end{array}$ & Low risk & $\begin{array}{l}\text { "The assessment of success was performed by an investigator blinded to allo- } \\
\text { cation" }\end{array}$ \\
\hline $\begin{array}{l}\text { Incomplete outcome data } \\
\text { (attrition bias) } \\
\text { All outcomes }\end{array}$ & Unclear risk & Unclear if any LTFU- not stated in paper and no response from study authors \\
\hline $\begin{array}{l}\text { Selective reporting (re- } \\
\text { porting bias) }\end{array}$ & High risk & $\begin{array}{l}\text { Minimal data provided on side effect and mortality data. Not all time points re- } \\
\text { ported as stated in methods }\end{array}$ \\
\hline Other bias & Low risk & No other sources of bias identified \\
\hline
\end{tabular}

Paschoalini 2005

\begin{tabular}{ll}
\hline Methods & Two-centre, prospective RCT of silver nitrate vs talc slurry in MPE (Brazil) \\
\hline Participants & $\begin{array}{l}\text { Inclusion: documented MPE (positive pleural biopsy or cytology - all cell types); karnofsky performance } \\
\text { score }>60 ; \text { life expectancy }>1 \text { month }\end{array}$ \\
& Exclusion: loculated or trapped lungs after drainage \\
60 participants randomised
\end{tabular}

Interventions

$26 / 28 \mathrm{Fr}$ chest tube. After study drug instilled, clamped for one hour with patient rotation. Then suction applied. Drain removed when $<100 \mathrm{ml}$ drained

Talc group: $5 \mathrm{~g}$ talc in $50 \mathrm{ml}$ saline. 1 dose intrapleurally

Silver nitrate group: $20 \mathrm{ml}$ of $0.5 \mathrm{ml}$ silver nitrate. 1 dose intrapleurally

Outcomes Radiological resolution of effusion on CXR (monthly for four months)

Pain before and after treatment (measured on a 0-10 linear scale)

\begin{tabular}{ll}
\hline Notes & People with trapped lung excluded from study entry \\
Not included in network meta-analysis
\end{tabular}

\section{Risk of bias}

Bias Authors' judgement Support for judgement




\section{Paschoalini 2005 (Continued)}

\begin{tabular}{l}
$\begin{array}{l}\text { Random sequence genera- } \\
\text { tion (selection bias) }\end{array} \quad$ Low risk $\quad$ Picking paper from a box \\
\hline
\end{tabular}

\begin{tabular}{lll}
\hline $\begin{array}{l}\text { Allocation concealment } \\
\text { (selection bias) }\end{array}$ & Low risk & Picking paper from a box
\end{tabular}

\begin{tabular}{|c|c|c|}
\hline $\begin{array}{l}\text { Blinding of participants } \\
\text { and personnel (perfor- } \\
\text { mance bias) } \\
\text { All outcomes }\end{array}$ & High risk & Not stated if blinded but agents have different appearances \\
\hline $\begin{array}{l}\text { Blinding of outcome as- } \\
\text { sessment (detection bias) } \\
\text { All outcomes }\end{array}$ & Unclear risk & $\begin{array}{l}\text { Not stated if CXR interpretation was blinded. Pain scores may be biased if par- } \\
\text { ticipants not blinded }\end{array}$ \\
\hline $\begin{array}{l}\text { Incomplete outcome data } \\
\text { (attrition bias) } \\
\text { All outcomes }\end{array}$ & Low risk & High rate of LTFU $(11 / 60(18 \%))$ but reasons explored in the discussion \\
\hline $\begin{array}{l}\text { Selective reporting (re- } \\
\text { porting bias) }\end{array}$ & Low risk & All stated outcomes reported \\
\hline Other bias & Low risk & No other biases identified \\
\hline
\end{tabular}

\section{Patz 1998}

\begin{tabular}{ll}
\hline Methods & Prospective RCT of bleomycin vs doxycycline in MPE (USA) \\
\hline Participants & $\begin{array}{l}\text { Inclusion: symptomatic effusion; proven or strongly suspected that malignancy is the cause for the ef- } \\
\text { fusion }\end{array}$ \\
& $\begin{array}{l}\text { Exclusion: previous pleurodesis; allergy to bleomycin or doxycycline; chemotherapy in the previous } 30 \\
\text { days }\end{array}$ \\
& 106 participants randomised
\end{tabular}

Interventions
All participants underwent a $14 \mathrm{Fr}$ chest drain insertion. When drainage $<200 \mathrm{ml} /$ day and lung fully re- expanded on CXR, participant randomised
Bleomycin group: 60 units bleomycin in $50 \mathrm{ml}$ saline intrapleurally
Doxycycline group: $500 \mathrm{mg}$ doxycycline in $50 \mathrm{ml}$ saline $+10 \mathrm{ml}$ lignocaine
After 18 - 24 hours, if drainage $<200 \mathrm{ml}$, drain removed. If $>200 \mathrm{ml}$, second dose of the same agent giv- en and drain then removed

\begin{tabular}{|c|c|}
\hline \multirow[t]{3}{*}{ Outcomes } & $\begin{array}{l}\text { Radiographic response at } 30 \text { days (classified as: complete response, partial response, progressive dis- } \\
\text { ease, expired with no re-accumulation, expired with re-accumulation, lost to follow up) }\end{array}$ \\
\hline & Mortality \\
\hline & Side effects \\
\hline \multirow[t]{2}{*}{ Notes } & Trapped lung not accounted for \\
\hline & $\begin{array}{l}\text { If participants died prior to day } 30 \text {, included in analysis according to their outcome at the time of their } \\
\text { death }\end{array}$ \\
\hline
\end{tabular}


Patz 1998 (Continued)

For this review, complete response, partial response and expired with no re-accumulation counted as pleurodesis success

Included in network meta-analysis for pleurodesis efficacy, mortality, fever and pain

\section{Risk of bias}

\begin{tabular}{|c|c|c|}
\hline Bias & Authors' judgement & Support for judgement \\
\hline $\begin{array}{l}\text { Random sequence genera- } \\
\text { tion (selection bias) }\end{array}$ & Low risk & Computer-generated randomisation \\
\hline $\begin{array}{l}\text { Allocation concealment } \\
\text { (selection bias) }\end{array}$ & Low risk & Computer-generated randomisation \\
\hline $\begin{array}{l}\text { Blinding of participants } \\
\text { and personnel (perfor- } \\
\text { mance bias) } \\
\text { All outcomes }\end{array}$ & High risk & $\begin{array}{l}\text { "Study investigators and participants not blinded to treatment alloca- } \\
\text { tion" (personal communication with study authors) }\end{array}$ \\
\hline $\begin{array}{l}\text { Blinding of outcome as- } \\
\text { sessment (detection bias) } \\
\text { All outcomes }\end{array}$ & High risk & $\begin{array}{l}\text { "Study investigators and participants not blinded to treatment alloca- } \\
\text { tion" (personal communication with authors) }\end{array}$ \\
\hline $\begin{array}{l}\text { Incomplete outcome data } \\
\text { (attrition bias) } \\
\text { All outcomes }\end{array}$ & High risk & Significant LTFU rate (26/106 (ie $25 \%)$ ) \\
\hline $\begin{array}{l}\text { Selective reporting (re- } \\
\text { porting bias) }\end{array}$ & Low risk & All stated outcomes reported \\
\hline Other bias & Low risk & Radiological outcome on CXR used to define pleurodesis success \\
\hline
\end{tabular}

Rafiei 2014

\begin{tabular}{ll}
\hline Methods & Single centre RCT comparing the pleurodesis success of doxycycline and bleomycin in MPE (Iran) \\
\hline Participants & $\begin{array}{l}\text { Inclusion: symptomatic, cytologically proven MPE } \\
\text { Exclusion: allergy to doxycycline or bleomycin; past history of sclerotherapy; systemic chemotherapy } \\
\text { immediately prior to or in the next two months after sclerotherapy } \\
42 \text { participants randomised }\end{array}$ \\
\hline Interventions & $\begin{array}{l}\text { All participants underwent 'fluid evacuation'. Agent then instilled through the tube, which was } \\
\text { clamped for one hour. Then suction applied and drain removed when < } 100 \text { ml/24 hr drainage }\end{array}$ \\
& Bleomycin group: 45 mg bleomycin intrapleurally \\
& Doxycyclline group: 600 mg doxycycline in 50 ml saline and $10 \mathrm{ml} 1 \%$ lignocaine intrapleurally \\
\hline Cutcomes & CXR appearances of the effusion size at two months (mild, moderate or severe) \\
Need for repeat pleural fluid drainage & Dyspnoea (mild, moderate or severe) \\
Complications
\end{tabular}


Rafiei 2014 (Continued)

Notes
People with trapped lung not excluded

Pleurodesis success primarily defined radiologically, but data presented at three months for need for repeat pleural intervention

For this review, need for repeat pleural drainage was used as measure of pleurodesis success

Included in network meta-analysis for pleurodesis efficacy, fever and pain

\section{Risk of bias}

\begin{tabular}{|c|c|c|}
\hline Bias & Authors' judgement & Support for judgement \\
\hline $\begin{array}{l}\text { Random sequence genera- } \\
\text { tion (selection bias) }\end{array}$ & Unclear risk & Not stated and no response from study authors to clarify \\
\hline $\begin{array}{l}\text { Allocation concealment } \\
\text { (selection bias) }\end{array}$ & Unclear risk & Not stated and no response from study authors to clarify \\
\hline $\begin{array}{l}\text { Blinding of participants } \\
\text { and personnel (perfor- } \\
\text { mance bias) } \\
\text { All outcomes }\end{array}$ & Unclear risk & Not stated if anyone was blinded. No response from study authors \\
\hline $\begin{array}{l}\text { Blinding of outcome as- } \\
\text { sessment (detection bias) } \\
\text { All outcomes }\end{array}$ & Unclear risk & Not stated if anyone was blinded. No response from study authors \\
\hline $\begin{array}{l}\text { Incomplete outcome data } \\
\text { (attrition bias) } \\
\text { All outcomes }\end{array}$ & Low risk & No loss to follow up \\
\hline $\begin{array}{l}\text { Selective reporting (re- } \\
\text { porting bias) }\end{array}$ & Low risk & All stated outcomes reported \\
\hline Other bias & Low risk & No other biases identified \\
\hline
\end{tabular}

\section{Rintoul 2014}

$\begin{array}{ll}\text { Methods } & \begin{array}{l}\text { Open label, multicentre parallel group RCT of VATS pleurectomy and talc pleurodesis (either slurry or } \\ \text { poudrage) in mesothelioma (UK) }\end{array}\end{array}$
poudrage) in mesothelioma (UK)

\section{Participants}

Inclusion: age > 18; confirmed or suspected MPM with pleural effusion; fit enough for VATS pleurectomy

Exclusion: previous pleurodesis; previous primary treatment for MPM; history of previous malignancy and suspected MPM

Those with suspected MPM who were found to have a different cause after randomisation were excluded from analysis

196 participants randomised

Interventions VATS pleurectomy group: thoracoscopic debulking pleurectomy-decortication under GA, according to agreed protocol

Pleurodesis group: $4 \mathrm{~g}$ talc pleurodesis (either slurry or poudrage)

Outcomes Primary outcome: survival at one year post randomisation


Secondary outcomes: presence or absence of effusion on CXR, QOL (EQ5D and QLQ-LC13, QLQ-C30), lung function and exercise tolerance, complications, healthcare utilisation costs

Notes

People with trapped lung included. No data available on whether participants in the pleurodesis arm who had poudrage may have had trapped lung released at the same time

Pleurodesis success defined according to CXR (as assessed by reporting radiologist, unblinded to treatment allocation)

Not included in network meta-analysis

\section{Risk of bias}

\begin{tabular}{|c|c|c|}
\hline Bias & Authors' judgement & Support for judgement \\
\hline $\begin{array}{l}\text { Random sequence genera- } \\
\text { tion (selection bias) }\end{array}$ & Low risk & $\begin{array}{l}\text { Computerised random-number generator in blocks of } 10.1: 1 \text {. stratified by } \\
\text { EORTC score (low or high) }\end{array}$ \\
\hline $\begin{array}{l}\text { Allocation concealment } \\
\text { (selection bias) }\end{array}$ & Low risk & Telephone randomisation line operated by staff independent to the study \\
\hline $\begin{array}{l}\text { Blinding of participants } \\
\text { and personnel (perfor- } \\
\text { mance bias) } \\
\text { All outcomes }\end{array}$ & High risk & Not possible to blind due to nature of the interventions \\
\hline $\begin{array}{l}\text { Blinding of outcome as- } \\
\text { sessment (detection bias) } \\
\text { All outcomes }\end{array}$ & High risk & $\begin{array}{l}\text { Participants and investigators not blinded, leading to potential bias in report- } \\
\text { ing of quality of life, exercise tolerance and complications. CXRs not interpret- } \\
\text { ed blindly (personal communication with authors) }\end{array}$ \\
\hline $\begin{array}{l}\text { Incomplete outcome data } \\
\text { (attrition bias) } \\
\text { All outcomes }\end{array}$ & Low risk & $\begin{array}{l}\text { Participants excluded after randomisation if MPM not confirmed, but this was } \\
\text { stated a-priori. Missing data well balanced between the treatment arms }\end{array}$ \\
\hline $\begin{array}{l}\text { Selective reporting (re- } \\
\text { porting bias) }\end{array}$ & Low risk & Very thorough reporting of all stated outcomes \\
\hline Other bias & Low risk & No other biases identified \\
\hline
\end{tabular}

\section{Ruckdeschel 1991}

\begin{tabular}{ll}
\hline Methods & Multicentre RCT of intrapleural bleomycin and tetracycline in MPE (USA) \\
\hline Participants & Inclusion: exudative MPE (proven on cytology or pleural biopsy); ECOG performance score (PS) 0-2 \\
& $\begin{array}{l}\text { Exclusion: previous intrapleural therapy; prior systemic therapy with bleomycin; severe congestive } \\
\text { heart failure; radiotherapy to the chest in the previous two weeks } \\
115 \text { participants randomised }\end{array}$ \\
\hline Interventions & $\begin{array}{l}\text { All participants had a chest tube placed and had evidence of lung re-expansion on CXR. After the study } \\
\text { drug was inserted the tube was clamed and the participant's position rotated. After several hours the }\end{array}$ \\
Group 1: tetracycline $1 \mathrm{~g}$ intrapleurally in $100 \mathrm{ml}$ saline \\
Group 2: bleomycin 120 units intrapleurally in $100 \mathrm{ml}$ saline (due to slow accrual, this group was \\
dropped after accruing 15 participants)
\end{tabular}


Ruckdeschel 1991 (Continued)

Group 3: bleomycin 60 units intrapleurally in $100 \mathrm{ml}$ saline

$\begin{array}{ll}\text { Outcomes } & \text { Recurrance of effusion at } 30 \text { days and } 90 \text { days (defined according to CXR) } \\ \text { Time to effusion recurrence within } 90 \text { days } \\ \text { Time to maximum change in ECOG PS } \\ \text { Change from initial PS to the best PS (worsened/no change/improved) } \\ \text { Adverse events } \\ \text { People with trapped lung excluded } \\ \text { Group } 2 \text { dropped due to slow accrual and data on the } 15 \text { participants assigned to this group not provid- } \\ \text { ed } \\ \text { Included in network meta-analysis for pleurodesis efficacy, mortality, pain and fever }\end{array}$

\section{Risk of bias}

\begin{tabular}{|c|c|c|}
\hline Bias & Authors' judgement & Support for judgement \\
\hline $\begin{array}{l}\text { Random sequence genera- } \\
\text { tion (selection bias) }\end{array}$ & Low risk & Computer-generated randomisation, with stratification \\
\hline $\begin{array}{l}\text { Allocation concealment } \\
\text { (selection bias) }\end{array}$ & Low risk & Computer randomisation \\
\hline $\begin{array}{l}\text { Blinding of participants } \\
\text { and personnel (perfor- } \\
\text { mance bias) } \\
\text { All outcomes }\end{array}$ & Unclear risk & Not stated if anyone was blinded \\
\hline $\begin{array}{l}\text { Blinding of outcome as- } \\
\text { sessment (detection bias) } \\
\text { All outcomes }\end{array}$ & Unclear risk & Not stated if anyone was blinded \\
\hline $\begin{array}{l}\text { Incomplete outcome data } \\
\text { (attrition bias) } \\
\text { All outcomes }\end{array}$ & High risk & $\begin{array}{l}\text { Lots of patients excluded from analysis ( } 41 / 115 \text { 'non-evaluable'). Reasons giv- } \\
\text { en }\end{array}$ \\
\hline $\begin{array}{l}\text { Selective reporting (re- } \\
\text { porting bias) }\end{array}$ & High risk & Data on 15 patients randomised to high dose bleomycin group not reported \\
\hline Other bias & Low risk & No other biases identified \\
\hline
\end{tabular}

\section{Salomaa 1995}

\begin{tabular}{ll}
\hline Methods & Single centre RCT of pleurodesis with doxycycline and C. parvum in MPE (Finland) \\
\hline Participants & $\begin{array}{l}\text { Inclusion: pleural effusion refractory to repeat aspirations; pleural malignancy - all cell types (histocy- } \\
\text { tologically proven or confirmed malignancy elsewhere) } \\
\text { Exclusion: none } \\
41 \text { participants randomised }\end{array}$ \\
\hline
\end{tabular}


Salomaa 1995 (Continued) Interventions
16 Fr Argyll drain inserted under local anaesthetic and drained with suction until output $<100 \mathrm{ml} /$ day. CXR to confirm lung re-expansion prior to pleurodesis

D100 group: doxycycline 100 mg given intrapleurally. 1 dose

D600 group: doxycycline 600 mg given intrapleurally. 1 dose

C1 group: C. parvum $1 \mathrm{mg}$ intrapleurally. 1 dose

C7 group: C. parvum $7 \mathrm{mg}$ intrapleurally. 1 dose

All drugs diluted in $20 \mathrm{ml}$ saline and a $50 \mathrm{ml}$ flush was administered after the dose. Chest tube removed immediately after sclerosant given
Notes For the purposes of our analysis, we have decided to combine the two doses of each agent to allow comparison between the agents themselves

People with trapped lung excluded from study

Included in network meta-analysis for pleurodesis efficacy, fever and pain

\section{Risk of bias}

\begin{tabular}{|c|c|c|}
\hline Bias & Authors' judgement & Support for judgement \\
\hline $\begin{array}{l}\text { Random sequence genera- } \\
\text { tion (selection bias) }\end{array}$ & Unclear risk & Not stated \\
\hline $\begin{array}{l}\text { Allocation concealment } \\
\text { (selection bias) }\end{array}$ & Unclear risk & Not stated \\
\hline $\begin{array}{l}\text { Blinding of participants } \\
\text { and personnel (perfor- } \\
\text { mance bias) } \\
\text { All outcomes }\end{array}$ & Unclear risk & Not stated if anyone was blinded. Unable to contact study authors \\
\hline $\begin{array}{l}\text { Blinding of outcome as- } \\
\text { sessment (detection bias) } \\
\text { All outcomes }\end{array}$ & Unclear risk & Not stated if anyone was blinded. Unable to contact study authors \\
\hline $\begin{array}{l}\text { Incomplete outcome data } \\
\text { (attrition bias) } \\
\text { All outcomes }\end{array}$ & Low risk & $6 / 41(15 \%)$ patients LTFU \\
\hline $\begin{array}{l}\text { Selective reporting (re- } \\
\text { porting bias) }\end{array}$ & High risk & $\begin{array}{l}\text { Minimal data provided on survival or biochemical markers. Minimal data on } \\
\text { baseline participant characteristics and whether the treatment groups were } \\
\text { well matched }\end{array}$ \\
\hline Other bias & Low risk & Underpowered \\
\hline
\end{tabular}


Sartori 2004

\section{Methods}

Participants

Single centre RCT evaluating intrapleural bleomycin vs interferon alfa- $2 \mathrm{~b}$ in the palliative treatment of malignant effusion (Italy)

Inclusion: cytologically proven MPE requiring at least two thoracenteses in preceding four weeks; at least $3 \mathrm{~L}$ drained in the preceding four weeks; adequate pulmonary re-expansion on CXR after thoracentesis; last systemic treatment administered at least six weeks prior to enrolment; no further chemotherapy options; Karnofsky performance score $>40$

Exclusion: none

160 participants randomised

Interventions $\quad$ All patients underwent a 9 Fr intercostal drain insertion under ultrasound scan (USS) guidance. Fluid was drained via a 3-way-tap until USS revealed no residual effusion. Study drug administered IP via the chest tube. Tube was then clamped for two hours and participants changed position every 15 minutes. Tube removed 24 - 48 hours after the last dose

Bleomycin group: $0.75 \mathrm{mg} / \mathrm{kg}$ bleomycin in $50 \mathrm{ml}$ saline. A repeated dose was given if $>100 \mathrm{ml} /$ day output three days after the first dose

IFN alfa-2b group: 1 million units/10 kg in $200 \mathrm{ml}$ saline. Six doses given every four days

$\begin{array}{ll}\text { Outcomes } & \begin{array}{l}\text { Treatment response at } 30 \text { days (complete response (no fluid re-accumulation), partial response } \\ \text { (asymptomatic fluid recurrence }<50 \% \text { of the original effusion, not requiring thoracentesis), no re- } \\ \text { sponse (fluid recurrence }>50 \% \text { of the original effusion, requiring thoracentesis)) } \\ \text { Time to progression } \\ \text { Number of thoracenteses until death }\end{array} \\ \text { Notes } & \text { Deaths included in the analysis as failures (as presented in the paper as ITT analysis) } \\ \text { Not included in network meta-analysis }\end{array}$

\section{Risk of bias}

\begin{tabular}{|c|c|c|}
\hline Bias & Authors' judgement & Support for judgement \\
\hline $\begin{array}{l}\text { Random sequence genera- } \\
\text { tion (selection bias) }\end{array}$ & Low risk & Computer-generated randomisation \\
\hline $\begin{array}{l}\text { Allocation concealment } \\
\text { (selection bias) }\end{array}$ & Low risk & Computer-generated randomisation \\
\hline $\begin{array}{l}\text { Blinding of participants } \\
\text { and personnel (perfor- } \\
\text { mance bias) } \\
\text { All outcomes }\end{array}$ & High risk & Not stated explicitly but two drugs were given as different volumes \\
\hline $\begin{array}{l}\text { Blinding of outcome as- } \\
\text { sessment (detection bias) } \\
\text { All outcomes }\end{array}$ & High risk & $\begin{array}{l}\text { Synptom recurrence and adverse event reporting may be biased by lack of } \\
\text { blinding. Mortality not biased by lack of blinding. Not stated if CXR interpreta- } \\
\text { tion was blinded }\end{array}$ \\
\hline $\begin{array}{l}\text { Incomplete outcome data } \\
\text { (attrition bias) } \\
\text { All outcomes }\end{array}$ & Low risk & ITT analysis performed \\
\hline
\end{tabular}


Sartori 2004 (Continued)

Selective reporting (re- Low risk $\quad$ All outcomes reported
porting bias)

Other bias Low risk No other biases identified

\section{Schmidt 1997}

\begin{tabular}{|c|c|}
\hline Methods & $\begin{array}{l}\text { Multi-centre RCT comparing pleurodesis using bleomycin with mitoxantrone (Germany). Paper in Ger- } \\
\text { man }\end{array}$ \\
\hline \multirow[t]{3}{*}{ Participants } & $\begin{array}{l}\text { Inclusion: symptomatic, cytologically proven MPE; life expectancy > } 3 \text { months; WHO performance score } \\
0-2\end{array}$ \\
\hline & $\begin{array}{l}\text { Exclusion: prior chemotherapy or pleurodesis in previous four weeks; contraindication to bleomycin } \\
\text { or mitoxantrone; persistent pneumothorax; leucopenia; thrombocytopaenia; incomplete pleural fluid } \\
\text { drainage }\end{array}$ \\
\hline & 102 participants randomised \\
\hline \multirow[t]{4}{*}{ Interventions } & All participants had a $24 \mathrm{Fr}$ chest drain inserted and left in situ for 48 hours \\
\hline & Bleomycin group: single dose of $60 \mathrm{mg}$ bleomycin in $100 \mathrm{ml}$ saline intrapleurally \\
\hline & Mitoxantrone group: single dose of $30 \mathrm{mg}$ mitoxantrone in $100 \mathrm{ml}$ saline intrapleurally \\
\hline & Drains clamped for six hours after instillation and left in place for 24 - 48 hours with or without suction \\
\hline \multirow[t]{4}{*}{ Outcomes } & $\begin{array}{l}\text { Pleurodesis success rate at four weeks (defined by recurrence of effusion requiring repeat pleural pro- } \\
\text { cedure) }\end{array}$ \\
\hline & Toxicity/adverse events \\
\hline & Length of hospital stay \\
\hline & Time to repeat pleural intervention \\
\hline \multirow[t]{3}{*}{ Notes } & Translated from German \\
\hline & People with trapped lung excluded from participation \\
\hline & Included in network meta-analysis for pleurodesis efficacy, mortality, fever and pain \\
\hline
\end{tabular}

\section{Risk of bias}

\begin{tabular}{lll}
\hline Bias & Authors' judgement & Support for judgement \\
\hline $\begin{array}{l}\text { Random sequence genera- } \\
\text { tion (selection bias) }\end{array}$ & Unclear risk & Not stated \\
\hline $\begin{array}{l}\text { Allocation concealment } \\
\text { (selection bias) }\end{array}$ & Low risk & Telephone randomisation \\
\hline $\begin{array}{l}\text { Blinding of participants } \\
\text { and personnel (perfor- } \\
\text { mance bias) }\end{array}$ & Unclear risk & Not stated if anyone was blinded \\
\begin{tabular}{l} 
All outcomes \\
\hline
\end{tabular} & \\
\hline
\end{tabular}


Schmidt 1997 (Continued)

Blinding of outcome as- Unclear risk Not stated if anyone was blinded. If unblinded, symptom recurrence, adverse sessment (detection bias) event reporting and length of stay could have been biased

All outcomes

\begin{tabular}{lll}
$\begin{array}{l}\text { Incomplete outcome data } \\
\text { (attrition bias) } \\
\text { All outcomes }\end{array}$ & Low risk & $\begin{array}{l}\text { Six participants excluded from analysis, but reasons given and balanced num- } \\
\text { bers in the two treatment arms }\end{array}$ \\
\hline $\begin{array}{l}\text { Selective reporting (re- } \\
\text { porting bias) }\end{array}$ & Low risk & All outcomes reported \\
\hline
\end{tabular}

Other bias Low risk No other biases identified

\section{Sorensen 1984}

Methods $\quad$ Single centre RCT comparing talc instillation with pleural drainage only in the treatment of MPE (Den-
mark)

Participants
and resistant to conventional therapy
Exclusion: failure of the underlying lung to totally re-expand within 72 hours of the thoracoscopy
31 participants randomised

All participants underwent thoracoscopy, during which multiple biopsies were taken and a drain insert-
ed. Suction applied until complete lung re-expansion
Drainage alone group: constant suction for 72 hours after complete lung re-expansion. Then, drain re-
moved
Talc and drainage group: $10 \mathrm{~g}$ sterile talc in $250 \mathrm{ml}$ saline instilled through chest tube and clamped for
two hours. Then suction applied for 72 hours and the drain was removed

\begin{tabular}{ll}
\hline Outcomes & Fluid re-accumulation on CXR every month for three months \\
\hline Notes & People with trapped lung excluded from trial entry \\
No data provided on whether treatment arms well matched at baseline \\
Power calculation performed \\
Unclear if adverse events reported for all participants or only those who completed the follow up \\
Pleurodesis defined using radiology only \\
Included in network meta-analysis for pleurodesis efficacy
\end{tabular}

\section{Risk of bias}

\begin{tabular}{lll}
\hline Bias & Authors' judgement & Support for judgement \\
\hline $\begin{array}{l}\text { Random sequence genera- } \\
\text { tion (selection bias) }\end{array}$ & Unclear risk & Not stated \\
\hline $\begin{array}{l}\text { Allocation concealment } \\
\text { (selection bias) }\end{array}$ & Low risk & "Closed envelope system" \\
\hline
\end{tabular}




\section{Sorensen 1984 (Continued)}

Blinding of participants and personnel (perfor-

High risk mance bias)

All outcomes
Unable to blind due to nature of the interventions (pleural drainage alone, or with talc administration)

\section{Blinding of outcome as- Unclear risk sessment (detection bias) \\ All outcomes \\ Adverse event reporting could be biased by lack of blinding. Not stated if CXR interpretation was blinded}

\section{Incomplete outcome data High risk} (attrition bias)

All outcomes
$10 / 31(32 \%)$ excluded from primary analysis (but well balanced between the two treatment arms)

\begin{tabular}{|c|c|c|}
\hline $\begin{array}{l}\text { Selective reporting (re- } \\
\text { porting bias) }\end{array}$ & Low risk & $\begin{array}{l}\text { No comment on mortality or survival, but an old study and not stated as an } \\
\text { outcome measure in the paper }\end{array}$ \\
\hline
\end{tabular}

Other bias Low risk No other biases identified

Terra 2009

\begin{tabular}{ll}
\hline Methods & Single centre RCT evaluating VATS talc poudrage and talc slurry in malignant pleural effusion (Brazil) \\
\hline Participants & $\begin{array}{l}\text { Inclusion: biopsy or cytology proven MPE (all cell types); recurrent and symptomatic effusion; chest ra- } \\
\text { diograph confirming lung expansion of }>90 \% \text { after thoracentesis; Karnofsky PS } \geq 70\end{array}$ \\
& $\begin{array}{l}\text { Exclusion: comorbidities that preclude GA; bleeding disorders; massive thoracic skin infiltration; active } \\
\text { infection; refusal to sign informed consent } \\
60 \text { participants randomised }\end{array}$
\end{tabular}

Interventions

One dose of $5 \mathrm{~g}$ non-calibrated talc given intrapleurally to both trial groups. Post procedure care and analgesia the same for the two groups. No suction used in either group. Drain removed when $<200$ $\mathrm{ml} / 24 \mathrm{hr}$ drainage, or after 10 days if drain volume too high, participants were discharged with the drain in situ and a Heimlich valve

VATS group: VATS performed under general anaesthesia, followed by talc poudrage. $28 \mathrm{Fr}$ chest drain inserted at end of procedure

Talc slurry group: $28 \mathrm{Fr}$ chest drain inserted under local anaesthetic. Following day, talc suspended in $60 \mathrm{ml}$ saline with $5 \mathrm{ml} \%$ lignocaine and instilled through chest drain. Clamped for one hour post procedure

\section{Outcomes}

Lung expansion on CT measured on a 3-point scale at baseline, 1, 3 and 6 months

Clinical efficacy (success defined as no need for a new pleural procedure due to symptoms and radiological effusion recurrence)

Quality of Life

Safety

Survival

Chest drain duration

Length of hospital stay

Perioperative complications 
Terra 2009 (Continued)

Notes
Raw data for survival, pleurodesis rates at certain time points, intervention rates at certain time points and QOL data not presented

People with trapped lung excluded from trial entry

Pleurodesis success rate defined using symptoms and radiology

Study authors contacted for further information, but no reply

Included in network meta-analysis for pleurodesis efficacy and fever

\section{Risk of bias}

\begin{tabular}{|c|c|c|}
\hline Bias & Authors' judgement & Support for judgement \\
\hline $\begin{array}{l}\text { Random sequence genera- } \\
\text { tion (selection bias) }\end{array}$ & Unclear risk & Not stated \\
\hline $\begin{array}{l}\text { Allocation concealment } \\
\text { (selection bias) }\end{array}$ & Unclear risk & Not stated \\
\hline $\begin{array}{l}\text { Blinding of participants } \\
\text { and personnel (perfor- } \\
\text { mance bias) } \\
\text { All outcomes }\end{array}$ & High risk & Unable to blind due to nature of the interventions (talc poudrage vs talc slurry) \\
\hline $\begin{array}{l}\text { Blinding of outcome as- } \\
\text { sessment (detection bias) } \\
\text { All outcomes }\end{array}$ & High risk & $\begin{array}{l}\text { Symptom recurrence, quality of life, inpatient stay and adverse event report- } \\
\text { ing could be biased by lack of blinding. Interpretation of CTs was done by two } \\
\text { blinded observers, however pleurodesis efficacy was defined by need for re- } \\
\text { peat intervention }\end{array}$ \\
\hline $\begin{array}{l}\text { Incomplete outcome data } \\
\text { (attrition bias) } \\
\text { All outcomes }\end{array}$ & Low risk & No loss to follow up \\
\hline $\begin{array}{l}\text { Selective reporting (re- } \\
\text { porting bias) }\end{array}$ & Low risk & All outcomes reported \\
\hline Other bias & Low risk & No other biases identified \\
\hline
\end{tabular}

Terra 2015

\begin{tabular}{ll} 
Methods & $\begin{array}{l}\text { Single centre RCT evaluating three different doses of silver nitrate for pleurodesis in malignant pleural } \\
\text { effusion (Brazil) }\end{array}$ \\
\hline Participants & $\begin{array}{l}\text { Inclusion criteria: recurrent and symptomatic MPE (with pleural histological or cytological confirma- } \\
\text { tion); previous CXR showing full lung expansion }(>90 \%) \text { after chest drainage; Karnofsky performance } \\
\text { score }>40 ; \text { written consent }\end{array}$ \\
& $\begin{array}{l}\text { Exclusion criteria: trapped lung after pleural catheter insertion; haemorrhagic diathesis (PT }<50 \% \text { or } \\
\text { platelets }<80,000) ; \text { active pleural or systemic infection; neoplastic infiltration of the skin at the site of } \\
\text { pleural catheter insertion; inability to understand QoL questionnaires; contralateral pleurodesis }<30 \\
\text { days before study entry }\end{array}$ \\
& 60 participants randomised
\end{tabular}


Terra 2015 (Continued)

Interventions

All participants were admitted for five days and had baseline assessment. All had a 14 Fr chest drain inserted under USS guidance prior to randomisation. The randomised interventions were given via the chest tube, which was then clamped for one hour. Drain removed on day 5.

The silver nitrate was dissolved in $100 \mathrm{ml}$ distilled water, which was passed through a 0.22 micrometer filter to ensure sterility within six hours of instillation

Group 1: $30 \mathrm{ml}$ of $0.3 \%$ silver nitrate $(90 \mathrm{mg})$ given as a single dose intrapleurally

Group 2: $30 \mathrm{ml}$ of $0.5 \%$ silver nitrate $(150 \mathrm{mg}$ ) given as a single dose intrapleurally

Group 3: $60 \mathrm{ml}$ of $0.3 \%$ silver nitrate $(180 \mathrm{mg}$ ) given as a single dose intrapleurally

\section{Outcomes}

Primary outcome: occurrence of serious or severe adverse event during follow up

Secondary outcomes: systemic inflammation (measured using CRP); chest pain (measured using VAS score); effusion recurrence (defined as need for additional pleural procedures during trial follow up); residual pleural cavity volume (calculated using difference between day 5 and day 30 on CT)

\begin{tabular}{|c|c|}
\hline \multirow[t]{2}{*}{ Notes } & People with trapped lung excluded from study entry \\
\hline & Pleurodesis failure defined as need for additional pleural procedure during follow up \\
\hline
\end{tabular}

\section{Risk of bias}

\begin{tabular}{|c|c|c|}
\hline Bias & Authors' judgement & Support for judgement \\
\hline $\begin{array}{l}\text { Random sequence genera- } \\
\text { tion (selection bias) }\end{array}$ & Low risk & Block randomisation \\
\hline $\begin{array}{l}\text { Allocation concealment } \\
\text { (selection bias) }\end{array}$ & Unclear risk & Not stated \\
\hline $\begin{array}{l}\text { Blinding of participants } \\
\text { and personnel (perfor- } \\
\text { mance bias) } \\
\text { All outcomes }\end{array}$ & Low risk & $\begin{array}{l}\text { Pharmacy employees and clinicians who instilled the sclerosant were aware of } \\
\text { treatment allocation, but these clinicians were not involved in patient follow } \\
\text { up. Participants, investigators that followed participants up and rated their } \\
\text { complications were blinded to group allocation }\end{array}$ \\
\hline
\end{tabular}

\begin{tabular}{lll}
\hline Blinding of outcome as- & Low risk & Pharmacy employees and clinicians who instilled the sclerosant were aware of \\
sessment (detection bias) & treatment allocation, but these clinicians were not involved in patient follow \\
All outcomes & $\begin{array}{l}\text { up. Participants, investigators that followed participants up and rated their } \\
\text { complications were blinded to group allocation }\end{array}$
\end{tabular}

Incomplete outcome data Low risk LTFU well balanced and justified
(attrition bias)

(attrition bias)

All outcomes

\begin{tabular}{lll}
\hline $\begin{array}{l}\text { Selective reporting (re- } \\
\text { porting bias) }\end{array}$ & Low risk & $\begin{array}{l}\text { No data provided for MRC dyspnoea score. Otherwise all predefined outcome } \\
\text { measures reported }\end{array}$ \\
\hline Other bias & Low risk & No other biases identified \\
\hline
\end{tabular}




\section{Methods}

Single centre RCT comparing intrapleural talc and mepacrine given via a chest tube after thoracoscopy (Sweden)

\section{Participants} Inclusion criteria: recurrant, symptomatic pleural effusions, known or suspected to be due to malignancy; eligible for thoracoscopy and pleurodesis

Exclusion criteria: incomplete lung re-expansion after thoracoscopy

89 participants with confirmed malignant pleural effusions were randomised (110 participants randomised in total, but some had benign causes)

Interventions
ed participants underwent a local anaesthetic thoracoscopy, with biopsies and a $20 \mathrm{Fr}$ drain was insert-
domisation
Mepacrine group: $500 \mathrm{mg}$ mepacrine in $200 \mathrm{ml}$ saline intrapleurally
Talc group: $5 \mathrm{~g}$ talc in $200 \mathrm{ml}$ saline intrapleurally
In both groups, a second dose was given if $>50 \mathrm{ml} /$ day drainage on day 3 . Drains removed when $<50$
$\mathrm{ml} / 24$ hour drainage

\section{Outcomes}

Primary: pleurodesis success (using clinical and radiological definition). Reported at day 6, 2 weeks, 2 months, 4 months and 6 months

Secondary: analgesia use; side effects; mortality

\begin{tabular}{ll}
\hline Notes & People with trapped lung excluded. Note that two doses may have been given \\
Included in network meta-analysis for pleurodesis efficacy and mortality
\end{tabular}

\section{Risk of bias}

\begin{tabular}{|c|c|c|}
\hline Bias & Authors' judgement & Support for judgement \\
\hline $\begin{array}{l}\text { Random sequence genera- } \\
\text { tion (selection bias) }\end{array}$ & Low risk & Computer-generated randomisation \\
\hline $\begin{array}{l}\text { Allocation concealment } \\
\text { (selection bias) }\end{array}$ & Low risk & Opaque sealed envelopes \\
\hline $\begin{array}{l}\text { Blinding of participants } \\
\text { and personnel (perfor- } \\
\text { mance bias) } \\
\text { All outcomes }\end{array}$ & High risk & Unable to blind as drugs different appearances \\
\hline $\begin{array}{l}\text { Blinding of outcome as- } \\
\text { sessment (detection bias) } \\
\text { All outcomes }\end{array}$ & Low risk & $\begin{array}{l}\text { Radiologists reporting CXRs were blind to treatment allocation. Symptom re- } \\
\text { currence and adverse event reporting may be biased by lack of blinding }\end{array}$ \\
\hline $\begin{array}{l}\text { Incomplete outcome data } \\
\text { (attrition bias) } \\
\text { All outcomes }\end{array}$ & Low risk & $\begin{array}{l}\text { Reasons for loss to follow up and exclusions reported and well matched be- } \\
\text { tween the groups }\end{array}$ \\
\hline $\begin{array}{l}\text { Selective reporting (re- } \\
\text { porting bias) }\end{array}$ & Low risk & Data for those with proven MPE obtained from authors \\
\hline Other bias & Low risk & No other biases identified \\
\hline
\end{tabular}


Villanueva 1994

\begin{tabular}{|c|c|}
\hline Methods & Single Centre RCT of short-term vs long-term drainage before tetracycline pleurodesis of MPE (USA) \\
\hline \multirow[t]{3}{*}{ Participants } & $\begin{array}{l}\text { Inclusion: moderate to large MPE, proved by cytology or pleural biopsy, causing respiratory symptoms; } \\
\text { expected survival of }>1 \text { month; KPS }>40 \%\end{array}$ \\
\hline & $\begin{array}{l}\text { Exclusion: previous chemical pleurodesis on the ipsilateral side; ipsilateral atelectasis due to complete } \\
\text { airway obstruction by tumour }\end{array}$ \\
\hline & 25 participants randomised \\
\hline \multirow[t]{3}{*}{ Interventions } & 28 Fr chest drain inserted. Tetracycline $1.5 \mathrm{~g}$ in $100-150 \mathrm{ml}$ pleurodesis \\
\hline & $\begin{array}{l}\text { Standard Care (long-term drainage): tube suction drainage until lung re-expansion and }<150 \mathrm{ml} / \text { day } \\
\text { drainage, then tetracycline pleurodesis and drain removed the following day }\end{array}$ \\
\hline & $\begin{array}{l}\text { Short-term drainage: tube suction drainage until lung re-expansion, then tetracycline pleurodesis and } \\
\text { drain removed the following day. }\end{array}$ \\
\hline \multirow[t]{3}{*}{ Outcomes } & Pleurodesis success at one month (defined using CXR and need for repeat procedure) \\
\hline & Duration of tube drainage \\
\hline & Patient outcome (dead/alive - ? time point) \\
\hline \multirow[t]{2}{*}{ Notes } & Lung re-expansion confirmed on CXR prior to instillation of tetracycline \\
\hline & Not included in network meta-analysis \\
\hline
\end{tabular}

\section{Risk of bias}

\begin{tabular}{|c|c|c|}
\hline Bias & Authors' judgement & Support for judgement \\
\hline $\begin{array}{l}\text { Random sequence genera- } \\
\text { tion (selection bias) }\end{array}$ & Low risk & Computer randomisation \\
\hline $\begin{array}{l}\text { Allocation concealment } \\
\text { (selection bias) }\end{array}$ & Low risk & Computer randomisation \\
\hline $\begin{array}{l}\text { Blinding of participants } \\
\text { and personnel (perfor- } \\
\text { mance bias) } \\
\text { All outcomes }\end{array}$ & High risk & Unable to blind as different timings of interventions \\
\hline $\begin{array}{l}\text { Blinding of outcome as- } \\
\text { sessment (detection bias) } \\
\text { All outcomes }\end{array}$ & High risk & $\begin{array}{l}\text { Symptom recurrence could be biased by lack of blinding. Not stated if radiolo- } \\
\text { gy was reported blindly }\end{array}$ \\
\hline $\begin{array}{l}\text { Incomplete outcome data } \\
\text { (attrition bias) } \\
\text { All outcomes }\end{array}$ & Low risk & $1 / 25$ patients LTFU \\
\hline $\begin{array}{l}\text { Selective reporting (re- } \\
\text { porting bias) }\end{array}$ & Low risk & All stated outcomes reported; minimal information on safety/complications \\
\hline Other bias & Low risk & None \\
\hline
\end{tabular}


Yildirim 2005

\begin{tabular}{ll}
\hline Methods & Single centre RCT of rapid vs standard pleurodesis with oxytetracycline (Turkey) \\
\hline Participants & $\begin{array}{l}\text { Symptomatic MPE, confirmed on cytology or pleural biopsy } \\
27 \text { participants randomised }\end{array}$ \\
\hline Interventions & $\begin{array}{l}12 \text { Fr drain inserted. Pleurodesis agent: oxytetracycline } 35 \mathrm{mg} / \mathrm{kg} \\
\text { Standard protocol: drainage until lung re-expansion \& fluid drainage }<150 \mathrm{ml} / \text { day. Then pleurodesis as } \\
\text { a single dose. Drain clamped for six hours and removed when }<150 \mathrm{ml} / \text { day drainage }\end{array}$ \\
& Rapid protocol: pleurodesis given as 4 divided doses, every six hours after aspiration through the drain \\
\hline Outcomes & $\begin{array}{l}\text { Response to pleurodesis (CR/PR/Failure) as defined by radiological recurrence and need for thoracen- } \\
\text { tesis }\end{array}$ \\
\hline Notes & People with trapped lung not excluded \\
& Not included in network meta-analysis
\end{tabular}

\section{Risk of bias}

\begin{tabular}{|c|c|c|}
\hline Bias & Authors' judgement & Support for judgement \\
\hline $\begin{array}{l}\text { Random sequence genera- } \\
\text { tion (selection bias) }\end{array}$ & Low risk & Random number table \\
\hline $\begin{array}{l}\text { Allocation concealment } \\
\text { (selection bias) }\end{array}$ & Low risk & Random number table \\
\hline $\begin{array}{l}\text { Blinding of participants } \\
\text { and personnel (perfor- } \\
\text { mance bias) } \\
\text { All outcomes }\end{array}$ & High risk & Unable to blind as different durations of drainage and aspiration schedules \\
\hline $\begin{array}{l}\text { Blinding of outcome as- } \\
\text { sessment (detection bias) } \\
\text { All outcomes }\end{array}$ & High risk & $\begin{array}{l}\text { Symptom recurrence and duration of hospital stay may be biased by lack of } \\
\text { blinding. Mortality not biased by lack of blinding }\end{array}$ \\
\hline $\begin{array}{l}\text { Incomplete outcome data } \\
\text { (attrition bias) } \\
\text { All outcomes }\end{array}$ & Low risk & $\begin{array}{l}\text { Missing data well balanced between the groups. At one month } 2 / 27 \text { had died } \\
\text { and were therefore non-evaluable }\end{array}$ \\
\hline $\begin{array}{l}\text { Selective reporting (re- } \\
\text { porting bias) }\end{array}$ & Low risk & All stated outcomes reported \\
\hline Other bias & Low risk & No other biases identified \\
\hline
\end{tabular}

Yim 1996

\begin{tabular}{ll}
\hline Methods & Single centre RCT of talc insufflation versus talc slurry for symptomatic MPE (Hong Kong) \\
\hline Participants & $\begin{array}{l}\text { Inclusion: established, symptomatic MPE (all cell types); dyspnoea improved after tube thoracostomy } \\
\text { or large volume thoracentesis }\end{array}$
\end{tabular}


Yim 1996 (Continued)

Exclusion: Karnofsky score < 30\%; FEV1 < 0.5 L; trapped lung; chemotherapy or radiotherapy within six months

57 participants randomised

Interventions

Talc insufflation group: all participants underwent a GA with one lung ventilation in the lateral decubitus position. $10 \mathrm{~mm}$ port inserted. Adehsions and loculations broken down. $5 \mathrm{~g}$ talc insufflated into the chest. $28 \mathrm{Fr}$ tube at end of procedure, connected to suction. Drain removed when $<50 \mathrm{ml} / 24$ hours drainage

Talc slurry group: chest tube. $5 \mathrm{~g}$ talc in $50 \mathrm{ml}$ saline and $10 \mathrm{ml} 2 \%$ lidocaine instilled through the drain. Drain clamped for two hours and participant turned Drain reconnected to suction and removed when output $<50 \mathrm{ml} / 24$ hours

\begin{tabular}{ll}
\hline Outcomes & Radiological recurrence of effusion \\
Complications of the procedure & Post-procedure chest drain duration \\
Length of hospital stay \\
Parenteral meperidine use
\end{tabular}

Notes $\quad$ People with trapped lung excluded from trial entry

Included in network meta-analysis for pleurodesis efficacy and mortality

\section{Risk of bias}

\begin{tabular}{|c|c|c|}
\hline Bias & Authors' judgement & Support for judgement \\
\hline $\begin{array}{l}\text { Random sequence genera- } \\
\text { tion (selection bias) }\end{array}$ & Unclear risk & Not stated \\
\hline $\begin{array}{l}\text { Allocation concealment } \\
\text { (selection bias) }\end{array}$ & Unclear risk & Not stated \\
\hline $\begin{array}{l}\text { Blinding of participants } \\
\text { and personnel (perfor- } \\
\text { mance bias) } \\
\text { All outcomes }\end{array}$ & High risk & Unable to blind due to nature of the interventions \\
\hline $\begin{array}{l}\text { Blinding of outcome as- } \\
\text { sessment (detection bias) } \\
\text { All outcomes }\end{array}$ & High risk & $\begin{array}{l}\text { Adverse event reporting and length of stay may be biased by lack of blinding. } \\
\text { Not stated whether radiology was reported blindly }\end{array}$ \\
\hline $\begin{array}{l}\text { Incomplete outcome data } \\
\text { (attrition bias) } \\
\text { All outcomes }\end{array}$ & Low risk & All data reported. Survial data not entirely clear \\
\hline $\begin{array}{l}\text { Selective reporting (re- } \\
\text { porting bias) }\end{array}$ & Low risk & All outcomes reported on \\
\hline Other bias & Low risk & $\begin{array}{l}\text { Unclear how many patients in the poudrage arm had a drain in situ at the time } \\
\text { of trial entry. Pleurodesis success only defined using radiology }\end{array}$ \\
\hline
\end{tabular}


Yoshida 2007

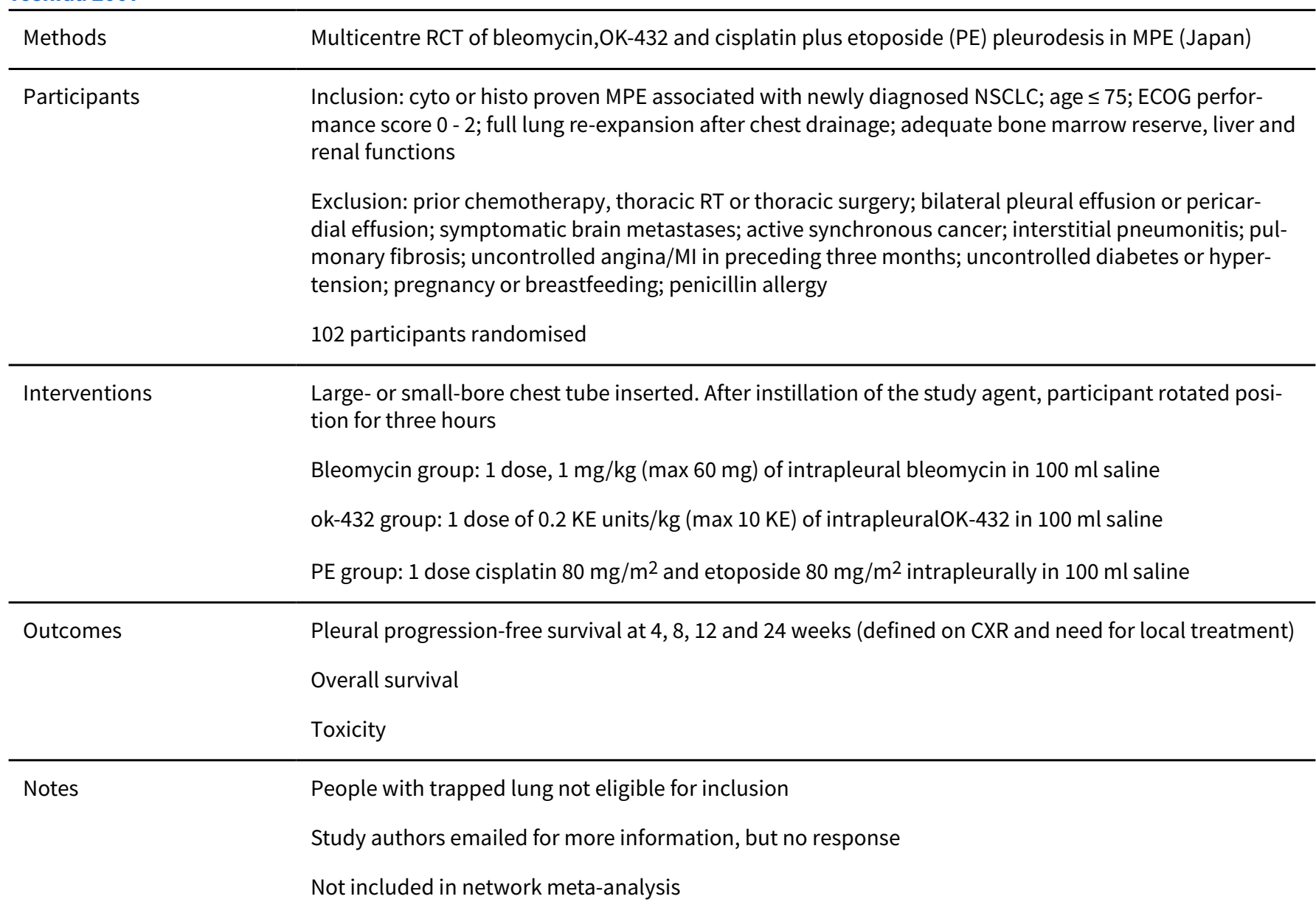

\section{Risk of bias}

\begin{tabular}{|c|c|c|}
\hline Bias & Authors' judgement & Support for judgement \\
\hline $\begin{array}{l}\text { Random sequence genera- } \\
\text { tion (selection bias) }\end{array}$ & Unclear risk & Not stated \\
\hline $\begin{array}{l}\text { Allocation concealment } \\
\text { (selection bias) }\end{array}$ & Unclear risk & Not stated \\
\hline $\begin{array}{l}\text { Blinding of participants } \\
\text { and personnel (perfor- } \\
\text { mance bias) } \\
\text { All outcomes }\end{array}$ & Unclear risk & Not stated if anyone was blinded. Same volume of instillate in both arms \\
\hline $\begin{array}{l}\text { Blinding of outcome as- } \\
\text { sessment (detection bias) } \\
\text { All outcomes }\end{array}$ & Unclear risk & $\begin{array}{l}\text { Not stated if anyone was blinded. If unblinded, reporting of symptom recur- } \\
\text { rence and toxicity could have been biased. Not stated if radiology was report- } \\
\text { ed blindly but the definition of pleurodesis also incorporated symptom recur- } \\
\text { rence }\end{array}$ \\
\hline $\begin{array}{l}\text { Incomplete outcome data } \\
\text { (attrition bias) } \\
\text { All outcomes }\end{array}$ & Low risk & No loss to follow up \\
\hline $\begin{array}{l}\text { Selective reporting (re- } \\
\text { porting bias) }\end{array}$ & Low risk & All stated outcomes reported \\
\hline
\end{tabular}


Yoshida 2007 (Continued)

Other bias Low risk Radiology may be difficult to assess as population has underlying lung cancer

Zaloznik 1983

Methods RCT of tetracycline pleurodesis versus placebo of the same $\mathrm{pH}$ as tetracycline (USA)

Participants

Inclusion: biopsy proven malignancy; recurrent pleural effusion; expected survival > 1 month; Karnof-

sky performance score $\geq 40 \%$

30 participants randomised

Interventions

Chest tube inserted and in place for at least 24 hours. After pleurodesis agent instilled, tube clamped for two hours and participant's position changed. Then left in place for 12 - 24 hours until minimal drainage

Tetracycline group: $500 \mathrm{mg}$ tetracycline in $50 \mathrm{ml}$ saline intrapleurally. 1 dose

Control group: $0.6 \mathrm{ml}$ multivitamins, $5 \mathrm{ml}$ of $0.1 \mathrm{~N} \mathrm{HCl}$ and $50 \mathrm{ml}$ saline intrapleurally. 1 dose

\begin{tabular}{ll}
\hline Outcomes & Reaccumulation of effusion on CXR at 1 month and 3 months (CR/PR/Stabilisation/progression) \\
& Side effects
\end{tabular}

Notes PR \& stable disease counted as pleurodesis success for purposes of analysis
Some participants with bilateral effusions entered into the study, but not clear whether both sides were
randomised. Therefore for purposes of analysis, only the first side has been included
Included in network meta-analysis for pleurodesis efficacy

\section{Risk of bias}

\begin{tabular}{|c|c|c|}
\hline Bias & Authors' judgement & Support for judgement \\
\hline $\begin{array}{l}\text { Random sequence genera- } \\
\text { tion (selection bias) }\end{array}$ & Unclear risk & Not stated \\
\hline $\begin{array}{l}\text { Allocation concealment } \\
\text { (selection bias) }\end{array}$ & Unclear risk & Not stated \\
\hline $\begin{array}{l}\text { Blinding of participants } \\
\text { and personnel (perfor- } \\
\text { mance bias) } \\
\text { All outcomes }\end{array}$ & Low risk & "Double-Blind" (no further details given) \\
\hline $\begin{array}{l}\text { Blinding of outcome as- } \\
\text { sessment (detection bias) } \\
\text { All outcomes }\end{array}$ & Low risk & "Double-Blind" (no further details given) \\
\hline $\begin{array}{l}\text { Incomplete outcome data } \\
\text { (attrition bias) } \\
\text { All outcomes }\end{array}$ & High risk & $\begin{array}{l}\text { Time point at which primary outcome measured not clear. Minimal data on } \\
\text { baseline participant characteristics. Participants who died within one month } \\
\text { excluded from analysis ( } 11 / 30 \text { not evaluable) }\end{array}$ \\
\hline $\begin{array}{l}\text { Selective reporting (re- } \\
\text { porting bias) }\end{array}$ & Low risk & All outcomes reported on \\
\hline Other bias & Low risk & No other biases identified \\
\hline
\end{tabular}


Zhao 2009

Methods Single centre RCT of intrapleural Ad-p53 and cisplatin, compared with cisplatin alone in MPE due to
lung cancer (China)

Participants Inclusion: MPE due to lung cancer confirmed by CT, thoracic ultrasound and cytohistological examina-
tion; expected survival of $>3$ months; Karnofsky PS $>60$

Exclusion: abnormal ECT, liver function, kidney function and routine blood examination; previous chemotherapy, radiotherapy or biological therapy

35 participants randomised

Interventions

All participants had chest drain inserted and effusion drained completely. All received systemic vinorelbine. All received $10 \mathrm{mg}$ intrapleural (IP) dexamethasone after instillation of trial drugs. Drug administration was repeated weekly for four weeks or until pleural effusion resolved

Combination group: Ad-p53 (1 x 1012VP) in $100 \mathrm{ml}$ saline IP. Then cisplatin $40 \mathrm{mg} / \mathrm{m}^{2}$ in $100 \mathrm{ml}$ saline IP Single agent group: cisplatin $40 \mathrm{mg} / \mathrm{m}^{2}$ in $100 \mathrm{ml}$ saline IP

\begin{tabular}{|c|c|}
\hline \multirow[t]{3}{*}{ Outcomes } & $\begin{array}{l}\text { Therapeutic efficacy (CR/PR/SD/PD) - as defined by extent of effusion and radiology and symptoms, at } \\
\text { four weeks }\end{array}$ \\
\hline & Change in Karnofsky performance status from baseline to four weeks \\
\hline & Adverse events \\
\hline \multirow[t]{4}{*}{ Notes } & People with trapped lung not excluded from the study \\
\hline & CR and PR counted as a successful pleurodesis for the purposes of analysis \\
\hline & Study authors emailed for further information, but no response \\
\hline & Not included in network meta-analysis \\
\hline
\end{tabular}

\section{Risk of bias}

\begin{tabular}{lll}
\hline Bias & Authors' judgement & Support for judgement \\
\hline $\begin{array}{l}\text { Random sequence genera- } \\
\text { tion (selection bias) }\end{array}$ & Unclear risk & Not stated \\
\hline $\begin{array}{l}\text { Allocation concealment } \\
\text { (selection bias) }\end{array}$ & Unclear risk & Not stated \\
\hline $\begin{array}{l}\text { Blinding of participants } \\
\text { and personnel (perfor- } \\
\text { mance bias) }\end{array}$ & High risk & Not stated explicitly but combination group received two intrapleural treat- \\
All outcomes & ments, while other arm only received one \\
\hline $\begin{array}{l}\text { Blinding of outcome as- } \\
\text { sessment (detection bias) } \\
\text { All outcomes }\end{array}$ & High risk & $\begin{array}{l}\text { Symptoms, quality of life and adverse events could be biased by lack of blind- } \\
\text { ing. Not stated if radiology was reported blindly }\end{array}$ \\
\hline $\begin{array}{l}\text { Incomplete outcome data } \\
\text { (attrition bias) } \\
\text { All outcomes }\end{array}$ & Low risk & No loss to follow up \\
\hline
\end{tabular}


Zhao 2009 (Continued)

Selective reporting (re- Low risk All outcomes reported on
porting bias)

Other bias Low risk No other biases identified

\section{Zimmer 1997}

\begin{tabular}{ll}
\hline Methods & Prospective RCT of talc vs bleomycin pleurodesis for symptomatic MPE (USA) \\
\hline Participants & Inclusion: MPE (all cell types); life expectancy > 1 month \\
& Exclusions: significant loculated effusions; trapped lung \\
& 40 procedures randomised in 35 participants \\
\hline
\end{tabular}

\begin{tabular}{ll} 
Interventions & All participants underwent tube thoracostomy (either at the end of a limited thoracotomy (two partici- \\
pants) or inserted at bedside ( 33 participants)). Tube remained on suction. After sclerosant injected in- \\
trapleurally, tube clamped for two hours and participant rotated \\
Talc group: $5 \mathrm{~g}$ talc in $50 \mathrm{ml}$ saline, with $20 \mathrm{ml} 1 \%$ lignocaine. 1 dose \\
Bleomycin group: $60 \mathrm{U}$ bleomycin in $50 \mathrm{ml}$ saline, with $20 \mathrm{ml} 1 \%$ lignocaine. 1 dose \\
\hline Outcomes & Dysfusion control on CXR (at a minimum of two weeks) \\
& Pain (according to scale 0 - 10) \\
Cost & Length of hospital stay \\
People with trapped lung excluded \\
Participants only included in primary analysis if out of hospital and able to attend follow up at two \\
weeks \\
Study authors emailed for more information, but no response \\
Included in network meta-analysis for pleurodesis efficacy \\
Notes
\end{tabular}

\section{Risk of bias}

\begin{tabular}{lll}
\hline Bias & Authors' judgement & Support for judgement \\
\hline $\begin{array}{l}\text { Random sequence genera- } \\
\text { tion (selection bias) }\end{array}$ & Unclear risk & Not stated \\
\hline $\begin{array}{l}\text { Allocation concealment } \\
\text { (selection bias) }\end{array}$ & Unclear risk & Not stated \\
\hline $\begin{array}{l}\text { Blinding of participants } \\
\text { and personnel (perfor- } \\
\text { mance bias) }\end{array}$ & High risk & Not explicitly stated but drugs had different appearances \\
All outcomes & \\
\hline
\end{tabular}


Zimmer 1997 (Continued)
Blinding of outcome as-
High risk
Symptom recurrence, pain, breathlessness, duration of stay and adverse sessment (detection bias) events could all be biased by lack of blinding. Not stated radiology reported All outcomes blindly

\begin{tabular}{lll}
\hline $\begin{array}{l}\text { Incomplete outcome data } \\
\text { (attrition bias) } \\
\text { All outcomes }\end{array}$ & High risk & $\begin{array}{l}\text { No clear time point when follow up performed. Only those available for follow } \\
\text { up included in the analysis. Unclear how many randomised to each arm (only } \\
\text { data on numbers analysed by treatment arm) }\end{array}$ \\
\hline $\begin{array}{l}\text { Selective reporting (re- } \\
\text { porting bias) }\end{array}$ & Low risk & All outcomes reported on \\
\hline Other bias & Low risk & No other biases identified
\end{tabular}

ECOG: electrocochleography

IV: intravenous

LTFU: loss to follow up

QOL: quality of life

$\mathrm{RCT}$ : randomised controlled trial

\section{Characteristics of excluded studies [ordered by study ID]}

\begin{tabular}{ll}
\hline Study & Reason for exclusion \\
\hline Caglayan 2008 & Study not truly randomised. Participants allocated to treatment groups using alternation. \\
\hline Dryzer 1993 & $\begin{array}{l}\text { Unable to differentiate between participants with benign and malignant disease in the results sec- } \\
\text { tion. Also high risk of bias from randomisation method (allocated to treatment groups based on the } \\
\text { last digit of their hospital number). }\end{array}$ \\
\hline Elayouty 2012 & $\begin{array}{l}\text { Unclear from text if truly randomised - participants given number on entering study - allocated to } \\
\text { bleomycin if number was odd and allocated to povidone group if number was even. Study authors } \\
\text { emailed for clarification but no response. }\end{array}$
\end{tabular}

Engel 1981

Study not truly randomised. Participants allocated to treatment groups based on the day of the calendar month.

\section{Gust 1990}

Pilot data (not randomised) and randomised data presented grouped together. Unable to split out the pilot group.

\section{Kwasniewska-Rokicinska 1979 Participants with pleural effusions and ascites included, but unable to differentiate between them in the results section.}

\begin{tabular}{ll}
\hline Lissoni 1995 & $\begin{array}{l}\text { Unable to differentiate between pleural, pericardial and peritoneal effusions in the results. No re- } \\
\text { sponse from study authors. }\end{array}$
\end{tabular}

\begin{tabular}{ll}
\hline Maiche 1993 & $\begin{array}{l}\text { Study not truly randomised. Participants allocated to bleomycin group if met a list of criteria, oth- } \\
\text { erwise given mitoxantrone. }\end{array}$ \\
\hline Manes 2000 & $\begin{array}{l}\text { Study not truly randomised. Participants allocated to treatment groups based on the month of } \\
\text { their diagnosis with MPE. }\end{array}$ \\
\hline Nio 1999 & $\begin{array}{l}\text { Participants with pleural and peritoneal effusions included in the study and unable to differentiate } \\
\text { them in the results. }\end{array}$ \\
\hline Tattersall 1982 & $\begin{array}{l}\text { Insufficient information in paper to extract required data (e.g. unclear how pleurodesis success was } \\
\text { defined and at what time point). }\end{array}$
\end{tabular}


Characteristics of studies awaiting assessment [ordered by study ID]

\section{Bo 1998}

\begin{tabular}{ll}
\hline Methods & $\begin{array}{l}\text { Randomised study comparing highly agglutinative staphylococcin plus cisplatin with cisplatin } \\
\text { alone. }\end{array}$ \\
\hline Participants & \begin{tabular}{l} 
Un participants with malignant pleural effusion and ascites \\
\hline Interventions
\end{tabular} \\
\hline Outcomes & Reduction in effusion/ascites volume \\
& Karnofsky score \\
\hline Notes & $\begin{array}{l}\text { Full text only available in Chinese and unable to translate. Need to confirm if pleural and ascites da- } \\
\text { ta is presented separately and how the agents were delivered }\end{array}$ \\
\hline
\end{tabular}

\section{Cong 2010}

\begin{tabular}{ll}
\hline Methods & RCT of pleural perfusion of nedaplatin and cisplatin in MPE due to non-small cell lung cancer \\
\hline Participants & 68 participants with lung cancer associated with malignant pleural effusion \\
\hline Interventions & Participants randomised into two groups: \\
& $\begin{array}{l}\text { 1. } 40 \mathrm{mg} / \mathrm{m}^{2} \text { nedaplatin and } 10 \mathrm{mg} \text { dexamethasone given intrapleurally } \\
\text { 2. } 40 \mathrm{mg} / \mathrm{m}^{2} \text { cisplatin and } 10 \mathrm{mg} \text { dexamethasone in } 40 \mathrm{ml} \text { saline given intrapleurally }\end{array}$ \\
& Agents given weekly for $2-4$ weeks \\
\hline Outcomes & Treatment response \\
Side effects \\
Karnofsky performance status \\
Survival
\end{tabular}

Fukuoka 1984

\begin{tabular}{ll}
\hline Methods & $\begin{array}{l}\text { RCT of intrapleural Adriamycin and Nocardia rubra cell wall skeleton, compared with Adriamycin } \\
\text { alone }\end{array}$ \\
\hline Participants & 55 participants with MPE due to lung cancer \\
\hline Interventions & Agents given via tube thoracostomy. No other details available \\
\hline Outcomes & Treatment response \\
\hline Notes & In Japanese. Unable to translate \\
\hline
\end{tabular}


Miyanaga 2011

Methods

Participants

Interventions

Outcomes

Notes

Trial comparing bleomycin,OK-432 and cisplatin plus etoposide in MPE due to non-small cell lung cancer
Malignant pleural effusion due to previously untreated non-small cell lung cancer

Intrapleural bleomycin,OK-432 and cisplatin plus etoposide

\section{Song 2013}

\begin{tabular}{ll}
\hline Methods & RCT comparing intrapleural pseudomonas aeruginosa, with cisplatin and interleukin-2 \\
\hline Participants & 90 participants with malignant pleural effusion \\
\hline Interventions & Agents administered through intrathoracic infusion. No other information available \\
\hline Outcomes & Clinical efficacy and adverse reactions \\
\hline Notes & Written in Chinese and unable to obtain a translation. Only abstract available in English \\
\hline
\end{tabular}

\section{Sun 2002}

\begin{tabular}{ll}
\hline Methods & RCT of intrapleural Ya-Dan-Zhi's grease (YDZ) and cisplatin in MPE \\
\hline Participants & 72 participants with MPE \\
\hline Interventions & Randomly divided between three groups: \\
& - YDZ $80 \mathrm{ml}$ and cisplatin $60 \mathrm{mg}$ intrapleurally once per week \\
& C Cisplatin $60 \mathrm{mg}$ intrapleurally once per week \\
\hline Outcomes & Treatment effect \\
& Side effects \\
\hline Notes & $\begin{array}{l}\text { In Chinese and unable to obtain a translation. Unclear from abstract if study would be eligible for } \\
\text { inclusion in the review }\end{array}$ \\
\hline
\end{tabular}

\section{Won 1997}

\begin{tabular}{ll}
\hline Methods & RCT comparing intrapleural doxycycline and bleomycin \\
\hline Participants & 34 patients with MPE requiring repeated thoracentesis \\
\hline
\end{tabular}


Won 1997 (Continued)

\begin{tabular}{ll} 
Interventions & Participants received either intrapleural doxycycline or bleomycin \\
\hline Outcomes & Fluid volume \\
& Side effects \\
& Response to treatment (on CXR and clinical examination) \\
& Survival \\
\hline Notes & In Korean. Only abstract available in English. Unable to obtain a translation \\
\hline
\end{tabular}

Xu 2010

Methods $\quad$ RCT evaluating the effect of intrapleural highly agglutinative staphylococcin (HAS) combined with
nedaplatin, compared to nedaplatin alone

\begin{tabular}{ll}
\hline Participants & 58 participants with MPE \\
\hline Interventions & Participants randomised to two groups: \\
& - intrapleural HAS with nedaplatin \\
& nedaplatin alone \\
\hline Outcomes & Treatment response \\
& Adverse effects \\
& Quality of life \\
\hline Notes & In Chinese. Only abstract available in English and unclear from it whether the study is eligible. Un- \\
able to obtain translation of the full text
\end{tabular}

Yu 2003

\begin{tabular}{ll}
\hline Methods & RCT comparing cisplatin and lentinan in malignant pleural effusion \\
\hline Participants & 64 participants with MPE \\
\hline Interventions & Randomised into two groups: \\
& $\begin{array}{l}\text { intrathoracic cisplatin and lentinan } \\
\text { intrathoracic cisplatin only }\end{array}$ \\
\hline Outcomes & Response rates \\
\hline Notes & $\begin{array}{l}\text { In Chinese. Only abstract available in English and unclear from it whether the study is eligible. Un- } \\
\text { able to obtain translation of the full text }\end{array}$ \\
\hline
\end{tabular}


Zhuang 2012

\begin{tabular}{ll}
\hline Methods & $\begin{array}{l}\text { RCT comparing matrine injection (yanshu) combined with intrapleural cisplatin for treatment of } \\
\text { haematologic malignancies complicated by pleural effusion }\end{array}$ \\
\hline Participants & 46 participants with haematological malignancy complicated by pleural effusion \\
\hline Interventions & Participants randomly divided into two groups: \\
& - intrapleural cisplatin $20 \mathrm{mg} / \mathrm{m}^{2}$ and yanshu $10 \mathrm{ml} / \mathrm{m}^{2}$ and dexamethasone $5 \mathrm{mg} / \mathrm{m}^{2}$ \\
\hline Outcomes & intrapleural cisplatin $20 \mathrm{mg} / \mathrm{m}^{2}$ and dexamethasone $5 \mathrm{mg} / \mathrm{m}^{2}$ \\
\hline Efficacy & Adverse effects \\
\hline In Chinese. Only abstract available in English and unclear from it whether the study is eligible. Un- \\
able to obtain translation of the full text
\end{tabular}

Characteristics of ongoing studies [ordered by study ID]

\section{AMPLE Trial}

\begin{tabular}{ll}
\hline Trial name or title & Australasian Malignant Pleural Effusion (AMPLE) Trial \\
\hline Methods & Multicentre, international RCT comparing IPC to talc pleurodesis \\
\hline Participants & Aiming to recruit 146 participants to the study \\
& Inclusion: symptomatic MPE requiring intervention and written informed consent \\
& $\begin{array}{l}\text { Exclusion: age }<18 ; \text { effusion }<2 \text { cm max depth; expected survival }<3 \text { months; chylothorax; previous } \\
\text { ipsilateral lobectomy or pneumonectomy; previous pleurodesis; pleural infection; white cell count } \\
\\
<1 \times 109 / L ; \text { hypercapnic ventilatory failure; pregnancy or lactation; irreversible bleeding diathesis; } \\
\text { irreversible visual impairment; inability to give informed consent or comply with the protocol }\end{array}$
\end{tabular}

\begin{tabular}{ll}
\hline Interventions & Participants randomised 1:1 to IPC or talc pleurodesis \\
\hline Outcomes & $\begin{array}{l}\text { Primary: number of days spent in hospital for any cause following intervention until death or end of } \\
\text { study follow-up } \\
\text { Secondary: admissions for pleural effusion-associated causes; survival and adverse events; breath- } \\
\text { lessness and QOL; health cost assessment }\end{array}$ \\
\hline Starting date & 1 June 2012 \\
\hline Contact information & gary.lee@uwa.ed.au \\
\hline Notes & \\
\hline
\end{tabular}

\section{IPC-Plus}

$\begin{array}{ll}\text { Trial name or title } & \begin{array}{l}\text { The efficacy of indwelling pleural catheter placement versus IPC placement plus sclerosant (talc) in } \\ \text { patients with malignant pleural effusions managed exclusively as outpatients }\end{array}\end{array}$


IPC-Plus (Continued)

Methods Multi-centre, single-blind RCT of talc slurry or placebo administered via an indwelling pleural catheter

\begin{tabular}{ll}
\hline Participants & Aiming to recruit 154 participants to the study \\
& Inclusion criteria: \\
& Exclusion criteria: \\
\hline Interventions & $\begin{array}{l}\text { Participants in both arms undergo IPC insertion. At day } 10 \text { post insertion, participants randomised } \\
\text { to } 4 \text { g intrapleural talc or placebo. Followed up for } 10 \text { weeks. Participants blinded to treatment al- } \\
\text { location }\end{array}$ \\
\hline Outcomes & Primary: pleurodesis success at five weeks post randomisation \\
& $\begin{array}{l}\text { Secondary: QOL; pain and breathlessness VAS Scores; volume of pleural fluid drained; mortality; } \\
\text { hospital inpatient bed days; degree of loculation on ultrasound; pleurodesis success at } 10 \text { weeks } \\
\text { post randomisation; number of pleural procedures required to relieve pleural fluid }\end{array}$ \\
\hline Starting date & 11 July 2012 \\
\hline Contact information & rbhatnagar@doctors.org.uk \\
\hline Notes &
\end{tabular}

\section{OPUS Trial}

Trial name or title Effectiveness of doxycycline for treating pleural effusions related to cancer in an outpatient population (OPUS)

\begin{tabular}{ll}
\hline Methods & RCT of doxycycline versus placebo administration via a PleurX catheter in MPE \\
\hline Participants & $\begin{array}{l}\text { Malignant pleural effusion; fully expanded lung post drainage of the pleural effusion } \\
\text { Target recruitment of } 50 \text { participants }\end{array}$ \\
\hline Interventions & $\begin{array}{l}\text { Participants have a PleurX catheter inserted and are then randomised to intrapleural doxycycline } \\
\text { or placebo }\end{array}$ \\
\hline Outcomes & Primary: pleurodesis rate at 90 days \\
\hline Starting date & Secondary: time to pleurodesis \\
\hline Contact information & 2009 \\
\hline Notes & brepatenaude@toh.on.ca; kamjadi@toh.on.ca \\
\hline
\end{tabular}

\section{TAPPS}

$\begin{array}{ll}\text { Trial name or title } & \begin{array}{l}\text { Evaluating the efficacy of thoracoscopy and talc poudrage versus pleurodesis using talc slurry: a } \\ \text { randomised trial to determine the most effective method for the management of malignant pleural } \\ \text { effusions in patients with a good performance status (The TAPPS Study) }\end{array}\end{array}$


TAPPS (Continued)

Methods

The TAPPS trial is a multi-centre randomised controlled study which compares the efficacy of chest drain insertion and talc slurry instillation with local anaesthetic thoracoscopy and talc poudrage, in the management of malignant pleural effusions
Inclusion: clinically confident diagnosis of malignant pleural effusion requiring pleurodesis; fit enough to undergo local anaesthetic thoracoscopy; expected survival > 3 months

Exclusion: patients requiring a thoracoscopy to make a diagnosis; age $<18$ years; pregnancy or lactation; evidence of extensive lung entrapment; insufficient pleural fluid to safely perform local anaesthetic thoracoscopy; adverse reaction to talc; contraindication to thoracoscopy or chest tube insertion

Aiming to recruit 330 participants.
Interventions

Control arm: 12 - 14 Fr seldinger drain, then $4 \mathrm{~g}$ talc slurry pleurodesis

Intervention arm: medical thoracoscopy, with $4 \mathrm{~g}$ talc poudrage at end of the procedure
Primary endpoint: the number of participants who experience pleurodesis failure up to three months (90 days) post randomisation

Secondary endpoints: requirement for further pleural procedures up to six months post-randomisation; percentage radiographic (chest X-ray) pleural opacification at 1, 3 and 6 months post randomisation; quality of life; thoracic pain; breathlessness; pleurodesis failure at 1 and 6 months; mortality

\begin{tabular}{ll}
\hline Starting date & 26 September 2012 \\
\hline Contact information & rbhatnagar@doctors.org.uk \\
\hline Notes & \\
\hline
\end{tabular}

TIME-1

\begin{tabular}{ll}
\hline Trial name or title & The first therapeutic interventions in malignant effusion trial (TIME-1) \\
\hline Methods & $\begin{array}{l}2 \times 2 \text { randomised factorial trial to assess whether non-steroidal analgesia and the use of small-bore } \\
\text { chest tubes will reduce pain during pleurodesis for MPE, compared to standard care }\end{array}$ \\
\hline Participants & 320 target recruitment (interim analysis after 120 participants) \\
& $\begin{array}{l}\text { Inclusion: clinically confident diagnosis of MPE requiring pleurodesis; written informed consent; } \\
\text { expected survival > } 1 \text { month }\end{array}$ \\
& $\begin{array}{l}\text { Exclusion: age < 18; primary lymphoma or small cell lung carcinoma; pregnancy or lactation; his- } \\
\text { tory of gastro intestinal (GI) bleeding or untreated peptic ulceration; known sensitivity to non- } \\
\text { steroidal anti-inflammatory drugs (NSAIDs) or opiates; hypercapnic ventilatory failure; intravenous } \\
\text { drug use; severe renal or liver disease; bleeding diathesis; warfarin therapy which must be contin- } \\
\text { ued; current or recent corticosteroid therapy }\end{array}$
\end{tabular}

Interventions

Participants will be randomised to one of the following arms:

- Large-bore (24 F) chest drain and NSAID-based analgesic regimen

- Small-bore (12 F)chest drain and NSAID-based analgesic regimen

- Large-bore chest drain (24 F) and opiate-based analgesic regimen

- Small-bore chest drain (12 F) and opiate-based analgesic regimen 
TIME-1 (Continued)

Outcomes Primary: pain score over 72 hours post pleurodesis

Secondary: success of pleurodesis at 6 weeks and 3 months; presence of ipsilateral, chronic chest pain at 6 weeks and 3 months

\begin{tabular}{ll}
\hline Starting date & 1 September 2006 \\
\hline Contact information & emma.hedley@ouh.nhs.uk \\
\hline
\end{tabular}

Notes

TIME-3

Trial name or title Adjuvant urokinase in the treatment of malignant pleural effusion: the third therapeutic intervention in malignant effusion trial (TIME3-UK)

Methods A double blind, randomised controlled trial to evaluate whether use of intrapleural urokinase aids the drainage of multi-septated pleural effusion compared to placebo

Participants

Inclusion: clinically confident diagnosis of pleural malignancy; significant multi-loculated pleural effusion despite the presence of a patent in-situ chest tube; MPE requiring drainage and pleurodesis for symptom control

Exclusion: age < 18; expected survival < 28 days; previous ipsilateral pneumonectomy; previous IP fibrinolytics; ipsilateral pleural infection; sensitivity to urokinase; coincidental stroke, major haemorrhage or trauma; major surgery in past five days; chylothorax; white cell count < 1 x 109; pregnancy or lactation; irreversible bleeding diathesis; platelets < 100 x 109; irreversible visual impairment

Interventions Participants randomised to three doses of 100,000 IU urokinase 12 hourly intrapleurally or placebo through an intercostal drain. All participants then undergo a talc pleurodesis. Followed up for 12 months

\begin{tabular}{ll}
\hline Outcomes & $\begin{array}{l}\text { Primary: mean daily breathlessness score over 28 days from randomisation; time to pleurodesis } \\
\text { failure }\end{array}$ \\
& $\begin{array}{l}\text { Secondary: improvement of effusion on radiology; volume of pleural fluid drained; QOL; healthcare } \\
\text { costs }\end{array}$ \\
\hline Starting date & 2008 \\
\hline Contact information & emma.hedley@ouh.nhs.uk \\
\hline
\end{tabular}

Notes

\section{DATA AND ANALYSES}




\section{Comparison 1. Bleomycin}

\begin{tabular}{|c|c|c|c|c|}
\hline Outcome or subgroup title & $\begin{array}{l}\text { No. of } \\
\text { studies }\end{array}$ & $\begin{array}{l}\text { No. of } \\
\text { partici- } \\
\text { pants }\end{array}$ & Statistical method & Effect size \\
\hline 1 Pleurodesis failure & 21 & & $\begin{array}{l}\text { Odds Ratio (M-H, Random, } \\
95 \% \mathrm{Cl})\end{array}$ & Subtotals only \\
\hline 1.1 Bleomycin vs iodine & 1 & 39 & $\begin{array}{l}\text { Odds Ratio (M-H, Random, } \\
95 \% \mathrm{Cl})\end{array}$ & $0.8[0.18,3.57]$ \\
\hline 1.2 Bleomycin vs talc slurry & 5 & 199 & $\begin{array}{l}\text { Odds Ratio (M-H, Random, } \\
95 \% \mathrm{Cl})\end{array}$ & $1.22[0.55,2.70]$ \\
\hline 1.3 Bleomycin vs tetracycline & 5 & 220 & $\begin{array}{l}\text { Odds Ratio (M-H, Random, } \\
95 \% \mathrm{Cl})\end{array}$ & $0.50[0.27,0.93]$ \\
\hline 1.4 Bleomycin vs talc poudrage & 2 & 57 & $\begin{array}{l}\text { Odds Ratio (M-H, Random, } \\
95 \% \mathrm{CI})\end{array}$ & $9.70[2.10,44.78]$ \\
\hline 1.5 Bleomycin vs C. parvum & 2 & 78 & $\begin{array}{l}\text { Odds Ratio (M-H, Random, } \\
95 \% \mathrm{Cl})\end{array}$ & $1.81[0.02,189.25]$ \\
\hline 1.6 Bleomycin vs doxycycline & 2 & 122 & $\begin{array}{l}\text { Odds Ratio (M-H, Random, } \\
95 \% \mathrm{Cl})\end{array}$ & $1.50[0.54,4.20]$ \\
\hline 1.7 Bleomycin vs IFN & 1 & 160 & $\begin{array}{l}\text { Odds Ratio (M-H, Random, } \\
95 \% \mathrm{Cl})\end{array}$ & $0.31[0.15,0.65]$ \\
\hline 1.8 Bleomycin vs mitoxantrone & 1 & 85 & $\begin{array}{l}\text { Odds Ratio (M-H, Random, } \\
95 \% \mathrm{Cl})\end{array}$ & $0.31[0.12,0.86]$ \\
\hline 1.9 Bleomycin vs mepacrine & 1 & 36 & $\begin{array}{l}\text { Odds Ratio (M-H, Random, } \\
95 \% \mathrm{Cl})\end{array}$ & $6.40[1.12,36.44]$ \\
\hline $\begin{array}{l}1.10 \text { Bleomycin vs combined tetracycline } \\
\text { and bleomycin }\end{array}$ & 1 & 38 & $\begin{array}{l}\text { Odds Ratio (M-H, Random, } \\
95 \% \mathrm{Cl})\end{array}$ & $5.57[0.25,124.19]$ \\
\hline 1.11 Bleomycin vs cisplatin and etoposide & 1 & 69 & $\begin{array}{l}\text { Odds Ratio (M-H, Random, } \\
95 \% \mathrm{Cl})\end{array}$ & $1.1[0.39,3.07]$ \\
\hline 1.12 Bleomycin vs OK- 432 & 1 & 68 & $\begin{array}{l}\text { Odds Ratio (M-H, Random, } \\
95 \% \mathrm{Cl})\end{array}$ & $1.43[0.49,4.17]$ \\
\hline 1.13 Bleomycin vs viscum & 1 & 17 & $\begin{array}{l}\text { Odds Ratio (M-H, Random, } \\
95 \% \mathrm{Cl})\end{array}$ & $5.33[0.62,45.99]$ \\
\hline 2 Pain & 14 & & $\begin{array}{l}\text { Odds Ratio (M-H, Random, } \\
95 \% \mathrm{Cl})\end{array}$ & Subtotals only \\
\hline 2.1 Bleomycin vs talc slurry & 2 & 73 & $\begin{array}{l}\text { Odds Ratio (M-H, Random, } \\
95 \% \mathrm{Cl})\end{array}$ & $1.66[0.41,6.80]$ \\
\hline 2.2 Bleomycin vs tetracycline & 4 & 220 & $\begin{array}{l}\text { Odds Ratio (M-H, Random, } \\
95 \% \mathrm{CI} \text { ) }\end{array}$ & $0.61[0.29,1.27]$ \\
\hline 2.3 Bleomycin vs talc poudrage & 1 & 32 & $\begin{array}{l}\text { Odds Ratio (M-H, Random, } \\
95 \% \mathrm{Cl})\end{array}$ & $0.28[0.01,7.31]$ \\
\hline
\end{tabular}




\begin{tabular}{|c|c|c|c|c|}
\hline Outcome or subgroup title & $\begin{array}{l}\text { No. of } \\
\text { studies }\end{array}$ & $\begin{array}{l}\text { No. of } \\
\text { partici- } \\
\text { pants }\end{array}$ & Statistical method & Effect size \\
\hline 2.4 Bleomycin vs C. parvum & 2 & 71 & $\begin{array}{l}\text { Odds Ratio (M-H, Random, } \\
95 \% \mathrm{Cl})\end{array}$ & $0.70[0.27,1.85]$ \\
\hline 2.5 Bleomycin vs IFN & 1 & 160 & $\begin{array}{l}\text { Odds Ratio (M-H, Random, } \\
95 \% \mathrm{Cl})\end{array}$ & $32.34[1.89,552.23]$ \\
\hline 2.6 Bleomycin vs mitoxantrone & 1 & 96 & $\begin{array}{l}\text { Odds Ratio (M-H, Random, } \\
95 \% \mathrm{Cl})\end{array}$ & $0.48[0.15,1.56]$ \\
\hline 2.7 Bleomycin vs mepacrine & 1 & 40 & $\begin{array}{l}\text { Odds Ratio (M-H, Random, } \\
95 \% \mathrm{Cl})\end{array}$ & $0.46[0.11,1.94]$ \\
\hline 2.8 Bleomycin vs doxycycline & 2 & 148 & $\begin{array}{l}\text { Odds Ratio (M-H, Random, } \\
95 \% \mathrm{Cl})\end{array}$ & $0.84[0.26,2.70]$ \\
\hline 2.9 Bleomycin vs OK-432 & 1 & 67 & $\begin{array}{l}\text { Odds Ratio (M-H, Random, } \\
95 \% \mathrm{Cl})\end{array}$ & $0.40[0.14,1.12]$ \\
\hline 2.10 Bleomycin vs cisplatin and etoposide & 1 & 69 & $\begin{array}{l}\text { Odds Ratio (M-H, Random, } \\
95 \% \mathrm{Cl})\end{array}$ & $0.83[0.32,2.16]$ \\
\hline 3 Mortality & 11 & & $\begin{array}{l}\text { Odds Ratio (M-H, Random, } \\
95 \% \mathrm{Cl})\end{array}$ & Subtotals only \\
\hline $\begin{array}{l}3.1 \text { Bleomycin vs combined tetracycline and } \\
\text { bleomycin }\end{array}$ & 1 & 40 & $\begin{array}{l}\text { Odds Ratio (M-H, Random, } \\
95 \% \mathrm{Cl})\end{array}$ & $1.0[0.06,17.18]$ \\
\hline 3.2 Bleomycin vs talc slurry & 2 & 116 & $\begin{array}{l}\text { Odds Ratio (M-H, Random, } \\
95 \% \mathrm{Cl})\end{array}$ & $0.89[0.29,2.75]$ \\
\hline 3.3 Bleomycin vs tetracycline & 2 & 125 & $\begin{array}{l}\text { Odds Ratio (M-H, Random, } \\
95 \% \mathrm{Cl})\end{array}$ & $0.63[0.27,1.44]$ \\
\hline 3.4 Bleomycin vs talc poudrage & 1 & 32 & $\begin{array}{l}\text { Odds Ratio (M-H, Random, } \\
95 \% \mathrm{Cl})\end{array}$ & $0.82[0.20,3.43]$ \\
\hline 3.5 Bleomycin vs C. parvum & 1 & 55 & $\begin{array}{l}\text { Odds Ratio (M-H, Random, } \\
95 \% \mathrm{Cl})\end{array}$ & $0.60[0.19,1.94]$ \\
\hline 3.6 Bleomycin vs IFN & 1 & 160 & $\begin{array}{l}\text { Odds Ratio (M-H, Random, } \\
95 \% \mathrm{Cl})\end{array}$ & $0.46[0.25,0.87]$ \\
\hline 3.7 Bleomycin vs mitoxantrone & 1 & 96 & $\begin{array}{l}\text { Odds Ratio (M-H, Random, } \\
95 \% \mathrm{Cl})\end{array}$ & $2.15[0.95,4.86]$ \\
\hline 3.8 Bleomycin vs OK- 432 & 1 & 68 & $\begin{array}{l}\text { Odds Ratio (M-H, Random, } \\
95 \% \mathrm{Cl})\end{array}$ & $2.66[0.98,7.23]$ \\
\hline 3.9 Bleomycin vs doxycycline & 2 & 122 & $\begin{array}{l}\text { Odds Ratio (M-H, Random, } \\
95 \% \mathrm{Cl})\end{array}$ & $1.44[0.53,3.90]$ \\
\hline 3.10 Bleomycin vs cisplatin and etoposide & 1 & 69 & $\begin{array}{l}\text { Odds Ratio (M-H, Random, } \\
95 \% \mathrm{Cl})\end{array}$ & $2.22[0.82,6.01]$ \\
\hline
\end{tabular}




\begin{tabular}{|c|c|c|c|c|}
\hline Outcome or subgroup title & $\begin{array}{l}\text { No. of } \\
\text { studies }\end{array}$ & $\begin{array}{l}\text { No. of } \\
\text { partici- } \\
\text { pants }\end{array}$ & Statistical method & Effect size \\
\hline 4 Fever & 16 & & $\begin{array}{l}\text { Odds Ratio (M-H, Random, } \\
95 \% \mathrm{Cl})\end{array}$ & Subtotals only \\
\hline 4.1 Bleomycin vs talc Slurry & 3 & 99 & $\begin{array}{l}\text { Odds Ratio (M-H, Random, } \\
95 \% \mathrm{Cl})\end{array}$ & $0.90[0.31,2.56]$ \\
\hline 4.2 Bleomycin vs talc poudrage & 1 & 32 & $\begin{array}{l}\text { Odds Ratio (M-H, Random, } \\
95 \% \mathrm{Cl})\end{array}$ & $0.87[0.11,7.05]$ \\
\hline 4.3 Bleomycin vs tetracycline & 5 & 250 & $\begin{array}{l}\text { Odds Ratio (M-H, Random, } \\
95 \% \mathrm{Cl})\end{array}$ & $2.05[0.67,6.34]$ \\
\hline 4.4 Tetracycline vs C. parvum & 2 & 80 & $\begin{array}{l}\text { Odds Ratio (M-H, Random, } \\
95 \% \mathrm{Cl})\end{array}$ & $0.43[0.17,1.12]$ \\
\hline 4.5 Bleomycin vs IFN & 1 & 160 & $\begin{array}{l}\text { Odds Ratio (M-H, Random, } \\
95 \% \mathrm{Cl})\end{array}$ & $151.35[9.08,2522.62]$ \\
\hline 4.6 Bleomycin vs mitoxantrone & 1 & 96 & $\begin{array}{l}\text { Odds Ratio (M-H, Random, } \\
95 \% \mathrm{Cl})\end{array}$ & $1.11[0.37,3.36]$ \\
\hline 4.7 Bleomycin vs mepacrine & 1 & 40 & $\begin{array}{l}\text { Odds Ratio (M-H, Random, } \\
95 \% \mathrm{Cl})\end{array}$ & $0.52[0.14,1.92]$ \\
\hline 4.8 Bleomycin vs doxycycline & 2 & 148 & $\begin{array}{l}\text { Odds Ratio (M-H, Random, } \\
95 \% \mathrm{Cl})\end{array}$ & $2.69[0.08,89.51]$ \\
\hline $\begin{array}{l}4.9 \text { Bleomycin vs combined tetracycline and } \\
\text { bleomycin }\end{array}$ & 1 & 40 & $\begin{array}{l}\text { Odds Ratio (M-H, Random, } \\
95 \% \mathrm{Cl})\end{array}$ & $0.47[0.04,5.69]$ \\
\hline 4.10 Bleomycin vs OK432 & 1 & 67 & $\begin{array}{l}\text { Odds Ratio (M-H, Random, } \\
95 \% \mathrm{Cl})\end{array}$ & $0.7[0.23,2.13]$ \\
\hline 4.11 Bleomycin vs cisplatin and etoposide & 1 & 69 & $\begin{array}{l}\text { Odds Ratio (M-H, Random, } \\
95 \% \mathrm{Cl})\end{array}$ & $2.22[0.82,6.01]$ \\
\hline
\end{tabular}

Analysis 1.1. Comparison 1 Bleomycin, Outcome 1 Pleurodesis failure.

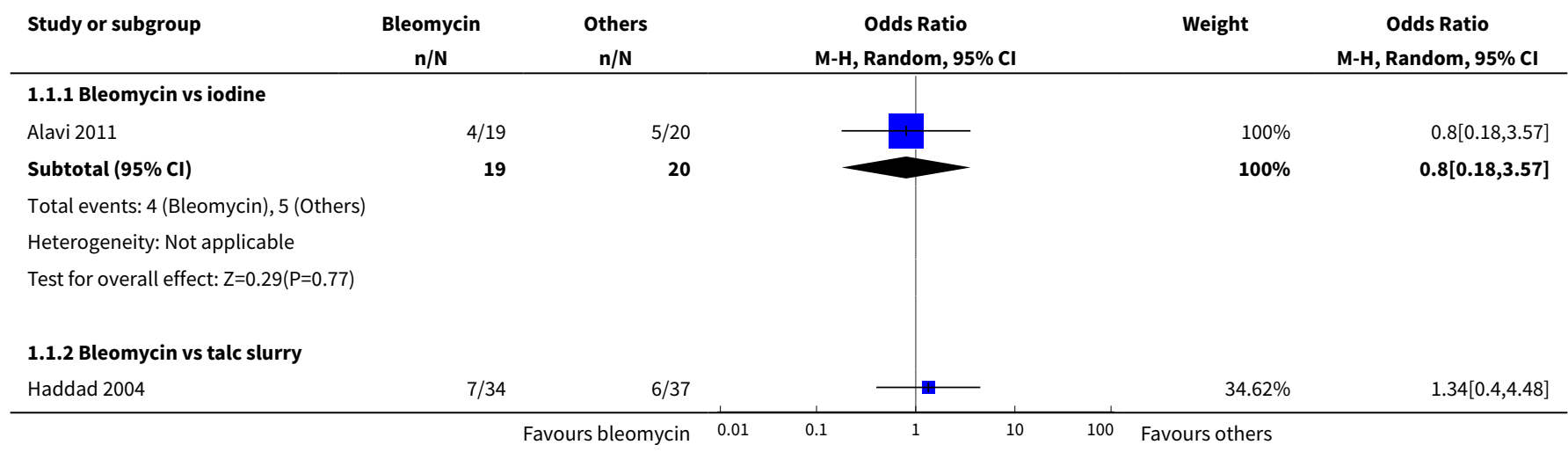




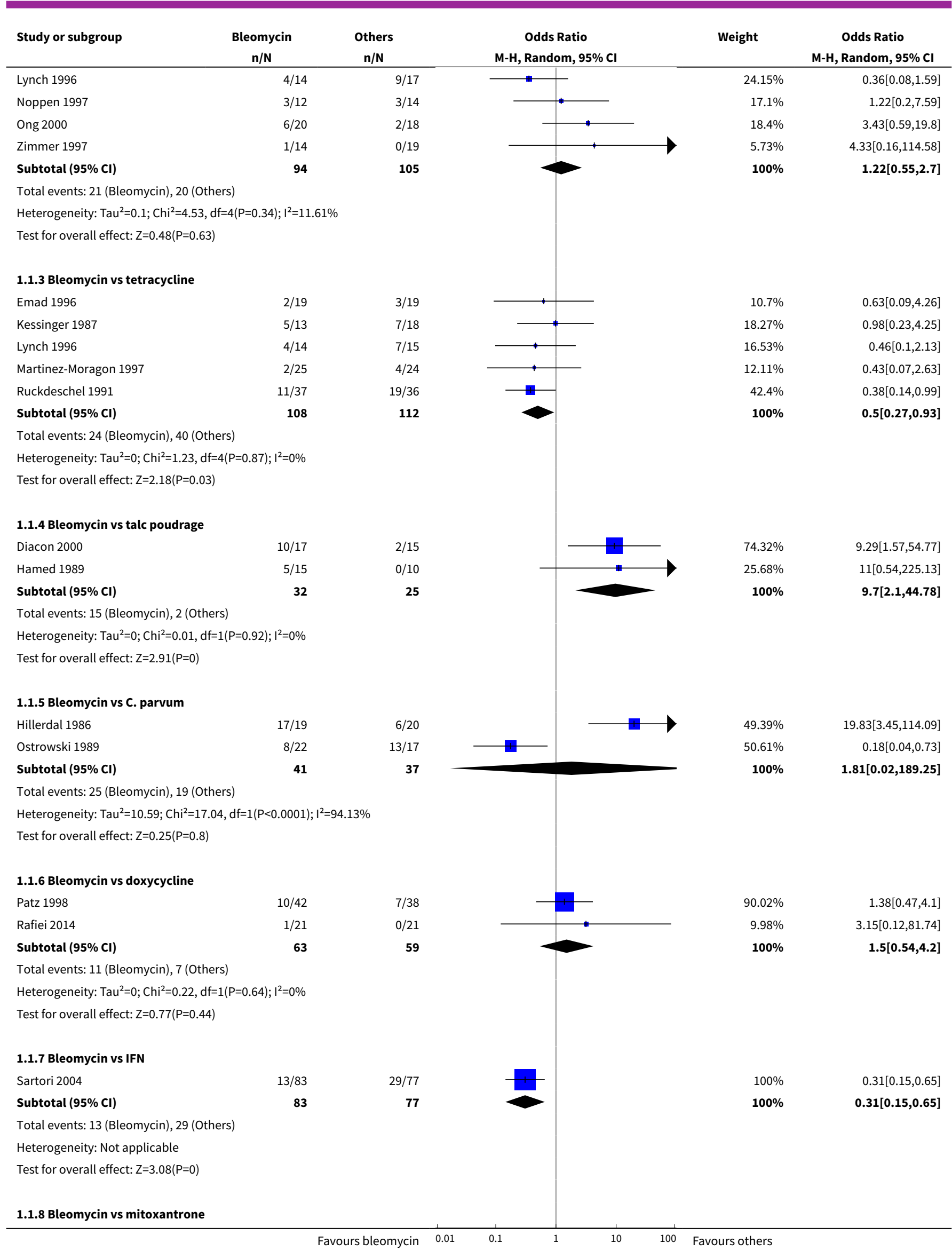




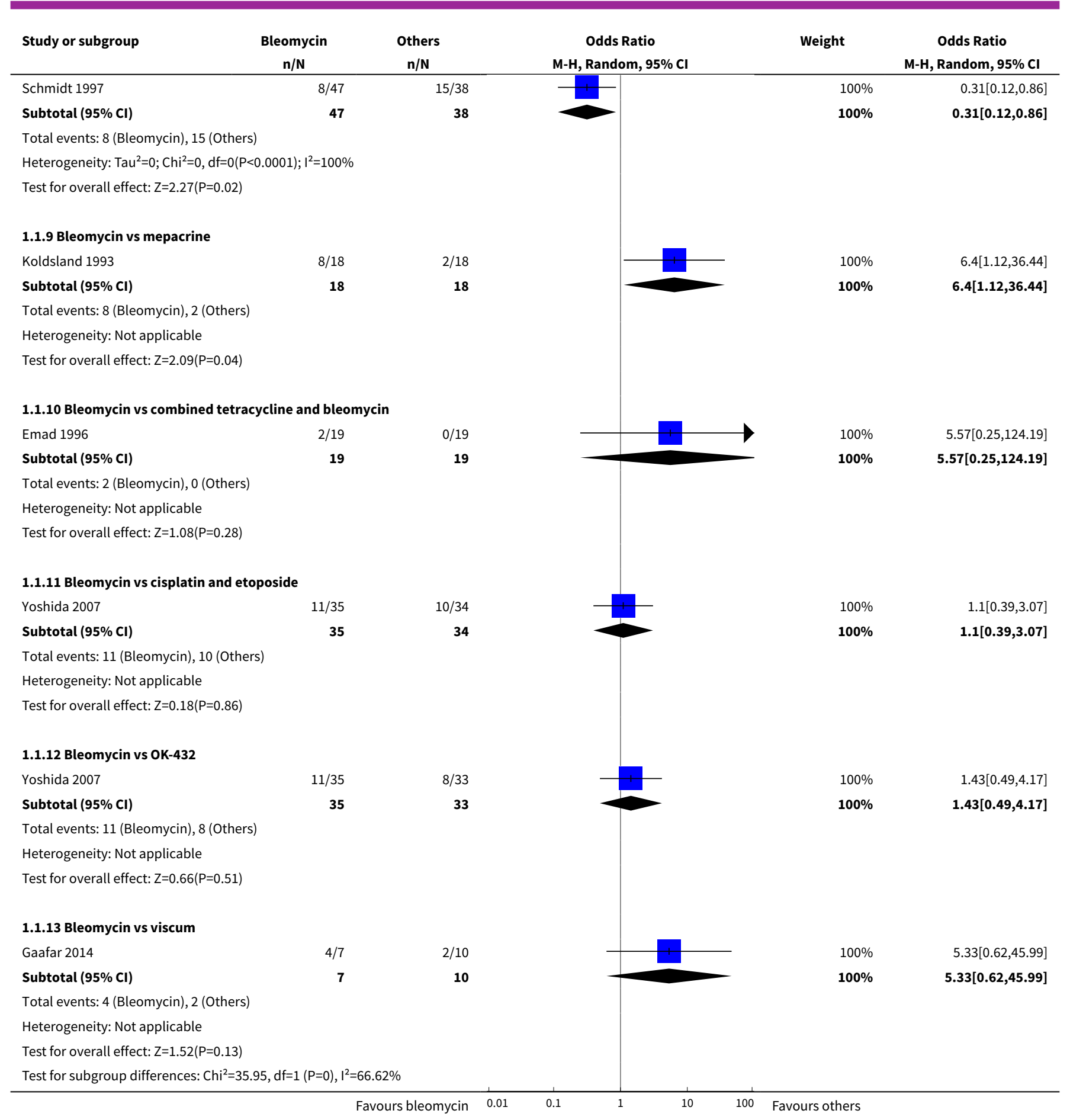

\section{Analysis 1.2. Comparison 1 Bleomycin, Outcome 2 Pain.}

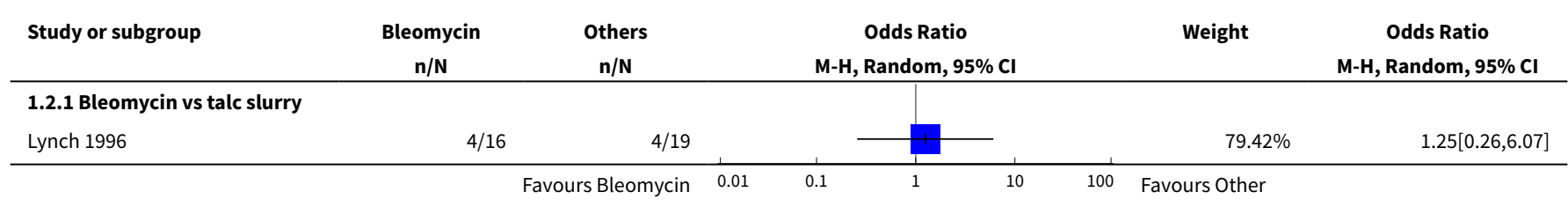




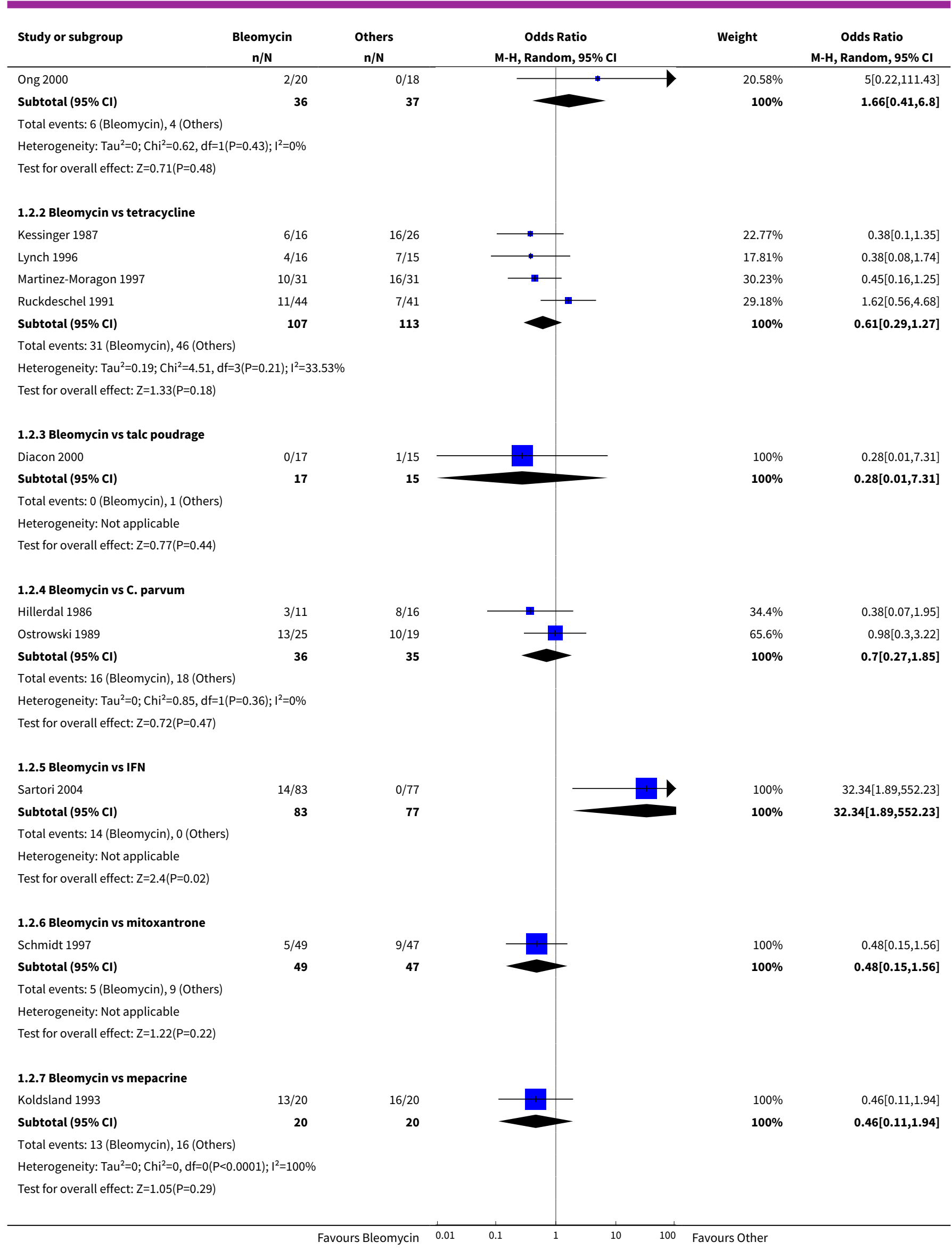




\begin{tabular}{|c|c|c|c|c|c|}
\hline Study or subgroup & $\begin{array}{c}\text { Bleomycin } \\
\mathrm{n} / \mathrm{N}\end{array}$ & $\begin{array}{c}\text { Others } \\
\mathrm{n} / \mathrm{N}\end{array}$ & $\begin{array}{c}\text { Odds Ratio } \\
\text { M-H, Random, } 95 \% \mathrm{Cl}\end{array}$ & Weight & $\begin{array}{c}\text { Odds Ratio } \\
\text { M-H, Random, } 95 \% \mathrm{Cl}\end{array}$ \\
\hline \multicolumn{6}{|c|}{ 1.2.8 Bleomycin vs doxycycline } \\
\hline Patz 1998 & $6 / 52$ & $11 / 54$ & & $58.26 \%$ & $0.51[0.17,1.5]$ \\
\hline Rafiei 2014 & $17 / 21$ & $15 / 21$ & - & $41.74 \%$ & $1.7[0.4,7.2]$ \\
\hline Subtotal $(95 \% \mathrm{CI})$ & 73 & 75 & & $100 \%$ & $0.84[0.26,2.7]$ \\
\hline \multicolumn{6}{|c|}{ Heterogeneity: $\operatorname{Tau}^{2}=0.3 ; \mathrm{Chi}^{2}=1.72, \mathrm{df}=1(\mathrm{P}=0.19) ; \mathrm{I}^{2}=41.75 \%$} \\
\hline \multicolumn{6}{|c|}{ Test for overall effect: $Z=0.29(P=0.77)$} \\
\hline \multicolumn{6}{|c|}{ 1.2.9 Bleomycin vs OK-432 } \\
\hline Yoshida 2007 & $19 / 35$ & $24 / 32$ & & $100 \%$ & $0.4[0.14,1.12]$ \\
\hline Subtotal $(95 \% \mathrm{CI})$ & 35 & 32 & & $100 \%$ & $0.4[0.14,1.12]$ \\
\hline \multicolumn{6}{|c|}{ Total events: 19 (Bleomycin), 24 (Others) } \\
\hline \multicolumn{6}{|c|}{ Heterogeneity: Not applicable } \\
\hline \multicolumn{6}{|c|}{ Test for overall effect: $\mathrm{Z}=1.75(\mathrm{P}=0.08)$} \\
\hline \multicolumn{6}{|c|}{ 1.2.10 Bleomycin vs cisplatin and etoposide } \\
\hline Yoshida 2007 & $19 / 35$ & $20 / 34$ & & $100 \%$ & $0.83[0.32,2.16]$ \\
\hline Subtotal $(95 \% \mathrm{CI})$ & 35 & 34 & & $100 \%$ & $0.83[0.32,2.16]$ \\
\hline \multicolumn{6}{|c|}{ Total events: 19 (Bleomycin), 20 (Others) } \\
\hline \multicolumn{6}{|c|}{ Heterogeneity: Not applicable } \\
\hline \multicolumn{6}{|c|}{ Test for overall effect: $\mathrm{Z}=0.38(\mathrm{P}=0.7)$} \\
\hline \multicolumn{6}{|c|}{ Test for subgroup differences: $\mathrm{Chi}^{2}=10.99, \mathrm{df}=1(\mathrm{P}=0.28), \mathrm{I}^{2}=18.14 \%$} \\
\hline
\end{tabular}

Analysis 1.3. Comparison 1 Bleomycin, Outcome 3 Mortality.

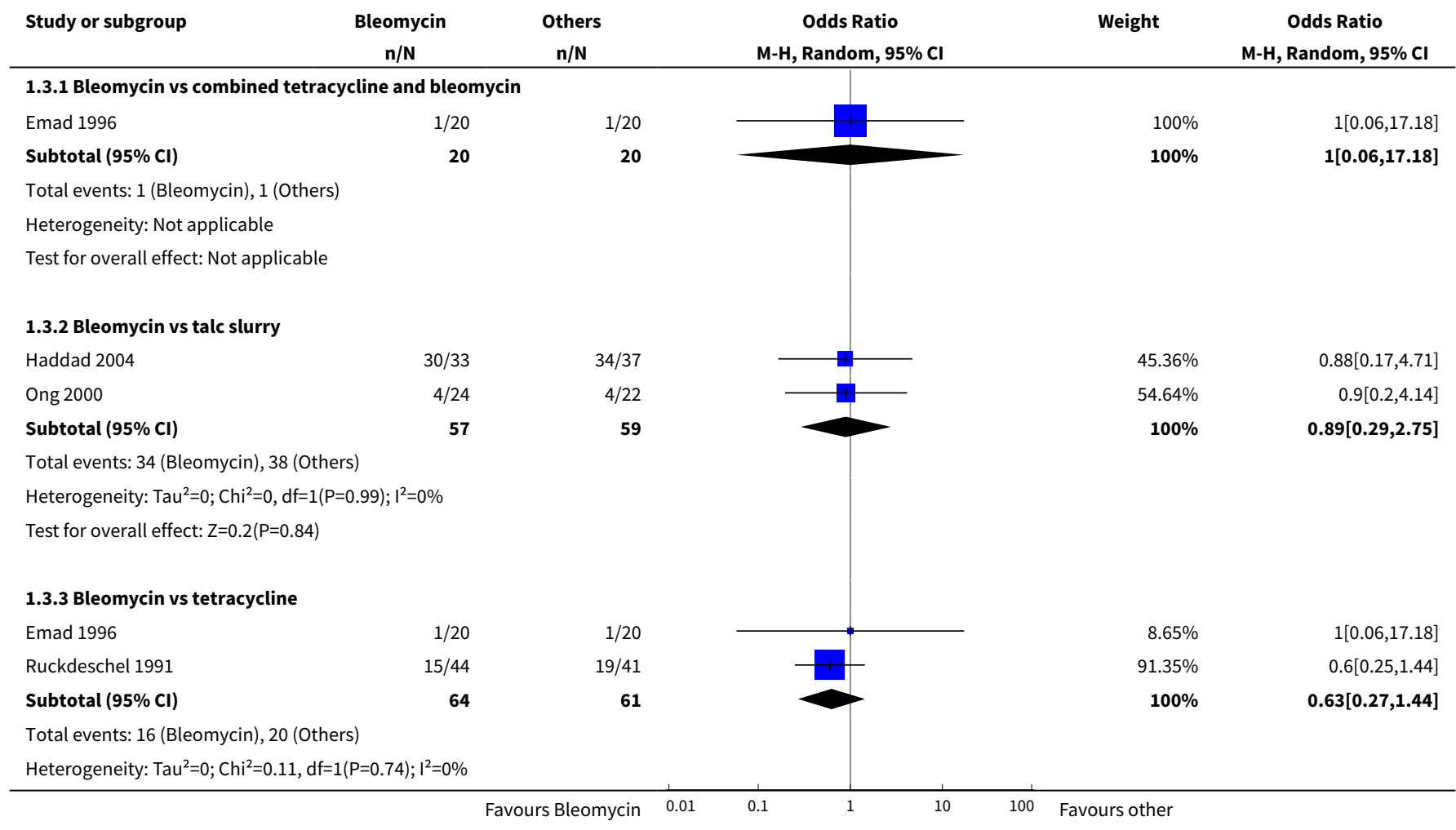




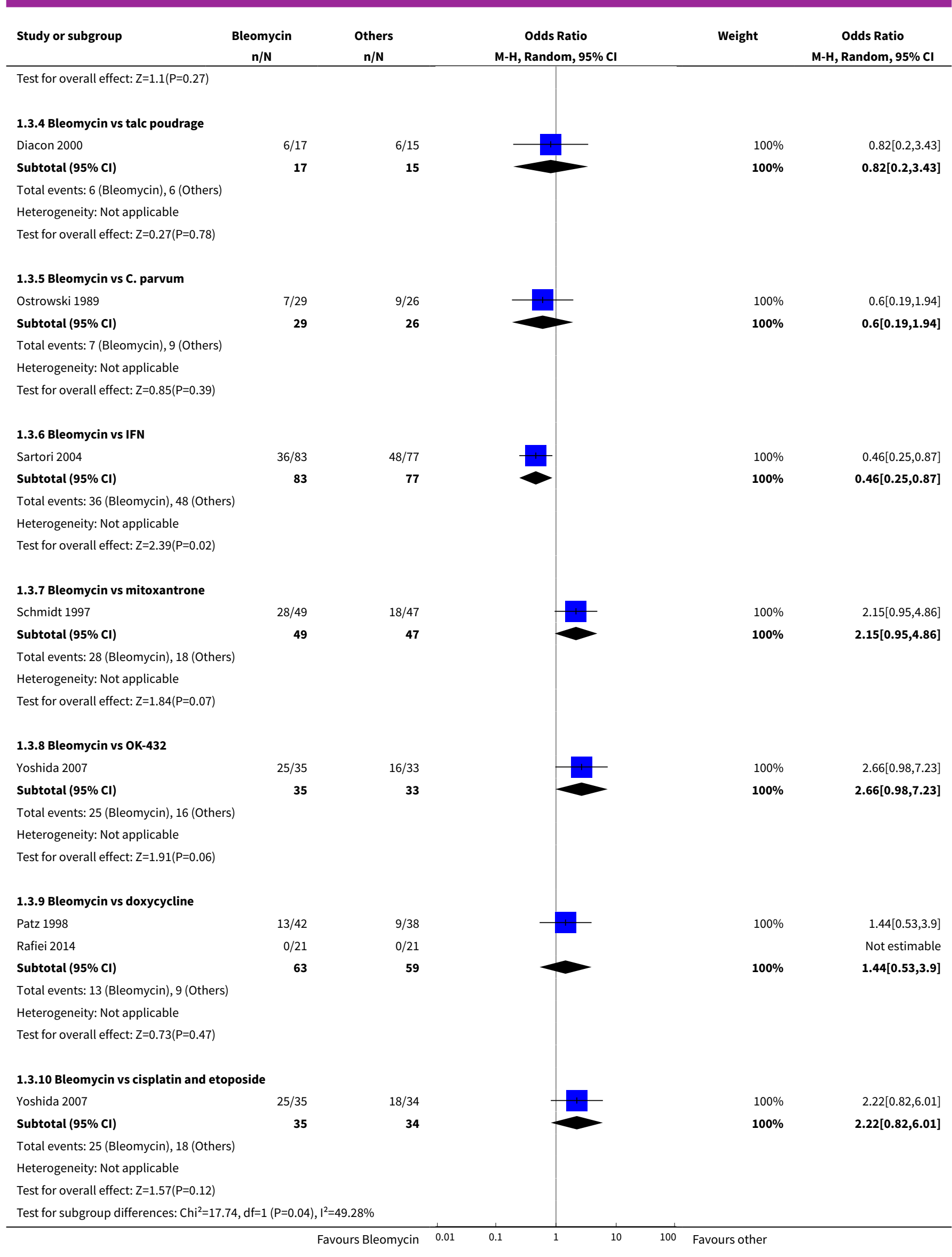


Analysis 1.4. Comparison 1 Bleomycin, Outcome 4 Fever.

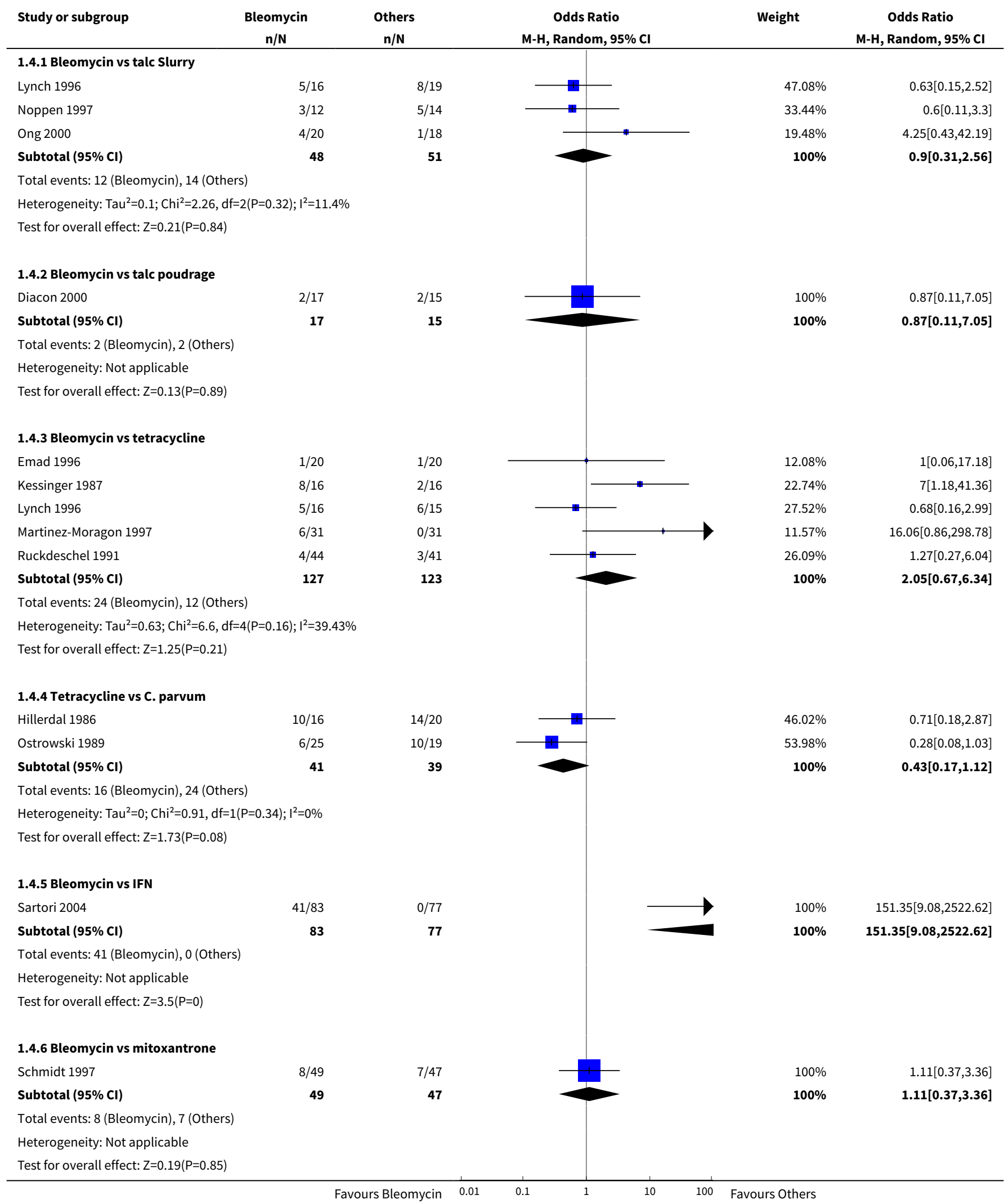




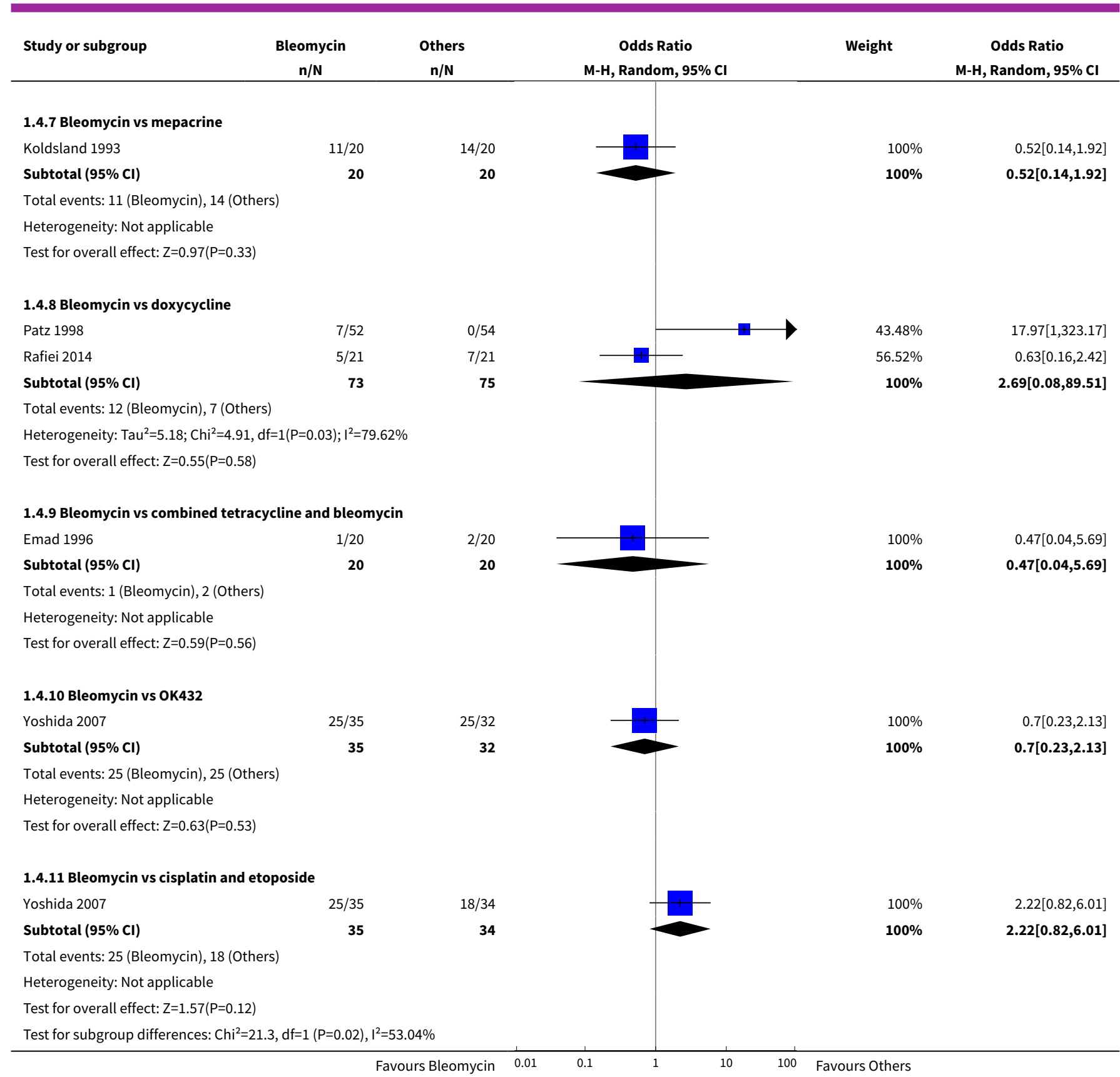

\section{Comparison 2. Talc slurry}

\begin{tabular}{lllll}
\hline Outcome or subgroup title & $\begin{array}{l}\text { No. of } \\
\text { studies }\end{array}$ & $\begin{array}{l}\text { No. of } \\
\text { partici- } \\
\text { pants }\end{array}$ & Statistical method & Effect size \\
\hline 1 Pleurodesis failure & 15 & & $\begin{array}{l}\text { Odds Ratio (M-H, Random, 95\% } \\
\text { Cl) }\end{array}$ & Subtotals only \\
\hline 1.1 Talc slurry vs talc poudrage & 3 & 599 & $\begin{array}{l}\text { Odds Ratio (M-H, Random, 95\% } \\
\text { Cl) }\end{array}$ & $1.31[0.92,1.85]$ \\
\hline
\end{tabular}




\begin{tabular}{|c|c|c|c|c|}
\hline Outcome or subgroup title & $\begin{array}{l}\text { No. of } \\
\text { studies }\end{array}$ & $\begin{array}{l}\text { No. of } \\
\text { partici- } \\
\text { pants }\end{array}$ & Statistical method & Effect size \\
\hline 1.2 Talc slurry vs bleomycin & 5 & 199 & $\begin{array}{l}\text { Odds Ratio (M-H, Random, 95\% } \\
\mathrm{Cl})\end{array}$ & $0.82[0.37,1.82]$ \\
\hline 1.3 Talc slurry vs IPC & 2 & 160 & $\begin{array}{l}\text { Odds Ratio (M-H, Random, 95\% } \\
\mathrm{Cl} \text { ) }\end{array}$ & $0.30[0.15,0.61]$ \\
\hline 1.4 Talc slurry vs mepacrine & 1 & 89 & $\begin{array}{l}\text { Odds Ratio (M-H, Random, 95\% } \\
\mathrm{Cl} \text { ) }\end{array}$ & $0.48[0.14,1.60]$ \\
\hline 1.5 Talc slurry vs placebo & 1 & 21 & $\begin{array}{l}\text { Odds Ratio (M-H, Random, 95\% } \\
\mathrm{Cl} \text { ) }\end{array}$ & $0.07[0.00,1.51]$ \\
\hline 1.6 Talc slurry vs iodine & 1 & 36 & $\begin{array}{l}\text { Odds Ratio (M-H, Random, 95\% } \\
\mathrm{Cl})\end{array}$ & $2.13[0.18,25.78]$ \\
\hline 1.7 Talc slurry vs tetracycline & 1 & 32 & $\begin{array}{l}\text { Odds Ratio (M-H, Random, 95\% } \\
\mathrm{Cl} \text { ) }\end{array}$ & $1.29[0.32,5.17]$ \\
\hline 1.8 Talc slurry vs silver nitrate & 1 & 25 & $\begin{array}{l}\text { Odds Ratio (M-H, Random, 95\% } \\
\mathrm{Cl} \text { ) }\end{array}$ & $5.82[0.21,158.82]$ \\
\hline 1.9 Talc slurry vs TMP & 1 & 87 & $\begin{array}{l}\text { Odds Ratio (M-H, Random, 95\% } \\
\mathrm{Cl} \text { ) }\end{array}$ & $2.31[0.77,6.93]$ \\
\hline 2 Mortality & 9 & & $\begin{array}{l}\text { Odds Ratio (M-H, Random, 95\% } \\
\mathrm{CI})\end{array}$ & Subtotals only \\
\hline 2.1 Talc slurry vs talc poudrage & 2 & 397 & $\begin{array}{l}\text { Odds Ratio (M-H, Random, 95\% } \\
\mathrm{Cl} \text { ) }\end{array}$ & $0.98[0.33,2.85]$ \\
\hline 2.2 Talc slurry vs bleomycin & 2 & 116 & $\begin{array}{l}\text { Odds Ratio (M-H, Random, 95\% } \\
\mathrm{Cl})\end{array}$ & $1.12[0.36,3.46]$ \\
\hline 2.3 Talc slurry vs iodine & 1 & 36 & $\begin{array}{l}\text { Odds Ratio (M-H, Random, 95\% } \\
\mathrm{Cl} \text { ) }\end{array}$ & $0.0[0.0,0.0]$ \\
\hline 2.4 Talc slurry vs IPC & 2 & 163 & $\begin{array}{l}\text { Odds Ratio (M-H, Random, 95\% } \\
\mathrm{Cl} \text { ) }\end{array}$ & $0.97[0.45,2.10]$ \\
\hline 2.5 Talc slurry vs mepacrine & 1 & 89 & $\begin{array}{l}\text { Odds Ratio (M-H, Random, 95\% } \\
\mathrm{Cl} \text { ) }\end{array}$ & $1.88[0.70,5.02]$ \\
\hline 2.6 Talc slurry vs TMP & 1 & 87 & $\begin{array}{l}\text { Odds Ratio (M-H, Random, 95\% } \\
\mathrm{Cl} \text { ) }\end{array}$ & $10.64[0.55,203.85]$ \\
\hline 3 Pain & 7 & & $\begin{array}{l}\text { Odds Ratio (M-H, Random, 95\% } \\
\mathrm{Cl} \text { ) }\end{array}$ & Subtotals only \\
\hline 3.1 Talc slurry vs bleomycin & 3 & 99 & $\begin{array}{l}\text { Odds Ratio (M-H, Random, 95\% } \\
\mathrm{Cl})\end{array}$ & $0.60[0.15,2.46]$ \\
\hline 3.2 Talc slurry vs talc poudrage & 1 & 482 & $\begin{array}{l}\text { Odds Ratio (M-H, Random, 95\% } \\
\mathrm{Cl} \text { ) }\end{array}$ & $2.13[1.04,4.36]$ \\
\hline
\end{tabular}




\begin{tabular}{|c|c|c|c|c|}
\hline Outcome or subgroup title & $\begin{array}{l}\text { No. of } \\
\text { studies }\end{array}$ & $\begin{array}{l}\text { No. of } \\
\text { partici- } \\
\text { pants }\end{array}$ & Statistical method & Effect size \\
\hline 3.3 Talc slurry vs tetracycline & 1 & 34 & $\begin{array}{l}\text { Odds Ratio (M-H, Random, 95\% } \\
\mathrm{Cl} \text { ) }\end{array}$ & $0.30[0.07,1.36]$ \\
\hline 3.4 Talc slurry vs iodine & 1 & 36 & $\begin{array}{l}\text { Odds Ratio (M-H, Random, 95\% } \\
\mathrm{Cl} \text { ) }\end{array}$ & $0.0[0.0,0.0]$ \\
\hline 3.5 Talc slurry vs IPC & 1 & 57 & $\begin{array}{l}\text { Odds Ratio (M-H, Random, 95\% } \\
\mathrm{Cl} \text { ) }\end{array}$ & $0.31[0.01,7.95]$ \\
\hline 3.6 Talc slurry vs placebo & 1 & 31 & $\begin{array}{l}\text { Odds Ratio (M-H, Random, 95\% } \\
\mathrm{Cl} \text { ) }\end{array}$ & $0.0[0.0,0.0]$ \\
\hline 4 Fever & 7 & & $\begin{array}{l}\text { Odds Ratio (M-H, Random, 95\% } \\
\mathrm{Cl} \text { ) }\end{array}$ & Subtotals only \\
\hline 4.1 Talc slurry vs talc poudrage & 2 & 479 & $\begin{array}{l}\text { Odds Ratio (M-H, Random, 95\% } \\
\mathrm{Cl} \text { ) }\end{array}$ & $1.65[0.42,6.48]$ \\
\hline 4.2 Talc slurry vs bleomycin & 3 & 98 & $\begin{array}{l}\text { Odds Ratio (M-H, Random, 95\% } \\
\mathrm{Cl} \text { ) }\end{array}$ & $0.95[0.36,2.51]$ \\
\hline 4.3 Talc slurry vs tetracycline & 1 & 34 & $\begin{array}{l}\text { Odds Ratio (M-H, Random, 95\% } \\
\mathrm{Cl} \text { ) }\end{array}$ & $1.09[0.28,4.32]$ \\
\hline 4.4 Talc slurry vs iodine & 1 & 36 & $\begin{array}{l}\text { Odds Ratio (M-H, Random, 95\% } \\
\mathrm{Cl} \text { ) }\end{array}$ & $1.6[0.23,10.94]$ \\
\hline 4.5 Talc slurry vs silver nitrate & 1 & 60 & $\begin{array}{l}\text { Odds Ratio (M-H, Random, 95\% } \\
\mathrm{Cl} \text { ) }\end{array}$ & $0.7[0.15,3.24]$ \\
\hline
\end{tabular}

Analysis 2.1. Comparison 2 Talc slurry, Outcome 1 Pleurodesis failure.

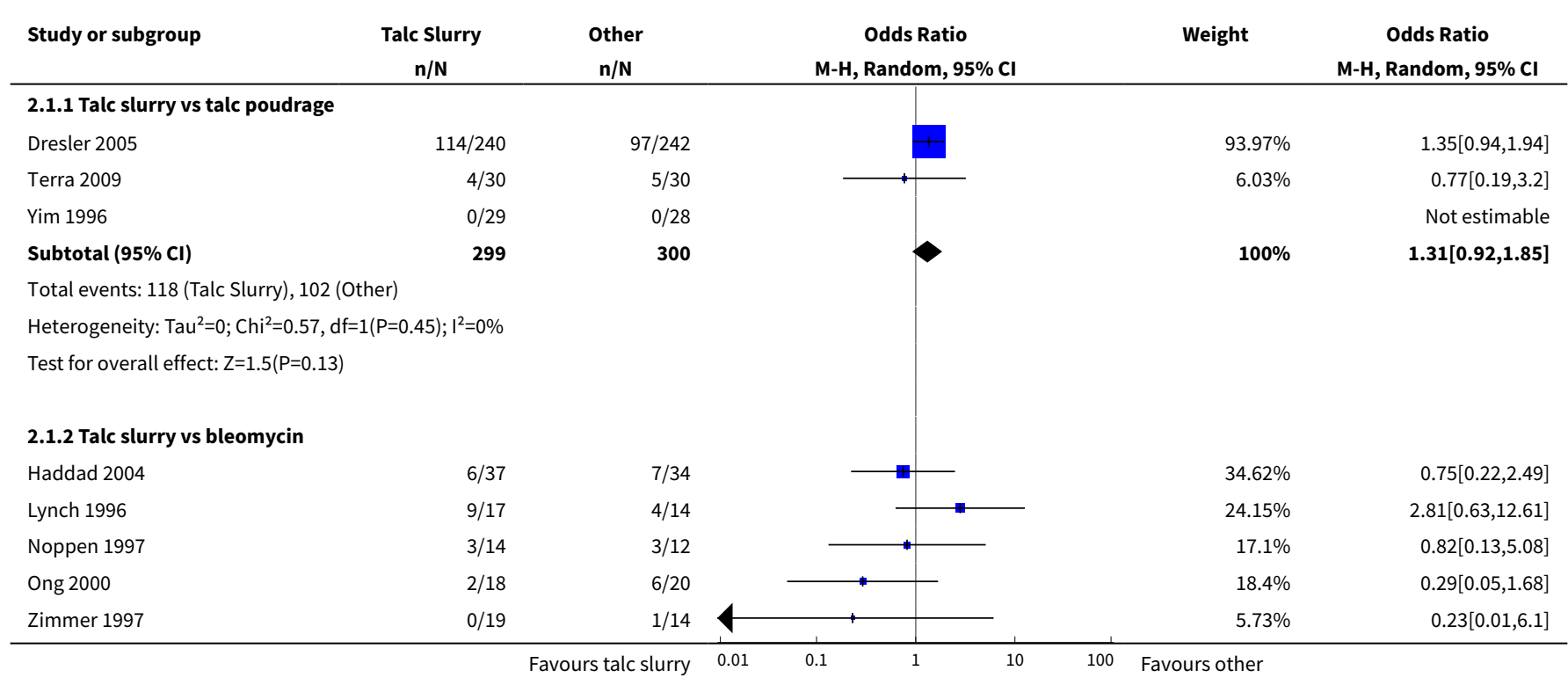




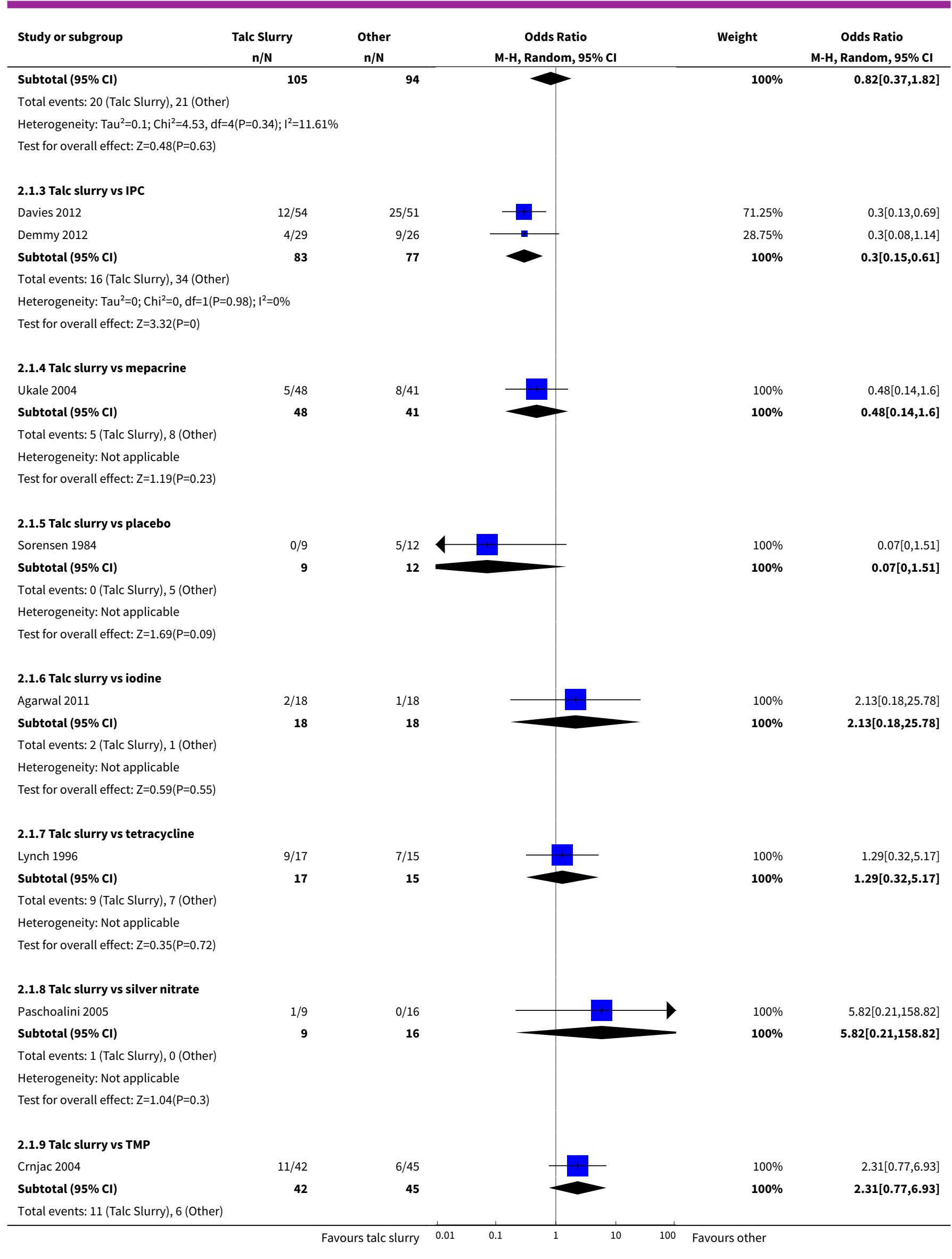




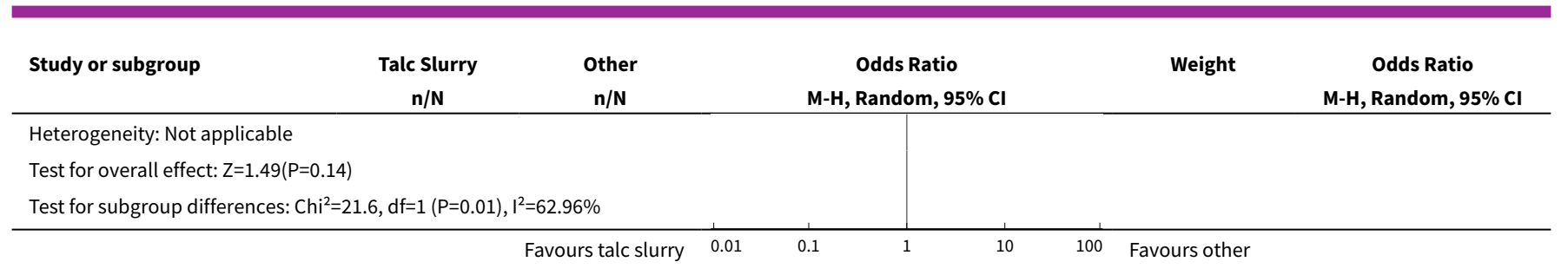

\section{Analysis 2.2. Comparison 2 Talc slurry, Outcome 2 Mortality.}

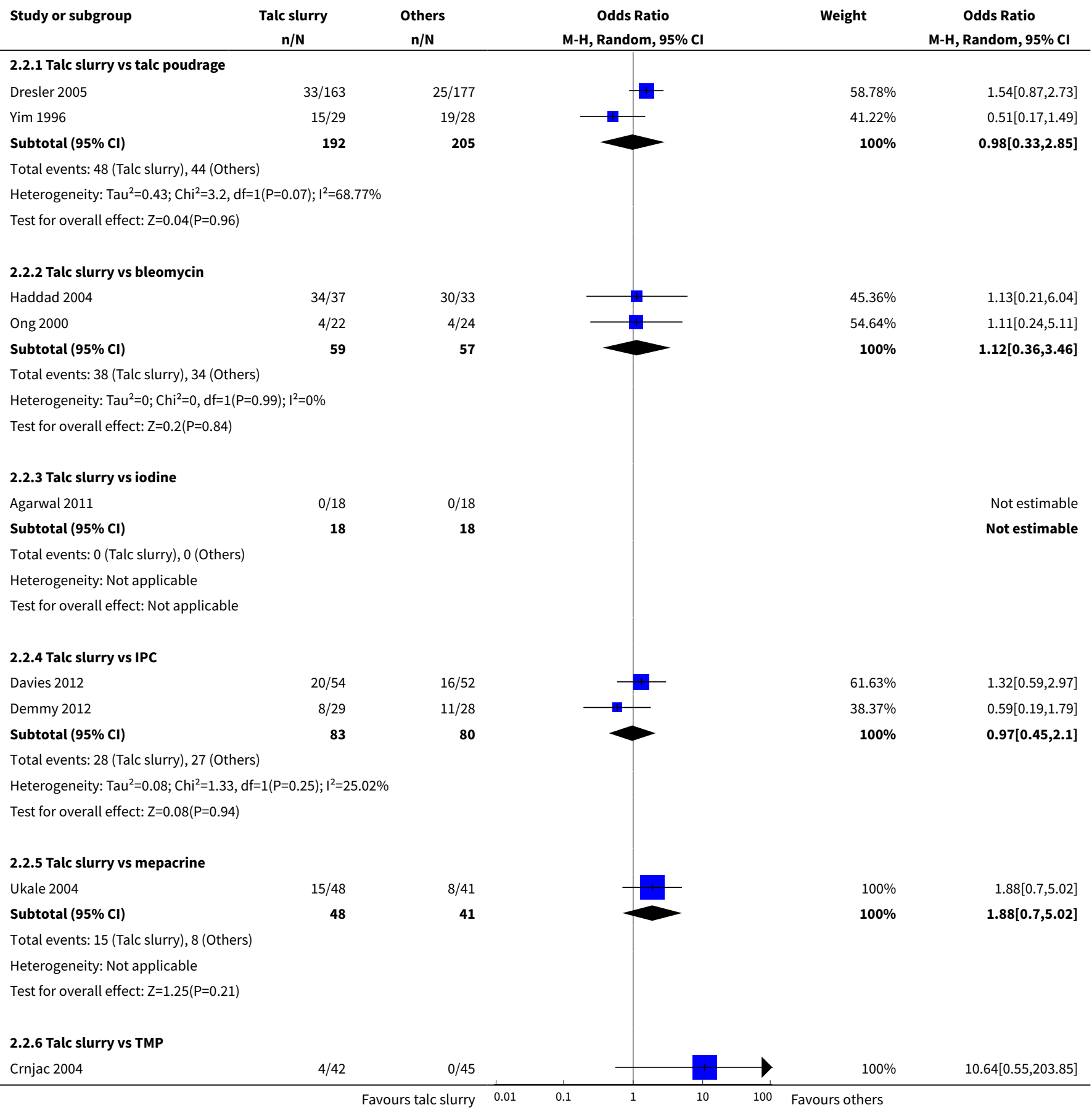




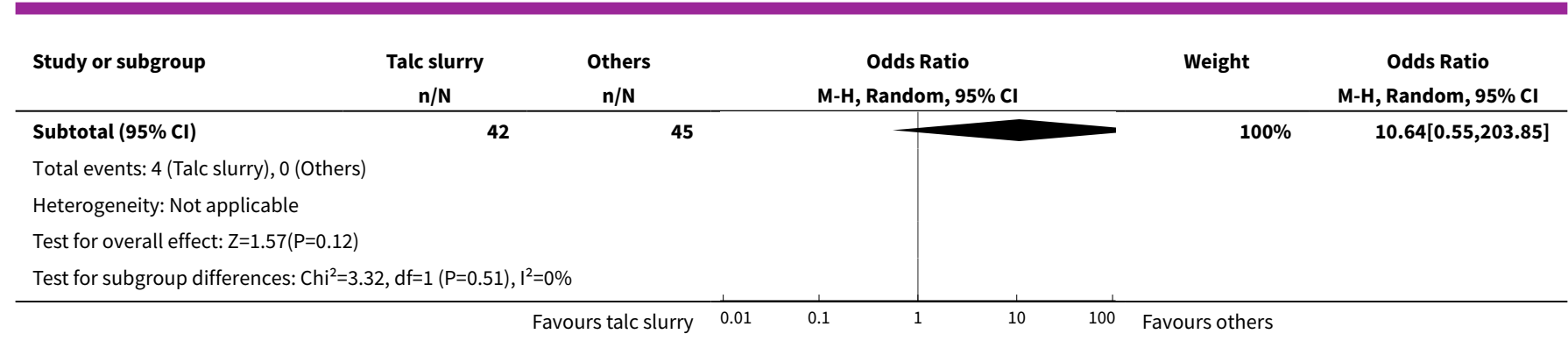

Analysis 2.3. Comparison 2 Talc slurry, Outcome 3 Pain.

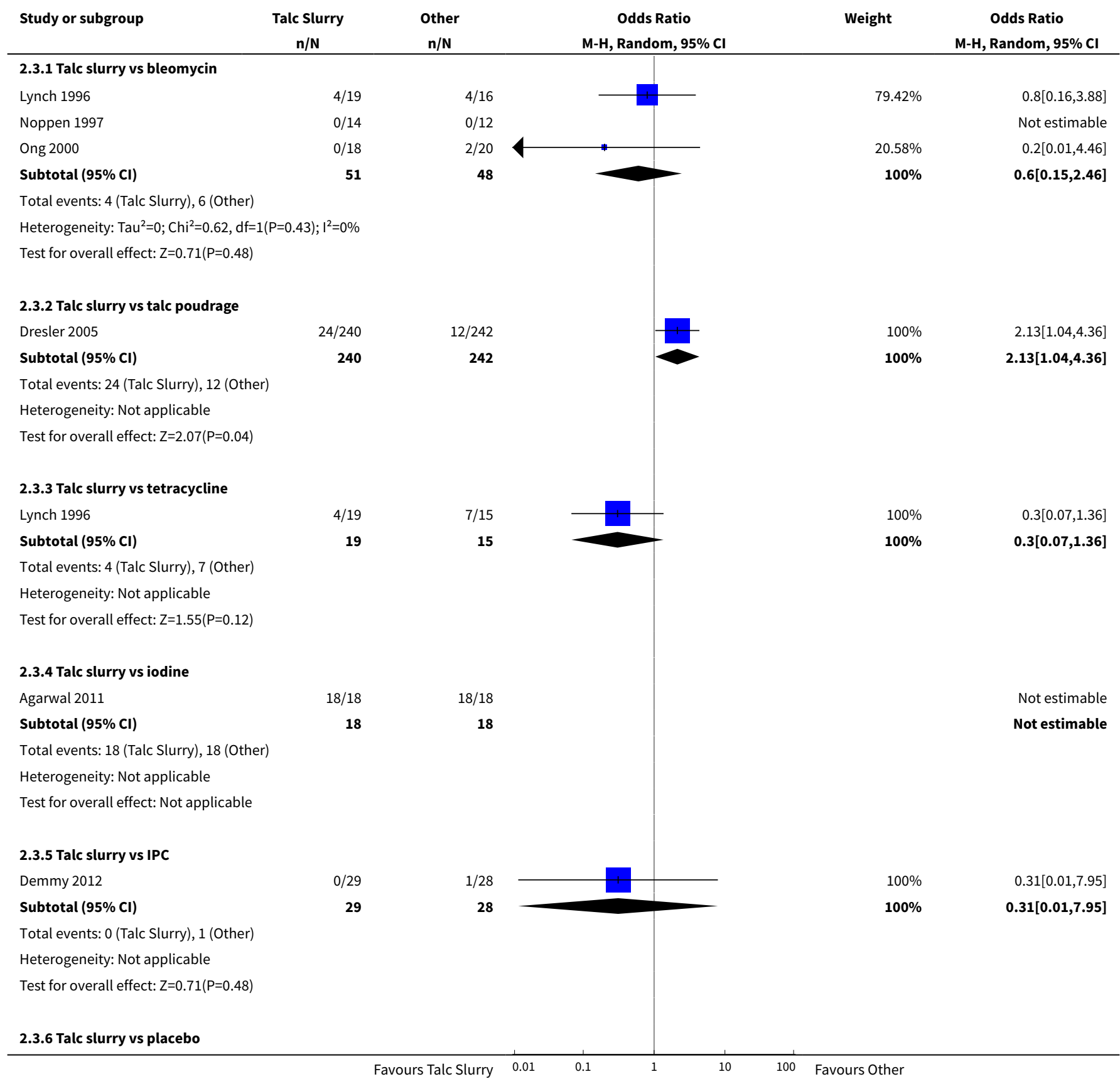




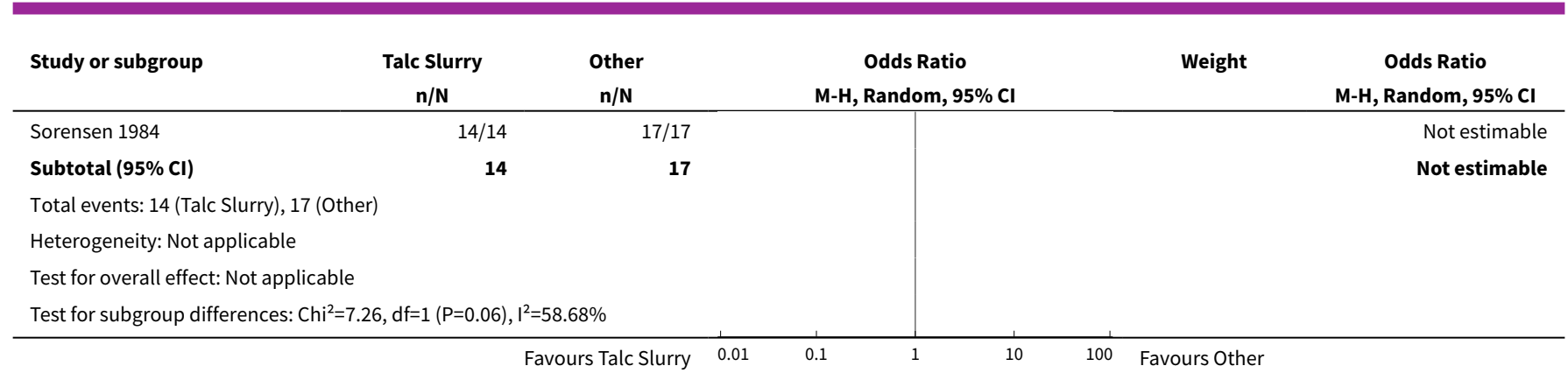

\section{Analysis 2.4. Comparison 2 Talc slurry, Outcome 4 Fever.}

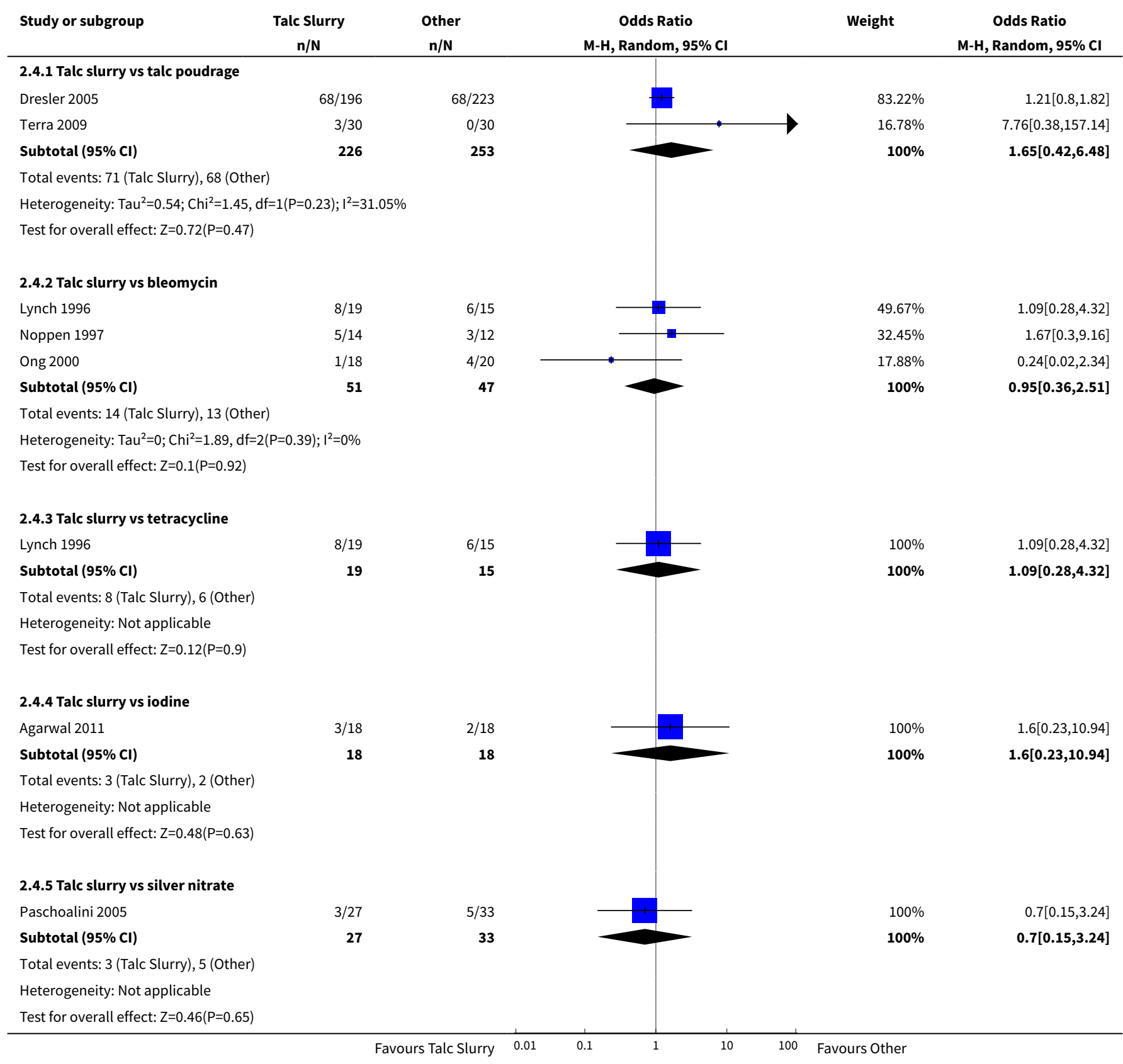




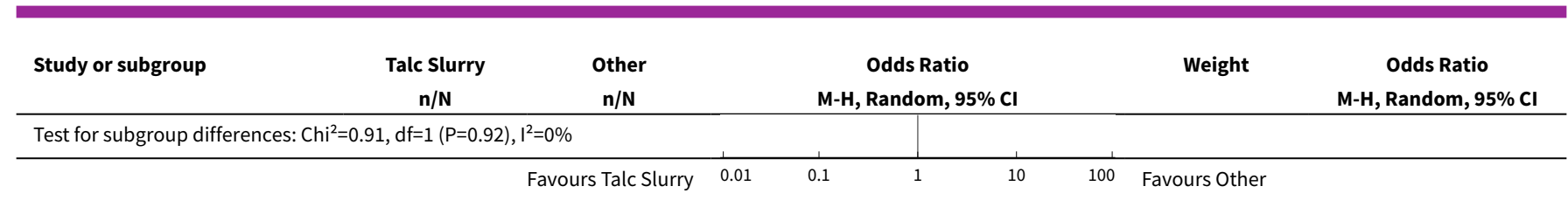

\section{Comparison 3. Talc poudrage}

\begin{tabular}{|c|c|c|c|c|}
\hline Outcome or subgroup title & $\begin{array}{l}\text { No. of } \\
\text { studies }\end{array}$ & $\begin{array}{l}\text { No. of } \\
\text { partici- } \\
\text { pants }\end{array}$ & Statistical method & Effect size \\
\hline 1 Pleurodesis failure & 9 & & $\begin{array}{l}\text { Odds Ratio (M-H, Fixed, 95\% } \\
\mathrm{Cl} \text { ) }\end{array}$ & Subtotals only \\
\hline 1.1 Talc poudrage vs talc slurry & 3 & 599 & $\begin{array}{l}\text { Odds Ratio (M-H, Fixed, 95\% } \\
\mathrm{Cl} \text { ) }\end{array}$ & $0.77[0.54,1.09]$ \\
\hline 1.2 Talc poudrage vs bleomycin & 2 & 57 & $\begin{array}{l}\text { Odds Ratio (M-H, Fixed, 95\% } \\
\mathrm{Cl} \text { ) }\end{array}$ & $0.10[0.02,0.48]$ \\
\hline 1.3 Talc poudrage vs tetracycline & 1 & 33 & $\begin{array}{l}\text { Odds Ratio (M-H, Fixed, 95\% } \\
\mathrm{Cl} \text { ) }\end{array}$ & $0.08[0.01,0.76]$ \\
\hline 1.4 Talc poudrage vs iodine & 1 & 42 & $\begin{array}{l}\text { Odds Ratio (M-H, Fixed, 95\% } \\
\mathrm{Cl} \text { ) }\end{array}$ & $0.57[0.08,3.80]$ \\
\hline 1.5 Talc poudrage vs mustine & 1 & 37 & $\begin{array}{l}\text { Odds Ratio (M-H, Fixed, 95\% } \\
\mathrm{Cl} \text { ) }\end{array}$ & $0.13[0.02,0.71]$ \\
\hline 1.6 Talc poudrage vs doxycycline & 1 & 31 & $\begin{array}{l}\text { Odds Ratio (M-H, Fixed, 95\% } \\
\mathrm{Cl} \text { ) }\end{array}$ & $0.02[0.00,0.47]$ \\
\hline 2 Mortality & 6 & & $\begin{array}{l}\text { Odds Ratio (M-H, Random, } \\
95 \% \mathrm{Cl})\end{array}$ & Subtotals only \\
\hline 2.1 Talc poudrage vs talc slurry & 2 & 397 & $\begin{array}{l}\text { Odds Ratio (M-H, Random, } \\
95 \% \mathrm{Cl})\end{array}$ & $1.02[0.35,3.00]$ \\
\hline 2.2 Talc poudrage vs bleomycin & 1 & 32 & $\begin{array}{l}\text { Odds Ratio (M-H, Random, } \\
95 \% \mathrm{Cl})\end{array}$ & $1.22[0.29,5.13]$ \\
\hline 2.3 Talc poudrage vs tetracycline & 1 & 41 & $\begin{array}{l}\text { Odds Ratio (M-H, Random, } \\
95 \% \mathrm{Cl})\end{array}$ & $5.25[0.91,30.22]$ \\
\hline 2.4 Talc poudrage vs iodine & 1 & 42 & $\begin{array}{l}\text { Odds Ratio (M-H, Random, } \\
95 \% \mathrm{Cl})\end{array}$ & $2.64[0.58,12.09]$ \\
\hline 2.5 Talc poudrage vs mustine & 1 & 46 & $\begin{array}{l}\text { Odds Ratio (M-H, Random, } \\
95 \% \mathrm{Cl})\end{array}$ & $0.43[0.09,1.96]$ \\
\hline 3 Pain & 3 & & $\begin{array}{l}\text { Odds Ratio (M-H, Random, } \\
95 \% \mathrm{Cl})\end{array}$ & Subtotals only \\
\hline 3.1 Talc poudrage vs talc slurry & 1 & 482 & $\begin{array}{l}\text { Odds Ratio (M-H, Random, } \\
95 \% \mathrm{Cl})\end{array}$ & $0.47[0.23,0.96]$ \\
\hline
\end{tabular}




\begin{tabular}{|c|c|c|c|c|}
\hline Outcome or subgroup title & $\begin{array}{l}\text { No. of } \\
\text { studies }\end{array}$ & $\begin{array}{l}\text { No. of } \\
\text { partici- } \\
\text { pants }\end{array}$ & Statistical method & Effect size \\
\hline 3.2 Talc poudrage vs bleomycin & 1 & 32 & $\begin{array}{l}\text { Odds Ratio (M-H, Random, } \\
95 \% \mathrm{Cl})\end{array}$ & $3.62[0.14,95.78]$ \\
\hline 3.3 Talc poudrage vs iodine & 1 & 42 & $\begin{array}{l}\text { Odds Ratio (M-H, Random, } \\
95 \% \mathrm{Cl})\end{array}$ & $9.97[0.50,198.04]$ \\
\hline 4 Fever & 4 & & $\begin{array}{l}\text { Odds Ratio (M-H, Random, } \\
95 \% \mathrm{Cl})\end{array}$ & Subtotals only \\
\hline 4.1 Talc poudrage vs talc slurry & 2 & 479 & $\begin{array}{l}\text { Odds Ratio (M-H, Random, } \\
95 \% \mathrm{Cl} \text { ) }\end{array}$ & $0.60[0.15,2.37]$ \\
\hline 4.2 Talc poudrage vs bleomycin & 1 & 32 & $\begin{array}{l}\text { Odds Ratio (M-H, Random, } \\
95 \% \mathrm{Cl})\end{array}$ & $1.15[0.14,9.38]$ \\
\hline 4.3 Talc poudrage vs iodine & 1 & 42 & $\begin{array}{l}\text { Odds Ratio (M-H, Random, } \\
95 \% \mathrm{Cl})\end{array}$ & $4.22[0.43,41.45]$ \\
\hline
\end{tabular}

Analysis 3.1. Comparison 3 Talc poudrage, Outcome 1 Pleurodesis failure.

\begin{tabular}{|c|c|c|c|c|c|}
\hline Study or subgroup & $\begin{array}{c}\text { Talc poudrage } \\
\mathrm{n} / \mathrm{N} \\
\end{array}$ & $\begin{array}{c}\text { Other } \\
\mathrm{n} / \mathrm{N}\end{array}$ & $\begin{array}{c}\text { Odds Ratio } \\
\text { M-H, Fixed, 95\% CI }\end{array}$ & Weight & $\begin{array}{c}\text { Odds Ratio } \\
\text { M-H, Fixed, } 95 \% \mathrm{Cl}\end{array}$ \\
\hline \multicolumn{6}{|c|}{ 3.1.1 Talc poudrage vs talc slurry } \\
\hline Dresler 2005 & $97 / 242$ & $114 / 240$ & & $95.37 \%$ & $0.74[0.52,1.06]$ \\
\hline Terra 2009 & $5 / 30$ & $4 / 30$ & & $4.63 \%$ & $1.3[0.31,5.4]$ \\
\hline Yim 1996 & $0 / 28$ & $0 / 29$ & & & Not estimable \\
\hline Subtotal $(95 \% \mathrm{Cl})$ & 300 & 299 & & $100 \%$ & $0.77[0.54,1.09]$ \\
\hline \multicolumn{6}{|c|}{ Total events: 102 (Talc poudrage), 118 (Other) } \\
\hline \multicolumn{6}{|c|}{ Heterogeneity: $\operatorname{Tau}^{2}=0 ; \mathrm{Chi}^{2}=0.57, \mathrm{df}=1(\mathrm{P}=0.45) ; \mathrm{I}^{2}=0 \%$} \\
\hline \multicolumn{6}{|c|}{ Test for overall effect: $Z=1.5(P=0.13)$} \\
\hline \multicolumn{6}{|c|}{ 3.1.2 Talc poudrage vs bleomycin } \\
\hline Diacon 2000 & $2 / 15$ & $10 / 17$ & & $65.51 \%$ & $0.11[0.02,0.64]$ \\
\hline Hamed 1989 & $0 / 10$ & $5 / 15$ & & $34.49 \%$ & $0.09[0,1.86]$ \\
\hline \multicolumn{6}{|c|}{ Total events: 2 (Talc poudrage), 15 (Other) } \\
\hline \multicolumn{6}{|c|}{ Heterogeneity: Tau $^{2}=0 ; \mathrm{Chi}^{2}=0.01, \mathrm{df}=1(\mathrm{P}=0.92) ; \mathrm{I}^{2}=0 \%$} \\
\hline \multicolumn{6}{|c|}{ Test for overall effect: $Z=2.9(P=0)$} \\
\hline \multicolumn{6}{|c|}{ 3.1.3 Talc poudrage vs tetracycline } \\
\hline Fentiman 1986 & $1 / 12$ & $11 / 21$ & & $100 \%$ & $0.08[0.01,0.76]$ \\
\hline Subtotal $(95 \% \mathrm{Cl})$ & 12 & 21 & & $100 \%$ & $0.08[0.01,0.76]$ \\
\hline \multicolumn{6}{|c|}{ Total events: 1 (Talc poudrage), 11 (Other) } \\
\hline \multicolumn{6}{|c|}{ Heterogeneity: Not applicable } \\
\hline \multicolumn{6}{|c|}{ Test for overall effect: $Z=2.2(P=0.03)$} \\
\hline \multicolumn{6}{|c|}{ 3.1.4 Talc poudrage vs iodine } \\
\hline Mohsen 2011 & $2 / 22$ & $3 / 20$ & & $100 \%$ & $0.57[0.08,3.8]$ \\
\hline
\end{tabular}




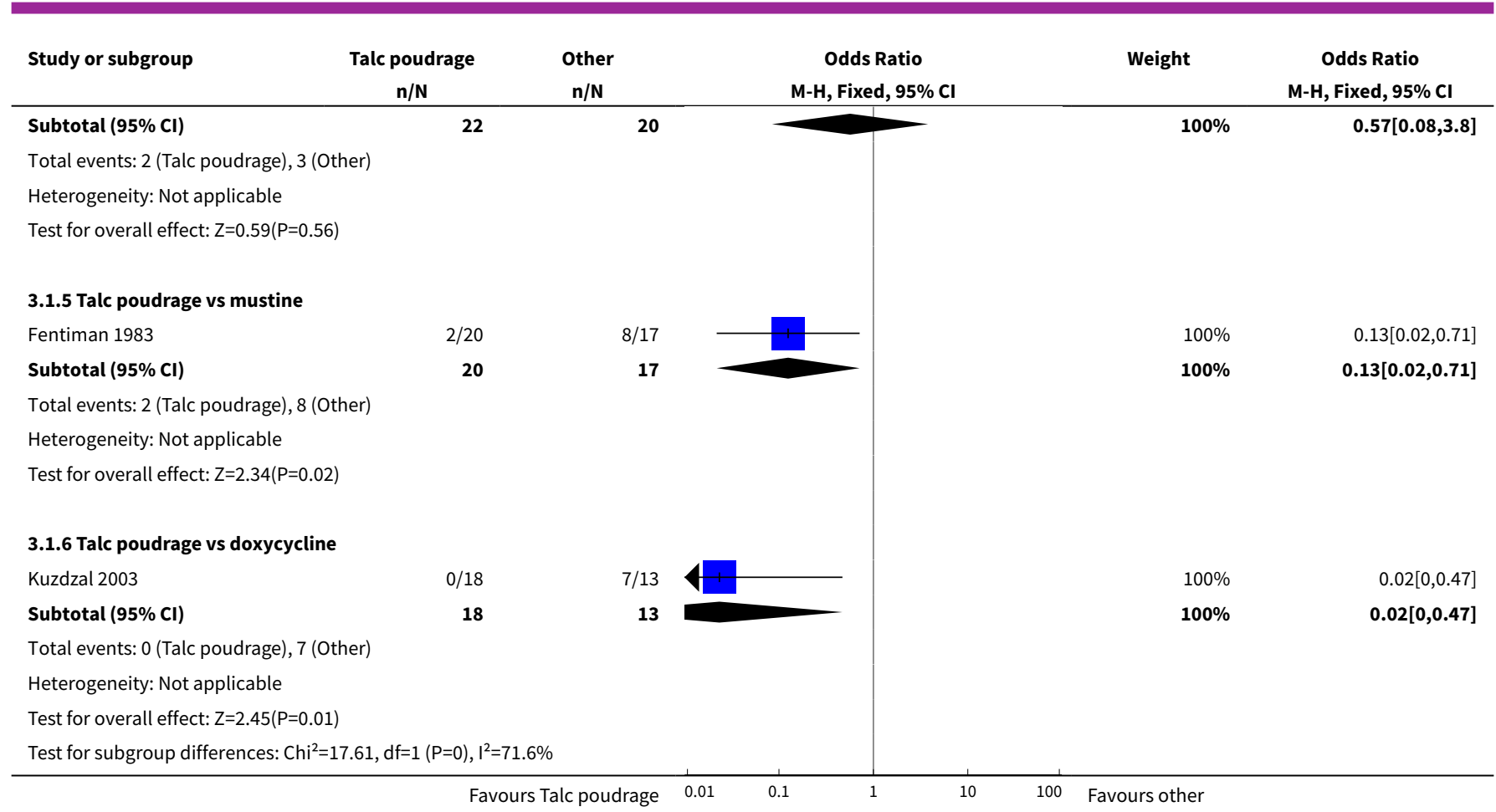

Analysis 3.2. Comparison 3 Talc poudrage, Outcome 2 Mortality.

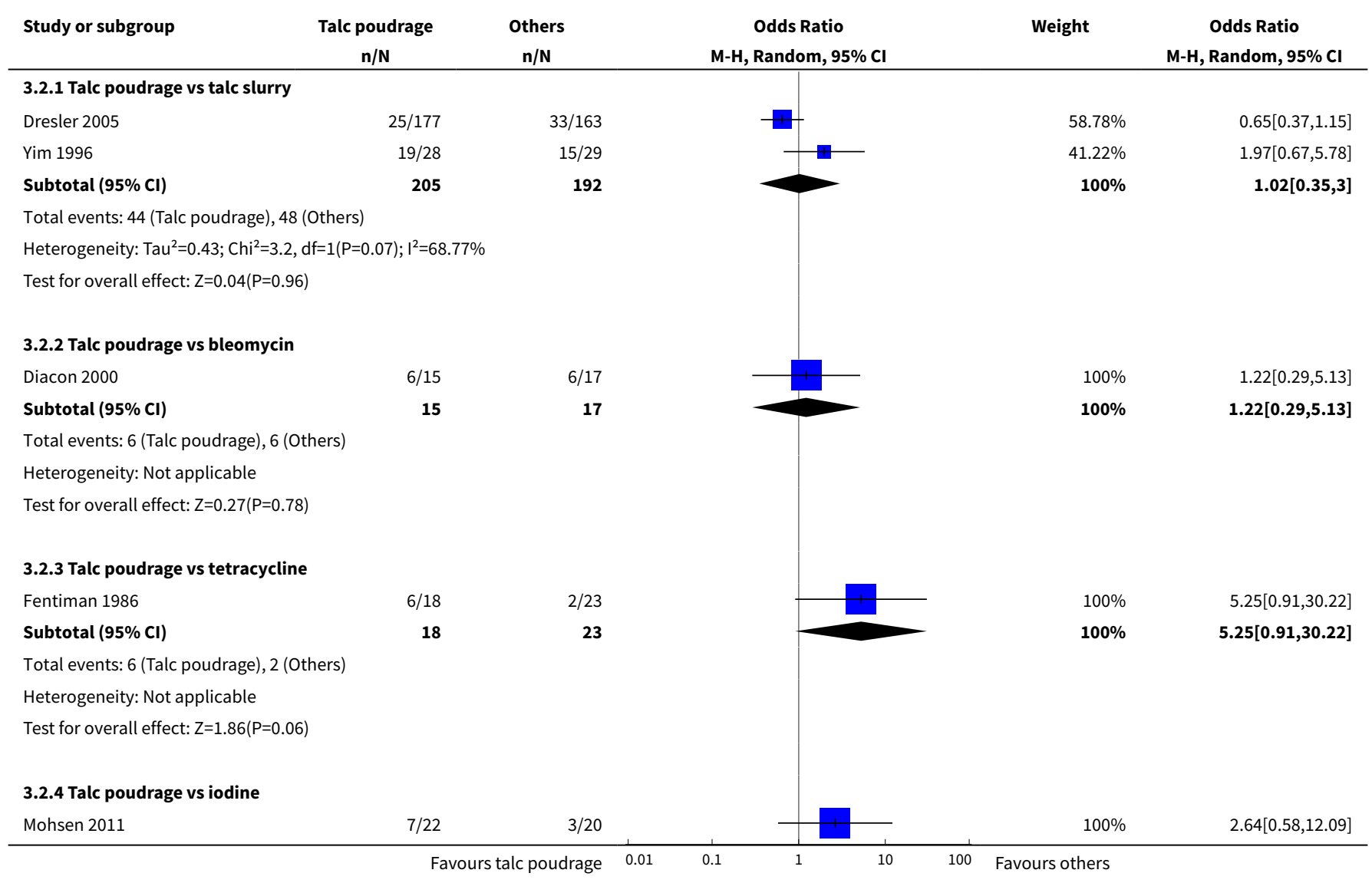




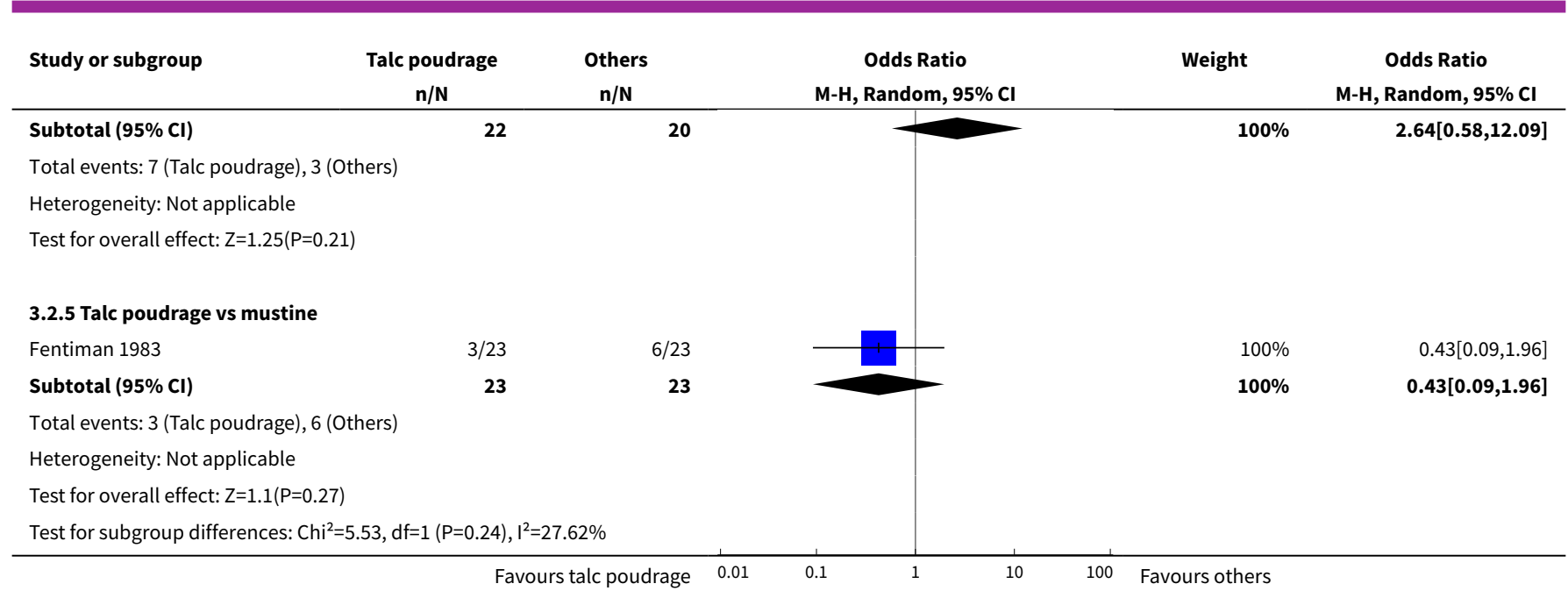

Analysis 3.3. Comparison 3 Talc poudrage, Outcome 3 Pain.

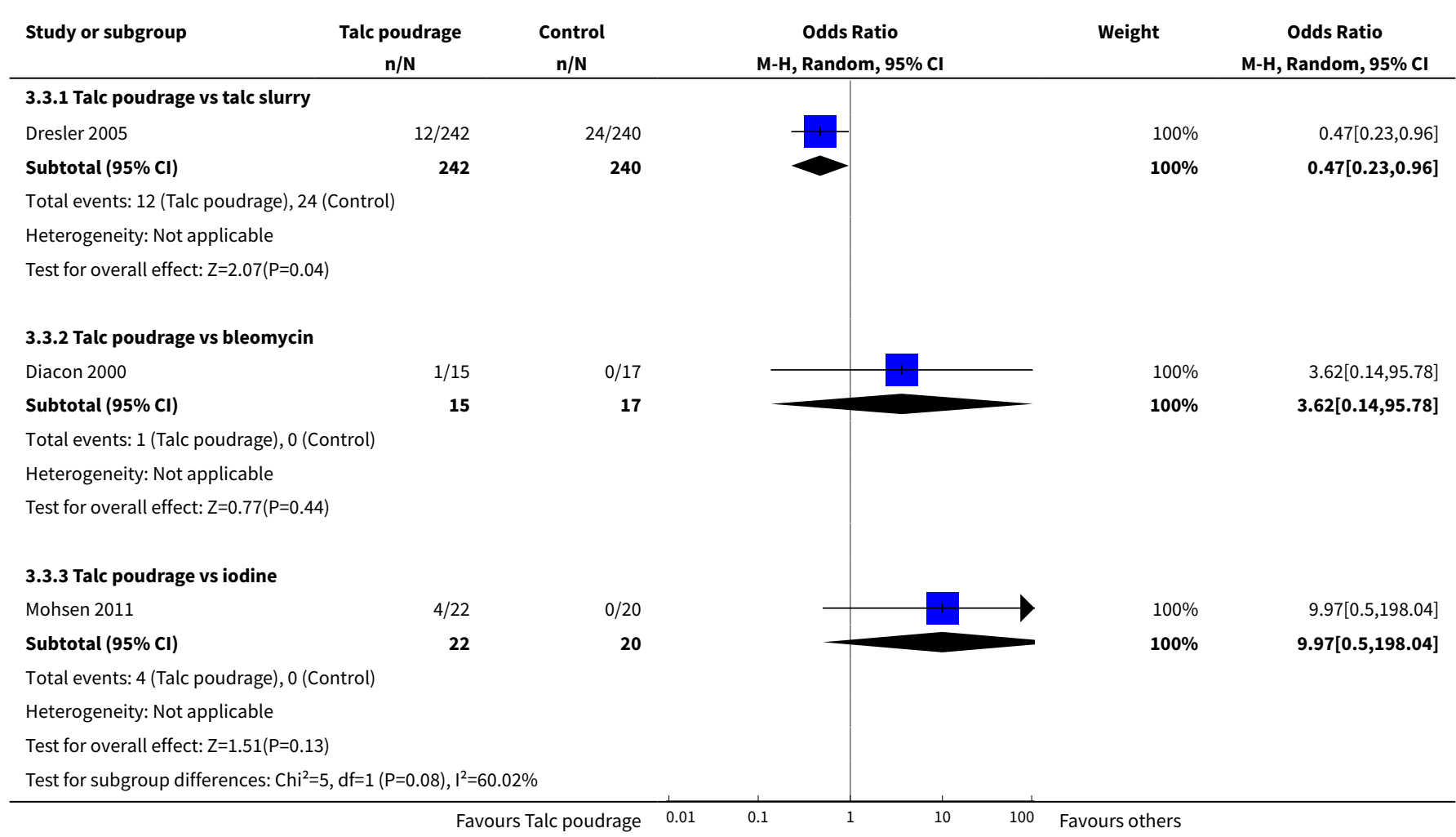

Analysis 3.4. Comparison 3 Talc poudrage, Outcome 4 Fever.

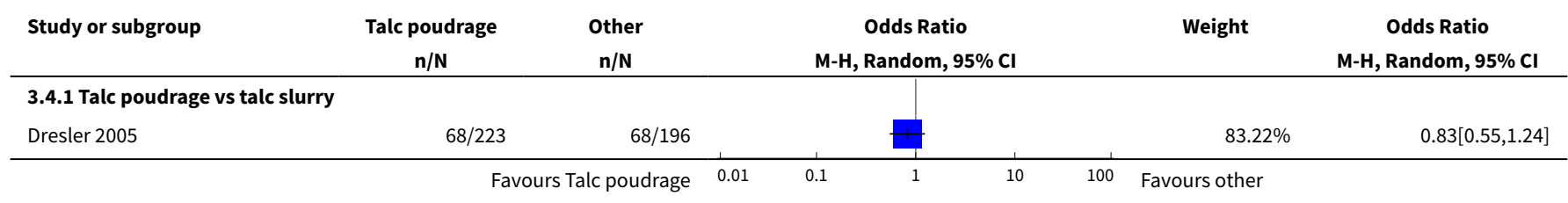




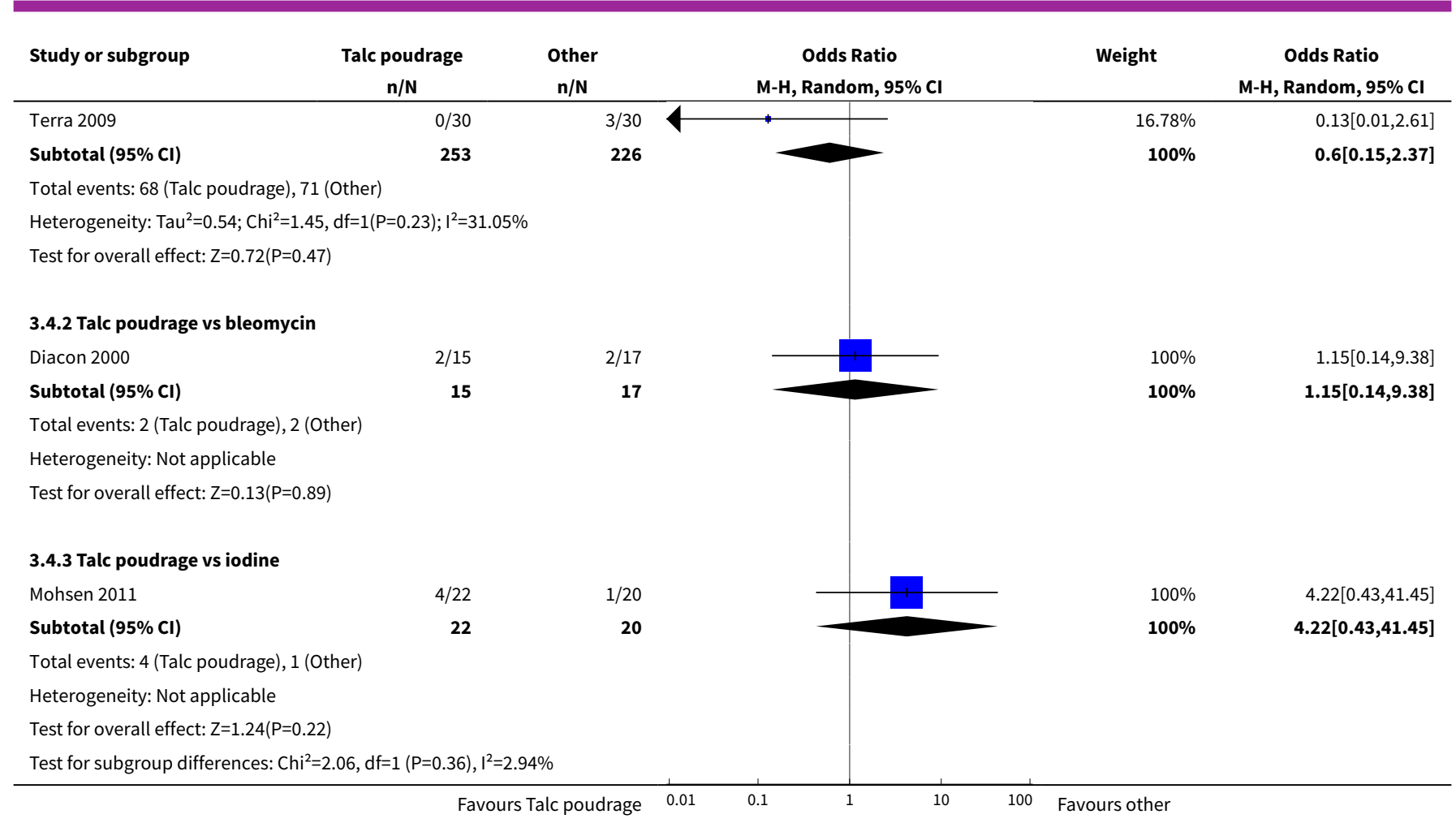

\section{Comparison 4. Tetracycline}

\begin{tabular}{|c|c|c|c|c|}
\hline Outcome or subgroup title & $\begin{array}{l}\text { No. of } \\
\text { studies }\end{array}$ & $\begin{array}{l}\text { No. of } \\
\text { partici- } \\
\text { pants }\end{array}$ & Statistical method & Effect size \\
\hline 1 Pleurodesis failure & 11 & & $\begin{array}{l}\text { Odds Ratio (M-H, Random, } \\
95 \% \mathrm{Cl})\end{array}$ & Subtotals only \\
\hline 1.1 Tetracycline vs C. parvum & 1 & 32 & $\begin{array}{l}\text { Odds Ratio (M-H, Random, } \\
95 \% \mathrm{Cl})\end{array}$ & $3.18[0.52,19.64]$ \\
\hline 1.2 Tetracycline vs talc slurry & 1 & 32 & $\begin{array}{l}\text { Odds Ratio (M-H, Random, } \\
95 \% \mathrm{Cl})\end{array}$ & $0.78[0.19,3.13]$ \\
\hline 1.3 Tetracycline vs Adriamycin & 1 & 21 & $\begin{array}{l}\text { Odds Ratio (M-H, Random, } \\
95 \% \mathrm{Cl})\end{array}$ & $0.9[0.05,16.59]$ \\
\hline 1.4 Tetracyclines vs placebo & 1 & 20 & $\begin{array}{l}\text { Odds Ratio (M-H, Random, } \\
95 \% \mathrm{Cl})\end{array}$ & $0.30[0.05,1.94]$ \\
\hline 1.5 Tetracycline vs talc poudrage & 1 & 33 & $\begin{array}{l}\text { Odds Ratio (M-H, Random, } \\
95 \% \mathrm{Cl})\end{array}$ & $12.10[1.32,111.30]$ \\
\hline 1.6 Tetracycline vs mustine & 2 & 59 & $\begin{array}{l}\text { Odds Ratio (M-H, Random, } \\
95 \% \mathrm{Cl})\end{array}$ & $0.37[0.10,1.35]$ \\
\hline $\begin{array}{l}\text { 1.7 Tetracycline vs combined tetracycline } \\
\text { and bleomycin }\end{array}$ & 1 & 38 & $\begin{array}{l}\text { Odds Ratio (M-H, Random, } \\
95 \% \mathrm{Cl})\end{array}$ & $8.27[0.40,172.05]$ \\
\hline
\end{tabular}




\begin{tabular}{|c|c|c|c|c|}
\hline Outcome or subgroup title & $\begin{array}{l}\text { No. of } \\
\text { studies }\end{array}$ & $\begin{array}{l}\text { No. of } \\
\text { partici- } \\
\text { pants }\end{array}$ & Statistical method & Effect size \\
\hline 1.8 Tetracycline vs bleomycin & 5 & 220 & $\begin{array}{l}\text { Odds Ratio (M-H, Random, } \\
95 \% \mathrm{Cl})\end{array}$ & $2.00[1.07,3.75]$ \\
\hline 1.9 Tetracycline vs mepacrine & 1 & 21 & $\begin{array}{l}\text { Odds Ratio (M-H, Random, } \\
95 \% \mathrm{Cl})\end{array}$ & $1.6[0.12,20.99]$ \\
\hline 2 Pain & 8 & & $\begin{array}{l}\text { Odds Ratio (M-H, Random, } \\
95 \% \mathrm{Cl})\end{array}$ & Subtotals only \\
\hline 2.1 Tetracycline vs talc slurry & 1 & 34 & $\begin{array}{l}\text { Odds Ratio (M-H, Random, } \\
95 \% \mathrm{Cl})\end{array}$ & $3.28[0.73,14.68]$ \\
\hline 2.2 Tetracycline vs bleomycin & 4 & 220 & $\begin{array}{l}\text { Odds Ratio (M-H, Random, } \\
95 \% \mathrm{Cl})\end{array}$ & $1.65[0.79,3.43]$ \\
\hline 2.3 Tetracycline vs C. parvum & 1 & 41 & $\begin{array}{l}\text { Odds Ratio (M-H, Random, } \\
95 \% \mathrm{Cl})\end{array}$ & $0.41[0.12,1.45]$ \\
\hline 2.4 Tetracycline vs mustine & 1 & 40 & $\begin{array}{l}\text { Odds Ratio (M-H, Random, } \\
95 \% \mathrm{Cl})\end{array}$ & $33.87[1.80,636.88]$ \\
\hline 2.5 Tetracycline vs mepacrine & 1 & 22 & $\begin{array}{l}\text { Odds Ratio (M-H, Random, } \\
95 \% \mathrm{Cl})\end{array}$ & $0.18[0.03,1.23]$ \\
\hline 2.6 Tetracycline vs placebo & 1 & 22 & $\begin{array}{l}\text { Odds Ratio (M-H, Random, } \\
95 \% \mathrm{Cl})\end{array}$ & $0.0[0.0,0.0]$ \\
\hline 3 Fever & 9 & & $\begin{array}{l}\text { Odds Ratio (M-H, Random, } \\
95 \% \mathrm{Cl})\end{array}$ & Subtotals only \\
\hline 3.1 Tetracycline vs talc slurry & 1 & 34 & $\begin{array}{l}\text { Odds Ratio (M-H, Random, } \\
95 \% \mathrm{Cl})\end{array}$ & $0.92[0.23,3.63]$ \\
\hline 3.2 Tetracycline vs bleomycin & 5 & 250 & $\begin{array}{l}\text { Odds Ratio (M-H, Random, } \\
95 \% \mathrm{Cl})\end{array}$ & $0.49[0.16,1.50]$ \\
\hline 3.3 Tetracycline vs C. parvum & 1 & 36 & $\begin{array}{l}\text { Odds Ratio (M-H, Random, } \\
95 \% \mathrm{Cl})\end{array}$ & $0.00[0.00,0.06]$ \\
\hline 3.4 Tetracycline vs mepacrine & 1 & 22 & $\begin{array}{l}\text { Odds Ratio }(\mathrm{M}-\mathrm{H}, \text { Random, } \\
95 \% \mathrm{Cl})\end{array}$ & $0.13[0.02,0.89]$ \\
\hline $\begin{array}{l}3.5 \text { Tetracycline vs combination tetracycline } \\
\text { and bleomycin }\end{array}$ & 1 & 40 & $\begin{array}{l}\text { Odds Ratio (M-H, Random, } \\
95 \% \mathrm{Cl})\end{array}$ & $0.47[0.04,5.69]$ \\
\hline 3.6 Tetracycline vs placebo & 1 & 22 & $\begin{array}{l}\text { Odds Ratio (M-H, Random, } \\
95 \% \mathrm{Cl})\end{array}$ & $0.0[0.0,0.0]$ \\
\hline 3.7 Tetracycline vs mustine & 1 & 40 & $\begin{array}{l}\text { Odds Ratio (M-H, Random, } \\
95 \% \mathrm{Cl})\end{array}$ & $0.0[0.0,0.0]$ \\
\hline 4 Mortality & 4 & 202 & $\begin{array}{l}\text { Odds Ratio (M-H, Random, } \\
95 \% \mathrm{Cl})\end{array}$ & $0.99[0.30,3.26]$ \\
\hline
\end{tabular}




\begin{tabular}{lllll}
\hline Outcome or subgroup title & $\begin{array}{l}\text { No. of } \\
\text { studies }\end{array}$ & $\begin{array}{l}\text { No. of } \\
\text { partici- } \\
\text { pants }\end{array}$ & Statistical method & Effect size \\
\hline 4.1 Tetracycline vs talc poudrage & 1 & 41 & $\begin{array}{l}\text { Odds Ratio (M-H, Random, } \\
95 \% \mathrm{Cl})\end{array}$ & $0.19[0.03,1.10]$ \\
\hline 4.2 Tetracycline vs bleomycin & 2 & 125 & $\begin{array}{l}\text { Odds Ratio (M-H, Random, } \\
95 \% \mathrm{Cl})\end{array}$ & $1.60[0.69,3.69]$ \\
\hline 4.3 Tetracycline vs C. parvum & 1 & 36 & $\begin{array}{l}\text { Odds Ratio (M-H, Random, } \\
95 \% \mathrm{Cl})\end{array}$ & $3.0[0.28,31.99]$ \\
\hline
\end{tabular}

Analysis 4.1. Comparison 4 Tetracycline, Outcome 1 Pleurodesis failure.

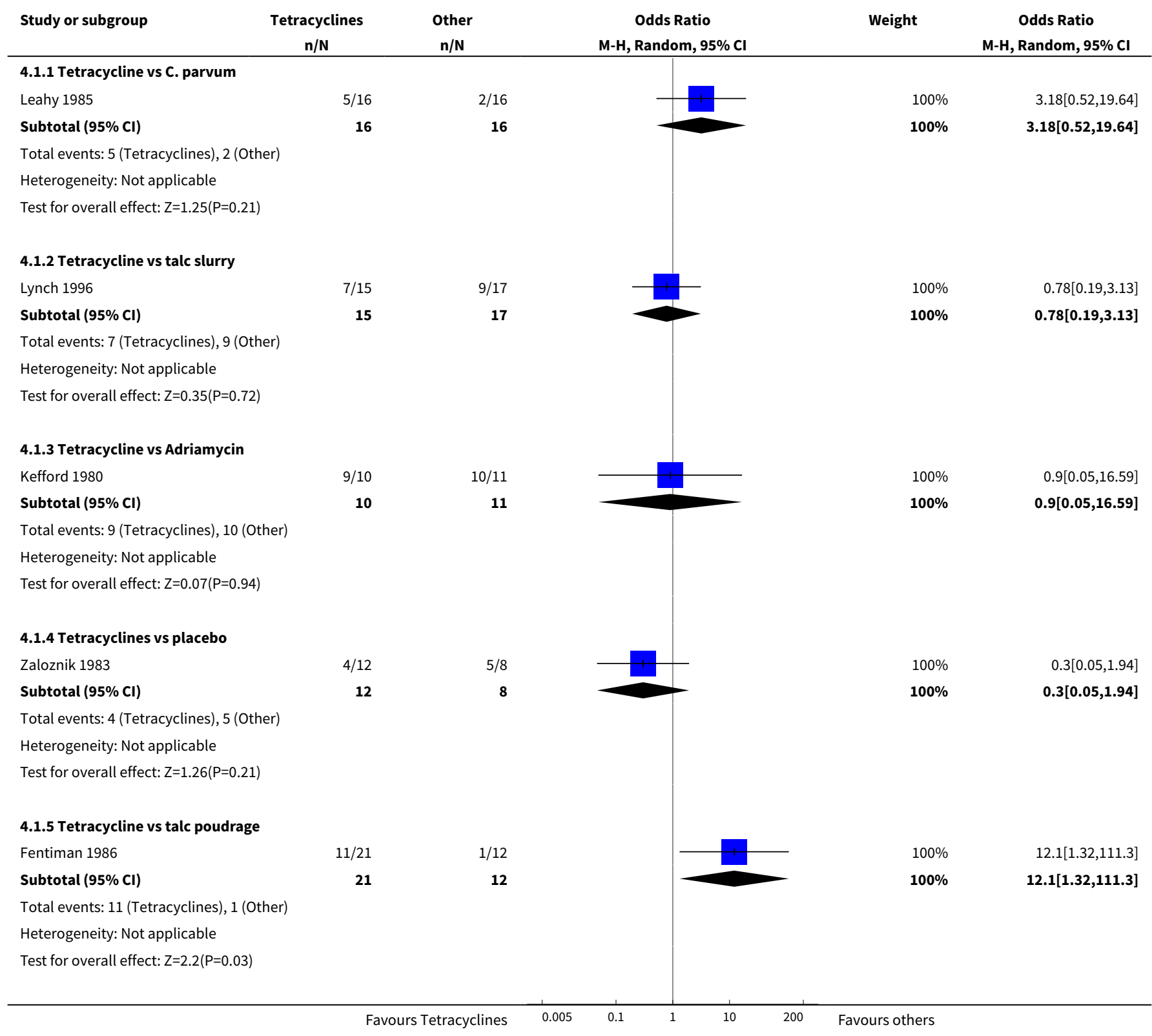




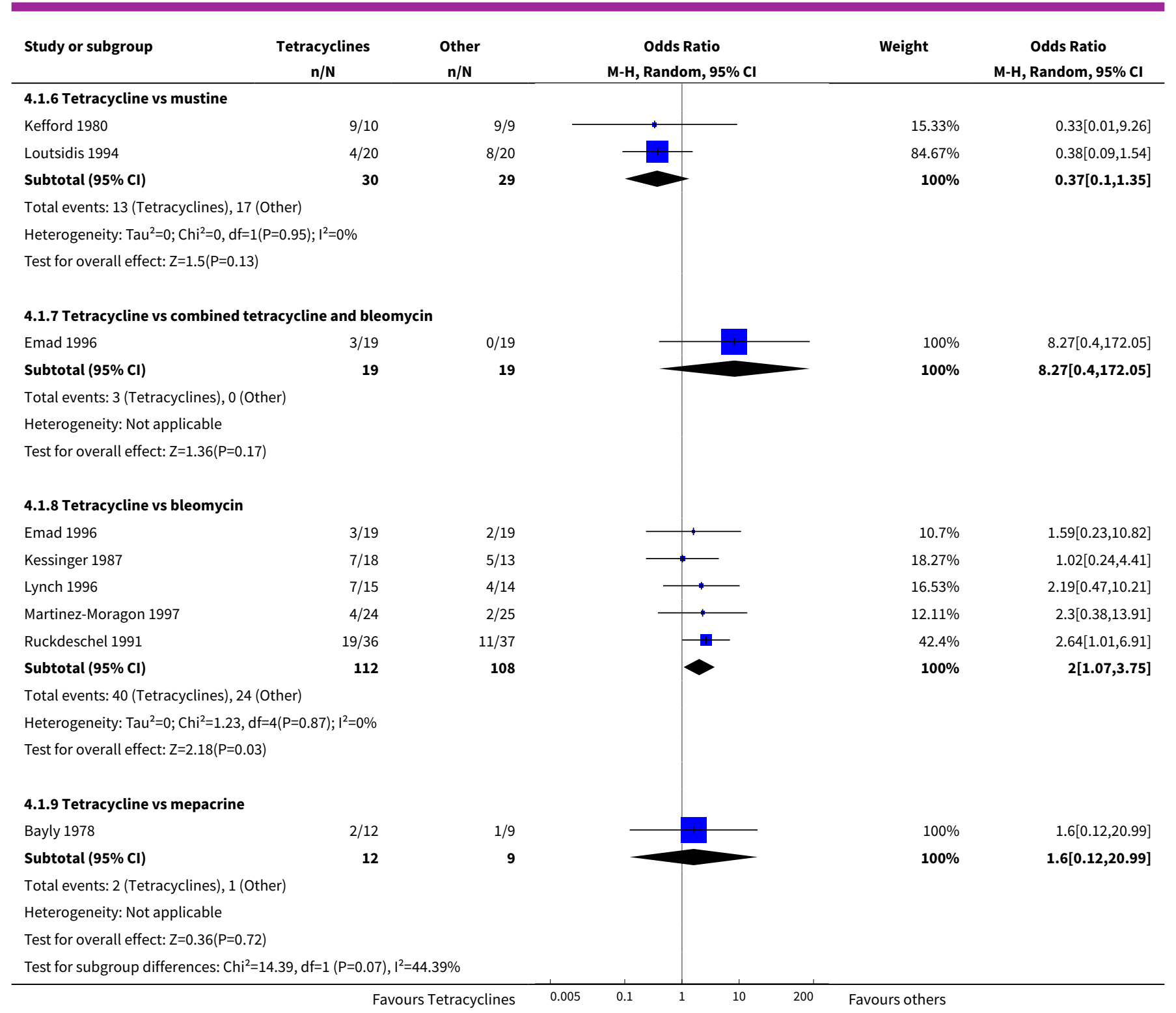

Analysis 4.2. Comparison 4 Tetracycline, Outcome 2 Pain.

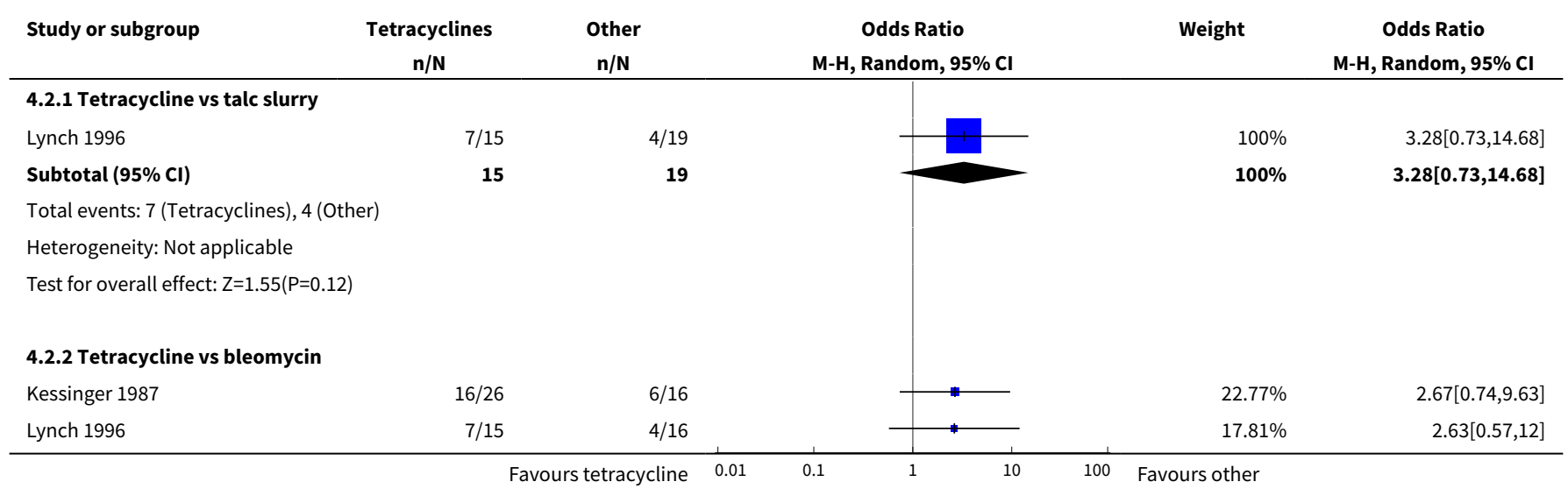




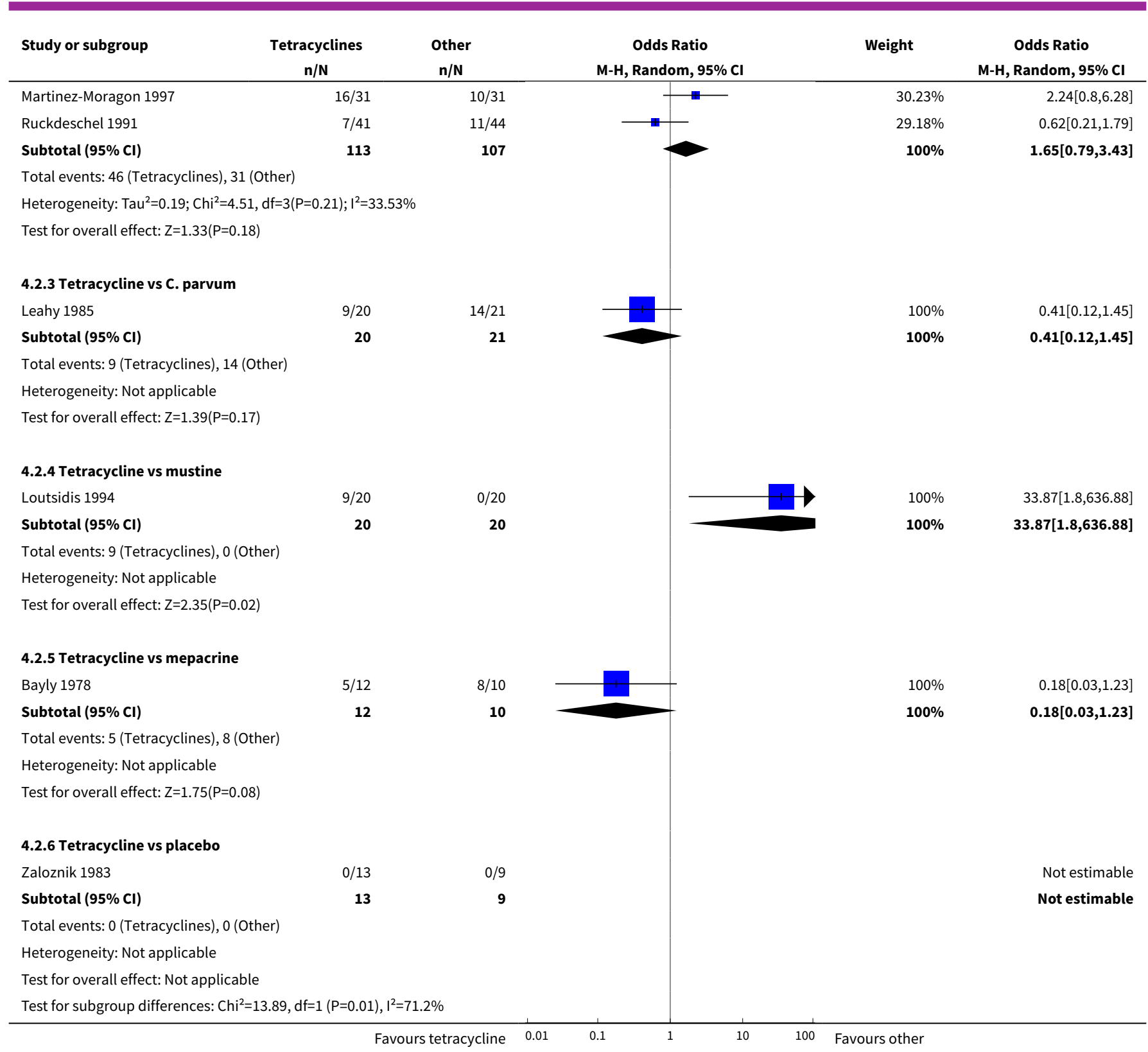

Analysis 4.3. Comparison 4 Tetracycline, Outcome 3 Fever.

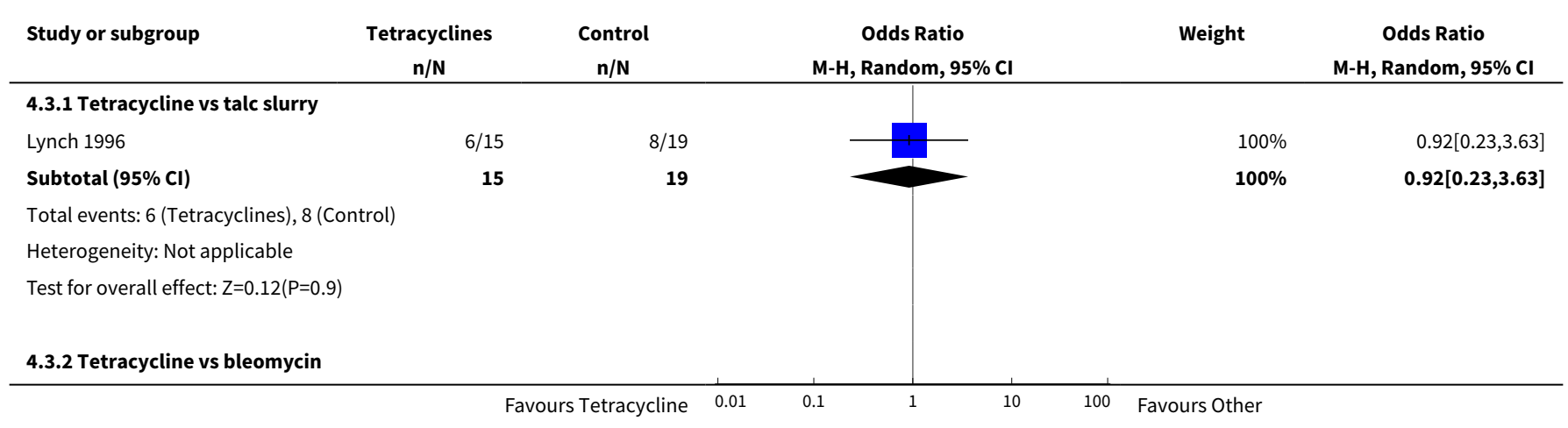




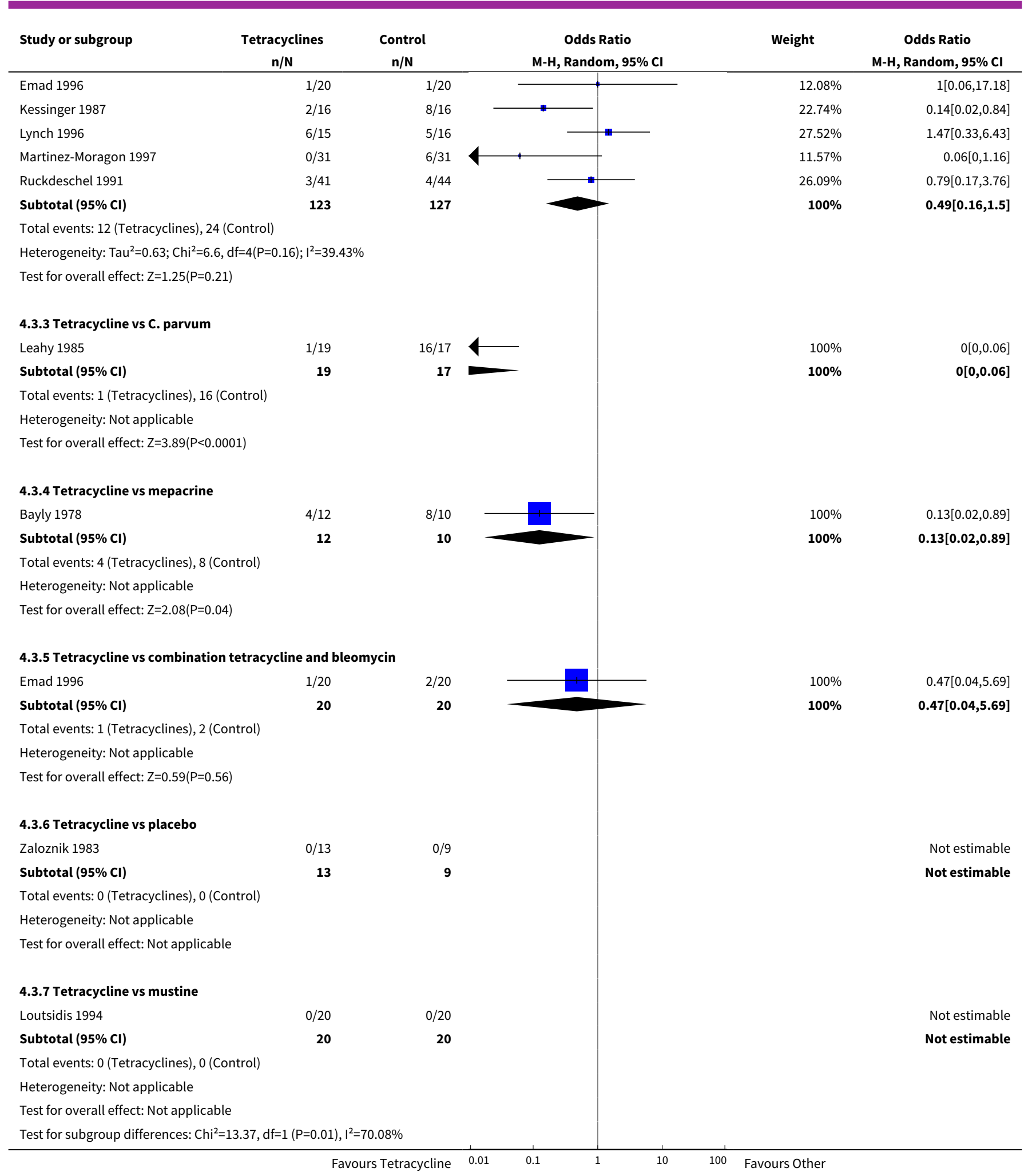




\section{Analysis 4.4. Comparison 4 Tetracycline, Outcome 4 Mortality.}

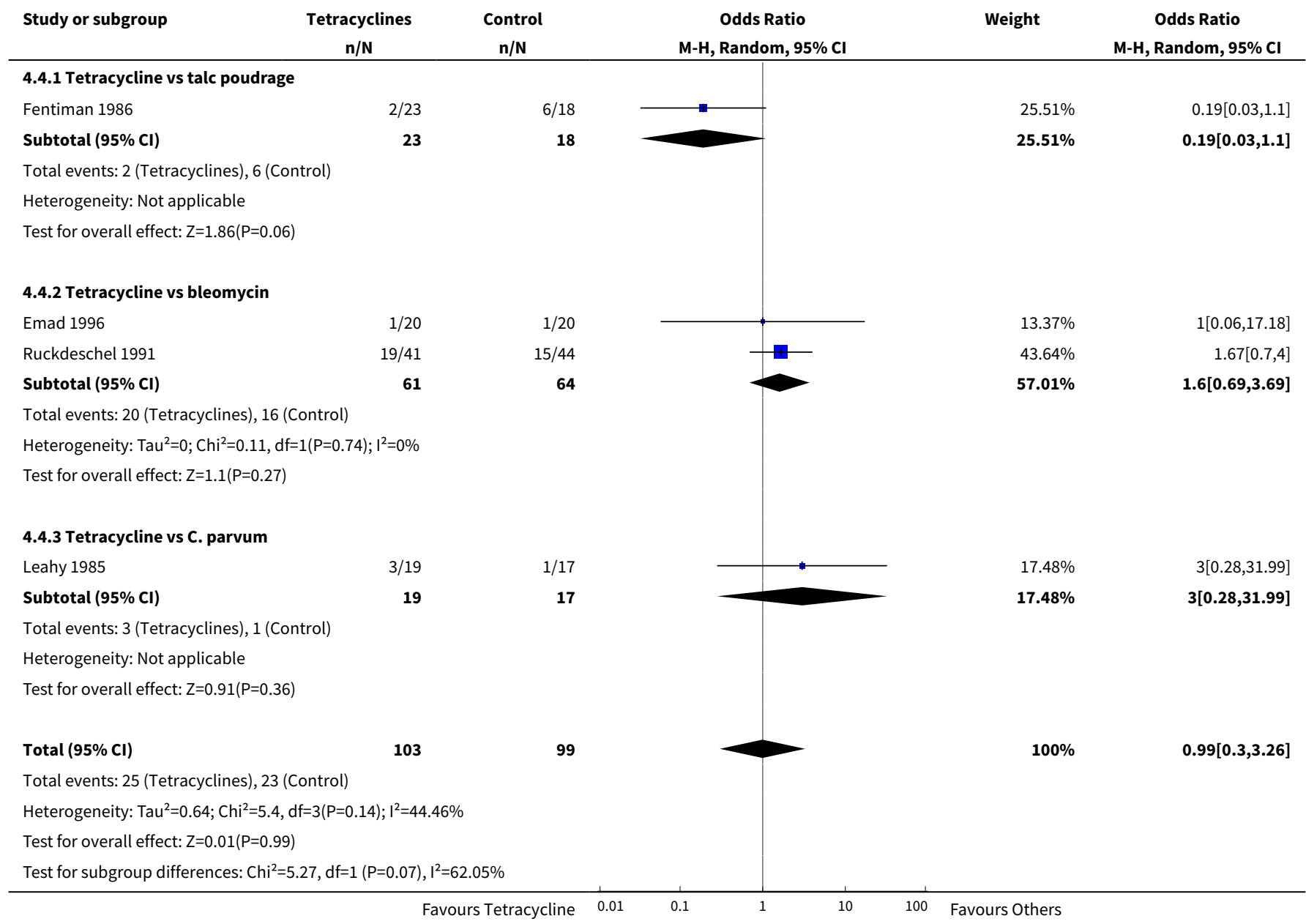

\section{Comparison 5. C. parvum}

\begin{tabular}{lllll}
\hline Outcome or subgroup title & $\begin{array}{l}\text { No. of } \\
\text { studies }\end{array}$ & $\begin{array}{l}\text { No. of } \\
\text { partici- } \\
\text { pants }\end{array}$ & Statistical method & Effect size \\
\hline 1 Pleurodesis failure & 5 & & $\begin{array}{l}\text { Odds Ratio (M-H, Random, 95\% } \\
\text { Cl) }\end{array}$ & Subtotals only \\
\hline 1.1 C. parvum vs bleomycin & 2 & 78 & $\begin{array}{l}\text { Odds Ratio (M-H, Random, 95\% } \\
\text { Cl) }\end{array}$ & $0.55[0.01,57.48]$ \\
\hline 1.2 C. parvum vs tetracycline & 1 & 32 & $\begin{array}{l}\text { Odds Ratio (M-H, Random, 95\% } \\
\text { Cl) }\end{array}$ & $0.31[0.05,1.94]$ \\
\hline 1.3 C. parvum vs doxycycline & 1 & 35 & $\begin{array}{l}\text { Odds Ratio (M-H, Random, 95\% } \\
\text { Cl) }\end{array}$ & $0.52[0.12,2.33]$ \\
\hline 1.4 C. parvum vs mustine & 1 & 18 & $\begin{array}{l}\text { Odds Ratio (M-H, Random, 95\% } \\
\text { Cl) }\end{array}$ & $0.33[0.04,2.52]$ \\
\hline
\end{tabular}




\begin{tabular}{|c|c|c|c|c|}
\hline Outcome or subgroup title & $\begin{array}{l}\text { No. of } \\
\text { studies }\end{array}$ & $\begin{array}{l}\text { No. of } \\
\text { partici- } \\
\text { pants }\end{array}$ & Statistical method & Effect size \\
\hline 2 Pain & 4 & 153 & $\begin{array}{l}\text { Odds Ratio (M-H, Random, 95\% } \\
\text { Cl) }\end{array}$ & $2.51[1.10,5.75]$ \\
\hline 2.1 C. parvum vs bleomycin & 2 & 71 & $\begin{array}{l}\text { Odds Ratio (M-H, Random, 95\% } \\
\mathrm{Cl} \text { ) }\end{array}$ & $1.42[0.54,3.75]$ \\
\hline 2.2 C. parvum vs tetracycline & 1 & 41 & $\begin{array}{l}\text { Odds Ratio (M-H, Random, 95\% } \\
\mathrm{Cl} \text { ) }\end{array}$ & $2.44[0.69,8.66]$ \\
\hline 2.3 C. parvum vs doxycycline & 1 & 41 & $\begin{array}{l}\text { Odds Ratio (M-H, Random, 95\% } \\
\mathrm{Cl} \text { ) }\end{array}$ & $7.37[1.84,29.55]$ \\
\hline 3 Fever & 5 & & $\begin{array}{l}\text { Odds Ratio (M-H, Random, 95\% } \\
\mathrm{Cl} \text { ) }\end{array}$ & Subtotals only \\
\hline 3.1 C. parvum vs bleomycin & 2 & 80 & $\begin{array}{l}\text { Odds Ratio (M-H, Random, 95\% } \\
\mathrm{Cl} \text { ) }\end{array}$ & $2.30[0.90,5.92]$ \\
\hline 3.2 C. parvum vs tetracycline & 1 & 36 & $\begin{array}{l}\text { Odds Ratio (M-H, Random, 95\% } \\
\mathrm{Cl} \text { ) }\end{array}$ & $288.00[16.62,4991.05]$ \\
\hline 3.3 C. parvum vs mustine & 1 & 21 & $\begin{array}{l}\text { Odds Ratio (M-H, Random, 95\% } \\
\text { Cl) }\end{array}$ & $4.41[0.16,121.68]$ \\
\hline 3.4 C. parvum vs doxycycline & 1 & 41 & $\begin{array}{l}\text { Odds Ratio (M-H, Random, 95\% } \\
\text { Cl) }\end{array}$ & $7.37[1.84,29.55]$ \\
\hline 4 Mortality & 3 & & $\begin{array}{l}\text { Odds Ratio (M-H, Random, 95\% } \\
\text { Cl) }\end{array}$ & Subtotals only \\
\hline 4.1 C. parvum vs bleomycin & 1 & 55 & $\begin{array}{l}\text { Odds Ratio (M-H, Random, 95\% } \\
\mathrm{Cl} \text { ) }\end{array}$ & $1.66[0.51,5.38]$ \\
\hline 4.2 C. parvum vs tetracycline & 1 & 36 & $\begin{array}{l}\text { Odds Ratio (M-H, Random, 95\% } \\
\mathrm{Cl} \text { ) }\end{array}$ & $0.33[0.03,3.55]$ \\
\hline 4.3 C. parvum vs mustine & 1 & 21 & $\begin{array}{l}\text { Odds Ratio (M-H, Random, 95\% } \\
\mathrm{Cl} \text { ) }\end{array}$ & $0.42[0.07,2.66]$ \\
\hline
\end{tabular}

Analysis 5.1. Comparison 5 C. parvum, Outcome 1 Pleurodesis failure.

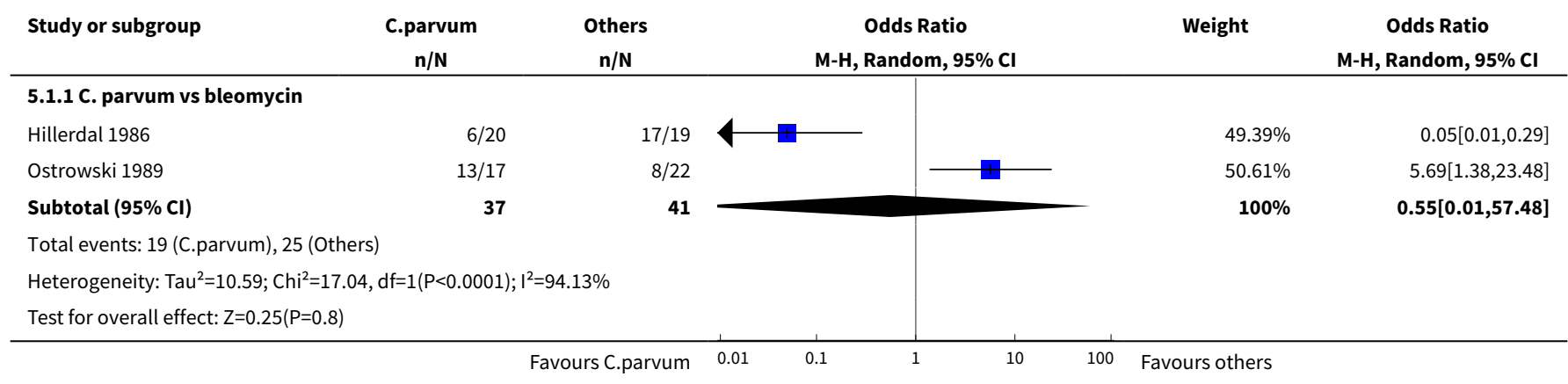




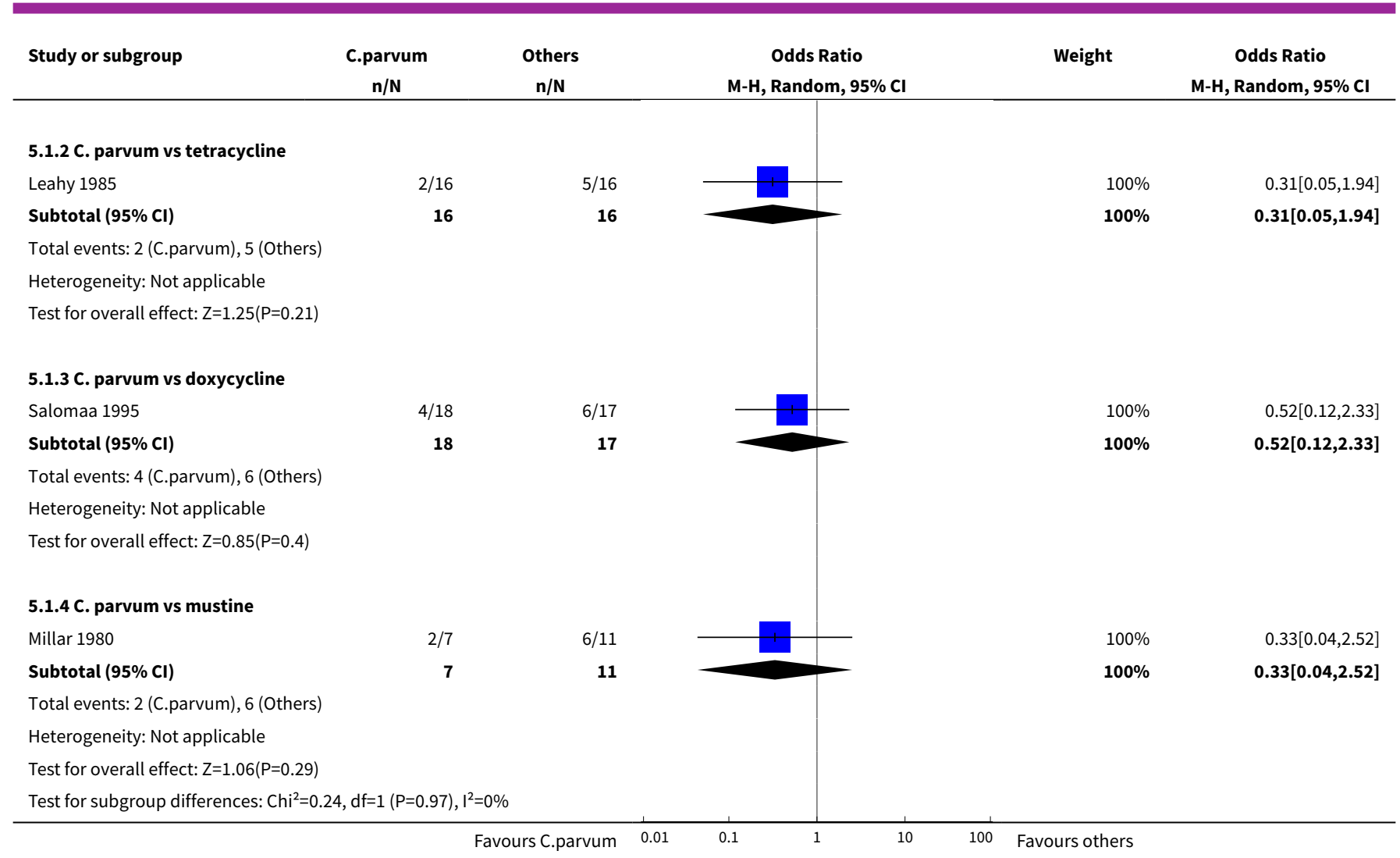

Analysis 5.2. Comparison 5 C. parvum, Outcome 2 Pain.

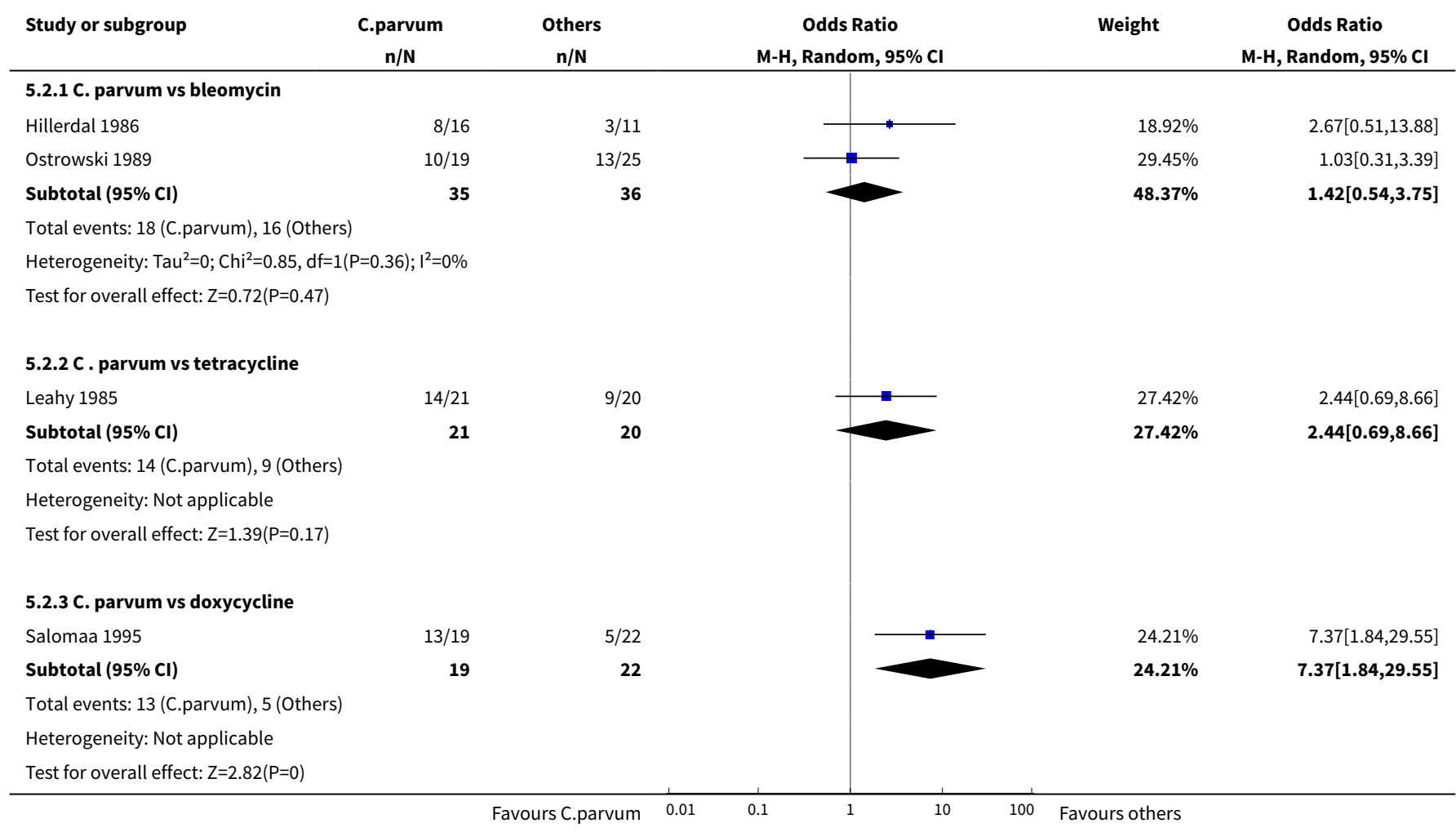




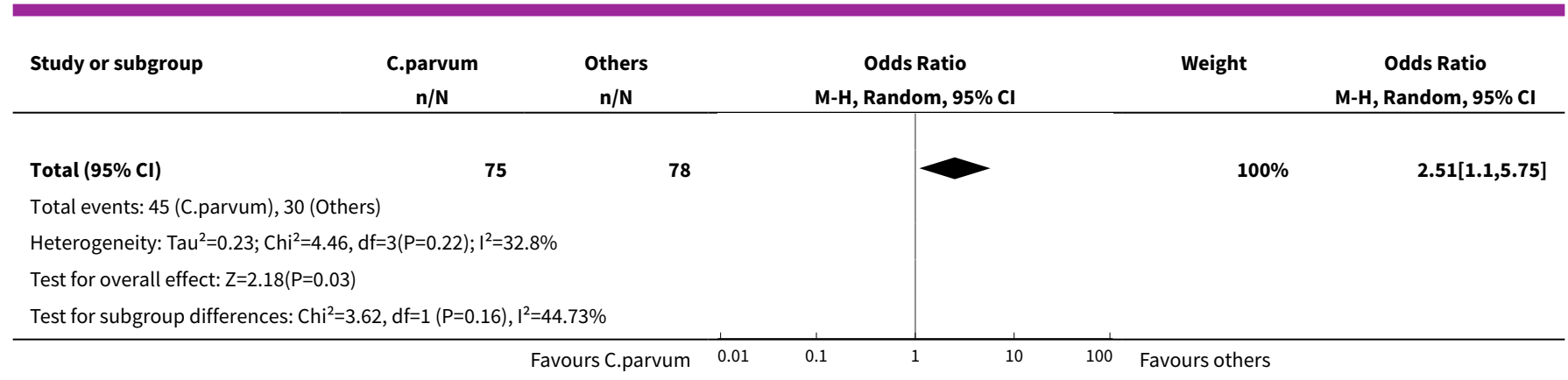

Analysis 5.3. Comparison 5 C. parvum, Outcome 3 Fever.

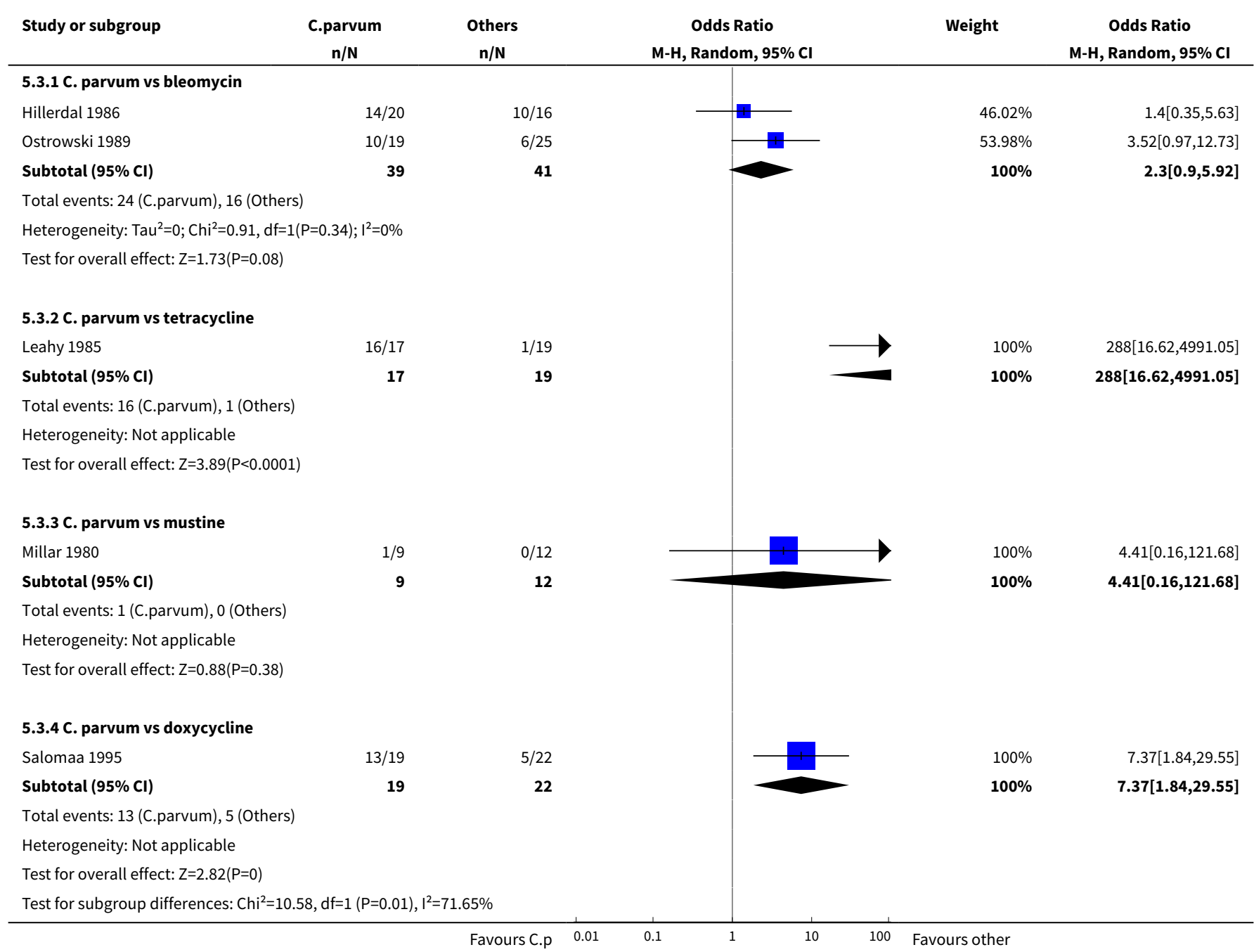


Analysis 5.4. Comparison 5 C. parvum, Outcome 4 Mortality.

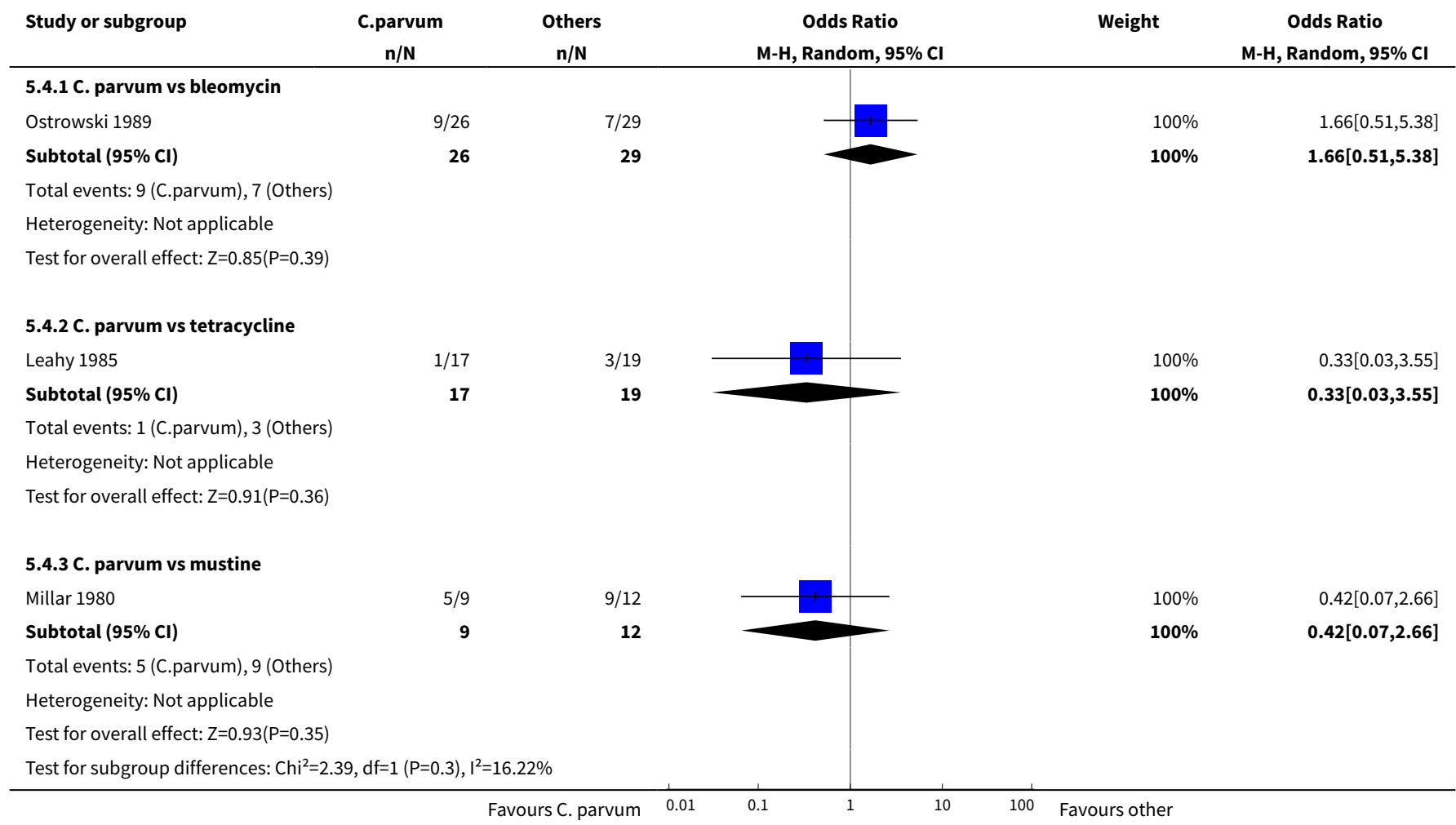

\section{Comparison 6. Indwelling pleural catheter (IPC)}

\begin{tabular}{lllll}
\hline Outcome or subgroup title & $\begin{array}{l}\text { No. of } \\
\text { studies }\end{array}$ & $\begin{array}{l}\text { No. of } \\
\text { partici- } \\
\text { pants }\end{array}$ & Statistical method & Effect size \\
\hline 1 Pleurodesis failure & 2 & & Odds Ratio $(\mathrm{M}-\mathrm{H}$, Random, 95\% Cl) & Subtotals only \\
\hline 1.1 IPC vs talc slurry & 2 & 160 & Odds Ratio (M-H, Random, 95\% Cl) & $3.35[1.64,6.83]$ \\
\hline 2 Mortality & 2 & 163 & Odds Ratio (M-H, Random, 95\% Cl) & $1.03[0.48,2.23]$ \\
\hline 3 Pain & 1 & & Odds Ratio (M-H, Random, $95 \% \mathrm{Cl})$ & Subtotals only \\
\hline
\end{tabular}

Analysis 6.1. Comparison 6 Indwelling pleural catheter (IPC), Outcome 1 Pleurodesis failure.

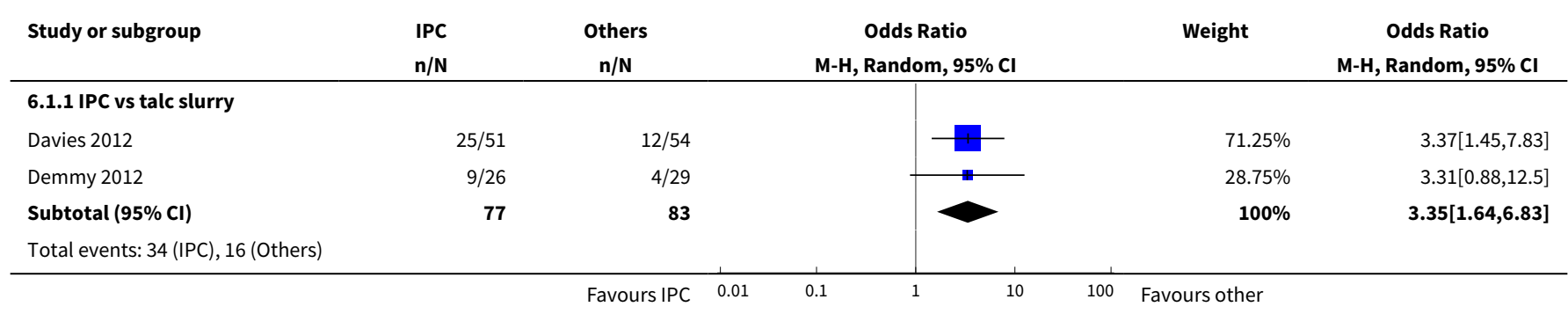




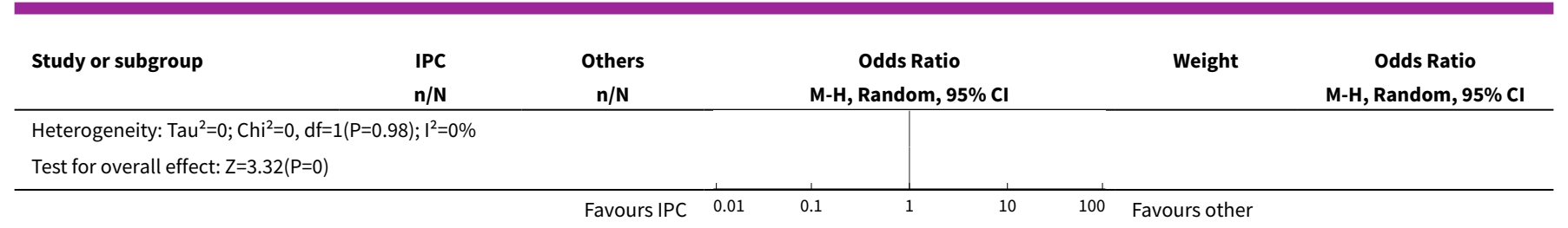

Analysis 6.2. Comparison 6 Indwelling pleural catheter (IPC), Outcome 2 Mortality.

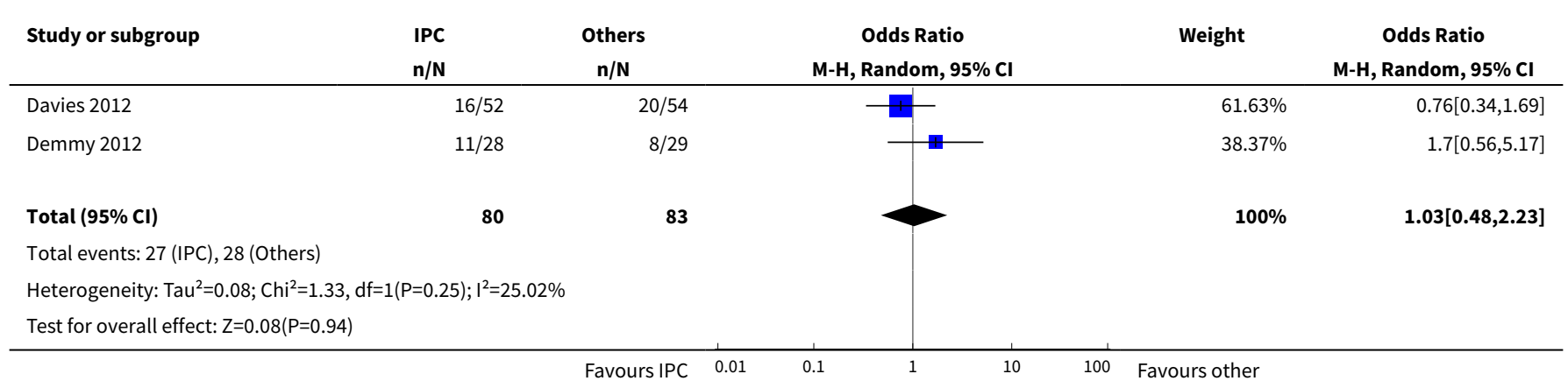

Analysis 6.3. Comparison 6 Indwelling pleural catheter (IPC), Outcome 3 Pain.

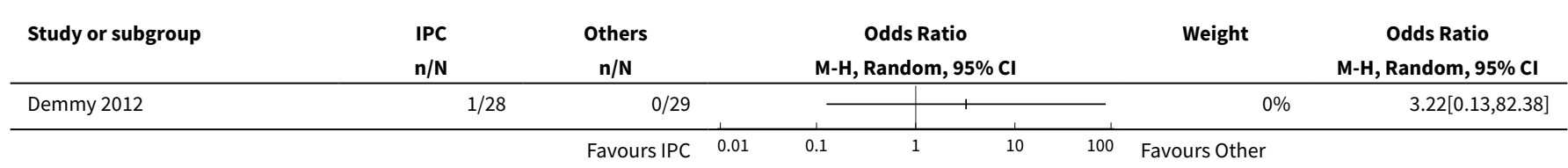

\section{Comparison 7. lodine}

\begin{tabular}{llllll}
\hline Outcome or subgroup title & $\begin{array}{l}\text { No. of } \\
\text { studies }\end{array}$ & $\begin{array}{l}\text { No. of } \\
\text { partici- } \\
\text { pants }\end{array}$ & Statistical method & Effect size \\
\hline 1 Pleurodesis failure & 3 & & Odds Ratio (M-H, Random, 95\% Cl) & Subtotals only \\
\hline 1.1 lodine vs talc poudrage & 1 & 42 & Odds Ratio (M-H, Random, 95\% Cl) & $1.76[0.26,11.83]$ \\
\hline 1.2 lodine vs talc slurry & 1 & 36 & Odds Ratio (M-H, Random, 95\% Cl) & $0.47[0.04,5.71]$ \\
\hline 1.3 lodine vs bleomycin & 1 & 39 & Odds Ratio (M-H, Random, 95\% Cl) & $1.25[0.28,5.59]$ \\
\hline 2 Fever & 2 & & Odds Ratio (M-H, Random, 95\% Cl) & Subtotals only \\
\hline 2.1 lodine vs talc slurry & 1 & 36 & Odds Ratio (M-H, Random, 95\% Cl) & $0.63[0.09,4.28]$ \\
\hline 2.2 lodine vs talc poudrage & 1 & 42 & Odds Ratio (M-H, Random, 95\% Cl) & $0.24[0.02,2.33]$ \\
\hline 3 Mortality & 1 & & Odds Ratio (M-H, Random, $95 \% \mathrm{Cl})$ & Subtotals only \\
\hline
\end{tabular}




\begin{tabular}{llllll}
\hline Outcome or subgroup title & $\begin{array}{l}\text { No. of } \\
\text { studies }\end{array}$ & $\begin{array}{l}\text { No. of } \\
\text { partici- } \\
\text { pants }\end{array}$ & Statistical method & Effect size \\
\hline 3.1 lodine vs talc poudrage & 1 & 42 & Odds Ratio (M-H, Random, 95\% Cl) & $0.38[0.08,1.73]$ \\
\hline 4 Pain & 2 & & Odds Ratio (M-H, Random, 95\% Cl) & Subtotals only \\
\hline 4.1 lodine vs talc slurry & 1 & 36 & Odds Ratio (M-H, Random, 95\% Cl) & $0.0[0.0,0.0]$ \\
\hline 4.2 lodine vs talc poudrage & 1 & 42 & Odds Ratio (M-H, Random, 95\% Cl) & $0.10[0.01,1.99]$ \\
\hline
\end{tabular}

Analysis 7.1. Comparison 7 lodine, Outcome 1 Pleurodesis failure.

\begin{tabular}{|c|c|c|c|c|c|}
\hline Study or subgroup & $\begin{array}{l}\text { lodine } \\
\mathrm{n} / \mathrm{N}\end{array}$ & $\begin{array}{l}\text { Others } \\
n / N\end{array}$ & $\begin{array}{c}\text { Odds Ratio } \\
\text { M-H, Random, } 95 \% \mathrm{CI}\end{array}$ & Weight & $\begin{array}{c}\text { Odds Ratio } \\
\text { M-H, Random, } 95 \% \mathrm{Cl}\end{array}$ \\
\hline \multicolumn{6}{|c|}{ 7.1.1 lodine vs talc poudrage } \\
\hline Mohsen 2011 & $3 / 20$ & $2 / 22$ & 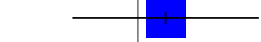 & $100 \%$ & $1.76[0.26,11.83]$ \\
\hline Subtotal $(95 \% \mathrm{Cl})$ & 20 & 22 & & $100 \%$ & $1.76[0.26,11.83]$ \\
\hline \multicolumn{6}{|c|}{ Total events: 3 (lodine), 2 (Others) } \\
\hline \multicolumn{6}{|c|}{ Heterogeneity: Not applicable } \\
\hline \multicolumn{6}{|c|}{ Test for overall effect: $Z=0.59(P=0.56)$} \\
\hline \multicolumn{6}{|c|}{ 7.1.2 lodine vs talc slurry } \\
\hline Agarwal 2011 & $1 / 18$ & $2 / 18$ & & $100 \%$ & $0.47[0.04,5.71]$ \\
\hline Subtotal $(95 \% \mathrm{Cl})$ & 18 & 18 & & $100 \%$ & $0.47[0.04,5.71]$ \\
\hline \multicolumn{6}{|c|}{ Total events: 1 (lodine), 2 (Others) } \\
\hline \multicolumn{6}{|c|}{ Heterogeneity: Not applicable } \\
\hline \multicolumn{6}{|c|}{ Test for overall effect: $Z=0.59(P=0.55)$} \\
\hline \multicolumn{6}{|c|}{ 7.1.3 lodine vs bleomycin } \\
\hline Alavi 2011 & $5 / 20$ & $4 / 19$ & & $100 \%$ & $1.25[0.28,5.59]$ \\
\hline Subtotal $(95 \% \mathrm{Cl})$ & 20 & 19 & & $100 \%$ & $1.25[0.28,5.59]$ \\
\hline \multicolumn{6}{|c|}{ Total events: 5 (lodine), 4 (Others) } \\
\hline \multicolumn{6}{|c|}{ Heterogeneity: Not applicable } \\
\hline \multicolumn{6}{|c|}{ Test for overall effect: $Z=0.29(P=0.77)$} \\
\hline \multicolumn{6}{|c|}{ Test for subgroup differences: $\mathrm{Chi}^{2}=0.7, \mathrm{df}=1(\mathrm{P}=0.71), \mathrm{I}^{2}=0 \%$} \\
\hline
\end{tabular}

Analysis 7.2. Comparison 7 lodine, Outcome 2 Fever.

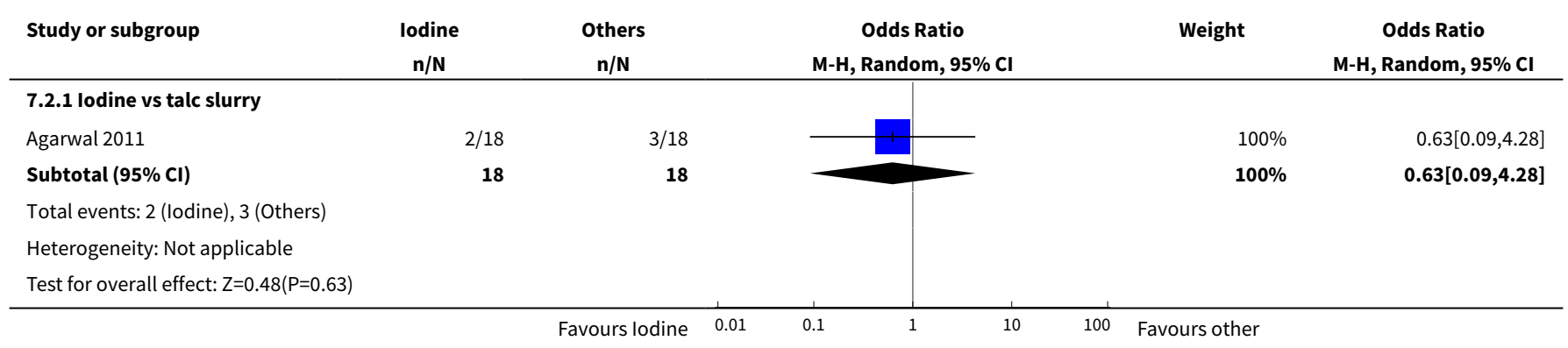




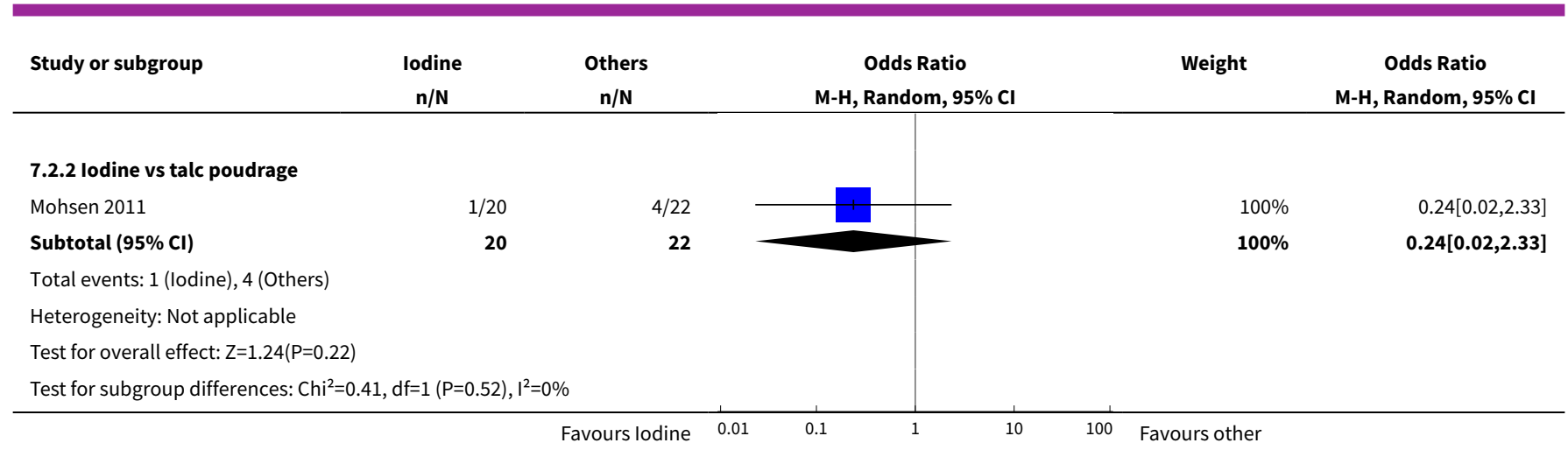

\section{Analysis 7.3. Comparison 7 lodine, Outcome 3 Mortality.}

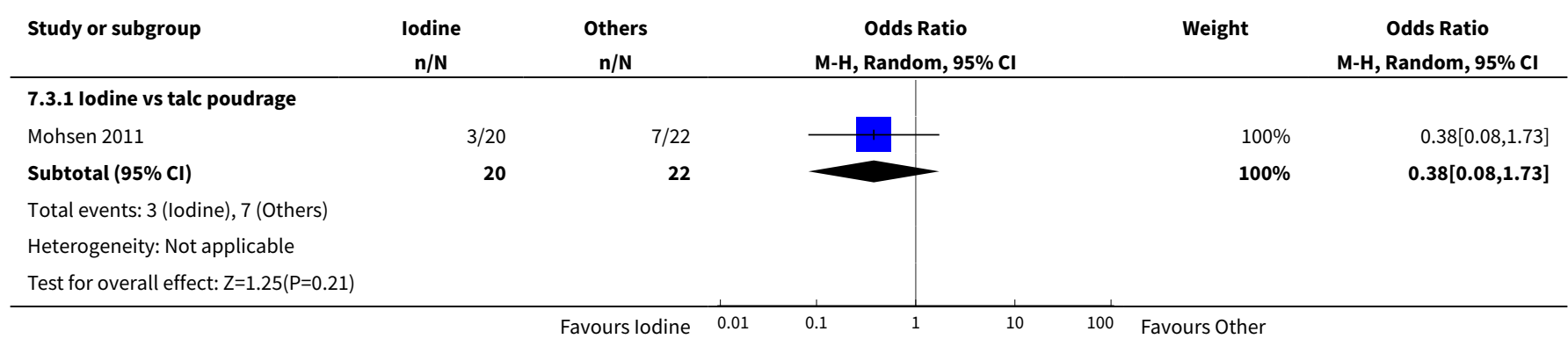

Analysis 7.4. Comparison 7 lodine, Outcome 4 Pain.

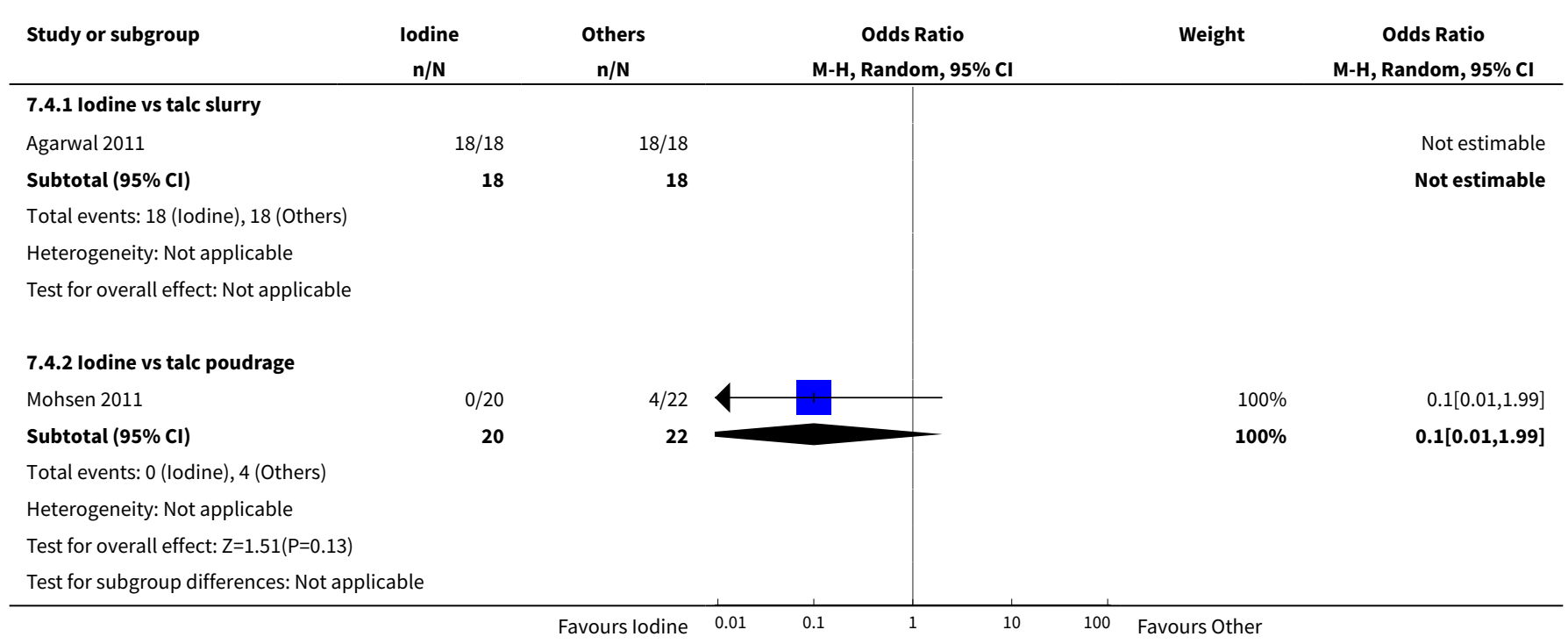


Comparison 8. Doxycycline

\begin{tabular}{|c|c|c|c|c|}
\hline Outcome or subgroup title & $\begin{array}{l}\text { No. of } \\
\text { studies }\end{array}$ & $\begin{array}{l}\text { No. of } \\
\text { partici- } \\
\text { pants }\end{array}$ & Statistical method & Effect size \\
\hline 1 Pleurodesis failure & 4 & & Odds Ratio (M-H, Fixed, 95\% Cl) & Subtotals only \\
\hline 1.1 Doxycycline vs talc poudrage & 1 & 31 & Odds Ratio (M-H, Fixed, 95\% Cl) & $42.69[2.13,856.61]$ \\
\hline 1.2 Doxycycline vs bleomycin & 2 & 122 & Odds Ratio (M-H, Fixed, 95\% Cl) & $0.66[0.24,1.83]$ \\
\hline 1.3 Doxycycline vs C. parvum & 1 & 35 & Odds Ratio (M-H, Fixed, 95\% Cl) & $1.91[0.43,8.48]$ \\
\hline 2 Pain & 3 & & $\begin{array}{l}\text { Odds Ratio (M-H, Random, 95\% } \\
\text { CI) }\end{array}$ & Subtotals only \\
\hline 2.1 Doxycycline vs bleomycin & 2 & 148 & $\begin{array}{l}\text { Odds Ratio (M-H, Random, 95\% } \\
\text { Cl) }\end{array}$ & $1.19[0.37,3.80]$ \\
\hline 2.2 Doxycycline vs C. parvum & 1 & 41 & $\begin{array}{l}\text { Odds Ratio (M-H, Random, 95\% } \\
\text { Cl) }\end{array}$ & $0.10[0.01,0.96]$ \\
\hline 3 Fever & 3 & 189 & $\begin{array}{l}\text { Odds Ratio (M-H, Random, 95\% } \\
\mathrm{Cl} \text { ) }\end{array}$ & $0.28[0.04,2.16]$ \\
\hline 3.1 Doxycycline vs bleomycin & 2 & 148 & $\begin{array}{l}\text { Odds Ratio (M-H, Random, 95\% } \\
\mathrm{Cl} \text { ) }\end{array}$ & $0.37[0.01,12.35]$ \\
\hline 3.2 Doxycycline vs C. parvum & 1 & 41 & $\begin{array}{l}\text { Odds Ratio (M-H, Random, 95\% } \\
\mathrm{Cl})\end{array}$ & $0.14[0.03,0.54]$ \\
\hline 4 Mortality & 1 & & $\begin{array}{l}\text { Odds Ratio (M-H, Random, 95\% } \\
\mathrm{Cl})\end{array}$ & Subtotals only \\
\hline 4.1 Doxycycline vs bleomycin & 1 & 80 & $\begin{array}{l}\text { Odds Ratio (M-H, Random, 95\% } \\
\text { Cl) }\end{array}$ & $0.69[0.26,1.87]$ \\
\hline
\end{tabular}

Analysis 8.1. Comparison 8 Doxycycline, Outcome 1 Pleurodesis failure.

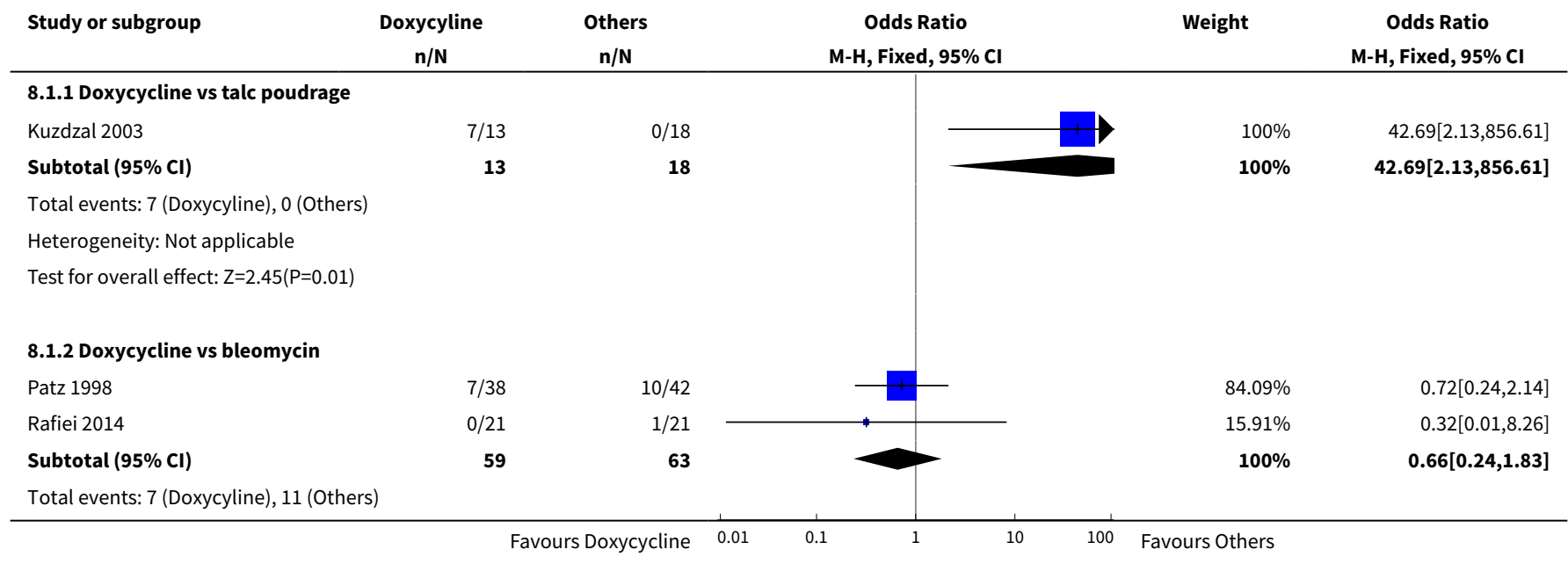




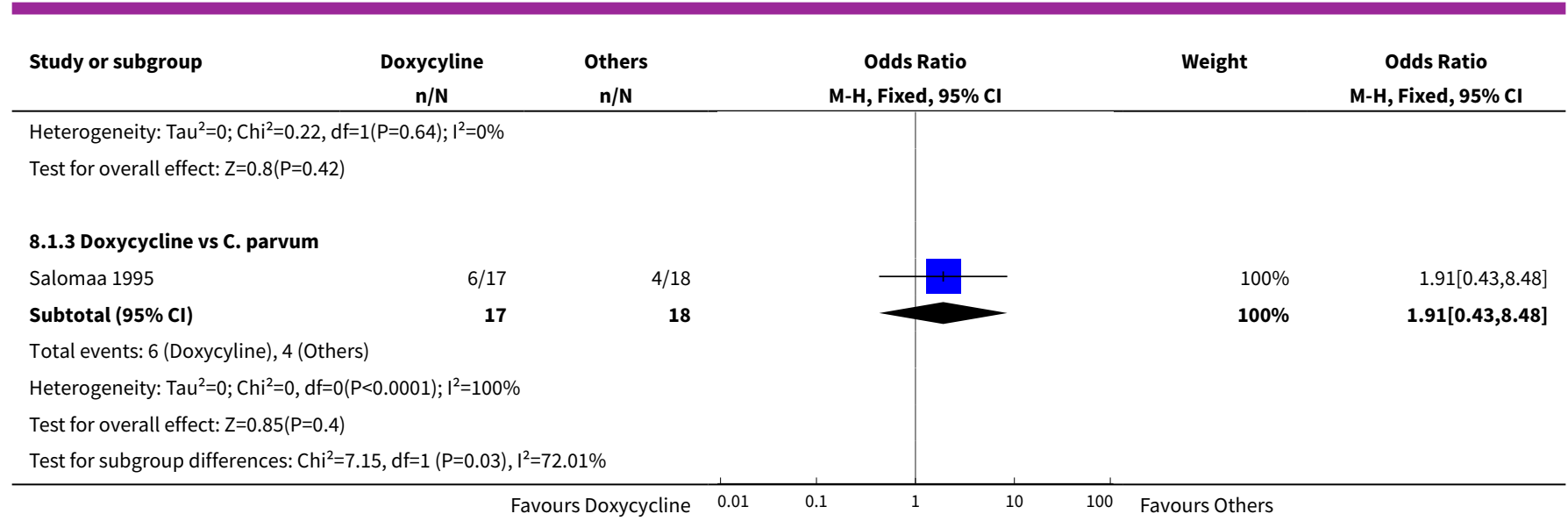

Analysis 8.2. Comparison 8 Doxycycline, Outcome 2 Pain.

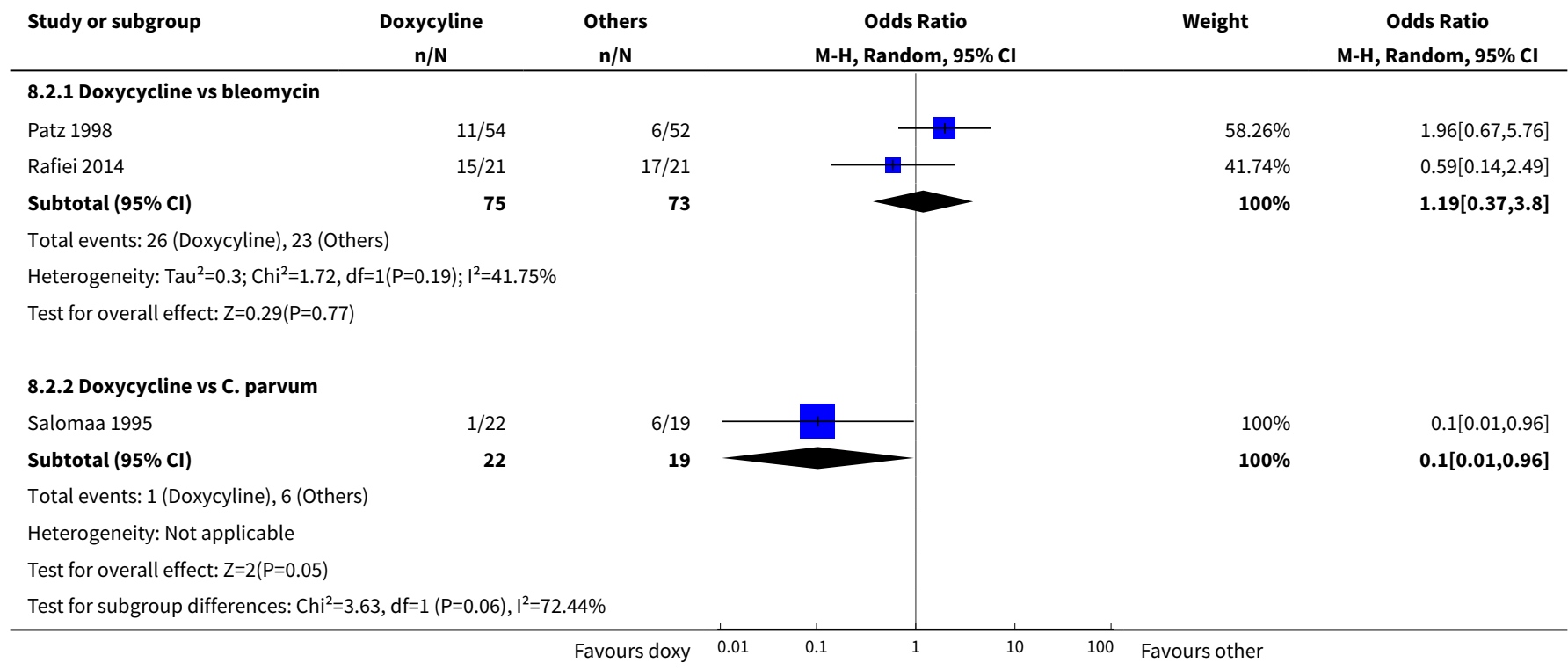

\section{Analysis 8.3. Comparison 8 Doxycycline, Outcome 3 Fever.}

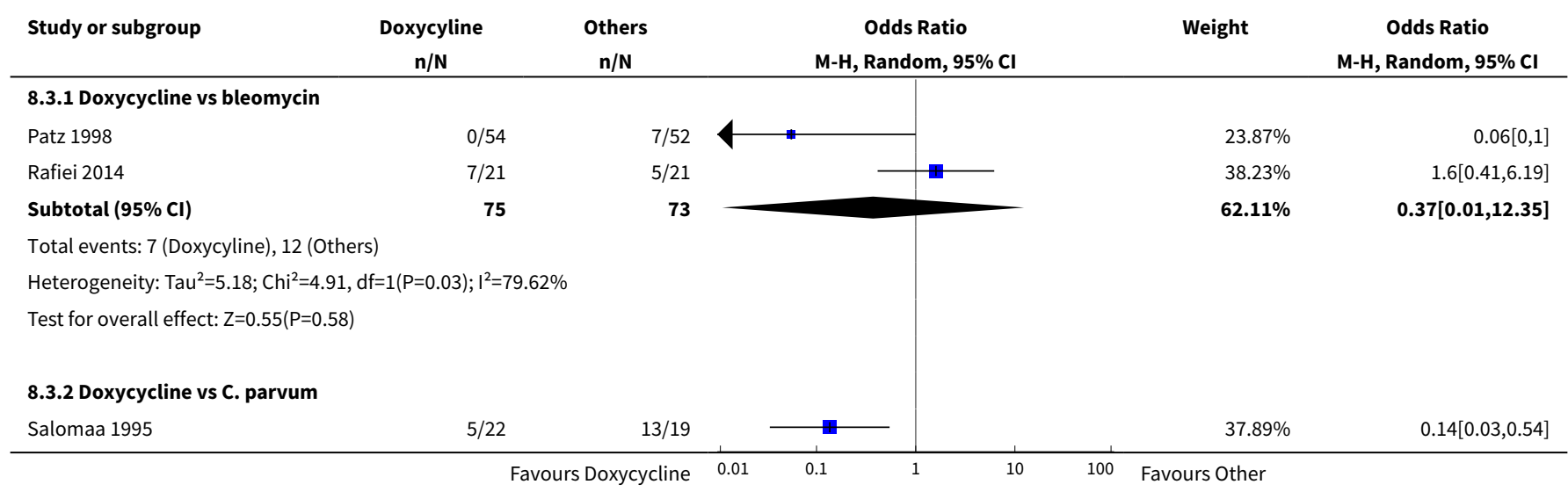




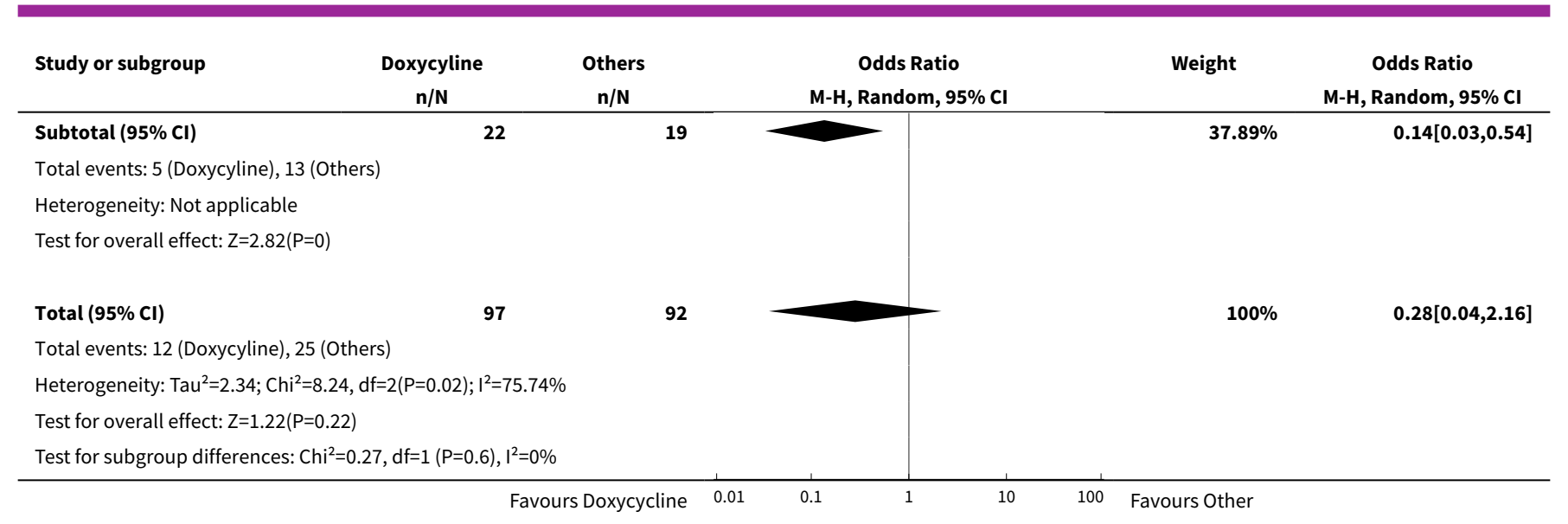

Analysis 8.4. Comparison 8 Doxycycline, Outcome 4 Mortality.

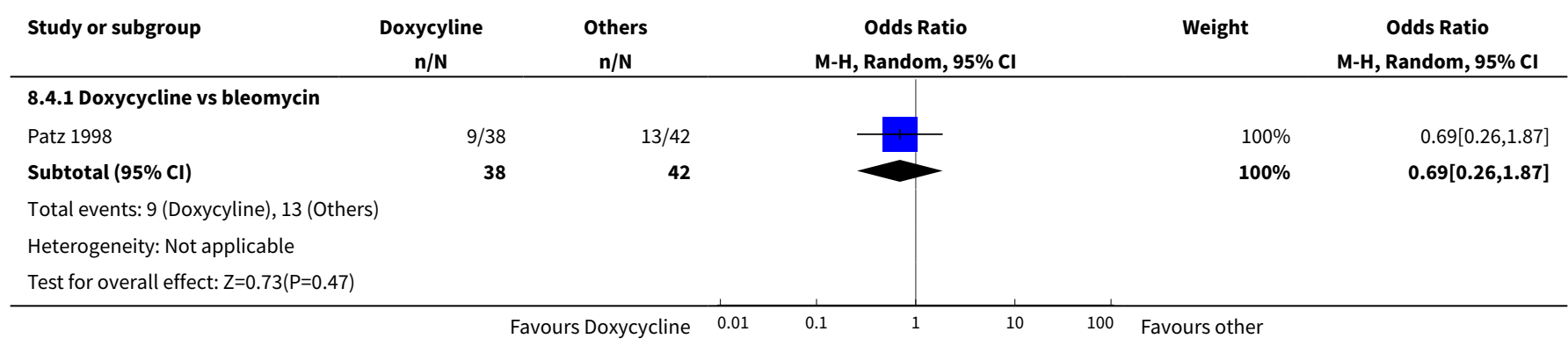

\section{Comparison 9. Mode of administration}

\begin{tabular}{lllll}
\hline Outcome or subgroup title & $\begin{array}{l}\text { No. of } \\
\text { studies }\end{array}$ & $\begin{array}{l}\text { No. of } \\
\text { partici- } \\
\text { pants }\end{array}$ & Statistical method & Effect size \\
\hline 1 Pleurodesis failure & 4 & 628 & Odds Ratio $(\mathrm{M}-\mathrm{H}$, Random, 95\% Cl) & $0.74[0.52,1.04]$ \\
\hline 1.1 Talc & 3 & 599 & Odds Ratio $(\mathrm{M}-\mathrm{H}$, Random, 95\% Cl) & $0.76[0.54,1.09]$ \\
\hline 1.2 Tetracycline & 1 & 29 & Odds Ratio $(\mathrm{M}-\mathrm{H}$, Random, $95 \% \mathrm{Cl})$ & $0.28[0.04,1.76]$ \\
\hline
\end{tabular}

Analysis 9.1. Comparison 9 Mode of administration, Outcome 1 Pleurodesis failure.

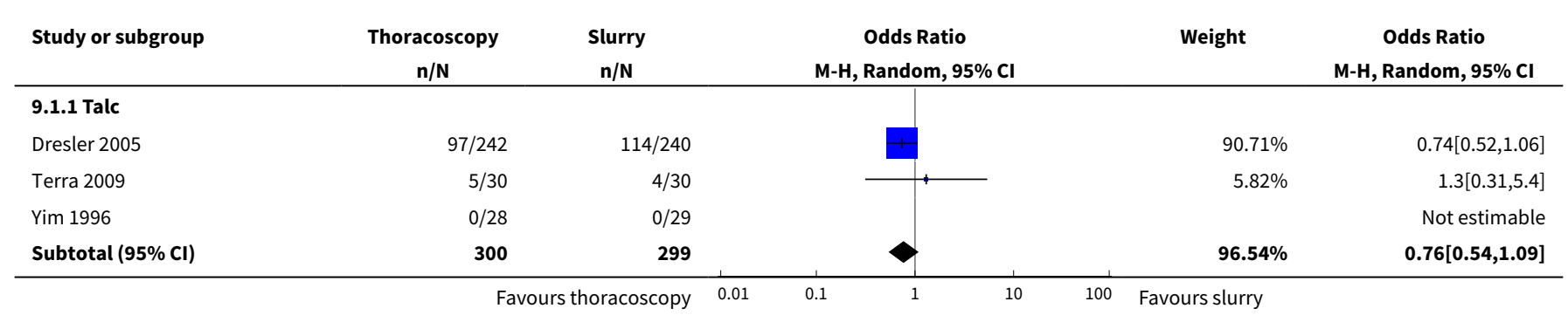




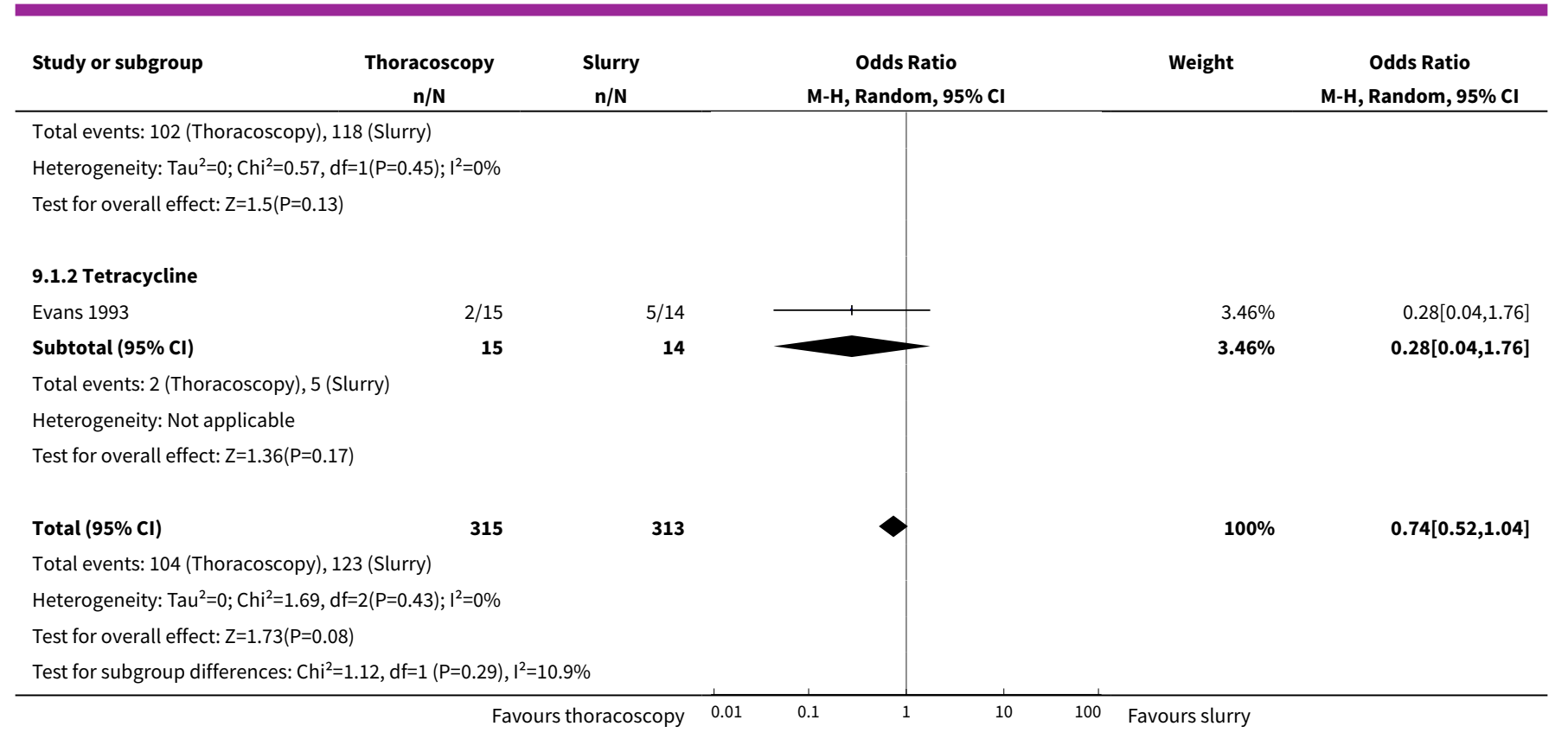

Comparison 10. Duration of drainage after pleurodesis administration

\begin{tabular}{lllll}
\hline Outcome or subgroup title & $\begin{array}{l}\text { No. of } \\
\text { studies }\end{array}$ & $\begin{array}{l}\text { No. of } \\
\text { partici- } \\
\text { pants }\end{array}$ & Statistical method & Effect size \\
\hline 1 Pleurodesis failure & 3 & & Odds Ratio $(\mathrm{M}-\mathrm{H}$, Fixed, $95 \% \mathrm{Cl})$ & Subtotals only \\
\hline 2 Mortality & 3 & & Odds Ratio $(\mathrm{M}-\mathrm{H}$, Random, $95 \% \mathrm{Cl})$ & Subtotals only \\
\hline
\end{tabular}

Analysis 10.1. Comparison 10 Duration of drainage after pleurodesis administration, Outcome 1 Pleurodesis failure.

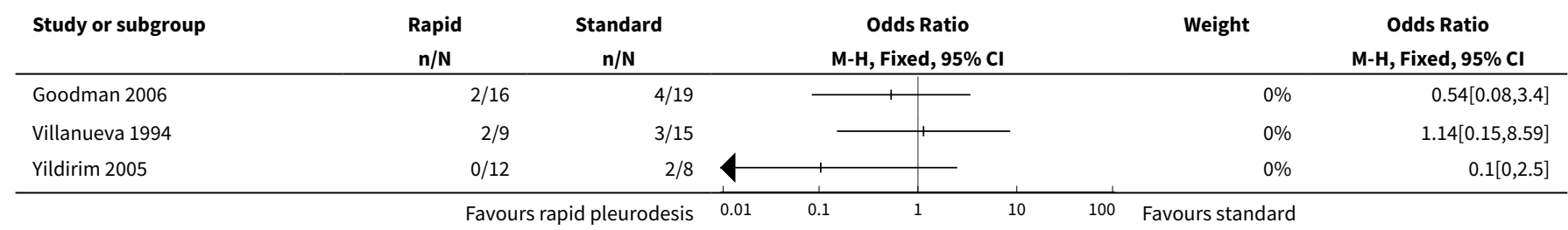

Analysis 10.2. Comparison 10 Duration of drainage after pleurodesis administration, Outcome 2 Mortality.

\begin{tabular}{|c|c|c|c|c|c|c|}
\hline Study or subgroup & $\begin{array}{c}\text { Rapid } \\
\mathrm{n} / \mathrm{N}\end{array}$ & $\begin{array}{c}\text { Standard } \\
\mathrm{n} / \mathrm{N}\end{array}$ & & $\begin{array}{c}\text { Odds Ratio } \\
\text { M-H, Random, } 95 \% \mathrm{Cl}\end{array}$ & Weight & $\begin{array}{c}\text { Odds Ratio } \\
\text { M-H, Random, } 95 \% \mathrm{Cl}\end{array}$ \\
\hline Goodman 2006 & $3 / 19$ & $3 / 22$ & & 1 & $0 \%$ & $1.19[0.21,6.72]$ \\
\hline Villanueva 1994 & $9 / 9$ & $13 / 15$ & & & $0 \%$ & $3.52[0.15,81.92]$ \\
\hline Yildirim 2005 & $3 / 15$ & $4 / 12$ & & \begin{tabular}{l|l} 
& \\
&
\end{tabular} & $0 \%$ & $0.5[0.09,2.86]$ \\
\hline
\end{tabular}




\section{Comparison 11. OK-432}

\begin{tabular}{|c|c|c|c|c|}
\hline Outcome or subgroup title & $\begin{array}{l}\text { No. of } \\
\text { studies }\end{array}$ & $\begin{array}{l}\text { No. of } \\
\text { partici- } \\
\text { pants }\end{array}$ & Statistical method & Effect size \\
\hline 1 Pleurodesis failure & 4 & & $\begin{array}{l}\text { Odds Ratio (M-H, Random, } \\
95 \% \mathrm{Cl})\end{array}$ & Subtotals only \\
\hline 1.1 OK-432 and mitomycin C & 1 & 53 & $\begin{array}{l}\text { Odds Ratio (M-H, Random, } \\
95 \% \mathrm{Cl})\end{array}$ & $0.26[0.06,1.11]$ \\
\hline $1.2 \mathrm{OK}-432$ vs cisplatin and etoposide & 1 & 67 & $\begin{array}{l}\text { Odds Ratio (M-H, Random, } \\
95 \% \mathrm{Cl})\end{array}$ & $0.77[0.26,2.27]$ \\
\hline $1.3 \mathrm{OK}-432$ and cisplatin & 1 & 34 & $\begin{array}{l}\text { Odds Ratio (M-H, Random, } \\
95 \% \mathrm{Cl})\end{array}$ & $0.48[0.12,1.92]$ \\
\hline 1.4 High dose vs low dose & 1 & 38 & $\begin{array}{l}\text { Odds Ratio (M-H, Random, } \\
95 \% \mathrm{Cl})\end{array}$ & $1.90[0.38,9.44]$ \\
\hline 1.5 OK-432 vs bleomycin & 1 & 68 & $\begin{array}{l}\text { Odds Ratio (M-H, Random, } \\
95 \% \mathrm{Cl})\end{array}$ & $0.70[0.24,2.03]$ \\
\hline 1.6 OK-432 vs OK-432 and cisplatin & 1 & 32 & $\begin{array}{l}\text { Odds Ratio (M-H, Random, } \\
95 \% \mathrm{Cl})\end{array}$ & $12.44[1.32,117.03]$ \\
\hline 2 Pain & 3 & & $\begin{array}{l}\text { Odds Ratio (M-H, Random, } \\
95 \% \mathrm{Cl})\end{array}$ & Subtotals only \\
\hline 2.1 OK-432 vs cisplatin & 1 & 34 & $\begin{array}{l}\text { Odds Ratio (M-H, Random, } \\
95 \% \mathrm{Cl})\end{array}$ & $6.67[1.15,38.60]$ \\
\hline 2.2 OK-432 vs OK-432 and cisplatin & 1 & 32 & $\begin{array}{l}\text { Odds Ratio (M-H, Random, } \\
95 \% \mathrm{Cl})\end{array}$ & $1.33[0.33,5.43]$ \\
\hline 2.3 OK-432 vs mitomycin C & 1 & 53 & $\begin{array}{l}\text { Odds Ratio (M-H, Random, } \\
95 \% \mathrm{Cl})\end{array}$ & $1.04[0.14,8.00]$ \\
\hline 2.4 OK-432 vs bleomycin & 1 & 67 & $\begin{array}{l}\text { Odds Ratio (M-H, Random, } \\
95 \% \mathrm{Cl})\end{array}$ & $2.53[0.89,7.15]$ \\
\hline 2.5 OK-432 vs cisplatin and etoposide & 1 & 66 & $\begin{array}{l}\text { Odds Ratio (M-H, Random, } \\
95 \% \mathrm{Cl})\end{array}$ & $2.1[0.73,6.01]$ \\
\hline 3 Fever & 3 & & $\begin{array}{l}\text { Odds Ratio (M-H, Random, } \\
95 \% \mathrm{Cl})\end{array}$ & Subtotals only \\
\hline 3.1 OK-432 vs cisplatin & 1 & 34 & $\begin{array}{l}\text { Odds Ratio (M-H, Random, } \\
95 \% \mathrm{Cl})\end{array}$ & $256.00[14.70,4457.27]$ \\
\hline 3.2 OK-432 vs OK-432 and cisplatin & 1 & 32 & $\begin{array}{l}\text { Odds Ratio (M-H, Random, } \\
95 \% \mathrm{Cl})\end{array}$ & $14.00[1.46,134.25]$ \\
\hline 3.3 OK-432 vs mitomycin C & 1 & 53 & $\begin{array}{l}\text { Odds Ratio (M-H, Random, } \\
95 \% \mathrm{Cl})\end{array}$ & $26.67[5.91,120.42]$ \\
\hline
\end{tabular}




\begin{tabular}{|c|c|c|c|c|}
\hline Outcome or subgroup title & $\begin{array}{l}\text { No. of } \\
\text { studies }\end{array}$ & $\begin{array}{l}\text { No. of } \\
\text { partici- } \\
\text { pants }\end{array}$ & Statistical method & Effect size \\
\hline 3.4 OK-432 vs bleomycin & 1 & 67 & $\begin{array}{l}\text { Odds Ratio (M-H, Random, } \\
95 \% \mathrm{Cl})\end{array}$ & $1.43[0.47,4.35]$ \\
\hline $3.5 \mathrm{OK}-432$ vs cisplatin and etoposide & 1 & 66 & $\begin{array}{l}\text { Odds Ratio (M-H, Random, } \\
95 \% \mathrm{Cl})\end{array}$ & $3.17[1.08,9.30]$ \\
\hline 4 Mortality & 2 & & $\begin{array}{l}\text { Odds Ratio (M-H, Random, } \\
95 \% \mathrm{Cl})\end{array}$ & Subtotals only \\
\hline 4.1 OK-432 vs cisplatin & 1 & 34 & $\begin{array}{l}\text { Odds Ratio (M-H, Random, } \\
95 \% \mathrm{Cl})\end{array}$ & $1.31[0.31,5.53]$ \\
\hline $\begin{array}{l}4.2 \text { OK- } 432 \text { vs combined OK- } 432 \text { and cis- } \\
\text { platin }\end{array}$ & 1 & 32 & $\begin{array}{l}\text { Odds Ratio (M-H, Random, } \\
95 \% \mathrm{Cl})\end{array}$ & $2.18[0.44,10.91]$ \\
\hline $4.3 \mathrm{OK}-432$ vs bleomycin & 1 & 68 & $\begin{array}{l}\text { Odds Ratio (M-H, Random, } \\
95 \% \mathrm{Cl} \text { ) }\end{array}$ & $0.38[0.14,1.03]$ \\
\hline 4.4 OK-432 vs cisplatin and etoposide & 1 & 67 & $\begin{array}{l}\text { Odds Ratio (M-H, Random, } \\
95 \% \mathrm{Cl})\end{array}$ & $0.84[0.32,2.18]$ \\
\hline
\end{tabular}

Analysis 11.1. Comparison 11 OK-432, Outcome 1 Pleurodesis failure.

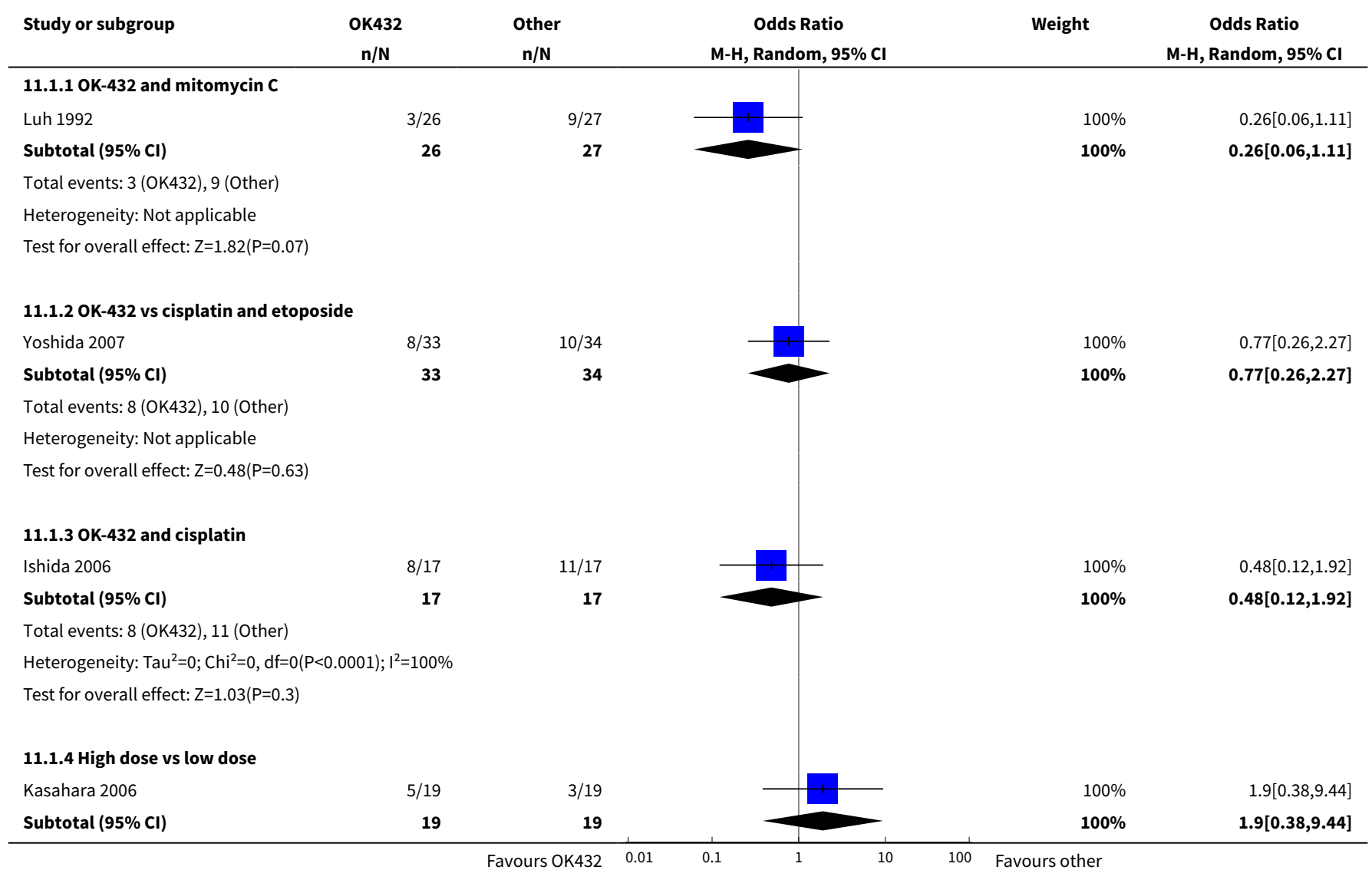




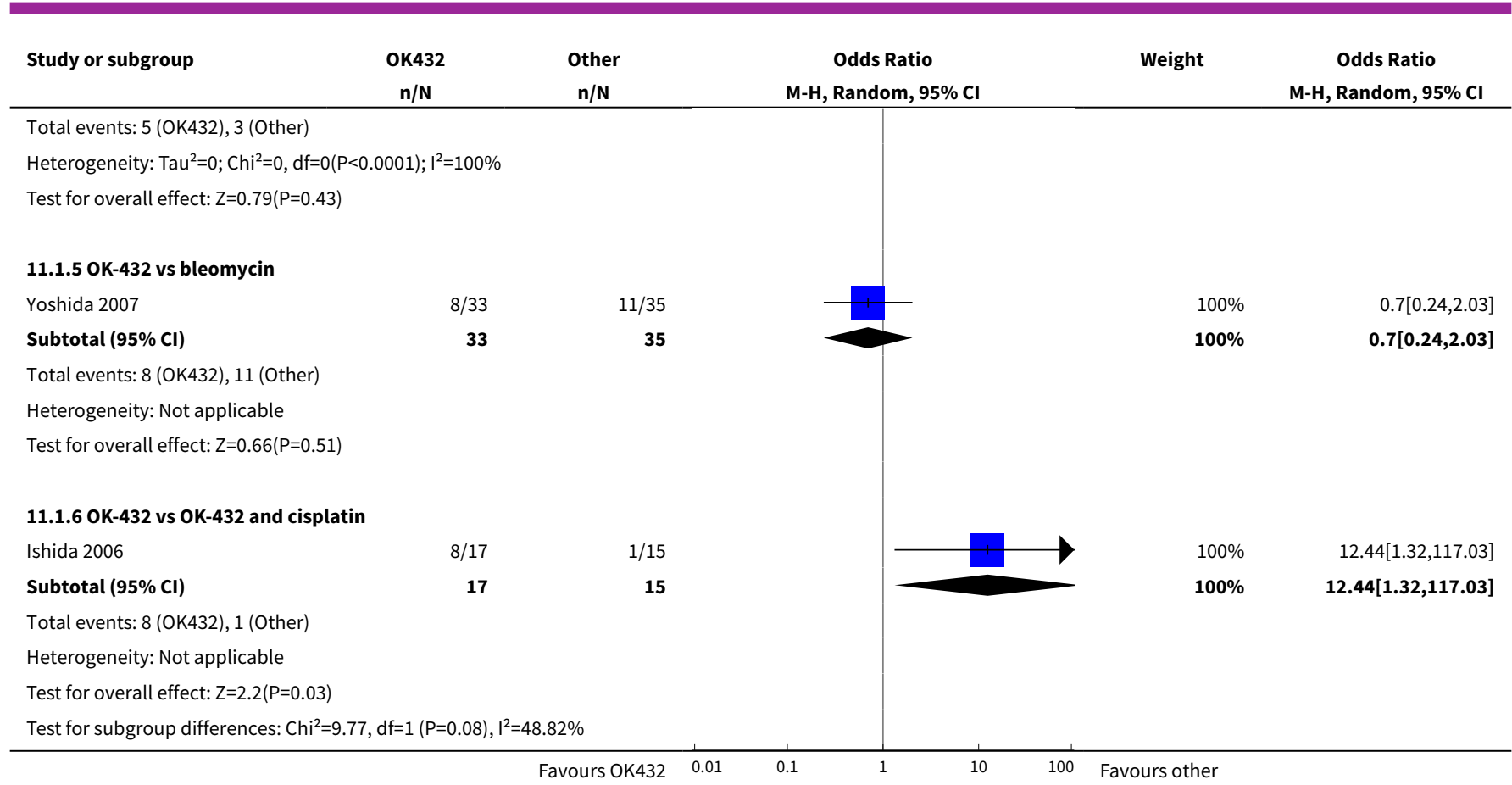

Analysis 11.2. Comparison 11 OK-432, Outcome 2 Pain.

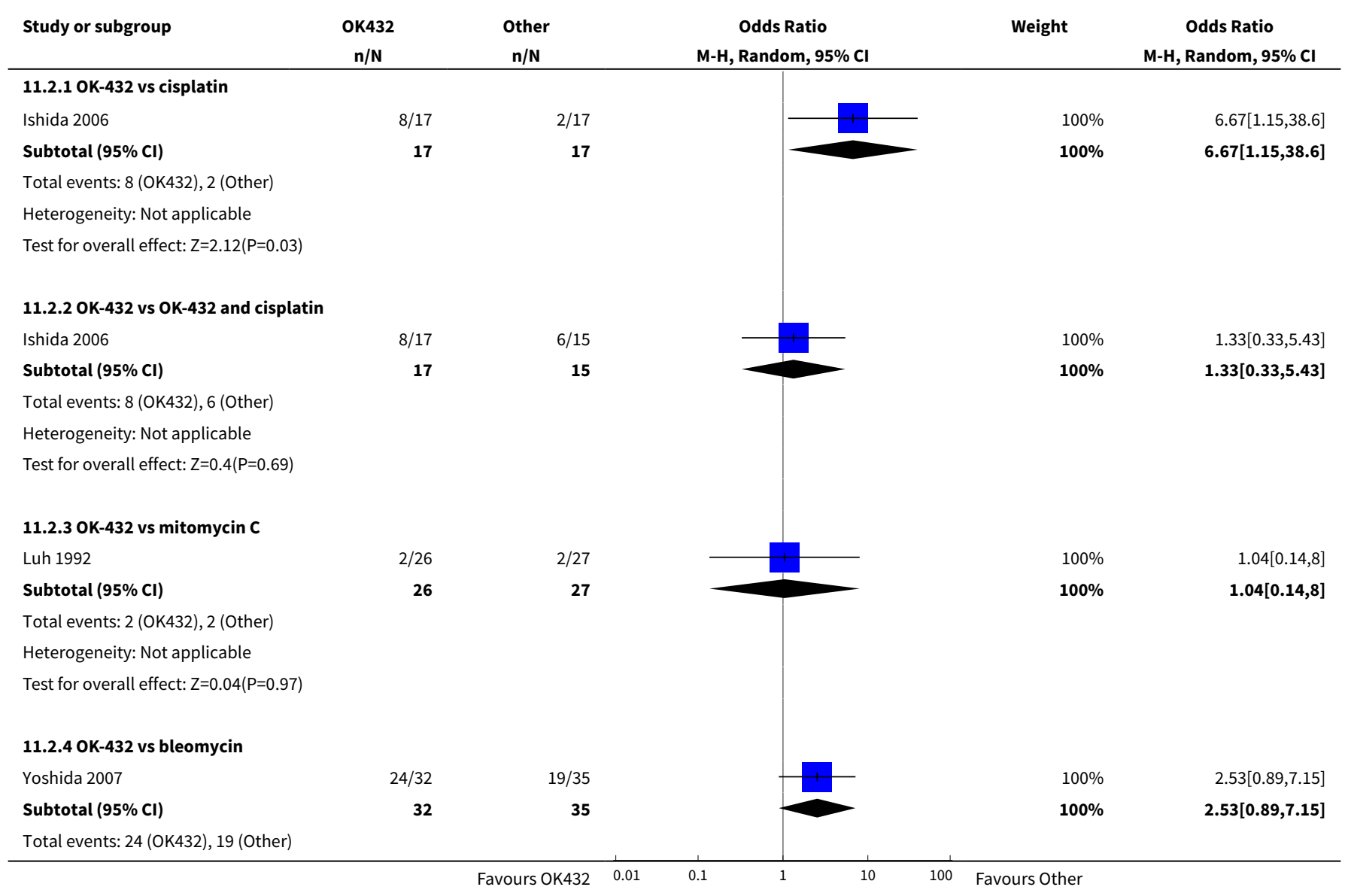




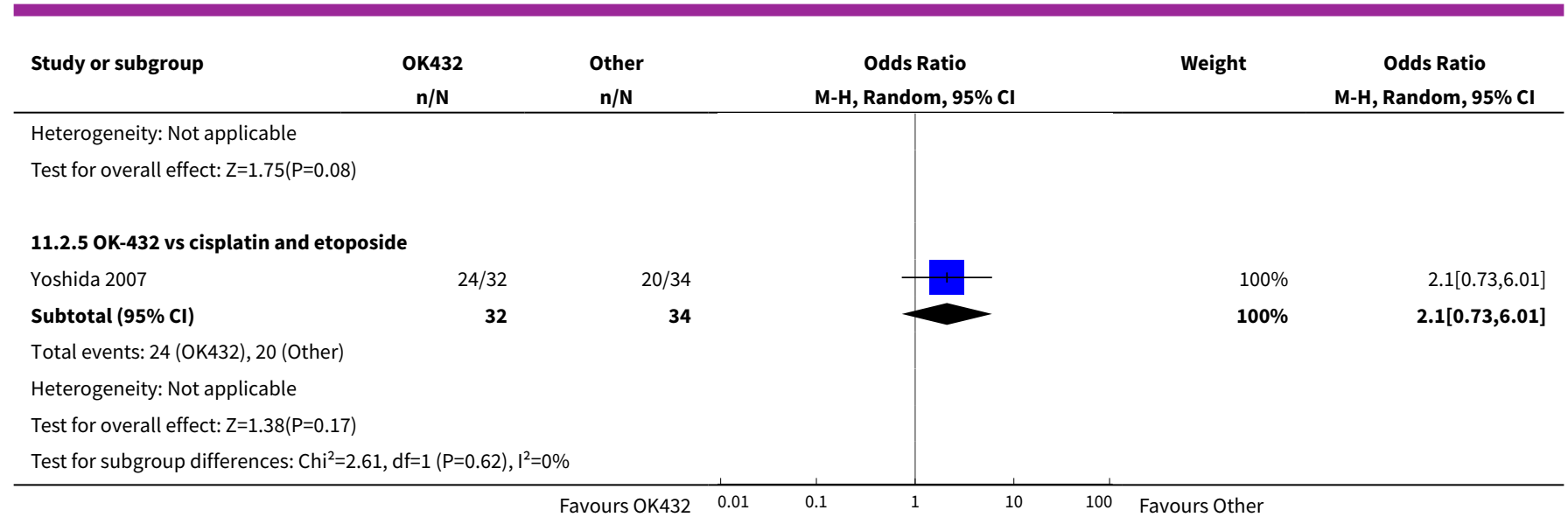

Analysis 11.3. Comparison 11 OK-432, Outcome 3 Fever.

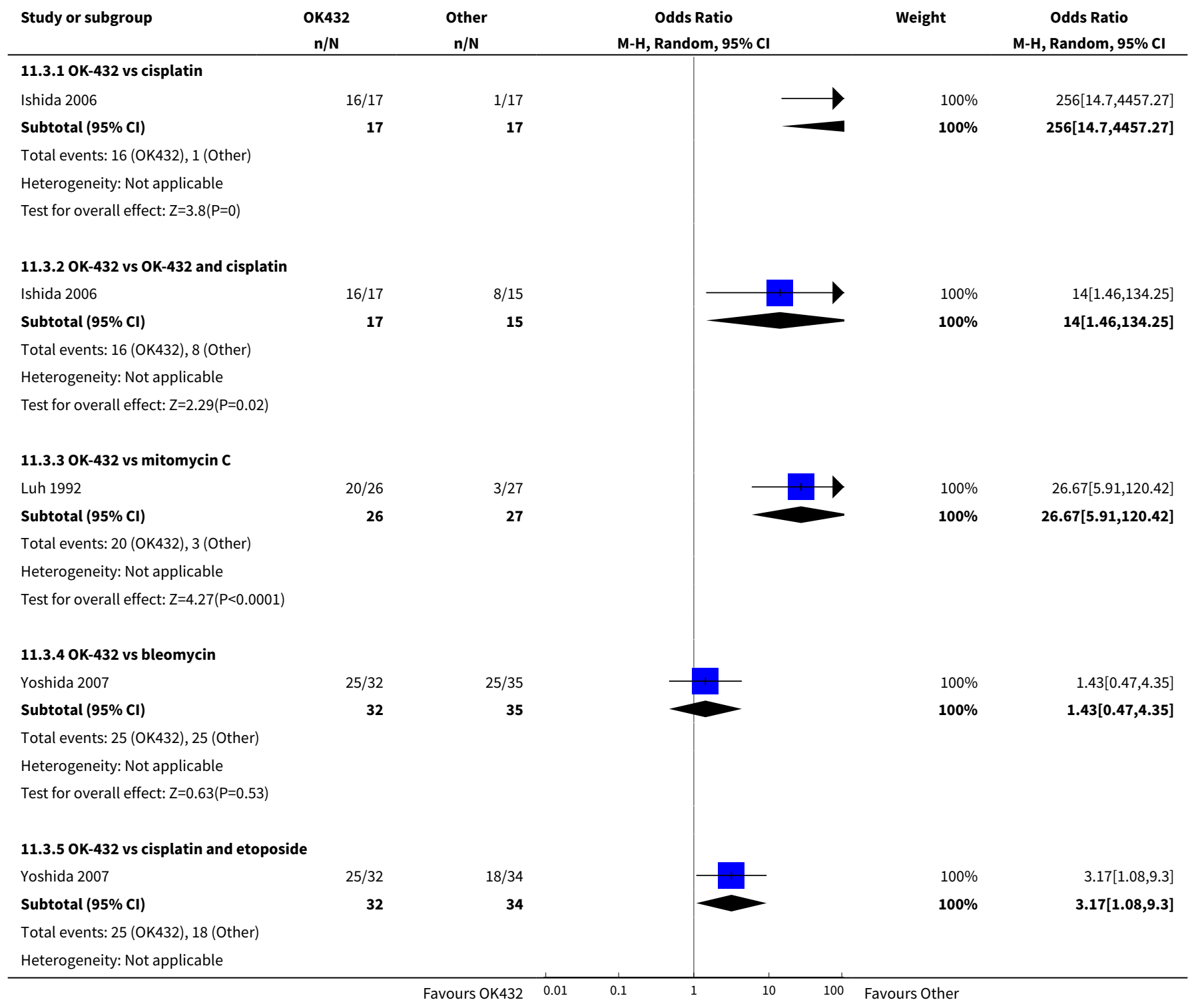




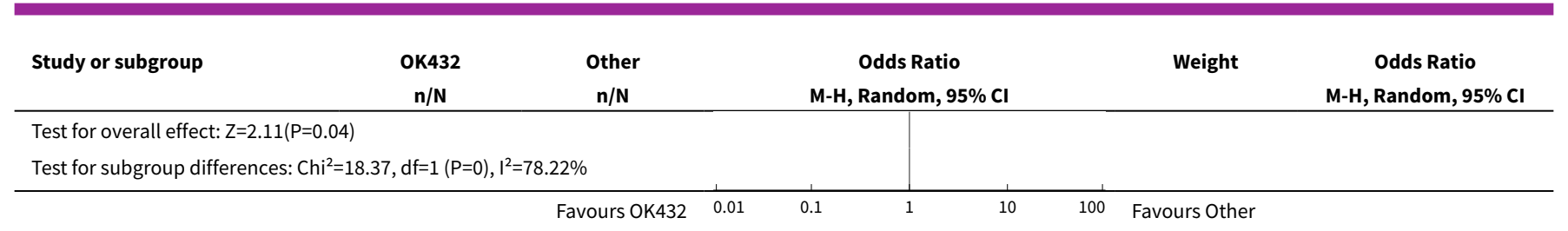

\section{Analysis 11.4. Comparison 11 OK-432, Outcome 4 Mortality.}

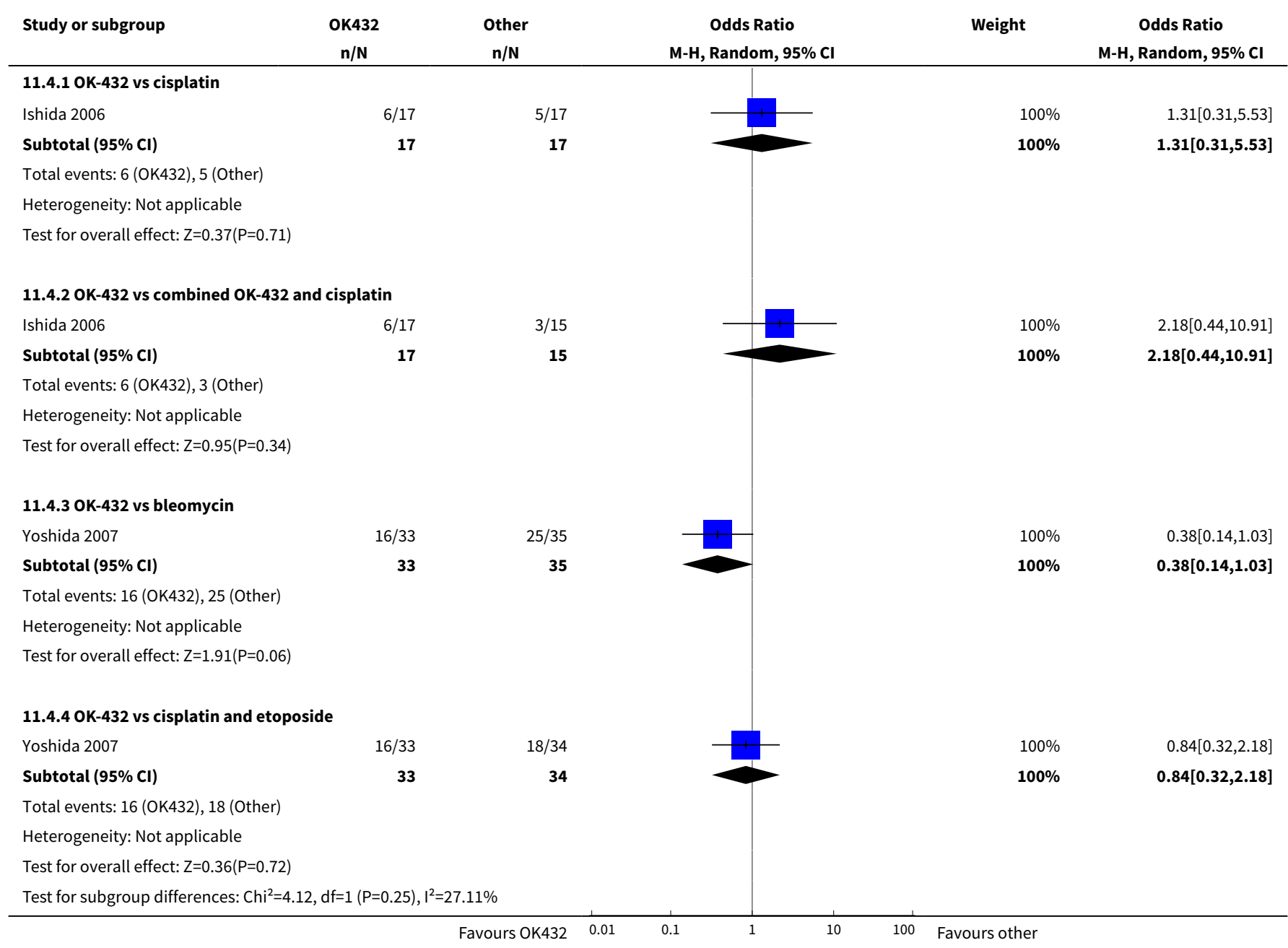

\section{Comparison 12. Mepacrine}

\begin{tabular}{lllll}
\hline Outcome or subgroup title & $\begin{array}{l}\text { No. of } \\
\text { studies }\end{array}$ & $\begin{array}{l}\text { No. of } \\
\text { partici- } \\
\text { pants }\end{array}$ & Statistical method & Effect size \\
\hline 1 Pain & 3 & 114 & $\begin{array}{l}\text { Odds Ratio (M-H, Random, 95\% } \\
\text { Cl) }\end{array}$ & $4.56[1.66,12.52]$ \\
\hline
\end{tabular}




\begin{tabular}{|c|c|c|c|c|}
\hline Outcome or subgroup title & $\begin{array}{l}\text { No. of } \\
\text { studies }\end{array}$ & $\begin{array}{l}\text { No. of } \\
\text { partici- } \\
\text { pants }\end{array}$ & Statistical method & Effect size \\
\hline 1.1 Mepacrine vs bleomycin & 1 & 40 & $\begin{array}{l}\text { Odds Ratio (M-H, Random, 95\% } \\
\mathrm{Cl})\end{array}$ & $2.15[0.52,9.00]$ \\
\hline 1.2 Mepacrine vs tetracycline & 1 & 22 & $\begin{array}{l}\text { Odds Ratio (M-H, Random, 95\% } \\
\mathrm{Cl})\end{array}$ & $5.6[0.81,38.51]$ \\
\hline 1.3 Mepacrine vs placebo & 1 & 23 & $\begin{array}{l}\text { Odds Ratio (M-H, Random, 95\% } \\
\mathrm{Cl})\end{array}$ & $14.53[0.71,298.21]$ \\
\hline $\begin{array}{l}\text { 1.4 Mepacrine vs triethylenethiophos- } \\
\text { phoramide }\end{array}$ & 1 & 29 & $\begin{array}{l}\text { Odds Ratio (M-H, Random, 95\% } \\
\mathrm{Cl})\end{array}$ & $23.71[1.19,474.06]$ \\
\hline 2 Fever & 3 & & $\begin{array}{l}\text { Odds Ratio (M-H, Random, 95\% } \\
\mathrm{Cl})\end{array}$ & Subtotals only \\
\hline 2.1 Mepacrine vs bleomycin & 1 & 40 & $\begin{array}{l}\text { Odds Ratio (M-H, Random, 95\% } \\
\mathrm{Cl})\end{array}$ & $1.91[0.52,7.01]$ \\
\hline 2.2 Mepacrine vs tetracycline & 1 & 22 & $\begin{array}{l}\text { Odds Ratio (M-H, Random, 95\% } \\
\mathrm{Cl})\end{array}$ & $8.00[1.13,56.79]$ \\
\hline 2.3 Mepacrine vs placebo & 1 & 23 & $\begin{array}{l}\text { Odds Ratio (M-H, Random, 95\% } \\
\mathrm{Cl})\end{array}$ & $62.43[2.85,1365.52]$ \\
\hline 2.4 Mepacrine vs triethylene... & 1 & 29 & $\begin{array}{l}\text { Odds Ratio (M-H, Random, 95\% } \\
\text { Cl) }\end{array}$ & $23.83[3.35,169.39]$ \\
\hline 3 Pleurodesis failure & 5 & & $\begin{array}{l}\text { Odds Ratio (M-H, Random, 95\% } \\
\mathrm{Cl})\end{array}$ & Subtotals only \\
\hline 3.1 Mepacrine vs talc slurry & 1 & 89 & $\begin{array}{l}\text { Odds Ratio (M-H, Random, 95\% } \\
\mathrm{Cl})\end{array}$ & $2.08[0.62,6.96]$ \\
\hline 3.2 Mepacrine vs bleomycin & 1 & 36 & $\begin{array}{l}\text { Odds Ratio (M-H, Random, 95\% } \\
\mathrm{Cl})\end{array}$ & $0.16[0.03,0.89]$ \\
\hline 3.3 Mepacrine vs tetracycline & 1 & 21 & $\begin{array}{l}\text { Odds Ratio (M-H, Random, 95\% } \\
\text { CI) }\end{array}$ & $0.63[0.05,8.20]$ \\
\hline 3.4 Mepacrine vs placebo & 1 & 23 & $\begin{array}{l}\text { Odds Ratio (M-H, Random, 95\% } \\
\mathrm{Cl})\end{array}$ & $0.07[0.01,0.73]$ \\
\hline 3.5 Mepacrine vs mitoxantrone & 1 & 26 & $\begin{array}{l}\text { Odds Ratio (M-H, Random, 95\% } \\
\text { Cl) }\end{array}$ & $7.61[0.35,163.82]$ \\
\hline 3.6 Mepacrine vs triethylene... & 1 & 29 & $\begin{array}{l}\text { Odds Ratio (M-H, Random, 95\% } \\
\text { Cl) }\end{array}$ & $0.20[0.04,0.98]$ \\
\hline 4 Mortality & 2 & & $\begin{array}{l}\text { Odds Ratio (M-H, Random, 95\% } \\
\mathrm{Cl})\end{array}$ & Subtotals only \\
\hline 4.1 Mepacrine vs talc slurry & 1 & 89 & $\begin{array}{l}\text { Odds Ratio (M-H, Random, 95\% } \\
\mathrm{Cl} \text { ) }\end{array}$ & $0.53[0.20,1.43]$ \\
\hline
\end{tabular}




\begin{tabular}{lllll}
\hline Outcome or subgroup title & $\begin{array}{l}\text { No. of } \\
\text { studies }\end{array}$ & $\begin{array}{l}\text { No. of } \\
\text { partici- } \\
\text { pants }\end{array}$ & Statistical method & Effect size \\
\hline 4.2 Mepacrine vs mitoxantrone & 1 & 28 & $\begin{array}{l}\text { Odds Ratio (M-H, Random, 95\% } \\
\text { Cl) }\end{array}$ & $1.64[0.23,11.70]$ \\
\hline
\end{tabular}

\section{Analysis 12.1. Comparison 12 Mepacrine, Outcome 1 Pain.}

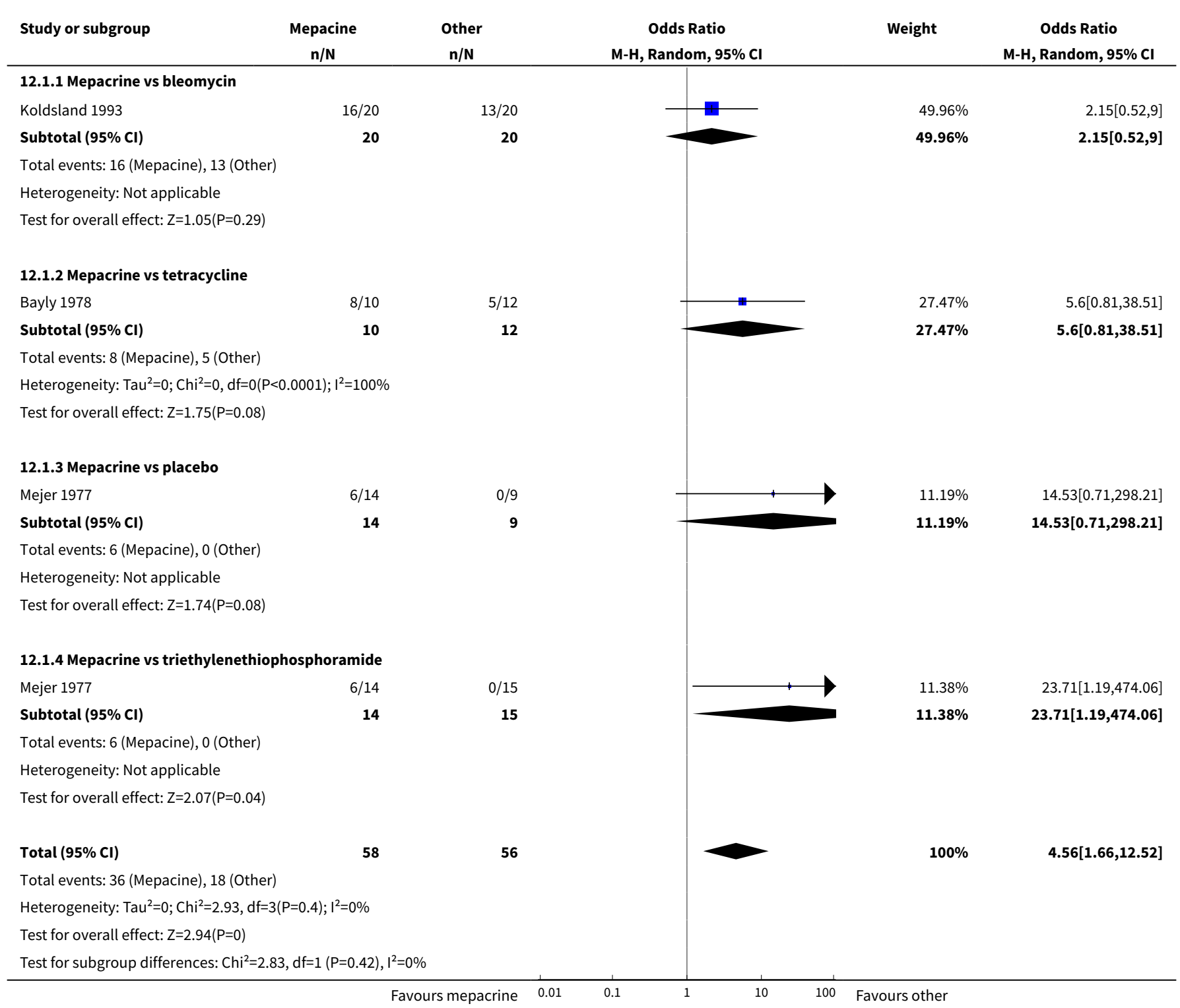




\section{Analysis 12.2. Comparison 12 Mepacrine, Outcome 2 Fever.}

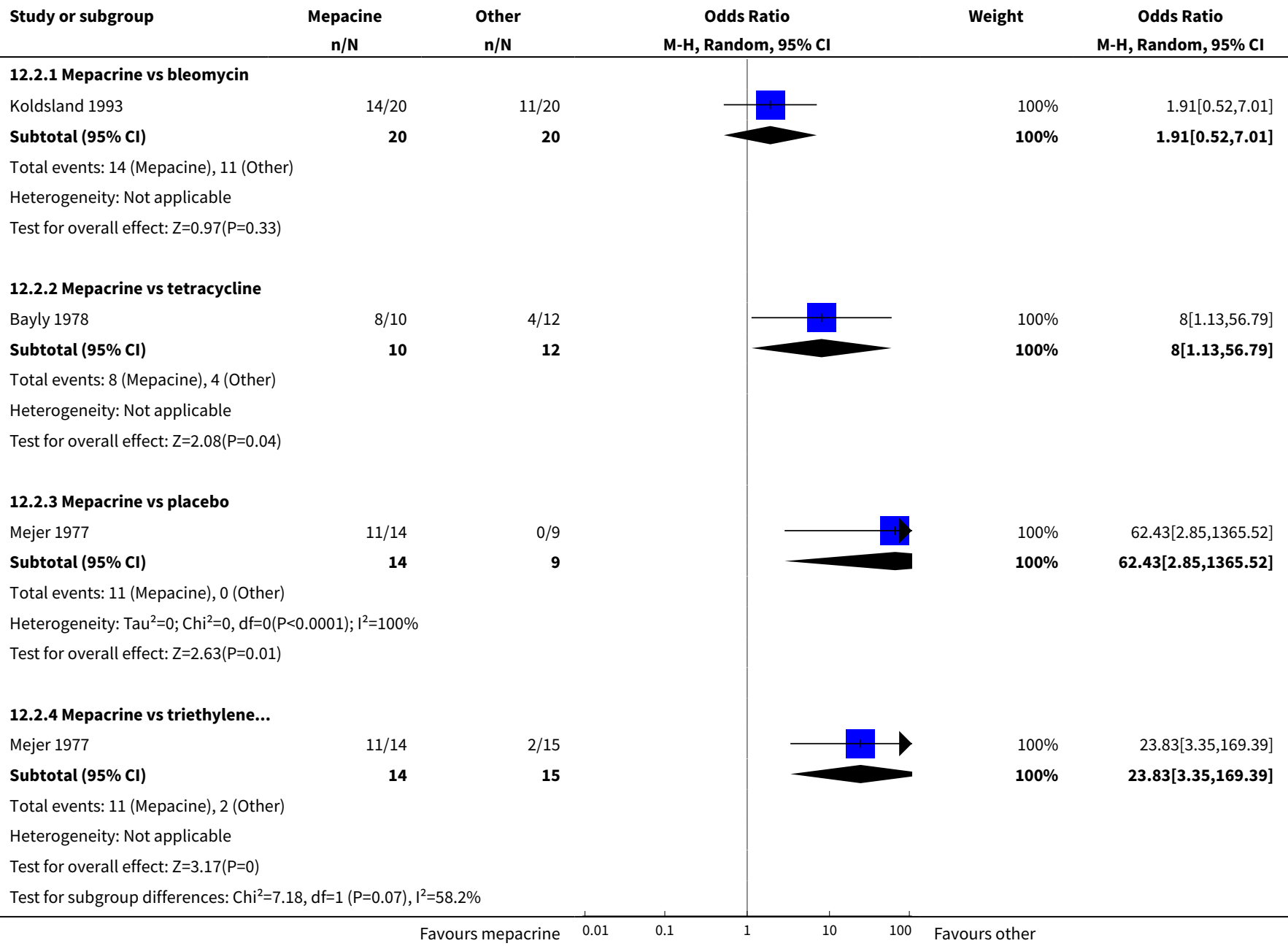

Analysis 12.3. Comparison 12 Mepacrine, Outcome 3 Pleurodesis failure.

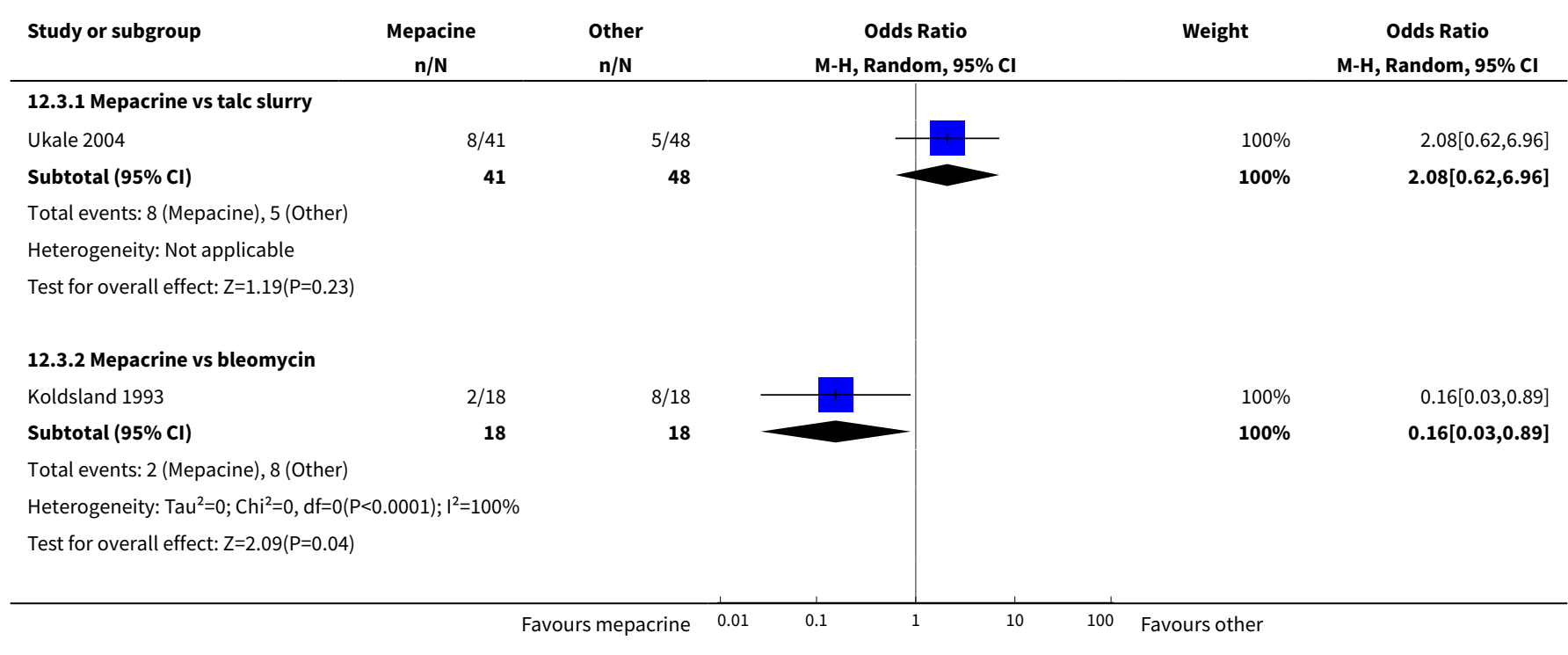




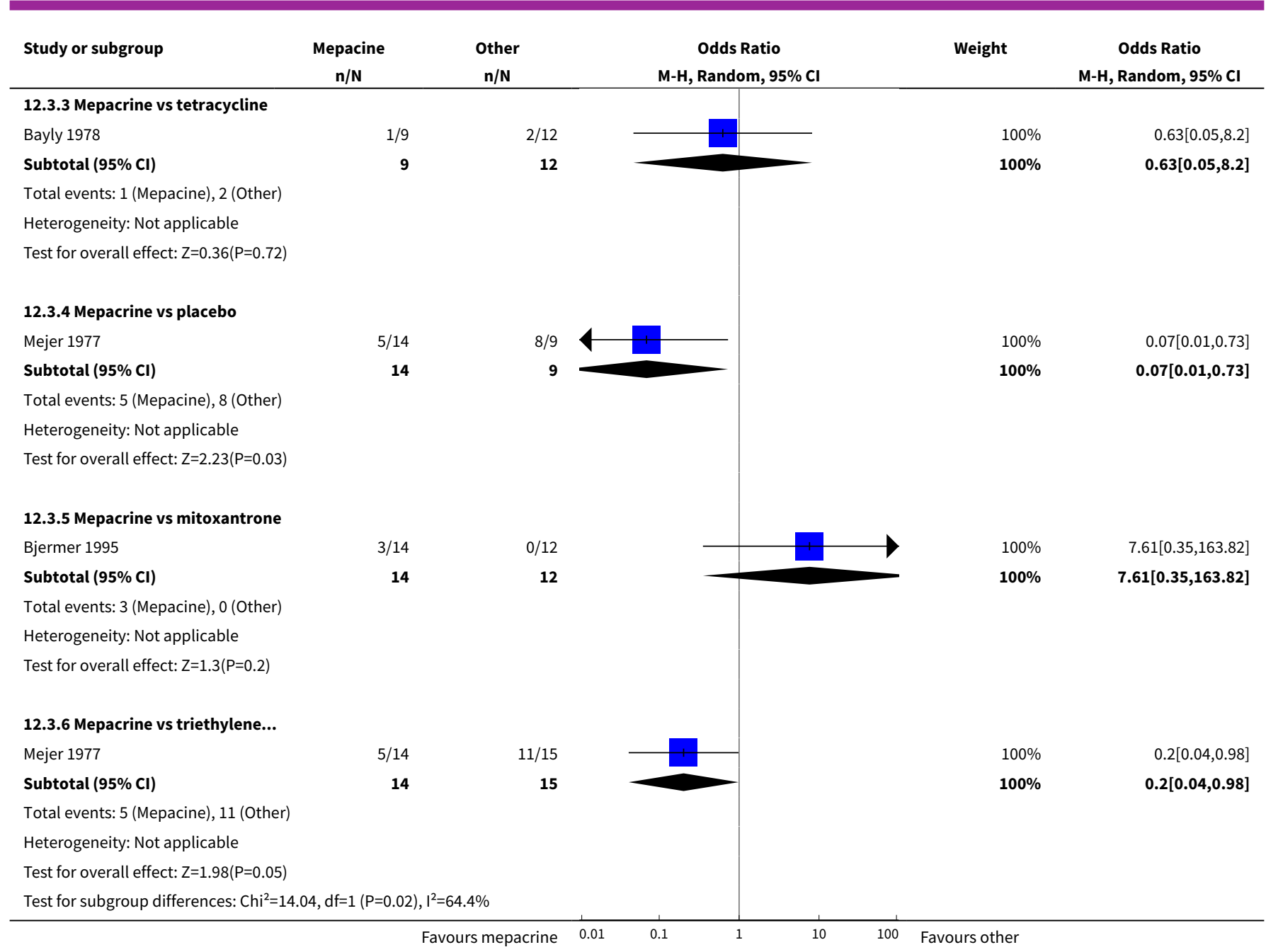

Analysis 12.4. Comparison 12 Mepacrine, Outcome 4 Mortality.

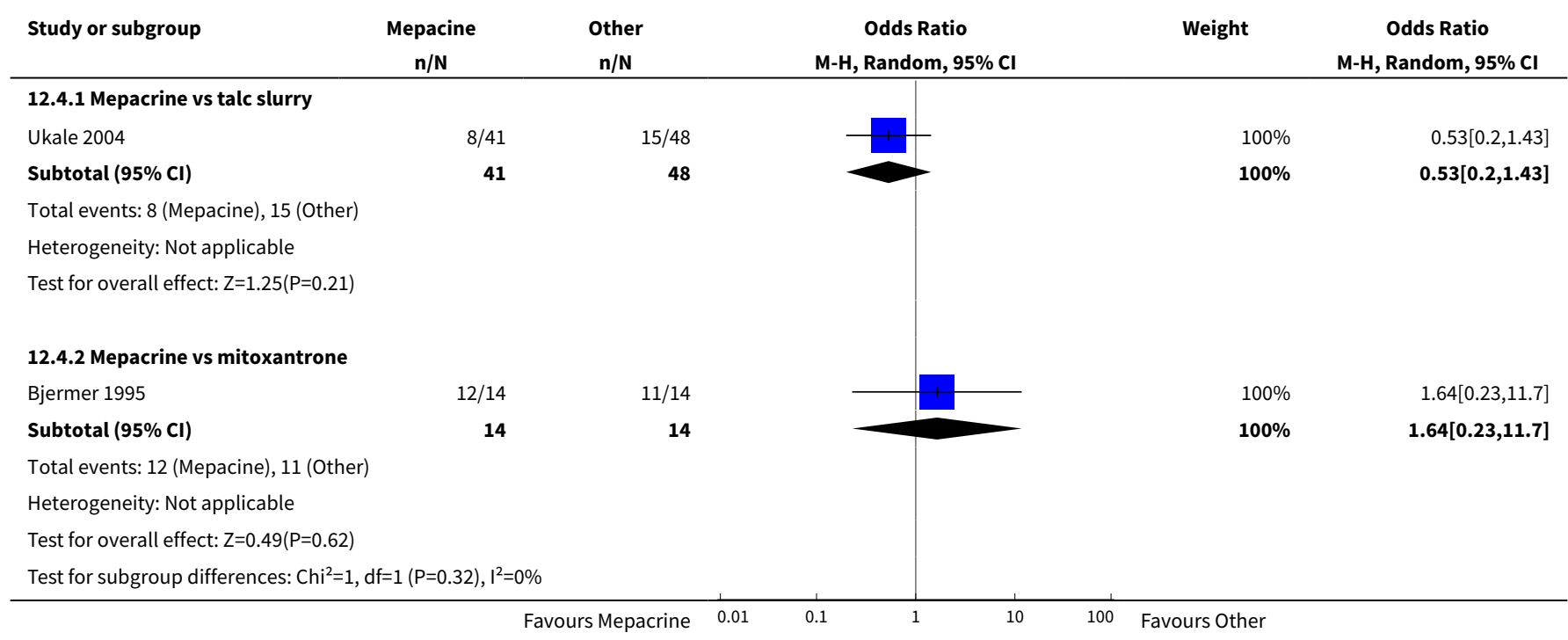


Comparison 13. Interferon (IFN)

\begin{tabular}{lllll}
\hline $\begin{array}{l}\text { Outcome or subgroup ti- } \\
\text { tle }\end{array}$ & $\begin{array}{l}\text { No. of } \\
\text { studies }\end{array}$ & $\begin{array}{l}\text { No. of } \\
\text { partici- } \\
\text { pants }\end{array}$ & Statistical method & Effect size \\
\hline 1 Pleurodesis failure & 1 & & Odds Ratio $(\mathrm{M}-\mathrm{H}$, Random, $95 \% \mathrm{Cl})$ & Subtotals only \\
\hline 1.1 IFN vs bleomycin & 1 & 160 & Odds Ratio $(\mathrm{M}-\mathrm{H}$, Random, $95 \% \mathrm{Cl})$ & $3.25[1.54,6.89]$ \\
\hline 2 Pain & 1 & 160 & Odds Ratio $(\mathrm{M}-\mathrm{H}$, Random, $95 \% \mathrm{Cl})$ & $0.03[0.00,0.53]$ \\
\hline 3 Fever & 1 & 160 & Odds Ratio $(\mathrm{M}-\mathrm{H}$, Random, $95 \% \mathrm{Cl})$ & $0.01[0.00,0.11]$ \\
\hline 4 Mortality & 1 & & Odds Ratio $(\mathrm{M}-\mathrm{H}$, Random, $95 \% \mathrm{Cl})$ & Subtotals only \\
\hline
\end{tabular}

Analysis 13.1. Comparison 13 Interferon (IFN), Outcome 1 Pleurodesis failure.

\begin{tabular}{|c|c|c|c|c|c|}
\hline Study or subgroup & $\begin{array}{l}\text { IFN } \\
\mathrm{n} / \mathrm{N}\end{array}$ & $\begin{array}{c}\text { other } \\
\mathrm{n} / \mathrm{N}\end{array}$ & $\begin{array}{c}\text { Odds Ratio } \\
\text { M-H, Random, } 95 \% \mathrm{CI}\end{array}$ & Weight & $\begin{array}{c}\text { Odds Ratio } \\
\text { M-H, Random, } 95 \% \mathrm{Cl}\end{array}$ \\
\hline \multicolumn{6}{|c|}{ 13.1.1 IFN vs bleomycin } \\
\hline Sartori 2004 & $29 / 77$ & $13 / 83$ & 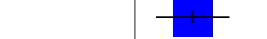 & $100 \%$ & $3.25[1.54,6.89]$ \\
\hline Subtotal $(95 \% \mathrm{Cl})$ & 77 & 83 & & $100 \%$ & $3.25[1.54,6.89]$ \\
\hline \multicolumn{6}{|c|}{ Total events: 29 (IFN), 13 (other) } \\
\hline \multicolumn{6}{|c|}{ Heterogeneity: Not applicable } \\
\hline
\end{tabular}

Analysis 13.2. Comparison 13 Interferon (IFN), Outcome 2 Pain.

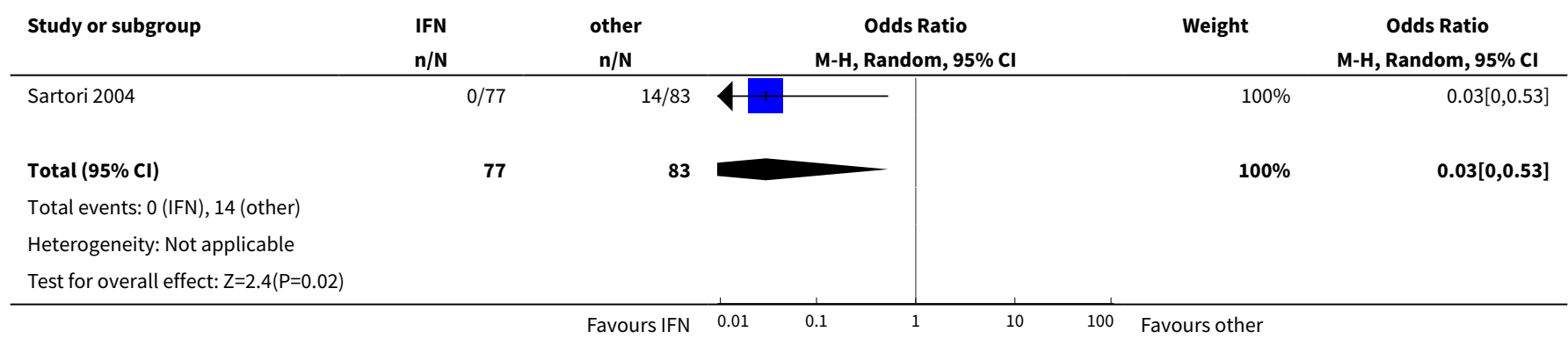

Analysis 13.3. Comparison 13 Interferon (IFN), Outcome 3 Fever.

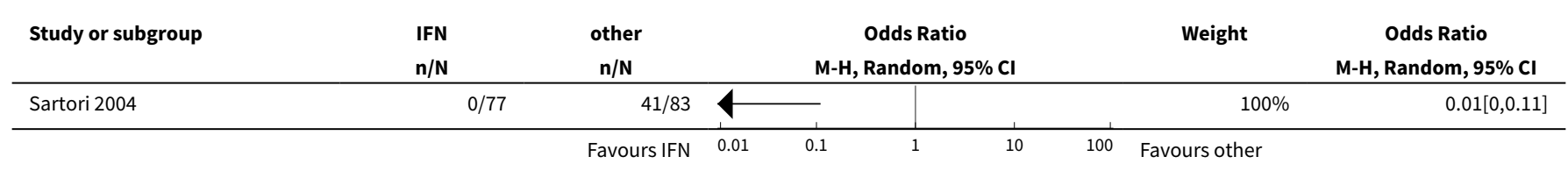




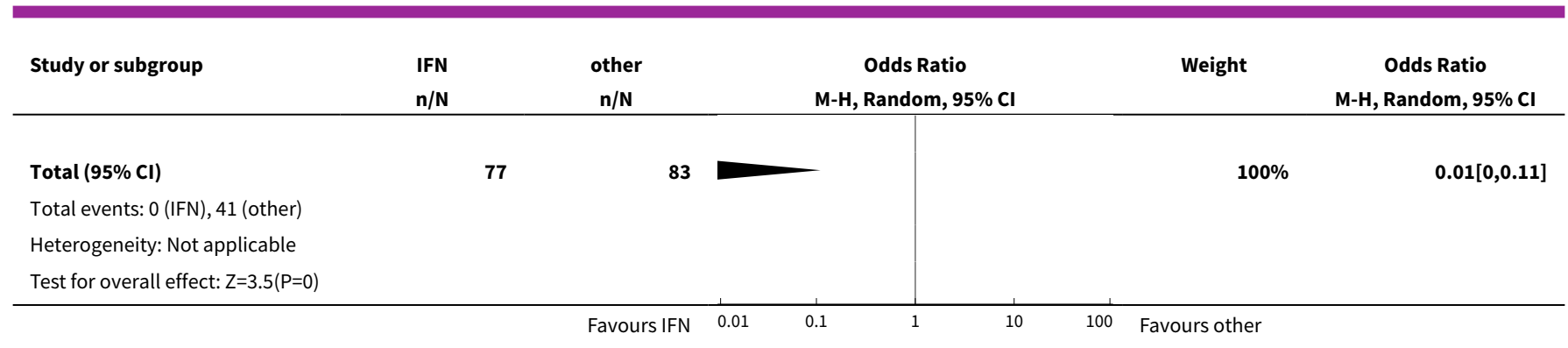

Analysis 13.4. Comparison 13 Interferon (IFN), Outcome 4 Mortality.

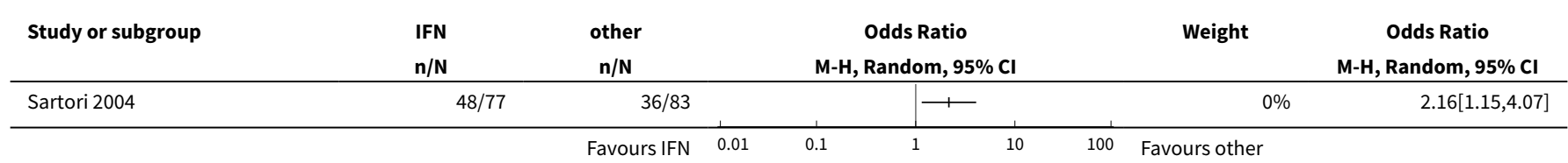

\section{Comparison 14. Triethylenethiophophoramide}

\begin{tabular}{|c|c|c|c|c|}
\hline Outcome or subgroup title & $\begin{array}{l}\text { No. of } \\
\text { studies }\end{array}$ & $\begin{array}{l}\text { No. of } \\
\text { partici- } \\
\text { pants }\end{array}$ & Statistical method & Effect size \\
\hline 1 Pleurodesis failure & 1 & & $\begin{array}{l}\text { Odds Ratio (M-H, Random, 95\% } \\
\text { Cl) }\end{array}$ & Subtotals only \\
\hline 1.1 Triethylene... vs placebo & 1 & 24 & $\begin{array}{l}\text { Odds Ratio (M-H, Random, 95\% } \\
\mathrm{Cl})\end{array}$ & $0.34[0.03,3.69]$ \\
\hline 1.2 Triethylene... vs mepacrine & 1 & 29 & $\begin{array}{l}\text { Odds Ratio (M-H, Random, 95\% } \\
\text { Cl) }\end{array}$ & $4.95[1.02,24.10]$ \\
\hline 2 Pain & 1 & 53 & $\begin{array}{l}\text { Odds Ratio (M-H, Random, 95\% } \\
\mathrm{Cl} \text { ) }\end{array}$ & $1.39[0.10,20.15]$ \\
\hline 2.1 Triethylene... vs mepacrine & 1 & 29 & $\begin{array}{l}\text { Odds Ratio (M-H, Random, 95\% } \\
\mathrm{Cl} \text { ) }\end{array}$ & $0.48[0.10,2.30]$ \\
\hline 2.2 Triethylene... vs placebo & 1 & 24 & $\begin{array}{l}\text { Odds Ratio (M-H, Random, 95\% } \\
\mathrm{Cl})\end{array}$ & $7.43[0.35,156.28]$ \\
\hline 3 Fever & 1 & 53 & $\begin{array}{l}\text { Odds Ratio (M-H, Random, 95\% } \\
\mathrm{Cl})\end{array}$ & $0.32[0.00,26.74]$ \\
\hline 3.1 Triethylene... vs placebo & 1 & 24 & $\begin{array}{l}\text { Odds Ratio (M-H, Random, 95\% } \\
\text { Cl) }\end{array}$ & $3.52[0.15,81.92]$ \\
\hline 3.2 Triethylene... vs mepacrine & 1 & 29 & $\begin{array}{l}\text { Odds Ratio (M-H, Random, 95\% } \\
\text { Cl) }\end{array}$ & $0.04[0.01,0.30]$ \\
\hline
\end{tabular}


Analysis 14.1. Comparison 14 Triethylenethiophophoramide, Outcome 1 Pleurodesis failure.

\begin{tabular}{|c|c|c|c|c|c|}
\hline Study or subgroup & $\begin{array}{c}\text { triethylene.... } \\
\mathrm{n} / \mathrm{N}\end{array}$ & $\begin{array}{l}\text { other } \\
\mathrm{n} / \mathrm{N}\end{array}$ & $\begin{array}{c}\text { Odds Ratio } \\
\text { M-H, Random, } 95 \% \mathrm{Cl}\end{array}$ & Weight & $\begin{array}{c}\text { Odds Ratio } \\
\text { M-H, Random, } 95 \% \mathrm{Cl}\end{array}$ \\
\hline \multicolumn{6}{|c|}{ 14.1.1 Triethylene... vs placebo } \\
\hline Mejer 1977 & $11 / 15$ & $8 / 9$ & & $100 \%$ & $0.34[0.03,3.69]$ \\
\hline Subtotal $(95 \% \mathrm{Cl})$ & 15 & 9 & & $100 \%$ & $0.34[0.03,3.69]$ \\
\hline \multicolumn{6}{|c|}{ Total events: 11 (triethylene....), 8 (other) } \\
\hline \multicolumn{6}{|c|}{ Heterogeneity: Not applicable } \\
\hline \multicolumn{6}{|c|}{ 14.1.2 Triethylene... vs mepacrine } \\
\hline Mejer 1977 & $11 / 15$ & $5 / 14$ & & $100 \%$ & $4.95[1.02,24.1]$ \\
\hline Subtotal $(95 \% \mathrm{Cl})$ & 15 & 14 & & $100 \%$ & $4.95[1.02,24.1]$ \\
\hline \multicolumn{6}{|c|}{ Total events: 11 (triethylene....), 5 (other) } \\
\hline \multicolumn{6}{|c|}{ Heterogeneity: Not applicable } \\
\hline \multicolumn{6}{|c|}{ Test for overall effect: $Z=1.98(P=0.05)$} \\
\hline Test for subgroup dif & $.36, d f=1(P=0.07)$, & & & & \\
\hline
\end{tabular}

Analysis 14.2. Comparison 14 Triethylenethiophophoramide, Outcome 2 Pain.

\begin{tabular}{|c|c|c|c|c|c|}
\hline Study or subgroup & $\begin{array}{c}\text { triethylene.... } \\
\mathrm{n} / \mathrm{N}\end{array}$ & $\begin{array}{c}\text { other } \\
\mathrm{n} / \mathrm{N}\end{array}$ & $\begin{array}{c}\text { Odds Ratio } \\
\text { M-H, Random, } 95 \% \mathrm{Cl}\end{array}$ & Weight & $\begin{array}{c}\text { Odds Ratio } \\
\text { M-H, Random, } 95 \% \mathrm{Cl}\end{array}$ \\
\hline \multicolumn{6}{|c|}{ 14.2.1 Triethylene... vs mepacrine } \\
\hline Mejer 1977 & $4 / 15$ & $6 / 14$ & 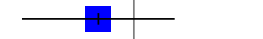 & $61.36 \%$ & $0.48[0.1,2.3]$ \\
\hline Subtotal $(95 \% \mathrm{CI})$ & 15 & 14 & & $61.36 \%$ & $0.48[0.1,2.3]$ \\
\hline \multicolumn{6}{|c|}{ Total events: 4 (triethylene....), 6 (other) } \\
\hline \multicolumn{6}{|c|}{ Heterogeneity: $\mathrm{Tau}^{2}=0 ; \mathrm{Chi}^{2}=0, \mathrm{df}=0(\mathrm{P}<0.0001) ; \mathrm{I}^{2}=100 \%$} \\
\hline \multicolumn{6}{|c|}{ 14.2.2 Triethylene... vs placebo } \\
\hline Mejer 1977 & $4 / 15$ & $0 / 9$ & & $38.64 \%$ & $7.43[0.35,156.28]$ \\
\hline Subtotal $(95 \% \mathrm{Cl})$ & 15 & 9 & & $38.64 \%$ & $7.43[0.35,156.28]$ \\
\hline \multicolumn{6}{|c|}{ Total events: 4 (triethylene....), 0 (other) } \\
\hline \multicolumn{6}{|c|}{ Heterogeneity: Not applicable } \\
\hline Total $(95 \% \mathrm{Cl})$ & 30 & 23 & & $100 \%$ & $1.39[0.1,20.15]$ \\
\hline \multicolumn{6}{|c|}{ Total events: 8 (triethylene....), 6 (other) } \\
\hline \multicolumn{6}{|c|}{ Heterogeneity: $\mathrm{Tau}^{2}=2.4 ; \mathrm{Chi}^{2}=2.57, \mathrm{df}=1(\mathrm{P}=0.11) ; \mathrm{I}^{2}=61.14 \%$} \\
\hline \multicolumn{6}{|c|}{ Test for overall effect: $\mathrm{Z}=0.24(\mathrm{P}=0.81)$} \\
\hline Test for subgroup dif & $.45, \mathrm{df}=1(\mathrm{P}=0.12)$, & & & & \\
\hline
\end{tabular}


Analysis 14.3. Comparison 14 Triethylenethiophophoramide, Outcome 3 Fever.

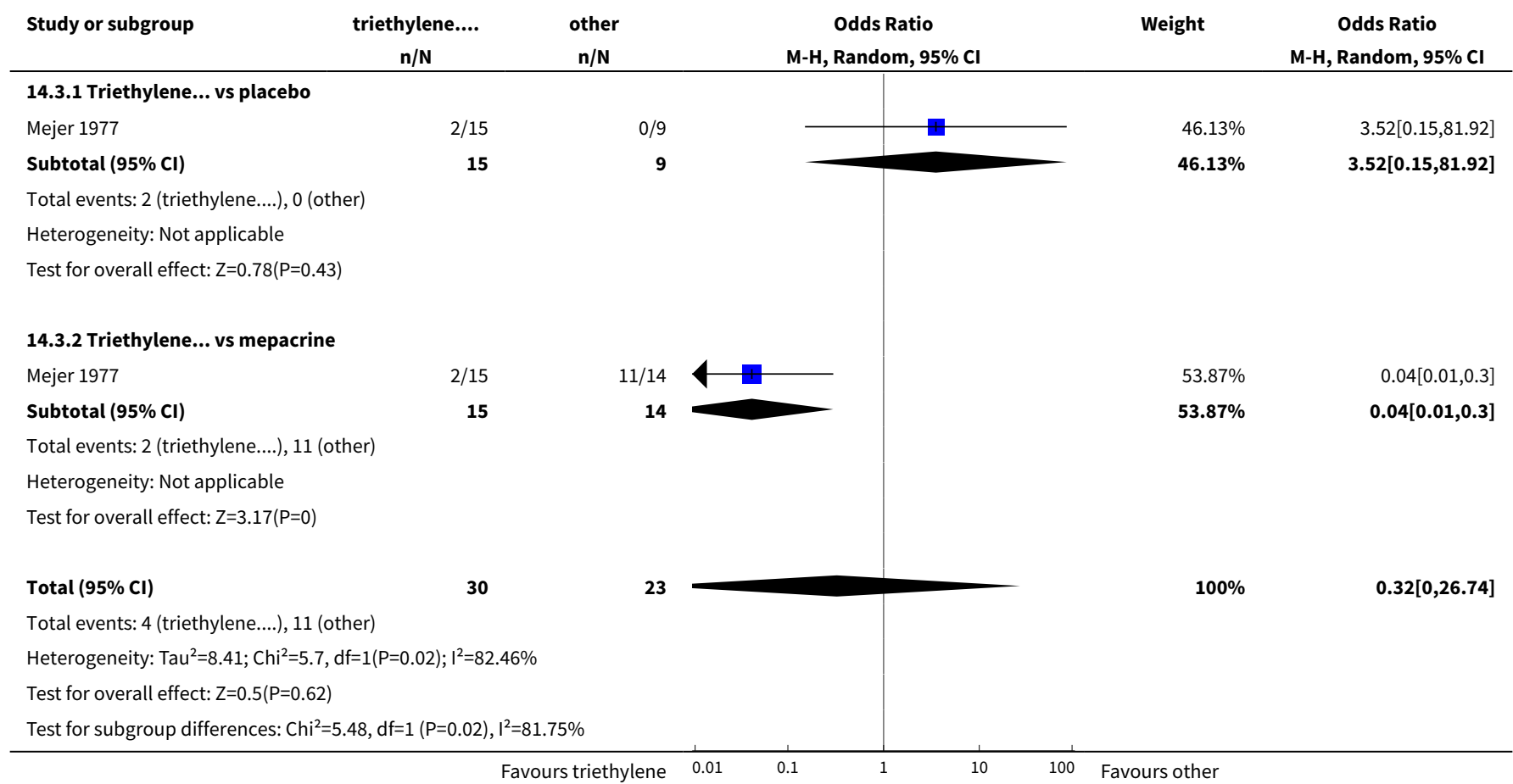

\section{Comparison 15. Adriamycin}

\begin{tabular}{|c|c|c|c|c|}
\hline Outcome or subgroup title & $\begin{array}{l}\text { No. of } \\
\text { studies }\end{array}$ & $\begin{array}{l}\text { No. of } \\
\text { partici- } \\
\text { pants }\end{array}$ & Statistical method & Effect size \\
\hline 1 Pleurodesis failure & 2 & & Odds Ratio (M-H, Random, 95\% Cl) & Subtotals only \\
\hline 1.1 Adriamycin vs mustine & 1 & 20 & Odds Ratio (M-H, Random, $95 \% \mathrm{Cl})$ & $0.37[0.01,10.18]$ \\
\hline 1.2 Adriamycin vs tetracycline & 1 & 21 & Odds Ratio (M-H, Random, 95\% Cl) & $1.11[0.06,20.49]$ \\
\hline $\begin{array}{l}1.3 \text { Adriamycin vs LC9018 and Adri- } \\
\text { amycin }\end{array}$ & 1 & 76 & Odds Ratio (M-H, Random, 95\% Cl) & $4.29[1.62,11.35]$ \\
\hline 2 Fever & 1 & & Odds Ratio (M-H, Random, 95\% Cl) & Subtotals only \\
\hline 3 Pain & 1 & & Odds Ratio (M-H, Random, 95\% Cl) & Subtotals only \\
\hline
\end{tabular}

Analysis 15.1. Comparison 15 Adriamycin, Outcome 1 Pleurodesis failure.

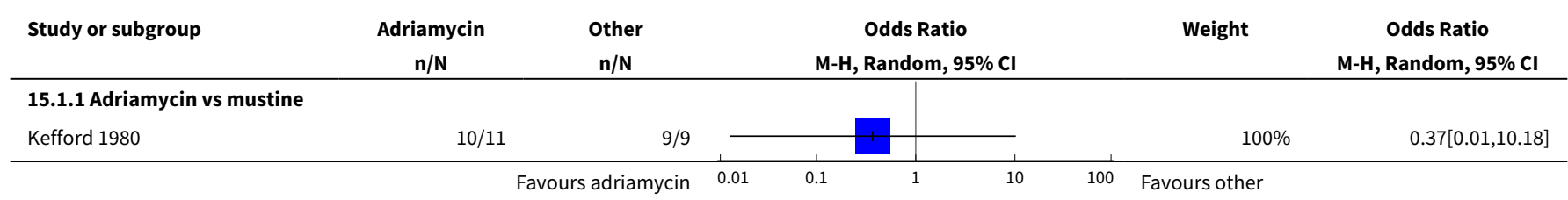




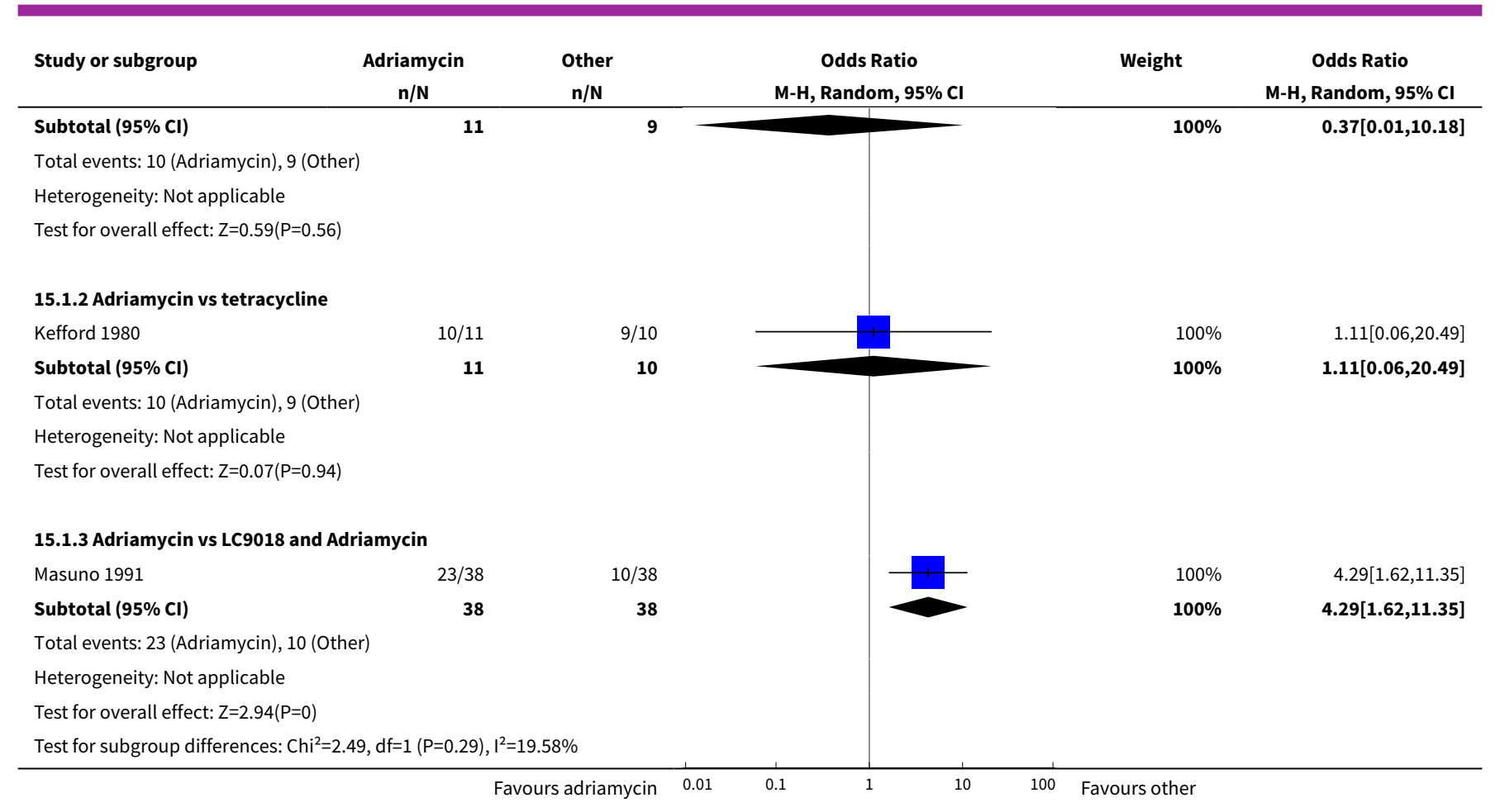

Analysis 15.2. Comparison 15 Adriamycin, Outcome 2 Fever.

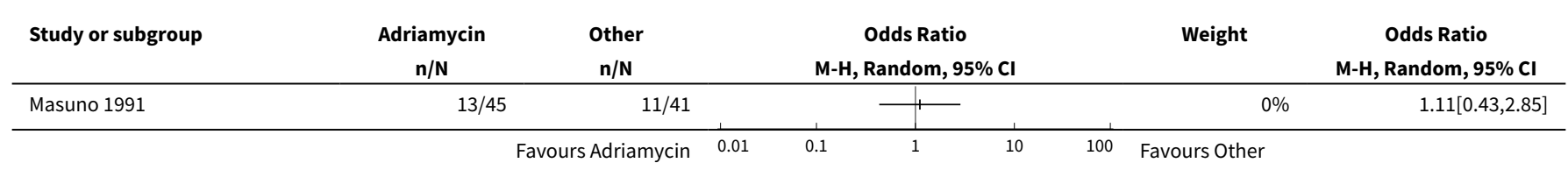

Analysis 15.3. Comparison 15 Adriamycin, Outcome 3 Pain.

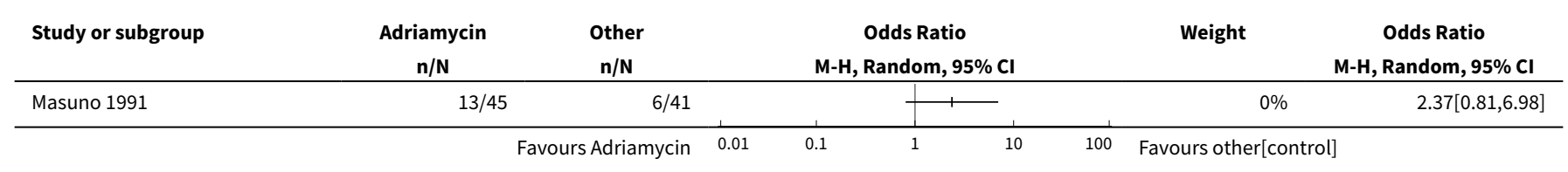

\section{Comparison 16. Placebo}

\begin{tabular}{lllll}
\hline Outcome or subgroup title & $\begin{array}{l}\text { No. of } \\
\text { studies }\end{array}$ & $\begin{array}{l}\text { No. of } \\
\text { partici- } \\
\text { pants }\end{array}$ & Statistical method & Effect size \\
\hline 1 Pleurodesis failure & 4 & & $\begin{array}{l}\text { Odds Ratio (M-H, Random, 95\% } \\
\text { Cl) }\end{array}$ & Subtotals only \\
\hline 1.1 Placebo vs mepacrine & 1 & 23 & $\begin{array}{l}\text { Odds Ratio (M-H, Random, 95\% } \\
\text { Cl) }\end{array}$ & $14.40[1.37,150.81]$ \\
\hline \hline
\end{tabular}




\begin{tabular}{|c|c|c|c|c|}
\hline Outcome or subgroup title & $\begin{array}{l}\text { No. of } \\
\text { studies }\end{array}$ & $\begin{array}{l}\text { No. of } \\
\text { partici- } \\
\text { pants }\end{array}$ & Statistical method & Effect size \\
\hline 1.2 Placebo vs mitoxantrone & 1 & 95 & $\begin{array}{l}\text { Odds Ratio (M-H, Random, 95\% } \\
\mathrm{Cl} \text { ) }\end{array}$ & $1.33[0.56,3.17]$ \\
\hline 1.3 Placebo vs triethylene... & 1 & 24 & $\begin{array}{l}\text { Odds Ratio (M-H, Random, 95\% } \\
\mathrm{Cl})\end{array}$ & $2.91[0.27,31.21]$ \\
\hline 1.4 Placebo vs talc slurry & 1 & 21 & $\begin{array}{l}\text { Odds Ratio (M-H, Random, 95\% } \\
\mathrm{Cl} \text { ) }\end{array}$ & $13.93[0.66,293.99]$ \\
\hline 1.5 Placebo vs tetracycline & 1 & 20 & $\begin{array}{l}\text { Odds Ratio (M-H, Random, 95\% } \\
\mathrm{Cl} \text { ) }\end{array}$ & $3.33[0.51,21.58]$ \\
\hline 2 Pain & 3 & 100 & $\begin{array}{l}\text { Odds Ratio (M-H, Random, 95\% } \\
\mathrm{Cl})\end{array}$ & $0.10[0.01,0.82]$ \\
\hline 2.1 Placebo vs talc slurry & 1 & 31 & $\begin{array}{l}\text { Odds Ratio (M-H, Random, 95\% } \\
\mathrm{Cl} \text { ) }\end{array}$ & $0.0[0.0,0.0]$ \\
\hline 2.2 Placebo vs tetracycline & 1 & 22 & $\begin{array}{l}\text { Odds Ratio (M-H, Random, 95\% } \\
\mathrm{Cl})\end{array}$ & $0.0[0.0,0.0]$ \\
\hline 2.3 Placebo vs mepacrine & 1 & 23 & $\begin{array}{l}\text { Odds Ratio (M-H, Random, 95\% } \\
\mathrm{Cl} \text { ) }\end{array}$ & $0.07[0.00,1.41]$ \\
\hline 2.4 Placebo vs triethylene... & 1 & 24 & $\begin{array}{l}\text { Odds Ratio (M-H, Random, 95\% } \\
\text { Cl) }\end{array}$ & $0.13[0.01,2.83]$ \\
\hline 3 Fever & 2 & & $\begin{array}{l}\text { Odds Ratio (M-H, Random, 95\% } \\
\text { Cl) }\end{array}$ & Subtotals only \\
\hline 3.1 Placebo vs mepacrine & 1 & 95 & $\begin{array}{l}\text { Odds Ratio (M-H, Random, 95\% } \\
\mathrm{Cl} \text { ) }\end{array}$ & $0.31[0.12,0.79]$ \\
\hline 3.2 Placebo vs mitoxantone & 1 & 23 & $\begin{array}{l}\text { Odds Ratio (M-H, Random, 95\% } \\
\mathrm{CI})\end{array}$ & $0.02[0.00,0.35]$ \\
\hline 3.3 Placebo vs triethylene... & 1 & 24 & $\begin{array}{l}\text { Odds Ratio (M-H, Random, 95\% } \\
\text { Cl) }\end{array}$ & $0.28[0.01,6.62]$ \\
\hline
\end{tabular}

Analysis 16.1. Comparison 16 Placebo, Outcome 1 Pleurodesis failure.

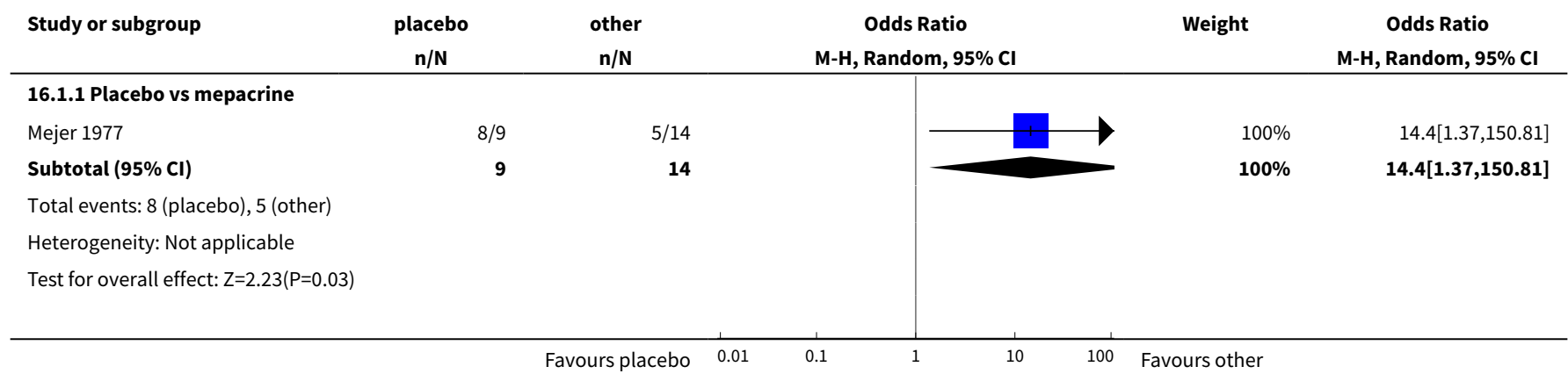




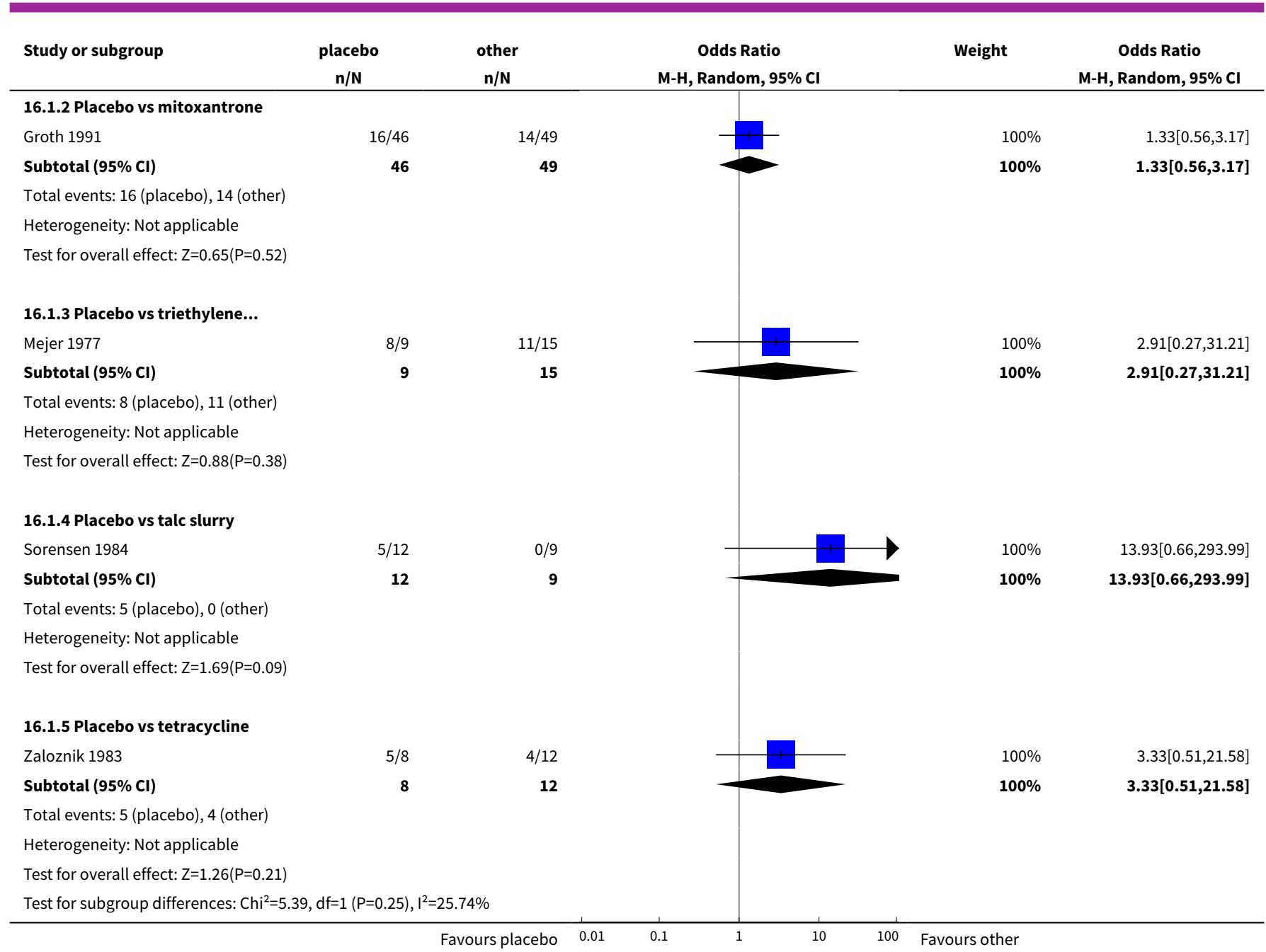

Analysis 16.2. Comparison 16 Placebo, Outcome 2 Pain.

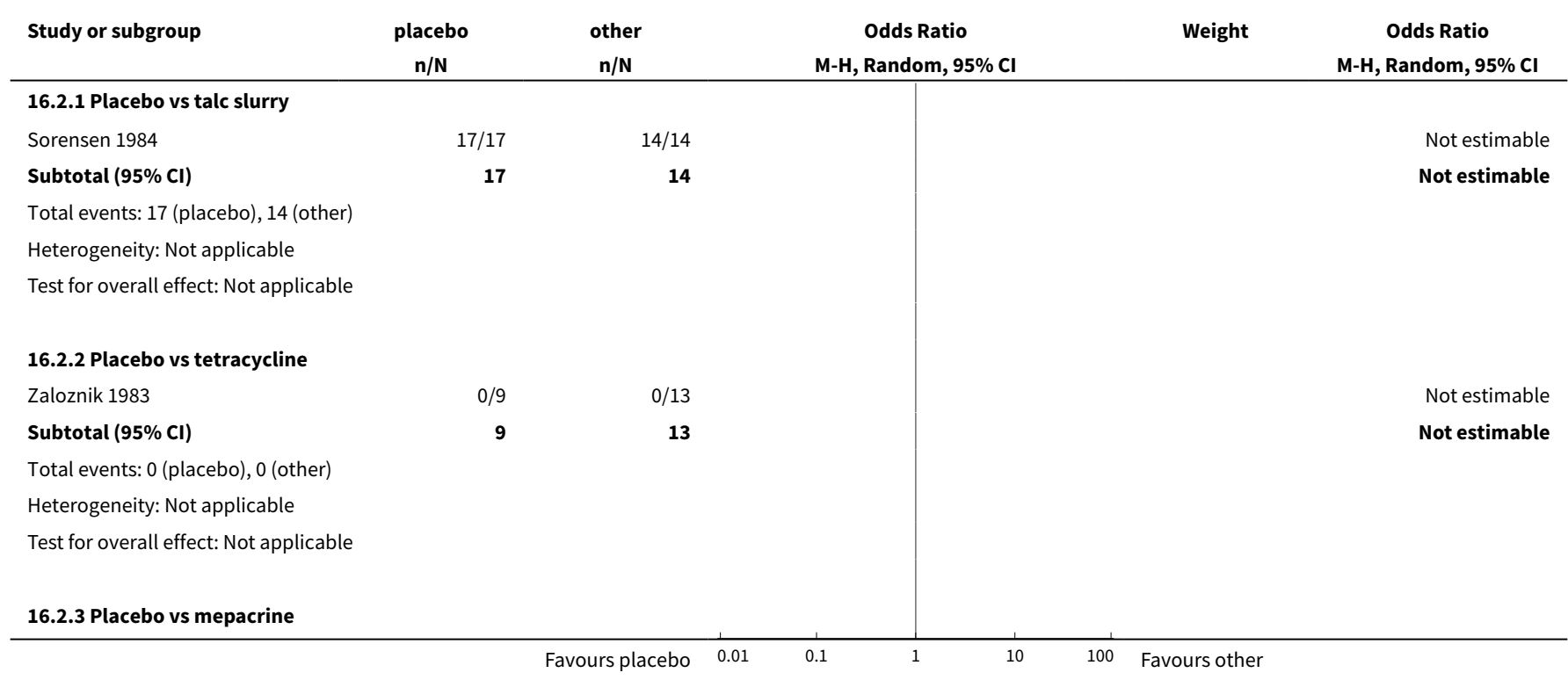




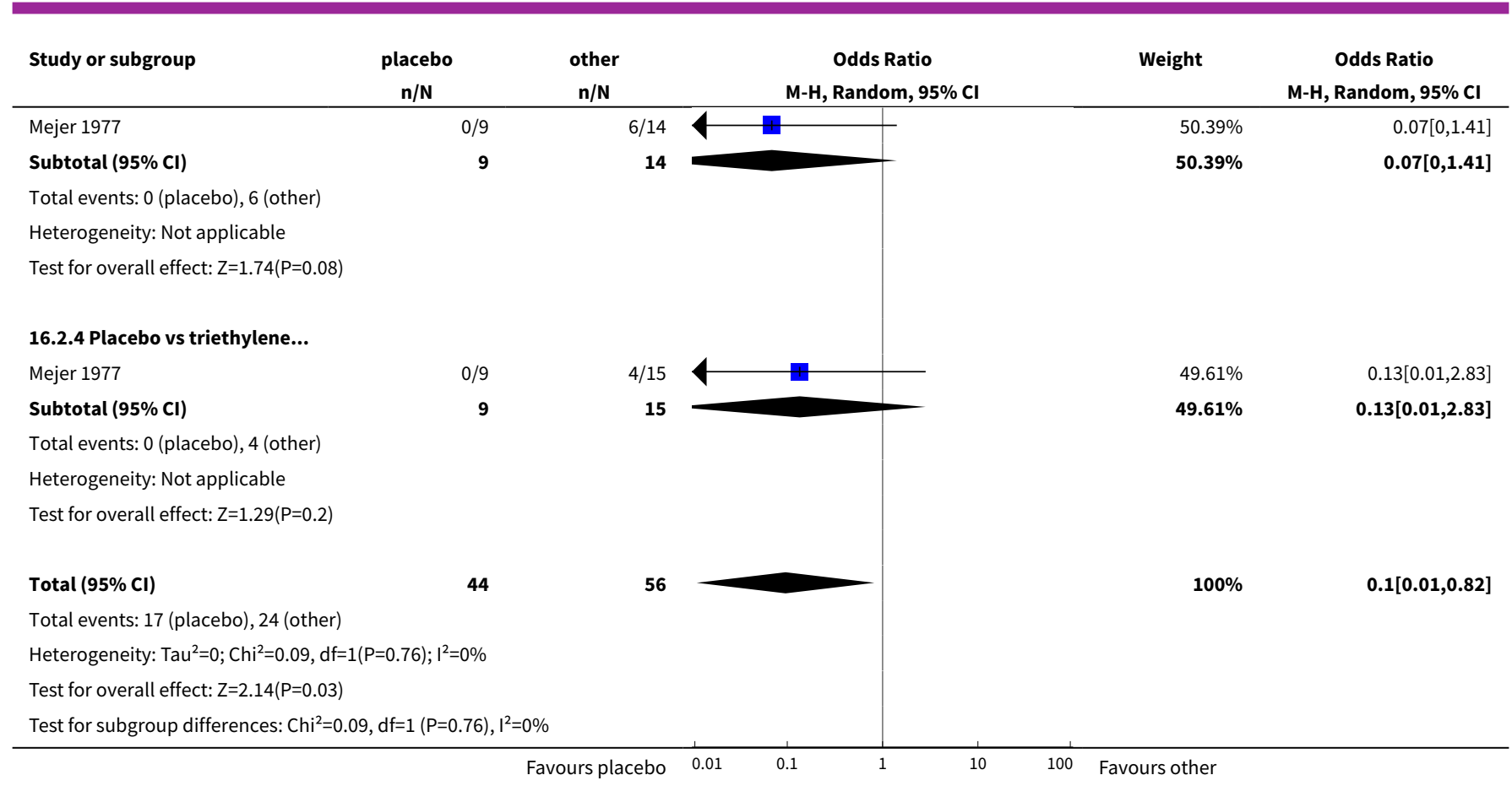

\section{Analysis 16.3. Comparison 16 Placebo, Outcome 3 Fever.}

\begin{tabular}{|c|c|c|c|c|c|}
\hline Study or subgroup & $\begin{array}{c}\text { placebo } \\
n / N\end{array}$ & $\begin{array}{c}\text { other } \\
\mathrm{n} / \mathrm{N}\end{array}$ & $\begin{array}{c}\text { Odds Ratio } \\
\text { M-H, Random, } 95 \% \mathrm{Cl}\end{array}$ & Weight & $\begin{array}{c}\text { Odds Ratio } \\
\text { M-H, Random, } 95 \% \mathrm{Cl}\end{array}$ \\
\hline \multicolumn{6}{|c|}{ 16.3.1 Placebo vs mepacrine } \\
\hline Groth 1991 & $8 / 46$ & $20 / 49$ & - & $100 \%$ & $0.31[0.12,0.79]$ \\
\hline Subtotal $(95 \% \mathrm{CI})$ & 46 & 49 & & $100 \%$ & $0.31[0.12,0.79]$ \\
\hline \multicolumn{6}{|c|}{ Total events: 8 (placebo), 20 (other) } \\
\hline \multicolumn{6}{|c|}{ Heterogeneity: Not applicable } \\
\hline \multicolumn{6}{|c|}{ Test for overall effect: $Z=2.44(P=0.01)$} \\
\hline \multicolumn{6}{|c|}{ 16.3.2 Placebo vs mitoxantone } \\
\hline Mejer 1977 & $0 / 9$ & $11 / 14$ & & $100 \%$ & $0.02[0,0.35]$ \\
\hline Subtotal $(95 \% \mathrm{Cl})$ & 9 & 14 & & $100 \%$ & $0.02[0,0.35]$ \\
\hline \multicolumn{6}{|c|}{ Total events: 0 (placebo), 11 (other) } \\
\hline \multicolumn{6}{|c|}{ Heterogeneity: Not applicable } \\
\hline \multicolumn{6}{|c|}{ 16.3.3 Placebo vs triethylene... } \\
\hline Mejer 1977 & $0 / 9$ & $2 / 15$ & & $100 \%$ & $0.28[0.01,6.62]$ \\
\hline Subtotal $(95 \% \mathrm{Cl})$ & 9 & 15 & & $100 \%$ & $0.28[0.01,6.62]$ \\
\hline \multicolumn{6}{|c|}{ Total events: 0 (placebo), 2 (other) } \\
\hline \multicolumn{6}{|c|}{ Heterogeneity: Not applicable } \\
\hline \multicolumn{6}{|c|}{ Test for overall effect: $Z=0.78(P=0.43)$} \\
\hline Test for subgroup dif & $, d f=1(P=0.2), I$ & & & & \\
\hline
\end{tabular}


Comparison 17. Mustine

\begin{tabular}{|c|c|c|c|c|}
\hline Outcome or subgroup title & $\begin{array}{l}\text { No. of } \\
\text { studies }\end{array}$ & $\begin{array}{l}\text { No. of } \\
\text { partici- } \\
\text { pants }\end{array}$ & Statistical method & Effect size \\
\hline 1 Pleurodesis failure & 4 & & Odds Ratio (M-H, Random, 95\% Cl) & Subtotals only \\
\hline 1.1 Mustine vs tetracycline & 2 & 59 & Odds Ratio (M-H, Random, $95 \% \mathrm{Cl})$ & $2.72[0.74,9.98]$ \\
\hline 1.2 Mustine vs talc poudrage & 1 & 37 & Odds Ratio (M-H, Random, $95 \% \mathrm{Cl})$ & $8.00[1.40,45.76]$ \\
\hline 1.3 Mustine vs C. parvum & 1 & 31 & Odds Ratio (M-H, Random, 95\% Cl) & $10.8[1.64,70.93]$ \\
\hline 1.4 Mustine vs Adriamycin & 1 & 20 & Odds Ratio (M-H, Random, 95\% Cl) & $2.71[0.10,74.98]$ \\
\hline 2 Fever & 2 & & Odds Ratio (M-H, Random, 95\% Cl) & Subtotals only \\
\hline 2.1 Mustine vs tetracycline & 1 & 40 & Odds Ratio (M-H, Random, 95\% Cl) & $0.0[0.0,0.0]$ \\
\hline 2.2 Mustine vs C. parvum & 1 & 21 & Odds Ratio (M-H, Random, 95\% Cl) & $0.23[0.01,6.25]$ \\
\hline 3 Mortality & 2 & & Odds Ratio (M-H, Random, 95\% Cl) & Subtotals only \\
\hline 3.1 Mustine vs talc poudrage & 1 & 46 & Odds Ratio (M-H, Random, 95\% Cl) & $2.35[0.51,10.86]$ \\
\hline 3.2 Mustine vs C. parvum & 1 & 21 & Odds Ratio (M-H, Random, 95\% Cl) & $2.4[0.38,15.32]$ \\
\hline 4 Pain & 1 & & Odds Ratio (M-H, Random, 95\% Cl) & Subtotals only \\
\hline
\end{tabular}

Analysis 17.1. Comparison 17 Mustine, Outcome 1 Pleurodesis failure.

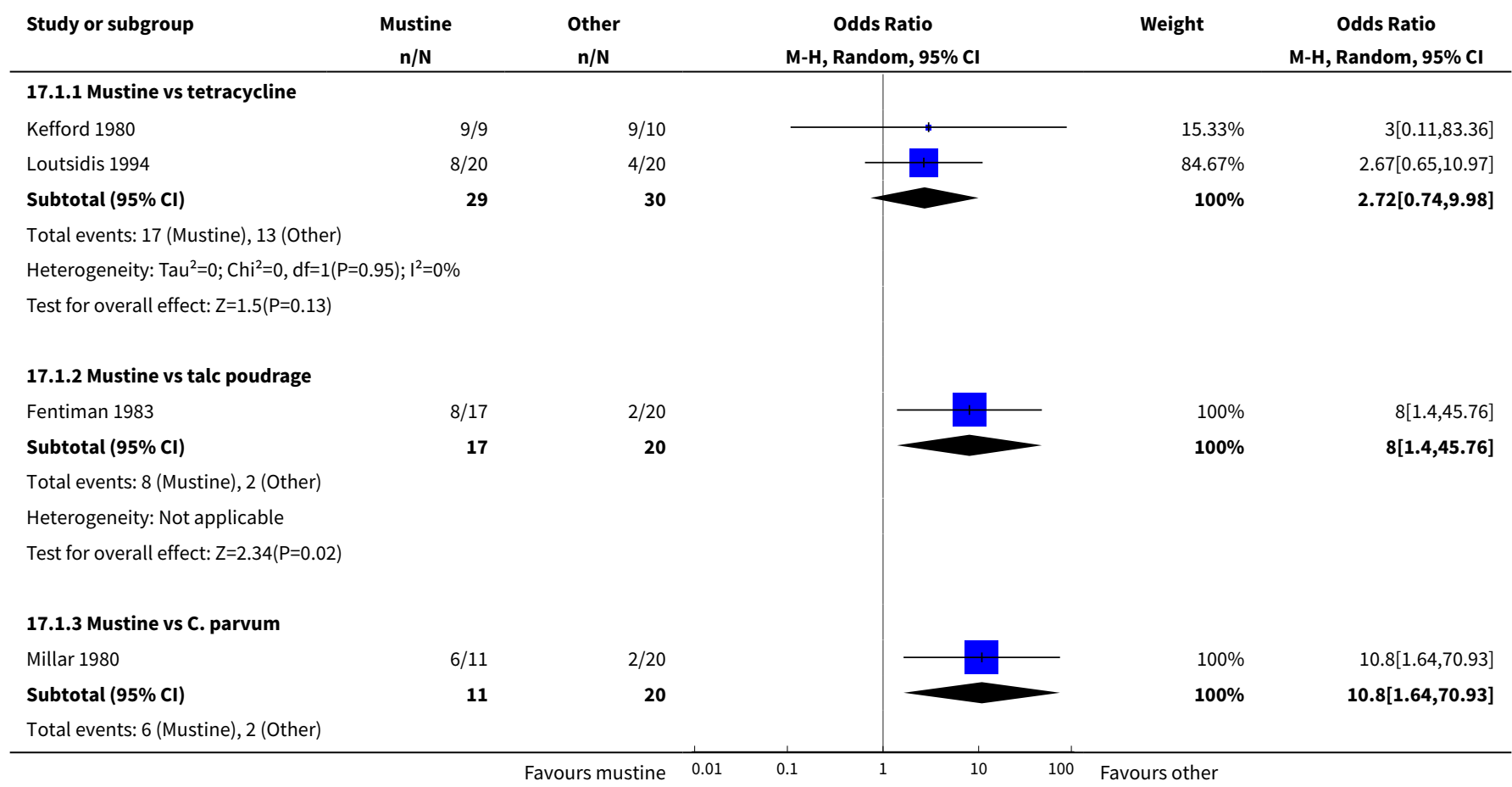




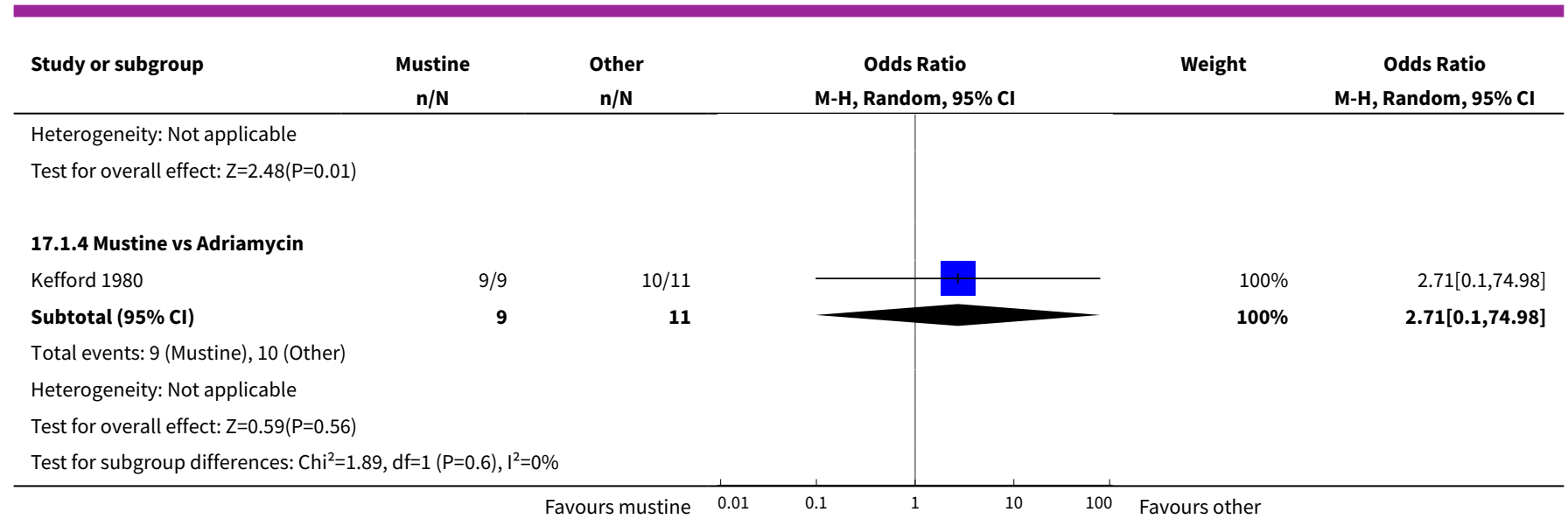

Analysis 17.2. Comparison 17 Mustine, Outcome 2 Fever.

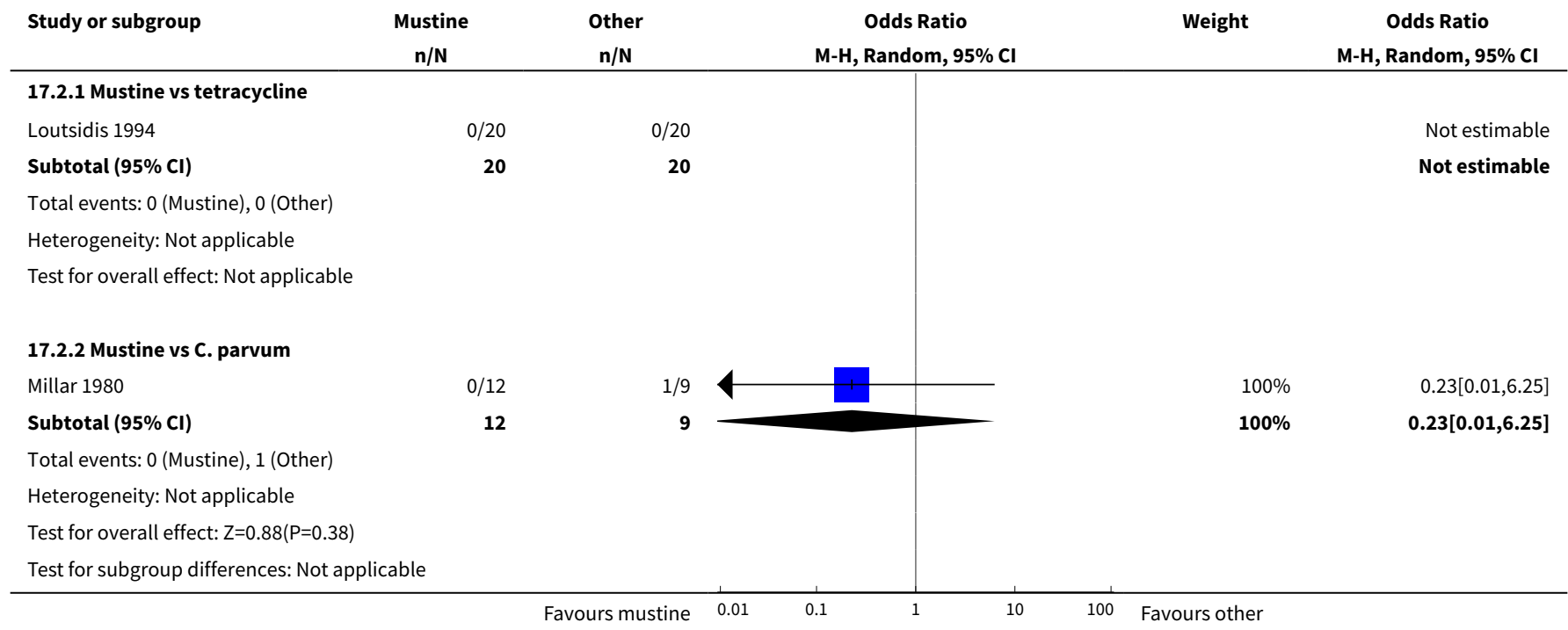

Analysis 17.3. Comparison 17 Mustine, Outcome 3 Mortality.

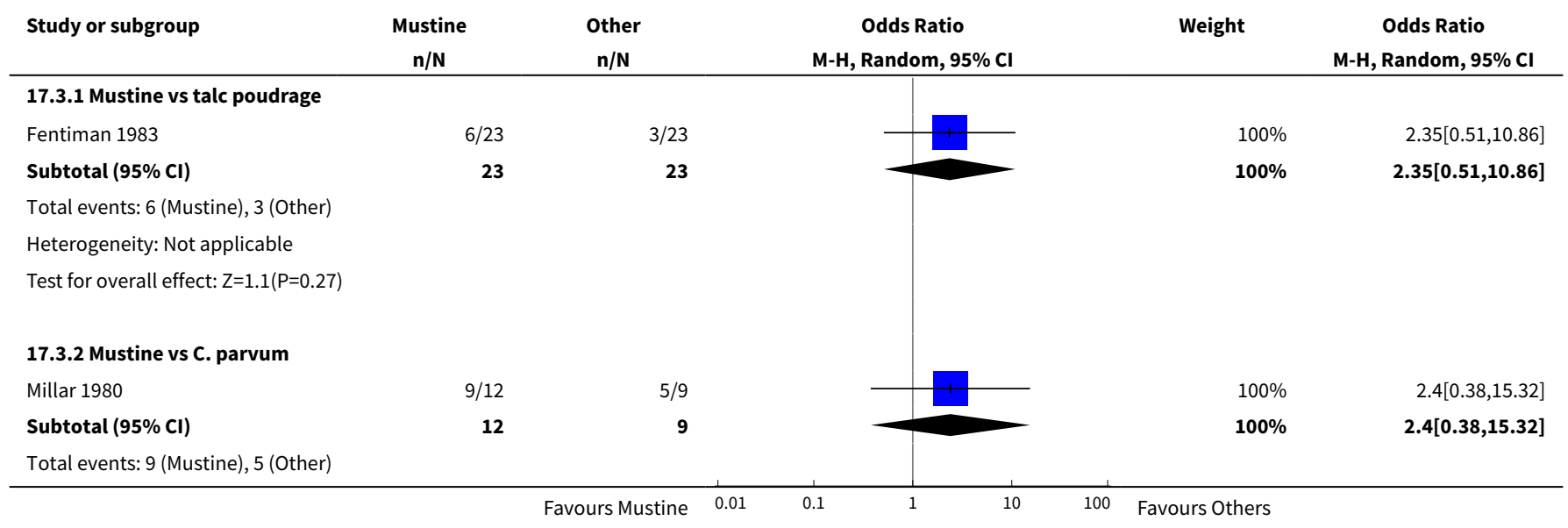




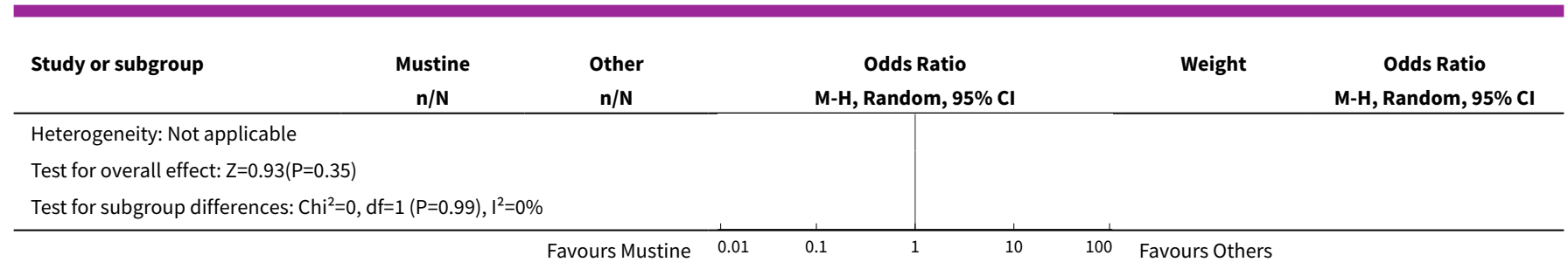

\section{Analysis 17.4. Comparison 17 Mustine, Outcome 4 Pain.}

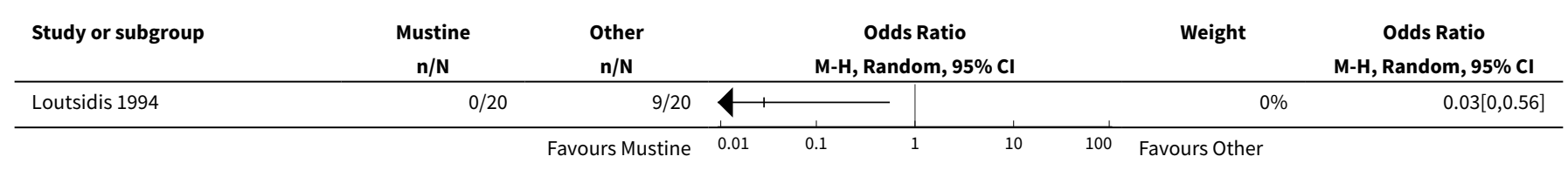

\section{Comparison 18. Mitoxantrone}

\begin{tabular}{lllll}
\hline Outcome or subgroup title & $\begin{array}{l}\text { No. of } \\
\text { studies }\end{array}$ & $\begin{array}{l}\text { No. of } \\
\text { partici- } \\
\text { pants }\end{array}$ & Statistical method & Effect size \\
\hline 1 Pleurodesis failure & 3 & & Odds Ratio (M-H, Random, 95\% Cl) & Subtotals only \\
\hline 1.1 Mitoxantrone vs placebo & 1 & 95 & Odds Ratio (M-H, Random, 95\% Cl) & 0.75 [0.32, 1.79] \\
\hline 1.2 Mitoxantrone vs mepacrine & 1 & 26 & Odds Ratio (M-H, Random, 95\% Cl) & $7.61[0.35,163.82]$ \\
\hline 1.3 Mitoxantrone vs bleomycin & 1 & 85 & Odds Ratio (M-H, Random, 95\% Cl) & $3.18[1.17,8.65]$ \\
\hline 2 Pain & 1 & 96 & Odds Ratio (M-H, Random, 95\% Cl) & $2.08[0.64,6.76]$ \\
\hline 3 Fever & 2 & & Odds Ratio (M-H, Random, 95\% Cl) & Subtotals only \\
\hline 3.1 Mitoxantrone vs bleomycin & 1 & 96 & Odds Ratio (M-H, Random, 95\% Cl) & $0.90[0.30,2.71]$ \\
\hline 3.2 Mitoxantrone vs placebo & 1 & 95 & Odds Ratio (M-H, Random, 95\% Cl) & $3.28[1.26,8.49]$ \\
\hline 4 Mortality & 2 & 1 & Odds Ratio (M-H, Random, 95\% Cl) & Subtotals only \\
\hline 4.1 Mitoxantrone vs bleomycin & 1 & 96 & Odds Ratio (M-H, Random, 95\% Cl) & $0.47[0.21,1.05]$ \\
\hline 4.2 Mitoxantrone vs mepacrine & 1 & 28 & Odds Ratio (M-H, Random, 95\% Cl) & $0.61[0.09,4.37]$ \\
\hline
\end{tabular}

Analysis 18.1. Comparison 18 Mitoxantrone, Outcome 1 Pleurodesis failure.

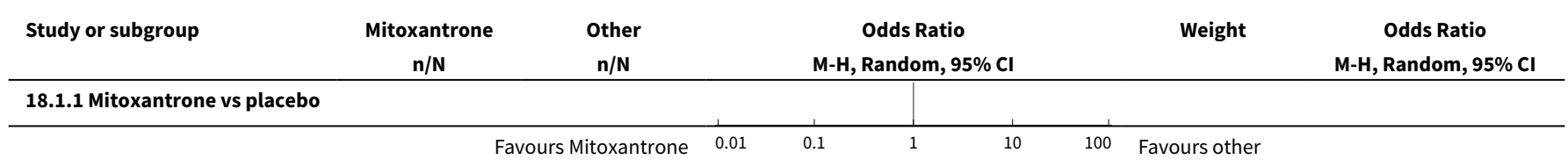




\begin{tabular}{|c|c|c|c|c|c|}
\hline Study or subgroup & $\begin{array}{c}\text { Mitoxantrone } \\
\mathrm{n} / \mathrm{N}\end{array}$ & $\begin{array}{c}\text { Other } \\
\mathrm{n} / \mathrm{N}\end{array}$ & $\begin{array}{c}\text { Odds Ratio } \\
\text { M-H, Random, } 95 \% \mathrm{CI}\end{array}$ & Weight & $\begin{array}{c}\text { Odds Ratio } \\
\text { M-H, Random, } 95 \% \mathrm{Cl}\end{array}$ \\
\hline Groth 1991 & $14 / 49$ & $16 / 46$ & & $100 \%$ & $0.75[0.32,1.79]$ \\
\hline Subtotal $(95 \% \mathrm{CI})$ & 49 & 46 & & $100 \%$ & $0.75[0.32,1.79]$ \\
\hline \multicolumn{6}{|c|}{ Total events: 14 (Mitoxantrone), 16 (Other) } \\
\hline \multicolumn{6}{|c|}{ Heterogeneity: Not applicable } \\
\hline \multicolumn{6}{|c|}{ Test for overall effect: $Z=0.65(P=0.52)$} \\
\hline \multicolumn{6}{|c|}{ 18.1.2 Mitoxantrone vs mepacrine } \\
\hline Bjermer 1995 & $3 / 14$ & $0 / 12$ & & $100 \%$ & $7.61[0.35,163.82]$ \\
\hline Subtotal $(95 \% \mathrm{Cl})$ & 14 & 12 & & $100 \%$ & $7.61[0.35,163.82]$ \\
\hline \multicolumn{6}{|c|}{ Total events: 3 (Mitoxantrone), 0 (Other) } \\
\hline \multicolumn{6}{|c|}{ Heterogeneity: Not applicable } \\
\hline \multicolumn{6}{|c|}{ Test for overall effect: $Z=1.3(P=0.2)$} \\
\hline \multicolumn{6}{|c|}{ 18.1.3 Mitoxantrone vs bleomycin } \\
\hline Schmidt 1997 & $15 / 38$ & $8 / 47$ & - & $100 \%$ & $3.18[1.17,8.65]$ \\
\hline Subtotal $(95 \% \mathrm{Cl})$ & 38 & 47 & & $100 \%$ & $3.18[1.17,8.65]$ \\
\hline \multicolumn{6}{|c|}{ Total events: 15 (Mitoxantrone), 8 (Other) } \\
\hline \multicolumn{6}{|c|}{ Heterogeneity: Not applicable } \\
\hline \multicolumn{6}{|c|}{ Test for overall effect: $Z=2.27(P=0.02)$} \\
\hline \multicolumn{6}{|c|}{ Test for subgroup differences: $\mathrm{Chi}^{2}=5.69, \mathrm{df}=1(\mathrm{P}=0.06), \mathrm{I}^{2}=64.87 \%$} \\
\hline
\end{tabular}

Analysis 18.2. Comparison 18 Mitoxantrone, Outcome 2 Pain.

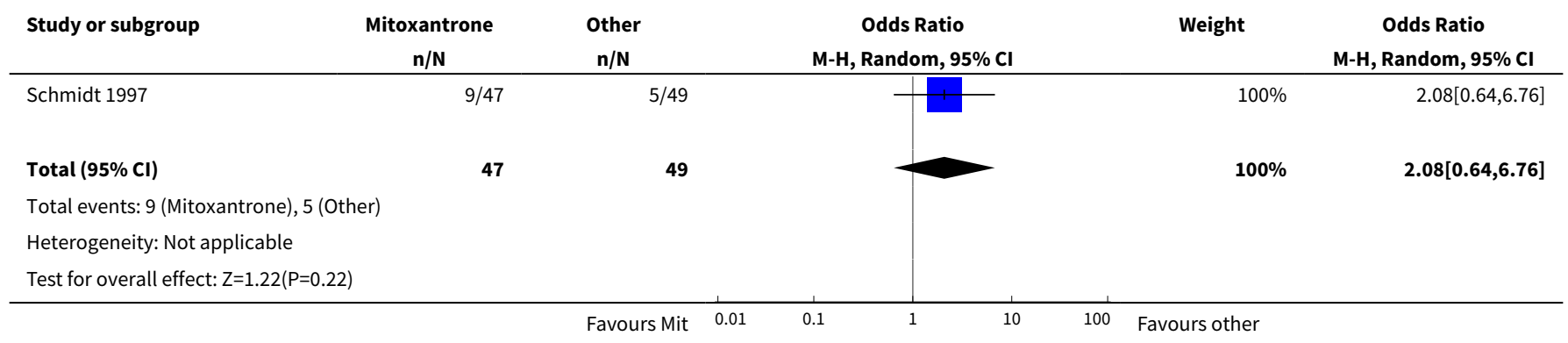

Analysis 18.3. Comparison 18 Mitoxantrone, Outcome 3 Fever.

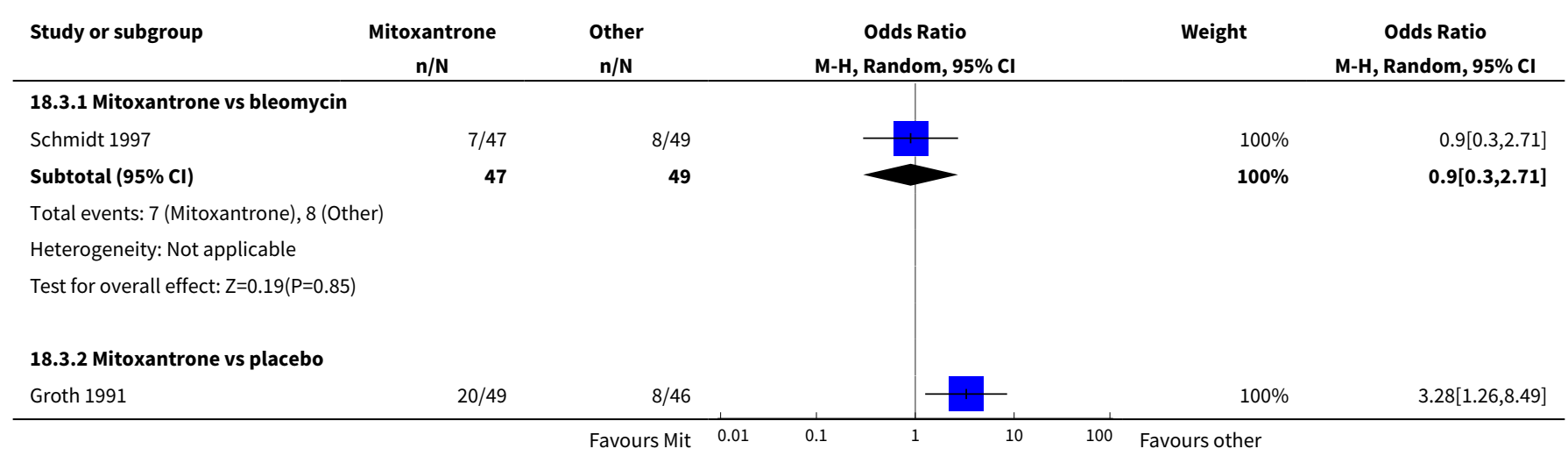




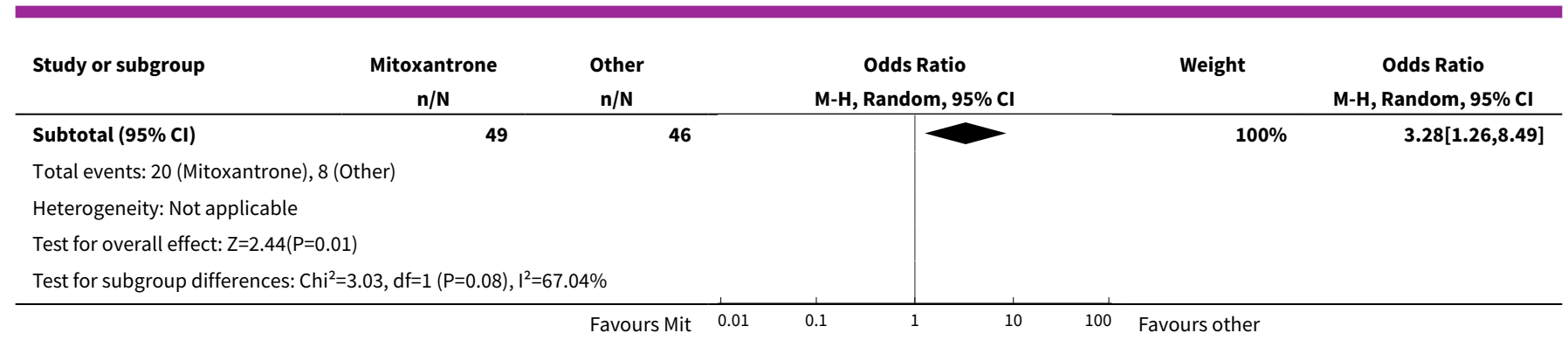

Analysis 18.4. Comparison 18 Mitoxantrone, Outcome 4 Mortality.

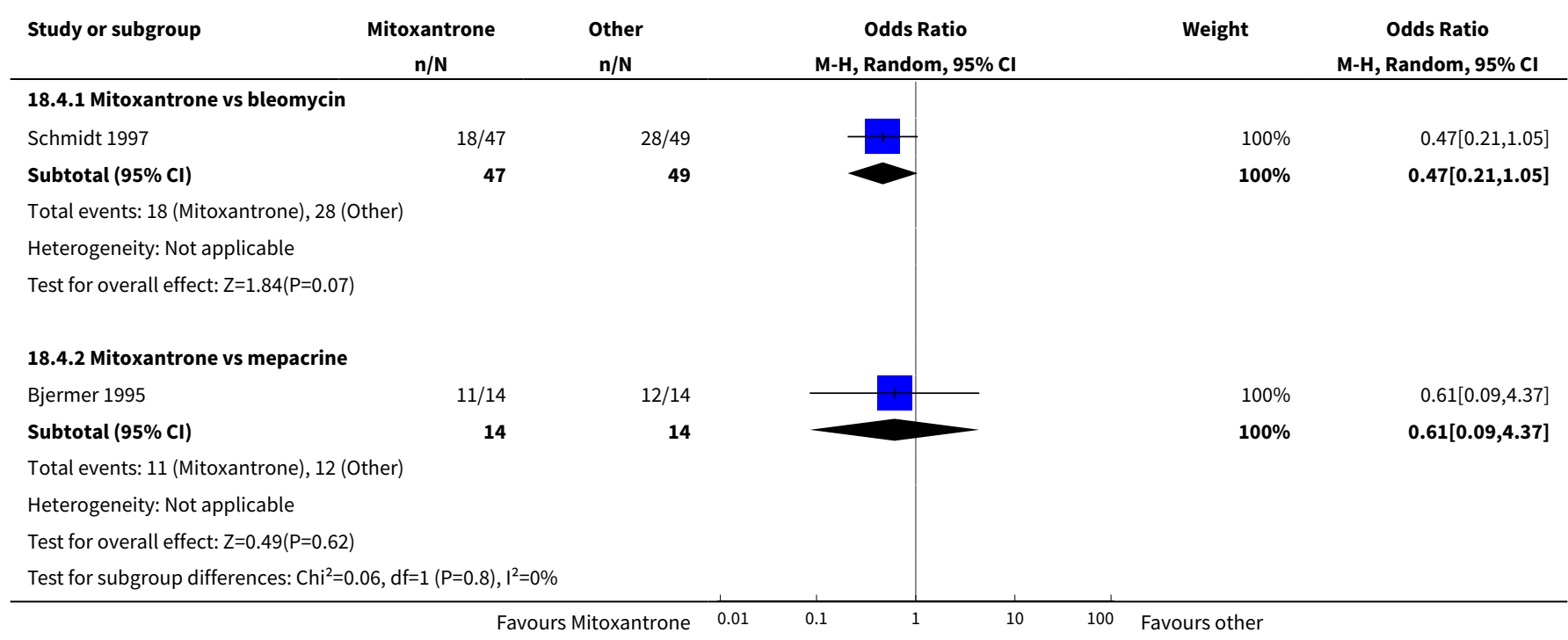

\section{Comparison 19. Drain size}

\begin{tabular}{lllll}
\hline Outcome or subgroup title & $\begin{array}{l}\text { No. of } \\
\text { studies }\end{array}$ & $\begin{array}{l}\text { No. of } \\
\text { partici- } \\
\text { pants }\end{array}$ & Statistical method & Effect size \\
\hline 1 Pleurodesis failure & 1 & 18 & Odds Ratio (M-H, Random, 95\% Cl) & $0.57[0.07,4.64]$ \\
\hline 2 Pain & 1 & & Odds Ratio $(\mathrm{M}-\mathrm{H}$, Random, 95\% Cl) & Subtotals only \\
\hline 3 Mortality & 1 & & Odds Ratio (M-H, Random, 95\% Cl) & Subtotals only \\
\hline
\end{tabular}

Analysis 19.1. Comparison 19 Drain size, Outcome 1 Pleurodesis failure.

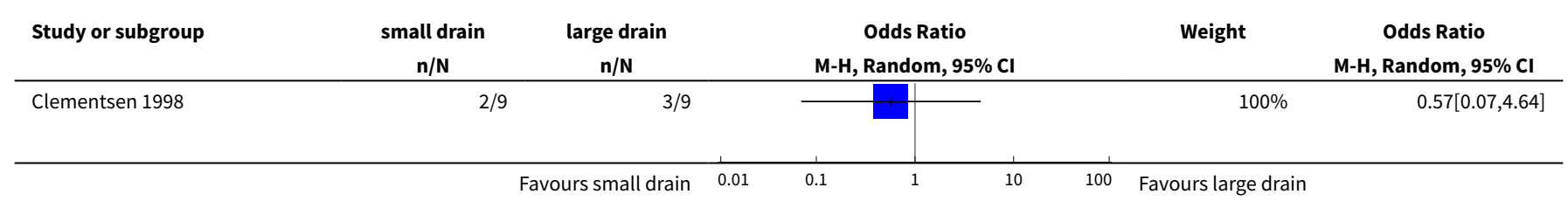




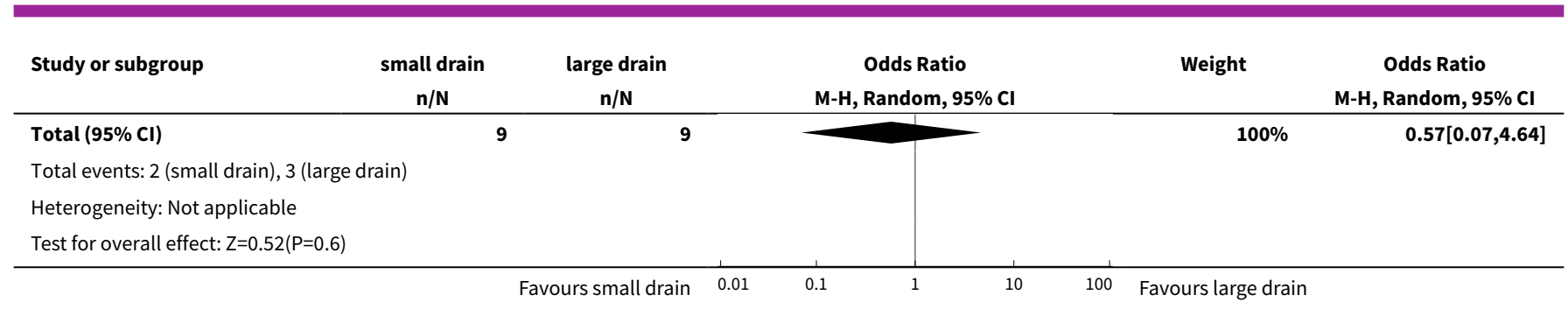

Analysis 19.2. Comparison 19 Drain size, Outcome 2 Pain.

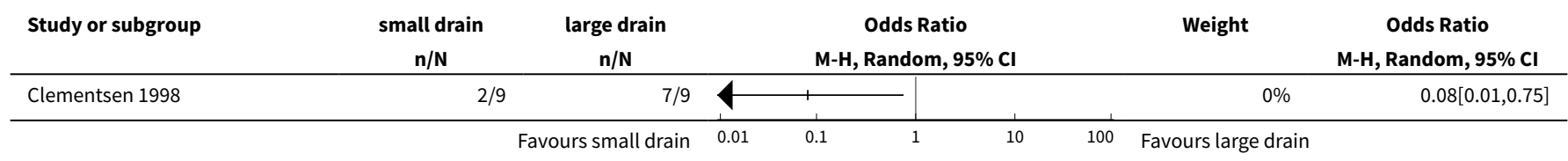

\section{Analysis 19.3. Comparison 19 Drain size, Outcome 3 Mortality.}

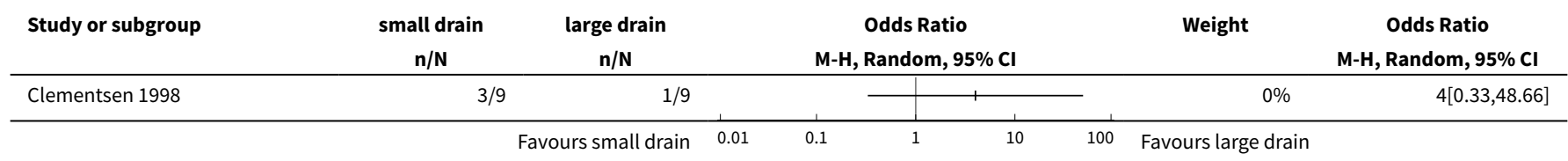

\section{Comparison 20. Thoracoscopic mechanical pleurodesis (TMP)}

\begin{tabular}{lllll}
\hline Outcome or subgroup title & $\begin{array}{l}\text { No. of } \\
\text { studies }\end{array}$ & $\begin{array}{l}\text { No. of } \\
\text { partici- } \\
\text { pants }\end{array}$ & Statistical method & Effect size \\
\hline 1 Pleurodesis failure & 1 & 87 & Odds Ratio (M-H, Random, 95\% Cl) & $0.43[0.14,1.30]$ \\
\hline 2 Mortality & 1 & & Odds Ratio (M-H, Random, 95\% Cl) & Subtotals only \\
\hline
\end{tabular}

Analysis 20.1. Comparison 20 Thoracoscopic mechanical pleurodesis (TMP), Outcome 1 Pleurodesis failure.

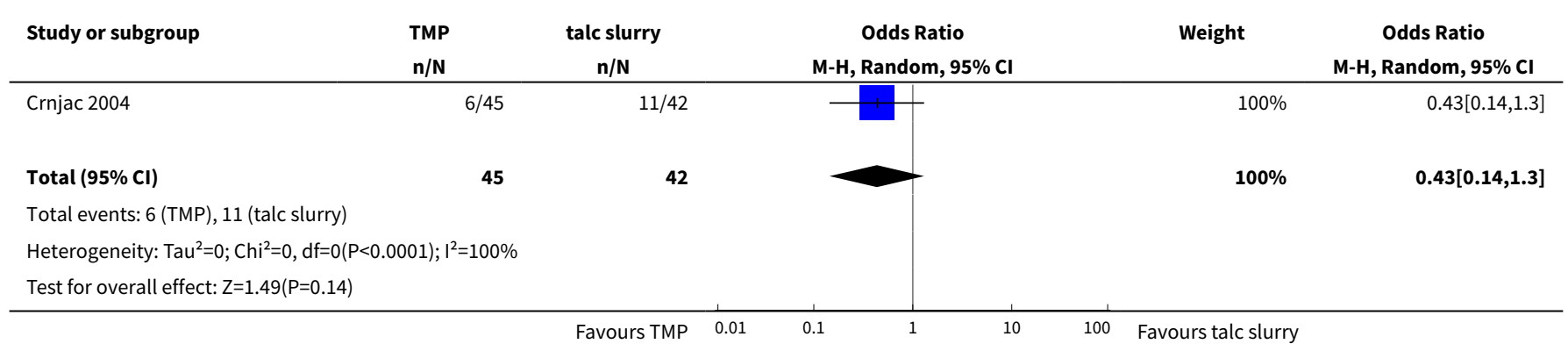


Analysis 20.2. Comparison 20 Thoracoscopic mechanical pleurodesis (TMP), Outcome 2 Mortality.

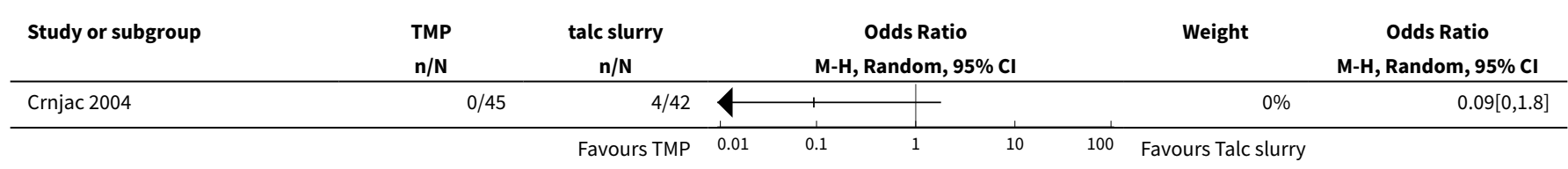

\section{Comparison 21. Other}

\begin{tabular}{|c|c|c|c|c|}
\hline Outcome or subgroup title & $\begin{array}{l}\text { No. of } \\
\text { studies }\end{array}$ & $\begin{array}{l}\text { No. of } \\
\text { partici- } \\
\text { pants }\end{array}$ & Statistical method & Effect size \\
\hline 1 Pleurodesis failure & 4 & 205 & $\begin{array}{l}\text { Odds Ratio (M-H, Random, } \\
95 \% \mathrm{Cl})\end{array}$ & $1.26[0.70,2.30]$ \\
\hline 1.1 Rotation vs no rotation & 1 & 20 & $\begin{array}{l}\text { Odds Ratio (M-H, Random, } \\
95 \% \mathrm{Cl})\end{array}$ & $2.25[0.17,29.77]$ \\
\hline 1.2 Streptokinase vs no streptokinase & 1 & 35 & $\begin{array}{l}\text { Odds Ratio (M-H, Random, } \\
95 \% \mathrm{Cl})\end{array}$ & $2.18[0.53,9.02]$ \\
\hline 1.3 Mixed particle talc vs graded talc & 1 & 28 & $\begin{array}{l}\text { Odds Ratio (M-H, Random, } \\
95 \% \mathrm{Cl})\end{array}$ & $1.64[0.23,11.70]$ \\
\hline $\begin{array}{l}1.4 \text { Talc pleurodesis vs VATS parietal pleurec- } \\
\text { tomy }\end{array}$ & 1 & 122 & $\begin{array}{l}\text { Odds Ratio (M-H, Random, } \\
95 \% \mathrm{Cl})\end{array}$ & $1.01[0.49,2.09]$ \\
\hline 2 Pain & 1 & & $\begin{array}{l}\text { Odds Ratio (M-H, Random, } \\
95 \% \mathrm{Cl})\end{array}$ & Subtotals only \\
\hline 2.1 Streptokinase vs control & 1 & 47 & $\begin{array}{l}\text { Odds Ratio (M-H, Random, } \\
95 \% \mathrm{Cl})\end{array}$ & $3.0[0.12,77.47]$ \\
\hline 3 Fever & 1 & & $\begin{array}{l}\text { Odds Ratio (M-H, Random, } \\
95 \% \mathrm{Cl})\end{array}$ & Subtotals only \\
\hline 3.1 Mixed particle talc vs graded talc & 1 & 46 & $\begin{array}{l}\text { Odds Ratio }(\mathrm{M}-\mathrm{H}, \text { Random, } \\
95 \% \mathrm{Cl})\end{array}$ & $15.92[1.81,140.16]$ \\
\hline 4 Mortality & 2 & & $\begin{array}{l}\text { Odds Ratio (M-H, Random, } \\
95 \% \mathrm{Cl})\end{array}$ & Subtotals only \\
\hline 4.1 Mixed particle talc vs graded talc & 1 & 43 & $\begin{array}{l}\text { Odds Ratio (M-H, Random, } \\
95 \% \mathrm{Cl})\end{array}$ & $0.88[0.25,3.07]$ \\
\hline $\begin{array}{l}4.2 \text { Talc pleurodesis vs VATS partial pleurecto- } \\
\text { my }\end{array}$ & 1 & 175 & $\begin{array}{l}\text { Odds Ratio (M-H, Random, } \\
95 \% \mathrm{Cl})\end{array}$ & $0.92[0.45,1.90]$ \\
\hline
\end{tabular}


Analysis 21.1. Comparison 21 Other, Outcome 1 Pleurodesis failure.

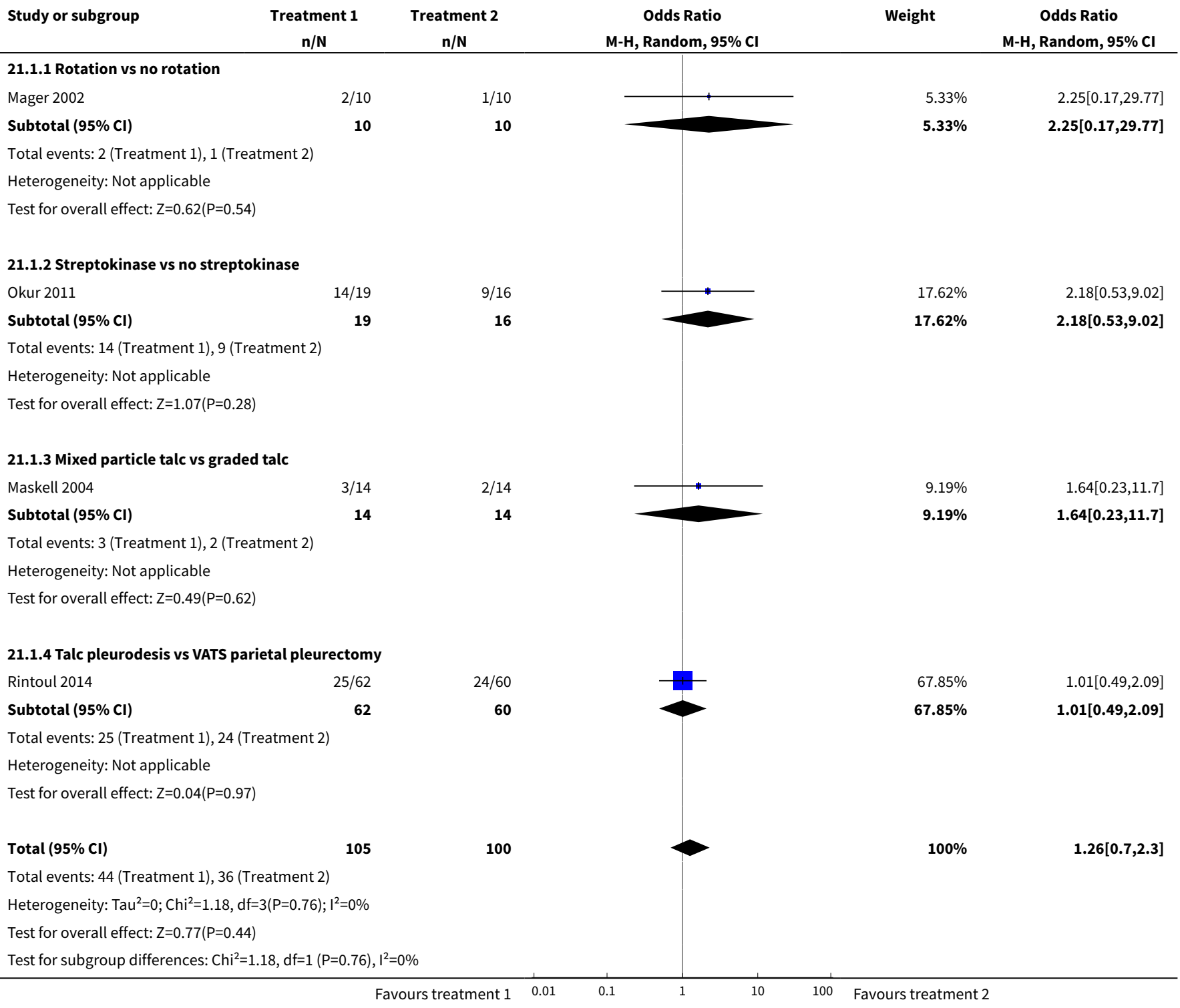

Analysis 21.2. Comparison 21 Other, Outcome 2 Pain.

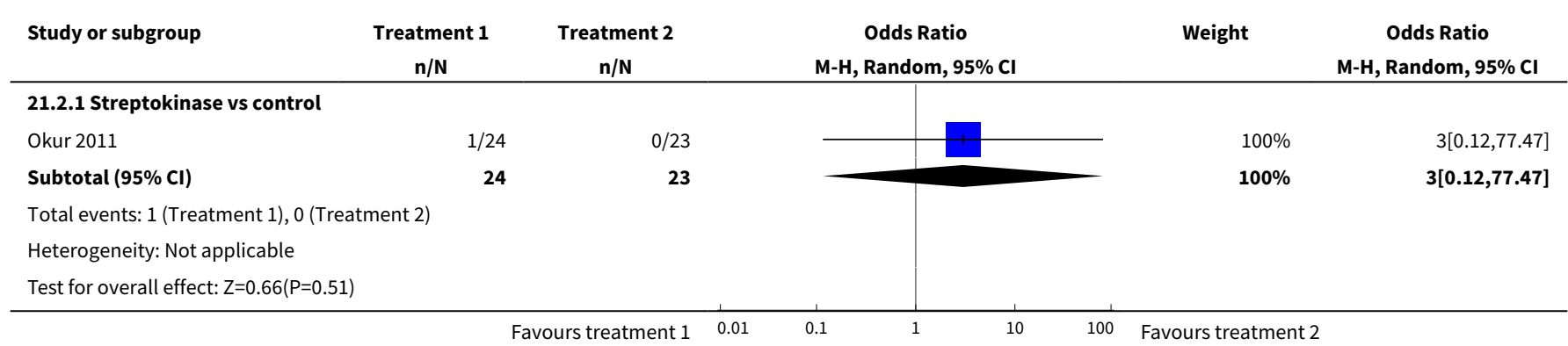


Analysis 21.3. Comparison 21 Other, Outcome 3 Fever.

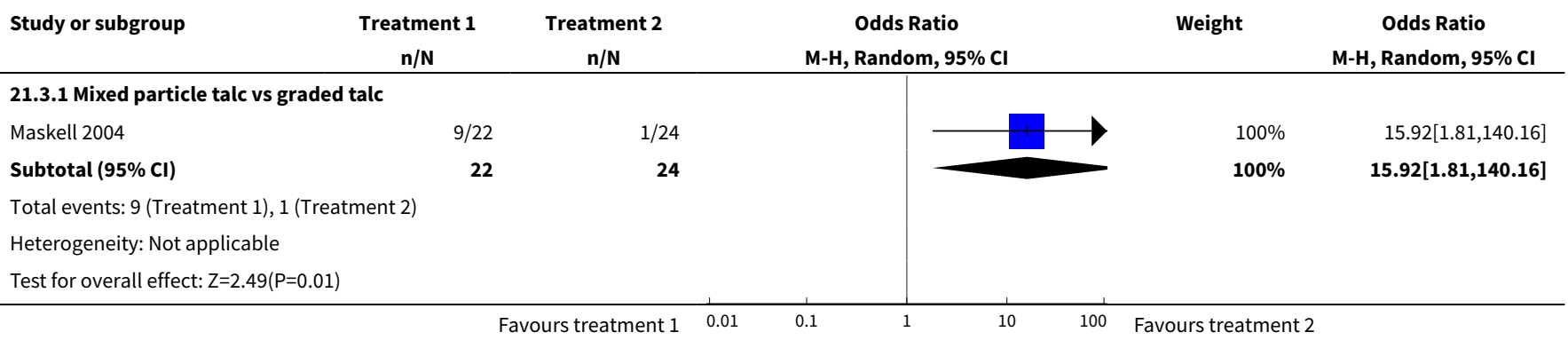

Analysis 21.4. Comparison 21 Other, Outcome 4 Mortality.

\begin{tabular}{|c|c|c|c|c|c|}
\hline Study or subgroup & $\begin{array}{c}\text { Treatment } 1 \\
\mathrm{n} / \mathrm{N}\end{array}$ & $\begin{array}{c}\text { Treatment } 2 \\
\mathrm{n} / \mathrm{N} \\
\end{array}$ & $\begin{array}{c}\text { Odds Ratio } \\
\text { M-H, Random, } 95 \% \mathrm{Cl}\end{array}$ & Weight & $\begin{array}{c}\text { Odds Ratio } \\
\text { M-H, Random, } 95 \% \mathrm{CI}\end{array}$ \\
\hline \multicolumn{6}{|c|}{ 21.4.1 Mixed particle talc vs graded talc } \\
\hline Maskell 2004 & $7 / 21$ & $8 / 22$ & & $100 \%$ & $0.88[0.25,3.07]$ \\
\hline Subtotal $(95 \% \mathrm{Cl})$ & 21 & 22 & & $100 \%$ & $0.88[0.25,3.07]$ \\
\hline \multicolumn{6}{|c|}{ Total events: 7 (Treatment 1), 8 (Treatment 2) } \\
\hline \multicolumn{6}{|c|}{ Heterogeneity: Not applicable } \\
\hline \multicolumn{6}{|c|}{ Test for overall effect: $Z=0.21(P=0.83)$} \\
\hline \multicolumn{6}{|c|}{ 21.4.2 Talc pleurodesis vs VATS partial pleurectomy } \\
\hline Rintoul 2014 & $18 / 88$ & $19 / 87$ & - & $100 \%$ & $0.92[0.45,1.9]$ \\
\hline Subtotal $(95 \% \mathrm{Cl})$ & 88 & 87 & & $100 \%$ & $0.92[0.45,1.9]$ \\
\hline \multicolumn{6}{|c|}{ Total events: 18 (Treatment 1), 19 (Treatment 2) } \\
\hline \multicolumn{6}{|c|}{ Heterogeneity: Not applicable } \\
\hline Test for subgroup dif & $\mathrm{df}=1(\mathrm{P}=0.95), \mathrm{I}^{2}$ & & & & \\
\hline
\end{tabular}

\section{Comparison 22. Silver nitrate}

\begin{tabular}{lllll}
\hline Outcome or subgroup title & $\begin{array}{l}\text { No. of } \\
\text { studies }\end{array}$ & $\begin{array}{l}\text { No. of } \\
\text { partici- } \\
\text { pants }\end{array}$ & Statistical method & Effect size \\
\hline 1 Pleurodesis failure & 1 & Odds Ratio $(\mathrm{M}-\mathrm{H}$, Random, $95 \% \mathrm{Cl})$ & Subtotals only \\
\hline 2 Fever & 1 & Odds Ratio $(\mathrm{M}-\mathrm{H}$, Random, $95 \% \mathrm{Cl})$ & Subtotals only \\
\hline
\end{tabular}

Analysis 22.1. Comparison 22 Silver nitrate, Outcome 1 Pleurodesis failure.

\begin{tabular}{|c|c|c|c|c|c|c|c|c|}
\hline Study or subgroup & $\begin{array}{c}\text { Silver Nitrate } \\
\mathrm{n} / \mathrm{N} \\
\end{array}$ & $\begin{array}{c}\text { Other } \\
\mathbf{n} / \mathbf{N}\end{array}$ & & & $\begin{array}{l}\text { s Ratio } \\
\text { dom, } 95 \% \mathrm{Cl}\end{array}$ & & Weight & $\begin{array}{c}\text { Odds Ratio } \\
\text { M-H, Random, } 95 \% \mathrm{Cl}\end{array}$ \\
\hline Paschoalini 2005 & $0 / 16$ & $1 / 9$ & 4 & 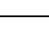 & - & & $0 \%$ & $0.17[0.01,4.68]$ \\
\hline
\end{tabular}


Analysis 22.2. Comparison 22 Silver nitrate, Outcome 2 Fever.

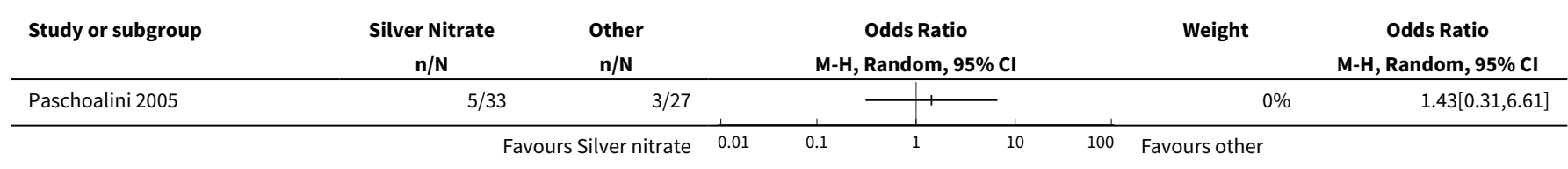

\section{Comparison 23. Cisplatin}

\begin{tabular}{|c|c|c|c|c|}
\hline Outcome or subgroup title & $\begin{array}{l}\text { No. of } \\
\text { studies }\end{array}$ & $\begin{array}{l}\text { No. of } \\
\text { partici- } \\
\text { pants }\end{array}$ & Statistical method & Effect size \\
\hline 1 Pleurodesis failure & 3 & & $\begin{array}{l}\text { Odds Ratio (M-H, Random, } \\
95 \% \mathrm{Cl})\end{array}$ & Subtotals only \\
\hline 1.1 Cisplatin vs cisplatin and bevacizumab & 1 & 70 & $\begin{array}{l}\text { Odds Ratio (M-H, Random, } \\
95 \% \mathrm{Cl})\end{array}$ & $5.0[1.66,15.09]$ \\
\hline 1.2 Cisplatin vs OK-432 & 1 & 34 & $\begin{array}{l}\text { Odds Ratio (M-H, Random, } \\
95 \% \mathrm{Cl})\end{array}$ & $2.06[0.52,8.17]$ \\
\hline 1.3 Cisplatin vs OK-432 and cisplatin & 1 & 32 & $\begin{array}{l}\text { Odds Ratio (M-H, Random, } \\
95 \% \mathrm{Cl})\end{array}$ & $25.67[2.68,245.84]$ \\
\hline 1.4 Cisplatin vs rAd-p53 and cisplatin & 1 & 35 & $\begin{array}{l}\text { Odds Ratio (M-H, Random, } \\
95 \% \mathrm{Cl})\end{array}$ & $4.67[0.99,22.03]$ \\
\hline 2 Pain & 1 & & $\begin{array}{l}\text { Odds Ratio (M-H, Random, } \\
95 \% \mathrm{Cl})\end{array}$ & Subtotals only \\
\hline 2.1 Cisplatin vs OK-432 & 1 & 34 & $\begin{array}{l}\text { Odds Ratio (M-H, Random, } \\
95 \% \mathrm{Cl})\end{array}$ & $0.15[0.03,0.87]$ \\
\hline 2.2 Cisplatin vs OK-432 and cisplatin & 1 & 32 & $\begin{array}{l}\text { Odds Ratio (M-H, Random, } \\
95 \% \mathrm{Cl})\end{array}$ & $0.2[0.03,1.21]$ \\
\hline 3 Fever & 2 & & $\begin{array}{l}\text { Odds Ratio (M-H, Random, } \\
95 \% \mathrm{Cl})\end{array}$ & Subtotals only \\
\hline 3.1 Cisplatin vs OK-432 & 1 & 34 & $\begin{array}{l}\text { Odds Ratio (M-H, Random, } \\
95 \% \mathrm{Cl})\end{array}$ & $0.00[0.00,0.07]$ \\
\hline 3.2 Cisplatin vs OK-432 and cisplatin & 1 & 32 & $\begin{array}{l}\text { Odds Ratio (M-H, Random, } \\
95 \% \mathrm{Cl})\end{array}$ & $0.05[0.01,0.52]$ \\
\hline 3.3 Cisplatin vs rAd-p53 and cisplatin & 1 & 35 & $\begin{array}{l}\text { Odds Ratio (M-H, Random, } \\
95 \% \mathrm{Cl})\end{array}$ & $0.09[0.02,0.51]$ \\
\hline 4 Mortality & 2 & & $\begin{array}{l}\text { Odds Ratio (M-H, Random, } \\
95 \% \mathrm{Cl})\end{array}$ & Subtotals only \\
\hline 4.1 Cisplatin vs OK-432 & 1 & 34 & $\begin{array}{l}\text { Odds Ratio (M-H, Random, } \\
95 \% \mathrm{Cl})\end{array}$ & $0.76[0.18,3.23]$ \\
\hline
\end{tabular}




\begin{tabular}{lllll}
\hline Outcome or subgroup title & $\begin{array}{l}\text { No. of } \\
\text { studies }\end{array}$ & $\begin{array}{l}\text { No. of } \\
\text { partici- } \\
\text { pants }\end{array}$ & Statistical method & Effect size \\
\hline $\begin{array}{l}4.2 \text { Cisplatin vs combination OK-432 and cis- } \\
\text { platin }\end{array}$ & 1 & 32 & $\begin{array}{l}\text { Odds Ratio (M-H, Random, } \\
95 \% \mathrm{Cl})\end{array}$ & $1.67[0.32,8.59]$ \\
\hline $\begin{array}{l}4.3 \text { Cisplatin vs combination rAd-p53 and cis- } \\
\text { platin }\end{array}$ & 1 & 35 & $\begin{array}{l}\text { Odds Ratio (M-H, Random, } \\
95 \% \mathrm{Cl})\end{array}$ & $0.0[0.0,0.0]$ \\
\hline
\end{tabular}

Analysis 23.1. Comparison 23 Cisplatin, Outcome 1 Pleurodesis failure.

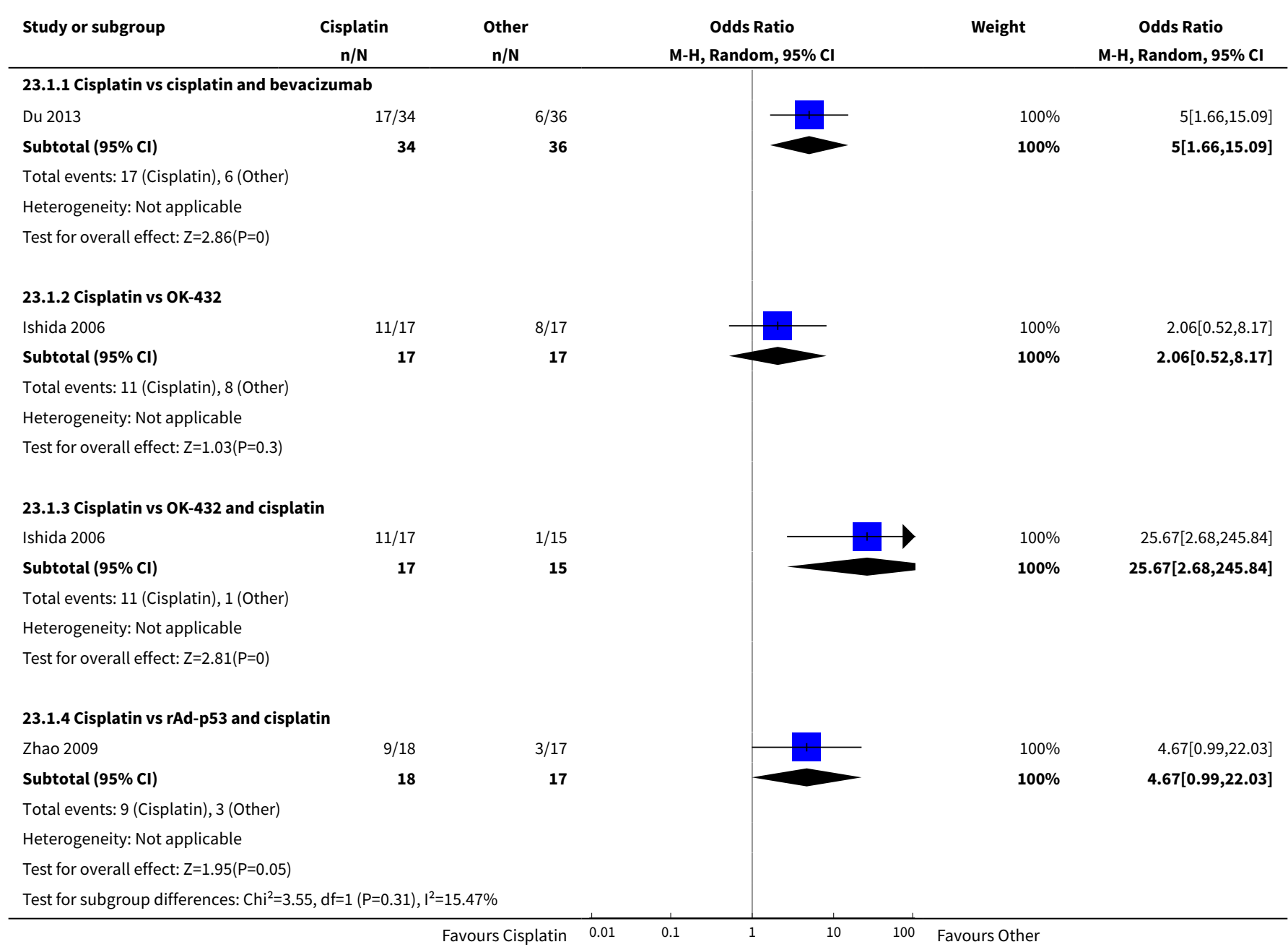

\section{Analysis 23.2. Comparison 23 Cisplatin, Outcome 2 Pain.}

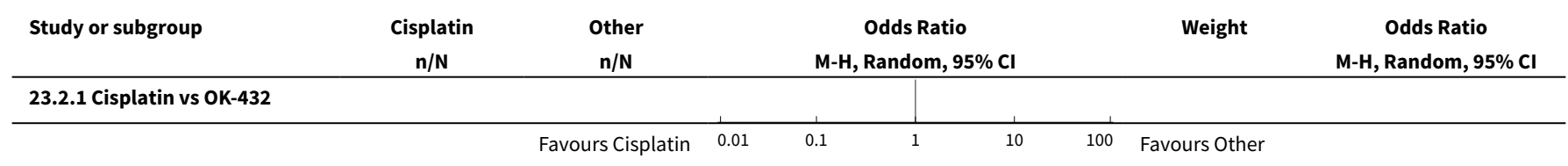




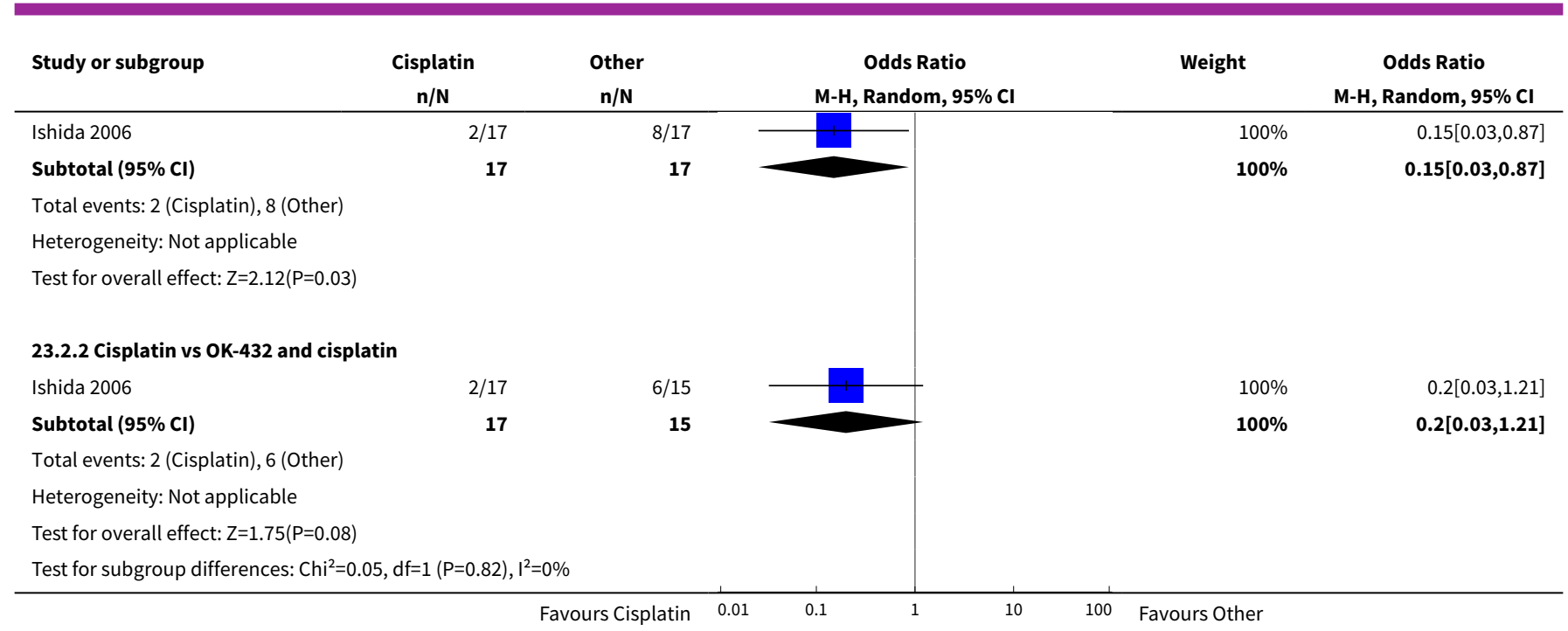

Analysis 23.3. Comparison 23 Cisplatin, Outcome 3 Fever.

\begin{tabular}{|c|c|c|c|c|c|}
\hline Study or subgroup & $\begin{array}{c}\text { Cisplatin } \\
\mathrm{n} / \mathrm{N}\end{array}$ & $\begin{array}{c}\text { Other } \\
\mathrm{n} / \mathrm{N}\end{array}$ & $\begin{array}{c}\text { Odds Ratio } \\
\text { M-H, Random, } 95 \% \mathrm{Cl}\end{array}$ & Weight & $\begin{array}{c}\text { Odds Ratio } \\
\text { M-H, Random, } 95 \% \mathrm{CI}\end{array}$ \\
\hline \multicolumn{6}{|c|}{ 23.3.1 Cisplatin vs OK-432 } \\
\hline Subtotal $(95 \% \mathrm{Cl})$ & 17 & 17 & & $100 \%$ & $0[0,0.07]$ \\
\hline \multicolumn{6}{|c|}{ Total events: 1 (Cisplatin), 16 (Other) } \\
\hline \multicolumn{6}{|c|}{ Heterogeneity: Not applicable } \\
\hline \multicolumn{6}{|c|}{ Test for overall effect: $Z=3.8(P=0)$} \\
\hline \multicolumn{6}{|c|}{ 23.3.2 Cisplatin vs OK-432 and cisplatin } \\
\hline Ishida 2006 & $1 / 17$ & $8 / 15$ & & $100 \%$ & $0.05[0.01,0.52]$ \\
\hline Subtotal $(95 \% \mathrm{Cl})$ & 17 & 15 & & $100 \%$ & $0.05[0.01,0.52]$ \\
\hline \multicolumn{6}{|c|}{ Total events: 1 (Cisplatin), 8 (Other) } \\
\hline \multicolumn{6}{|c|}{ Heterogeneity: Not applicable } \\
\hline \multicolumn{6}{|c|}{ 23.3.3 Cisplatin vs rAd-p53 and cisplatin } \\
\hline Zhao 2009 & $2 / 18$ & $10 / 17$ & & $100 \%$ & $0.09[0.02,0.51]$ \\
\hline Subtotal $(95 \% \mathrm{Cl})$ & 18 & 17 & & $100 \%$ & $0.09[0.02,0.51]$ \\
\hline \multicolumn{6}{|c|}{ Total events: 2 (Cisplatin), 10 (Other) } \\
\hline \multicolumn{6}{|c|}{ Heterogeneity: Not applicable } \\
\hline \multicolumn{6}{|c|}{ Test for overall effect: $Z=2.71(P=0.01)$} \\
\hline \multicolumn{6}{|c|}{ Test for subgroup differences: $\mathrm{Chi}^{2}=3.38, \mathrm{df}=1(\mathrm{P}=0.18), \mathrm{I}^{2}=40.76 \%$} \\
\hline
\end{tabular}

Analysis 23.4. Comparison 23 Cisplatin, Outcome 4 Mortality.

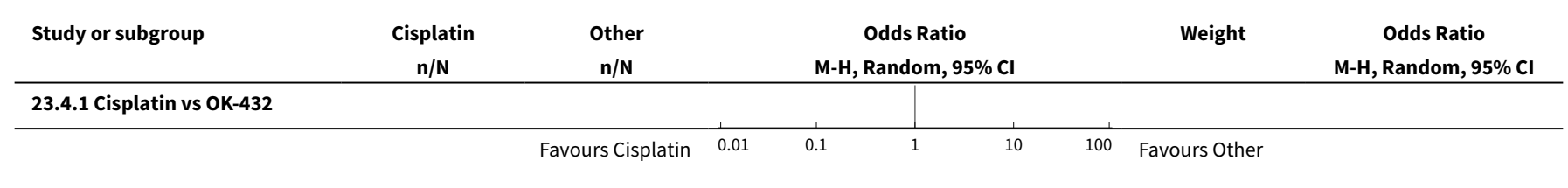




\begin{tabular}{|c|c|c|c|c|c|}
\hline Study or subgroup & $\begin{array}{c}\text { Cisplatin } \\
\mathrm{n} / \mathrm{N}\end{array}$ & $\begin{array}{c}\text { Other } \\
\mathrm{n} / \mathrm{N}\end{array}$ & $\begin{array}{c}\text { Odds Ratio } \\
\text { M-H, Random, } 95 \% \mathrm{Cl}\end{array}$ & Weight & $\begin{array}{c}\text { Odds Ratio } \\
\text { M-H, Random, } 95 \% \mathrm{Cl}\end{array}$ \\
\hline Ishida 2006 & $5 / 17$ & $6 / 17$ & 5 & $100 \%$ & $0.76[0.18,3.23]$ \\
\hline Subtotal $(95 \% \mathrm{Cl})$ & 17 & 17 & & $100 \%$ & $0.76[0.18,3.23]$ \\
\hline \multicolumn{6}{|c|}{ Total events: 5 (Cisplatin), 6 (Other) } \\
\hline \multicolumn{6}{|c|}{ Heterogeneity: Not applicable } \\
\hline \multicolumn{6}{|c|}{ Test for overall effect: $Z=0.37(P=0.71)$} \\
\hline \multicolumn{6}{|c|}{ 23.4.2 Cisplatin vs combination $\mathrm{OK}-432$ and cisplatin } \\
\hline Ishida 2006 & $5 / 17$ & $3 / 15$ & 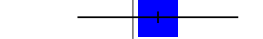 & $100 \%$ & $1.67[0.32,8.59]$ \\
\hline Subtotal $(95 \% \mathrm{CI})$ & 17 & 15 & & $100 \%$ & $1.67[0.32,8.59]$ \\
\hline \multicolumn{6}{|c|}{ Total events: 5 (Cisplatin), 3 (Other) } \\
\hline \multicolumn{6}{|c|}{ Heterogeneity: Not applicable } \\
\hline \multicolumn{6}{|c|}{ Test for overall effect: $Z=0.61(P=0.54)$} \\
\hline \multicolumn{6}{|c|}{ 23.4.3 Cisplatin vs combination rAd-p53 and cisplatin } \\
\hline Zhao 2009 & $0 / 18$ & $0 / 17$ & & & Not estimable \\
\hline Subtotal $(95 \% \mathrm{Cl})$ & 18 & 17 & & & Not estimable \\
\hline \multicolumn{6}{|c|}{ Total events: 0 (Cisplatin), 0 (Other) } \\
\hline \multicolumn{6}{|c|}{ Heterogeneity: Not applicable } \\
\hline \multicolumn{6}{|c|}{ Test for overall effect: Not applicable } \\
\hline Test for subgroup dif & , $d f=1(P=0.48)$ & & & & \\
\hline
\end{tabular}

\section{Comparison 24. Duration of drainage prior to administration of sclerosant}

\begin{tabular}{lllll}
\hline Outcome or subgroup title & $\begin{array}{l}\text { No. of } \\
\text { studies }\end{array}$ & $\begin{array}{l}\text { No. of partici- } \\
\text { pants }\end{array}$ & Statistical method & Effect size \\
\hline 1 Pleurodesis failure & 1 & 79 & Odds Ratio (M-H, Random, 95\% Cl) & $0.79[0.22,2.82]$ \\
\hline
\end{tabular}

Analysis 24.1. Comparison 24 Duration of drainage prior to administration of sclerosant, Outcome 1 Pleurodesis failure.

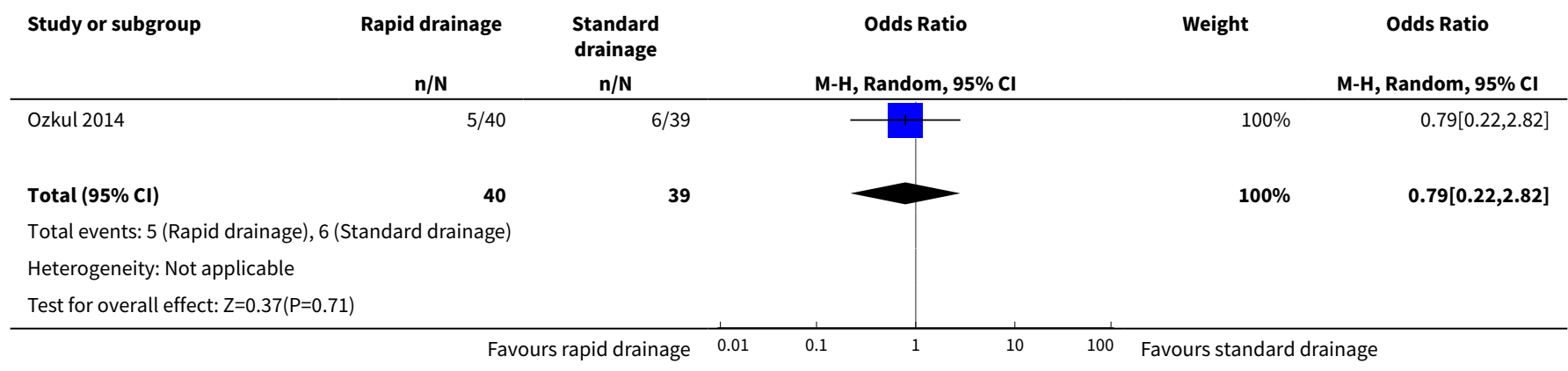




\section{Comparison 25. Dose of silver nitrate}

\begin{tabular}{|c|c|c|c|c|}
\hline Outcome or subgroup title & $\begin{array}{l}\text { No. of } \\
\text { studies }\end{array}$ & $\begin{array}{l}\text { No. of } \\
\text { partici- } \\
\text { pants }\end{array}$ & Statistical method & Effect size \\
\hline 1 Pleurodesis failure & 1 & & $\begin{array}{l}\text { Odds Ratio (M-H, Random, } \\
95 \% \mathrm{Cl} \text { ) }\end{array}$ & Subtotals only \\
\hline 1.1 Silver nitrate $90 \mathrm{mg}$ vs $150 \mathrm{mg}$ & 1 & 40 & $\begin{array}{l}\text { Odds Ratio (M-H, Random, } \\
95 \% \mathrm{Cl})\end{array}$ & $0.0[0.0,0.0]$ \\
\hline 1.2 Silver nitrate $90 \mathrm{mg}$ vs $180 \mathrm{mg}$ & 1 & 40 & $\begin{array}{l}\text { Odds Ratio (M-H, Random, } \\
95 \% \mathrm{Cl})\end{array}$ & $0.18[0.01,4.01]$ \\
\hline 1.3 Silver nitrate $150 \mathrm{mg}$ vs $180 \mathrm{mg}$ & 1 & 40 & $\begin{array}{l}\text { Odds Ratio (M-H, Random, } \\
95 \% \mathrm{Cl})\end{array}$ & $0.18[0.01,4.01]$ \\
\hline 2 Mortality & 1 & & $\begin{array}{l}\text { Odds Ratio (M-H, Random, } \\
95 \% \mathrm{Cl})\end{array}$ & Subtotals only \\
\hline 2.1 Silver nitrate $90 \mathrm{mg}$ vs $150 \mathrm{mg}$ & 1 & 39 & $\begin{array}{l}\text { Odds Ratio (M-H, Random, } \\
95 \% \mathrm{Cl})\end{array}$ & $3.18[0.30,33.58]$ \\
\hline 2.2 Silver nitrate $90 \mathrm{mg}$ vs $180 \mathrm{mg}$ & 1 & 39 & $\begin{array}{l}\text { Odds Ratio (M-H, Random, } \\
95 \% \mathrm{Cl})\end{array}$ & $7.80[0.38,161.87]$ \\
\hline 2.3 Silver nitrate $150 \mathrm{mg}$ vs $180 \mathrm{mg}$ & 1 & 38 & $\begin{array}{l}\text { Odds Ratio (M-H, Random, } \\
95 \% \mathrm{Cl})\end{array}$ & $3.16[0.12,82.64]$ \\
\hline 3 Pain & 1 & & $\begin{array}{l}\text { Odds Ratio (M-H, Random, } \\
95 \% \mathrm{Cl})\end{array}$ & Subtotals only \\
\hline 3.1 Silver nitrate $90 \mathrm{mg}$ vs $150 \mathrm{mg}$ & 1 & 40 & $\begin{array}{l}\text { Odds Ratio (M-H, Random, } \\
95 \% \mathrm{Cl})\end{array}$ & $1.0[0.13,7.89]$ \\
\hline 3.2 Silver nitrate $90 \mathrm{mg}$ vs $180 \mathrm{mg}$ & 1 & 40 & $\begin{array}{l}\text { Odds Ratio (M-H, Random, } \\
95 \% \mathrm{Cl})\end{array}$ & $1.0[0.13,7.89]$ \\
\hline 3.3 Silver nitrate $150 \mathrm{mg}$ vs $180 \mathrm{mg}$ & 1 & 40 & $\begin{array}{l}\text { Odds Ratio (M-H, Random, } \\
95 \% \mathrm{Cl})\end{array}$ & $1.0[0.13,7.89]$ \\
\hline 4 Fever & 1 & & $\begin{array}{l}\text { Odds Ratio (M-H, Random, } \\
95 \% \mathrm{Cl})\end{array}$ & Subtotals only \\
\hline 4.1 Silver nitrate $90 \mathrm{mg}$ vs $150 \mathrm{mg}$ & 1 & 40 & $\begin{array}{l}\text { Odds Ratio (M-H, Random, } \\
95 \% \mathrm{Cl})\end{array}$ & $0.63[0.09,4.24]$ \\
\hline 4.2 Silver nitrate $90 \mathrm{mg}$ vs $180 \mathrm{mg}$ & 1 & 40 & $\begin{array}{l}\text { Odds Ratio (M-H, Random, } \\
95 \% \mathrm{Cl})\end{array}$ & $1.0[0.13,7.89]$ \\
\hline 4.3 Silver nitrate $150 \mathrm{mg}$ vs $180 \mathrm{mg}$ & 1 & 40 & $\begin{array}{l}\text { Odds Ratio (M-H, Random, } \\
95 \% \mathrm{Cl})\end{array}$ & $1.59[0.24,10.70]$ \\
\hline
\end{tabular}


Analysis 25.1. Comparison 25 Dose of silver nitrate, Outcome 1 Pleurodesis failure.

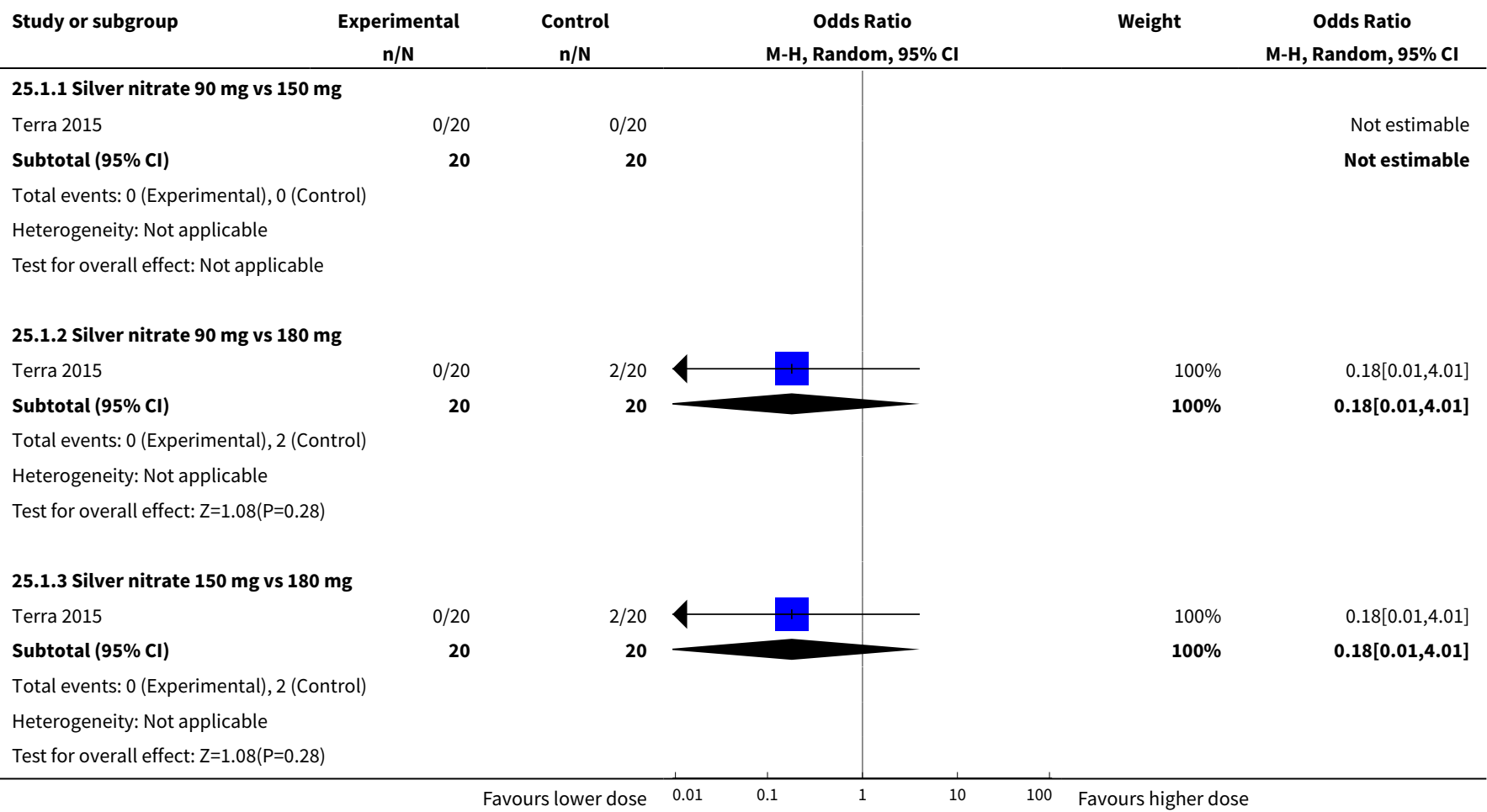

Analysis 25.2. Comparison 25 Dose of silver nitrate, Outcome 2 Mortality.

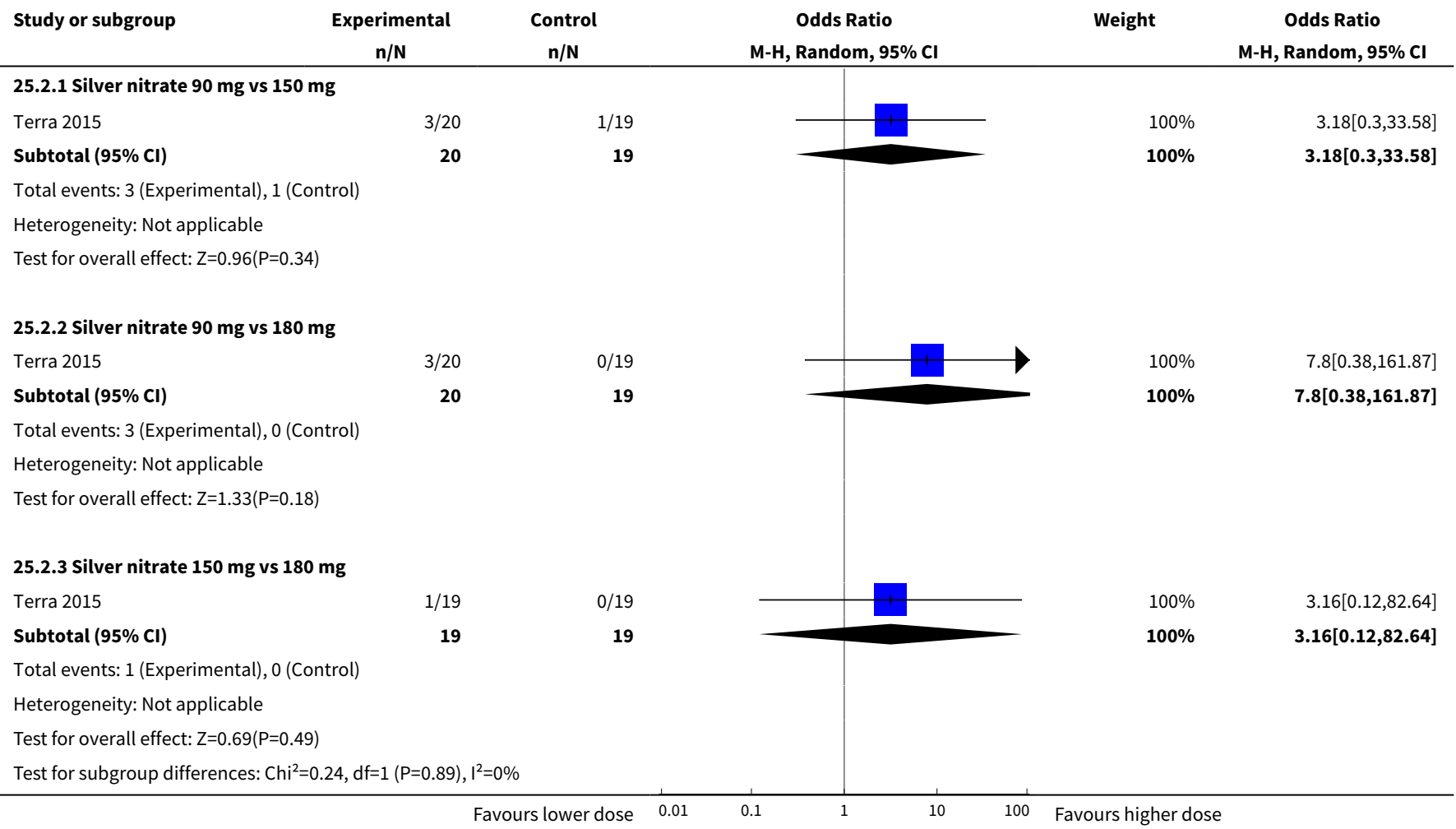


Analysis 25.3. Comparison 25 Dose of silver nitrate, Outcome 3 Pain.

\begin{tabular}{|c|c|c|c|c|c|}
\hline Study or subgroup & $\begin{array}{c}\text { Experimental } \\
\mathrm{n} / \mathrm{N}\end{array}$ & $\begin{array}{c}\text { Control } \\
\mathrm{n} / \mathrm{N}\end{array}$ & $\begin{array}{c}\text { Odds Ratio } \\
\text { M-H, Random, } 95 \% \mathrm{CI}\end{array}$ & Weight & $\begin{array}{c}\text { Odds Ratio } \\
\text { M-H, Random, } 95 \% \mathrm{Cl}\end{array}$ \\
\hline \multicolumn{6}{|c|}{ 25.3.1 Silver nitrate $90 \mathrm{mg}$ vs $150 \mathrm{mg}$} \\
\hline Terra 2015 & $2 / 20$ & $2 / 20$ & & $100 \%$ & $1[0.13,7.89]$ \\
\hline Subtotal $(95 \% \mathrm{Cl})$ & 20 & 20 & & $100 \%$ & $1[0.13,7.89]$ \\
\hline \multicolumn{6}{|c|}{ Total events: 2 (Experimental), 2 (Control) } \\
\hline \multicolumn{6}{|c|}{ Heterogeneity: Not applicable } \\
\hline \multicolumn{6}{|c|}{ Test for overall effect: Not applicable } \\
\hline \multicolumn{6}{|c|}{ 25.3.2 Silver nitrate $90 \mathrm{mg}$ vs $180 \mathrm{mg}$} \\
\hline Terra 2015 & $2 / 20$ & $2 / 20$ & & $100 \%$ & $1[0.13,7.89]$ \\
\hline Subtotal (95\% Cl) & 20 & 20 & & $100 \%$ & $1[0.13,7.89]$ \\
\hline \multicolumn{6}{|c|}{ Total events: 2 (Experimental), 2 (Control) } \\
\hline \multicolumn{6}{|c|}{ Heterogeneity: Not applicable } \\
\hline \multicolumn{6}{|c|}{ Test for overall effect: Not applicable } \\
\hline \multicolumn{6}{|c|}{ 25.3.3 Silver nitrate $150 \mathrm{mg}$ vs $180 \mathrm{mg}$} \\
\hline Terra 2015 & $2 / 20$ & $2 / 20$ & & $100 \%$ & $1[0.13,7.89]$ \\
\hline Subtotal (95\% Cl) & 20 & 20 & & $100 \%$ & $1[0.13,7.89]$ \\
\hline \multicolumn{6}{|c|}{ Total events: 2 (Experimental), 2 (Control) } \\
\hline \multicolumn{6}{|c|}{ Heterogeneity: Not applicable } \\
\hline \multicolumn{6}{|c|}{ Test for overall effect: Not applicable } \\
\hline Test for subgroup dif & plicable & & & & \\
\hline
\end{tabular}

Analysis 25.4. Comparison 25 Dose of silver nitrate, Outcome 4 Fever.

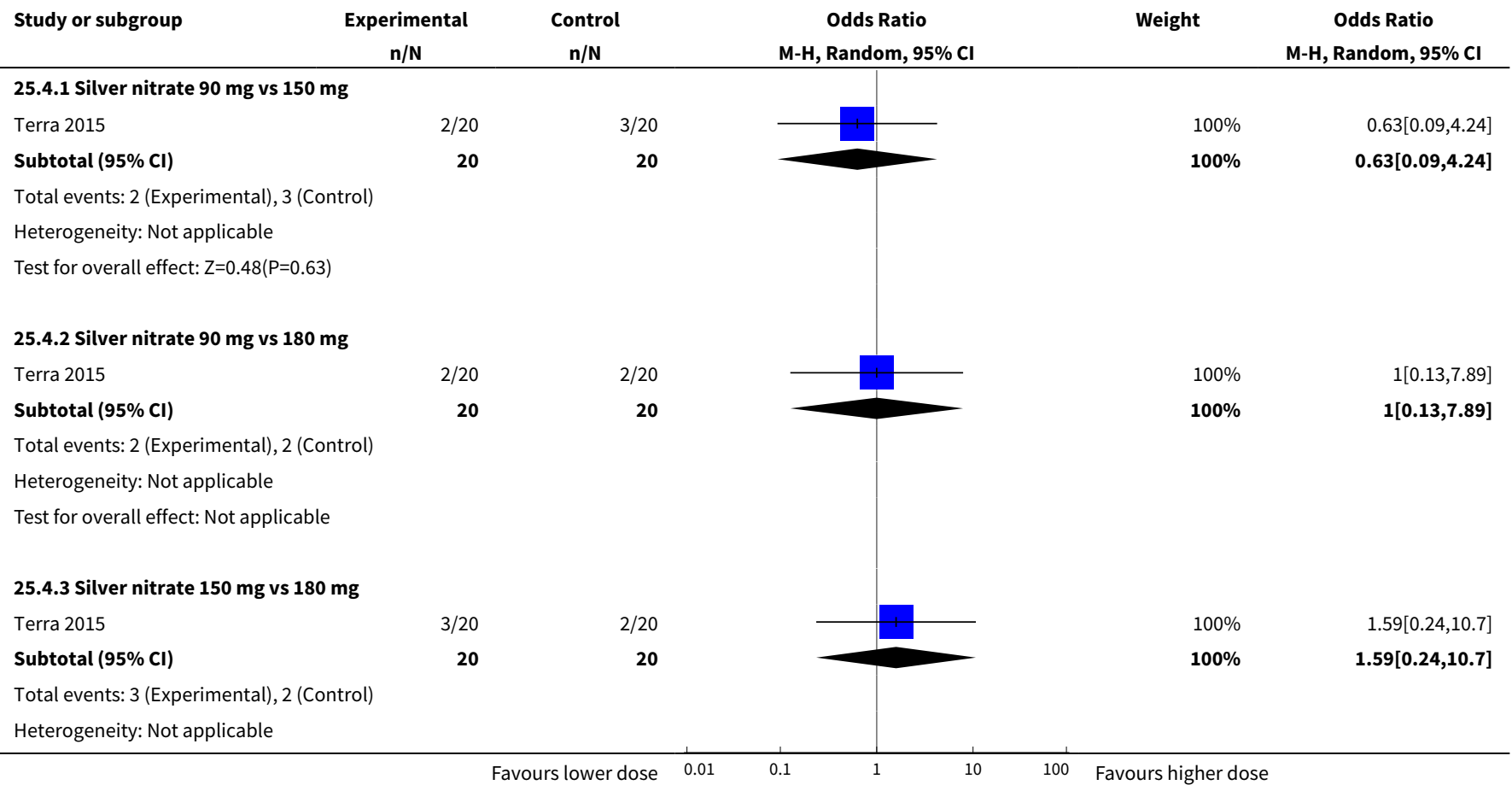




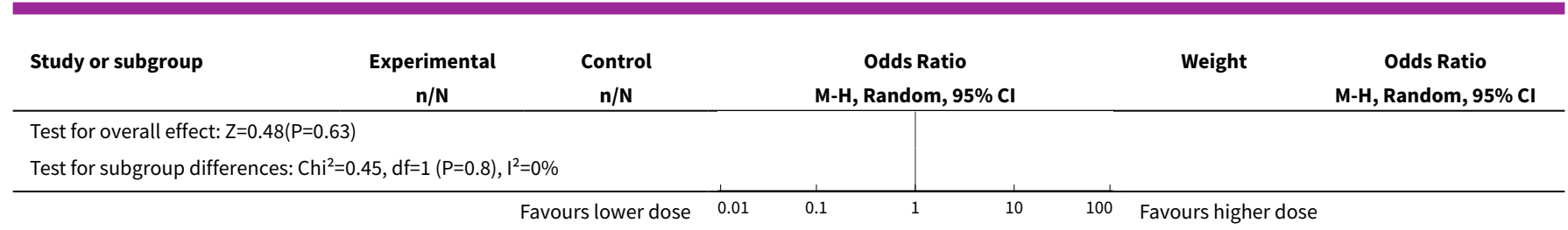

\section{ADDITIONAL TABLES}




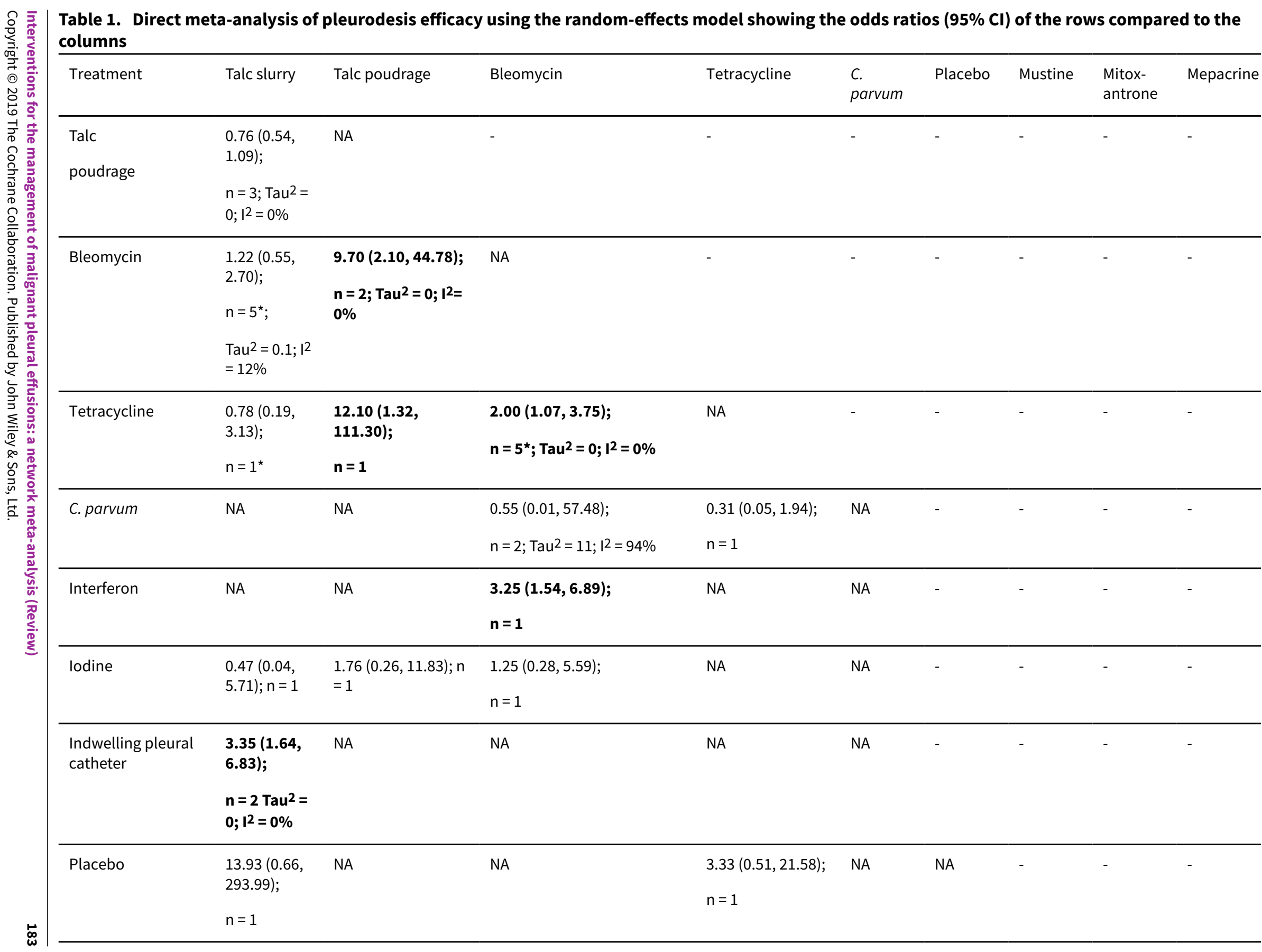




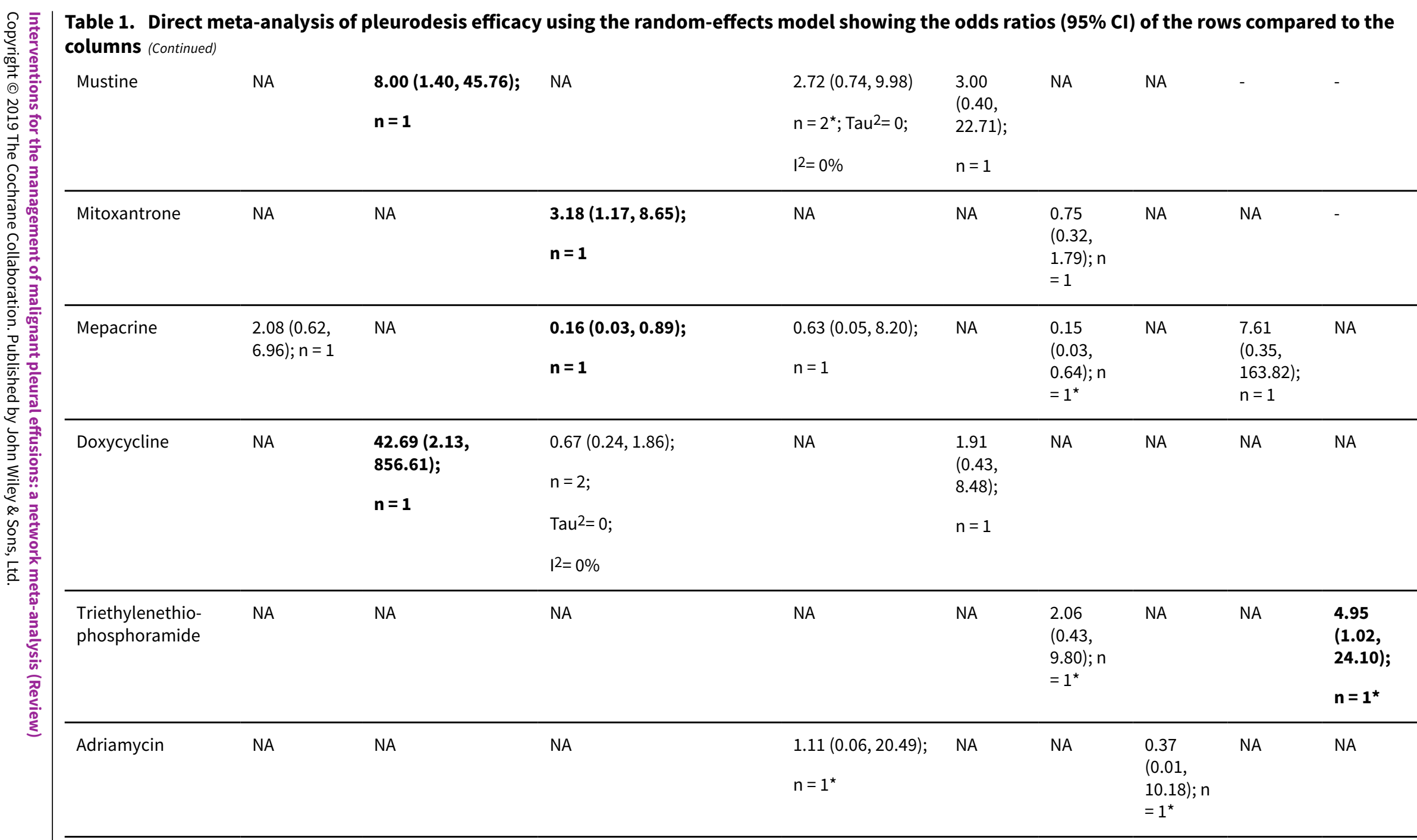

$\mathrm{n}=$ the number of studies included in the pair-wise comparison. * Indicates that the comparison included a three-arm study. NA= no direct pair-wise comparison available. Results that are statistically significant at the conventional level of $\mathrm{P}<0.05$ are shaded in grey. - indicates the odds ratio is already expressed elsewhere in the table comparing the interventions the other way around. 


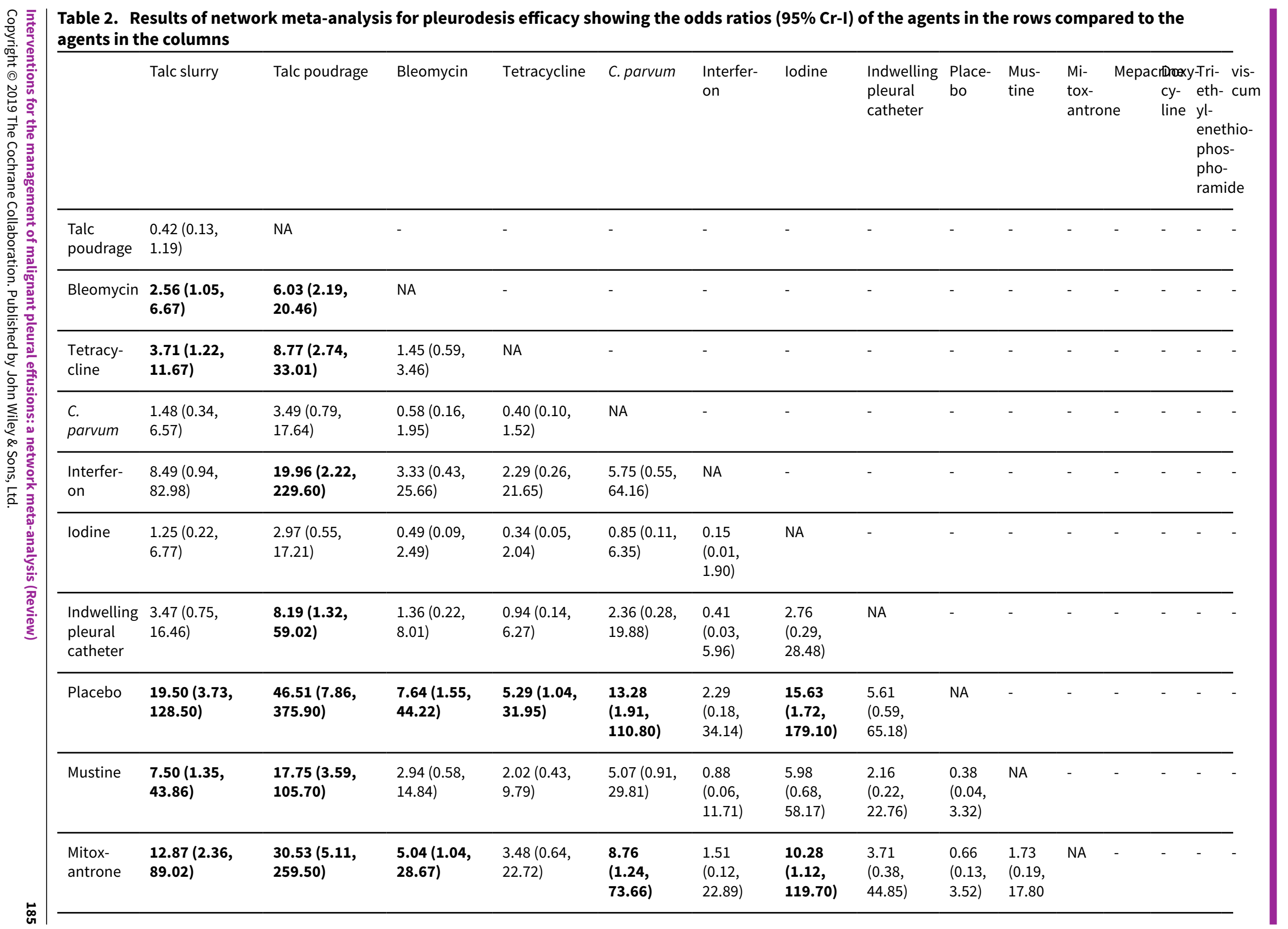




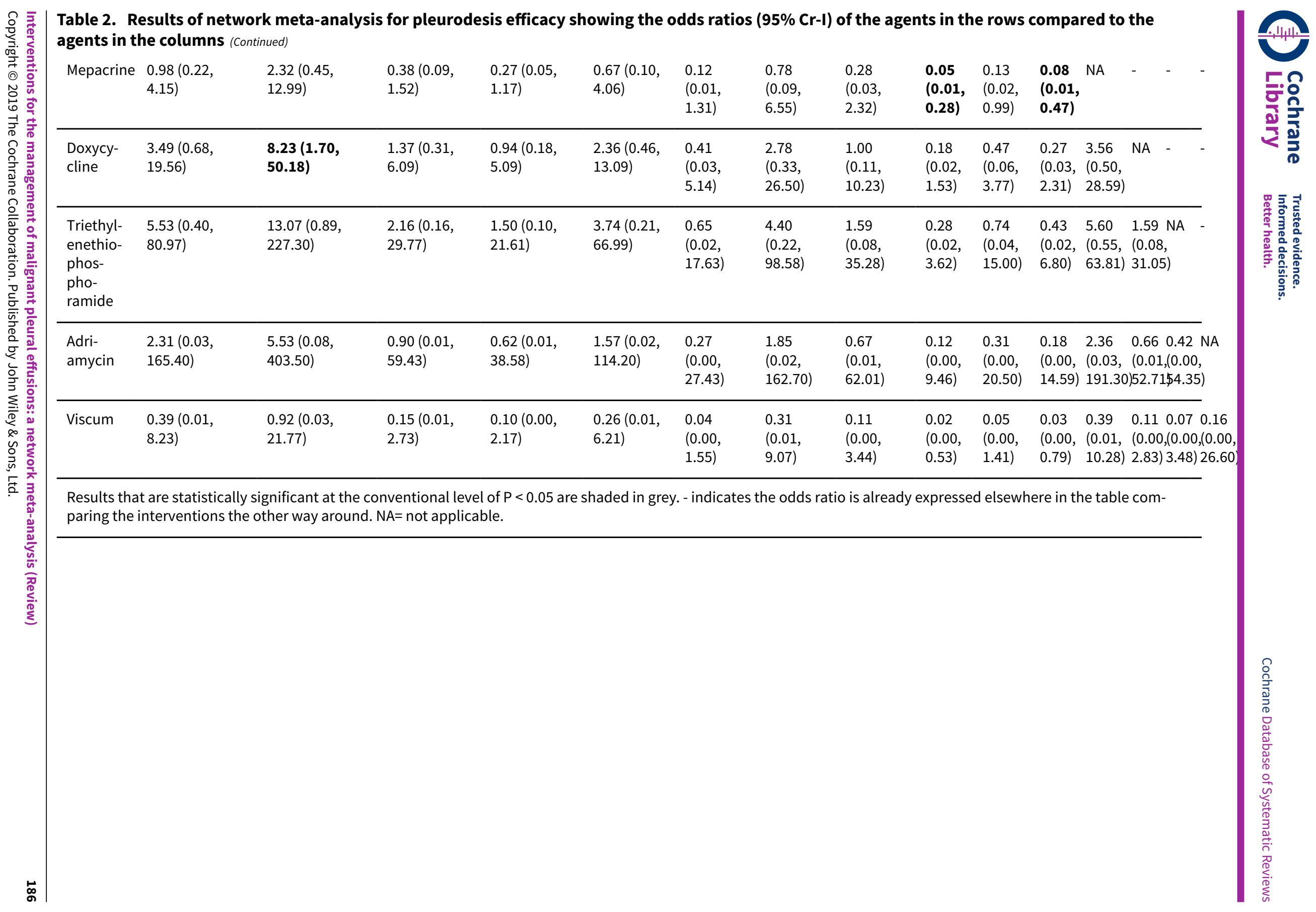


Table 3. Results for pleurodesis efficacy of the studies evaluating pleurodesis methods, which were not included in the network meta-analysis

\begin{tabular}{|c|c|c|c|c|c|c|}
\hline Study & $\begin{array}{l}\text { Reason } \\
\text { study ex- } \\
\text { cluded from } \\
\text { network }\end{array}$ & $\begin{array}{l}\text { Intrapleural agent } \\
\text { or intervention } 1\end{array}$ & $\begin{array}{l}\text { Pleurode- } \\
\text { sis failure } \\
\text { rate for } \\
\text { agent } 1\end{array}$ & $\begin{array}{l}\text { Intrapleural agent or in- } \\
\text { tervention } 2\end{array}$ & $\begin{array}{l}\text { Pleurode- } \\
\text { sis failure } \\
\text { rate for } \\
\text { agent } 2\end{array}$ & $\begin{array}{l}\text { OR }(95 \% \mathrm{Cl}) \text { of agent } 1 \\
\text { compared with agent } \\
2^{\star \star \star}\end{array}$ \\
\hline Du 2013 & $\begin{array}{l}\text { Lung cancer } \\
\text { specific ther- } \\
\text { apy }\end{array}$ & $\begin{array}{l}\text { Cisplatin and beva- } \\
\text { cizumab }\end{array}$ & $6 / 36$ & Cisplatin & $17 / 34$ & $0.20(0.07,0.60)$ \\
\hline \multirow[t]{2}{*}{$\begin{array}{l}\text { Emad } \\
1996^{\star}\end{array}$} & \multirow{2}{*}{$\begin{array}{l}\text { No pleurode- } \\
\text { sis failures } \\
\text { in the Com- } \\
\text { bined group }\end{array}$} & Tetracycline** & $3 / 19$ & $\begin{array}{l}\text { Combined tetracycline } \\
\text { and bleomycin }\end{array}$ & $0 / 19$ & $8.27(0.40,172.05)$ \\
\hline & & Bleomycin** & $2 / 19$ & $\begin{array}{l}\text { Combined tetracycline } \\
\text { and bleomycin }\end{array}$ & $0 / 19$ & $5.57(0.25,124.19)$ \\
\hline \multirow{3}{*}{$\begin{array}{l}\text { Ishida } \\
2006^{\star}\end{array}$} & \multirow{3}{*}{$\begin{array}{l}\text { Lung cancer } \\
\text { specific ther- } \\
\text { apy }\end{array}$} & OK-432 & $8 / 17$ & Cisplatin & $11 / 17$ & $0.48(0.12,1.92)$ \\
\hline & & OK-432 & $8 / 17$ & OK-432 and cisplatin & $1 / 15$ & $12.44(1.32,117.03)$ \\
\hline & & Cisplatin & $11 / 17$ & OK-432 and cisplatin & $1 / 15$ & $25.67(2.68,245.84)$ \\
\hline $\begin{array}{l}\text { Kasahara } \\
2006\end{array}$ & $\begin{array}{l}\text { Lung cancer } \\
\text { specific ther- } \\
\text { apy }\end{array}$ & High dose OK-432 & $5 / 19$ & Low dose OK-432 & $3 / 19$ & $1.90(0.38,9.44)$ \\
\hline Luh 1992 & $\begin{array}{l}\text { Lung cancer } \\
\text { specific ther- } \\
\text { apy }\end{array}$ & OK-432 & $3 / 26$ & Mitomycin C & $9 / 27$ & $0.26(0.06,1.11)$ \\
\hline $\begin{array}{l}\text { Maskell } \\
2004\end{array}$ & $\begin{array}{l}\text { Two Talc } \\
\text { slurry prepa- } \\
\text { rations }\end{array}$ & Mixed particle talc & $3 / 14$ & $\begin{array}{l}\text { Graded talc (particles } \\
>20 \mu \mathrm{m})\end{array}$ & $2 / 14$ & $1.64(0.23,11.70))$ \\
\hline $\begin{array}{l}\text { Masuno } \\
1991\end{array}$ & $\begin{array}{l}\text { Lung cancer } \\
\text { specific ther- } \\
\text { apy }\end{array}$ & $\begin{array}{l}\text { LC9018 and Adri- } \\
\text { amycin }\end{array}$ & $10 / 38$ & Adriamycin & $23 / 38$ & $0.23(0.09,0.62)$ \\
\hline $\begin{array}{l}\text { Paschoali- } \\
\text { ni } 2005\end{array}$ & $\begin{array}{l}\text { No pleurode- } \\
\text { sis failures in } \\
\text { Silver Nitrate } \\
\text { group }\end{array}$ & Talc slurry & $1 / 9$ & Silver nitrate & $0 / 16$ & $5.85(0.21,158.82)$ \\
\hline $\begin{array}{l}\text { Rintoul } \\
2014\end{array}$ & $\begin{array}{l}\text { MPM specif- } \\
\text { ic surgical } \\
\text { technique }\end{array}$ & $\begin{array}{l}\text { Talc pleurodesis } \\
\text { (slurry or poudrage) }\end{array}$ & $25 / 62$ & VATS pleurectomy & $24 / 60$ & $0.88(0.43,1.82)$ \\
\hline \multirow{3}{*}{$\begin{array}{l}\text { Terra } \\
2015^{\star}\end{array}$} & \multirow{3}{*}{$\begin{array}{l}\text { Comparison } \\
\text { of different } \\
\text { doses of Sil- } \\
\text { ver Nitrate }\end{array}$} & 90 mg silver nitrate & $0 / 20$ & 150 mg silver nitrate & $0 / 20$ & not estimable \\
\hline & & 90 mg silver nitrate & $0 / 20$ & 180 mg silver nitrate & $2 / 20$ & $0.18(0.01,4.01)$ \\
\hline & & $\begin{array}{l}150 \text { mg silver ni- } \\
\text { trate }\end{array}$ & $0 / 20$ & 180 mg silver nitrate & $2 / 20$ & $0.19(0.01,4.01)$ \\
\hline $\begin{array}{l}\text { Yoshida } \\
2007^{\star}\end{array}$ & $\begin{array}{l}\text { Lung cancer } \\
\text { specific ther- } \\
\text { apy }\end{array}$ & OK-432 & $8 / 33$ & Bleomycin & $11 / 35$ & $0.70(0.24,2.03)$ \\
\hline
\end{tabular}


Table 3. Results for pleurodesis efficacy of the studies evaluating pleurodesis methods, which were not included in the network meta-analysis (Continued)

\begin{tabular}{|c|c|c|c|c|c|c|}
\hline & & OK-432 & $8 / 33$ & Cisplatin and etoposide & $10 / 34$ & $0.77(0.26,2.27)$ \\
\hline & & Bleomycin & $11 / 35$ & Cisplatin and etoposide & $10 / 34$ & $1.10(0.39,3.07)$ \\
\hline Zhao 2009 & $\begin{array}{l}\text { Lung cancer } \\
\text { specific ther- } \\
\text { apy }\end{array}$ & $\begin{array}{l}\text { rAd-p53 and cis- } \\
\text { platin }\end{array}$ & $3 / 17$ & Cisplatin & $9 / 18$ & $0.21(0.05,1.01)$ \\
\hline
\end{tabular}

*Three-arm study. ${ }^{\star \star}$ The results for the pair-wise comparison between tetracycline and bleomycin are included in the network metaanalysis.

${ }^{\star \star *}$ Results that are statistically significant at the conventional level of $\mathrm{P}<0.05$ are shaded in grey

Table 4. Results for pleurodesis efficacy of the studies evaluating interventions to optimise pleurodesis, which were not included in the network meta-analysis

\begin{tabular}{|c|c|c|c|c|c|c|}
\hline $\begin{array}{l}\text { Type of method to } \\
\text { optimise pleurodesis }\end{array}$ & Study & Intervention 1 & $\begin{array}{l}\text { Pleurode- } \\
\text { sis failure } \\
\text { rate for in- } \\
\text { tervention } \\
1\end{array}$ & Intervention 2 & $\begin{array}{l}\text { Pleurode- } \\
\text { sis failure } \\
\text { rate for in- } \\
\text { tervention } \\
2\end{array}$ & $\begin{array}{l}\text { OR }(95 \% \mathrm{Cl}) \text { of } \\
\text { intervention } 1 \\
\text { compared with } \\
\text { intervention } 2^{*}\end{array}$ \\
\hline $\begin{array}{l}\text { Mode of administra- } \\
\text { tion }\end{array}$ & $\begin{array}{l}\text { Evans } \\
1993\end{array}$ & $\begin{array}{l}\text { Tetracycline pleurodesis at } \\
\text { the end of thoracoscopy }\end{array}$ & $2 / 15$ & $\begin{array}{l}\text { Tetracycline } \\
\text { pleurodesis } \\
\text { through an in- } \\
\text { tercostal can- } \\
\text { nula }\end{array}$ & $5 / 14$ & $0.28(0.04,1.76)$ \\
\hline Chest tube size & $\begin{array}{l}\text { Clementsen } \\
1998\end{array}$ & Small-bore chest drain & $2 / 9$ & $\begin{array}{l}\text { Large-bore } \\
\text { chest drain }\end{array}$ & $3 / 9$ & $0.57(0.07,4.64)$ \\
\hline Patient rotation & $\begin{array}{l}\text { Mager } \\
2002\end{array}$ & $\begin{array}{l}\text { Rotation after instillation of } \\
\text { talc }\end{array}$ & $2 / 10$ & $\begin{array}{l}\text { No rotation af- } \\
\text { ter instillation } \\
\text { of talc }\end{array}$ & $1 / 10$ & $\begin{array}{l}2.25(0.17 \\
29.77)\end{array}$ \\
\hline \multirow[t]{3}{*}{$\begin{array}{l}\text { Duration of drainage } \\
\text { after administration } \\
\text { of the sclerosant }\end{array}$} & $\begin{array}{l}\text { Goodman } \\
2006\end{array}$ & $\begin{array}{l}\text { Drain removed } 24 \text { hours after } \\
\text { pleurodesis }\end{array}$ & $2 / 16$ & $\begin{array}{l}\text { Drain removed } \\
72 \text { hours after } \\
\text { pleurodesis }\end{array}$ & $4 / 19$ & $0.54(0.08,3.40)$ \\
\hline & $\begin{array}{l}\text { Villanueva } \\
1994\end{array}$ & $\begin{array}{l}\text { Drain removal the day after } \\
\text { pleurodesis }\end{array}$ & $2 / 9$ & $\begin{array}{l}\text { Drain removal } \\
\text { when }<150 \mathrm{ml} / \\
\text { day output }\end{array}$ & $3 / 15$ & $1.14(0.15,8.59)$ \\
\hline & $\begin{array}{l}\text { Yildirim } \\
2005\end{array}$ & $\begin{array}{l}\text { Fractionated dose oxytetra- } \\
\text { cycline (4 divided doses at } 6- \\
\text { hourly intervals) }\end{array}$ & $0 / 12$ & $\begin{array}{l}\text { Single bedside } \\
\text { instillation of } \\
\text { oxytetracycline }\end{array}$ & $2 / 8$ & $0.10(0.00,2.50)$ \\
\hline $\begin{array}{l}\text { Duration of drainage } \\
\text { prior to administra- } \\
\text { tion of the sclerosant }\end{array}$ & $\begin{array}{l}\text { Ozkul } \\
2014\end{array}$ & $\begin{array}{l}\text { Early instillation of talc slurry } \\
\text { after drain insertion }\end{array}$ & $5 / 40$ & $\begin{array}{l}\text { Instillation of } \\
\text { talc slurry when } \\
\text { daily drainage } \\
\text { from chest tube } \\
<300 \mathrm{ml} / \text { day }\end{array}$ & $6 / 39$ & $0.79(0.22,2.82)$ \\
\hline
\end{tabular}


Table 4. Results for pleurodesis efficacy of the studies evaluating interventions to optimise pleurodesis, which were not included in the network meta-analysis (Continued)

\begin{tabular}{lllllll}
$\begin{array}{l}\text { Intrapleural fibri- } \\
\text { nolytics }\end{array}$ & Okur 2011 & Intrapleural streptokinase & $14 / 19$ & $\begin{array}{l}\text { No intrapleural } \\
\text { streptokinase }\end{array}$ & $9 / 16$ & $2.18(0.53,9.02)$ \\
\hline $\begin{array}{l}\text { Pleural abrasion at } \\
\text { thoracoscopy }\end{array}$ & $\begin{array}{l}\text { Crnjac } \\
2004\end{array}$ & Talc slurry & $11 / 42$ & $\begin{array}{l}\text { Thoracoscop- } \\
\text { ic mechanical } \\
\text { pleurodesis }\end{array}$ & $6 / 45$ & $2.31(0.77,6.93)$ \\
\end{tabular}

${ }^{\star}$ Results that are statistically significant at the conventional level of $\mathrm{P}<0.05$ are shaded in grey 


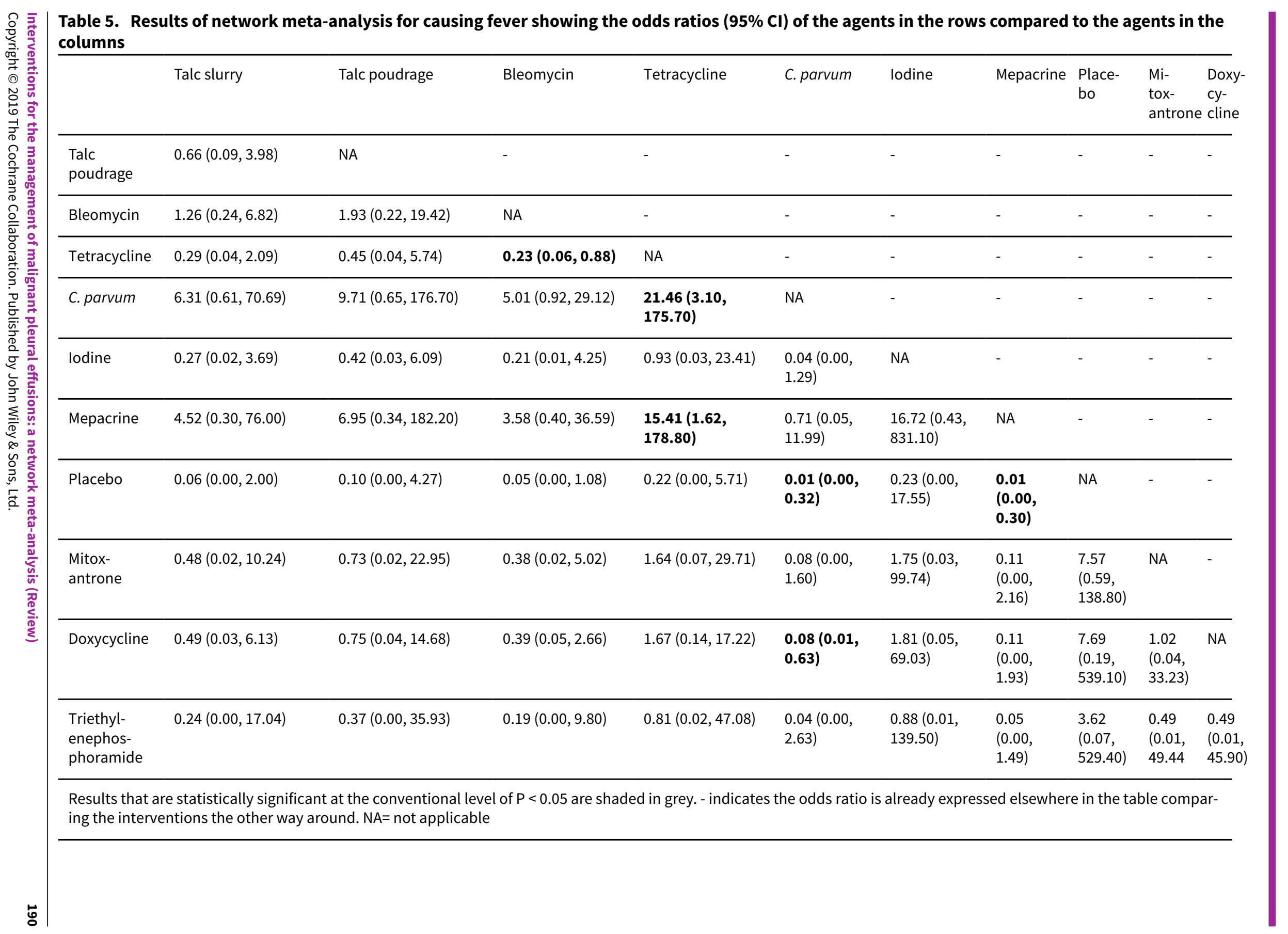




\section{AP PEN DICES}

\section{Appendix 1. Search strategies}

\section{CENTRAL ( THE COCHRANE LIBRARY)}

\#1 MeSH descriptor: [Pleural Effusion] explode all trees

\#2 (pleura* near/5 (effusion* or fluid*)):ti,ab,kw (Word variations have been searched)

\#3 \#1 or \#2

\#4 MeSH descriptor: [Neoplasms] explode all trees

\#5 (cancer* or tumor* or tumour ${ }^{\star}$ or neoplas* or carcinom* or malignan*):ti,ab,kw (Word variations have been searched)

\#6 \#4 or \#5

\#7 \#3 and \#6

MEDLINE (OVID)

1 exp Pleural Effusion/

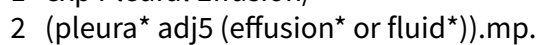

31 or 2

4 exp Neoplasms/

5 (cancer $^{\star}$ or tumor ${ }^{\star}$ or tumour ${ }^{\star}$ or neoplas ${ }^{\star}$ or carcinom ${ }^{\star}$ or malignan $\left.{ }^{\star}\right) . m p$.

64 or 5

7 randomized controlled trial.pt.

8 controlled clinical trial.pt.

9 randomized.ab.

10 placebo.ab.

11 clinical trials as topic.sh.

12 randomly.ab.

13 trial.ti.

147 or 8 or 9 or 10 or 11 or 12 or 13

153 and 6 and 14

\section{key:}

$\mathrm{mp}=$ protocol supplementary concept, rare disease supplementary concept, title, original title, abstract, name of substance word, subject heading word, unique identifier

pt $=$ publication type

sh = subject heading

$a b=a b s t r a c t$

$\mathrm{ti}=\mathrm{title}$

\section{EMBASE (OVID)}

1 exp Pleural Effusion/

2 (pleura* ${ }^{\star}$ dj5 (effusion* or fluid*)).mp.

3 or $/ 1-2$

4 exp neoplasm/

5 (cancer $^{\star}$ or tumor $^{\star}$ or tumour $^{\star}$ or neoplas $^{\star}$ or carcinom $^{\star}$ or malignan $\left.{ }^{\star}\right)$.mp.

6 or/4-5

7 random\$.tw. 
8 factorial\$.tw.

9 crossover\$.tw.

10 cross over\$.tw.

11 cross-over\$.tw.

12 placebo $\$ . t w$.

13 (doubl\$ adj blind\$).tw.

14 (singl\$ adj blind\$).tw.

15 assign\$.tw.

16 allocat\$.tw.

17 volunteer\$.tw.

18 Crossover Procedure/

19 double-blind procedure.tw.

20 Randomized Controlled Trial/

21 Single Blind Procedure/

22 or/ $7-21$

23 (animal/ or nonhuman/) not human/

2422 not 23

253 and 6 and 24

CINAHL (EBSCO)

\section{S25 S18 AND S21 AND S24}

\section{S24 S22 OR S23}

S23 (cancer ${ }^{\star}$ or tumor ${ }^{\star}$ or tumour ${ }^{\star}$ or neoplas ${ }^{\star}$ or carcinom* or malignan*) Search modes -

S22 (MH "Neoplasms+")

S21 S19 OR S20

S20 (pleura* N5 (effusion* or fluid $\left.{ }^{\star}\right)$ )

S19 (MH "Pleural Effusion+")

S18 S10 OR S11 OR S12 OR S13 OR S14 OR S15 OR S16 OR S17

S17 (allocat* random*)

S16 (MH "Quantitative Studies")

S15 (MH "Placebos")

S14 placebo*

S13 (random* allocat $\left.{ }^{\star}\right)$

S12 (MH "Random Assignment")

S11 (Randomi?ed control ${ }^{\star}$ trial $^{\star}$ ) 


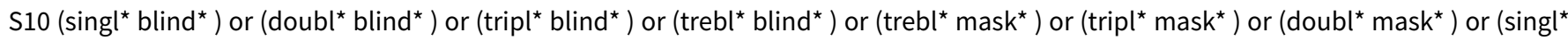
mask $\left.^{*}\right)$

S9 S1 OR S2 OR S3 OR S4 OR S5 OR S6 OR S7 OR S8

S8 (allocat* random $^{\star}$ )

S7 (MH "Quantitative Studies")

S6 (MH "Placebos")

S5 placebo*

S4 (random* allocat $^{\star}$ )

S3 (MH "Random Assignment")

S2 (Randomi?ed control ${ }^{\star}$ trial $^{\star}$ )

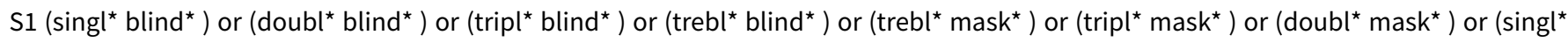
mask $^{\star}$ )

\section{Web of Science (ISI) SSCI \& SCI}

\#11 \#10 AND \#2

\#10 \#9 OR \#8 OR \#7 OR \#6 OR \#5 OR \#4 OR \#3

\#9 Topic=(((("random* allocat*") or ("random* assign*"))))

\#8 Topic=(((crossover) $))$

\#7 Topic=(((("tripl* blind*") or ("tripl* mask*"))))

\#6 Topic=(((("trebl* blind*") or ("trebl* mask*"))))

\#5 Topic=(((("doubl* blind" $)$ or ("doubl* mask*"))))

\#4 Topic=(((("singl* blind*") or ("singl* mask*"))))

\#3 Topic=(((("clin* trial $\left.\left.\left.\left.^{\star} "\right)\right)\right)\right)$

\#2 Topic=((pleura* near/5 (effusion* or fluid $\left.\left.\left.{ }^{\star}\right)\right)\right)$ AND Topic=((cancer ${ }^{\star}$ or tumor ${ }^{\star}$ or tumour ${ }^{\star}$ or neoplas ${ }^{\star}$ or carcinom or malignan $\left.\left.^{\star}\right)\right)$

\#1 Topic=((pleura* near/5 (effusion* or fluid*)))

Appendix 2. Distribution of study population characteristics across all the included studies and within each pairwise comparison 


\begin{tabular}{|c|c|c|c|c|c|c|c|c|c|c|}
\hline \multicolumn{2}{|c|}{ Potential effect modifiers } & $\begin{array}{l}\text { Total } \\
\mathrm{n}(\%)\end{array}$ & $\begin{array}{l}\text { Talc } \\
\text { poudrage } \\
\text { vs talc } \\
\text { slurry. } \mathrm{n} \\
(\%)\end{array}$ & $\begin{array}{l}\text { Bleomycin } \\
\text { vs talc } \\
\text { slurry. n } \\
(\%)\end{array}$ & $\begin{array}{l}\text { Bleomycin } \\
\text { vs talc } \\
\text { poudrage. } \\
\mathrm{n}(\%)\end{array}$ & $\begin{array}{l}\text { Tetracy- } \\
\text { cline vs } \\
\text { bleomycin. } \\
n(\%)\end{array}$ & $\begin{array}{l}\text { C. } \\
\text { parvum } \\
\text { vs } \\
\text { bleomycin. } \\
\mathrm{n}(\%)\end{array}$ & $\begin{array}{l}\text { IPC vs } \\
\text { talc slur- } \\
\text { ry. n (\%) }\end{array}$ & $\begin{array}{l}\text { Mus- } \\
\text { tine vs } \\
\text { tetra- } \\
\text { cy- } \\
\text { cline. } n \\
(\%)\end{array}$ & $\begin{array}{l}\text { Doxycy- } \\
\text { cline vs } \\
\text { bleomycin. } \\
n(\%)\end{array}$ \\
\hline \multicolumn{2}{|c|}{ Number of studies } & 59 & 3 & 5 & 2 & 5 & 2 & 2 & 2 & 2 \\
\hline \multirow{3}{*}{$\begin{array}{l}\text { Cell types in- } \\
\text { cluded }\end{array}$} & Only breast & $6(10)$ & 0 & 0 & $1(50)$ & 0 & 0 & 0 & 0 & 0 \\
\hline & Only Lung & $7(12)$ & 0 & 0 & 0 & 0 & 0 & 0 & 0 & 0 \\
\hline & Other & $4(7)$ & 0 & 0 & 0 & 0 & $1(50)$ & 0 & 0 & 0 \\
\hline Trapped lung & Excluded & $24(41)$ & $2(67)$ & $3(60)$ & $1(50)$ & $1(20)$ & 0 & $1(50)$ & 0 & 0 \\
\hline \multirow[t]{4}{*}{ Drain size } & Unknown & $26(44)$ & $1(33)$ & $1(20)$ & $1(50)$ & $4(80)$ & $1(50)$ & 0 & 0 & $1(50)$ \\
\hline & Small $<20 \mathrm{Fr}$ & $13(22)$ & 0 & $1(20)$ & $1(50)$ & 0 & $1(50)$ & $1(50$ & $1(50)$ & $1(50)$ \\
\hline & Large $\geq 20 \mathrm{Fr}$ & $17(29)$ & $2(67)$ & $3(60)$ & 0 & $1(20)$ & 0 & $1(50)$ & $1(50)$ & 0 \\
\hline & $\begin{array}{l}\text { Study comparing large with small } \\
\text { drains }\end{array}$ & $3(5)$ & 0 & 0 & 0 & 0 & 0 & 0 & 0 & 0 \\
\hline \multirow{2}{*}{$\begin{array}{l}\text { How pleu- } \\
\text { rodesis was } \\
\text { defined }\end{array}$} & $\begin{array}{l}\text { Recurrence of effusion and need } \\
\text { for repeat intervention }\end{array}$ & $41(69)$ & $1(33)$ & $4(80)$ & $1(50)$ & $4(80)$ & $2(100)$ & $2(100)$ & $2(100)$ & $1(50)$ \\
\hline & Radiological recurrence only & $18(31)$ & $2(66)$ & $1(20)$ & $1(50)$ & $1(20)$ & 0 & 0 & 0 & $1(50)$ \\
\hline \multirow{3}{*}{$\begin{array}{l}\text { Time point } \\
\text { pleurodesis } \\
\text { defined }^{\star}\end{array}$} & 2- 4 months & $23(39)$ & $1(33)$ & $1(20)$ & $1(50)$ & $2(40)$ & $1(50)$ & 0 & $2(100)$ & $1(5)$ \\
\hline & $>4-7$ months & $1(2)$ & $1(33)$ & 0 & 0 & 0 & 0 & 0 & 0 & 0 \\
\hline & $<2$ months & $29(49)$ & $1(33)$ & $2(40)$ & 0 & $3(60)$ & $1(50)$ & $1(50)$ & 0 & $1(50)$ \\
\hline
\end{tabular}




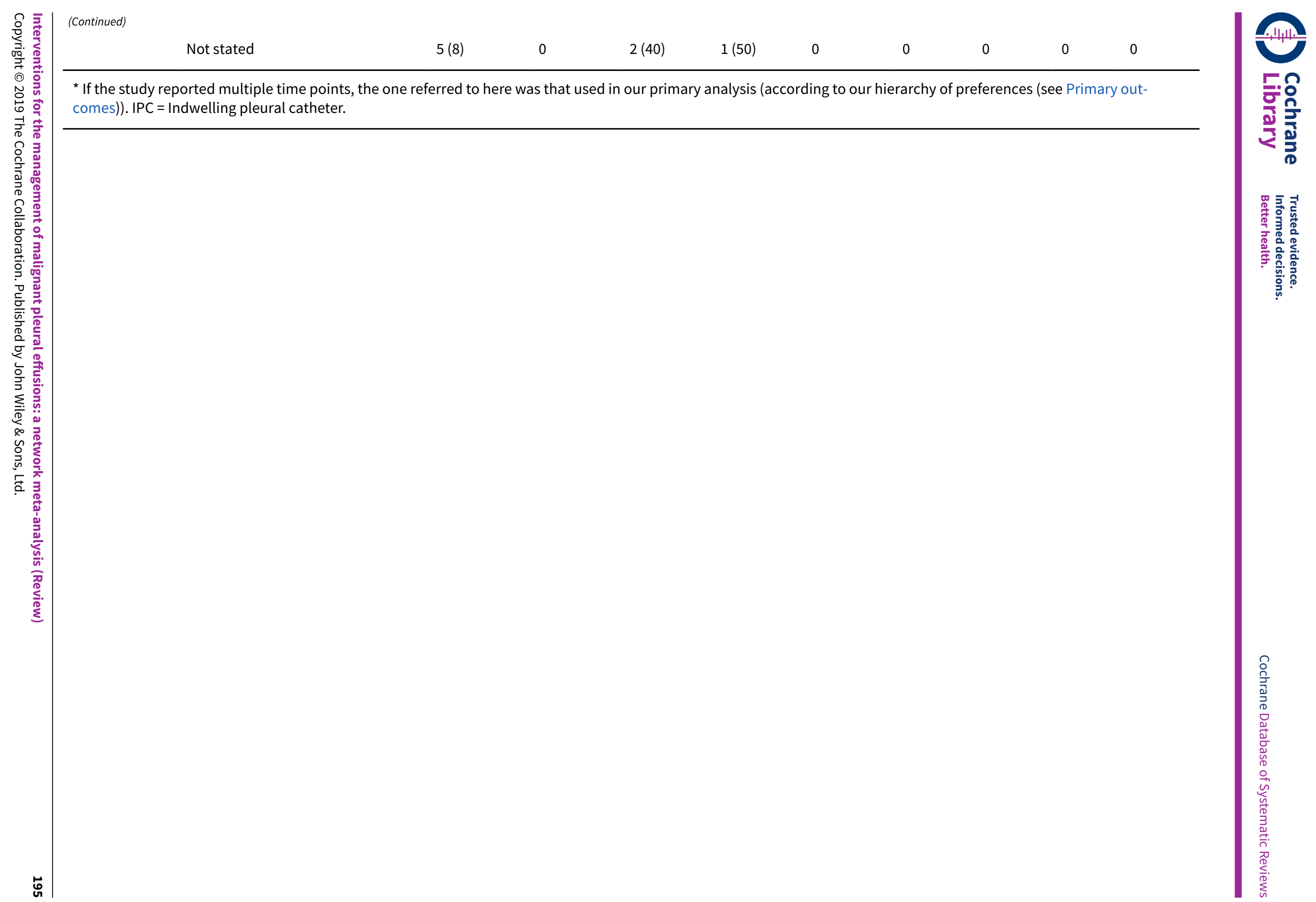


Appendix 3. Sensitivity analysis of the direct meta-analysis results for pleurodesis efficacy using the fixed-effect model showing odds ratios $(95 \% \mathrm{Cl})$ of the rows compared to the columns

\begin{tabular}{|c|c|c|c|c|}
\hline & Talc slurry & Talc poudrage & Bleomycin & Tetracycline \\
\hline Talc poudrage & $\begin{array}{l}0.77(0.54,1.09) ; \\
n=3 ; \text { Chi }^{2}=0.57 ;\left.\right|^{2}=0 \%\end{array}$ & NA & - & NA \\
\hline Bleomycin & $\begin{array}{l}1.22(0.61,2.45) ; n=5^{\star} \\
\text { Chi }^{2}=4.53 ;\left.\right|^{2}=12 \%\end{array}$ & $\begin{array}{l}9.81(2.10 \\
45.89) ; \\
n=2 ; C^{2} i^{2}= \\
0.01 ;\left.\right|^{2}=0 \%\end{array}$ & NA & - \\
\hline Tetracycline & NA & NA & $\begin{array}{l}2.00(1.07,3.73) ; \\
n=5\left(^{\star}\right) ; C h i^{2}=1.23 ; I^{2}=0 \%\end{array}$ & NA \\
\hline C. parvum & NA & NA & $\begin{array}{l}0.72(0.32,1.61) ; n=2 ; \\
C h i^{2}=17.04 ; I^{2}=94 \%\end{array}$ & NA \\
\hline $\begin{array}{l}\text { Indwelling pleural } \\
\text { catheter }\end{array}$ & $\begin{array}{l}3.35(1.64,6.83) ; n=2 ; \\
C h i^{2}=0.00 . I^{2}=0 \%\end{array}$ & NA & NA & NA \\
\hline Mustine & NA & NA & NA & $\begin{array}{l}2.72(0.74 \\
9.99) \\
n=2^{*} ; \\
\text { Chi² }=0.00 ; 1^{2} \\
=0 \%\end{array}$ \\
\hline Doxycycline & NA & NA & $\begin{array}{l}0.66(0.24,1.83) ; n=2 ; \\
C h i^{2}=0.22 ; 1^{2}=0 \%\end{array}$ & NA \\
\hline
\end{tabular}

$\mathrm{n}=$ the number of studies included in the pair-wise comparison. * ilndicates that the comparison included a three- arm study. NA= no direct pair-wise comparison available. Results that are statistically significant at the conventional level of $\mathrm{pP}<0.05$ are shaded in grey.

Appendix 4. Overview of the network meta-analysis results for pleurodesis efficacy in the sensitivity analyses

\begin{tabular}{llllll}
\hline & $\begin{array}{l}\text { Number } \\
\text { of pleu- } \\
\text { rodesis } \\
\text { methods } \\
\text { evaluated }\end{array}$ & $\begin{array}{l}\text { Number } \\
\text { of trials } \\
\text { includ- } \\
\text { ed in net- } \\
\text { work }\end{array}$ & Tau2 $(95 \% \mathrm{Cl})$ & $\begin{array}{l}\text { Global in- } \\
\text { consisten- } \\
\text { cy identi- } \\
\text { fied? }\end{array}$ & $\begin{array}{l}\text { Loop-specific inconsistency } \\
\text { identified? If so, loop show- } \\
\text { inconsistency with ROR } \\
(95 \% \text { Cl) }\end{array}$ \\
\hline Whole network & 16 & 41 & $0.88(0.42,1.482)$ & No & Yes
\end{tabular}

TS-TP-BL $7.0(1.1,43.8)$ 


\begin{tabular}{llllll}
\hline Only data collected at 1 month & 13 & 24 & $0.80(0.14,1.66)$ & No & Yes
\end{tabular}

BL-MX-ME 54.2 (2.0, 1469.5)

\begin{tabular}{llllll}
\hline Only data collected at 3 months & 9 & 10 & $0.55(0.02,1.84)$ & No & No \\
\hline Only data collected at 6 months & 7 & 10 & $1.09(0.09,1.95)$ & No & Yes \\
& & & & TS-TP-BL 11.7 (1.1, 123.3) \\
\hline
\end{tabular}

Trials excluding patients with trapped
lung

$9 \quad 13$

$0.71(0.04,1.85) \quad$ No

No

Trials using a clinico-radiological defini- 16 tion of pleurodesis

$29 \quad 1.16(0.59,1.87) \quad$ No $\quad$ Yes

TS-BL-ME 12.9 (1.3, 126.3)

TS-TP-BL $11.6(1.02,132.5)$

\begin{tabular}{llllll}
\hline Trials using large-bore chest tubes & 9 & 16 & $1.32(0.51,1.95)$ & No & Yes
\end{tabular}

TS-BL-TC $15.2(1.5,151.4)$

TS-BL-ME $(12.2(1.2,121.2)$

$\begin{array}{llllll}\begin{array}{l}\text { Trials with a lower risk of bias (high risk } \\ \text { of bias for }<2 \text { domains) }\end{array} & 16 & 36 & 0.46(0.03,1.09) & \text { No } & \text { Yes }\end{array}$

Trials with a lower risk of
of bias for $<2$ domains)

TS-BL-ME $12.2(1.2,125.3)$

TS-TP-BL $8.5(1.2,60.3)$

$\mathrm{BL}=$ Bleomycin; $\mathrm{CP}=$ C. parvum; $\mathrm{DX}=$ Doxycycline; $\mathrm{IO}=$ lodine; $\mathrm{ME}=$ Mepacrine; $\mathrm{MU}=$ Mustine; $\mathrm{MX}=\mathrm{Mitoxantrone} ; \mathrm{PL}=\mathrm{Placebo} ; \mathrm{TC}=$ Tetracycline; $\mathrm{TP}=$ Talc poudrage; TS = Talc slurry

\section{Appendix 5. Results of the sensitivity analysis only evaluating those studies with a lower risk of bias. Table of odds ratios ( $95 \% \mathrm{Cr}-\mathrm{I})$ from network meta-analysis (agents in the rows compared to those in the columns)}




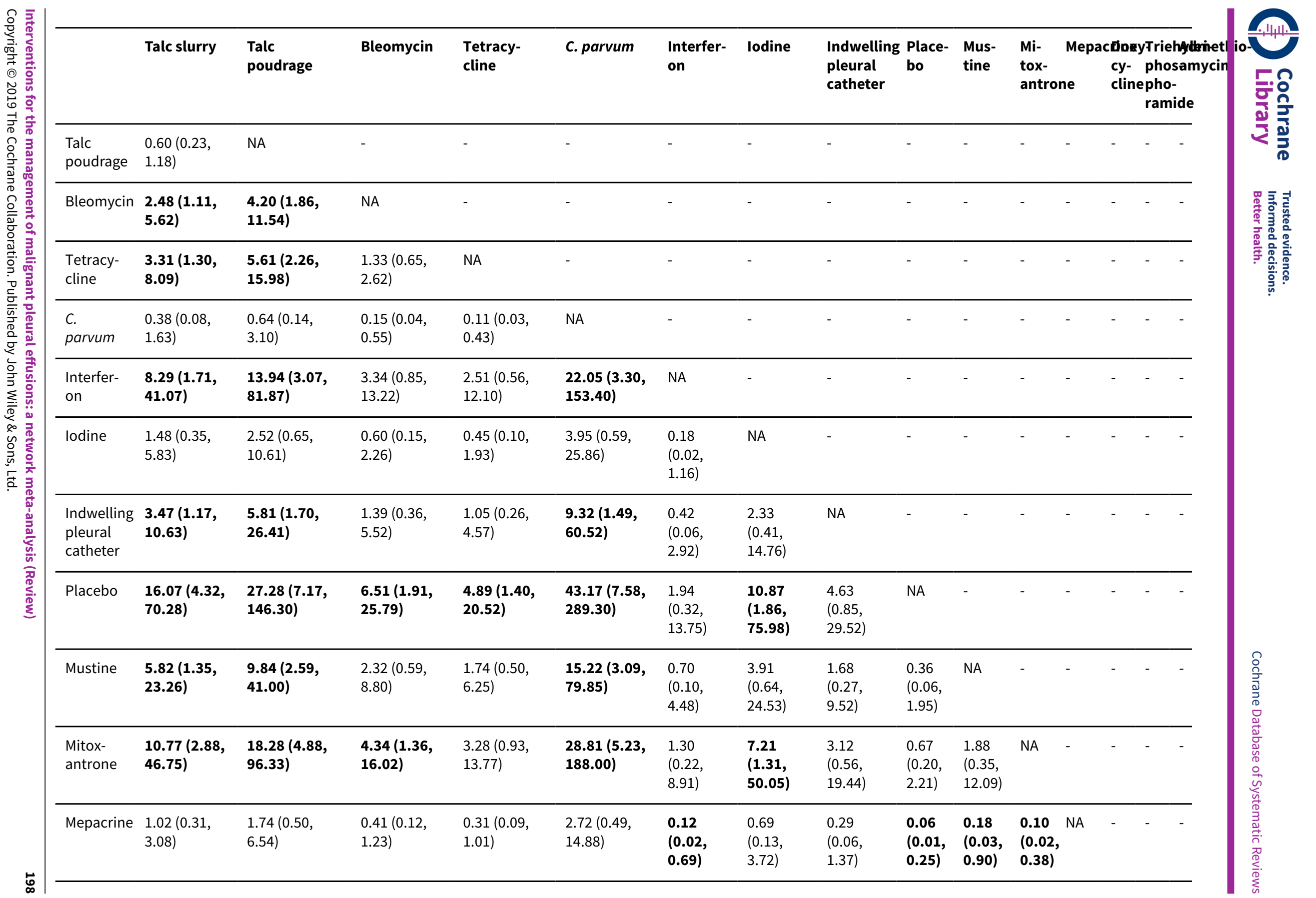




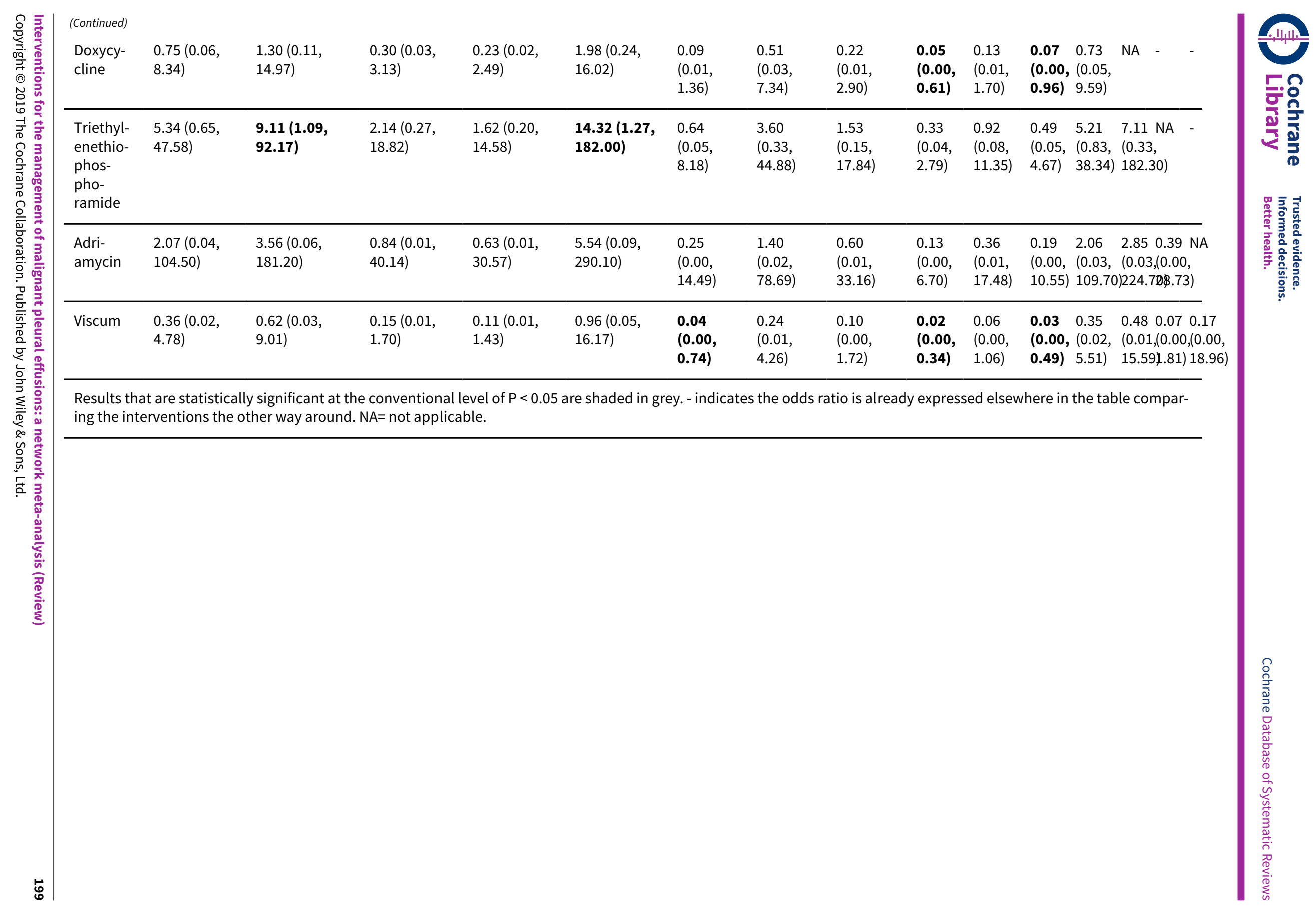


Appendix 6. Estimated rank $(95 \% \mathrm{Cr}-\mathrm{I})$ for pleurodesis efficacy in the sensitivity analysis only evaluating those trials with a lower risk of bias

\begin{tabular}{|c|c|}
\hline Pleurodesis method & Estimated rank $(95 \% \mathrm{Cr}-\mathrm{I})$ \\
\hline C. parvum & $2(1,6)$ \\
\hline Viscum & $2(1,11)$ \\
\hline Talc poudrage & $3(1,6)$ \\
\hline Doxycycline & $4(1,13)$ \\
\hline Talc slurry & $5(3,8)$ \\
\hline Mepacrine & $5(2,9)$ \\
\hline lodine & $7(2,12)$ \\
\hline Adriamycin & $8(1,16)$ \\
\hline Bleomycin & $9(6,12)$ \\
\hline Tetracycline & $10(7,13)$ \\
\hline Indwelling pleural catheter & $10(6,15)$ \\
\hline Mustine & $12(7,16)$ \\
\hline Triethylenethoiphosphoramide & $12(5,16)$ \\
\hline Interferon & $13(8,16)$ \\
\hline Mitoxantrone & $14(11,16)$ \\
\hline Placebo & $15(12,16)$ \\
\hline
\end{tabular}

Appendix 7. Results of the sensitivity analysis only evaluating agents given by bedside pleurodesis. Table of odds ratios ( $95 \% \mathrm{Cr}-\mathrm{I})$ from network meta-analysis (the agents in the rows compared to the agents in the columns) for pleurodesis success 


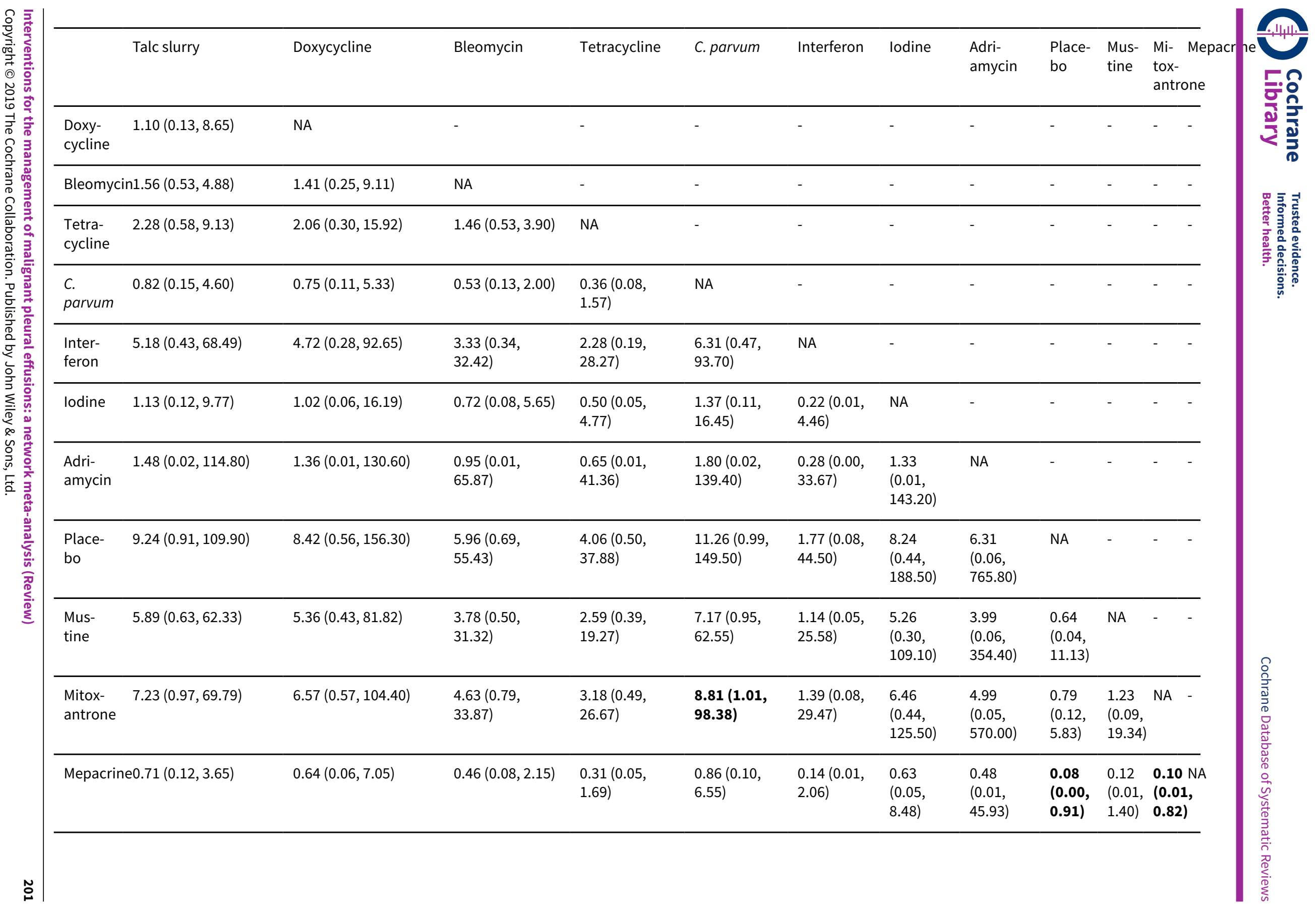




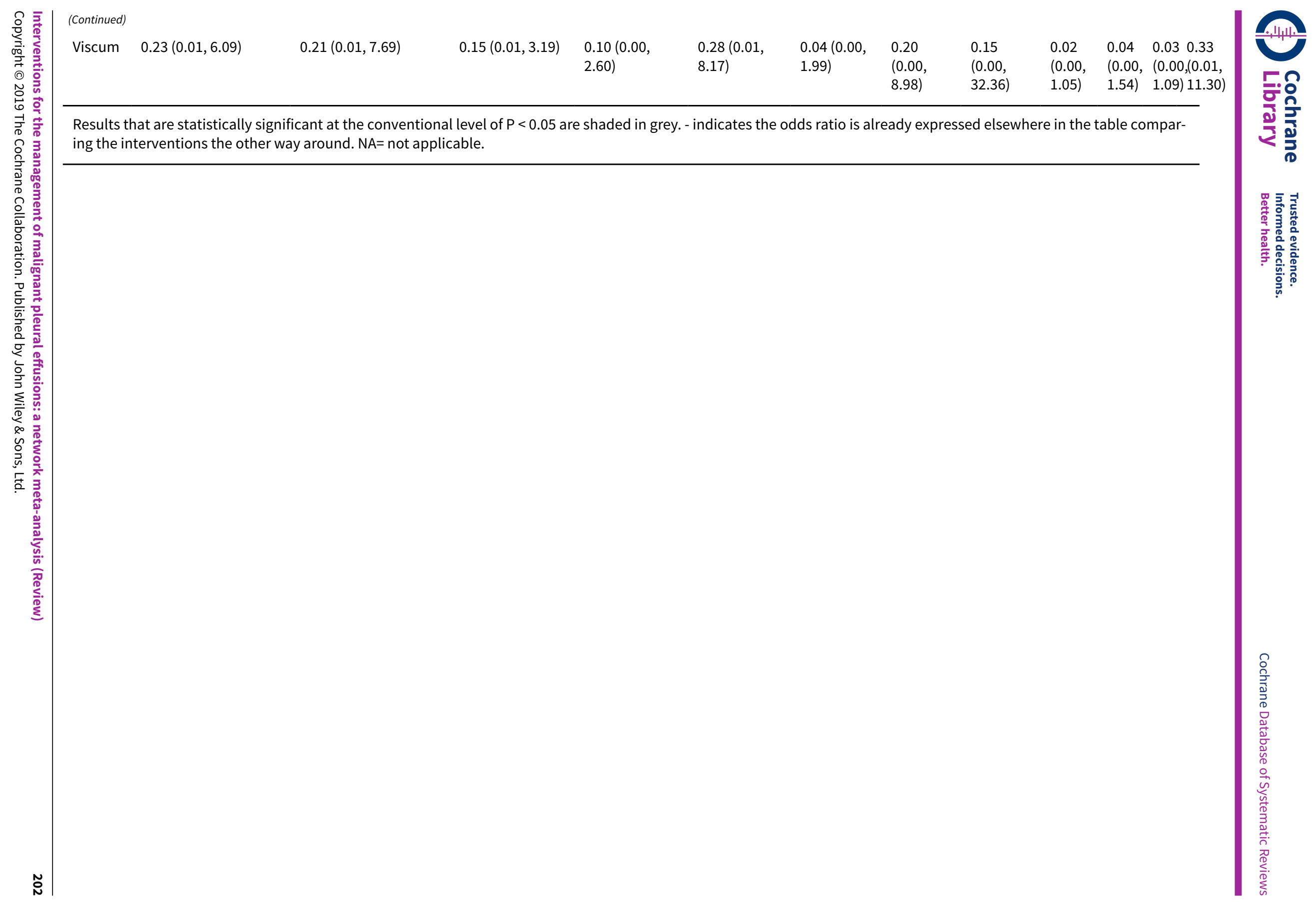


Appendix 8. Estimated rank ( $95 \% \mathrm{Cr}-\mathrm{I})$ for the subgroup analysis evaluating the network of agents given via a chest tube (IPC and talc poudrage studies excluded)

\begin{tabular}{ll}
\hline Pleurodesis agent & Estimated rank $(95 \%$ Cr-I) \\
\hline Viscum & $1(1,10)$ \\
\hline Mepacrine & $3(1,9)$ \\
\hline C. parvum & $4(1,9)$ \\
\hline Talc slurry & $5(2,9)$ \\
\hline Doxycycline & $5(1,10)$ \\
\hline lodine & $5(1,12)$ \\
\hline Bleomycin & $6(1,13)$ \\
\hline Adriamycin & $7(4,10)$ \\
\hline Tetracycline & $8(4,11)$ \\
\hline Mitoxantrone & $11(5,13)$ \\
\hline Mustine & $11(6,13)$ \\
\hline Interferon & $11(3,13)$ \\
\hline Placebo & $12(6,13)$ \\
\hline
\end{tabular}

Appendix 9. Direct pair-wise evidence for fever, expressed as odds ratios $(95 \% \mathrm{Cl})$ for the rows compared to the columns, using random-effects meta-analysis 


\begin{tabular}{|c|c|c|c|c|c|c|c|}
\hline Treatment & Talc slurry & $\begin{array}{l}\text { Talc } \\
\text { poudrage }\end{array}$ & Bleomycin & Tetracycline & C.parvum & Placebo & Mepacrine \\
\hline Talc poudrage & $\begin{array}{l}0.60(0.15,2.37) \\
\operatorname{Tau}^{2}=0.54 ; \\
\mathrm{I}^{2}=31 \% ; \mathrm{n}=2\end{array}$ & NA & - & - & - & - & - \\
\hline Bleomycin & $\begin{array}{l}0.90(0.31,2.56) \\
\operatorname{Tau}^{2}=0.10 ; 1^{2}=11 \% \\
\mathrm{n}=3^{\star}\end{array}$ & $\begin{array}{l}0.87(0.11 \\
7.05) ; \mathrm{n}=1\end{array}$ & NA & - & - & - & - \\
\hline Tetracycline & $\begin{array}{l}0.92(0.23,3.63) \\
n=1^{\star}\end{array}$ & - & $\begin{array}{l}0.49(0.16,1.50) \\
\operatorname{Tau}^{2}=0.63 \\
\mathrm{I}^{2}=39 \% \\
\mathrm{n}=5\end{array}$ & NA & - & - & - \\
\hline $\begin{array}{l}\text { C. } \\
\text { parvum }\end{array}$ & NA & NA & $\begin{array}{l}2.30(0.90,5.92) \\
\operatorname{Tau}^{2}=0 ; n=2 ;\left.\right|^{2}=0 \%\end{array}$ & $\begin{array}{l}288.00 \\
(16.62 \\
4991) \\
n=1\end{array}$ & NA & - & - \\
\hline Interferon & NA & NA & $\begin{array}{l}0.01,(0.00,0.11) \\
n=1\end{array}$ & NA & NA & NA & NA \\
\hline lodine & $\begin{array}{l}0.63(0.09,4.28) ; \\
n=1\end{array}$ & $\begin{array}{l}0.24(0.02 \\
2.33) \\
n=1\end{array}$ & NA & NA & NA & NA & NA \\
\hline Placebo & NA & NA & NA & NA & NA & NA & - \\
\hline Mustine & NA & NA & NA & NA & $\begin{array}{l}0.23(0.01, \\
6.25) \\
n=1\end{array}$ & NA & NA \\
\hline
\end{tabular}




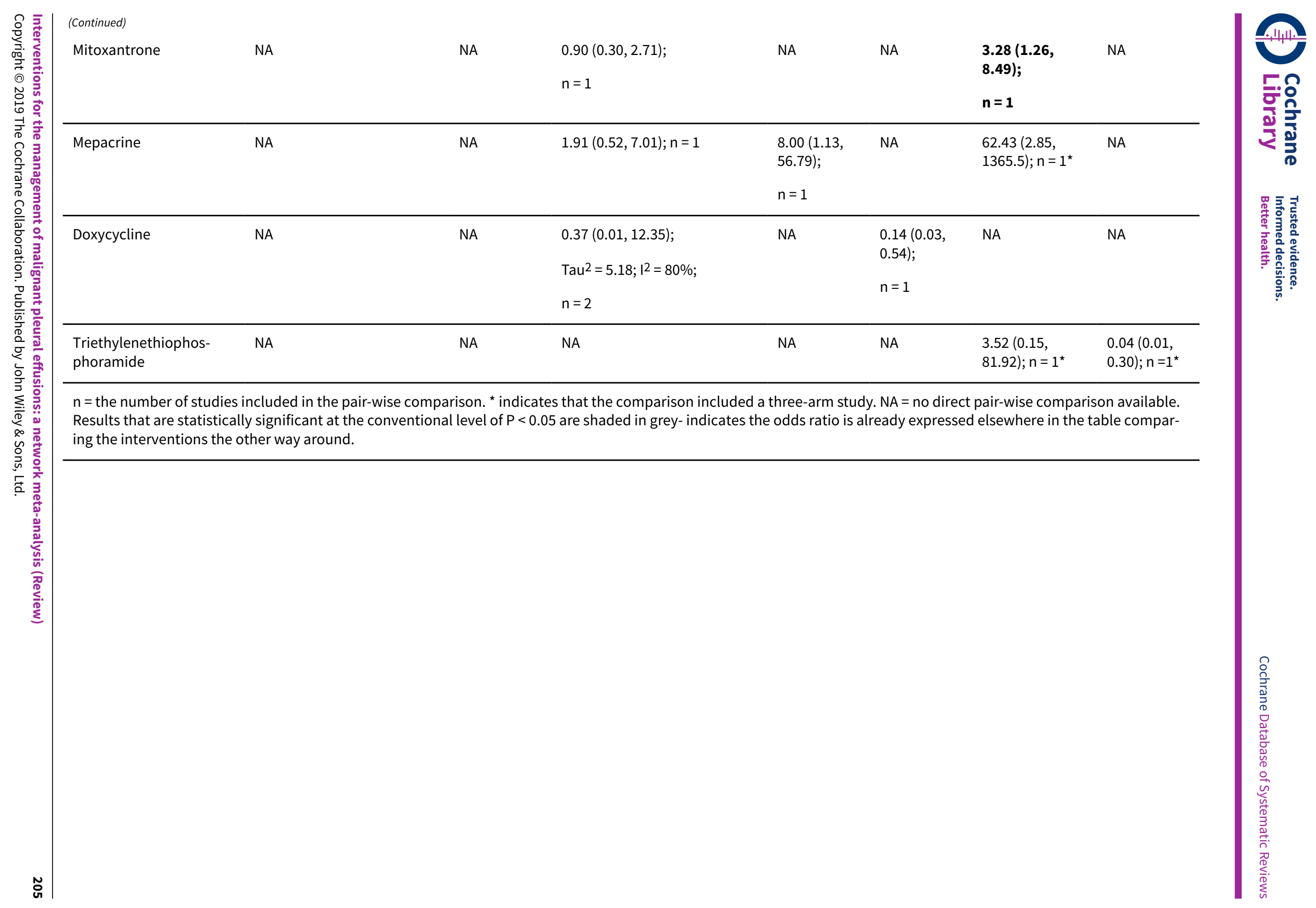


Appendix 10. Table of the relative chance of pain from direct pair-wise evidence using random-effects model (odds ratios (95\% Cr-I) (rows compared to columns) 


\begin{tabular}{|c|c|c|c|c|c|c|c|}
\hline Treatment & Talc slurry & $\begin{array}{l}\text { Talc } \\
\text { poudrage }\end{array}$ & Bleomycin & Tetracycline & C. parvum & Placebo & Mepacrine \\
\hline Talc poudrage & $0.47(0.23,0.96) ; \mathrm{n}=1$ & NA & - & - & - & - & - \\
\hline \multirow[t]{3}{*}{ Bleomycin } & $1.66(0.41,6.80)$ & 0.28 (0.01, & NA & - & - & - & - \\
\hline & $\operatorname{Tau}^{2}=0 ; 12=0 \%$ & 工 & & & & & \\
\hline & $\mathrm{n}=2^{*}$ & & & & & & \\
\hline \multirow[t]{2}{*}{ Tetracycline } & $3.28(0.73,14.68) ; n=1$ & NA & $\begin{array}{l}1.65(0.79,3.43) ; \operatorname{Tau}^{2}=0.19 \\
L^{2}=34 \%\end{array}$ & NA & - & - & - \\
\hline & & & $\mathrm{n}=4^{\star}$ & & & & \\
\hline C. & NA & NA & $1.42(0.54,3.75) ; \operatorname{Tau}^{2}=0 ; 1^{2}=$ & $2.44(0.69,8.66)$ & NA & - & - \\
\hline \multicolumn{8}{|l|}{ parvum } \\
\hline Interferon & NA & NA & $0.03(0.00,0.53) ; n=1$ & NA & NA & NA & NA \\
\hline lodine & NA & $\begin{array}{l}0.10(0.01 \\
1.99) ; \mathrm{n}=1\end{array}$ & NA & NA & NA & NA & NA \\
\hline Indwelling pleural catheter & $3.22(0.13,82.38) ; \mathrm{n}=1$ & NA & NA & NA & NA & NA & NA \\
\hline Placebo & NA & NA & NA & NA & NA & NA & - \\
\hline Mustine & NA & NA & NA & $\begin{array}{l}0.03(0.00 \\
0.56) ; n=1\end{array}$ & NA & NA & NA \\
\hline Mitoxantrone & NA & NA & $2.08(0.64,6.76) ; \mathrm{n}=1$ & NA & NA & NA & NA \\
\hline Mepacrine & NA & NA & $2.15(0.52,9.00)$ & 5.60 & NA & $14.53(0.71$ & NA \\
\hline & & & & 38.51 & & $\begin{array}{l}298.21) ; n= \\
1^{*}\end{array}$ & \\
\hline Doxycycline & NA & NA & $\begin{array}{l}1.19(0.37,3.80) ; \text { Tau}^{2}=0.30 \\
1^{2}=42 \% ; n=2\end{array}$ & NA & $\begin{array}{l}0.10(0.01 \\
0.96) ; n=1\end{array}$ & NA & NA \\
\hline
\end{tabular}


$\mathrm{n}=$ the number of studies included in the pair-wise comparison. ${ }^{*}$ indicates that the comparison included a three-arm study. NA = no direct pair-wise comparison available. Results that are statistically significant at the conventional level of $\mathrm{P}<0.05$ are shaded in grey. - indicates the odds ratio is already expressed elsewhere in the table comparing the interventions the other way around 
Appendix 11. Table of the relative chances of pain from network meta-analysis (expressed as odds ratios (95\%Cr-I) (columns compared to the rows) 


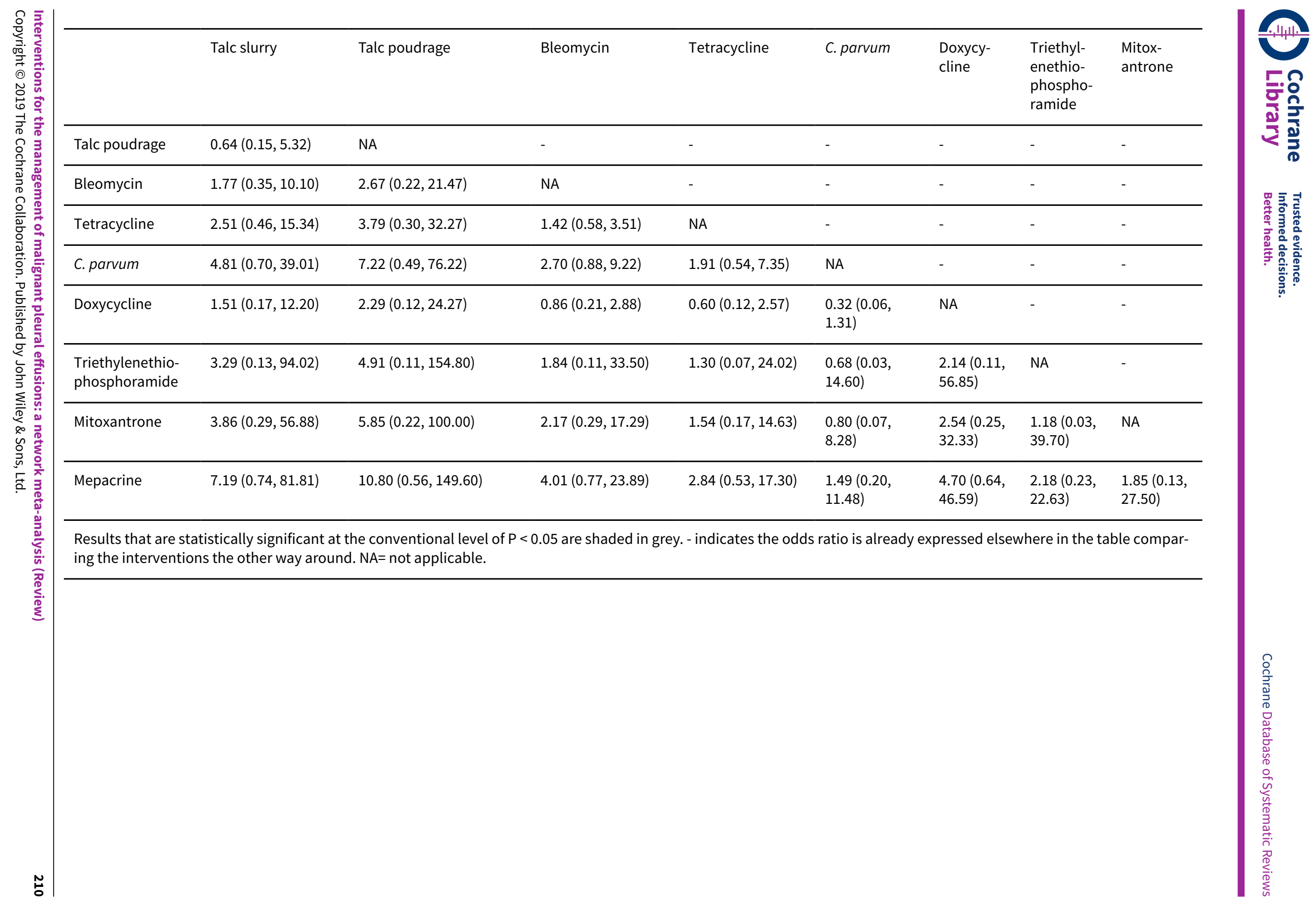


Appendix 12. Estimated rank (95\% Cr-I) for causing pain (a low rank suggesting less pain)

\begin{tabular}{lc}
\hline Pleurodesis agent & Estimated rank $(95 \% \mathrm{Cr}-\mathrm{I})$ \\
\hline Talc poudrage & $1(1,8)$ \\
\hline Talc slurry & $2(1,7)$ \\
\hline Doxycycline & $3(1,8)$ \\
\hline Bleomycin & $4(2,6)$ \\
\hline Tetracycline & $5(2,8)$ \\
\hline Triethylenethiophosphoramide & $6(1,9)$ \\
\hline C. parvum & $7(4,9)$ \\
\hline Mitoxantrone & $7(1,9)$ \\
\hline Mepacrine & $8(4,9)$ \\
\hline
\end{tabular}

Appendix 13. Table of the relative chance of mortality from direct evidence using random-effects model (odds ratios (95\% Cr-I) (rows compared to columns)

\begin{tabular}{|c|c|c|c|c|c|c|}
\hline Treatment & Talc slurry & Talc poudrage & Bleomycin & $\begin{array}{l}\text { Tetracy- } \\
\text { cline }\end{array}$ & C. parvum & $\begin{array}{l}\text { Mitox- } \\
\text { antrone }\end{array}$ \\
\hline Talc poudrage & $\begin{array}{l}1.02(0.35,3.00) \\
\operatorname{Tau}^{2}=0.43 ;\left.\right|^{2}= \\
69 \% ; n=2\end{array}$ & NA & - & - & - & - \\
\hline Bleomycin & $\begin{array}{l}0.89(0.29,2.75) ; \\
\mathrm{Tau}^{2}=0 ; 1^{2}=0 \% \\
\mathrm{n}=2\end{array}$ & $\begin{array}{l}0.82(0.20,3.43) ; \mathrm{n} \\
=1\end{array}$ & NA & - & - & - \\
\hline Tetracycline & NA & $\begin{array}{l}0.19(0.03,0.10) ; n \\
=1\end{array}$ & $\begin{array}{l}1.60(0.69,3.69) ; \mathrm{Tau}^{2}= \\
0.0 ; 1^{2}=0 \% ; \\
\mathrm{n}=2\end{array}$ & NA & - & - \\
\hline $\begin{array}{l}\text { C. } \\
\text { parvum }\end{array}$ & NA & NA & $1.66(0.51,5.38) ; \mathrm{n}=1$ & $\begin{array}{l}0.33(0.03 \\
3.55) ; n=1\end{array}$ & NA & - \\
\hline Interferon & NA & NA & $2.16(1.15,4.07) ; n=1$ & NA & NA & NA \\
\hline lodine & NA & $\begin{array}{l}0.38(0.08,1.73) ; \mathrm{n} \\
=1\end{array}$ & NA & NA & NA & NA \\
\hline
\end{tabular}




\begin{tabular}{|c|c|c|c|c|c|c|}
\hline $\begin{array}{l}\text { Indwelling pleural } \\
\text { catheter }\end{array}$ & $\begin{array}{l}1.30(0.48,2.23) \\
\mathrm{Tau}^{2}=0.08 ; 1^{2}= \\
25 \% ; n=2\end{array}$ & NA & NA & NA & NA & NA \\
\hline Mustine & NA & $\begin{array}{l}2.35(0.51,10.86) \\
n=1\end{array}$ & NA & NA & $\begin{array}{l}2.40(0.38 \\
15.32) ; \mathrm{n} \\
=1\end{array}$ & NA \\
\hline Mitoxantrone & NA & NA & $0.47(0.21,1.05) ; \mathrm{n}=1$ & NA & NA & NA \\
\hline Mepacrine & $\begin{array}{l}0.53(0.28,1.61) \\
n=1\end{array}$ & NA & NA & NA & NA & $\begin{array}{l}1.64(0.23 \\
11.70) ; \mathrm{n} \\
=1\end{array}$ \\
\hline Doxycycline & NA & NA & $0.69(0.26,1.87) ; \mathrm{n}=1$ & NA & NA & NA \\
\hline
\end{tabular}

$\mathrm{n}=$ the number of studies included in the pair-wise comparison. * indicates that the comparison included a three-arm study. NA $=$ no direct pair-wise comparison available. Results that are statistically significant at the conventional level of $\mathrm{P}<0.05$ are shaded in grey. - indicates the odds ratio is already expressed elsewhere in the table comparing the interventions the other way around

Appendix 14. Table of the relative chances of mortality from network meta-analysis (expressed as odds ratios (95\% Cr-I) (rows compared to columns) 


\begin{tabular}{|c|c|c|c|c|c|c|c|c|c|c|c|}
\hline & Talc slurry & Talc poudrage & Bleomycin & Tetracycline & C. parvum & Interferon & lodine & $\begin{array}{l}\text { Indwelling } \\
\text { pleural } \\
\text { catheter }\end{array}$ & $\begin{array}{l}\text { Mus- } \\
\text { tine }\end{array}$ & $\begin{array}{l}\text { Mi- } \\
\text { tox- } \\
\text { antron }\end{array}$ & $\begin{array}{l}\text { Mepac } \\
\text { ne }\end{array}$ \\
\hline Bleomycin & $1.03(0.38,2.83)$ & $1.19(0.43,3.33)$ & NA & - & - & - & - & - & - & - & - \\
\hline C. parvum & $1.33(0.28,6.08)$ & $1.56(0.34,6.66)$ & $1.29(0.35,4.60)$ & $\begin{array}{l}0.49(0.10 \\
2.00)\end{array}$ & NA & - & - & - & - & - & - \\
\hline Interferon & $2.23(0.44,11.82)$ & $2.61(0.50,13.64)$ & $2.18(0.59,8.03)$ & $\begin{array}{l}0.83(0.14 \\
4.03)\end{array}$ & $\begin{array}{l}1.68(0.28 \\
10.74)\end{array}$ & NA & - & - & - & - & - \\
\hline lodine & $0.30(0.03,2.39)$ & $0.35(0.04,2.27)$ & $0.29(0.03,2.53)$ & $\begin{array}{l}0.11(0.01 \\
1.01)\end{array}$ & $\begin{array}{l}0.23(0.02 \\
2.49)\end{array}$ & $\begin{array}{l}0.13(0.01 \\
1.62)\end{array}$ & NA & - & - & - & - \\
\hline $\begin{array}{l}\text { Indwelling } \\
\text { pleural } \\
\text { catheter }\end{array}$ & $1.04(0.38,3.02)$ & $1.22(0.32,4.69)$ & $1.02(0.24,4.27)$ & $\begin{array}{l}0.39(0.07 \\
1.94)\end{array}$ & $\begin{array}{l}0.78(0.13 \\
5.13)\end{array}$ & $\begin{array}{l}0.47(0.07 \\
3.29)\end{array}$ & $\begin{array}{l}3.47 \\
(0.35 \\
42.07)\end{array}$ & NA & - & - & - \\
\hline Mustine & $2.60(0.48,15.49)$ & $3.04(0.63,15.55)$ & $\begin{array}{l}2.53(0.47 \\
14.49)\end{array}$ & $\begin{array}{l}0.97(0.14 \\
6.01)\end{array}$ & $\begin{array}{l}1.97(0.38 \\
11.03)\end{array}$ & $\begin{array}{l}1.17(0.14 \\
10.17)\end{array}$ & $\begin{array}{l}8.68 \\
(0.76, \\
118.1)\end{array}$ & $\begin{array}{l}2.50 \\
(0.34 \\
19.18)\end{array}$ & NA & - & - \\
\hline $\begin{array}{l}\text { Mitox- } \\
\text { antrone }\end{array}$ & $0.44(0.10,1.85)$ & $0.51(0.11,2.25)$ & $0.43(0.12,1.43)$ & $\begin{array}{l}0.16(0.03 \\
0.72)\end{array}$ & $\begin{array}{l}0.33(0.06 \\
1.94)\end{array}$ & $\begin{array}{l}0.20(0.03 \\
1.13)\end{array}$ & $\begin{array}{l}1.47 \\
(0.12 \\
18.53)\end{array}$ & $\begin{array}{l}0.42 \\
(0.07 \\
2.42)\end{array}$ & $\begin{array}{l}0.17 \\
(0.02, \\
1.27)\end{array}$ & NA & - \\
\hline Mepacrine & $0.58(0.15,2.16)$ & $0.68(0.14,3.02)$ & $0.56(0.12,2.56)$ & $\begin{array}{l}0.21(0.03 \\
1.17)\end{array}$ & $\begin{array}{l}0.43(0.06 \\
3.07)\end{array}$ & $\begin{array}{l}0.26(0.03 \\
1.87)\end{array}$ & $\begin{array}{l}1.92 \\
(0.17 \\
25.19)\end{array}$ & $\begin{array}{l}0.55 \\
(0.10 \\
2.90)\end{array}$ & $\begin{array}{l}0.22 \\
(0.03, \\
1.82)\end{array}$ & $\begin{array}{l}1.32 \\
(0.27 \\
6.75)\end{array}$ & NA \\
\hline Doxycycline & $0.69(0.12,4.34)$ & $0.81(0.13,4.99)$ & $0.68(0.15,3.01)$ & $\begin{array}{l}0.26(0.04 \\
1.49)\end{array}$ & $\begin{array}{l}0.52(0.07 \\
3.81)\end{array}$ & $\begin{array}{l}0.31(0.04 \\
2.26)\end{array}$ & $\begin{array}{l}2.32 \\
(0.17, \\
35.56)\end{array}$ & $\begin{array}{l}0.66 \\
(0.08 \\
5.37)\end{array}$ & $\begin{array}{l}0.27 \\
(0.03, \\
2.52)\end{array}$ & $\begin{array}{l}1.59 \\
(0.24, \\
11.70)\end{array}$ & $\begin{array}{l}1.21 \\
(0.15 \\
10.30)\end{array}$ \\
\hline
\end{tabular}

Results that are statistically significant at the conventional level of $\mathrm{p}<0.05$ are shaded in grey. - indicates the odds ratio is already expressed elsewhere in the table comparing the interventions the other way around. NA= not applicable. 
Appendix 15. Estimated rank ( $95 \% \mathrm{Cr}-\mathrm{l}$ ) for mortality (a low rank suggesting lower mortality)

\begin{tabular}{ll}
\hline Pleurodesis agent & Estimated rank $(95 \% \mathrm{Cr}-\mathrm{I})$ \\
\hline lodine & $1(1,10)$ \\
\hline Mitoxantrone & $2(1,8)$ \\
\hline Mepacrine & $3(1,10)$ \\
\hline Doxycycline & $4(1,11)$ \\
\hline Talc poudrage & $5(2,10)$ \\
\hline Bleomycin & $7(3,10)$ \\
\hline Talc slurry & $7(3,10)$ \\
\hline Indwelling pleural catheter & $7(2,12)$ \\
\hline C. parvum & $8(2,12)$ \\
\hline Interferon & $10(3,12)$ \\
\hline Tetracycline & $11(7,12)$ \\
\hline Mustine & $11(3,12)$ \\
\hline
\end{tabular}

WHAT'S NEW

\begin{tabular}{lll}
\hline Date & Event & Description \\
\hline 9 April 2019 & Amended & Comma deleted in ongoing study reference (OPUS Trial). \\
\hline 11 January 2018 & Review declared as stable & See Published notes. \\
\hline
\end{tabular}

\section{HIST O R Y}

Protocol first published: Issue 5, 2013

Review first published: Issue 5, 2016

\begin{tabular}{lll}
\hline Date & Event & Description \\
\hline 2 April 2019 & Amended & Published Notes text amended. \\
\hline 21 August 2014 & Amended & Updated the authors' Declaration of Interest statements. \\
\hline
\end{tabular}




\section{CONTRIBUTIONS OF AUTHORS}

The protocol was written collaboratively by all authors.

The searches were performed by Jane Hayes and Joanne Abbott.

AOC screened the titles and abstracts and obtained the full text papers.

AOC and NAM assessed the full text articles for inclusion.

AOC, NP, RB and NAM performed the data extractions.

AOC entered the data into RevMan and undertook the direct pair-wise comparisons in RevMan.

$\mathrm{HJ}$ performed the network meta-analysis and provided statistical support.

AOC drafted the final report, which was reviewed and amended by all the authors.

$A O C$ and NAM are responsible for the update.

\section{DECLARATIONSOF INTEREST}

$A O C$ is involved in co-ordinating and recruiting to the TIME-3 trial (TIME-3).

HJ: none known.

RB has been the trial co-ordinator for the TAPPS and IPC-Plus studies since 2012 (IPC-Plus; TAPPS) but did not perform the data extractions for these studies for the purposes of this review.

NJP: none known.

NM is a member of the trial steering committee for TIME-1 and TIME-3 trials (TIME-1; TIME-3). NM is a co-author for one of the included studies (Maskell 2004). However, he did not perform the data extractions for this study for the purposes of this review. North Bristol NHS Trust received unrestricted research funding from CareFusion, to run the IPC-Plus trial (IPC-Plus) (2013-2016) for which NM was the chief investigator. NM also received honoraria from CareFusion for medical advisory board meetings (2013-2015). This has no direct link with the Cochrane Review.

\section{DIFFERENCES BETWEEN PROTOCOLANDREVIEW}

The wording of the background and methods sections have been improved to make them more concise, minimise repetition and to reflect the recently published literature.

In the original protocol, we stated we would use relative risk for dichotomous outcomes, however, we elected to use odds ratios instead, since network meta-analysis models are more readily available for these.

Although the use of network meta-analysis was mentioned in the published protocol, further details have been included to clarify the methodology, including details on evaluating heterogeneity, inconsistency and imprecision. These changes are based on the protocol template from the Comparing Multiple Interventions Methods Group, which was not available when we wrote our original protocol.

The protocol stated that the size of the study would be assessed to look for bias associated with small study effects. This was not performed, as size in itself should not affect the study results and inclusion of sample size in risk of bias tables would be against the advice in the Cochrane Handbook (Higgins 2011a) and training provided by the Cochrane Bias Methods Group.

The protocol combined blinding of participants and personnel and outcome assessment into a single domain. However, in light of new guidance from Cochrane, this was separated into 'blinding of participants and personnel' and 'blinding of outcome assessment', as per the Cochrane Handbook (Higgins 2011a).

The protocol stated we would evaluate mortality in the short, medium and long term. However, due to a paucity of evidence at all these different time points, an overall assessment was done using the available study data closest to three months after the intervention.

The wording of the planned sensitivity analyses have been amended for clarity.

Post-hoc, we chose to perform a sensitivity analysis of the main network excluding talc poudrage and IPCs in order to remove the effect of mode of administration to identify which agent may be best delivered via a standard chest tube.

For clarity, we added 'a network meta-analysis' to the title. 


\section{NOTES}

A restricted search in January 2018 identified ongoing studies which are expected to report in the next 18 months (July 2019). The review will then be assessed for updating. Therefore, this review has been stabilised following discussion with the authors and editors. If appropriate, we will update the review before this date if new evidence likely to change the conclusions is published, or if standards change substantially which necessitate major revisions

\section{N DEX TERMS}

\section{Medical Subject Headings (MeSH)}

Bleomycin [therapeutic use]; Doxycycline [therapeutic use]; Fever [etiology]; lodine [therapeutic use]; Pleural Effusion, Malignant [etiology] [ ${ }^{*}$ therapy]; Pleurodesis [ ${ }^{*}$ methods]; Quinacrine [therapeutic use]; Randomized Controlled Trials as Topic; Talc [therapeutic use]; Treatment Failure

\section{MeSH check words}

Adult; Humans 